\title{
Analysis of Production Data from Horizontal Shale Wells Using Decline Curves
}

Atoosa Mashayekhi

West Virginia University

Follow this and additional works at: https://researchrepository.wvu.edu/etd

\section{Recommended Citation}

Mashayekhi, Atoosa, "Analysis of Production Data from Horizontal Shale Wells Using Decline Curves" (2014). Graduate Theses, Dissertations, and Problem Reports. 118.

https://researchrepository.wvu.edu/etd/118

This Thesis is protected by copyright and/or related rights. It has been brought to you by the The Research Repository @ WVU with permission from the rights-holder(s). You are free to use this Thesis in any way that is permitted by the copyright and related rights legislation that applies to your use. For other uses you must obtain permission from the rights-holder(s) directly, unless additional rights are indicated by a Creative Commons license in the record and/ or on the work itself. This Thesis has been accepted for inclusion in WVU Graduate Theses, Dissertations, and Problem Reports collection by an authorized administrator of The Research Repository @ WVU. For more information, please contact researchrepository@mail.wvu.edu. 


\section{Analysis of Production Data from Horizontal Shale Wells Using Decline Curves}

Atoosa Mashayekhi

Thesis submitted to the

Benjamin M. Statler College of Engineering and Mineral Resources

at West Virginia University

In Partial fulfillment of the requirements for the degree of

Master of Science

In

Petroleum and Natural Gas Engineering

Khashayar Aminian, Ph.D., Chair

Samuel Ameri, M.S.

Alan Brannon, Ph.D.

Department of Petroleum and Natural Gas Engineering

Morgantown, West Virginia

2014

Keywords: Decline Curves, Marcellus Shale, Horizontal Wells, Gas Production Prediction

Copyright 2014 Atoosa Mashayekhi 


\section{ABSTRACT \\ Analysis of Production Data from Horizontal Shale Wells Using Decline Curves \\ Atoosa Mashayekhi}

Recent interest in the exploitation of Marcellus shale play, using horizontal drilling and multistage hydraulic fracturing, has increased the demand for reliable estimation of recoverable reserves from ultra-low permeability shale gas formations. Due to the limited field experience, the production performances of Marcellus shale gas reservoirs as well as the key parameters that affect the long-term production of the horizontal wells have not been well-established.

Among all the prediction methods, only the Decline Curve Analysis (DCA) technique has proved successful in forecasting production data rapidly and to a high degree of accuracy. Several DCA models including conventional Arps, PLE, and Duong have been utilized in this study to determine the most appropriate method for production data from horizontal Marcellus shale wells. Fekete (Fast Evolution) simulator has been used to generate the thirty year production data from 3000 feet of horizontal lateral. The two base scenarios include seven and thirteen hydraulic fracture stages. The gas adsorbed to shale is also considered. The applicability of several DCA models to shale gas production history was examined using the simulated production profiles. The impact of the permeability, fracture half length, and matrix porosity on DCA models constants were also investigated. Finally, the proposed ratio methodology was applied to the limited production profile (3.5 years of production history) from a well in Upshur County, WV to estimate the DCA constants, and predict the long-term production performance. The prediction results from DCA models then compared to the history-matched simulation model predictions for confirmation. 


\section{Acknowledgments}

I would like to express my special appreciation and thanks to my advisor Dr. Kashy Aminian for his continuous support, excellent guidance, and engagement through the learning process of my master studies.

I would also like to thank my committee members, Professor Sam Ameri and Dr. Alan Brannon for serving as my committee members, and for your brilliant comments and suggestions.

Lastly, I want to thank my family for their unconditional support they provided for me through my entire life. 


\section{TABLE OF CONTENTS}

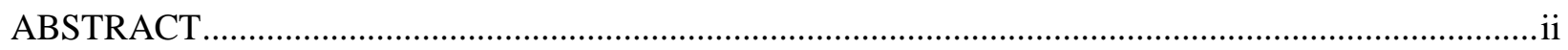

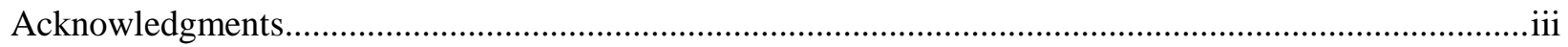

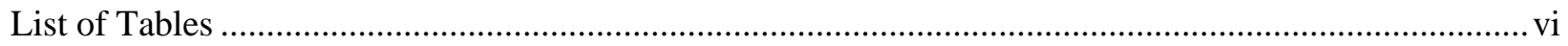

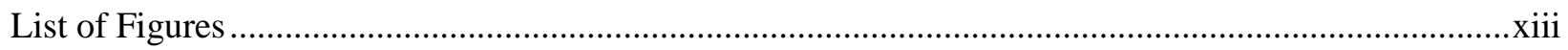

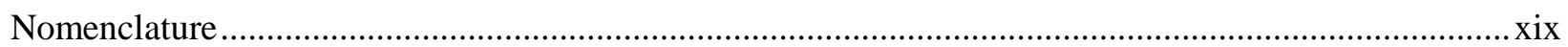

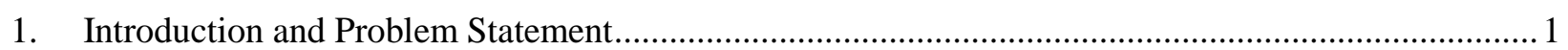

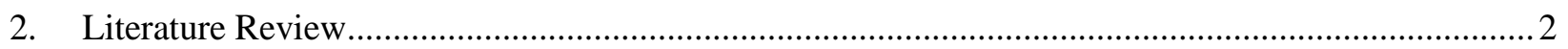

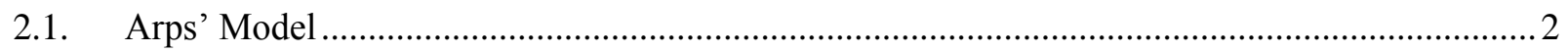

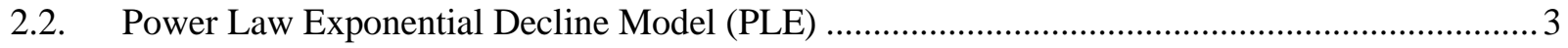

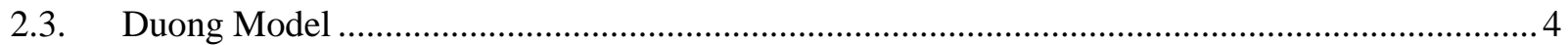

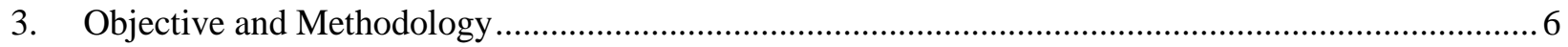

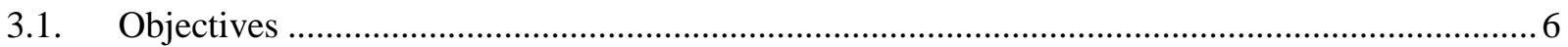

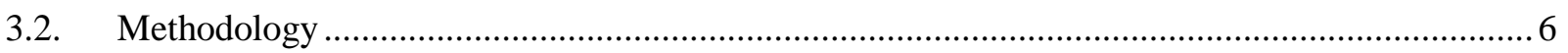

3.2.1. Development of a Marcellus Shale Reservoir Model …………………………………......

3.2.2. Application of Decline Curve Analysis to All Simulated Data ......................................... 10

3.2.3. Application of Selected DCA Models to Limited Production Profiles ................................. 10

3.2.4. Adjusting Decline Curve Constants using Correlations...................................................... 10

3.2.5. Effect of Formation and Hydraulic Fracture Properties on Production Decline Behavior . 10

3.2.6. Error Compared to the Base Case Model........................................................................ 11

3.2.7. Confirmation with Field Data ........................................................................................ 11

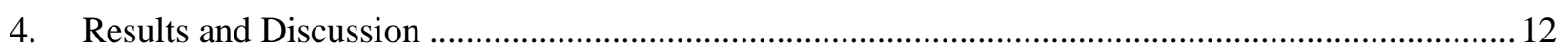

4.1. Development of a Marcellus Shale Reservoir Model …………………………………......... 12

4.2. Application of Selected DCA Models to All Simulated Data..................................................... 13

4.3. Application of Selected DCA Models to Limited Production Profiles ......................................... 14

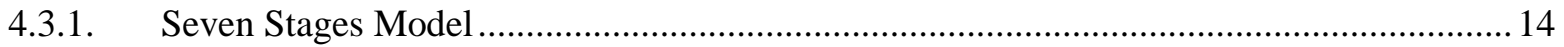

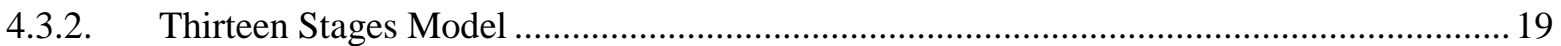

4.4. Effect of Formation and Hydraulic Fracture Properties on Production Decline Behavior …….23

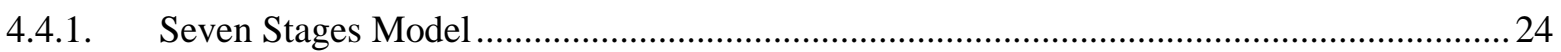

4.4.1.1. Arps Decline Curve Analysis.........................................................................2

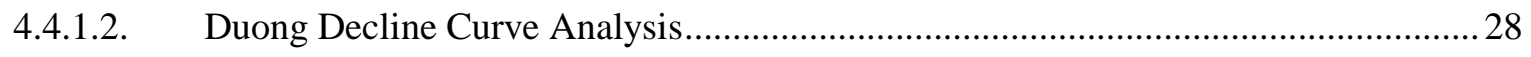

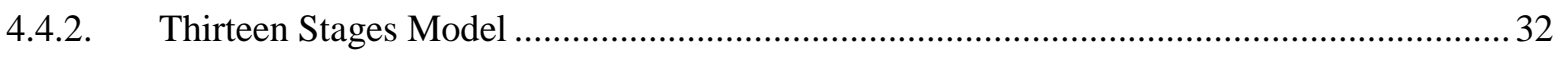




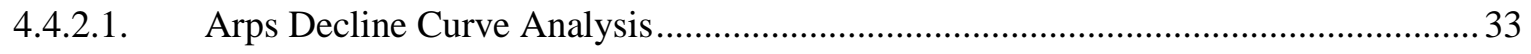

4.4.2.2. Duong Decline Curve Analysis.................................................................................. 36

4.5. Error Compared to the Base Case Model................................................................................. 40

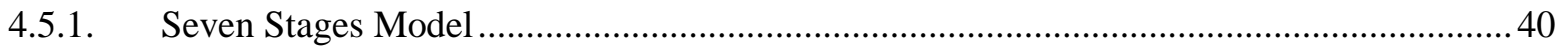

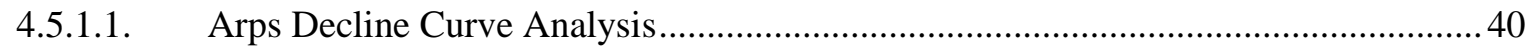

4.5.1.2. Duong Decline Curve Analysis......................................................................... 44

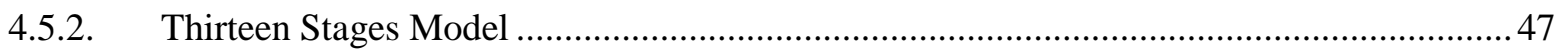

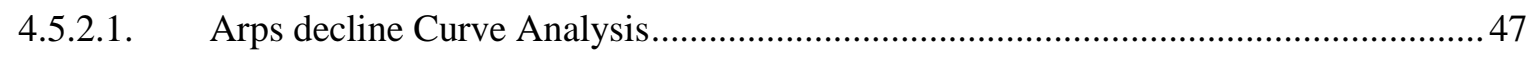

4.5.2.2. Duong Decline Curve Analysis......................................................................... 51

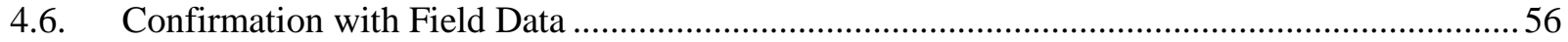

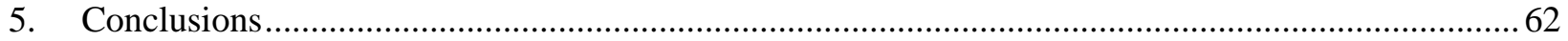

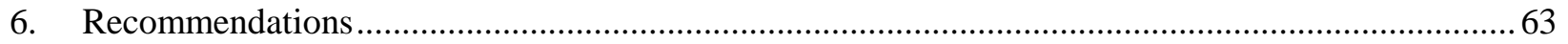

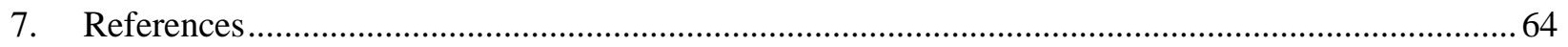

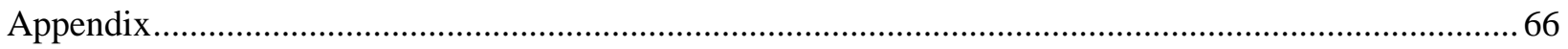

A. Application of Decline Curve Analysis to Simulated Data Using Excel-Solve Method ....................66

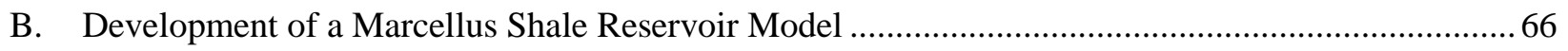

C. Application of Selected DCA Models to All Simulated Data..........................................................69

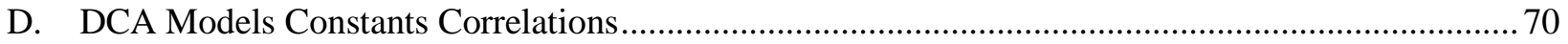

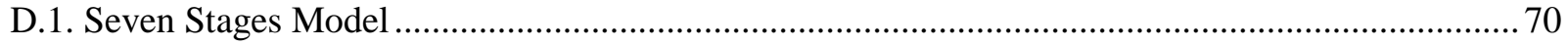

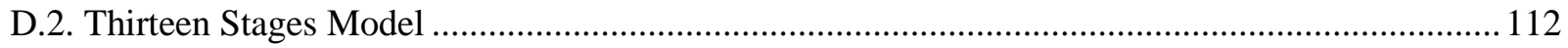

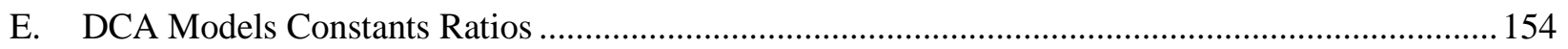

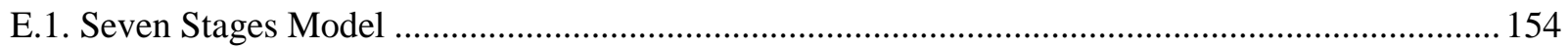

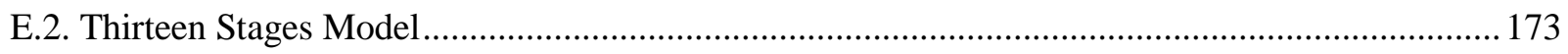

F. Effect of Formation and Hydraulic Fracture Properties on Production Decline Behavior ............... 192

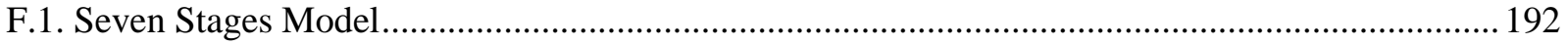

F.1.1. Arps Decline Curve Analysis ......................................................................................... 192

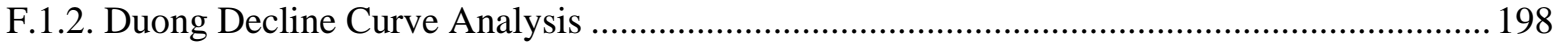

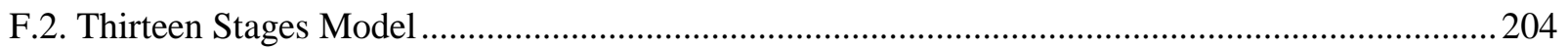

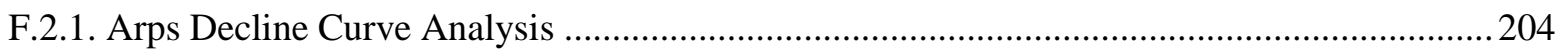

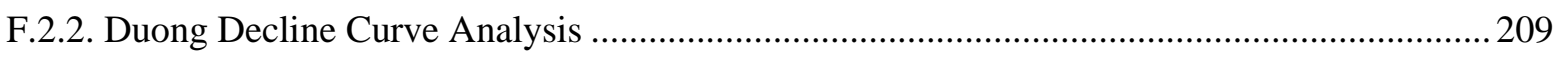

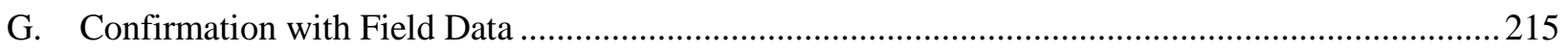




\section{List of Tables}

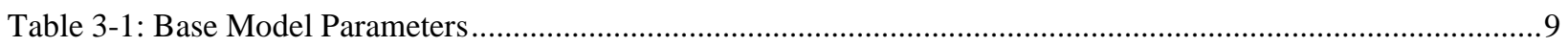

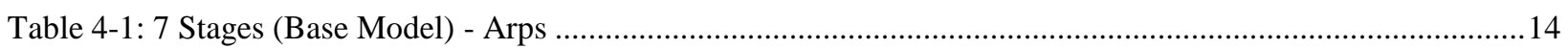

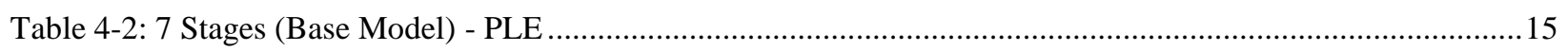

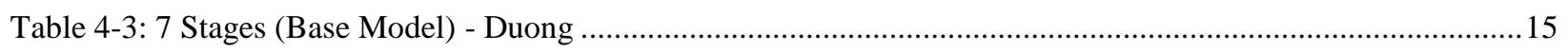

Table 4-4: 7 Stages (Fracture Half Length) - Arps- Correlations ........................................................................... 16

Table 4-5:7 Stages (Fracture Half Length) - PLE- Correlations................................................................................. 16

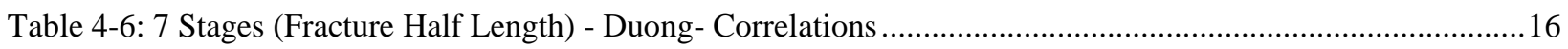

Table 4-7: 7 Stages (Permeability) - Arps- Correlations ....................................................................................... 17

Table 4-8: 7 Stages (Permeability) - PLE - Correlations ...........................................................................................17

Table 4-9: 7 Stages (Permeability) - Duong- Correlations …………………………...............................................17

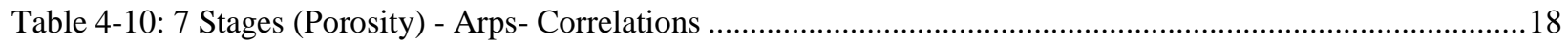

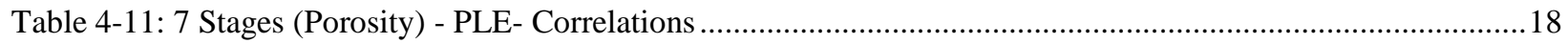

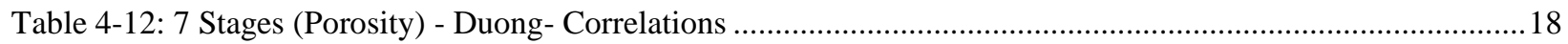

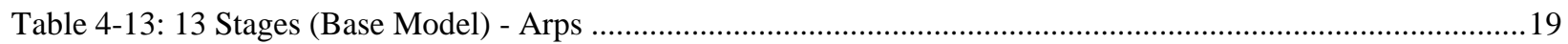

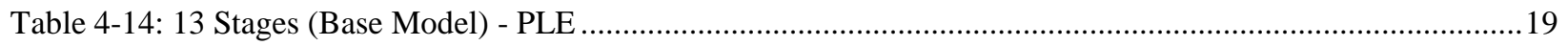

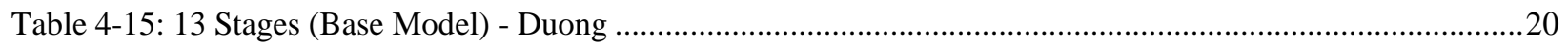

Table 4-16: 13 Stages (Fracture Half-Length) - Arps - Correlations ........................................................................20

Table 4-17: 13 Stages (Fracture Half-Length) - PLE - Correlations .......................................................................20

Table 4-18: 13 Stages (Fracture Half-Length) - Duong - Correlations.....................................................................21

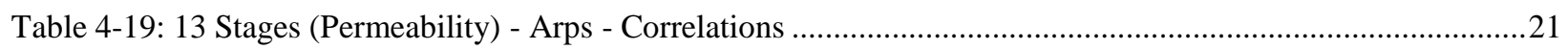

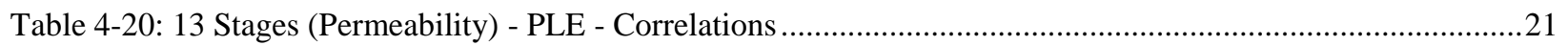

Table 4-21: 13 Stages (Permeability) - Duong - Correlations...................................................................................22

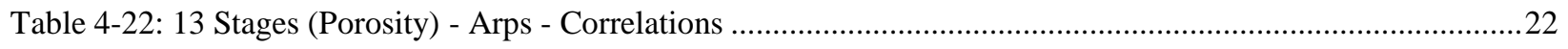

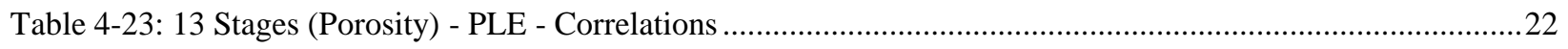

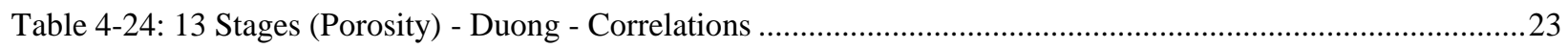

Table 4-25: 7 Stages (Base Model) - Arps- Recalculated Constants ........................................................................24

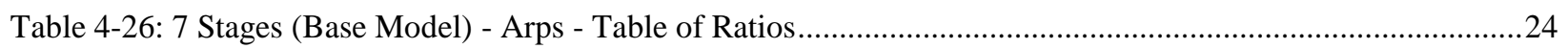

Table 4-27: 7 Stages (Base Model) - Duong- Recalculated Constants .....................................................................24

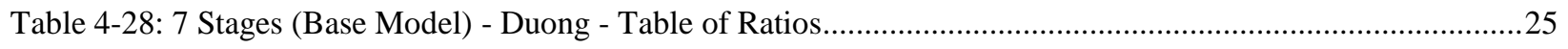

Table 4-29: 13 Stages (Base Model) - Arps- Recalculated Constants .......................................................................32

Table 4-30: 13 Stages (Base Model) - Arps- Table of Ratios...................................................................................32

Table 4-31: 13 Stages (Base Model) - Duong- Recalculated Constants .......................................................................32 
Table 4-32: 13 Stages (Base Model) - Duong- Table of Ratios...............................................................................

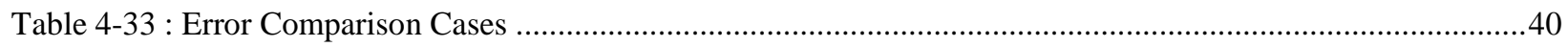

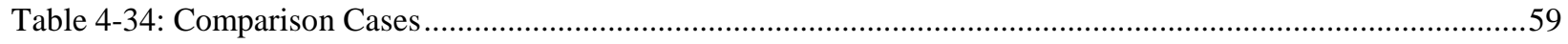

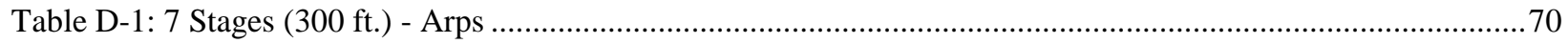

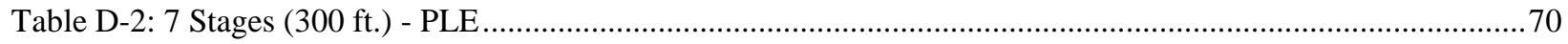

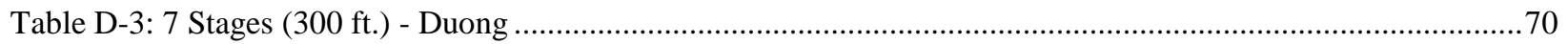

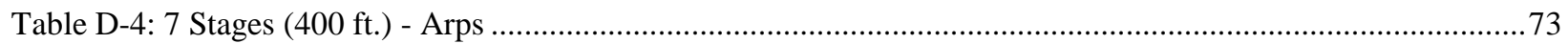

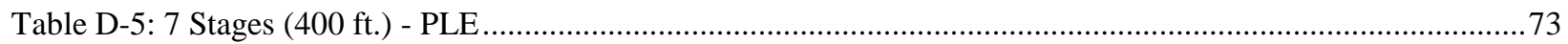

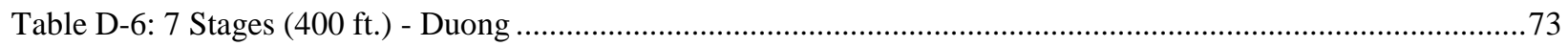

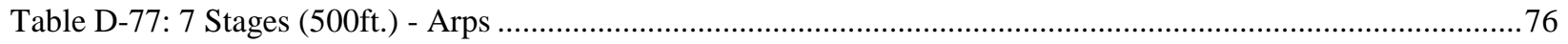

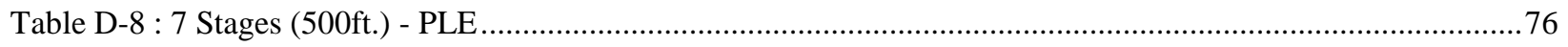

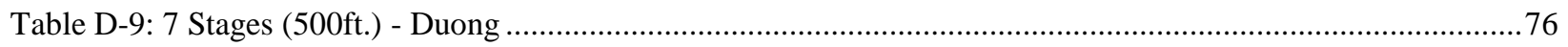

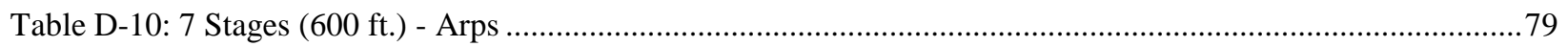

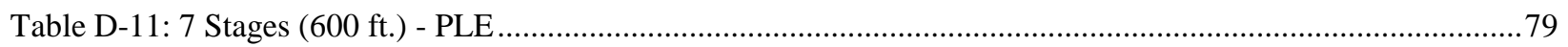

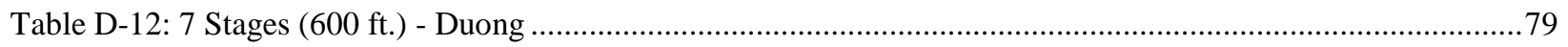

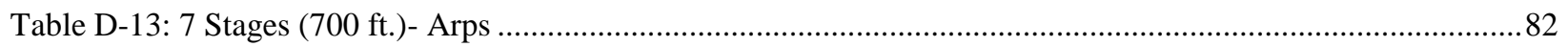

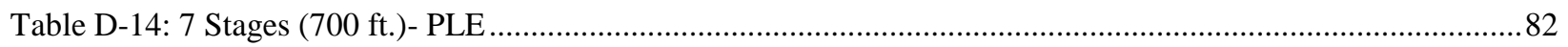

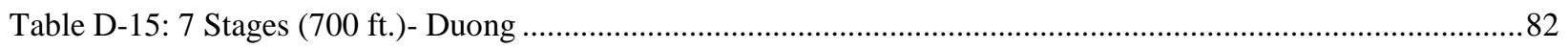

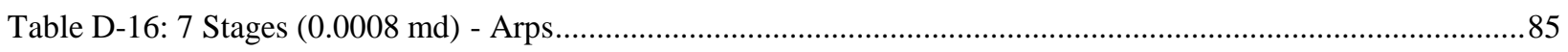

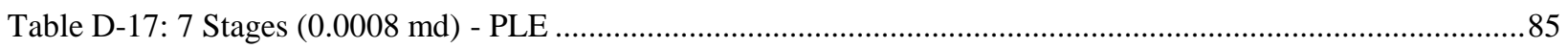

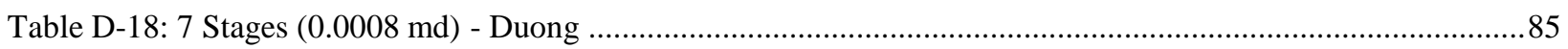

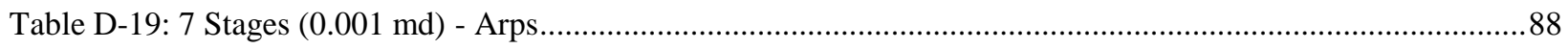

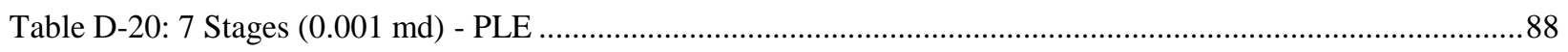

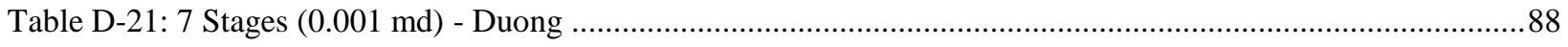

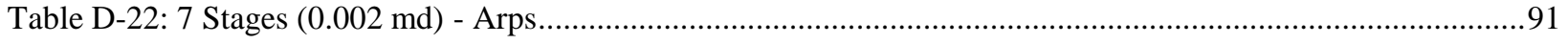

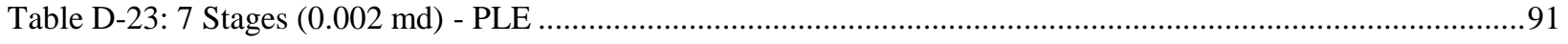

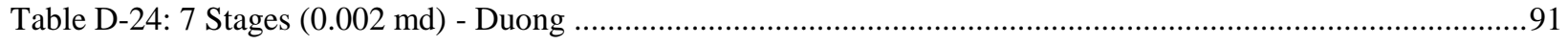

Table D-25: 7 Stages (0.004 md) - Arps.........................................................................................................

Table D-26: 7 Stages (0.004 md) - PLE ........................................................................................................94

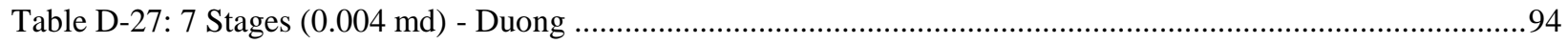

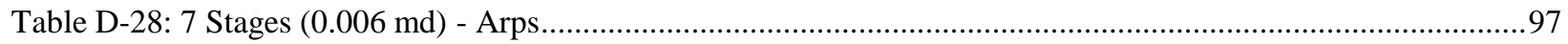

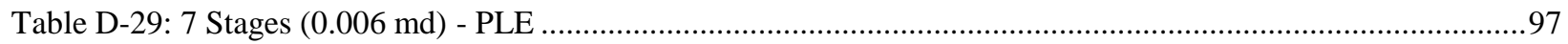

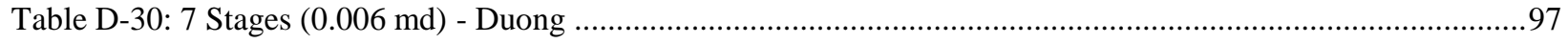

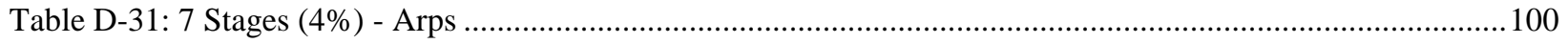




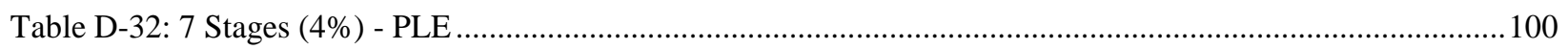

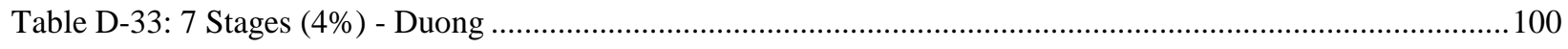

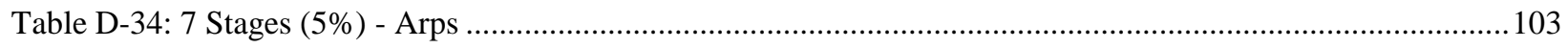

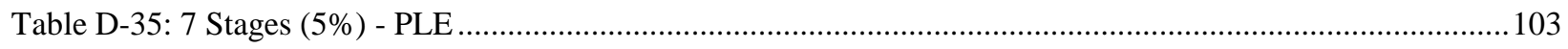

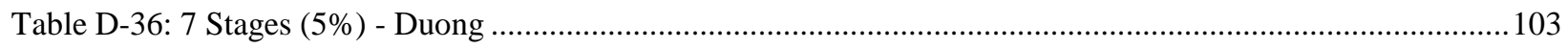

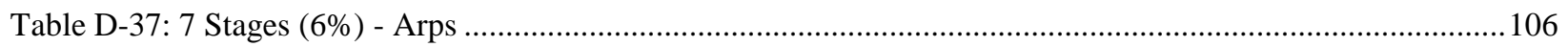

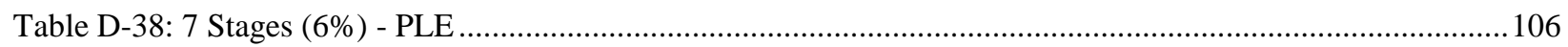

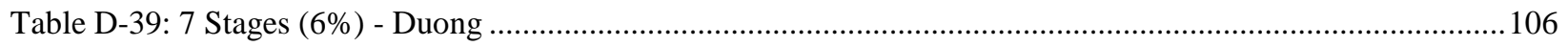

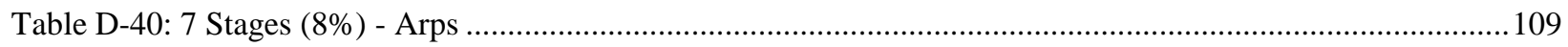

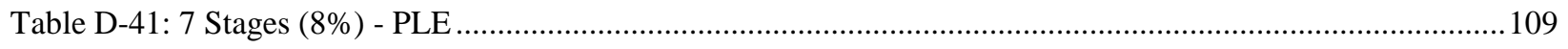

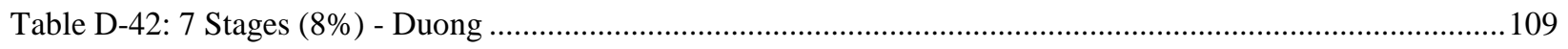

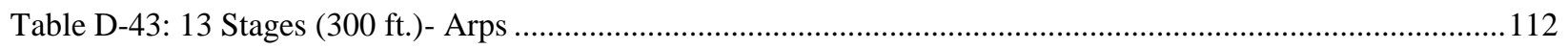

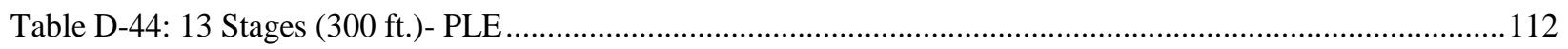

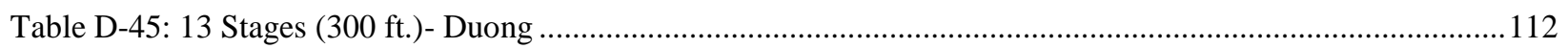

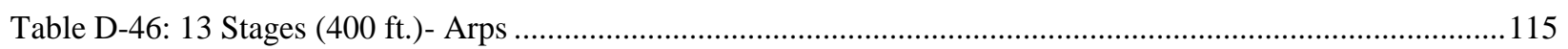

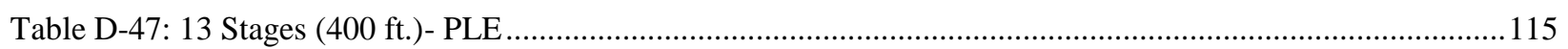

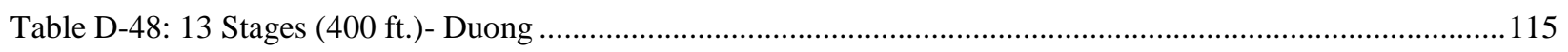

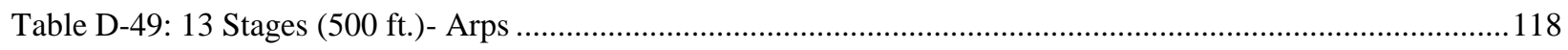

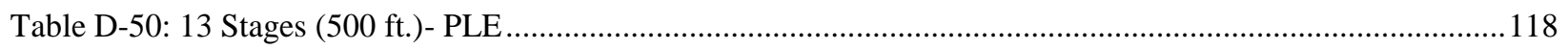

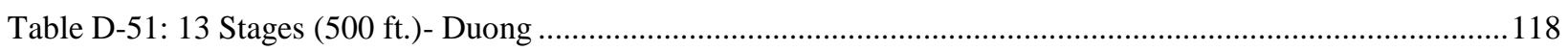

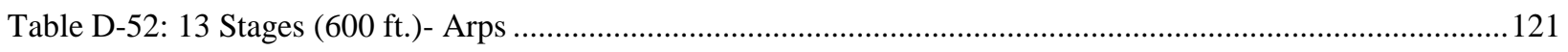

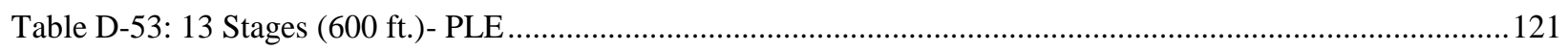

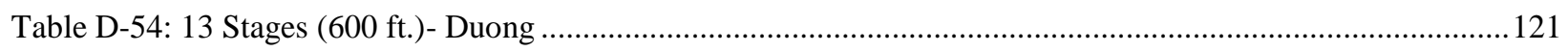

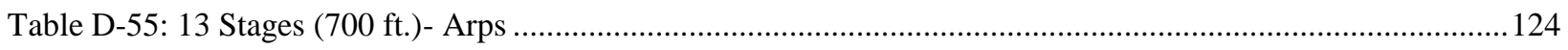

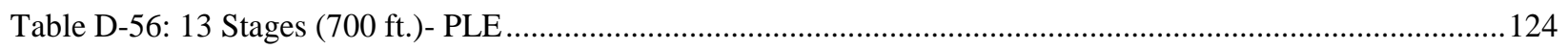

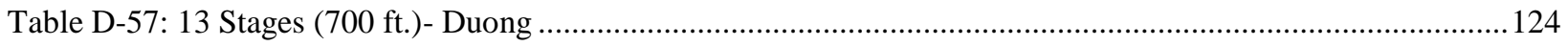

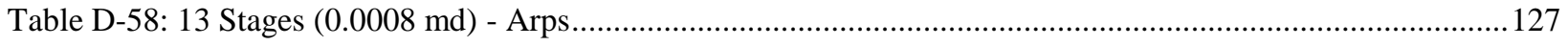

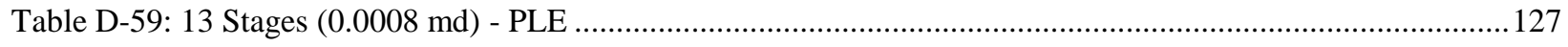

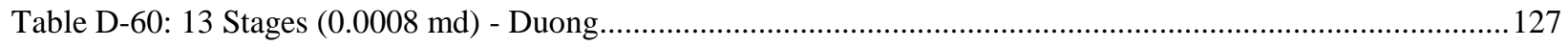

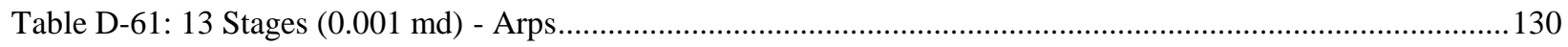

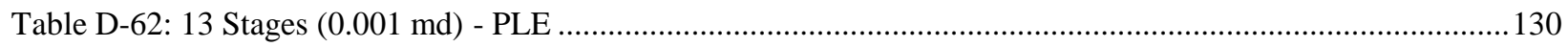

Table D-63: 13 Stages (0.001 md) - Duong …………….................................................................................130

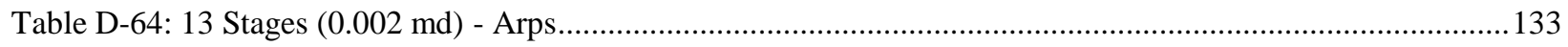

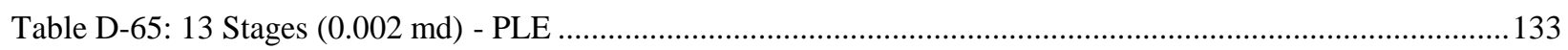




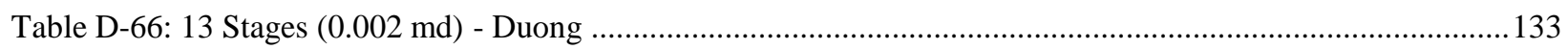

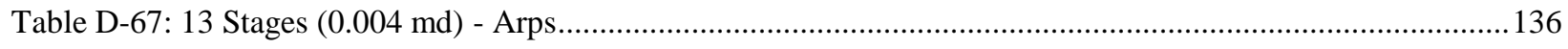

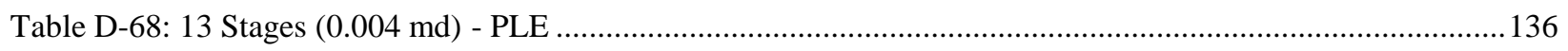

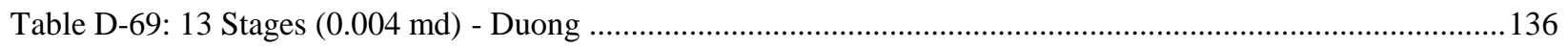

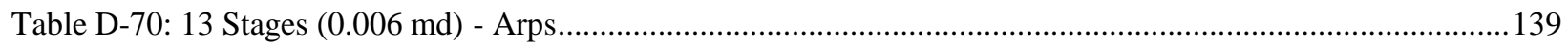

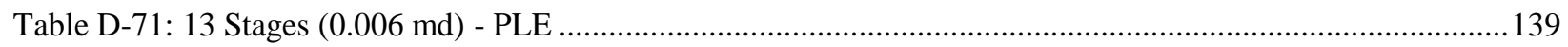

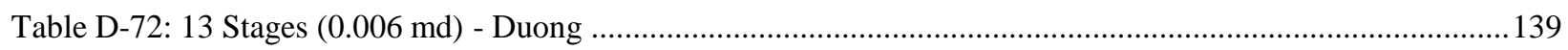

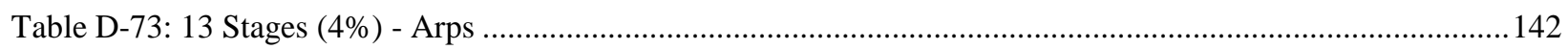

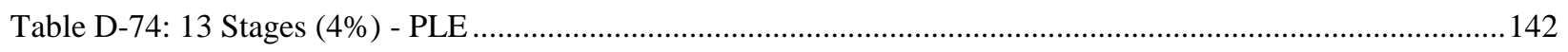

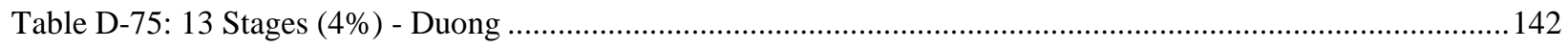

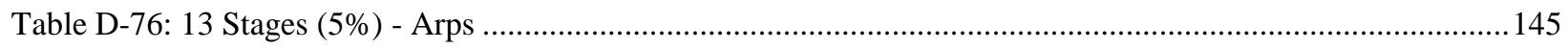

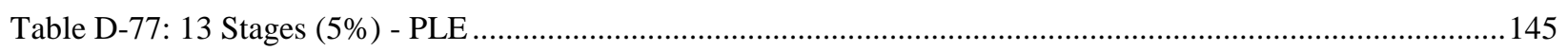

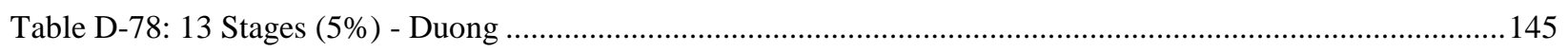

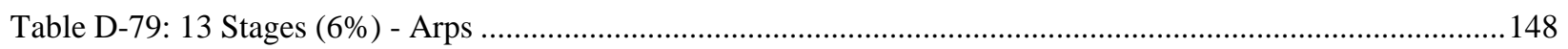

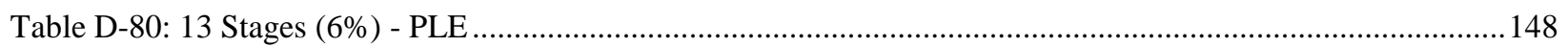

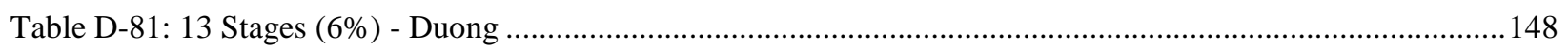

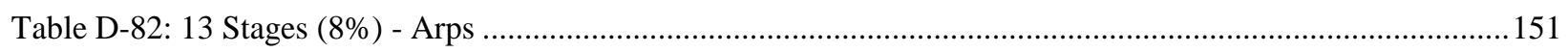

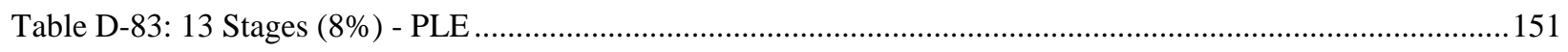

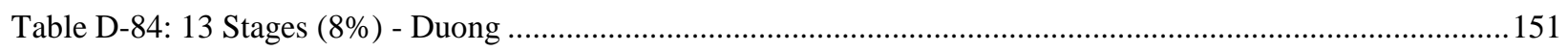

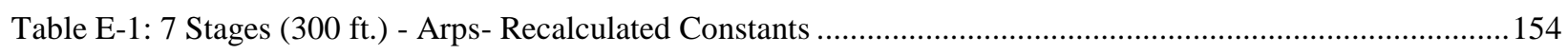

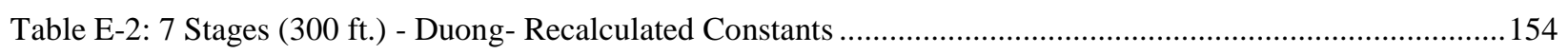

Table E-3: 7 Stages (400 ft.) - Arps- Recalculated Constants ..............................................................................154

Table E-4: 7 Stages (400 ft.) - Duong - Recalculated Constants ..........................................................................155

Table E-5: 7 Stages (500 ft.) - Arps- Recalculated Constants .............................................................................. 155

Table E-6: 7 Stages (500 ft.) - Duong- Recalculated Constants ...........................................................................155

Table E-7: 7 Stages (600 ft.) - Arps- Recalculated Constants ...................................................................................156

Table E-8: 7 Stages (600 ft.) - Duong- Recalculated Constants ............................................................................. 156

Table E-9: 7 Stages (700 ft.) - Arps- Recalculated Constants .................................................................................156

Table E-10: 7 Stages (700 ft.) - Duong- Recalculated Constants ...............................................................................157

Table E-11: 7 Stages (0.0008 m-D) - Arps- Recalculated Constants .......................................................................157

Table E-12: 7 Stages (0.0008 m-D) - Duong- Recalculated Constants ...................................................................157

Table E-13: 7 Stages (0.001 m-D) - Arps- Recalculated Constants ..........................................................................158

Table E-14: 7 Stages (0.001 m-D) - Duong- Recalculated Constants .....................................................................158

Table E-15: 7 Stages (0.002 m-D) - Arps- Recalculated Constants ........................................................................158 


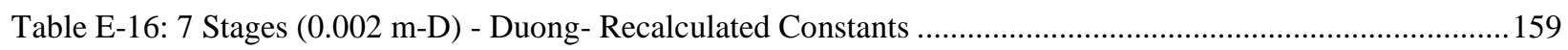

Table E-17: 7 Stages (0.004 m-D) - Arps- Recalculated Constants .....................................................................159

Table E-18: 7 Stages (0.004 m-D) - Duong- Recalculated Constants .....................................................................159

Table E-19: 7 Stages (0.006 m-D) - Arps- Recalculated Constants ...................................................................... 160

Table E-20: 7 Stages (0.006 m-D) - Duong- Recalculated Constants ...................................................................... 160

Table E-21: 7 Stages (4\%) - Arps- Recalculated Constants .................................................................................. 160

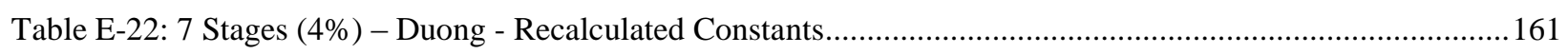

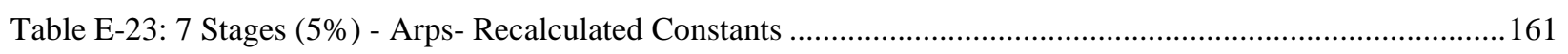

Table E-24: 7 Stages (5\%) - Duong- Recalculated Constants ................................................................................. 161

Table E-25: 7 Stages (6\%) - Arps- Recalculated Constants ................................................................................. 162

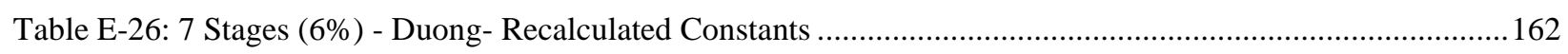

Table E-27: 7 Stages (8\%) - Arps- Recalculated Constants .................................................................................. 162

Table E-28: 7 Stages (8\%) - Duong- Recalculated Constants ............................................................................. 163

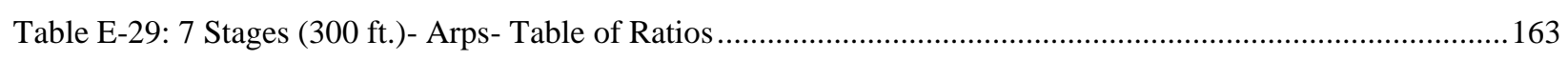

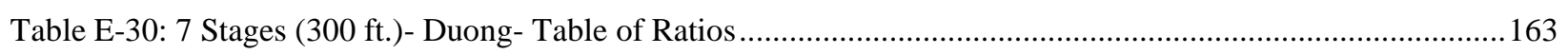

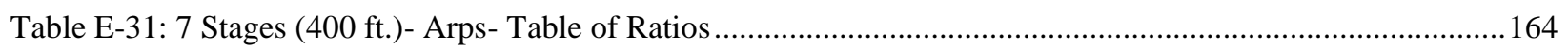

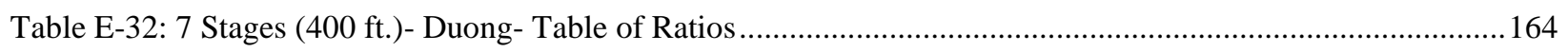

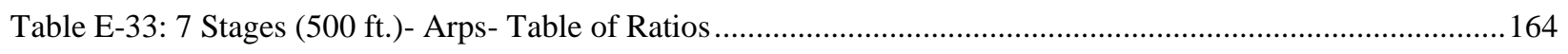

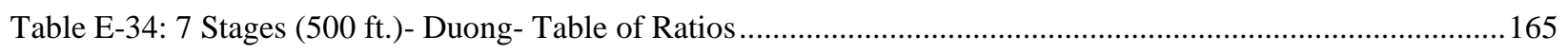

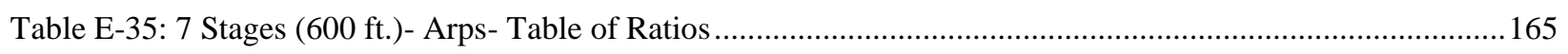

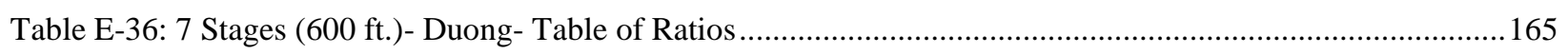

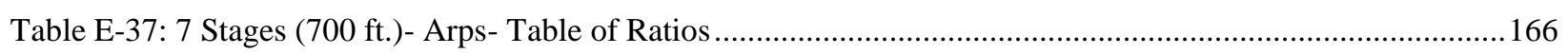

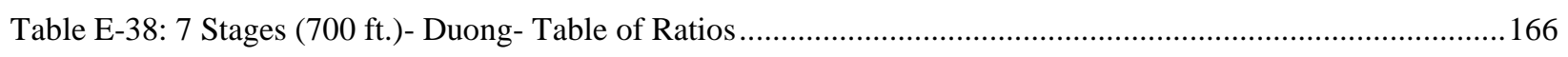

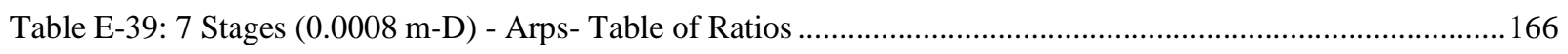

Table E-40: 7 Stages (0.0008 m-D) - Duong- Table of Ratios .............................................................................. 167

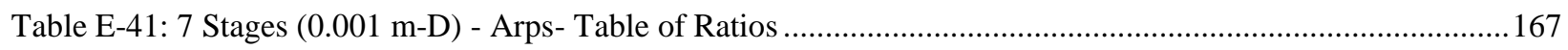

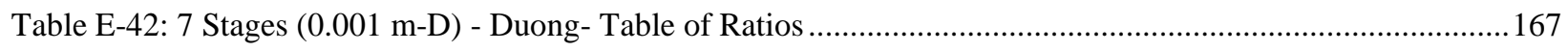

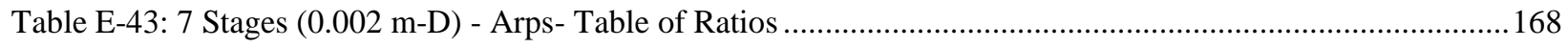

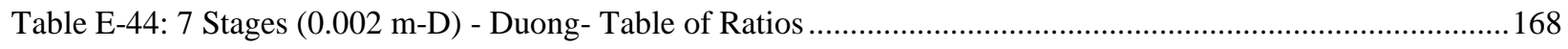

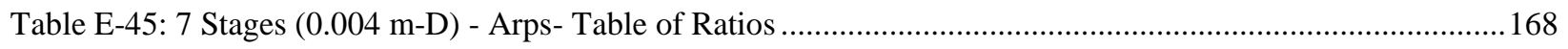

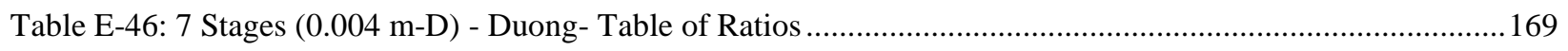

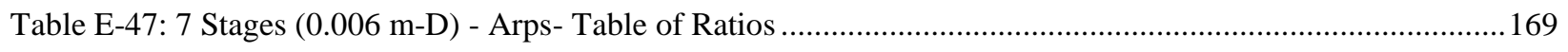

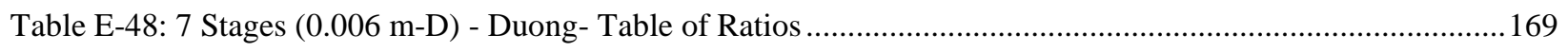

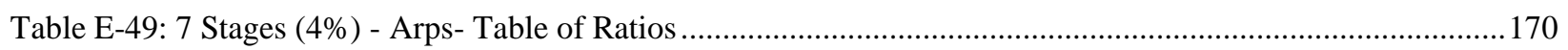




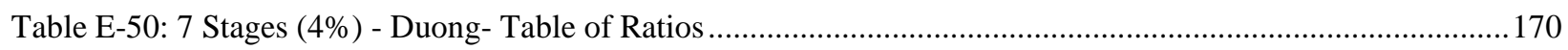

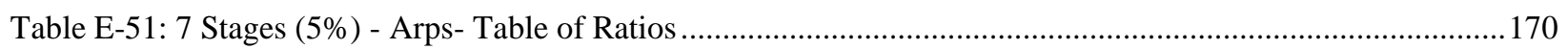

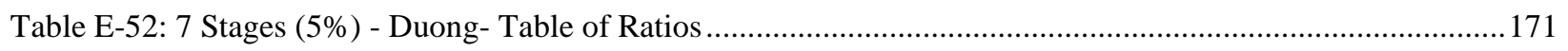

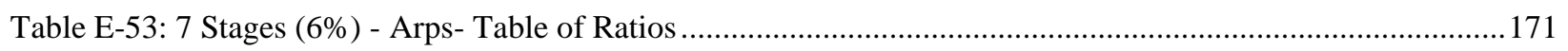

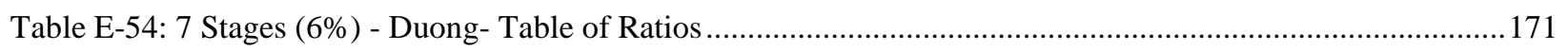

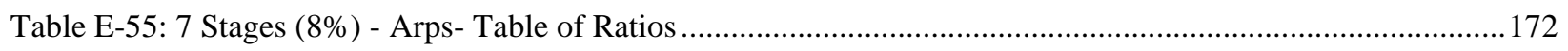

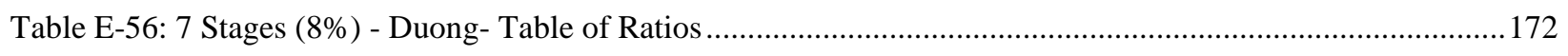

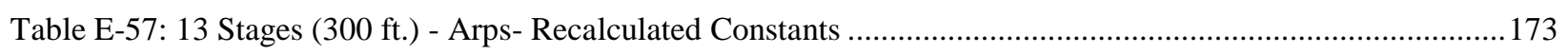

Table E-58: 13 Stages (300 ft.) - Duong- Recalculated Constants ......................................................................... 173

Table E-59: 13 Stages (400 ft.) - Arps- Recalculated Constants ........................................................................... 173

Table E-60: 13 Stages (400 ft.) - Duong- Recalculated Constants .......................................................................174

Table E-61: 13 Stages (500 ft.) - Arps- Recalculated Constants .......................................................................... 174

Table E-62: 13 Stages (500 ft.) - Duong- Recalculated Constants ......................................................................174

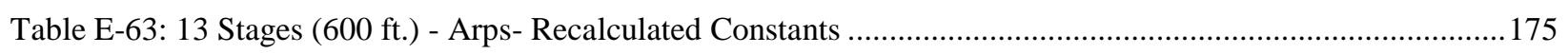

Table E-64: 13 Stages (600 ft.) - Duong- Recalculated Constants ........................................................................175

Table E-65: 13 Stages (700 ft.) - Arps- Recalculated Constants ...........................................................................175

Table E-66: 13 Stages (700 ft.) - Duong- Recalculated Constants .......................................................................... 176

Table E-67: 13 Stages (0.0008 m-D) - Arps- Recalculated Constants ..................................................................176

Table E-68: 13 Stages (0.0008 m-D) - Duong- Recalculated Constants ................................................................. 176

Table E-69: 13 Stages (0.001 m-D) - Arps- Recalculated Constants ..................................................................177

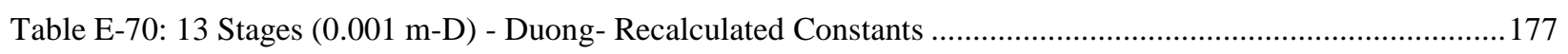

Table E-71: 13 Stages (0.002 m-D) - Arps- Recalculated Constants ................................................................... 177

Table E-72: 13 Stages (0.002 m-D) - Duong- Recalculated Constants ................................................................. 178

Table E-73: 13 Stages (0.004 m-D) - Arps- Recalculated Constants .....................................................................178

Table E-74: 13 Stages (0.004 m-D) - Duong- Recalculated Constants ................................................................178

Table E-75: 13 Stages (0.006 m-D) - Arps- Recalculated Constants ...................................................................... 179

Table E-76: 13 Stages (0.006 m-D) - Duong- Recalculated Constants ...................................................................179

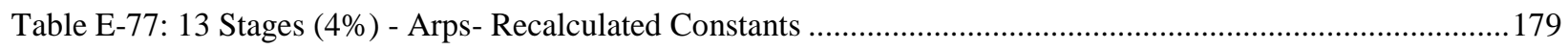

Table E-78: 13 Stages (4\%) - Duong- Recalculated Constants .............................................................................. 180

Table E-79: 13 Stages (5\%) - Arps- Recalculated Constants ................................................................................. 180

Table E-80: 13 Stages (5\%) - Duong- Recalculated Constants ............................................................................... 180

Table E-81: 13 Stages (6\%) - Arps- Recalculated Constants ................................................................................181

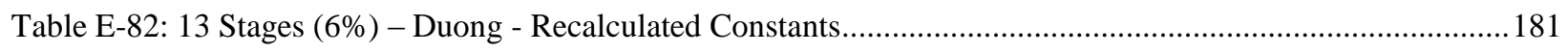

Table E-83: 13 Stages (8\%) - Arps- Recalculated Constants ................................................................................ 181 


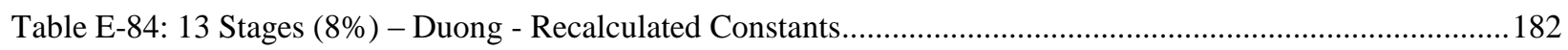

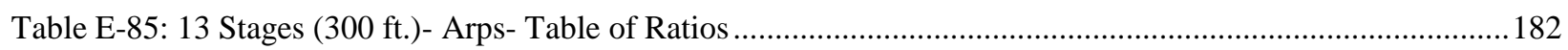

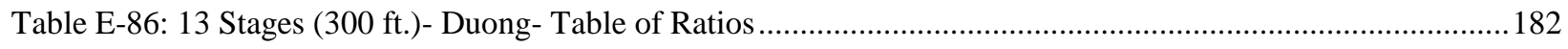

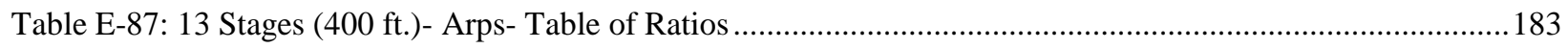

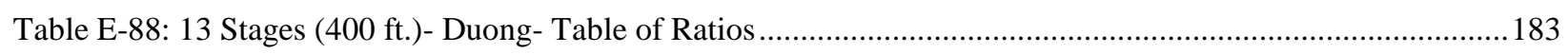

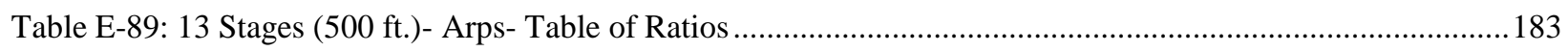

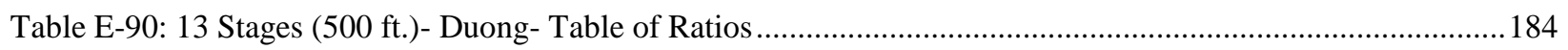

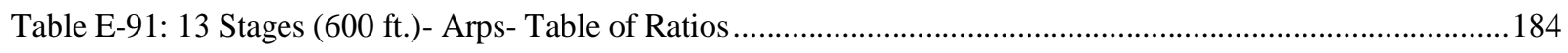

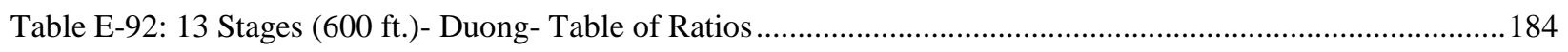

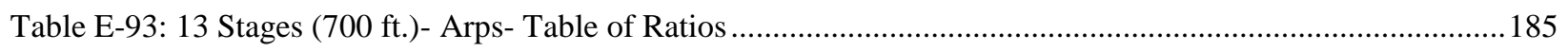

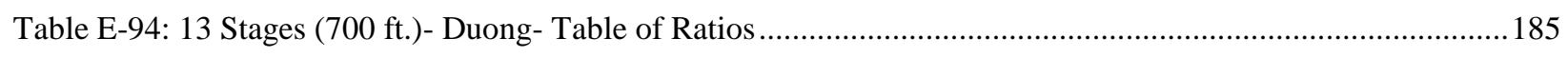

Table E-95: 13 Stages (0.0008 m-D) - Arps-Table of Ratios ............................................................................... 185

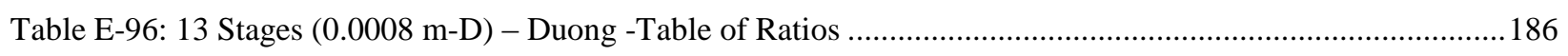

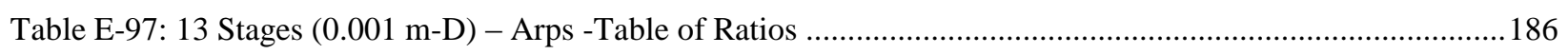

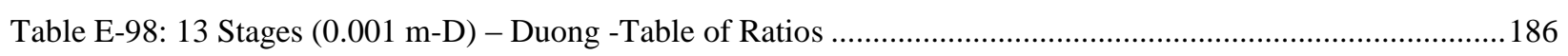

Table E-99: 13 Stages (0.002 m-D) - Arps -Table of Ratios ................................................................................ 187

Table E-100: 13 Stages (0.002 m-D) - Duong -Table of Ratios ............................................................................187

Table E-101: 13 Stages (0.004 m-D) - Arps -Table of Ratios ............................................................................. 187

Table E-102: 13 Stages (0.004 m-D) - Duong -Table of Ratios ........................................................................ 188

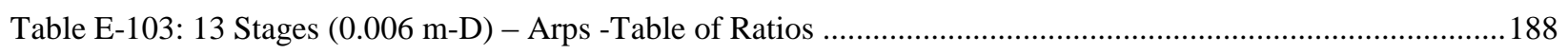

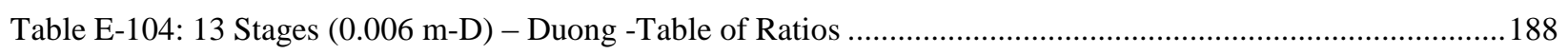

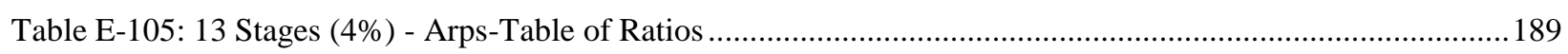

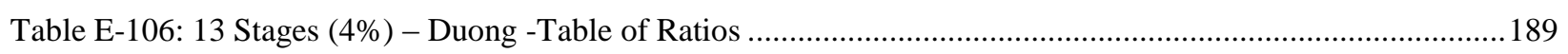

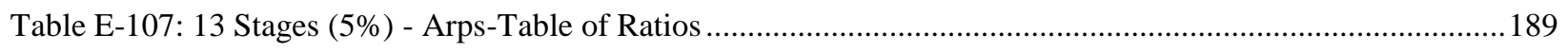

Table E-108: 13 Stages (5\%) - Duong-Table of Ratios ...................................................................................... 190

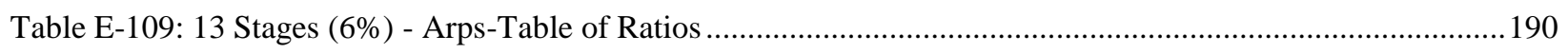

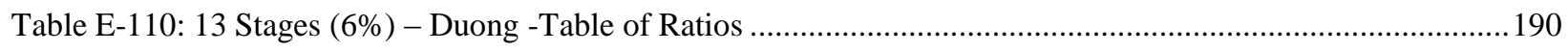

Table E-111: 13 Stages (8\%) - Arps-Table of Ratios ........................................................................................... 191

Table E-112: 13 Stages (8\%) - Duong -Table of Ratios ............................................................................................ 191

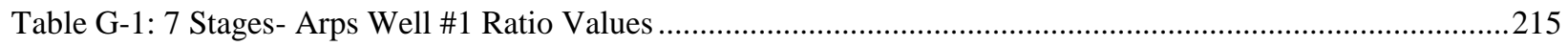

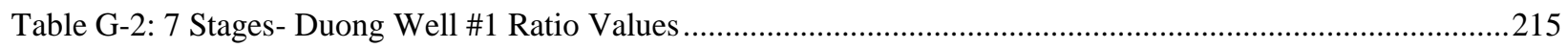

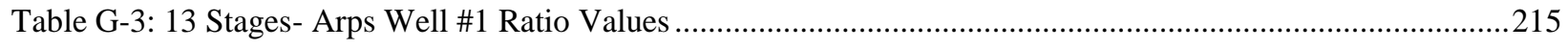

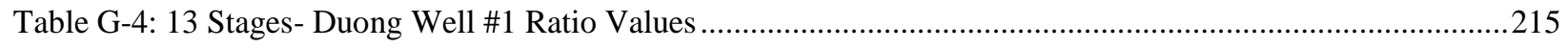

Table G-5: 7 Stages - Arps Well 1 Actual and Predicted Values ...........................................................................2216 
Table G-6: 7 Stages - Duong Well 1 Actual and Predicted Values .....................................................................216

Table G-7: 13 Stages - Arps Well 1 Actual and Predicted Values ......................................................................216

Table G-8: 13 Stages - Duong Well 1 Actual and Predicted Values .......................................................................216

\section{List of Figures}

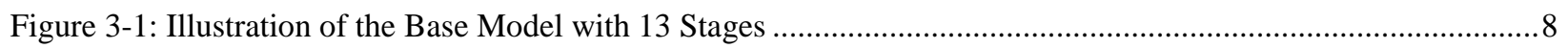

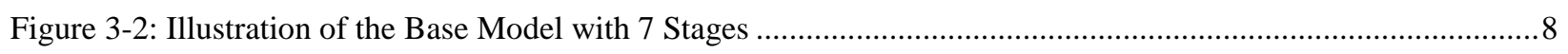

Figure 4-1: 7 Stages Production Profile- Various Fracture Half Length .............................................................12

Figure 4-2: 13 Stages Production Profile-Various Fracture Half Length ................................................................12

Figure 4-3 : Arps, PLE, and Duong DCAs Simulated Data History Match - Seven Stages ......................................13

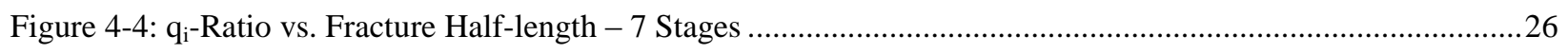

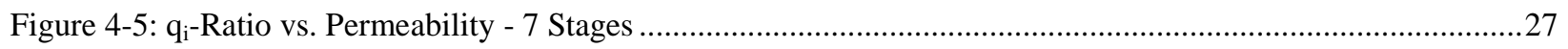

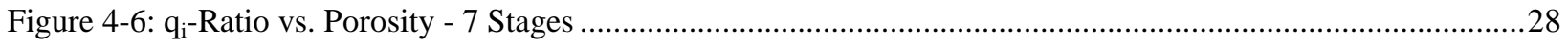

Figure 4-7: q q $_{1}$-Ratio vs. Fracture Half Length- 7 Stages ......................................................................................22

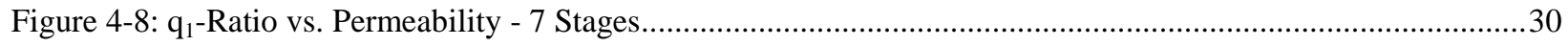

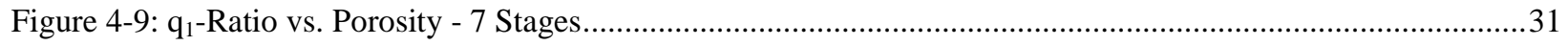

Figure 4-10: qi Ratio vs. Fracture Half-length - 13 Stages ..................................................................................... 34

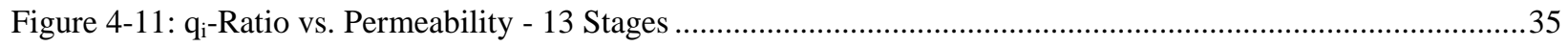

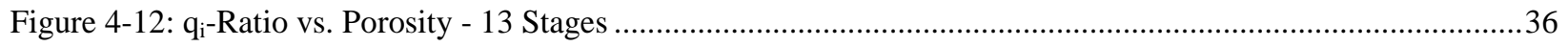

Figure 4-13: q

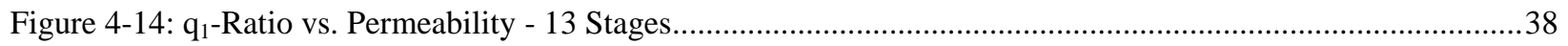

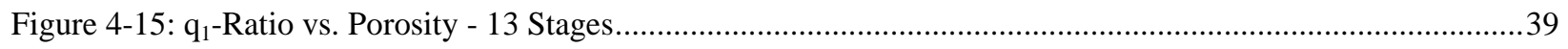

Figure 4-16: n-Ratio Error with the Base Case Model- 7 Stages...............................................................................40

Figure 4-17: $\mathrm{d}_{\mathrm{i}}$-Ratio Error with the Base Case Model- 7 Stages ........................................................................ 41

Figure 4-18: qi -Ratio Error with the Base Case Model- 7 Stages .........................................................................

Figure 4-19: n-ratio Error with the Base Case Model - Permeability- 7 Stages........................................................42

Figure 4-20: di-ratio Error with the Base Case Model - Permeability- 7 Stages........................................................42

Figure 4-21: qi

Figure 4-22: n- Ratio Error with the Base Case Model - 7 Stages ........................................................................43

Figure 4-23: $\mathrm{d}_{\mathrm{i}}$ - Ratio Error with the Base Case Model - 7 Stages ......................................................................

Figure 4-24: qi- Ratio Error with the Base Case Model - 7 Stages .......................................................................43

Figure 4-25: a- Ratio Error with the Base Case Model - Fracture Half length - 7 Stages..........................................4

Figure 4-26: m- Ratio Error with the Base Case Model - Fracture Half length- 7 Stages .............................................44 
Figure 4-27: $\mathrm{q}_{1}$ - Ratio Error with the Base Case Model - Fracture Half length- 7 Stages.....

Figure 4-28: $\mathrm{q}_{\infty}$ - Ratio Error with the Base Case Model - Fracture Half length - 7 Stages..................................45

Figure 4-29: a- Ratio Error with the Base Case Model- Permeability - 7 Stages...............................................46

Figure 4-30: m- Ratio Error with the Base Case Model- Permeability - 7 Stages .............................................46

Figure 4-31: q - Ratio Error with the Base Case Model- Permeability - 7 Stages ...........................................46

Figure 4-32: $\mathrm{q}_{\infty}$ - Ratio Error with the Base Case Model- Permeability - 7 Stages ............................................47

Figure 4-33: n- Ratio Error with the Base Case Model - Fracture Half length - 13 Stages .................................47

Figure 4-34: $d_{i}-$ Ratio Error with the Base Case Model - Fracture Half length- 13 Stages ....................................48

Figure 4-35: $\mathrm{q}_{\mathrm{i}}$ - Ratio Error with the Base Case Model- Fracture Half Length -13 Stages .................................48

Figure 4-36: n- Ratio Error with the Base Case Model - Permeability - 13 Stages..........................................49

Figure 4-37: $\mathrm{d}_{\mathrm{i}}$ - Ratio Error with the Base Case Model - Permeability - 13 Stages ...........................................49

Figure 4-38: $\mathrm{q}_{\mathrm{i}}$ - Ratio Error with the Base Case Model - Permeability - 13 Stages ...........................................49

Figure 4-39: n- Ratio Error with the Base Case Model - Porosity - 13 Stages....................................................50

Figure 4-40: di- Ratio Error with the Base Case Model - Porosity - 13 Stages...................................................50

Figure 4-41: $\mathrm{q}_{\mathrm{i}}$ - Ratio Error with the Base Case Model - Porosity - 13 Stages ..................................................50

Figure 4-42: a- Ratio Error with the Base Case Model - Fracture Half length -13 Stages.......................................

Figure 4-43: m- Ratio Error with the Base Case Model - Fracture Half length -13 Stages .....................................51

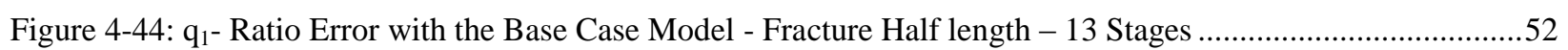

Figure 4-45: $\mathrm{q}_{\infty}$ - Ratio Error with the Base Case Model - Fracture Half length - 13 Stages..................................52

Figure 4-46: a- Ratio Error with the Base Case Model - Permeability- 13 Stages................................................53

Figure 4-47: m- Ratio Error with the Base Case Model - Permeability- 13 Stages ..............................................53

Figure 4-48: q1- Ratio Error with the Base Case Model - Permeability-13 Stages ............................................53

Figure 4-49: $\mathrm{q}_{\infty}$ - Ratio Error with the Base Case Model - Permeability- 13 Stages ............................................54

Figure 4-50: a- Ratio Error with the Base Case Model - Porosity- 13 Stages ...................................................54

Figure 4-51: m- Ratio Error with the Base Case Model - Porosity- 13 Stages..................................................55

Figure 4-52: q1- Ratio Error with the Base Case Model - Porosity- 13 Stages .................................................55

Figure 4-53: $\mathrm{q}_{\infty}$ - Ratio Error with the Base Case Model - Porosity- 13 Stages ................................................55

Figure 4-54: Well 1 Production History Match at 3.5 years (By the Fekete Simulator) .......................................56

Figure 4-55: Well 1 Production Prediction for 360 Months (By the Fekete Simulator) .......................................56

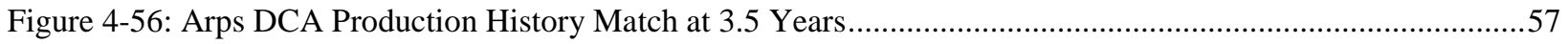

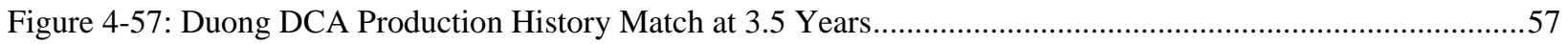

Figure 4-58: Well 1 Production Prediction Comparison ................................................................................58

Figure 4-59: Well 1 Production Prediction Comparison at 30 years (Various Fracture Half length) ......................60

Figure 4-60: Well 1 Production Prediction Comparison at 30 years (Various Permeability) ..................................60 
Figure 4-61: Well 1 Production Prediction Comparison at 30 years (Various Porosity) .............................................61

Figure B-1: 7 Stages Production Profile- Various Permeability ..................................................................................67

Figure B-2: 7 Stages Production Profile- Various Porosity ……………….........................................................67

Figure B-3: 13 Stages Production Profile- Various Permeability ............................................................................68

Figure B-4: 13 Stages Production Profile- Various Porosity ………….................................................................68

Figure C-1: Arps, PLE, and Duong DCA Models Simulated Data History Match - Thirteen Stages ........................69

Figure D-1: 7 Stages - PLE Constants Correlations (300ft.) ………......................................................................

Figure D-2: 7 Stages - Duong Constants Correlations (300ft.),...............................................................................

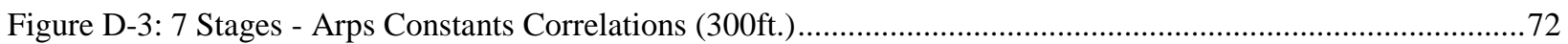

Figure D-4: 7 Stages - PLE Constants Correlations (400ft.) …………............................................................. 74

Figure D-5: 7 Stages - Duong Constants Correlations (400ft.)..........................................................................

Figure D-6: 7 Stages - Arps Constants Correlations (400ft.)............................................................................... 75

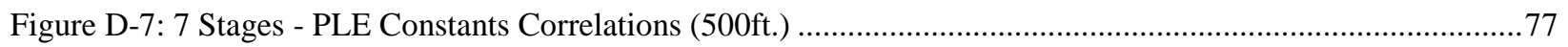

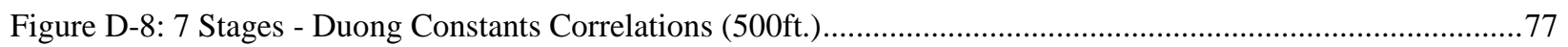

Figure D-9: 7 Stages - Arps Constants Correlations (500ft.)...................................................................................... 78

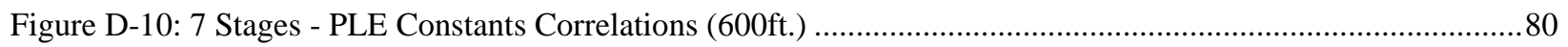

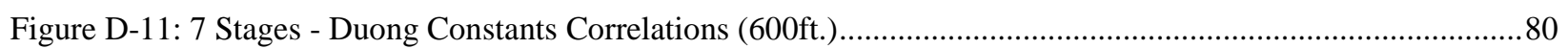

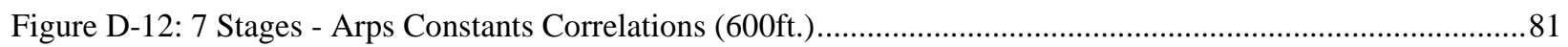

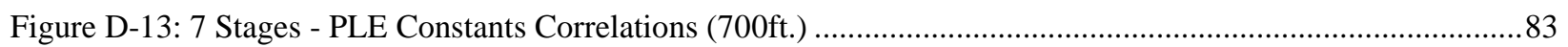

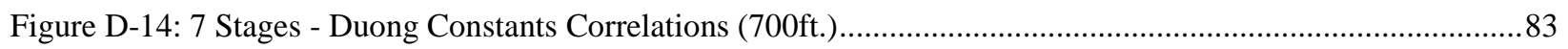

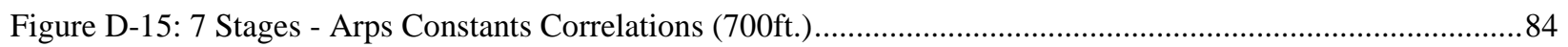

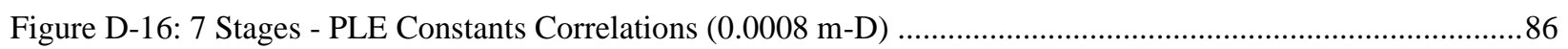

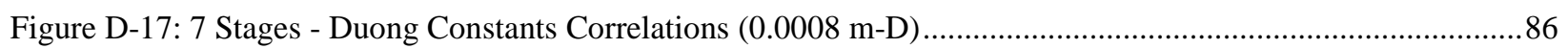

Figure D-18: 7 Stages - Arps Constants Correlations (0.0008 m-D) .................................................................... 87

Figure D-19: 7 Stages - PLE Constants Correlations (0.001 m-D) ……....................................................................89

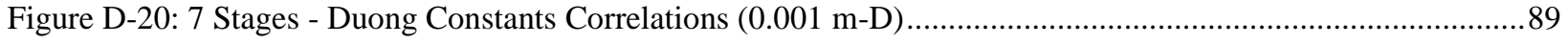

Figure D-21: 7 Stages - Arps Constants Correlations (0.001 m-D) ...........................................................................90

Figure D-22: 7 Stages - PLE Constants Correlations (0.002 m-D) …….................................................................92

Figure D-23: 7 Stages - Duong Constants Correlations (0.002 m-D) ......................................................................92

Figure D-24: 7 Stages - Arps Constants Correlations (0.002 m-D) .........................................................................93

Figure D-25: 7 Stages - PLE Constants Correlations (0.004 m-D) ……….......................................................95

Figure D-26: 7 Stages - Duong Constants Correlations (0.004 m-D) ................................................................95

Figure D-27: 7 Stages - Arps Constants Correlations (0.004 m-D) .......................................................................

Figure D-28: 7 Stages - PLE Constants Correlations (0.006 m-D) …………......................................................98 
Figure D-29: 7 Stages - Duong Constants Correlations (0.006 m-D) ...................................................................98

Figure D-30: 7 Stages - Arps Constants Correlations (0.006 m-D) .........................................................................99

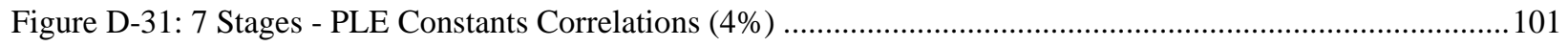

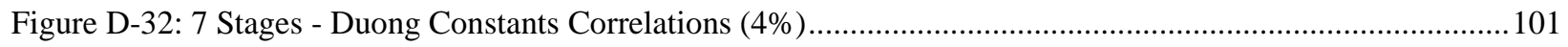

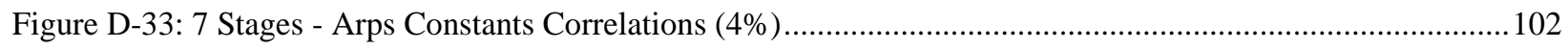

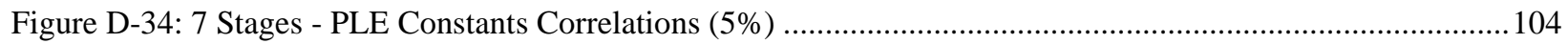

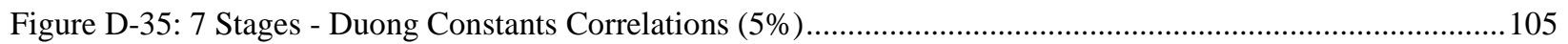

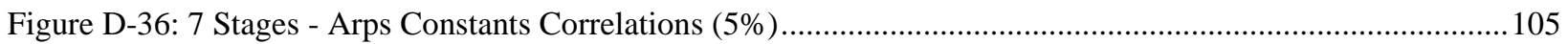

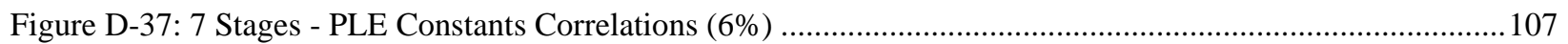

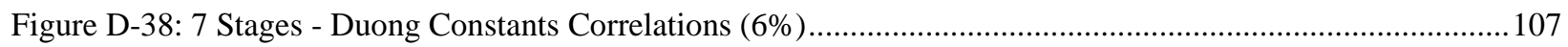

Figure D-39: 7 Stages - Arps Constants Correlations (6\%)................................................................................. 108

Figure D-40: 7 Stages - PLE Constants Correlations (8\%) …………...............................................................

Figure D-41: 7 Stages - Duong Constants Correlations (8\%)........................................................................110

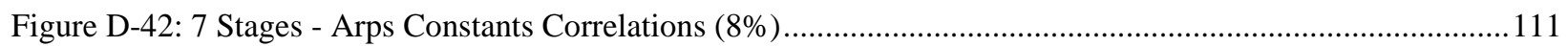

Figure D-43: 13 Stages - PLE Constants Correlation (300ft.) ……..........................................................................113

Figure D-44: 13 Stages - Duong Constants Correlation (300ft.) ……………...................................................113

Figure D-45: 13 Stages - Arps Constants Correlation (300ft.) …………….......................................................114

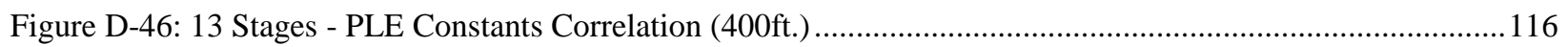

Figure D-47:13 Stages - Duong Constants Correlation (400ft.) ……………............................................................116

Figure D-48: 13 Stages - Arps Constants Correlation (400ft.) ………….......................................................... 117

Figure D-49: 13 Stages - PLE Constants Correlation (500ft.) ………...................................................................119

Figure D-50: 13 Stages - Duong Constants Correlation (500ft.) …….............................................................119

Figure D-51: 13 Stages - Arps Constants Correlation (500ft.) ………............................................................. 120

Figure D-52: 13 Stages - PLE Constants Correlation (600ft.) ………............................................................... 122

Figure D-53: 13 Stages - Duong Constants Correlation (600ft.) …….....................................................................122

Figure D-54: 13 Stages - Arps Constants Correlation (600ft.) ……….....................................................................123

Figure D-55: 13 Stages - PLE Constants Correlation (700ft.) ……........................................................................125

Figure D-56: 13 Stages - Duong Constants Correlation (700ft.) ……..................................................................125

Figure D-57: 13 Stages - Arps Constants Correlation (700ft.) …….....................................................................126

Figure D-58: 13 Stages - PLE Constants Correlation (0.0008 m-D) ......................................................................128

Figure D-59: 13 Stages - Duong Constants Correlation (0.0008 m-D) …….....................................................128

Figure D-60: 13 Stages - Arps Constants Correlation (0.0008 m-D) ................................................................129

Figure D-61: 13 Stages - PLE Constants Correlation (0.001 m-D) ...................................................................... 131

Figure D-62: 13 Stages - Duong Constants Correlation (0.001 m-D) ……….....................................................131 
Figure D-63: 13 Stages - Arps Constants Correlation (0.001 m-D)

Figure D-64: 13 Stages - PLE Constants Correlation (0.002 m-D) ………………….........................................134

Figure D-65: 13 Stages - Duong Constants Correlation (0.002 m-D) ………………................................................134

Figure D-66: 13 Stages - Arps Constants Correlation (0.002 m-D) ......................................................................135

Figure D-67: 13 Stages - PLE Constants Correlation (0.004 m-D) …………........................................................137

Figure D-68: 13 Stages - Duong Constants Correlation (0.004 m-D) ……......................................................137

Figure D-69: 13 Stages - Arps Constants Correlation (0.004 m-D) ......................................................................138

Figure D-70: 13 Stages - PLE Constants Correlation (0.006 m-D) ........................................................................ 140

Figure D-71: 13 Stages - Duong Constants Correlation (0.006 m-D) ……….................................................... 140

Figure D-72: 13 Stages - Arps Constants Correlation (0.006 m-D) ................................................................ 141

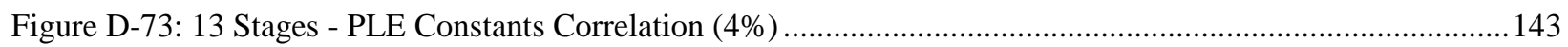

Figure D-74: 13 Stages - Duong Constants Correlation (4\%) ......................................................................... 143

Figure D-75: 13 Stages - Arps Constants Correlation (4\%) ............................................................................ 144

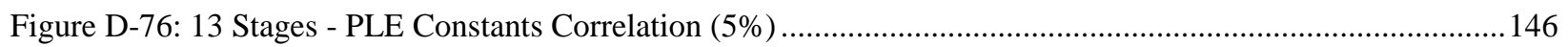

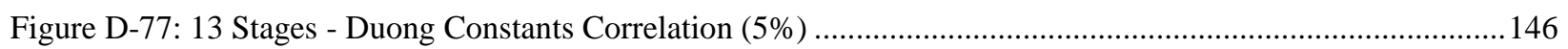

Figure D-78: 13 Stages - Arps Constants Correlation (5\%) ............................................................................ 147

Figure D-79: 13 Stages - PLE Constants Correlation (6\%) ............................................................................. 149

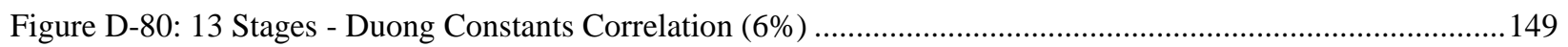

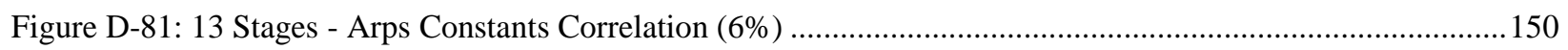

Figure D-82: 13 Stages - PLE Constants Correlation (8\%) ........................................................................... 152

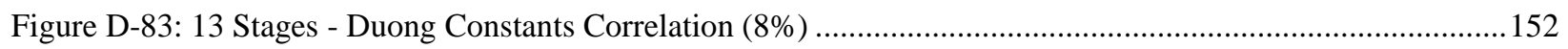

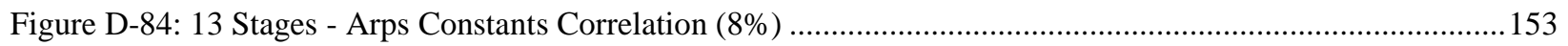

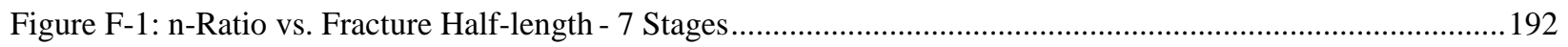

Figure F-2: $\mathrm{d}_{\mathrm{i}}$-Ratio vs. Fracture Half-length - 7 Stages ...................................................................................... 193

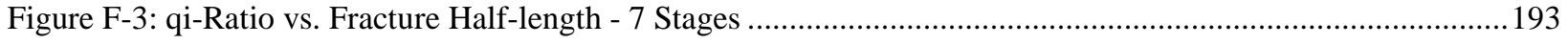

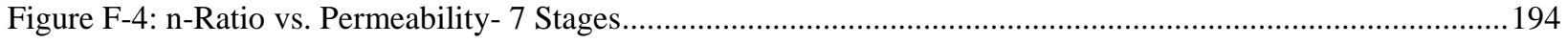

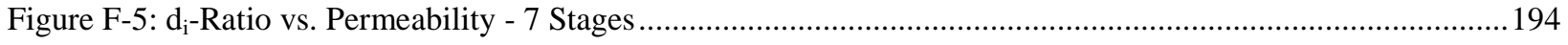

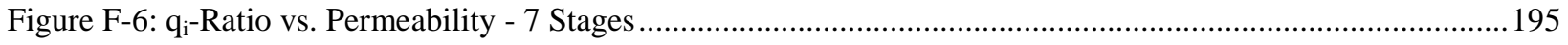

Figure F-7: n-Ratio vs. Porosity- 7 Fractures .................................................................................................. 196

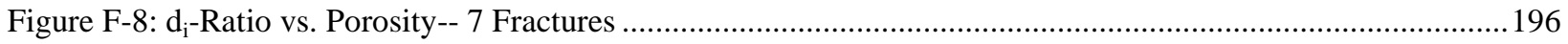

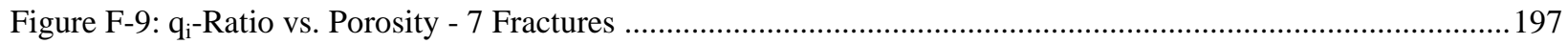

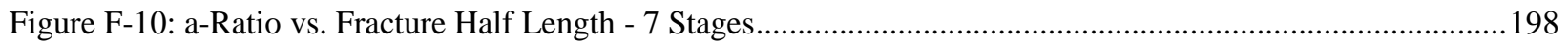

Figure F-11: m-Ratio vs. Fracture half-length- 7 Stages ....................................................................................... 198

Figure F-12: q 


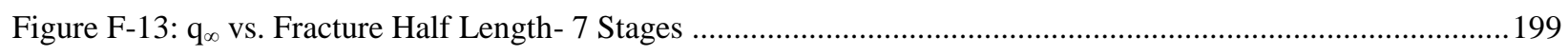

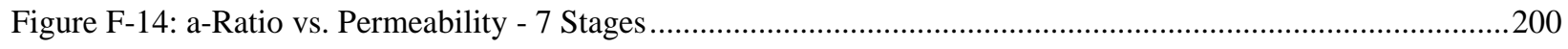

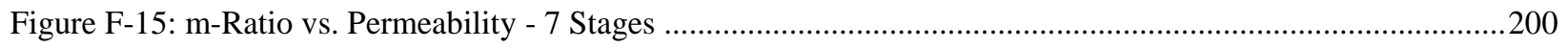

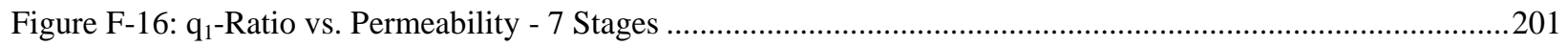

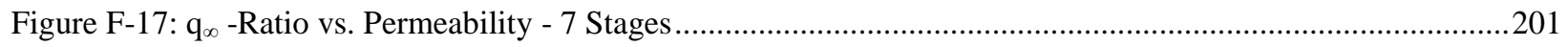

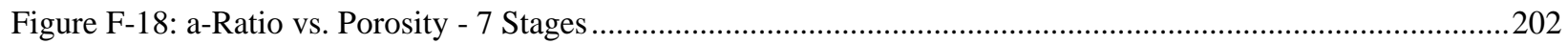

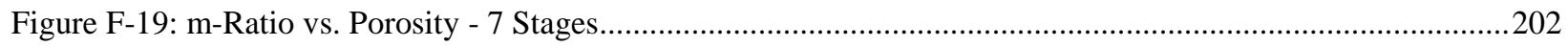

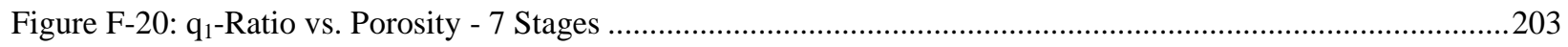

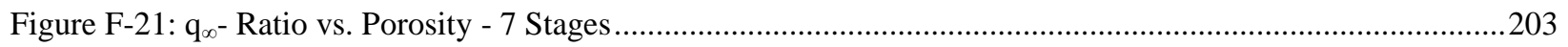

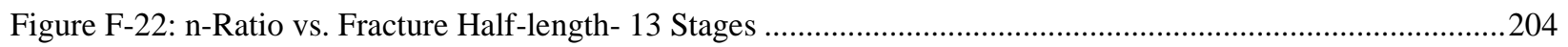

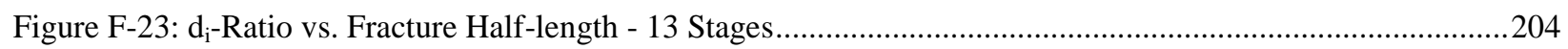

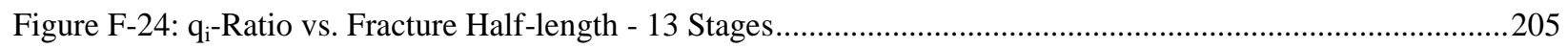

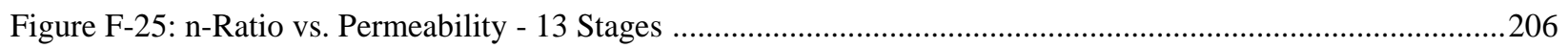

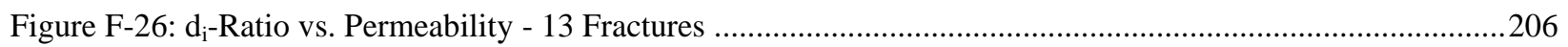

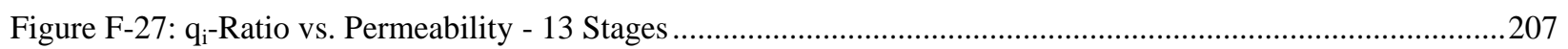

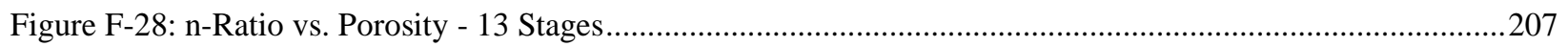

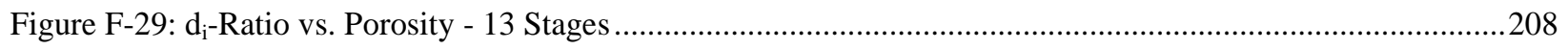

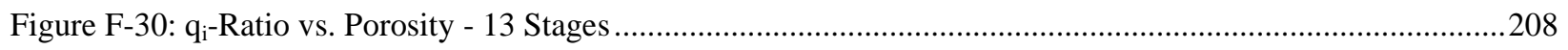

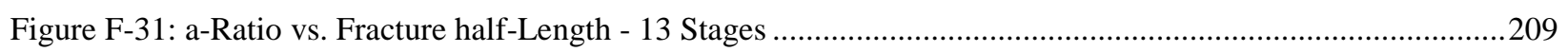

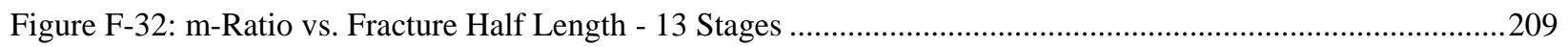

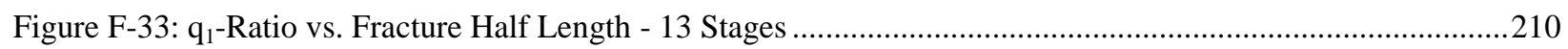

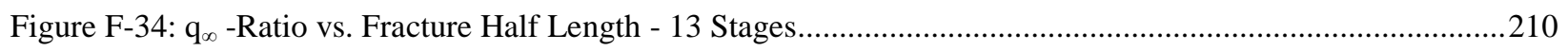

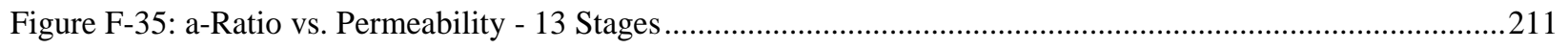

Figure F-36 : m-Ratio vs. Permeability - 13 Stages ……...............................................................................211

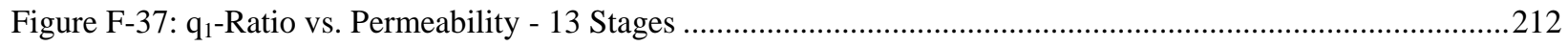

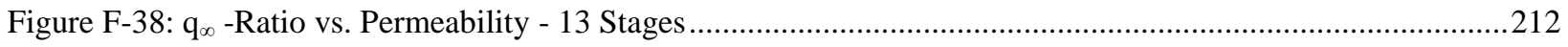

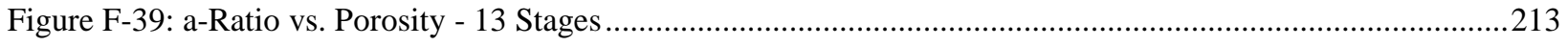

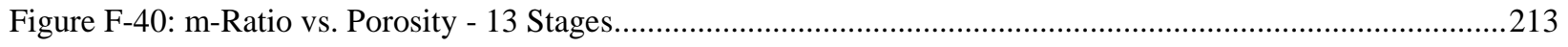

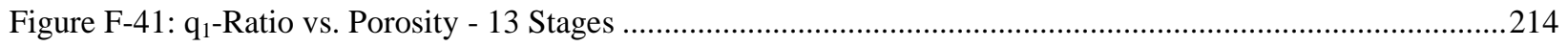

Figure F-42: q

Figure G-1: Well 1 History Match Comparison (at 3.5 years) - Various Fracture half Length ................................2217

Figure G-2: Well 1 History Match Comparison (at 3.5 years) - Various Permeability .............................................217

Figure G-3: Well 1 History Match Comparison (at 3.5 years) - Various Porosity ...................................................218 


\section{Nomenclature}

$\mathrm{d}_{\mathrm{i}}=$ Loss Ratio, $1 /$ time

$\mathrm{q}_{\mathrm{i}}=$ Initial flow rate, volume/time

$\mathrm{n}=$ Derivative of Loss Ratio, dimensionless

$\mathrm{G}_{\mathrm{p}}=$ Cumulative gas production, volume

$\mathrm{D}_{\infty}=$ Loss ratio at $(\mathrm{t}=\infty), 1 /$ time

$\mathrm{D}_{1}=$ Loss ratio at $(\mathrm{t}=1), 1 /$ time

$\mathrm{q}=$ Flow rate, volume/time

$\mathrm{a}=$ Vertical axis intercept of $\mathrm{q} / \mathrm{G}_{\mathrm{p}}$ vs. time plot, dimensionless

$\mathrm{m}=$ Slope of $\log -\log$ plot of $\mathrm{q} / \mathrm{G}_{\mathrm{p}}$ vs. time plot, dimensionless

$\mathrm{t}(\mathrm{a}, \mathrm{m})=$ Duong time function, dimensionless

$\mathrm{q}_{1}=$ Slope of q vs. $\mathrm{t}(\mathrm{a}, \mathrm{m})$ plot, volume

$\mathrm{q}_{\infty}=$ Vertical axis intercept of $\mathrm{q}$ vs. $\mathrm{t}(\mathrm{a}, \mathrm{m})$ plot, dimensionless

$\mathrm{t}=$ time, years

$\mathrm{K}=$ permeability, m-Darcy

$X_{\mathrm{f}}=$ Fracture Half-length, feet

$\Phi=$ Porosity, Fraction

$\mathrm{S}_{\mathrm{SE}}=$ Sum of error squared

$\mathrm{S}_{\mathrm{ST}}=$ Total of error squared

$\mathrm{R}^{2}=$ Regression Coefficient, dimensionless 


\section{Introduction and Problem Statement}

Shale gas reservoirs have become a significant source of gas supply in North America after development of the Barnett Shale in Texas, USA (Belvalkar 2010). The exploitation of these ultra-low permeability formations has been possible due to advancement of drilling and stimulation techniques. The key to maximizing gas production in these reservoirs is the development of an interconnected fracture system through effective simulation treatment. The main objective of stimulation treatments is to obtain a large, highly fractured network that can produce from the ultra-low permeability rock. The primary method of stimulating these formations is by means of horizontal wells with multi-stage hydraulic fractures. Large water-fracs with light proppant are currently being used with good success in many areas (Belyadi et al, 2012). Although both vertical and horizontal wells can be used, horizontal wells are considered to be more cost effective in achieving commercial production from the shale (Belyadi et al, 2010).

Analytical and empirical approaches for forecasting production for horizontal wells with multi-stage hydraulic fractures are not well established due to the limited field experience. Yet, rigorous techniques are highly in demand from the industry to assist with forecasting of horizontal wells with multiple fractures, which is a critical step for reserve estimation and development planning (Nobakht, 2011).

Various techniques have been discussed in the literature for production analysis and estimating the shale-gas reserves. One of the most commonly used procedures is decline-curve analysis (DCA). Prior to the development of DCA models, estimation of oil reserves was accomplished by calculating the contents of a reservoir based on saturation and percentage of recoverable oil over a certain known area (Valko, 2010). This resulted in a very rough estimate of recoverable hydrocarbons (Valko, 2010). Traditional Arps' Decline Analysis equation (1945) estimates a reliable ultimate recovery for conventional oil and gas wells; since they exhibit boundary dominated flow (BDF) to abandonment. Unlike conventional reservoirs, analyzing shale production data using traditional decline curve methods is problematic because of the nature of the reservoir properties and flow behavior. Shale wells have a long transient flow due to the very low matrix permeability (Kanfar 2012). Therefore, application of Arps' DCA to production data from the unconventional reservoirs results in significant overestimation of reserves (Okouma, 2012).

The issues related to misapplications of the Arps' equation have led to the development of new empirical equations more suitable for shale production decline analysis. The recent methods are the Power Law Exponential Decline (PLE) and Duong's method which account for production during transient flow followed by the boundary dominated flow (Joshi, 2013). While it has been demonstrated 
that these new decline curves can be used to successfully match the complete production history of the shale wells, their ability to predict future production rates from the limited production history remain uncertain. In addition, the impact of the formation and hydraulic fracture characteristics cannot be incorporated in the production forecasts due to empirical nature of the decline curves.

\section{Literature Review}

Production decline analysis is probably the most prominent method for forecasting future production from tight gas and shale formations (Lee and Sidle, 2010; Mishra, 2012). Arps' hyperbolic model is used for estimating ultimate recovery of conventional oil and gas wells. However, this model usually results in overestimation of the reserves for shale gas due to the long transient flow. This has brought about several alternative decline curve analysis methods which are empirically formulated for shale and tight gas wells. The two recent methods considered here besides the traditional Arps' DCA are: the Power Law Exponential Decline and Duong's method. Each of these methods might be applicable for specific cases (Kanfar, 2012).

\subsection{Arps' Model}

Production rates exhibit three different types of declines during BDF: Exponential, Hyperbolic and Harmonic. Aprs models these declines using the concept of loss ratio and its derivative (Kanfar, 2012).

Johnson and Bollens (1928) and later Arps (1945) presented the well's "loss ratio (rate of change of the reciprocal of instantaneous decline rate)" and the "derivative of the loss-ratio" functions respectively as:

$$
\begin{aligned}
& \frac{1}{D}=-\frac{q}{d q / d t} \ldots \ldots \ldots \ldots \ldots \ldots \ldots \ldots \ldots \ldots \ldots \\
& n=\frac{d}{d t}\left[-\frac{q}{d q / d t}\right] \ldots \ldots \ldots \ldots \ldots \ldots \ldots \ldots \ldots \ldots
\end{aligned}
$$

Equations 1 and 2 are empirical results based on observations (Ilk, 2008).

When $\boldsymbol{D}$ is constant, equation 1 leads to an exponential decline which can be derived for the case of pseudo-steady state (or boundary dominated) flow in a closed reservoir containing a constant compressibility liquid and being produced at a constant wellbore flowing pressure (Ilk, 2008). The other two cases, on the other hand, were not totally based on any physical basis, but can be utilized in 
multilayered reservoirs during BDF. Decline exponent ( $\boldsymbol{n}$ - values) ranging from 0 to 1 for these three cases. Where $\boldsymbol{n}=\boldsymbol{0}$ indicates the exponential decline, $\boldsymbol{0}<\boldsymbol{n}<\boldsymbol{1}$ the hyperbolic decline, and $\boldsymbol{n}=\boldsymbol{1}$ the harmonic decline (Kanfar, 2012).

Assuming constant loss ratio, $\boldsymbol{n}$, Arps derived his hyperbolic decline model in equation 3.

$$
q=q_{i}\left(1+n d_{i} t\right)^{-1 / n}
$$

For the boundary dominated flow regime the $\boldsymbol{n}$ value lies between 0 and 1, depending on the reservoir fluid, reservoir characteristics, and operating conditions (Fetkovich et al., 1996). However, "high" $\boldsymbol{n}$ values $(\boldsymbol{n}>\mathbf{1})$ seem to match the field data from the transient-flow period. For instance, transient linear flow, multi-fracture flow, and bilinear flow which often observed in shale gas reservoirs can be matched with Arps hyperbolic model with $\boldsymbol{n}$ values of 2,3, and 4 respectively (Okouma, 2012).

Integration of Eq. (3) leads to an expression for cumulative production, $\boldsymbol{G}_{\boldsymbol{p}}$ (Mishra, 2012):

$$
G_{p}=\frac{q_{i}^{n}}{d_{i}(n-1)}\left(q(t)^{(1-n)}-q_{i}^{(1-n)}\right)
$$

\subsection{Power Law Exponential Decline Model (PLE)}

Power Law Exponential has been proposed by Ilk et al. (2008) to address the problem with overestimating the reserves from the wells with transient flow (Seshadri, 2010). Traditional exponential decline often does not fit production rates from unconventional reservoirs; since they have a large decline rate in early production period, but over time the decline rate becomes smaller. Power Law Exponential decline model is empirically developed for tight/shale gas production data analysis by matching early transient data without over-estimating reserves as compared to hyperbolic decline prediction with a high $n$-exponent.

Loss ratio during transient linear and bilinear flow has a power law relation with time. Therefore, the PLE loss ratio $(\boldsymbol{D})$ model developed by the following equation:

$$
D=D_{\infty}+D_{1} t^{-(1-n)}
$$

In case $\boldsymbol{D}_{\infty}=\mathbf{0}$ and $\boldsymbol{n}=\mathbf{1}$, the Power Law loss ratio turns into traditional exponential.

This forecast is sensitive to $\boldsymbol{D}_{\infty}$ values; since it sets a limit on how low the loss ratio can become. Therefore, it prevents the reserves over-prediction (Seshadri, 2010). In early production time, $\boldsymbol{D}_{\infty}$ is 
insignificant; so the model becomes a power law function to match linear or bilinear flow. On the other hand, at late times, $\boldsymbol{D}_{\infty}$ is more effective and Eq. 5 becomes constant and fit the loss ratio of exponential decline (Kanfar, 2012).

The Power Law rate-time relation is given in equation 6 below:

$$
q=q_{i} \exp \left(-D_{\infty} t-\frac{D_{1}}{n} t^{n}\right)
$$

The $\boldsymbol{n}$ value typically lies between 0 and 1. As $\boldsymbol{n}$ gets closer to zero, the power law's decline rates start off large, and then gets smaller over time. This is very similar to how tight gas reservoirs behave. Although zero value for $\boldsymbol{n}$ makes the Eq. 5 undefined, it can be shown analytically that transient linear flow corresponds to $\boldsymbol{n = 0}$ (Mattar and Moghadam, 2009).

\subsection{Duong Model}

The dominant flow in shale gas reservoirs with hydraulic fractures is the fracture flow, and it rarely reaches pseudo-radial and boundary dominated flow even over several years of production. This suggests that matrix contribution is not considerable in compare to fracture contribution. Therefore, there should be an expansion in connected fracture area or stimulated rock volume (SRV) over time to support these fracture flows. This increase is possible by reactivating existing faults and fractures through changing depletion pressure and local stress. Duong introduced an empirically derived decline model based on the SRV expansion which leads to long-term linear flow (Doung, 2012; Kanfar, 2012).

In case of finite conductivity fractures, the flow will be bilinear which can be shown as a quarterslope line on a log-log plot of rate vs. time; while for infinite conductivity fractures, flow will be linear and indicates by a half-slope line on the same plot.

If a fracture flow regime (either linear or bilinear) extends through the life of the well, productionrate and time would have a power law relation and form a straight line on a log-log scale with a slope of 1 (Doung, 2012; Kanfar, 2012). However, by analyzing of field data from different shale gas wells, Duong substitute the time exponent (slope) with a negative slope of $\boldsymbol{- m}$, and an intercept of $\boldsymbol{a}$. The modified equation is:

$$
\frac{q}{G_{p}}=a t^{-m}
$$

The $\log$ - $\log$ plot of $\boldsymbol{q} / \boldsymbol{G}_{\boldsymbol{p}}$ vs. time is generated to determine the values of $\boldsymbol{a}$ and $\boldsymbol{m}$ through a linear regression analysis. The $\boldsymbol{R}^{2}$ value is used to determine the best fit of data, and it is recommended to accept 
$\boldsymbol{R}^{2}$ more than 0.95 . The slope, $\boldsymbol{m}$, is always greater than unity for shale reservoirs; while $\boldsymbol{m}$ less than unity indicates a conventional tight well (Duong, 2012).

Once $\boldsymbol{a}$ and $\boldsymbol{m}$ are determined, by plotting flow rate versus $\boldsymbol{t}(\boldsymbol{a}, \boldsymbol{m})$ and using following equations $\boldsymbol{q}_{1}$ and $\boldsymbol{q}_{\infty}$ will be obtained. During production, due to many factors such as water production or liquid dropout/hold up in the fracture system and wellbore there might be a deviation from fracture flow which results in high decline rate. Thus, the values of $\boldsymbol{q}_{1}$ and $\boldsymbol{q}_{\infty}$ (the rate at infinite time) are designed to represent this increase in production (Duong, 2012).

$$
\begin{aligned}
& t(a, m)=t^{-m} e^{\frac{a}{1-m}\left(t^{1-m}-1\right)} \\
& q=q_{1} t(a, m)+q_{\infty} \ldots \ldots \ldots
\end{aligned}
$$

The $\boldsymbol{q}$-vs. $\boldsymbol{t}(\boldsymbol{a}, \boldsymbol{m})$ plot will give a straight line with slope of $\boldsymbol{q}_{\boldsymbol{l}}$ and intercept of $\boldsymbol{q}_{\infty}$. Since $\boldsymbol{q}_{\infty}$ is the rate at infinite time, it can be zero, positive, or negative. Nonetheless, the original model did not include the term $\boldsymbol{q}_{\infty}$. It has been added to the equation to consider the cases that showed an intercept instead of a straight line to the origin on the plot of $\boldsymbol{q}$ vs. $\boldsymbol{t}(\boldsymbol{a}, \boldsymbol{m})$ (Duong, 2012).

Duong (2011) derived expressions for production rate and cumulative production vs. time that satisfy Eq. 10 as given below:

$$
G_{p}=\frac{q_{1} t(a, m)}{a t^{-m}}
$$

As shown in Eq. 10, cumulative production is not related to $\boldsymbol{q}_{\infty}$ and can only be used when $\boldsymbol{q}_{\infty}$ is zero (Kanfar, 2012). 


\section{Objective and Methodology}

\subsection{Objectives}

The three main goals of this study are:

1) To determine which decline curve model is most appropriate for Marcellus shale production data analysis.

2) To evaluate the impact of the formation and hydraulic fracture properties $\left(\boldsymbol{X}_{f}, \boldsymbol{K}, \boldsymbol{\phi}\right)$ on decline curve model parameters.

3) To predict Marcellus shale production from limited production history using different decline curve model.

\subsection{Methodology}

In order to study the decline behavior of a shale gas reservoir three steps have been undertaken:

1) A simulator developed by Fekete (Fast Evolution), was utilized to generate simulated production profile for a horizontal well with multiple hydraulic fractures in an ultra-low permeability formation which contains adsorbed gas (Marcellus shale). Thirty years of production data for a horizontal well with seven and thirteen fracture stages have been generated. For each scenario (7 and 13 stages), production profiles were generated for three different values of fracture half length $\left(\boldsymbol{X}_{f}\right)$, permeability $(\boldsymbol{K})$, and matrix porosity $(\boldsymbol{\Phi})$.

2) Three decline curve models which were discussed earlier are used to match the thirty-year production profiles. Comparing these DCA models will determine the best model that provides the minimum error in predicting the future production.

3) Correlations were established to adjust DCA model parameters obtained by fitting limitedduration production profile (3-5 years) to estimate DCA model parameters for long term production prediction. 
4) In the final step, the effect of different formation and hydraulic fracture properties $\left(\boldsymbol{X}_{\boldsymbol{f}}, \boldsymbol{K}, \boldsymbol{\Phi}\right)$ on production decline model parameters is examined. Model parameters are estimated via non-linear regression using Excel-SOLVER.

\subsubsection{Development of a Marcellus Shale Reservoir Model}

In the first step a base model for a horizontal well with multiple hydraulic fracture stages in a shale formation was developed. The Fekete simulation model, Fast Evolution, was selected to generate 30-year production profiles. The model consisted of a 4000 feet by 2000 feet rectangular area with 3000 feet of horizontal lateral (Figure 3-1 and Figure 3-2). Two base scenarios include seven- and thirteen-stage hydraulic fracture, in a single porosity system with adsorbed gas.

Values of permeability, fracture half length, and matrix porosity were changed as presented in the Table 3-1 along with the base model parameters (fracture half-length of 500-ft, permeability of 0.002$\mathrm{mD}$, and porosity of $5 \%$ ).

It should be noted that previous studies (Belyadi, 2011) shows that in the ultra-low permeability, natural fractures disguise the effect of dual porosity system. 


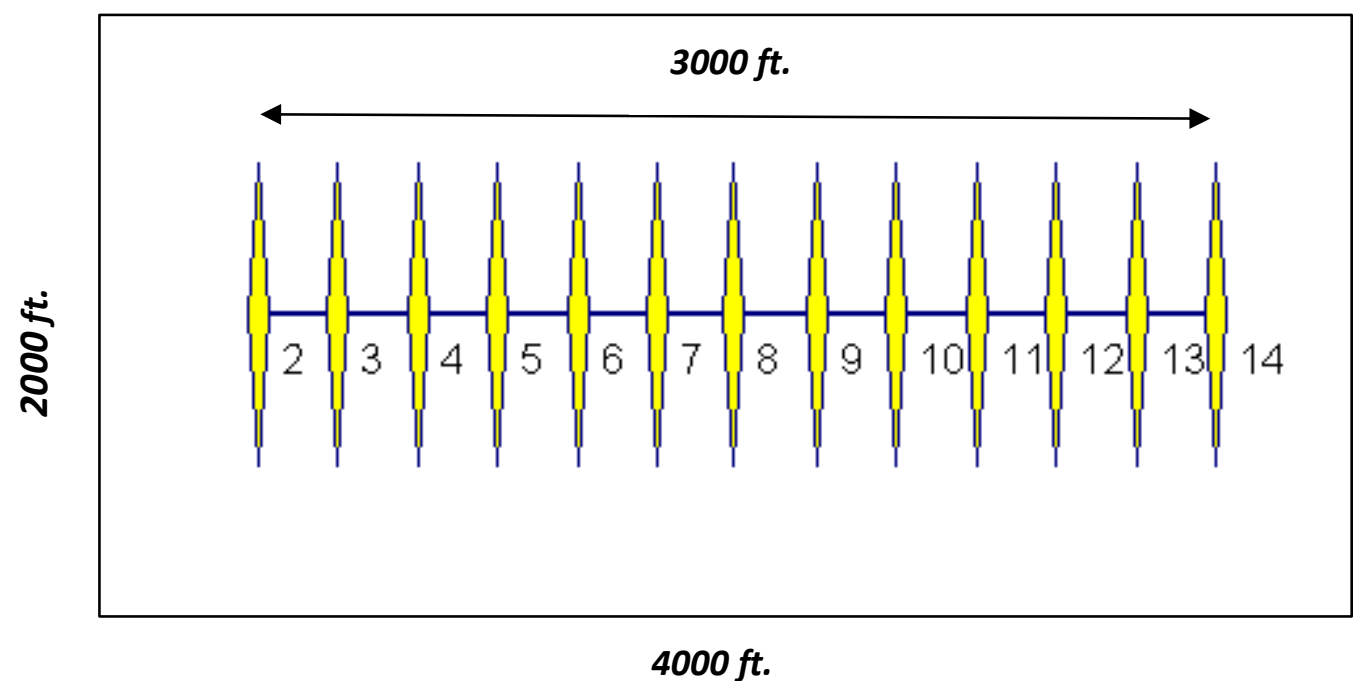

Figure 3-1: Illustration of the Base Model with 13 Stages

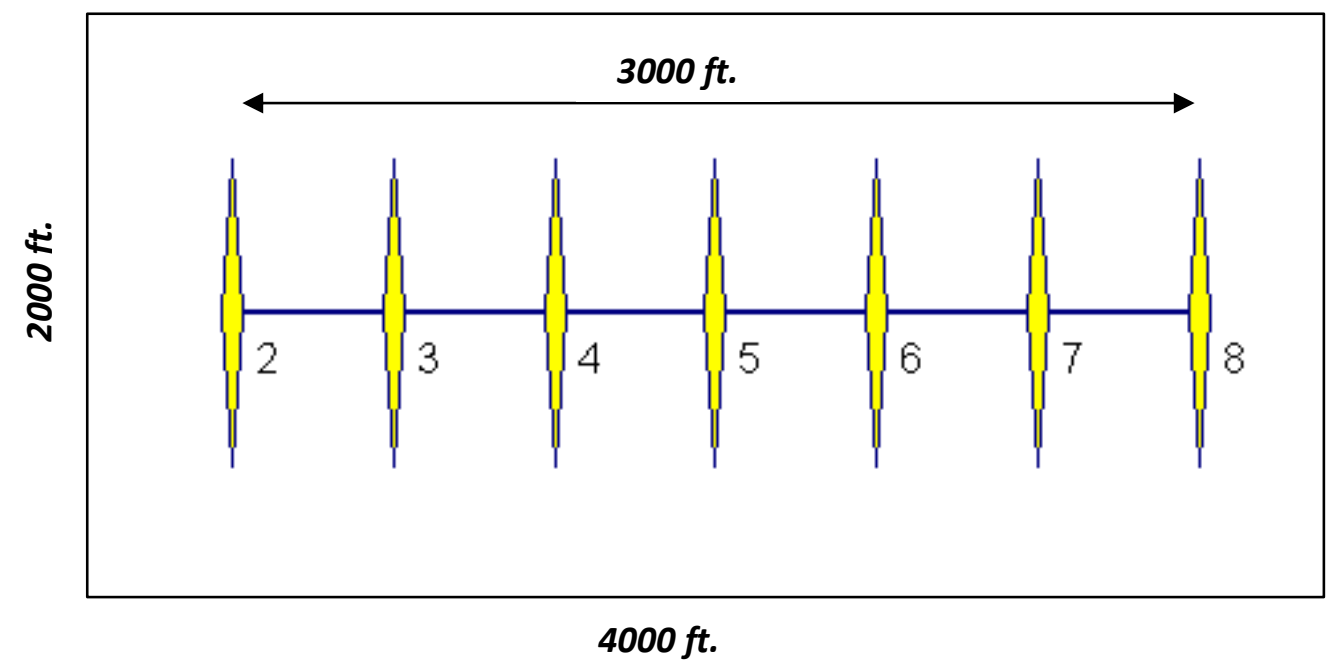

Figure 3-2: Illustration of the Base Model with 7 Stages 
Table 3-1: Base Model Parameters

\begin{tabular}{|c|c|c|}
\hline \multicolumn{2}{|c|}{ Base Model Parameters } & \\
\hline \multicolumn{2}{|c|}{ Reservoir Parameters } & Ranges of Properties \\
\hline Layer Name & Marcellus & \\
\hline Depth, ft. & 7000 & \\
\hline Thickness, ft. & 75 & \\
\hline Length, ft. & 4000 & \\
\hline Width, ft. & 2000 & \\
\hline Initial pressure, psia & 3000 & \\
\hline Water saturation, fraction & 0.15 & \\
\hline Temperature, ${ }^{\circ} \mathrm{F}$ & 120 & \\
\hline \multicolumn{2}{|l|}{ Rock Properties } & \\
\hline Type & Single Porosity & \\
\hline Fracture Porosity, frac. & 0.005 & \\
\hline Matrix Porosity, frac. & 0.05 & $0.04,0.05,0.06,0.08$ \\
\hline Fracture Bulk Permeability, $i, j, k, m d$ & $0.002,0.002,0.0002$ & $0.0008,0.001,0.002,0.004,0.006$ \\
\hline Matrix Permeability, $i, j, k, m d$ & $0.0004,0.0004,0.00004$ & \\
\hline Matrix fracture sigma, $\sigma, 1 / \mathrm{ft}^{2}$ & 0.0073 & \\
\hline Coal Compressibility, 1/psia & $1 \times 10^{-6}$ & \\
\hline Rock Density, $l b / f t^{3}$ & 150 & \\
\hline \multicolumn{3}{|c|}{ Hydraulic Fracture Properties } \\
\hline Half length, $f t$. & 500 & $300,400,500,600,700$ \\
\hline Width, in & 0.01 & \\
\hline Top of Fracture, ft. & 7000 & \\
\hline Bottom of Fracture, $\mathrm{ft}$. & 7075 & \\
\hline$X$ Center, $f t$. & 500 & \\
\hline$Y$ Center, $f t$. & 1000 & \\
\hline Permeability, $m d$ & 20,000 & \\
\hline Porosity, fraction & 0.2 & \\
\hline Number of fracture stages & $7 \& 13$ & \\
\hline Stage Spacing, $f t$. & $500 \& 250$ & \\
\hline \multicolumn{2}{|c|}{ Well Production Controls } & \\
\hline$P_{w f}, p s i a$ & 500 & \\
\hline \multicolumn{2}{|l|}{ Adsorption } & \\
\hline Diffusion Coefficient, ft ${ }^{2} /$ day & 1 & \\
\hline Sorption Time, day & 62 & \\
\hline Langmuir Pressure, psia & 635 & \\
\hline Langmuir Concentration, MSCF/ton & 0.08899 & \\
\hline
\end{tabular}




\subsubsection{Application of Decline Curve Analysis to All Simulated Data}

Three different DCA models: Arps, PLE, and Duong have been applied to the simulated production profiles. Towler (2002) introduced a non-linear regression technique using Excel-Solver for decline curve parameters determination which was discussed more in the Appendix. These three DCA models were compared in terms of a "goodness of fit" to the history data as well as production forecast.

\subsubsection{Application of Selected DCA Models to Limited Production Profiles}

The 30-year simulated production profile for each case (7 and 13 stages) with various fracture and formation properties combination were truncated at different production times including two, three, four, five, seven, ten, fifteen, twenty, and twenty-five. All three DCA models were then analyzed for each limited production profile. This analysis allows for determination of the appropriate constants for each DCA model as well as studying the trend of each constant as a function of production time. By performing regression curve fit on the constants from each of the DCA models, a technique can be developed to predict future production performance with limited production history.

\subsubsection{Adjusting Decline Curve Constants using Correlations}

Since horizontal Shale wells often exhibit long transient flow regimes, and do not reach BDF for most of their production life; decline curve constants which were evaluated based on the early production periods such as 2, 3, 4 years most probably will overestimate the later production. In order to overcome this problem the decline curve constants should be adjusted for prediction purposes. One possible approach is to generate a ratio of each decline curve constant to the value of the same constant for the 30year production profile.

\subsubsection{Effect of Formation and Hydraulic Fracture Properties on Production Decline Behavior}

After obtaining the various decline curves constant ratios for each time interval, these ratios were compared at each production time interval by plotting them over varied fracture half-lengths from $300-\mathrm{ft}$ to 700 -ft, permeability from $0.0008-\mathrm{mD}$ to $0.006-\mathrm{mD}$, and porosity from 0.04 to 0.08 in order to show the effect of these properties on decline curve constants. 


\subsubsection{Error Compared to the Base Case Model}

Since detailed information on fracture half-length, permeability, and porosity is not readily available for Marcellus wells, there would be a potential error in each DCA constant if these properties are not chosen precisely. In order to evaluate the significance of these errors, the higher and lower values of the base model's assumed fracture half-length, permeability, and porosity were compared to the base case model's corresponding properties value. These errors then plotted versus production time.

\subsubsection{Confirmation with Field Data}

In order to understand the behavior of the aforementioned decline curve methodology, it is necessary to validate the results with an actual field data. Since shale plays are among the most recently developed type of resources, there is a lack of long term field production data, formation properties, and fracture spacing. Therefore, an actual Marcellus horizontal well containing seven or thirteen stages data was not available. In order to investigate the reliability of this method, data from a well in Upshur County, West Virginia (Well 1) was used containing 3.5 years of production history and five fracture stages. Well 1 has 1812 feet of horizontal lateral, thus having a fracture spacing of 453 feet.

Well 1 production history data matched with single porosity model using Fekete (Fast Evolution) in order to predict the production behavior in time beyond 3.5 years. Arps, PLE, and Duong decline curves were also fitted to the same 3.5 years of well 1 monthly production data and the constants for each decline curve were estimated. Finally, the decline curve constants were adjusted using the established correlations from previous steps. The production rates for 30 years were predicted based on the adjusted constants. The predicted production rates by the simulator were then compared with predictions by different decline curves to evaluate the accuracy of these DCA models. 


\section{Results and Discussion}

\subsection{Development of a Marcellus Shale Reservoir Model}

Various models were generated for the two scenarios of seven and thirteen stages based on the ranges which were given in Table 3-1.

Figure 4-1 and Figure 4-2 show the thirty year production profile generated from Fekete (Fast Evolution) simulator for the seven and thirteen stages scenarios (for various fracture half-length).

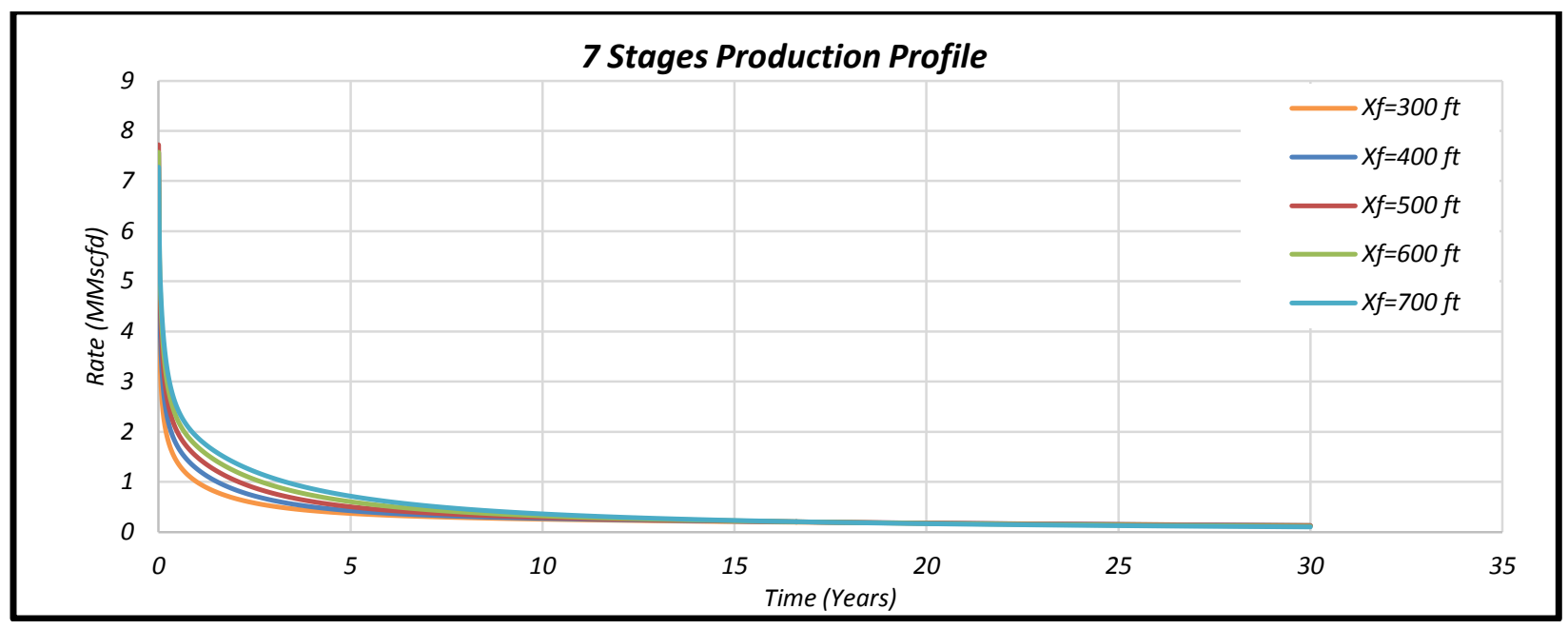

Figure 4-1: 7 Stages Production Profile- Various Fracture Half Length

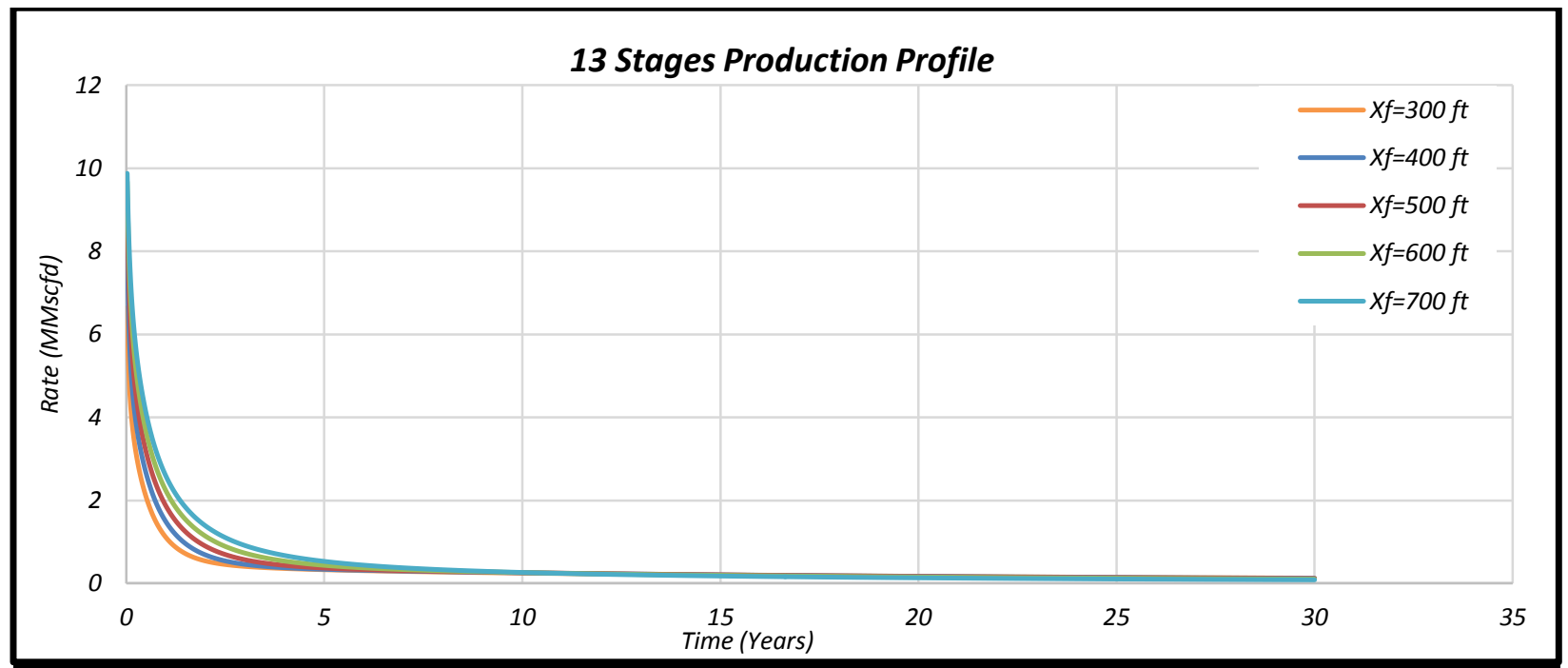

Figure 4-2: 13 Stages Production Profile-Various Fracture Half Length 
Thirty year production profile generated from Fekete (Fast Evolution) simulator for the seven and thirteen stages scenarios (for various permeability and porosity) shown in Figure B-1 through Figure B-4, located in the Appendix.

\subsection{Application of Selected DCA Models to All Simulated Data}

Three different DCA models: Arps, PLE, and Duong have been applied to the simulated production profiles using Excel-Solver method. Matching these DCA models to all simulated production history yielded the results presented below for seven stages (Base Model) in Figure 4-3. Results for thirteen stages shown in Figure C-1, located in the Appendix. The correspondent DCA models' constants at thirty years of production has been shown in Table 4-1 through Table 4-3 for seven stages case; and Table 4-13 through Table 4-15 for thirteen stages case.

Using this technique for all simulated production data, it was found that these three decline models can provide equally good fits to the history data for both seven- and thirteen- stage cases.

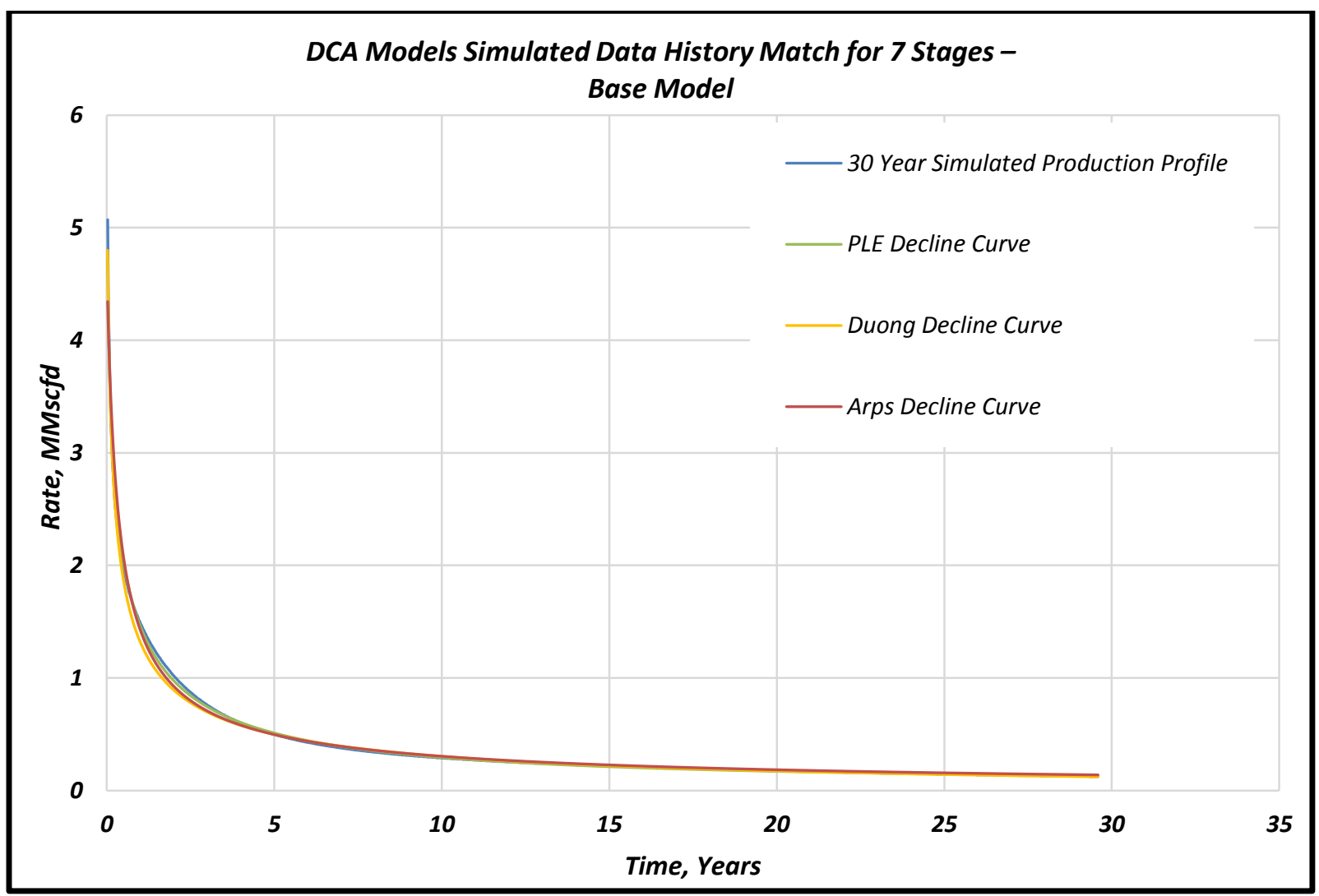

Figure 4-3 : Arps, PLE, and Duong DCAs Simulated Data History Match - Seven Stages 


\subsection{Application of Selected DCA Models to Limited Production Profiles}

As it is mentioned in the previous sections, the Arps DCA model depends on three parameters: "n", " $\boldsymbol{d}_{\boldsymbol{i}}$ ", and " $\boldsymbol{q}_{\boldsymbol{i}}$ ". The PLE model depends on four variables: " $\boldsymbol{D}_{\infty}$ ", " $\boldsymbol{n}$ ", " $\boldsymbol{q}_{\boldsymbol{i}}$ ", and " $\boldsymbol{D}_{\boldsymbol{1}}$ ". The Duong model also depends on four variables: " $a$ ", " $m$ ", " $q_{1}$ ", and " $q_{\infty}$ ".

Since these three decline models can provide equally good fits to the simulated history data, using Excel-Solver technique, another method has been acquired to select the best DCA model to predict the future production behavior. So, the production data has been truncated into two, three, five, seven, ten, fifteen, twenty, and twenty-five of production time in order to get a correlation between the decline curves' constants versus the production time. The DCA models which present the highest $\boldsymbol{R}^{2}$ on the regression curve of their constants vs. time will be chosen as the most appropriate model to predict the future production performance.

\subsubsection{Seven Stages Model}

For seven fracture model with various fracture half-length, permeability and porosity the Arps, PLE, and Duong models were compared. The results for the basic model over two, three, five, seven, ten, fifteen, twenty, twenty-five, and thirty years of production time are shown in Table 4-1 through Table 4-3, respectively as a sample. Results for the rest of the cases are shown in Table D-1 through Table D-42, located in the Appendix.

Table 4-1: 7 Stages (Base Model) - Arps

\begin{tabular}{|c|c|c|c|c|}
\hline \multicolumn{5}{|c|}{ 7 Fractures (Base Model)- Arps } \\
\hline Years & $n$ & di & qi & $\boldsymbol{R}^{2}$ \\
\hline 3 & 2.1055 & 0.0259 & 6.0292 & 0.9950 \\
\hline 5 & 1.7534 & 0.0149 & 5.3604 & 0.9902 \\
\hline 7 & 1.5965 & 0.0118 & 5.0889 & 0.9885 \\
\hline 10 & 1.4858 & 0.0099 & 4.8918 & 0.9885 \\
\hline 15 & 1.4195 & 0.0089 & 4.7677 & 0.9895 \\
\hline 20 & 1.3931 & 0.0085 & 4.7153 & 0.9903 \\
\hline 25 & 1.3769 & 0.0083 & 4.6821 & 0.9909 \\
\hline 30 & 1.3647 & 0.0081 & 4.6569 & 0.9912 \\
\hline
\end{tabular}


Table 4-2: 7 Stages (Base Model) - PLE

\begin{tabular}{|c|c|c|c|c|c|}
\hline \multicolumn{7}{|c|}{ 7 Fractures (Base Model)- PLE } \\
\hline Years & $\boldsymbol{D}_{\infty}$ & $\boldsymbol{n}$ & $\boldsymbol{q}_{\boldsymbol{i}}$ & $\boldsymbol{D}_{1}$ & $\boldsymbol{R}^{\mathbf{2}}$ \\
\hline 2 & -0.000994 & 0.397486 & 7.754779 & 0.077834 & 0.998041 \\
\hline 3 & -0.000460 & 0.362622 & 7.766450 & 0.078970 & 0.997015 \\
\hline 4 & -0.000242 & 0.343609 & 7.778605 & 0.079894 & 0.996721 \\
\hline 5 & -0.000141 & 0.333277 & 7.788613 & 0.080465 & 0.996772 \\
\hline 7 & -0.000077 & 0.325283 & 7.801243 & 0.081104 & 0.997153 \\
\hline 10 & -0.000081 & 0.326343 & 7.806431 & 0.080959 & 0.997574 \\
\hline 15 & -0.000100 & 0.329156 & 7.806475 & 0.080775 & 0.997838 \\
\hline 20 & -0.000116 & 0.333219 & 7.788616 & 0.080075 & 0.997987 \\
\hline 25 & -0.000118 & 0.333970 & 7.788459 & 0.079975 & 0.998105 \\
\hline 30 & -0.000114 & 0.332869 & 7.789941 & 0.080144 & 0.998170 \\
\hline
\end{tabular}

Table 4-3: 7 Stages (Base Model) - Duong

\begin{tabular}{|c|c|c|c|c|c|}
\hline \multicolumn{7}{|c|}{ 7 Fractures (Base Model) - Duong } \\
\hline Years & $\boldsymbol{a}$ & $\boldsymbol{m}$ & $\boldsymbol{q}_{\boldsymbol{1}}$ & $\boldsymbol{q}_{\infty}$ & $\boldsymbol{R}^{2}$ \\
\hline 2 & 0.808 & 0.989 & 12.151 & -3.519 & 0.970 \\
\hline 3 & 0.812 & 0.992 & 11.050 & -2.853 & 0.973 \\
\hline 4 & 0.850 & 1.011 & 9.802 & -1.851 & 0.994 \\
\hline 5 & 0.891 & 1.029 & 8.870 & -1.109 & 0.999 \\
\hline 7 & 0.940 & 1.044 & 8.021 & -0.776 & 0.999 \\
\hline 10 & 1.022 & 1.066 & 7.025 & -0.461 & 0.998 \\
\hline 15 & 1.117 & 1.089 & 6.175 & -0.247 & 0.997 \\
\hline 20 & 1.202 & 1.106 & 5.501 & -0.151 & 0.996 \\
\hline 25 & 1.261 & 1.122 & 5.074 & -0.061 & 0.988 \\
\hline 30 & 1.320 & 1.130 & 4.650 & -0.035 & 0.991 \\
\hline
\end{tabular}

The obtained correlations from plotting DCA models' constants versus time (for various $\boldsymbol{X}_{f}$ ) as shown in Figure D-1 through Figure D-15, located in the Appendix, are summarized in Table 4-4 through Table 4-6 for Arps, PLE, and Duong models, respectively. 
Table 4-4: 7 Stages (Fracture Half Length) - Arps- Correlations

\begin{tabular}{|c|c|c|c|}
\hline \multicolumn{2}{|c|}{ 7 Fractures (Fracture Half Length) - Arps } \\
\hline \multirow{2}{*}{$X_{f}(\mathrm{ft.})$} & $n$ & $d_{i}$ & $q_{i}$ \\
\hline \multirow{2}{*}{300} & $y=3.0275 x^{-0.311}$ & $y=0.1333 x^{-1.081}$ & $y=6.8693 x^{-0.289}$ \\
\cline { 2 - 4 } & $R^{2}=0.9942$ & $R^{2}=0.9917$ & $R^{2}=0.9978$ \\
\hline \multirow{2}{*}{500} & $y=2.6555 x^{-0.24}$ & $y=0.069 x^{-0.76}$ & $y=6.8735 x^{-0.19}$ \\
\cline { 2 - 4 } & $R^{2}=0.9699$ & $R^{2}=0.9704$ & $R^{2}=0.9836$ \\
\hline \multirow{2}{*}{600} & $y=2.3629 x^{-0.176}$ & $y=0.0335 x^{-0.458}$ & $y=6.415 x^{-0.103}$ \\
\cline { 2 - 4 } & $R^{2}=0.8977$ & $R^{2}=0.8706$ & $R^{2}=0.8847$ \\
\hline \multirow{2}{*}{700} & $y=2.3646 x^{-0.13}$ & $y=0.0224 x^{-0.207}$ & $y=6.204 x^{-0.031}$ \\
\cline { 2 - 4 } & $R^{2}=0.9638$ & $R^{2}=0.8926$ & $R^{2}=0.8182$ \\
\hline & $y=2.237 x^{-0.12}$ & $y=0.014 x^{-0.146}$ & $y=5.8513 x^{-0.015}$ \\
\hline
\end{tabular}

Table 4-5:7 Stages (Fracture Half Length) - PLE- Correlations

\begin{tabular}{|c|c|c|c|c|}
\hline \multicolumn{5}{|c|}{7 Fractures (Fracture Half Length) - PLE } \\
\hline$X_{f}(f t)$. & $D_{\infty}$ & $n$ & $D_{1}$ & $q_{i}$ \\
\hline \multirow{2}{*}{300} & $y=6 E-05 \ln (x)-0.0004$ & $y=-0.008 \ln (x)+0.3216$ & $y=0.0007 \ln (x)+0.1017$ & $y=0.0024 \ln (x)+6.9017$ \\
\hline & $R^{2}=0.8368$ & $R^{2}=0.8383$ & $R^{2}=0.6886$ & $R^{2}=0.0965$ \\
\hline \multirow{2}{*}{400} & $y=5 E-05 \ln (x)-0.0003$ & $y=-0.004 \ln (x)+0.3266$ & $y=4 E-05 \ln (x)+0.092$ & $y=-0.007 \ln (x)+7.6086$ \\
\hline & $R^{2}=0.3245$ & $R^{2}=0.2679$ & $R^{2}=0.0125$ & $R^{2}=0.494$ \\
\hline \multirow{2}{*}{500} & $y=0.0002 \ln (x)-0.0007$ & $y=-0.008 \ln (x)+0.3534$ & $y=0.0002 \ln (x)+0.0798$ & $y=0.0072 \ln (x)+7.7741$ \\
\hline & $R^{2}=0.5143$ & $R^{2}=0.3204$ & $R^{2}=0.0673$ & $R^{2}=0.2114$ \\
\hline \multirow{2}{*}{600} & $y=0.0002 \ln (x)-0.0005$ & $y=-0.017 \ln (x)+0.3908$ & $y=0.0006 \ln (x)+0.0673$ & $y=-0.009 \ln (x)+7.6669$ \\
\hline & $R^{2}=0.6006$ & $R^{2}=0.5802$ & $R^{2}=0.3669$ & $R^{2}=0.1273$ \\
\hline \multirow{2}{*}{700} & $y=0.0002 \ln (x)-0.0007$ & $y=-0.034 \ln (x)+0.4448$ & $y=0.0027 \ln (x)+0.0528$ & $y=0.0641 \ln (x)+7.2263$ \\
\hline & $R^{2}=0.7116$ & $R^{2}=0.7539$ & $R^{2}=0.7361$ & $R^{2}=0.638$ \\
\hline
\end{tabular}

Table 4-6: 7 Stages (Fracture Half Length) - Duong- Correlations

\begin{tabular}{|c|c|c|c|c|}
\hline \multicolumn{5}{|c|}{7 Fractures (Fracture Half Length) - Duong } \\
\hline$X_{f}(f t)$. & $a$ & $m$ & $q_{1}$ & $q^{\infty}$ \\
\hline \multirow{2}{*}{300} & $y=0.1034 \ln (x)+0.6565$ & $y=0.0499 \ln (x)+0.9267$ & $y=-2.343 \ln (x)+12.999$ & $y=1.6809 \ln (x)-4.9752$ \\
\hline & $R^{2}=0.6253$ & $R^{2}=0.9075$ & $R^{2}=0.999$ & $R^{2}=0.8761$ \\
\hline \multirow{2}{*}{400} & $y=0.1778 \ln (x)+0.5838$ & $y=0.0547 \ln (x)+0.9336$ & $y=-2.525 \ln (x)+13.258$ & $y=1.1572 \ln (x)-3.4918$ \\
\hline & $R^{2}=0.8814$ & $R^{2}=0.9674$ & $R^{2}=1$ & $R^{2}=0.8935$ \\
\hline \multirow{2}{*}{500} & $y=0.2005 \ln (x)+0.594$ & $y=0.056 \ln (x)+0.9383$ & $y=-2.75 \ln (x)+13.706$ & $y=1.2274 \ln (x)-3.7281$ \\
\hline & $R^{2}=0.9614$ & $R^{2}=0.99$ & $R^{2}=0.9866$ & $R^{2}=0.8598$ \\
\hline \multirow{2}{*}{600} & $y=0.2205 \ln (x)+0.5613$ & $y=0.0564 \ln (x)+0.9323$ & $y=-3.396 \ln (x)+16.043$ & $y=1.5355 \ln (x)-4.8051$ \\
\hline & $R^{2}=0.8981$ & $R^{2}=0.9709$ & $R^{2}=0.9821$ & $R^{2}=0.8259$ \\
\hline \multirow{2}{*}{700} & $y=0.2073 \ln (x)+0.542$ & $y=0.0587 \ln (x)+0.9148$ & $y=-3.94 \ln (x)+18.393$ & $y=2.3453 \ln (x)-7.277$ \\
\hline & $R^{2}=0.8973$ & $R^{2}=0.9258$ & $R^{2}=0.9781$ & $R^{2}=0.8653$ \\
\hline
\end{tabular}


The obtained correlations from plotting DCA models' constants vs. time (for various $\boldsymbol{K}$ ) as shown in Figure D-16 through Figure D-30, located in the Appendix, are summarized in Table 4-7 through Table 4-9 for Arps, PLE, and Duong models, respectively.

Table 4-7: 7 Stages (Permeability) - Arps- Correlations

\begin{tabular}{|c|c|c|c|}
\hline \multirow{2}{*}{$K(\mathrm{md})$} & \multicolumn{2}{|c|}{ 7 Fractures (Permeability) - Arps } \\
\hline \multirow{2}{*}{0.0008} & $y=2.9269 x^{-0.16}$ & $y=0.1972 x^{-0.782}$ & $y=6.6519 x^{-0.197}$ \\
\cline { 2 - 4 } & $R^{2}=0.9811$ & $R^{2}=0.9908$ & $R^{2}=0.9917$ \\
\hline \multirow{2}{*}{0.001} & $y=2.7097 x^{-0.157}$ & $y=0.1345 x^{-0.746}$ & $y=6.6857 x^{-0.186}$ \\
\cline { 2 - 4 } & $R^{2}=0.9959$ & $R^{2}=0.9913$ & $R^{2}=0.9927$ \\
\hline \multirow{2}{*}{0.002} & $y=2.3117 x^{-0.169}$ & $y=0.0306 x^{-0.427}$ & $y=6.2848 x^{-0.096}$ \\
& $R^{2}=0.9124$ & $R^{2}=0.8965$ & $R^{2}=0.9101$ \\
\hline \multirow{2}{*}{0.004} & $y=1.4461 x^{-0.055}$ & $y=0.01 x^{-0.091}$ & $y=6.754 x^{-0.019}$ \\
\cline { 2 - 4 } & $R^{2}=0.7784$ & $R^{2}=0.8169$ & $R^{2}=0.8424$ \\
\hline \multirow{2}{*}{0.006} & $y=1.2484 x^{-0.024}$ & $y=0.0087 x^{-0.041}$ & $y=7.8428 x^{-0.01}$ \\
\cline { 2 - 4 } & $R^{2}=0.6793$ & $R^{2}=0.6724$ & $R^{2}=0.6684$ \\
\hline
\end{tabular}

Table 4-8: 7 Stages (Permeability) - PLE - Correlations

\begin{tabular}{|c|c|c|c|c|}
\hline \multicolumn{5}{|c|}{7 Fractures (Permeability) - PLE } \\
\hline$\kappa(m d)$ & $D_{\infty}$ & $n$ & $D_{1}$ & $q_{i}$ \\
\hline \multirow{2}{*}{0.0008} & $y=0.0004 \ln (x)-0.0013$ & $y=-0.047 \ln (x)+0.4048$ & $y=0.003 \ln (x)+0.0943$ & $y=0.032 \ln (x)+5.8492$ \\
\hline & $R^{2}=0.8495$ & $R^{2}=0.9299$ & $R^{2}=0.9508$ & $R^{2}=0.9519$ \\
\hline \multirow{2}{*}{0.001} & $y=0.0004 \ln (x)-0.0011$ & $y=-0.047 \ln (x)+0.4125$ & $y=0.0027 \ln (x)+0.0903$ & $y=0.0331 \ln (x)+6.2825$ \\
\hline & $R^{2}=0.8069$ & $R^{2}=0.8911$ & $R^{2}=0.937$ & $R^{2}=0.964$ \\
\hline \multirow{2}{*}{0.002} & $y=1 E-04 \ln (x)-0.0004$ & $y=-0.007 \ln (x)+0.3529$ & $y=2 E-05 \ln (x)+0.08$ & $y=-0.007 \ln (x)+7.788$ \\
\hline & $R^{2}=0.4324$ & $R^{2}=0.2894$ & $R^{2}=0.0004$ & $R^{2}=0.1074$ \\
\hline \multirow{2}{*}{0.004} & $y=-8 E-05 \ln (x)-3 E-05$ & $y=0.0074 \ln (x)+0.3876$ & $y=-6 E-04 \ln (x)+0.0623$ & $y=-0.049 \ln (x)+9.4046$ \\
\hline & $R^{2}=0.4152$ & $R^{2}=0.2353$ & $R^{2}=0.1442$ & $R^{2}=0.8203$ \\
\hline \multirow{2}{*}{0.006} & $y=4 E-05 \ln (x)-0.0005$ & $y=-0.014 \ln (x)+0.4935$ & $y=0.0023 \ln (x)+0.0457$ & $y=0.0657 \ln (x)+10.163$ \\
\hline & $R^{2}=0.0355$ & $R^{2}=0.2429$ & $R^{2}=0.4151$ & $R^{2}=0.2844$ \\
\hline
\end{tabular}

Table 4-9: 7 Stages (Permeability) - Duong- Correlations

\begin{tabular}{|c|c|c|c|c|}
\hline \multicolumn{5}{|c|}{7 Fractures (Permeability) - Duong } \\
\hline$K(m d)$ & $a$ & $m$ & $q_{1}$ & $q \infty$ \\
\hline \multirow{2}{*}{0.0008} & $y=0.1557 \ln (x)+0.718$ & $y=0.0167 \ln (x)+1.0526$ & $y=-1.295 \ln (x)+7.2718$ & $y=-0.087 \ln (x)+0.2203$ \\
\hline & $R^{2}=0.9771$ & $R^{2}=0.8126$ & $R^{2}=0.9906$ & $R^{2}=0.8302$ \\
\hline \multirow{2}{*}{0.001} & $y=0.1835 \ln (x)+0.6816$ & $y=0.0246 \ln (x)+1.0344$ & $y=-1.325 \ln (x)+7.6966$ & $y=-0.147 \ln (x)+0.3145$ \\
\hline & $R^{2}=0.9947$ & $R^{2}=0.9812$ & $R^{2}=0.9595$ & $R^{2}=0.9608$ \\
\hline \multirow{2}{*}{0.002} & $y=0.2282 \ln (x)+0.7322$ & $y=0.0408 \ln (x)+1.013$ & $y=-2.03 \ln (x)+9.879$ & $y=0.3542 \ln (x)-1.0735$ \\
\hline & $R^{2}=0.985$ & $R^{2}=0.9827$ & $R^{2}=0.927$ & $R^{2}=0.9435$ \\
\hline \multirow{2}{*}{0.004} & $y=0.2633 \ln (x)+0.798$ & $y=0.0478 \ln (x)+1.0166$ & $y=-2.3 \ln (x)+11.306$ & $y=0.7135 \ln (x)-2.1718$ \\
\hline & $R^{2}=0.9738$ & $R^{2}=0.991$ & $R^{2}=0.988$ & $R^{2}=0.898$ \\
\hline \multirow{2}{*}{0.006} & $y=0.2721 \ln (x)+0.7984$ & $y=0.051 \ln (x)+1.0133$ & $y=-2.889 \ln (x)+13.859$ & $y=1.033 \ln (x)-3.1298$ \\
\hline & $R^{2}=0.9396$ & $R^{2}=0.9764$ & $R^{2}=0.9753$ & $R^{2}=0.8331$ \\
\hline
\end{tabular}


The obtained correlations from plotting DCA models' constants vs. time (for various $\boldsymbol{\Phi}$ ) as shown in Figure D-31 through Figure D-42, located in the Appendix, are summarized in Table 4-10, Table 4-11, and Table 4-12 for Arps, PLE, and Duong models, respectively.

Table 4-10: 7 Stages (Porosity) - Arps- Correlations

\begin{tabular}{|c|c|c|c|}
\hline \multicolumn{4}{|c|}{ 7 Fractures (Porosity) - Arps } \\
\hline $\boldsymbol{\phi}(\%)$ & $n$ & $d i$ & $q i$ \\
\hline \multirow{2}{*}{4} & $y=2.0438 x^{-0.137}$ & $y=0.0234 x^{-0.321}$ & $y=5.5356 x^{-0.072}$ \\
\cline { 2 - 4 } & $R^{2}=0.8655$ & $R^{2}=0.8552$ & $R^{2}=0.871$ \\
\hline \multirow{2}{*}{5} & $y=2.3123 x^{-0.169}$ & $y=0.0307 x^{-0.427}$ & $y=6.2876 x^{-0.096}$ \\
\cline { 2 - 4 } & $R^{2}=0.9132$ & $R^{2}=0.8976$ & $R^{2}=0.9117$ \\
\hline \multirow{2}{*}{6} & $y=2.5379 x^{-0.19}$ & $y=0.0386 x^{-0.513}$ & $y=6.9906 x^{-0.114}$ \\
\cline { 2 - 4 } & $R^{2}=0.9456$ & $R^{2}=0.9297$ & $R^{2}=0.9414$ \\
\hline \multirow{2}{*}{8} & $y=2.8603 x^{-0.211}$ & $y=0.0537 x^{-0.627}$ & $y=8.1968 x^{-0.138}$ \\
\cline { 2 - 4 } & $R^{2}=0.9803$ & $R^{2}=0.9702$ & $R^{2}=0.9773$ \\
\hline
\end{tabular}

Table 4-11: 7 Stages (Porosity) - PLE- Correlations

\begin{tabular}{|c|c|c|c|c|}
\hline \multicolumn{5}{|c|}{ 7Fractures (Porosity) - PLE } \\
\hline $\boldsymbol{\phi}(\%)$ & $D_{\infty}$ & $n$ & $D_{1}$ & $q_{i}$ \\
\hline \multirow{2}{*}{4} & $y=0.0001 \ln (x)-0.0005$ & $y=-0.008 \ln (x)+0.3596$ & $y=-2 E-04 \ln (x)+0.0819$ & $y=-0.008 \ln (x)+7.4105$ \\
\cline { 2 - 5 } & $R^{2}=0.3596$ & $R^{2}=0.2322$ & $R^{2}=0.0522$ & $R^{2}=0.2443$ \\
\hline \multirow{2}{*}{5} & $y=0.0002 \ln (x)-0.0007$ & $y=-0.017 \ln (x)+0.3784$ & $y=0.0006 \ln (x)+0.0788$ & $y=0.0098 \ln (x)+7.7634$ \\
\cline { 2 - 5 } & $R^{2}=0.5061$ & $R^{2}=0.4914$ & $R^{2}=0.3216$ & $R^{2}=0.4788$ \\
\hline \multirow{2}{*}{$\mathbf{6}$} & $y=0.0003 \ln (x)-0.0009$ & $y=-0.026 \ln (x)+0.3974$ & $y=0.0013 \ln (x)+0.0757$ & $y=0.0214 \ln (x)+8.0566$ \\
\cline { 2 - 5 } & $R^{2}=0.6064$ & $R^{2}=0.6514$ & $R^{2}=0.6412$ & $R^{2}=0.7462$ \\
\hline \multirow{2}{*}{$\boldsymbol{N}$} & $y=0.0002 \ln (x)-0.0008$ & $y=-0.028 \ln (x)+0.4009$ & $y=0.0017 \ln (x)+0.072$ & $y=0.0187 \ln (x)+8.5758$ \\
\cline { 2 - 5 } & $R^{2}=0.699$ & $R^{2}=0.7379$ & $R^{2}=0.7061$ & $R^{2}=0.6224$ \\
\hline
\end{tabular}

Table 4-12: 7 Stages (Porosity) - Duong- Correlations

\begin{tabular}{|c|c|c|c|c|}
\hline \multicolumn{5}{|c|}{ 7Fractures (Porosity) - Duong } \\
\hline $\boldsymbol{\phi}(\%)$ & $a$ & $\boldsymbol{m}$ & $\boldsymbol{q}_{1}$ & $q^{\infty}$ \\
\hline \multirow{2}{*}{4} & $y=0.2582 \ln (x)+0.697$ & $y=0.0483 \ln (x)+1.0013$ & $y=-1.922 \ln (x)+9.1644$ & $y=0.3232 \ln (x)-1.0152$ \\
\cline { 2 - 5 } & $R^{2}=0.9877$ & $R^{2}=0.9801$ & $R^{2}=0.9509$ & $R^{2}=0.9413$ \\
\hline \multirow{2}{*}{5} & $y=0.239 \ln (x)+0.6433$ & $y=0.047 \ln (x)+0.9864$ & $y=-2.168 \ln (x)+10.725$ & $y=0.3599 \ln (x)-1.1833$ \\
\cline { 2 - 5 } & $R^{2}=0.9949$ & $R^{2}=0.9982$ & $R^{2}=0.987$ & $R^{2}=0.981$ \\
\hline \multirow{2}{*}{$\mathbf{6}$} & $y=0.2114 \ln (x)+0.689$ & $y=0.0443 \ln (x)+0.9779$ & $y=-2.258 \ln (x)+11.876$ & $y=0.4165 \ln (x)-1.3863$ \\
& $R^{2}=0.9871$ & $R^{2}=0.9944$ & $R^{2}=0.9943$ & $R^{2}=0.9801$ \\
\hline \multirow{2}{*}{$\boldsymbol{8}$} & $y=0.1592 \ln (x)+0.6128$ & $y=0.0394 \ln (x)+0.9596$ & $y=-2.526 \ln (x)+14.791$ & $y=0.7121 \ln (x)-2.3848$ \\
\cline { 2 - 5 } & $R^{2}=0.8887$ & $R^{2}=0.9404$ & $R^{2}=0.9673$ & $R^{2}=0.9768$ \\
\hline
\end{tabular}


According to Table 4-4 through Table 4-12, trends of the constants plotted versus time show a high $\boldsymbol{R}^{2}$ only for Arps and Duong models. Arps model constants have a more consistent trend with time at a higher porosity cases as well as a lower permeability ranges which is probably due to the accuracy of Arps model at BDF period.

\subsubsection{Thirteen Stages Model}

For thirteen stages model with various fracture half-length, permeability and porosity the Arps, PLE, and Duong models were compared. The results for the basic model over two, three, five, seven, ten, fifteen, twenty, twenty-five, and thirty years of production time are shown in Table 4-13 through Table 4-15, respectively as a sample. Results for the rest of the cases are shown in Table D-43 through Table D-48, located in the Appendix.

Table 4-13: 13 Stages (Base Model) - Arps

\begin{tabular}{|c|c|c|c|c|}
\hline \multicolumn{5}{|c|}{ 13 Fractures (Base Model)-Arps } \\
\hline Years & $n$ & $d_{i}$ & $q_{i}$ & $R^{2}$ \\
\hline 3 & 1.5027 & 0.0281 & 11.76 & 0.971 \\
\hline 5 & 1.4045 & 0.0265 & 11.71 & 0.971 \\
\hline 7 & 1.3575 & 0.0252 & 11.61 & 0.974 \\
\hline 10 & 1.3221 & 0.0240 & 11.48 & 0.978 \\
\hline 15 & 1.3046 & 0.0233 & 11.41 & 0.980 \\
\hline 20 & 1.2946 & 0.0229 & 11.35 & 0.982 \\
\hline 25 & 1.2800 & 0.0221 & 11.25 & 0.984 \\
\hline 30 & 1.2765 & 0.0220 & 11.23 & 0.984 \\
\hline
\end{tabular}

Table 4-14: 13 Stages (Base Model) - PLE

\begin{tabular}{|c|c|c|c|c|c|}
\hline \multicolumn{7}{|c|}{ 13 Fractures (Base Model)- PLE } \\
\hline Years & $\boldsymbol{D}_{\infty}$ & $\boldsymbol{n}$ & $\boldsymbol{q}_{\boldsymbol{i}}$ & $\boldsymbol{D}_{\boldsymbol{1}}$ & $\boldsymbol{R}^{2}$ \\
\hline 2 & 0.0004 & 0.3897 & 13.9609 & 0.0730 & 0.9997 \\
\hline 3 & 0.0003 & 0.3970 & 13.9637 & 0.0729 & 0.9997 \\
\hline 4 & 0.0001 & 0.4138 & 13.9337 & 0.0719 & 0.9995 \\
\hline 5 & -0.0001 & 0.4286 & 13.9121 & 0.0710 & 0.9991 \\
\hline 7 & -0.0005 & 0.4574 & 13.8354 & 0.0685 & 0.9984 \\
\hline 10 & -0.0008 & 0.4830 & 13.7405 & 0.0656 & 0.9980 \\
\hline 15 & -0.0008 & 0.4834 & 13.7383 & 0.0656 & 0.9980 \\
\hline 20 & -0.0007 & 0.4728 & 13.7375 & 0.0668 & 0.9976 \\
\hline 25 & -0.0006 & 0.4615 & 13.7385 & 0.0682 & 0.9968 \\
\hline 30 & -0.0006 & 0.4526 & 13.7400 & 0.0694 & 0.9958 \\
\hline
\end{tabular}


Table 4-15: 13 Stages (Base Model) - Duong

\begin{tabular}{|c|c|c|c|c|c|}
\hline \multicolumn{7}{|c|}{ 13 Fractures (Base Model)- Duong } \\
\hline Years & $\boldsymbol{a}$ & $\boldsymbol{m}$ & $\boldsymbol{q}_{\mathbf{1}}$ & $\boldsymbol{q}_{\infty}$ & $\boldsymbol{R}^{2}$ \\
\hline 2 & 0.946 & 1.049 & 16.1 & -2.577 & 0.954 \\
\hline 3 & 0.986 & 1.051 & 15.0 & -2.556 & 0.982 \\
\hline 4 & 1.063 & 1.081 & 14.0 & -1.591 & 0.996 \\
\hline 5 & 1.118 & 1.099 & 13.2 & -1.081 & 0.994 \\
\hline 7 & 1.199 & 1.124 & 12.3 & -0.609 & 0.990 \\
\hline 10 & 1.262 & 1.143 & 11.8 & -0.324 & 0.986 \\
\hline 15 & 1.340 & 1.162 & 11.2 & -0.144 & 0.983 \\
\hline 20 & 1.399 & 1.181 & 10.9 & -0.038 & 0.977 \\
\hline 25 & 1.465 & 1.185 & 10.2 & -0.024 & 0.980 \\
\hline 30 & 1.650 & 1.220 & 9.8 & 0.050 & 0.963 \\
\hline
\end{tabular}

The obtained correlations from plotting DCA models constants versus time (for various $\boldsymbol{X}_{\boldsymbol{f}}$ ) as shown in Figure D-43 through Figure D-57, located in the Appendix, are summarized in Table 4-16 through Table 4-18 for Arps, PLE, and Duong models, respectively.

Table 4-16: 13 Stages (Fracture Half-Length) - Arps - Correlations

\begin{tabular}{|c|c|c|c|}
\hline \multicolumn{4}{|c|}{13 Fractures (Fracture Half Length) - Arps } \\
\hline \multirow{2}{*}{$X_{f}(\mathrm{ft})$} & $n$ & $d i$ & $q i$ \\
\hline \multirow{2}{*}{300} & $y=1.5095 x^{-0.079}$ & $y=0.0413 x^{-0.26}$ & $y=9.4778 x^{-0.075}$ \\
\cline { 2 - 4 } & $R^{2}=0.9299$ & $R^{2}=0.9853$ & $R^{2}=0.9924$ \\
\hline \multirow{2}{*}{400} & $y=1.5816 x^{-0.075}$ & $y=0.041 x^{-0.192}$ & $y=11.481 x^{-0.049}$ \\
\cline { 2 - 4 } & $R^{2}=0.9543$ & $R^{2}=0.9896$ & $R^{2}=0.9807$ \\
\hline \multirow{2}{*}{500} & $y=1.571 x^{-0.066}$ & $y=0.0313 x^{-0.107}$ & $y=12.073 x^{-0.021}$ \\
\cline { 2 - 4 } & $R^{2}=0.9112$ & $R^{2}=0.9859$ & $R^{2}=0.9815$ \\
\hline \multirow{2}{*}{600} & $y=1.5452 x^{-0.063}$ & $y=0.0248 x^{-0.089}$ & $y=12.314 x^{-0.014}$ \\
\cline { 2 - 4 } & $R^{2}=0.9911$ & $R^{2}=0.988$ & $R^{2}=0.9218$ \\
\hline \multirow{2}{*}{700} & $y=1.5782 x^{-0.057}$ & $y=0.021 x^{-0.083}$ & $y=12.351 x^{-0.011}$ \\
\cline { 2 - 4 } & $R^{2}=0.9816$ & $R^{2}=0.9292$ & $R^{2}=0.9227$ \\
\hline
\end{tabular}

Table 4-17: 13 Stages (Fracture Half-Length) - PLE - Correlations

\begin{tabular}{|c|c|c|c|c|}
\hline \multicolumn{5}{|c|}{ 13 Fractures (Fracture Half Length) - PLE } \\
\hline \multirow{2}{*}{$X_{f}$ (ft.) } & $D_{\infty}$ & $n$ & $D_{1}$ & $q_{i}$ \\
\hline \multirow{2}{*}{300} & $y=-3 E-05 x+4 E-05$ & $y=0.0005 x+0.3751$ & $y=0.0003 x+0.0958$ & $y=0.0562 \ln (x)+12.266$ \\
\cline { 2 - 5 } & $R^{2}=0.2008$ & $R^{2}=0.0198$ & $R^{2}=0.5073$ & $R^{2}=0.22$ \\
\hline \multirow{2}{*}{400} & $y=-3 E-05 x+0.0001$ & $y=0.0017 x+0.3906$ & $y=-8 E-06 x+0.0842$ & $y=-0.041 \ln (x)+13.666$ \\
\cline { 2 - 5 } & $R^{2}=0.3383$ & $R^{2}=0.2034$ & $R^{2}=0.0008$ & $R^{2}=0.2736$ \\
\hline \multirow{2}{*}{500} & $y=-3 E-05 x+4 E-05$ & $y=0.0021 x+0.4181$ & $y=-0.0002 x+0.0711$ & $y=-0.102 \ln (x)+14.049$ \\
\cline { 2 - 5 } & $R^{2}=0.4498$ & $R^{2}=0.3774$ & $R^{2}=0.2787$ & $R^{2}=0.8824$ \\
\cline { 2 - 5 } & $y=-2 E-05 x-1 E-04$ & $y=0.0017 x+0.4543$ & $y=-8 E-05 x+0.0578$ & $y=-0.005 \ln (x)+13.639$ \\
\hline \multirow{2}{*}{700} & $R^{2}=0.4616$ & $R^{2}=0.3555$ & $R^{2}=0.1385$ & $R^{2}=0.0033$ \\
\cline { 2 - 5 } & $y=-2 E-05 x-0.0002$ & $y=0.0017 x+0.4849$ & $y=-0.0001 x+0.0471$ & $y=-0.092 \ln (x)+13.196$ \\
\hline
\end{tabular}


Table 4-18: 13 Stages (Fracture Half-Length) - Duong - Correlations

\begin{tabular}{|c|c|c|c|c|}
\hline \multicolumn{5}{|c|}{ 13 Fractures (Fracture Half Length) - Duong } \\
\hline \multirow{2}{*}{$x_{f}(\mathrm{ft}$ ) } & $a$ & $m$ & $q_{1}$ & $q^{\infty}$ \\
\hline \multirow{2}{*}{300} & $y=0.1484 \ln (x)+0.7232$ & $y=0.058 \ln (x)+0.983$ & $y=-1.614 \ln (x)+15.764$ & $y=1.1358 \ln (x)-3.1835$ \\
\cline { 2 - 5 } & $R^{2}=0.9384$ & $R^{2}=0.970$ & $R^{2}=0.9838$ & $R^{2}=0.6807$ \\
\hline \multirow{2}{*}{400} & $y=0.2009 \ln (x)+0.7566$ & $y=0.0612 \ln (x)+0.9962$ & $y=-1.81 \ln (x)+16.176$ & $y=1.1225 \ln (x)-3.235$ \\
\cline { 2 - 5 } & $R^{2}=0.9115$ & $R^{2}=0.9748$ & $R^{2}=0.9763$ & $R^{2}=0.7797$ \\
\hline \multirow{2}{*}{500} & $y=0.2347 \ln (x)+0.7415$ & $y=0.0621 \ln (x)+0.9968$ & $y=-2.212 \ln (x)+17.156$ & $y=1.0272 \ln (x)-3.0835$ \\
\cline { 2 - 5 } & $R^{2}=0.958$ & $R^{2}=0.9793$ & $R^{2}=0.974$ & $R^{2}=0.8807$ \\
\hline \multirow{2}{*}{600} & $y=0.2543 \ln (x)+0.732$ & $y=0.0627 \ln (x)+0.9916$ & $R^{2}=-2.775 \ln (x)+18.281$ & $y=1.7826 \ln (x)-5.2705$ \\
\hline \multirow{2}{*}{700} & $R^{2}=0.9945$ & $y=0.0649 \ln (x)+0.978$ & $y=-3.393 \ln (x)+20.304$ & $R^{2}=0.7891$ \\
\cline { 2 - 5 } & $R^{2}=0.9669$ & $R^{2}=0.9781$ & $R^{2}=0.9701$ & $y=2.2697 \ln (x)-6.7527$ \\
\hline
\end{tabular}

The obtained correlations from plotting DCA models constants versus time (for various $\boldsymbol{K}$ ) as shown in Figure D-58 through Figure D-72, located in the Appendix, are summarized in Table 4-19 through Table 4-21 for Arps, PLE, and Duong models, respectively.

Table 4-19: 13 Stages (Permeability) - Arps - Correlations

\begin{tabular}{|c|c|c|c|}
\hline \multirow{4}{*}{$K(m d)$} & \multicolumn{3}{|c|}{ 13 Fractures (Permeability) - Arps } \\
\hline \multirow{2}{*}{0.0008} & $y=1.8353 x^{-0.084}$ & $y=0.0309 x^{-0.102}$ & $y=7.7348 x^{-0.014}$ \\
\cline { 2 - 4 } & $R^{2}=0.954$ & $R^{2}=0.9778$ & $R^{2}=0.9773$ \\
\hline \multirow{2}{*}{0.001} & $y=1.8246 x^{-0.08}$ & $y=0.0338 x^{-0.094}$ & $y=8.8291 x^{-0.012}$ \\
\cline { 2 - 4 } & $R^{2}=0.9471$ & $R^{2}=0.9939$ & $R^{2}=0.9223$ \\
\hline \multirow{2}{*}{0.002} & $y=1.8166 x^{-0.07}$ & $y=0.0461 x^{-0.059}$ & $y=13.434 x^{-0.011}$ \\
\cline { 2 - 4 } & $R^{2}=0.9366$ & $R^{2}=0.9553$ & $R^{2}=0.9934$ \\
\hline \multirow{2}{*}{0.004} & $y=1.5519 x^{-0.061}$ & $y=0.0451 x^{-0.049}$ & $y=17.203 x^{-0.008}$ \\
\cline { 2 - 4 } & $R^{2}=0.9927$ & $R^{2}=0.9735$ & $R^{2}=0.9492$ \\
\hline \multirow{2}{*}{0.006} & $y=1.7655 x^{-0.052}$ & $y=0.0712 x^{-0.032}$ & $y=23.294 x^{-0.007}$ \\
\cline { 2 - 4 } & $R^{2}=0.9923$ & $R^{2}=0.8745$ & $R^{2}=0.8741$ \\
\hline
\end{tabular}

Table 4-20: 13 Stages (Permeability) - PLE - Correlations

\begin{tabular}{|c|c|c|c|c|}
\hline \multicolumn{5}{|c|}{13 Fractures (Permeability) - PLE } \\
\hline$K(m d)$ & $D_{\infty}$ & $n$ & $D_{1}$ & $q_{i}$ \\
\hline \multirow{2}{*}{0.0008} & $y=-5 E-06 x-5 E-05$ & $y=0.0009 x+0.3271$ & $y=-0.0001 x+0.0967$ & $y=-0.0035 x+10.759$ \\
\hline & $R^{2}=0.2013$ & $R^{2}=0.5959$ & $R^{2}=0.9101$ & $R^{2}=0.8741$ \\
\hline \multirow{2}{*}{0.001} & $y=-1 E-05 x+7 E-05$ & $y=0.0018 x+0.3372$ & $y=-0.0002 x+0.0915$ & $y=-0.0057 x+11.523$ \\
\hline & $R^{2}=0.8285$ & $R^{2}=0.8901$ & $R^{2}=0.9364$ & $R^{2}=0.9513$ \\
\hline \multirow{2}{*}{0.002} & $y=-3 E-05 x+4 E-05$ & $y=0.0015 x+0.429$ & $y=-5 E-05 x+0.0701$ & $y=0.0003 x+13.87$ \\
\hline & $R^{2}=0.444$ & $R^{2}=0.2358$ & $R^{2}=0.0407$ & $R^{2}=0.001$ \\
\hline \multirow{2}{*}{0.004} & $y=6 E-05 x-0.0024$ & $y=-0.0052 x+0.6253$ & $y=0.0006 x+0.0468$ & $y=0.0265 x+16.363$ \\
\hline & $R^{2}=0.6197$ & $R^{2}=0.8148$ & $R^{2}=0.9003$ & $R^{2}=0.8146$ \\
\hline \multirow{2}{*}{0.006} & $y=0.0002 x-0.0063$ & $y=-0.0105 x+0.7614$ & $y=0.0009 x+0.0391$ & $y=0.0561 x+17.585$ \\
\hline & $R^{2}=0.816$ & $R^{2}=0.9099$ & $R^{2}=0.9169$ & $R^{2}=0.896$ \\
\hline
\end{tabular}


Table 4-21: 13 Stages (Permeability) - Duong - Correlations

\begin{tabular}{|c|c|c|c|c|}
\hline \multicolumn{5}{|c|}{13 Fractures (Permeability) - Duong } \\
\hline$K(m d)$ & $a$ & $m$ & $q_{1}$ & $q^{\infty}$ \\
\hline \multirow{2}{*}{0.0008} & $y=0.2551 \ln (x)+0.7188$ & $y=0.0477 \ln (x)+1.0193$ & $y=-2.264 \ln (x)+11.873$ & $y=0.3464 \ln (x)-1.1335$ \\
\hline & $R^{2}=0.9788$ & $R^{2}=0.9815$ & $R^{2}=0.9925$ & $R^{2}=0.9898$ \\
\hline \multirow{2}{*}{0.001} & $y=0.3114 \ln (x)+0.7383$ & $y=0.055 \ln (x)+1.0242$ & $y=-2.493 \ln (x)+11.97$ & $y=0.3998 \ln (x)-1.2821$ \\
\hline & $R^{2}=0.9832$ & $R^{2}=0.9942$ & $R^{2}=0.9749$ & $R^{2}=0.9724$ \\
\hline \multirow{2}{*}{0.002} & $y=0.3667 \ln (x)+0.8288$ & $y=0.0601 \ln (x)+1.0508$ & $y=-2.841 \ln (x)+13.502$ & $y=0.4413 \ln (x)-1.3594$ \\
\hline & $R^{2}=0.9969$ & $R^{2}=0.9884$ & $R^{2}=0.9841$ & $R^{2}=0.9379$ \\
\hline \multirow{2}{*}{0.004} & $y=0.4439 \ln (x)+0.9146$ & $y=0.0634 \ln (x)+1.082$ & $y=-3.861 \ln (x)+16.425$ & $y=0.8428 \ln (x)-2.3521$ \\
\hline & $R^{2}=0.9926$ & $R^{2}=0.9813$ & $R^{2}=0.9938$ & $R^{2}=0.7202$ \\
\hline \multirow{2}{*}{0.006} & $y=0.4523 \ln (x)+0.8899$ & $y=0.0641 \ln (x)+1.0859$ & $y=-4.886 \ln (x)+20.43$ & $y=0.5404 \ln (x)-1.5052$ \\
\hline & $R^{2}=0.9915$ & $R^{2}=0.9678$ & $R^{2}=0.991$ & $R^{2}=0.6603$ \\
\hline
\end{tabular}

The obtained correlations from plotting DCA models constants versus time (for various $\boldsymbol{\phi}$ ) as shown in Figure D-73 through Figure D-84, located in the Appendix, are summarized in Table 4-22 through Table 4-24 for Arps, PLE, and Duong models, respectively.

Table 4-22: 13 Stages (Porosity) - Arps - Correlations

\begin{tabular}{|c|c|c|c|}
\hline \multirow{2}{*}{$\boldsymbol{\phi}(\%)$} & $\boldsymbol{n}$ & $\boldsymbol{d}_{i}$ & $q_{i}$ \\
\hline \multirow{2}{*}{4} & $y=1.8713 x^{-0.098}$ & $y=0.0775 x^{-0.265}$ & $y=14.476 x^{-0.065}$ \\
\cline { 2 - 4 } & $R^{2}=0.9757$ & $R^{2}=0.9869$ & $R^{2}=0.9764$ \\
\hline \multirow{2}{*}{5} & $y=1.9621 x^{-0.117}$ & $y=0.0699 x^{-0.295}$ & $y=14.874 x^{-0.069}$ \\
\cline { 2 - 4 } & $R^{2}=0.9845$ & $R^{2}=0.9711$ & $R^{2}=0.9396$ \\
\hline \multirow{2}{*}{6} & $y=2.0256 x^{-0.132}$ & $y=0.0616 x^{-0.315}$ & $y=15.171 x^{-0.073}$ \\
\cline { 2 - 4 } & $R^{2}=0.9653$ & $R^{2}=0.9898$ & $R^{2}=0.9772$ \\
\hline \multirow{2}{*}{8} & $y=2.2511 x^{-0.169}$ & $y=0.0592 x^{-0.384}$ & $y=16.014 x^{-0.082}$ \\
\cline { 2 - 4 } & $R^{2}=0.9925$ & $R^{2}=0.9852$ & $R^{2}=0.967$ \\
\hline
\end{tabular}

Table 4-23: 13 Stages (Porosity) - PLE - Correlations

\begin{tabular}{|c|c|c|c|c|}
\hline \multicolumn{5}{|c|}{13 Fractures (Porosity) - PLE } \\
\hline $\boldsymbol{\phi}(\%)$ & $D_{\infty}$ & $n$ & $D_{1}$ & $q_{i}$ \\
\hline \multirow{2}{*}{4} & $y=-3 E-04 \ln (x)+6 E-05$ & $y=0.0103 \ln (x)+0.4369$ & $y=0.0008 \ln (x)+0.0702$ & $y=0.0548 \ln (x)+13.11$ \\
\cline { 2 - 5 } & $R^{2}=0.3228$ & $R^{2}=0.0934$ & $R^{2}=0.0421$ & $R^{2}=0.1632$ \\
\hline \multirow{2}{*}{5} & $y=-4 E-04 \ln (x)+0.0005$ & $y=0.0257 \ln (x)+0.3904$ & $y=-0.002 \ln (x)+0.0729$ & $y=-0.045 \ln (x)+13.96$ \\
\cline { 2 - 5 } & $R^{2}=0.6264$ & $R^{2}=0.4964$ & $R^{2}=0.2419$ & $R^{2}=0.1639$ \\
\hline \multirow{2}{*}{$\mathbf{6}$} & $y=-4 E-04 \ln (x)+0.0006$ & $y=0.0327 \ln (x)+0.3639$ & $y=-0.003 \ln (x)+0.0735$ & $y=-0.08 \ln (x)+14.588$ \\
\cline { 2 - 5 } & $R^{2}=0.7889$ & $R^{2}=0.7316$ & $R^{2}=0.6062$ & $R^{2}=0.4764$ \\
\hline \multirow{2}{*}{8} & $y=-3 E-04 \ln (x)+0.0006$ & $y=0.0378 \ln (x)+0.3378$ & $y=-0.004 \ln (x)+0.0737$ & $y=-0.156 \ln (x)+15.634$ \\
& $R^{2}=0.9176$ & $R^{2}=0.9156$ & $R^{2}=0.9088$ & $R^{2}=0.8961$ \\
\hline
\end{tabular}


Table 4-24: 13 Stages (Porosity) - Duong - Correlations

\begin{tabular}{|c|c|c|c|c|}
\hline \multicolumn{5}{|c|}{ 13 Fractures (Porosity) - Duong } \\
\hline $\boldsymbol{\phi}(\%)$ & $a$ & $\boldsymbol{m}$ & $q_{1}$ & $q^{\infty}$ \\
\hline \multirow{2}{*}{$\mathbf{5}$} & $y=0.1862 \ln (x)+0.9319$ & $y=0.0496 \ln (x)+1.044$ & $y=-1.686 \ln (x)+14.013$ & $y=0.8214 \ln (x)-2.4067$ \\
& $R^{2}=0.9825$ & $R^{2}=0.9721$ & $R^{2}=0.9757$ & $R^{2}=0.8092$ \\
\hline \multirow{2}{*}{5} & $y=0.175 \ln (x)+0.9575$ & $y=0.0469 \ln (x)+1.0423$ & $y=-1.665 \ln (x)+14.217$ & $y=0.9216(x)-2.754$ \\
\cline { 2 - 5 } & $R^{2}=0.9908$ & $R^{2}=0.9808$ & $R^{2}=0.9382$ & $R^{2}=0.8447$ \\
\hline \multirow{2}{*}{$\mathbf{8}$} & $y=0.1643 \ln (x)+0.9051$ & $y=0.0472 \ln (x)+1.0246$ & $y=-1.822 \ln (x)+16.036$ & $y=1.1095 \ln (x)-3.3831$ \\
& $R^{2}=0.9859$ & $R^{2}=0.9889$ & $R^{2}=0.9809$ & $R^{2}=0.8914$ \\
\hline \multirow{2}{*}{} & $y=0.1558 \ln (x)+0.9207$ & $y=0.0432 \ln (x)+1.0252$ & $y=-1.91 \ln (x)+16.678$ & $y=1.1611 \ln (x)-3.6625$ \\
& $R^{2}=0.9838$ & $R^{2}=0.9867$ & $R^{2}=0.972$ & $R^{2}=0.9424$ \\
\hline
\end{tabular}

According to Table 4-16 through Table 4-24, trends of the constants plotted vs. time show a high $\boldsymbol{R}^{2}$ only for Arps and Duong models.

Additionally, values of " $n$ " in the Arps model begins at approximately two, indicating transient linear flow. The " $n$ " values approach a harmonic decline $(n=1)$ as time progresses, especially for a higher ranges of fracture half-length and permeability; and lower porosity.

The Duong and Arps models were finally selected due to the consistent trend of constants plotted versus time at various fracture half-length, permeability, and porosity.

\subsection{Effect of Formation and Hydraulic Fracture Properties on Production}

\section{Decline Behavior}

In order to accurately predict the long term (30-year) decline model parameters based on the limited production histories $(2,3$, and 4 years), the ratio of decline curve constants obtained from fitting the limited production history (Table E-1 through Table E-28 for seven stages case; and Table E-57 through Table E-84 for thirteen stages case, located in the Appendix), to the same constant obtained from fitting the 30-year production profile were determined for Arps and Duong decline curve models. However, the constant values were re-calculated based on the obtained correlations in Table 4-4 through Table 4-12. This re-calculation results in a higher $\boldsymbol{R}^{2}$ when the regression curve applied to the plot of ratios vs. various ranges of fracture half-length, permeability, and porosity at each truncated production time $(2,3,4,5,7$, $10,15,20,25$, and 30 years). Comparing these plots will assist us to investigate the effect of formation and hydraulic fracture properties on the decline curve constants as well as the changing behavior of the constants over 30-year production time. 


\subsubsection{Seven Stages Model}

The results for re-calculated Arps and Duong constants and their ratios are shown in Table 4-25 through Table 4-28, for the base case only. The ratio calculation for other ranges of $\boldsymbol{X}_{f}, \boldsymbol{K}$, and $\boldsymbol{\phi}$ can be seen in Table E-29 though Table E-56, located in the Appendix.

Table 4-25: 7 Stages (Base Model) - Arps- Recalculated Constants

\begin{tabular}{|c|c|c|c|c|c|c|}
\hline \multicolumn{7}{|c|}{ 7 Fractures (Base Model)-Arps } \\
\hline Years & $n$ & $n(E q)$. & $d_{i}$ & $d_{i}($ Eq.) & $q_{i}$ & $q_{i}($ Eq.) \\
\hline 3 & 2.1055 & 1.9475 & 0.0259 & 0.0203 & 6.0292 & 5.7287 \\
\hline 5 & 1.7534 & 1.7800 & 0.0149 & 0.0160 & 5.3604 & 5.4350 \\
\hline 7 & 1.5965 & 1.6777 & 0.0118 & 0.0137 & 5.0889 & 5.2499 \\
\hline 10 & 1.4858 & 1.5756 & 0.0099 & 0.0117 & 4.8918 & 5.0605 \\
\hline 15 & 1.4195 & 1.4671 & 0.0089 & 0.0097 & 4.7677 & 4.8535 \\
\hline 20 & 1.3931 & 1.3946 & 0.0085 & 0.0085 & 4.7153 & 4.7118 \\
\hline 25 & 1.3769 & 1.3409 & 0.0083 & 0.0077 & 4.6821 & 4.6048 \\
\hline 30 & 1.3647 & 1.2986 & 0.0081 & 0.0071 & 4.6569 & 4.5191 \\
\hline
\end{tabular}

Table 4-26: 7 Stages (Base Model) - Arps - Table of Ratios

\begin{tabular}{|c|c|c|c|}
\hline \multicolumn{4}{|c|}{7 Fractures (Base Model)-Arps- Table of Ratios } \\
\hline Years & $n$ - Ratio & $d_{\text {i- } \text { Ratio }}$ & $q_{i}$ - Ratio \\
\hline 3 & 1.499685 & 2.870781 & 1.267652 \\
\hline 5 & 1.370739 & 2.271921 & 1.202679 \\
\hline 7 & 1.291921 & 1.947451 & 1.161712 \\
\hline 10 & 1.213314 & 1.653947 & 1.119808 \\
\hline 15 & 1.129747 & 1.373636 & 1.074004 \\
\hline 20 & 1.07397 & 1.204065 & 1.042647 \\
\hline 25 & 1.032609 & 1.087089 & 1.018957 \\
\hline 30 & 1 & 1 & 1 \\
\hline
\end{tabular}

Table 4-27: 7 Stages (Base Model) - Duong- Recalculated Constants

\begin{tabular}{|c|c|c|c|c|c|c|c|c|}
\hline \multicolumn{9}{|c|}{ 7 Fractures (Base Model)- Duong } \\
\hline Years & $a$ & $a(E q)$. & $m$ & $m$ (Eq.) & $q_{1}$ & $q_{1}$ (Eq.) & $q_{\infty}$ & $q_{\infty}$ (Eq.) \\
\hline 2 & 0.808 & 0.733 & 0.989 & 0.979 & 12.151 & 11.800 & -3.519 & -2.877 \\
\hline 3 & 0.812 & 0.814 & 0.992 & 1.001 & 11.050 & 10.685 & -2.853 & -2.380 \\
\hline 4 & 0.850 & 0.872 & 1.011 & 1.017 & 9.802 & 9.894 & -1.851 & -2.027 \\
\hline 5 & 0.891 & 0.917 & 1.029 & 1.030 & 8.870 & 9.280 & -1.109 & -1.753 \\
\hline 7 & 0.940 & 0.984 & 1.044 & 1.049 & 8.021 & 8.355 & -0.776 & -1.340 \\
\hline 10 & 1.022 & 1.056 & 1.066 & 1.069 & 7.025 & 7.374 & -0.461 & -0.902 \\
\hline 15 & 1.117 & 1.137 & 1.089 & 1.091 & 6.175 & 6.259 & -0.247 & -0.404 \\
\hline 20 & 1.202 & 1.195 & 1.106 & 1.108 & 5.501 & 5.468 & -0.151 & -0.051 \\
\hline 25 & 1.261 & 1.239 & 1.122 & 1.120 & 5.074 & 4.854 & -0.061 & 0.223 \\
\hline 30 & 1.320 & 1.276 & 1.130 & 1.130 & 4.650 & 4.353 & -0.035 & 0.447 \\
\hline
\end{tabular}


Table 4-28: 7 Stages (Base Model) - Duong - Table of Ratios

\begin{tabular}{|c|c|c|c|c|}
\hline \multicolumn{5}{|c|}{ 7 Fractures (Base Model)- Duong- Table of Ratios } \\
\hline Years & a-Ratio & m-Ratio & $\boldsymbol{q}_{1}$ - Ratio & $q_{\infty}$ - Ratio \\
\hline 2 & 0.57446 & 0.865827 & 2.710921 & -6.4437626 \\
\hline 3 & 0.638174 & 0.885917 & 2.454752 & -5.3292389 \\
\hline 4 & 0.68338 & 0.90017 & 2.272997 & -4.5384718 \\
\hline 5 & 0.718445 & 0.911226 & 2.132017 & -3.9251052 \\
\hline 7 & 0.771318 & 0.927897 & 1.919437 & -3.0002259 \\
\hline 10 & 0.827365 & 0.945568 & 1.694093 & -2.0198144 \\
\hline 15 & 0.89108 & 0.965657 & 1.437924 & -0.9052908 \\
\hline 20 & 0.936286 & 0.979911 & 1.256169 & -0.1145237 \\
\hline 25 & 0.97135 & 0.990967 & 1.115189 & 0.49884298 \\
\hline 30 & 1 & 1 & 1 & 1 \\
\hline
\end{tabular}

Section 4.4.1 and section 4.4.2 show the changes of Arps and Duong models' constants with fracture half-length, permeability, and porosity. However, the plot of the initial flow rate $\left(\boldsymbol{q}_{i}\right)$ has been only presented in this chapter. The rest of the plots for other Arps and Duong models' constants were shown in the Figure F-1 through Figure F-21, located in the Appendix. 


\subsubsection{Arps Decline Curve Analysis}

Figure 4-4 shows that initial flow rate $\left(\boldsymbol{q}_{i}\right)$ ratio does not change significantly at higher ranges of fracture half length; while lower ranges of fracture half-length has more impact on the constant. This is probably due to the Arps model assumption that the boundary-dominated flow regime exists. At the higher ranges of fracture half-length, well reaches the boundary flow sooner; and the constant ratios at each production time interval are closer to 1 . Whereas, for lower ranges of fracture half-length reservoir exhibits a long linear transient flow because of the domination of the fracture flow. This results in an overestimation of the Arps constants, and the constants ratios are further from 1 (Figure F-1 through Figure F-3). Thus, adjusting Arps constants need to be done at lower ranges of fracture half-length.

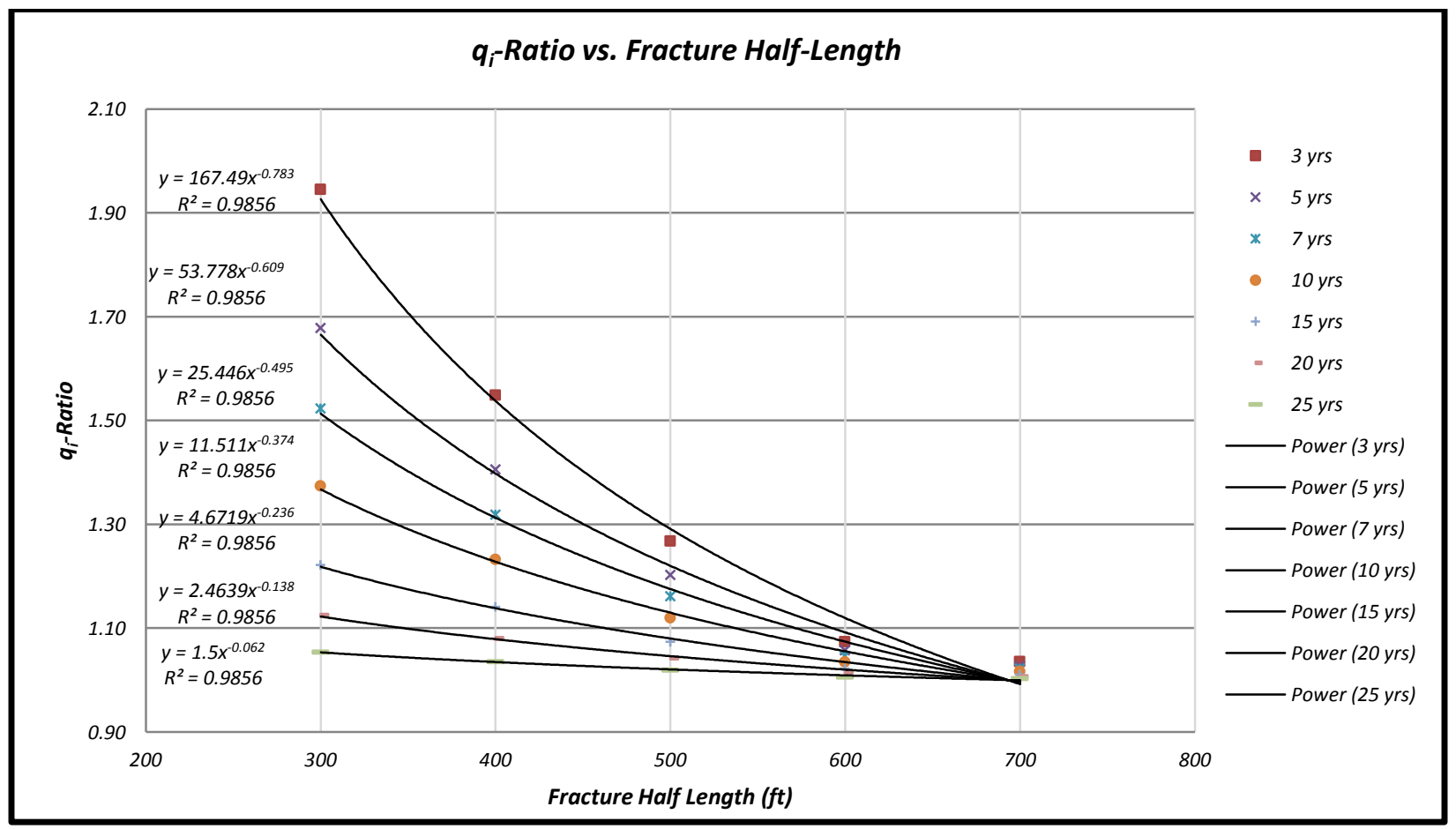

Figure 4-4: $q_{i}$-Ratio vs. Fracture Half-length - 7 Stages

Figure 4-5 shows that higher ranges of permeability slightly impact the initial flow rate $\left(\boldsymbol{q}_{i}\right)$ ratio; and the constant ratio at each production time interval is closer to 1. So, the Arps model is more precise for higher ranges of permeability; since the reservoir reaches the boundaries sooner. On the other hand, lower ranges of permeability impact the Arps model constants more significantly; and the constant ratios are further from 1 (Figure F-4 through Figure F-6). This is probably because of longer linear transient flow in horizontal shale wells with lower ranges of permeability which makes Arps model not as accurate. Therefore, adjusting Arps constants need to be done at lower range of permeability. 


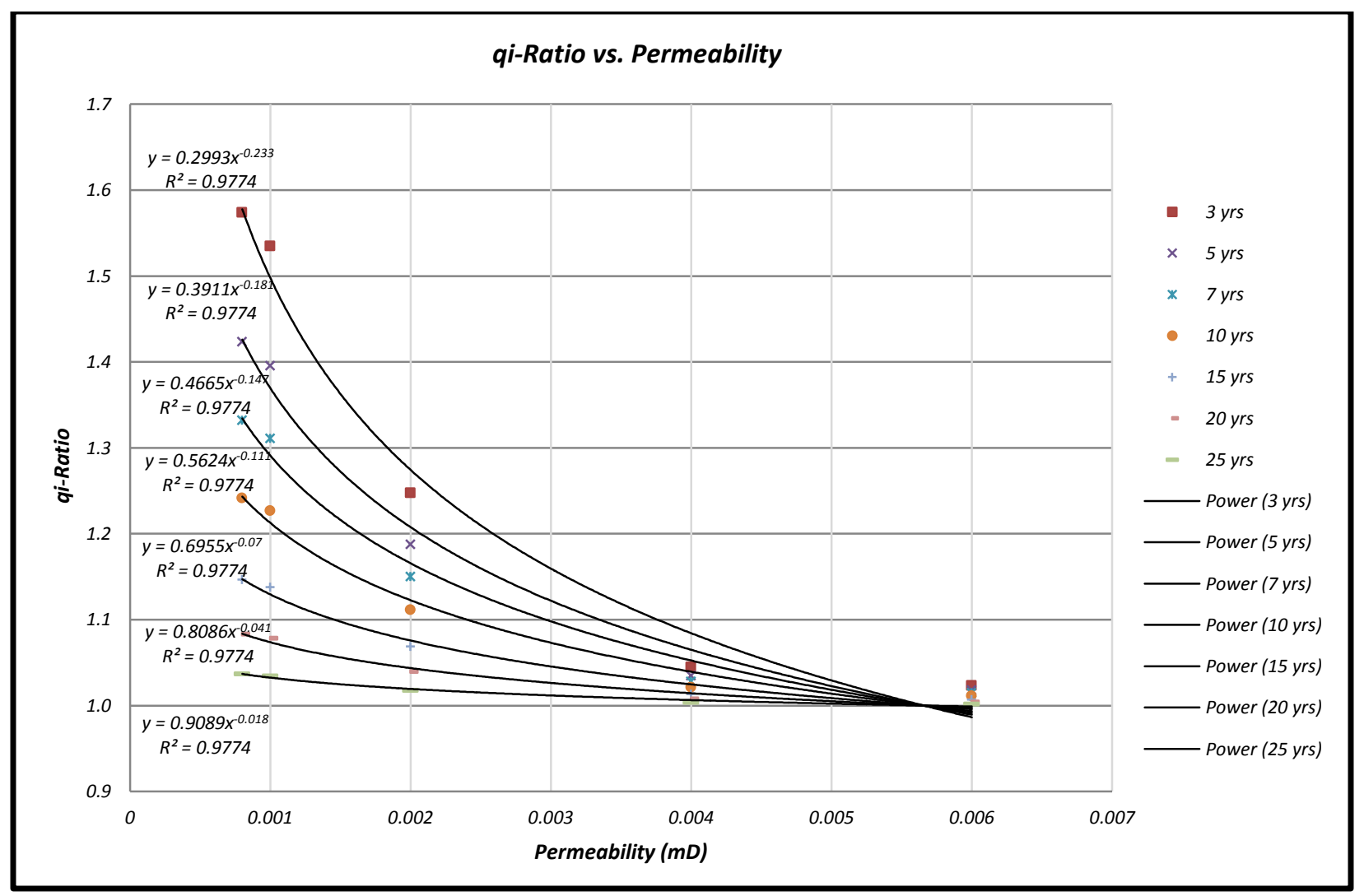

Figure 4-5: $q_{i}-$ Ratio vs. Permeability - 7 Stages

Figure 4-6 shows that changing porosity doesn't seem to have a significant impact on initial flow rate $\left(\boldsymbol{q}_{i}\right)$ ratio. However, the higher ranges of porosity means higher gas volume which causes long linear transient flow in a low-permeability reservoir. This will result in an overestimation of the Arps model constants; and the constant ratios are further from 1 at each production time interval. The lower ranges of porosity, on the other hand, causes lower gas volume and consequently a low-permeability reservoir reaches the boundary dominated flow sooner. Therefore, Arps' constants are closer to 1 and not much adjustment is needed compare to higher ranges of porosity (Figure F-7 through Figure F-9). 


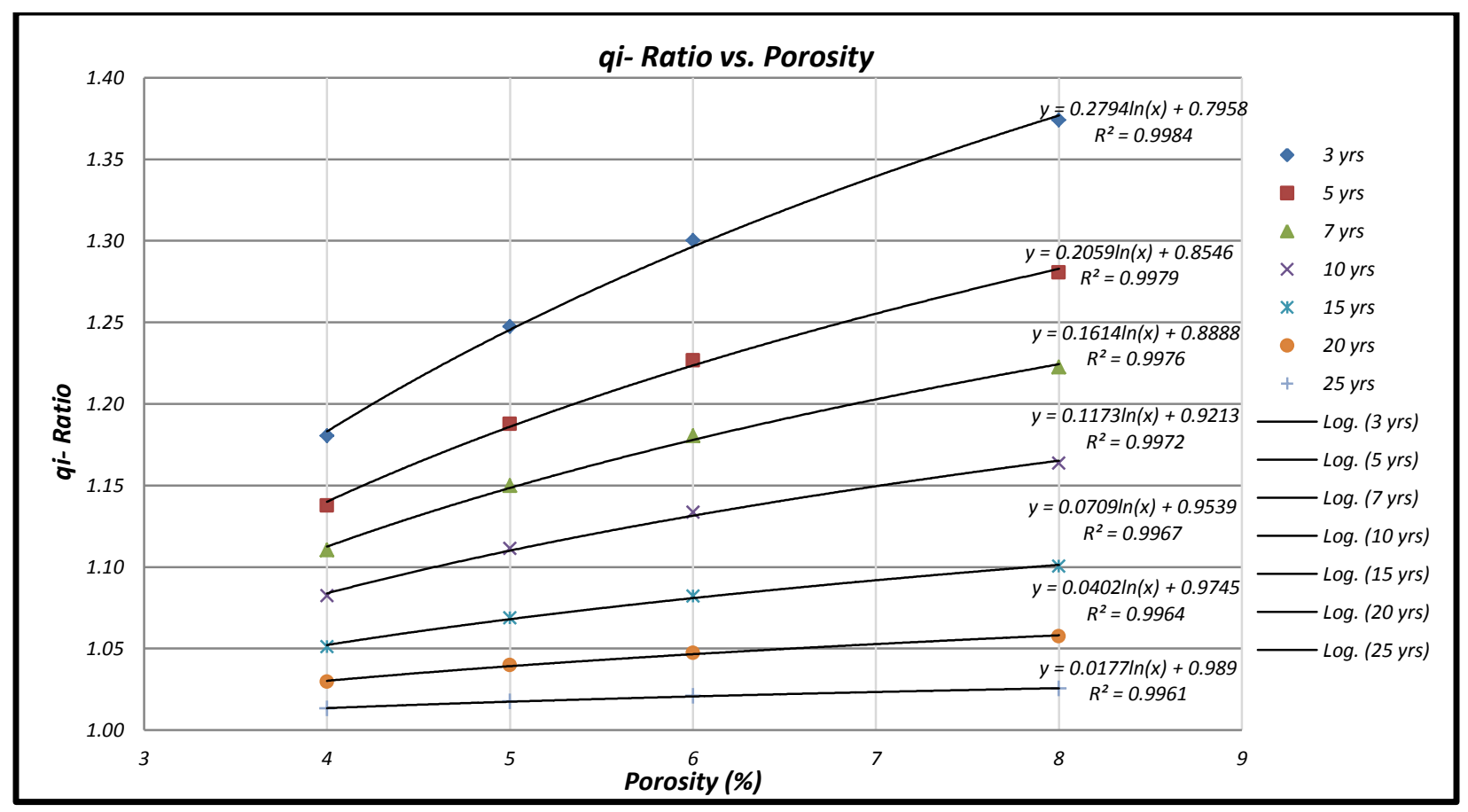

Figure 4-6: $q_{i}$-Ratio vs. Porosity - 7 Stages

As shown in Figure F-1 through Figure F-9, the changes of " $\boldsymbol{d}_{i}$-Ratio" and " $\boldsymbol{q}_{\boldsymbol{i}}$-Ratio" with fracture half-length and permeability present a higher slope compare to changes of " $n$-Ratio". So, " $\boldsymbol{d}_{i}$ " and " $\boldsymbol{q}_{i}$ " constants seem to get more effected with increasing the corresponding properties, over thirty years of production. However, according to Figure F-7 through Figure F-9, increasing porosity will have more or less same impact on the Arps model constants $\left(\boldsymbol{n}, \boldsymbol{d}_{\boldsymbol{i}}, \boldsymbol{q}_{\boldsymbol{i}}\right)$.

It is also clear that constants change with fracture half-length, permeability, and porosity at a higher slope during the early years and then the changes approach to a zero slope by thirty years of production.

\subsubsection{Duong Decline Curve Analysis}

Figure 4-7 shows that initial flow rate $\left(\boldsymbol{q}_{\boldsymbol{i}}\right)$ ratio does not change significantly at lower ranges of fracture half length; while higher ranges of fracture half-length has more impact on the constant. This is probably due to the accuracy of Duong model at transient linear flow. At the lower ranges of fracture half-length owing to fracture dominated flow, Duong model constant ratios are closer to 1 . On the contrary, at the higher ranges of fracture half-length well reaches the boundary flow sooner; and the constants ratios at each production time interval are further from 1 (Figure F-10 through Figure F-13). Therefore, adjusting Duong constants need to be done at higher ranges of fracture half-length. 


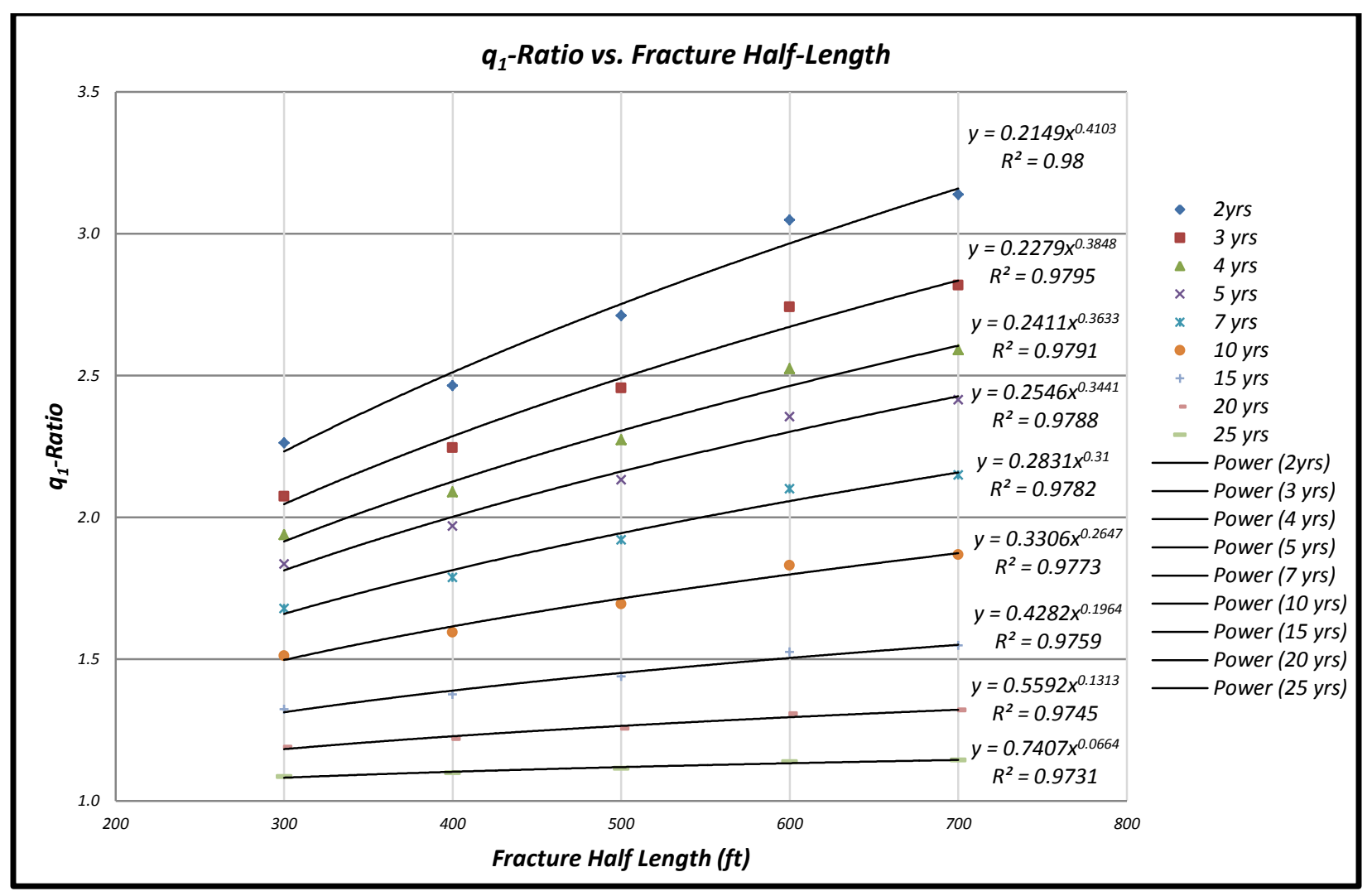

Figure 4-7: q1-Ratio vs. Fracture Half Length- 7 Stages

Figure 4-8 shows that lower ranges of permeability slightly impact initial flow rate $\left(\boldsymbol{q}_{i}\right)$ ratio compared to higher ranges of permeability. This is probably because of Duong model accuracy for transient linear flow. At the lower ranges of permeability owing to fracture dominated flow, Duong model constant ratios are closer to 1 . On the other hand, at the higher ranges of permeability well reaches the boundary dominated flow sooner; and the constant ratios at each production time interval are further from 1 (Figure F-14 through Figure F-17). Therefore, adjusting Duong constants need to be done at lower ranges of permeability. 


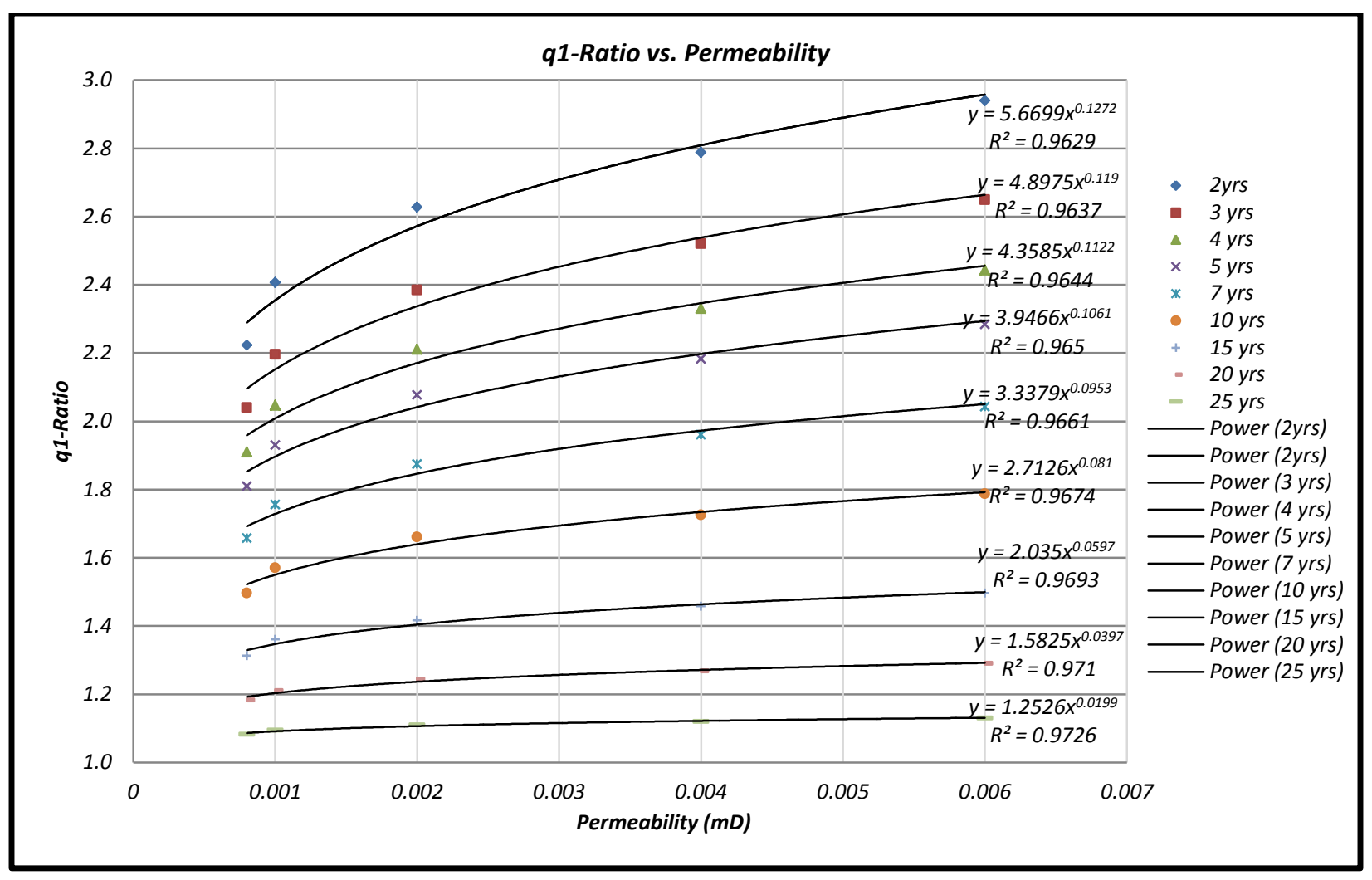

Figure 4-8: $q_{1}$-Ratio vs. Permeability - 7 Stages

Figure 4-9 shows initial flow rate $\left(\boldsymbol{q}_{i}\right)$ ratio get less affected at higher ranges of porosity which is probably due to accuracy of Duong model at longer linear transient flow. On the other hand, lower ranges of porosity have more impact on the constant. The lower ranges of porosity causes lower gas volume and consequently a low-permeability reservoir reaches the boundary dominated flow sooner. This will result in an overestimation of the Duong model constants, and the constants ratios are further from 1 at each production time interval. On the contrary, the higher ranges of porosity means higher gas volume which causes long linear transient flow in a low-permeability reservoir. So, the Duong constant ratios are closer to 1; and not much adjustment is needed (Figure F-18 through Figure F-21). 


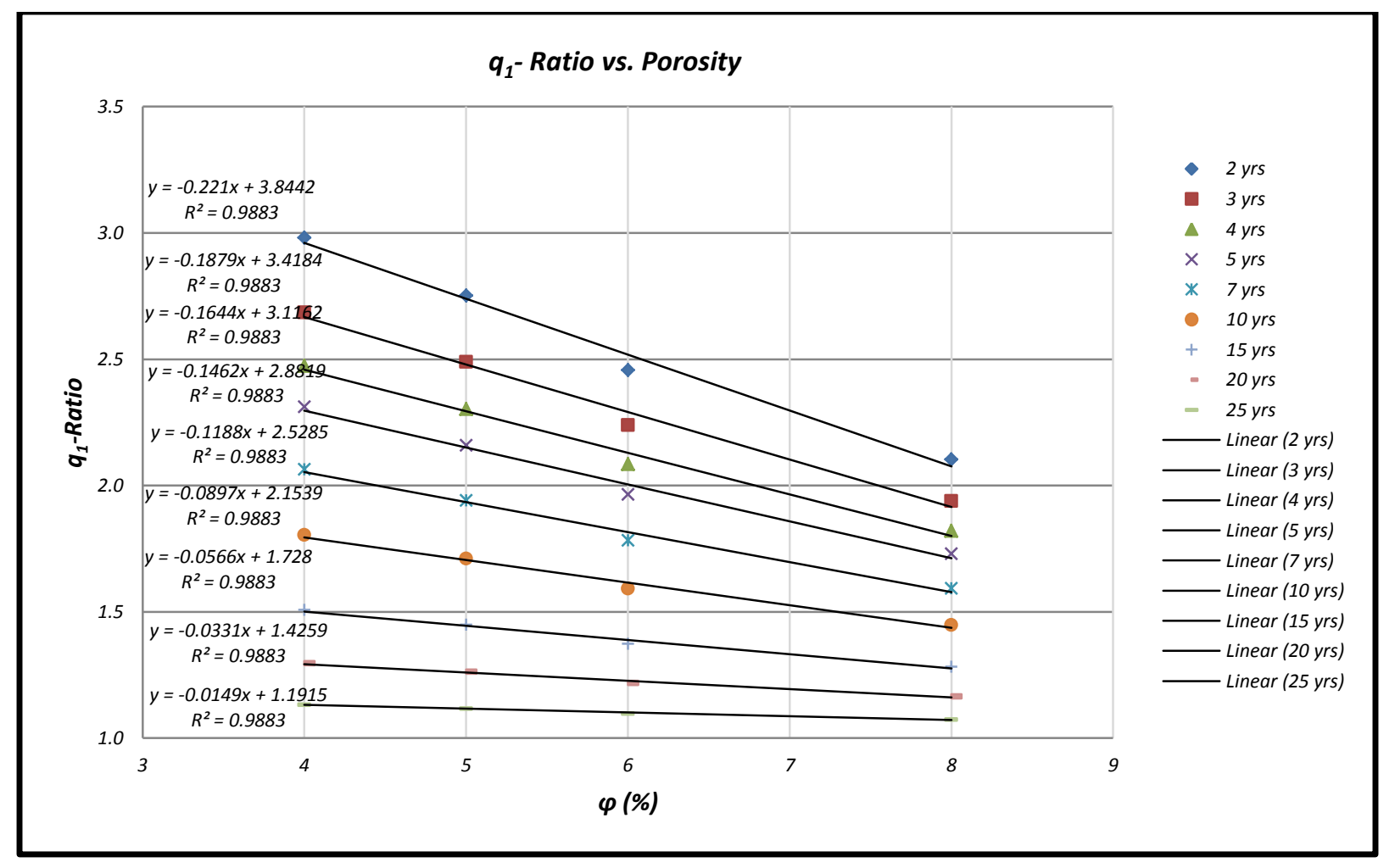

Figure 4-9: $q_{1}$-Ratio vs. Porosity - 7 Stages

As shown in Figure F-10 through Figure F-21, the changes of " $\boldsymbol{a}$-Ratio" and " $\boldsymbol{m}$-Ratio" with fracture half length, permeability, and porosity present a lower slope compare to changes of " $\boldsymbol{q}_{1}$-Ratio" and " $\boldsymbol{q}_{\infty}$-Ratio". So, " $\boldsymbol{a}$ " and " $\boldsymbol{m}$ " constants seem to get less effected with increasing the corresponding properties, over thirty years of production.

It is also clear that constants change with fracture half-length, permeability, and porosity at a higher slope during the early years and then the changes approach to a zero slope by thirty years of production.

It should be noted that the reason $\mathrm{q}_{\infty}$-Ratio values don't seem reasonable is due to the fact that $\mathrm{q}_{\infty}$ doesn't have any physical meaning. It is just added to the Duong Equation to provide a better fit to some field data that showed an intercept instead of a straight line to the origin when plotting (q vs. $t(a, m)$ ). 


\subsubsection{Thirteen Stages Model}

The results for re-calculated Arps and Duong constants and their ratios are shown in Table 4-29 through Table 4-32, for the base case only. The ratio calculation for other ranges of $\boldsymbol{X}_{f}, \boldsymbol{K}$, and $\boldsymbol{\Phi}$ can be seen in Table E-57 though Table E-112, located in the Appendix.

Table 4-29: 13 Stages (Base Model) - Arps- Recalculated Constants

\begin{tabular}{|c|c|c|c|c|c|c|}
\hline \multicolumn{7}{|c|}{ 13 Fractures (Base Model)-Arps } \\
\hline Years & $n$ & $n(E q)$. & $d_{i}$ & $d_{i}($ Eq.) & $q_{i}$ & $q_{i}($ Eq.) \\
\hline 3 & 1.5027 & 1.4611 & 0.0281 & 0.0278 & 11.7560 & 11.7977 \\
\hline 5 & 1.4045 & 1.4127 & 0.0265 & 0.0263 & 11.7097 & 11.6718 \\
\hline 7 & 1.3575 & 1.3817 & 0.0252 & 0.0254 & 11.6079 & 11.5896 \\
\hline 10 & 1.3221 & 1.3495 & 0.0240 & 0.0245 & 11.4800 & 11.5031 \\
\hline 15 & 1.3046 & 1.3139 & 0.0233 & 0.0234 & 11.4094 & 11.4056 \\
\hline 20 & 1.2946 & 1.2892 & 0.0229 & 0.0227 & 11.3525 & 11.3369 \\
\hline 25 & 1.2800 & 1.2703 & 0.0221 & 0.0222 & 11.2519 & 11.2839 \\
\hline 30 & 1.2765 & 1.2551 & 0.0220 & 0.0218 & 11.2320 & 11.2408 \\
\hline
\end{tabular}

Table 4-30: 13 Stages (Base Model) - Arps- Table of Ratios

\begin{tabular}{|c|c|c|c|}
\hline \multicolumn{4}{|c|}{ 13Fractures (Base Model)- Arps- Table of Ratios } \\
\hline Years & $n$ - Ratio & $d_{i}$ - Ratio & $q_{i}$ - Ratio \\
\hline 3 & 1.164126 & 1.279381 & 1.049542 \\
\hline 5 & 1.125532 & 1.211329 & 1.038344 \\
\hline 7 & 1.100813 & 1.168494 & 1.031033 \\
\hline 10 & 1.075202 & 1.12474 & 1.023339 \\
\hline 15 & 1.04681 & 1.076986 & 1.014663 \\
\hline 20 & 1.027122 & 1.04434 & 1.008551 \\
\hline 25 & 1.012106 & 1.0197 & 1.003836 \\
\hline 30 & 1 & 1 & 1 \\
\hline
\end{tabular}

Table 4-31: 13 Stages (Base Model) - Duong- Recalculated Constants

\begin{tabular}{|c|c|c|c|c|c|c|c|c|}
\hline \multicolumn{9}{|c|}{ 13 Fractures (Base Model)- Duong } \\
\hline Years & $\boldsymbol{a}$ & $\boldsymbol{a}$ (Eq.) & $\boldsymbol{m}$ & $\boldsymbol{m}$ (Eq.) & $\boldsymbol{q}_{\mathbf{1}}$ & $\boldsymbol{q}_{\mathbf{1}}$ (Eq.) & $\boldsymbol{q}_{\infty}$ & $\boldsymbol{q}_{\infty}$ (Eq.) \\
\hline 2 & 0.9457 & 0.9042 & 1.0494 & 1.0398 & 16.0602 & 15.6228 & -2.5770 & -2.3715 \\
\hline 3 & 0.9859 & 0.9993 & 1.0506 & 1.0650 & 15.0210 & 14.7259 & -2.5563 & -1.9550 \\
\hline 4 & 1.0626 & 1.0669 & 1.0809 & 1.0829 & 14.0400 & 14.0895 & -1.5909 & -1.6595 \\
\hline 5 & 1.1180 & 1.1192 & 1.0992 & 1.0967 & 13.1801 & 13.5959 & -1.0808 & -1.4303 \\
\hline 7 & 1.1985 & 1.1982 & 1.1236 & 1.1176 & 12.2501 & 12.8516 & -0.6089 & -1.0847 \\
\hline 10 & 1.2621 & 1.2819 & 1.1430 & 1.1398 & 11.8010 & 12.0627 & -0.3241 & -0.7183 \\
\hline 15 & 1.3396 & 1.3771 & 1.1621 & 1.1650 & 11.1505 & 11.1658 & -0.1441 & -0.3018 \\
\hline 20 & 1.3988 & 1.4446 & 1.1808 & 1.1828 & 10.8500 & 10.5294 & -0.0376 & -0.0063 \\
\hline 25 & 1.4654 & 1.4970 & 1.1851 & 1.1967 & 10.1590 & 10.0358 & -0.0240 & 0.2229 \\
\hline 30 & 1.6505 & 1.5398 & 1.2199 & 1.2080 & 9.8000 & 9.6326 & 0.0500 & 0.4102 \\
\hline
\end{tabular}


Table 4-32: 13 Stages (Base Model) - Duong- Table of Ratios

\begin{tabular}{|c|c|c|c|c|}
\hline \multicolumn{5}{|c|}{13 Fractures (Base Model)- Duong-Table of Ratios } \\
\hline Years & a-Ratio & m-Ratio & $q_{1}$-Ratio & $q_{\infty}$ - Ratio \\
\hline 2 & 0.587222 & 0.860788 & 1.621871 & -5.781184 \\
\hline 3 & 0.649026 & 0.881632 & 1.528761 & -4.7658655 \\
\hline 4 & 0.692876 & 0.896421 & 1.462698 & -4.0454856 \\
\hline 5 & 0.726889 & 0.907892 & 1.411456 & -3.4867155 \\
\hline 7 & 0.778176 & 0.925189 & 1.334189 & -2.6441609 \\
\hline 10 & 0.832543 & 0.943524 & 1.252283 & -1.751017 \\
\hline 15 & 0.894346 & 0.964368 & 1.159173 & -0.7356985 \\
\hline 20 & 0.938196 & 0.979156 & 1.09311 & -0.0153185 \\
\hline 25 & 0.972209 & 0.990627 & 1.041868 & 0.54345158 \\
\hline 30 & 1 & 1 & 1 & 1 \\
\hline
\end{tabular}

Section 4.4.2.1 and section 4.4.2.2 show the changes of Arps and Duong models' constants with fracture half-length, permeability and porosity. However, the plot of the initial flow rate $\left(\boldsymbol{q}_{i}\right)$ has been only presented in this chapter. The rest of the plots for other Arps and Duong models' constants were shown in the Figure F-22 through Figure F-42.

\subsubsection{Arps Decline Curve Analysis}

Figure 4-10 shows that initial flow rate " $\boldsymbol{q}_{i}$ " ratio does not change significantly at higher ranges of fracture half-length; while lower ranges of fracture half-length has more impact on the constant. This is probably due to Arps model assumption that boundary dominated flow exists. At the lower ranges of fracture half-length owing to fracture dominated flow, Arps model constant ratios are further from 1. On the other hand, at the higher ranges of fracture half-length well reaches the boundary dominated flow sooner; and the constants ratios at each production time interval are further from 1 (Figure F-22 through Figure F-24). Therefore, adjusting Arps constants need to be done at lower ranges of fracture half-length. 


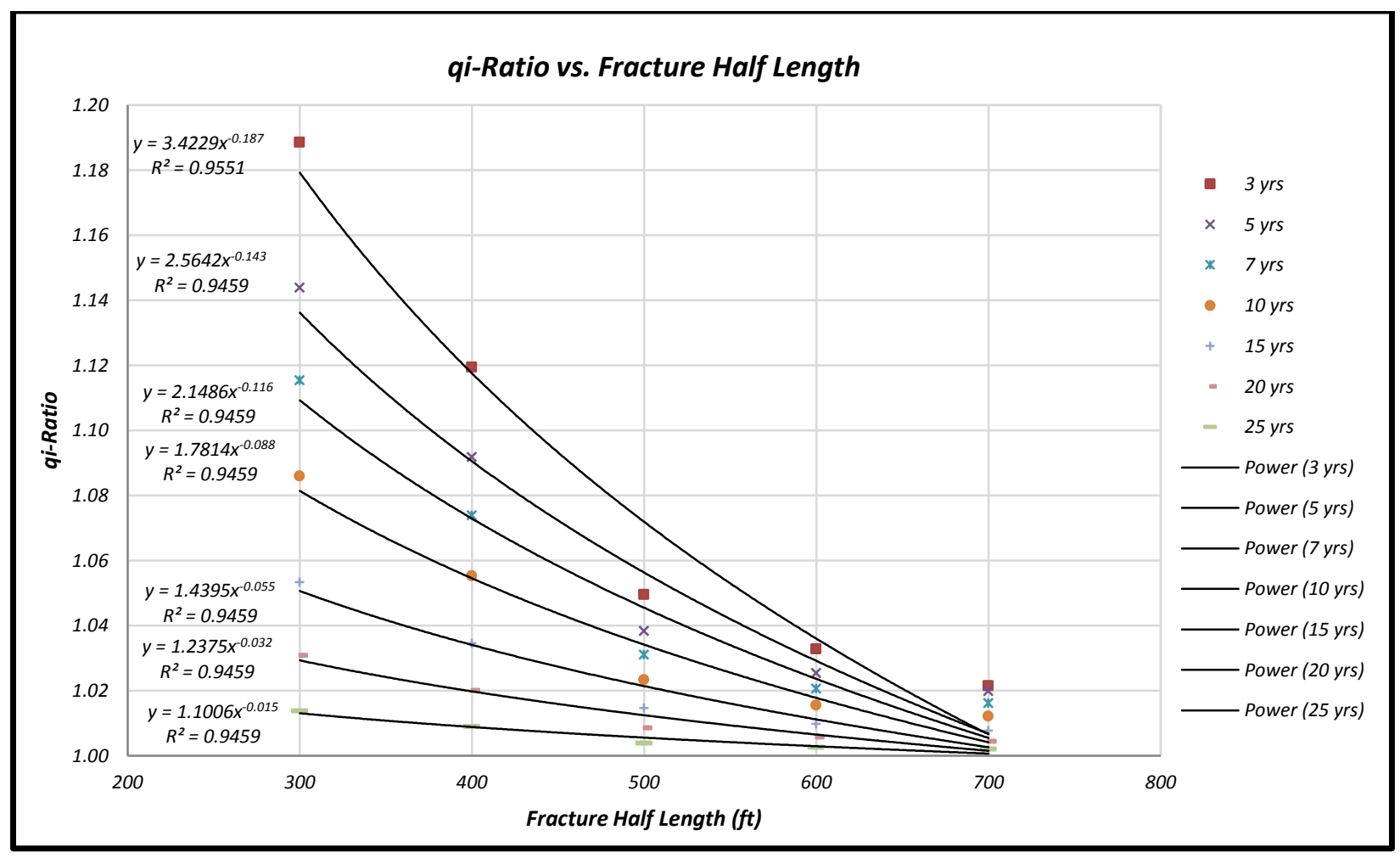

Figure 4-10: $q_{i}$-Ratio vs. Fracture Half-length - 13 Stages

Figure 4-11 shows that at higher ranges of permeability slightly impact the initial flow rate " $\boldsymbol{q}_{\boldsymbol{i}}-$ ratio" compare to lower ranges of permeability. This is probably due to Arps model assumption that boundary dominated flow exist. At the lower ranges of permeability owing to fracture dominated flow, Arps model constants ratios are further from 1. Oppositely, at the higher ranges of permeability, well reaches the boundary dominated flow sooner; and the constant ratios at each production time interval are closer to 1 (Figure F-25 through Figure F-27). Therefore, adjusting Arps constants need to be done at lower ranges of permeability. 


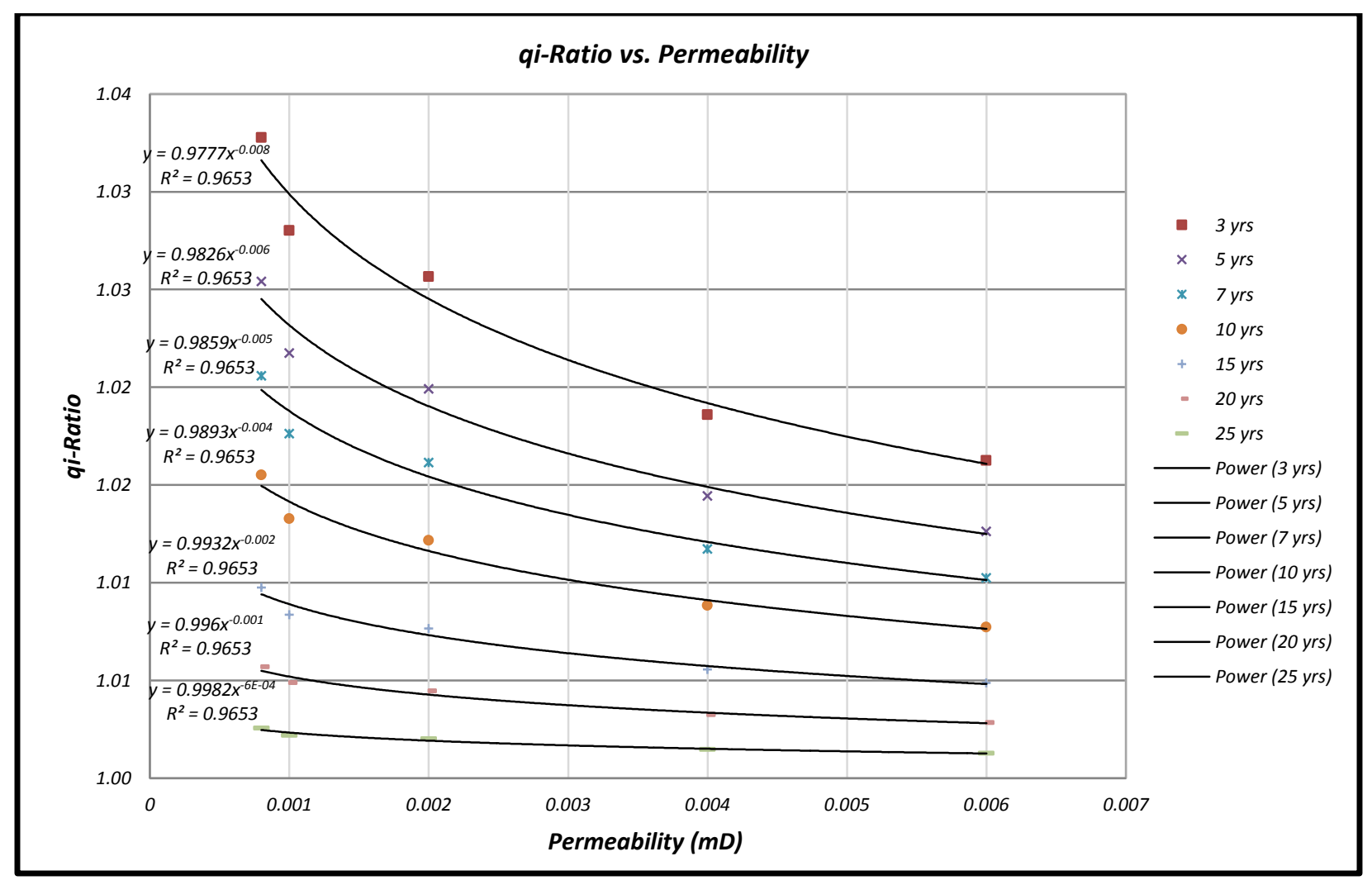

Figure 4-11: $q_{i}$-Ratio vs. Permeability - 13 Stages

Figure 4-12 shows that initial flow rate " $q_{i}$ " ratio does not change significantly at lower ranges of porosity; while higher ranges of porosity has more impact on the constants. Since at the lower ranges of porosity the reservoir will contain less gas volume, it reaches the boundaries sooner and therefore the Arps model predict the future production more accurately (constants ratios closer to 1). However, as higher gas volume in the reservoir causes the longer linear flow from stimulated parts, the Arps model is not as accurate; and the constants ratios further from 1 (Figure F-28 through Figure F-30). So, it can be concluded that Arps' model constants need more adjustment when the matrix porosity is in higher ranges. 


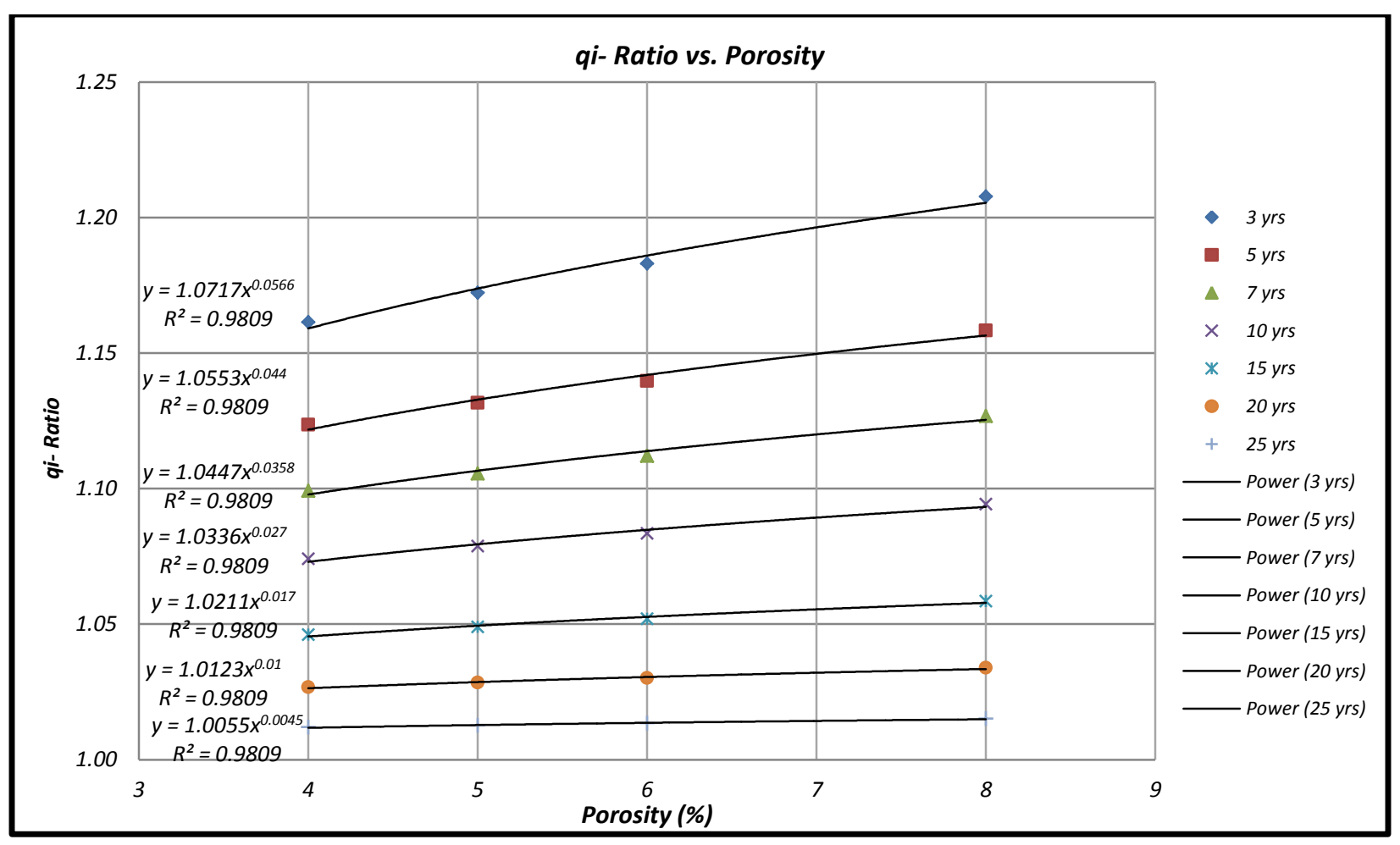

Figure 4-12: $q_{i}$-Ratio vs. Porosity - 13 Stages

As shown in Figure F-22 through Figure F-30, the changes of " $\boldsymbol{d}_{i}$-Ratio" and " $\boldsymbol{q}_{i}$-Ratio" with fracture half- length and permeability present a higher slope compare to changes of " $\boldsymbol{n}$-Ratio". So, " $\boldsymbol{d}_{\boldsymbol{i}}$ " and " $q_{i}$ " constants seem to get more effected with increasing the corresponding properties, over thirty years of production. However, according to Figure F-28 through Figure F-30, increasing porosity will have more or less same impact on the Arps model constants $\left(\boldsymbol{n}, \boldsymbol{d}_{\boldsymbol{i}}, \boldsymbol{q}_{i}\right)$.

It is also clear that constants change with fracture half-length, permeability, and porosity at a higher slope during the early years and then the changes approach to a zero slope by thirty years of production.

\subsubsection{Duong Decline Curve Analysis}

Figure 4-13 shows that initial flow rate " $\boldsymbol{q}_{i}$ " ratio does not change significantly at lower ranges of fracture half-length (ratios are closer to 1); while higher ranges of fracture half-length has more impact on the constant (ratios are further from 1). Since the higher the fracture half length, the sooner the reservoir reaches the boundaries; Duong model does not estimate the future reserves as accurate as when the 
fracture half-length is shorter. This is probably because of the accuracy of Duong model at transient linear flow which is longer at lower ranges of fracture half length. Therefore, adjusting Duong constants need to be done at higher ranges of fracture half-length (Figure F-31 through Figure F-34).

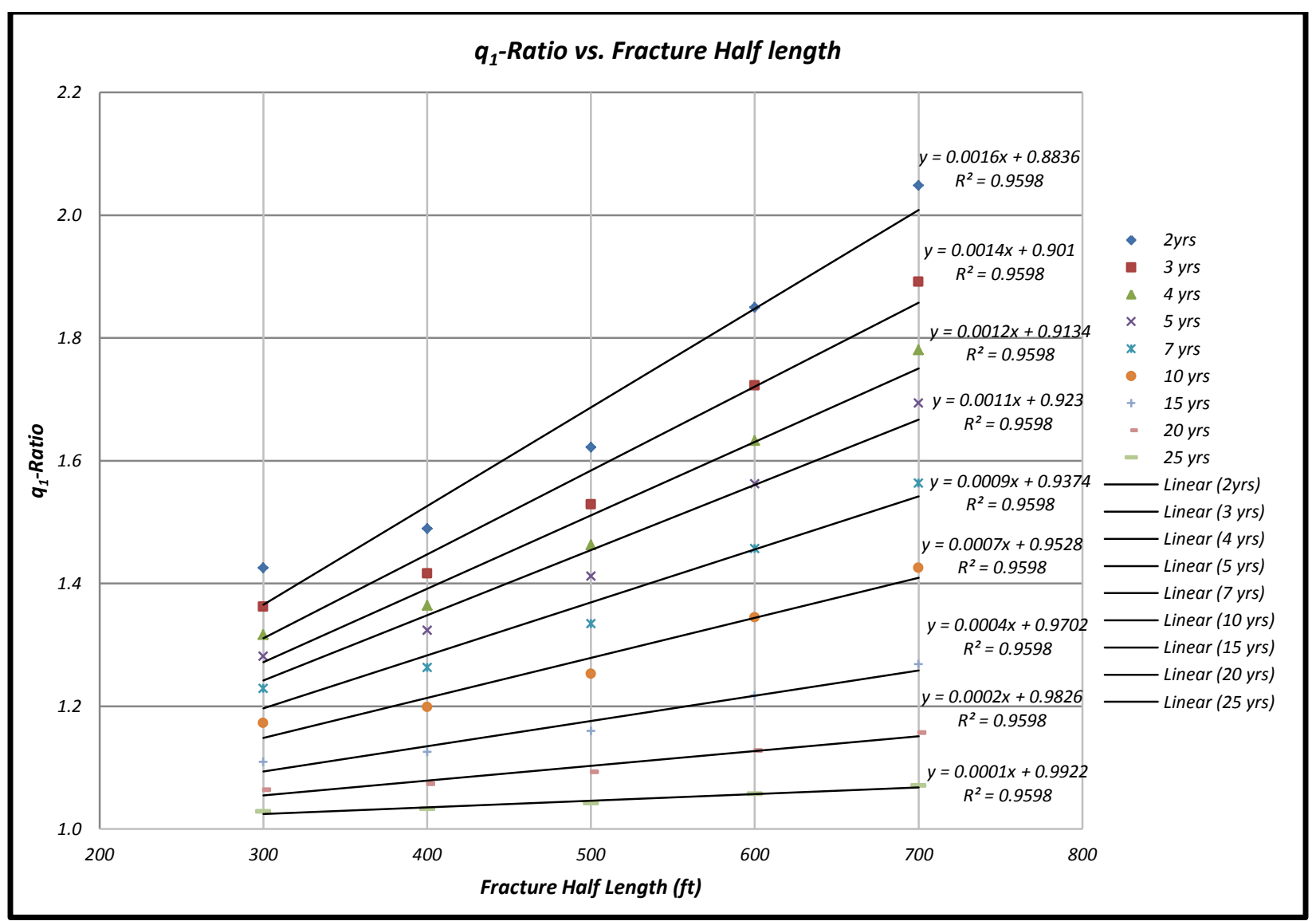

Figure 4-13: q1-Ratio vs. Fracture Half Length - 13 Stages

Figure 4-14 shows that initial flow rate " $\boldsymbol{q}_{i}$ " constant ratio does not change significantly at lower ranges of permeability (ratios are closer to 1); while higher ranges of permeability has more impact on the constants (ratios are further from 1). As at the lower ranges of permeability, production would be mainly from the stimulated section; Duong model predict the future production more exact. This is probably due to the accuracy of the Duong model at transient linear flow which is longer at lower ranges of permeability. Therefore, adjusting Duong constants need to be done at higher ranges of permeability (Figure F-35 through Figure F-38). 


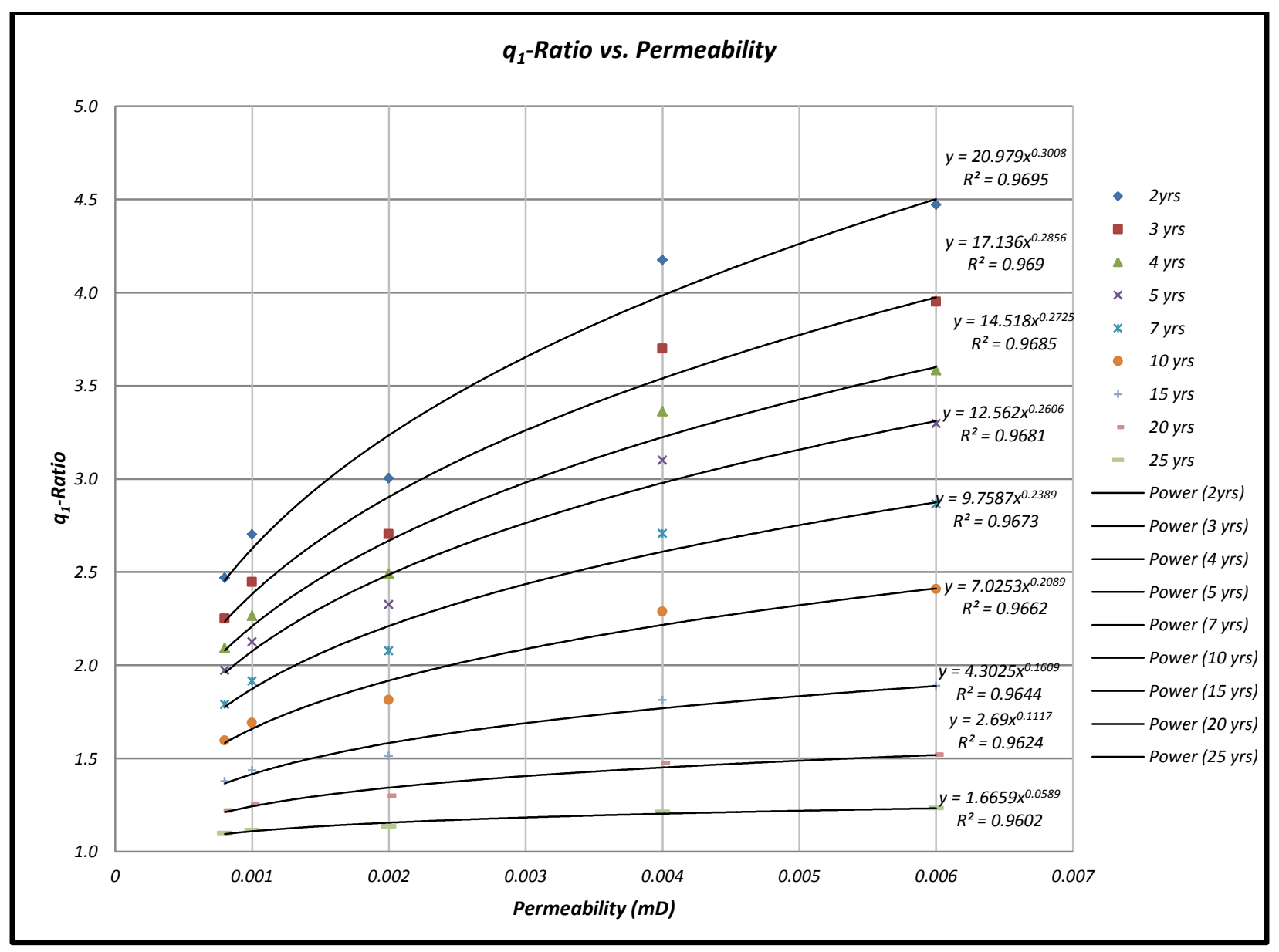

Figure 4-14: $\mathrm{q}_{1}$-Ratio vs. Permeability - 13 Stages

Figure 4-15 shows that initial flow rate " $\boldsymbol{q}_{i}$ " ratio get less effected at higher ranges of porosity which is probably due to accuracy of Duong model at longer linear transient flow. On the other hand, lower ranges of porosity have more impact on the constant. The lower ranges of porosity causes lower gas volume and consequently a low-permeability reservoir reaches the boundary dominated flow sooner. This will result in an overestimation of the Duong model constants, and the constants ratios are further from 1 at each production time interval. On the contrary, the higher ranges of porosity means higher gas volume which causes long linear transient flow in a low-permeability reservoir. So, the Duong constant ratios are closer to 1; and not much adjustment is needed (Figure F-39 through Figure F-42). 


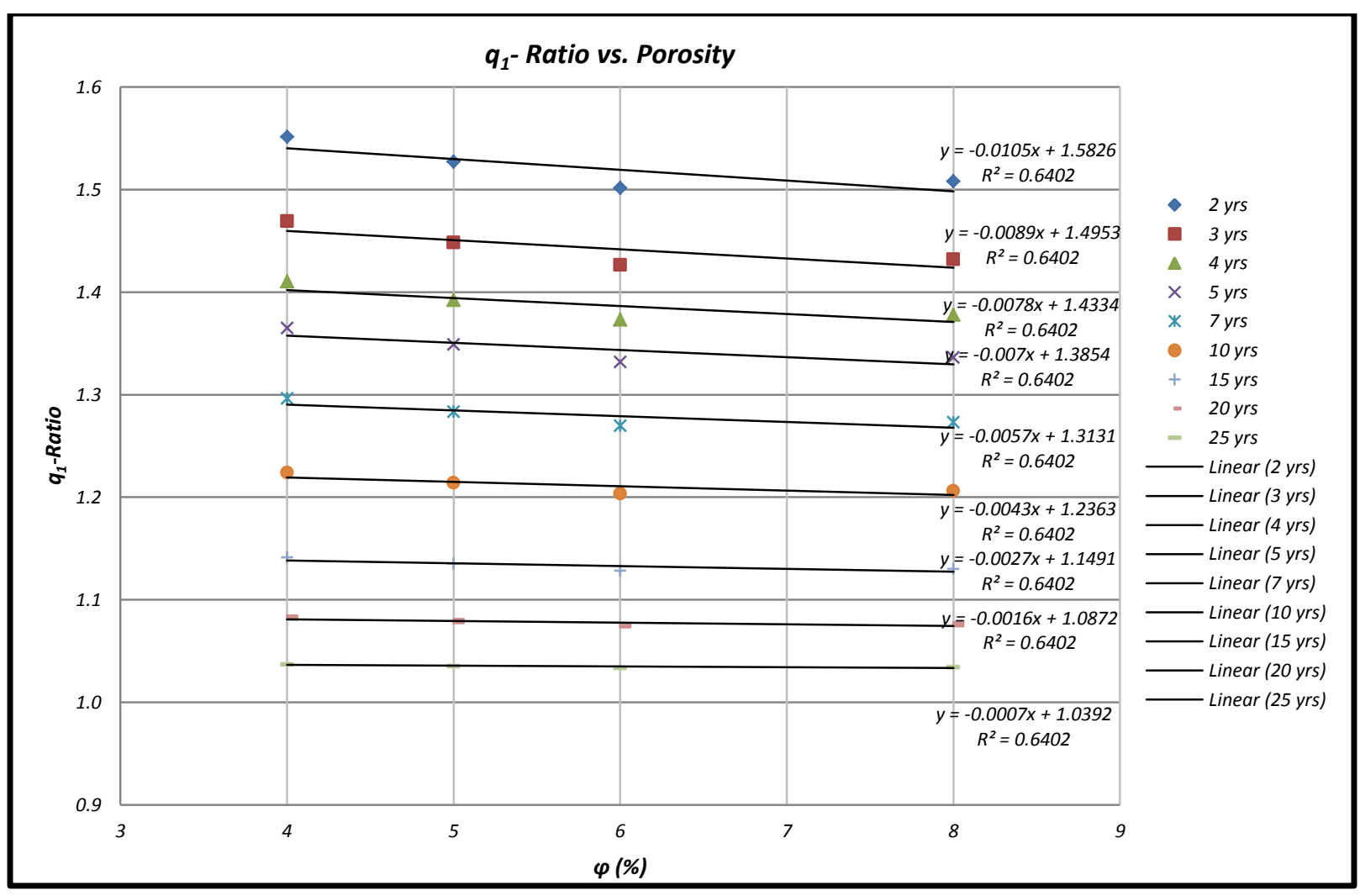

Figure 4-15: $q_{1}$-Ratio vs. Porosity - 13 Stages

As shown in Figure F-31 through Figure F-42, the changes of " $\boldsymbol{a}$-Ratio" and " $\boldsymbol{m}$-Ratio" with fracture half length, permeability, and porosity present a lower slope compare to changes of " $\boldsymbol{q}_{1}$-Ratio" and " $q_{\infty}$-Ratio". So, " $a$ " and " $\boldsymbol{m}$ " constants seem to get less effected with increasing the corresponding properties, over thirty years of production.

It is also clear that constants change with fracture half-length, permeability, and porosity at a higher slope during the early years and then the changes approach to a zero slope by thirty years of production.

It should be noted that the reason $\boldsymbol{q}_{\infty}$-Ratio values don't seem reasonable is due to the fact that $\mathrm{q}_{\infty}$ doesn't have any physical meaning. It is just added to the Duong Equation to provide a better fit to some field data that showed an intercept instead of a straight line to the origin when plotting (q vs. $t$ (a, m)). 


\subsection{Error Compared to the Base Case Model}

The effect of underestimating or overestimating the fracture and formation properties on each Arps and Duong model constants studied by comparing the cases were shown in the following table, for both seven- and thirteen- stage models.

Table 4-33 : Error Comparison Cases

\begin{tabular}{|c|c|c|}
\hline Lower Value Case & Base Case Model Properties Value & Higher Value Case \\
\hline \multicolumn{3}{|c|}{ Fracture Half-Length (ft.) } \\
\hline 400 & 500 & 600 \\
\hline \multicolumn{3}{|c|}{ Natural Fracture Permeability in $x$-direction (m-D) } \\
\hline 0.001 & 0.002 & 0.004 \\
\hline 4 & Matrix Porosity (\%) \\
\hline
\end{tabular}

\subsubsection{Seven Stages Model}

\subsubsection{Arps Decline Curve Analysis}

According to Figure 4-16 through Figure 4-18, underestimating fracture half-length results in a larger error in calculating the Arps model constants, particularly for initial decline rate $\left(\boldsymbol{d}_{\boldsymbol{i}}\right)$ values. However, after 15 or 20 years the effect of fracture half-length reduced and there is not much difference in errors compared to the base case model (less than $10 \%$ for $\boldsymbol{d}_{i}$, and $5 \%$ for $\boldsymbol{q}_{\boldsymbol{i}}$ and $\boldsymbol{n}$ ).

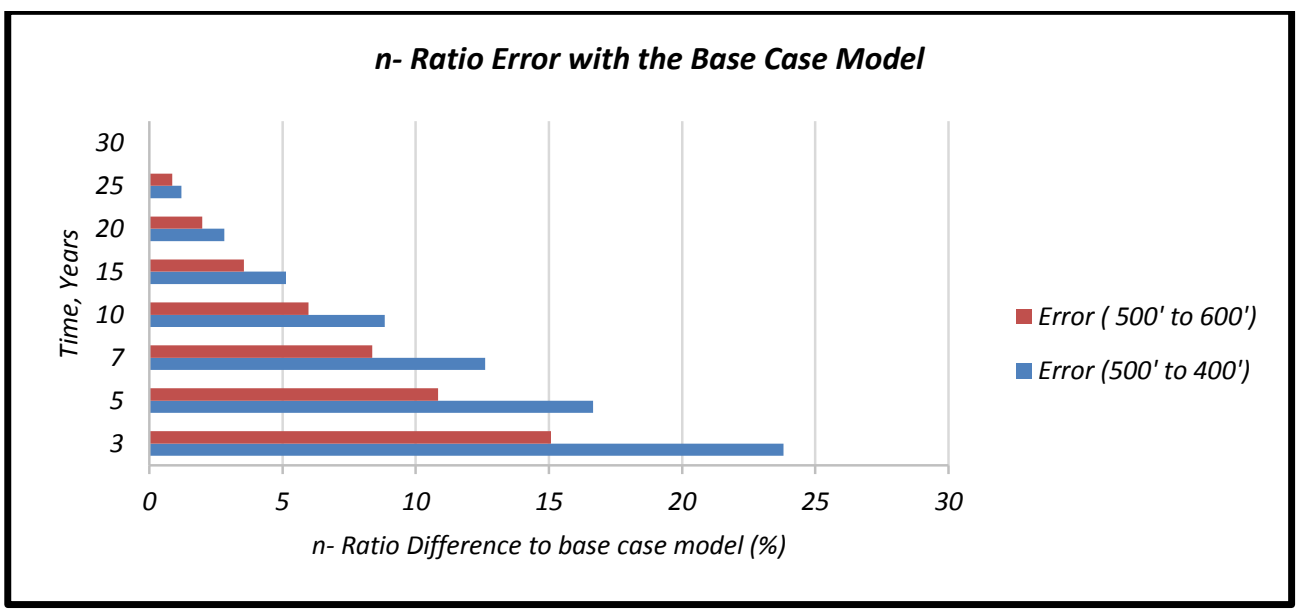

Figure 4-16: n-Ratio Error with the Base Case Model- 7 Stages 


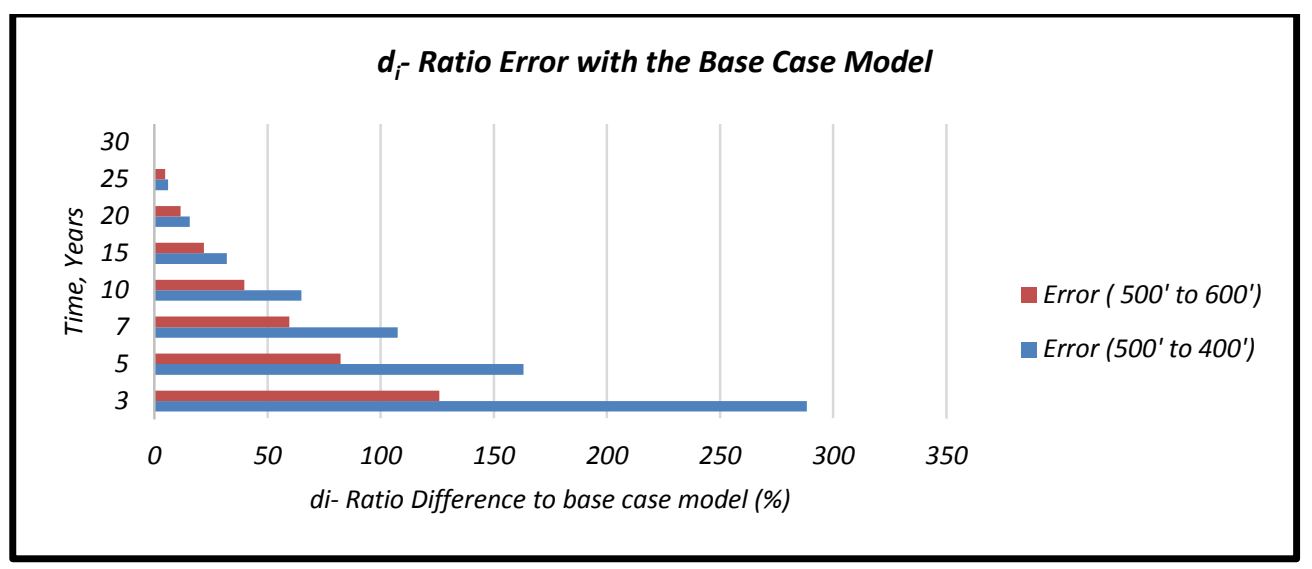

Figure 4-17: $d_{i}$-Ratio Error with the Base Case Model- 7 Stages

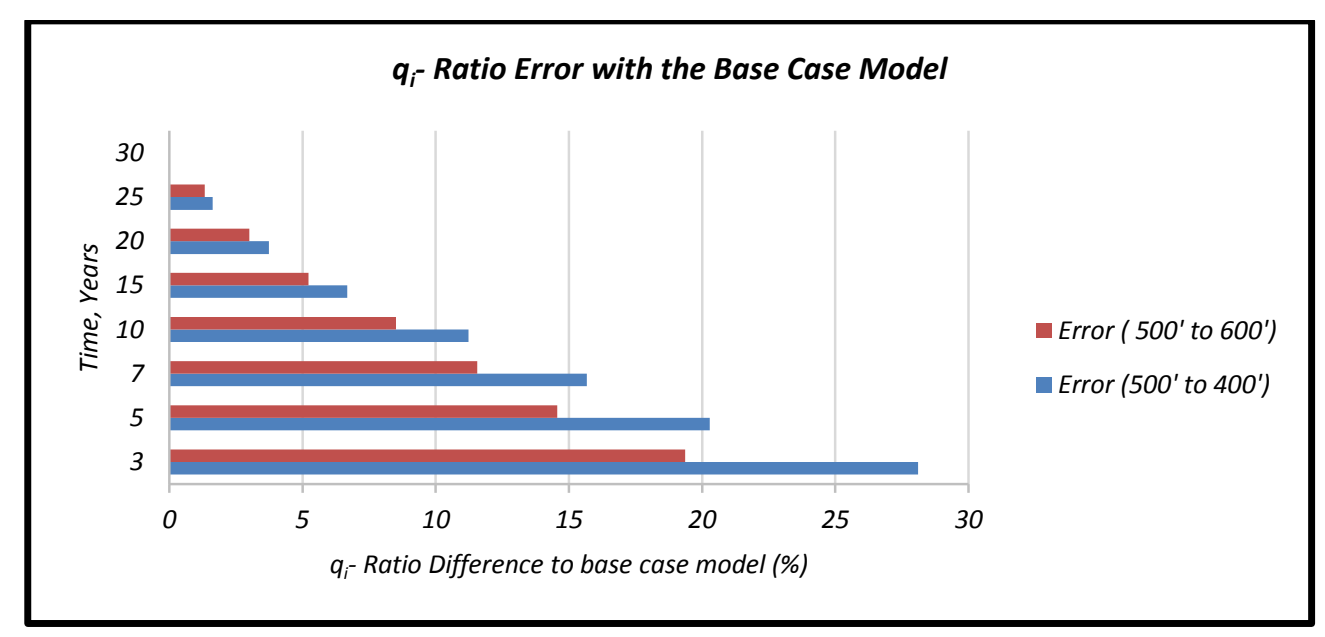

Figure 4-18: $q_{i}$-Ratio Error with the Base Case Model- 7 Stages

According to Figure 4-19 through Figure 4-21, underestimating permeability results in a larger error in calculating the $\left(\boldsymbol{q}_{i}\right)$ and $\left(\boldsymbol{d}_{i}\right)$ constants, and adversely for $(\boldsymbol{n})$. Although, after 15 or 20 years the effect of permeability will be diminished and there is not much difference in errors compared to the base case model (less than $1 \%$ for $\boldsymbol{n}$, and $5 \%$ for $\boldsymbol{q}_{i}$ ), $\boldsymbol{d}_{\boldsymbol{i}}$ values deviate from the base case model with $20 \%$ error. 


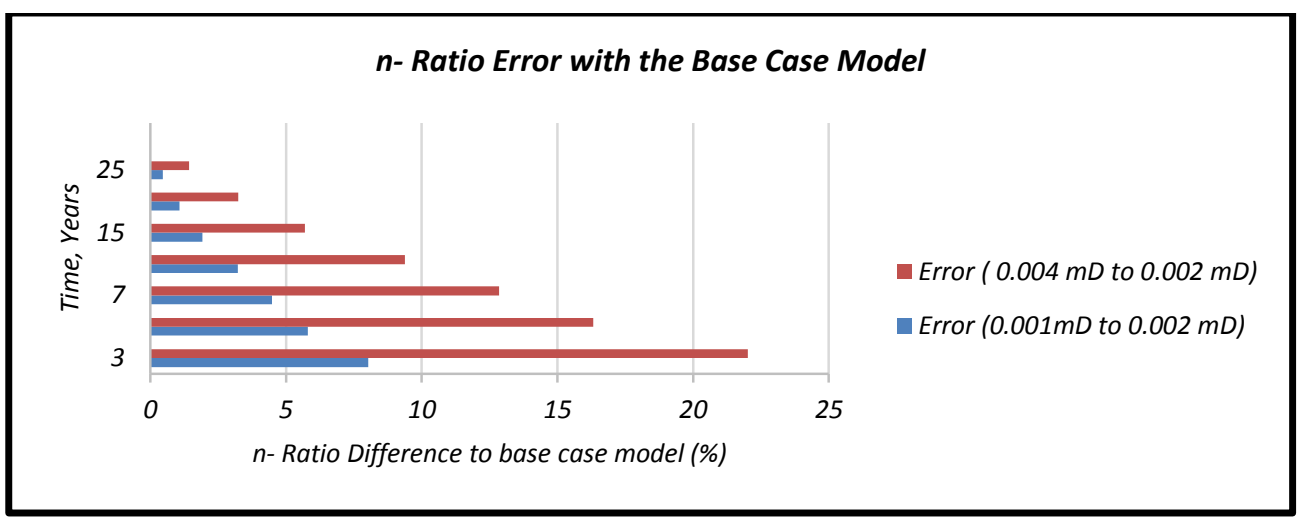

Figure 4-19: n-ratio Error with the Base Case Model - Permeability- 7 Stages

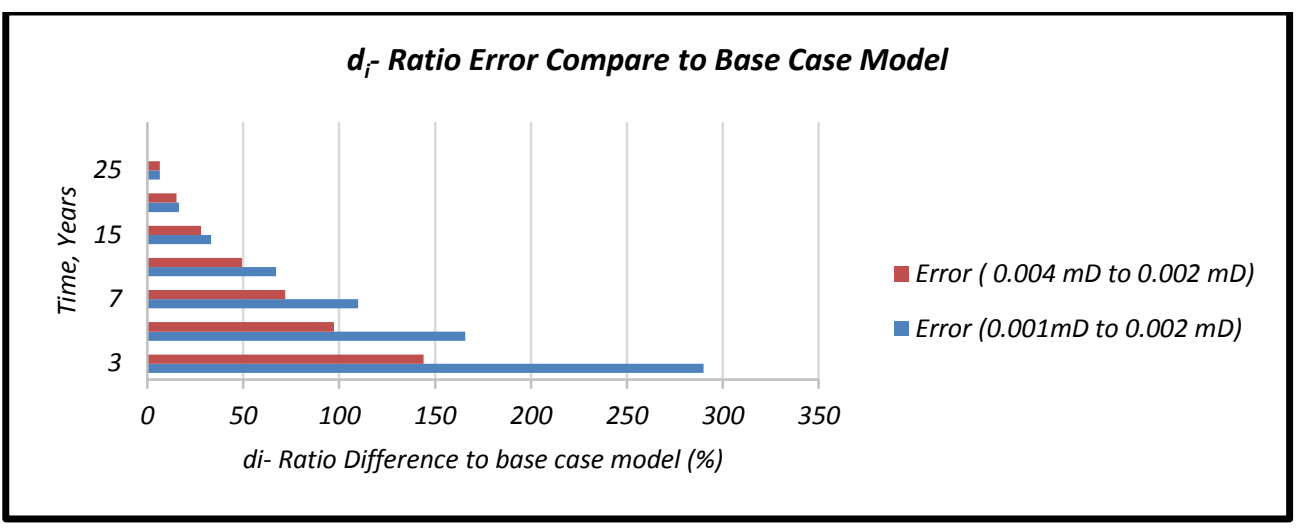

Figure 4-20: di-ratio Error with the Base Case Model - Permeability- 7 Stages

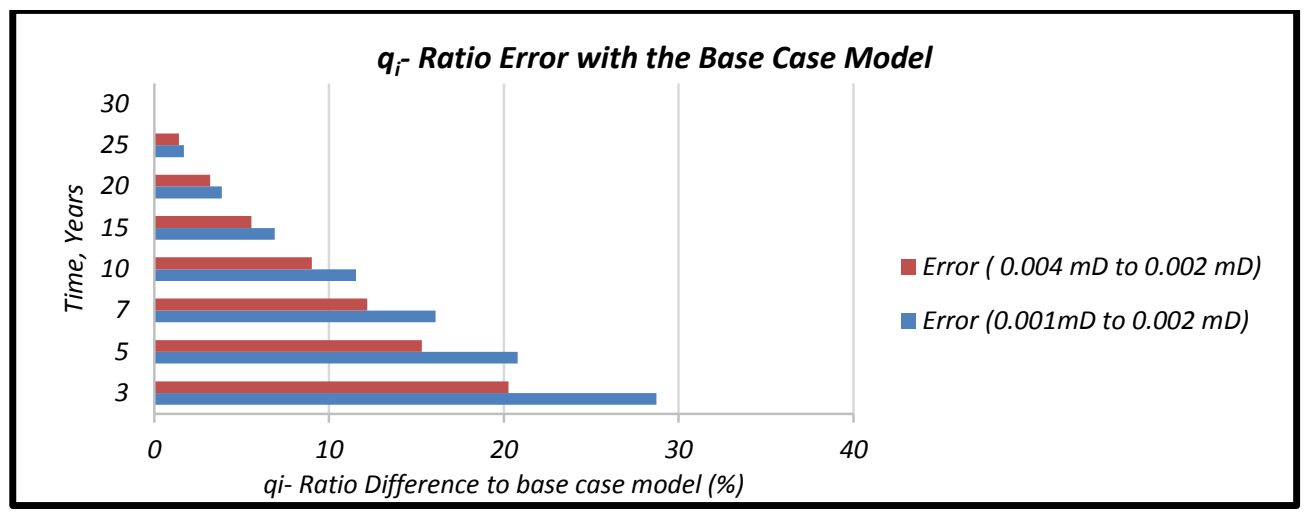

Figure 4-21: $\mathrm{q}_{\mathrm{i}}$-ratio Error with the Base Case Model - Permeability

As it is shown in Figure 4-22 through Figure 4-24, estimating a lower porosity causes a larger error in calculating the Arps model constants; yet same effect on $\boldsymbol{d}_{\boldsymbol{i}}$. However, after 15 years the effect of porosity will be diminished and there is not much difference in errors compared to the base case model (less than $1 \%$ for $\mathrm{n}$ and $\boldsymbol{q}_{i}$; and $10 \%$ for $\boldsymbol{d}_{i}$ ). 


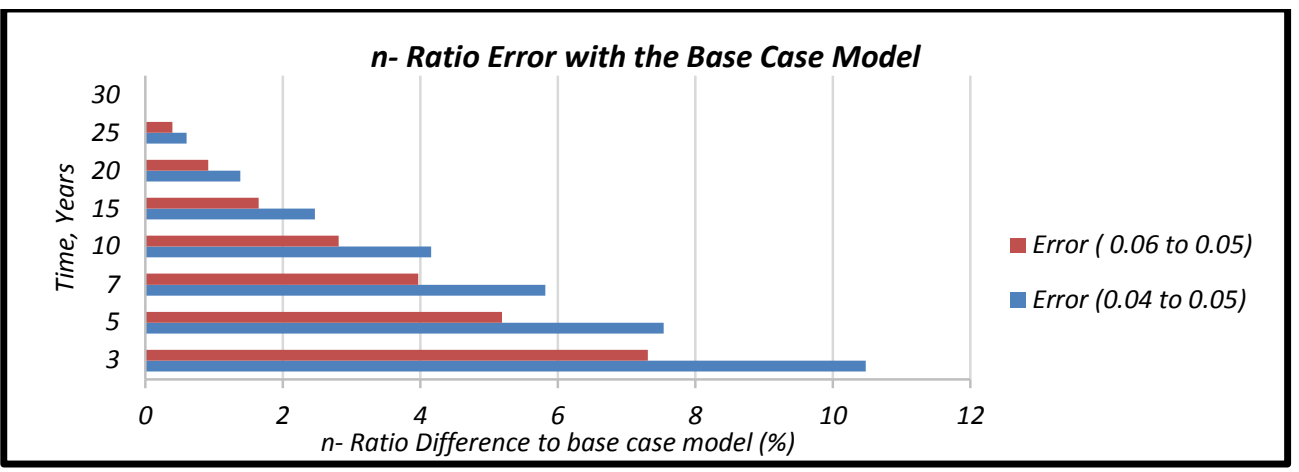

Figure 4-22: n- Ratio Error with the Base Case Model - 7 Stages

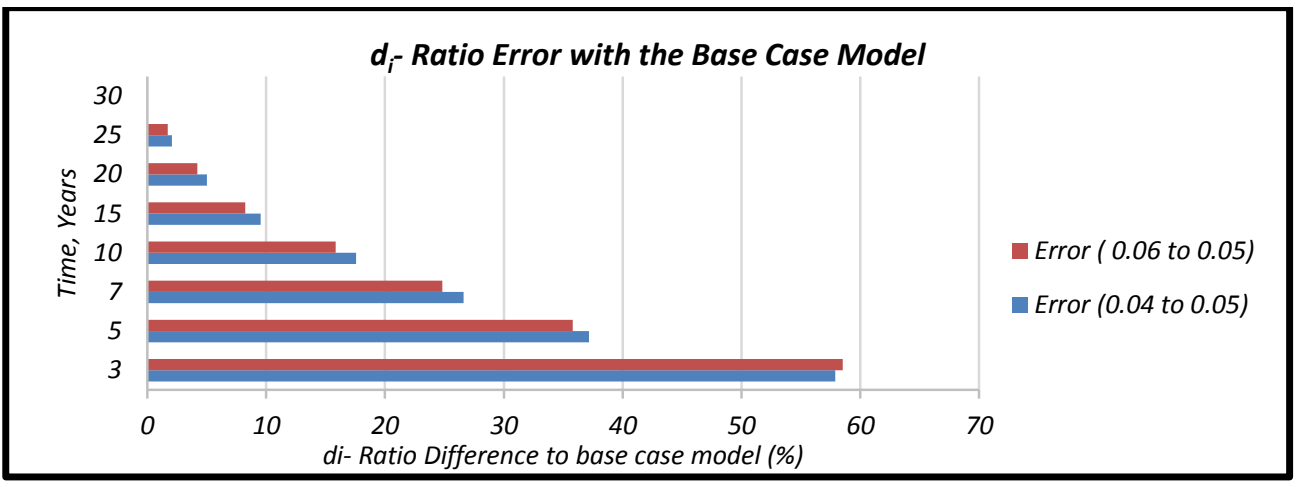

Figure 4-23: $d_{i}$ - Ratio Error with the Base Case Model - 7 Stages

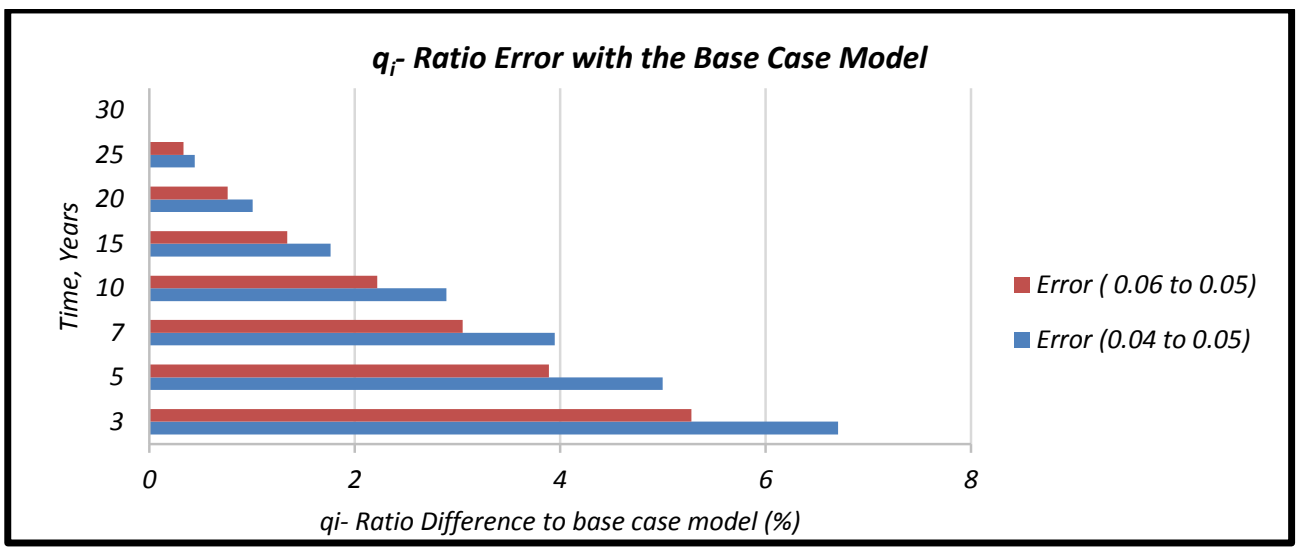

Figure 4-24: $q_{i}$ - Ratio Error with the Base Case Model - 7 Stages 


\subsubsection{Duong Decline Curve Analysis}

As it is shown in Figure 4-25 through Figure 4-28, estimating a higher fracture half-length generates a larger error in calculating the Arps model constants; particularly for initial and infinite flow rate. However, after 15 or 20 years the effect of fracture half-length will be diminished and there is not much difference in errors compared to the base case model (less than $0.5 \%$ for $\boldsymbol{a}, 0.05 \%$ for $\boldsymbol{m}, 10 \%$ for $\boldsymbol{q}_{i}$ and $\boldsymbol{q}_{\infty}$ ).

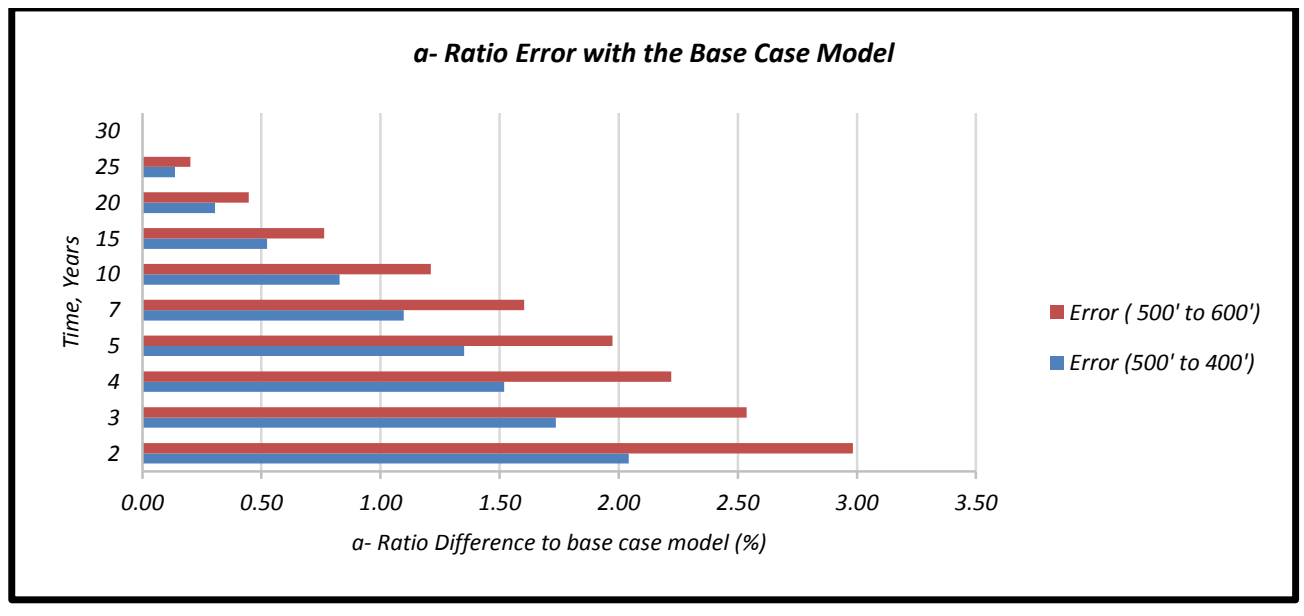

Figure 4-25: a- Ratio Error with the Base Case Model - Fracture Half length - 7 Stages

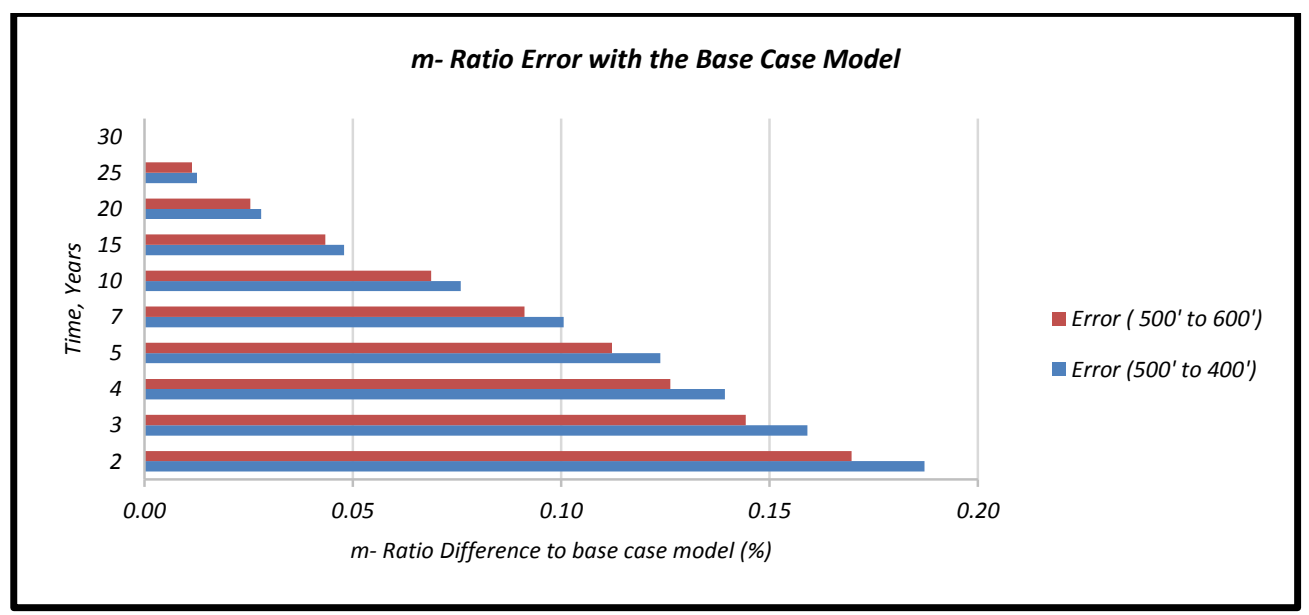

Figure 4-26: m- Ratio Error with the Base Case Model - Fracture Half length- 7 Stages 


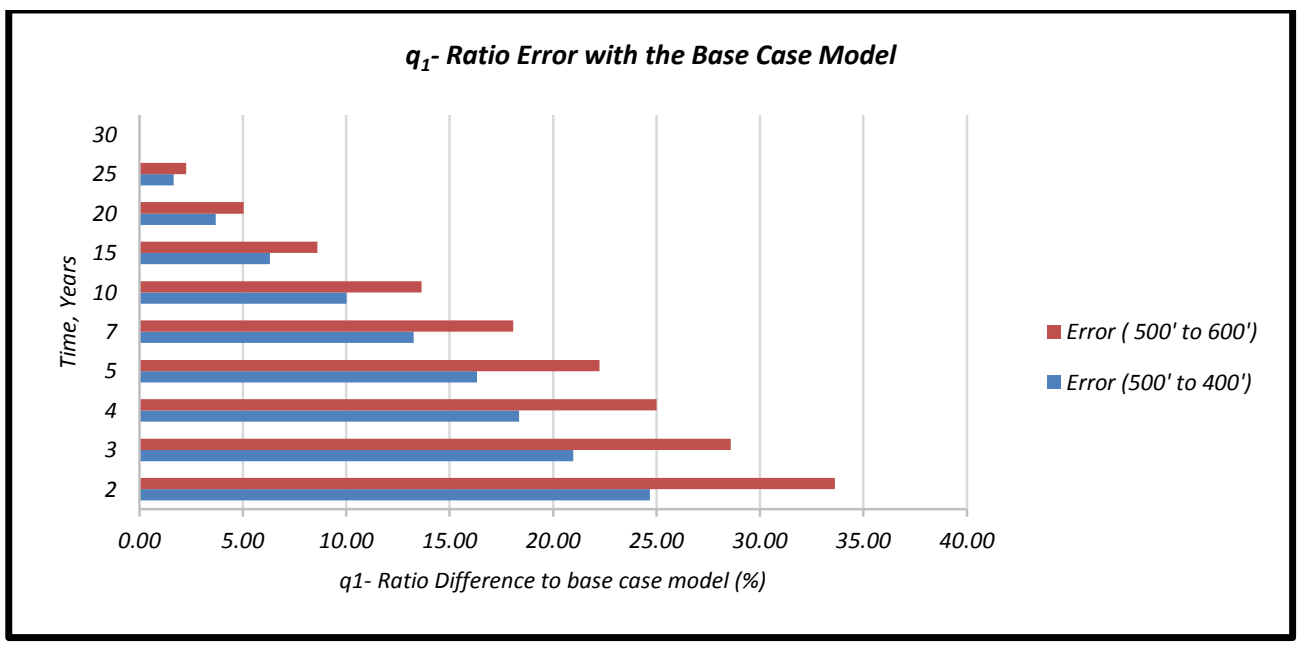

Figure 4-27: $q_{1}$ - Ratio Error with the Base Case Model - Fracture Half length- 7 Stages

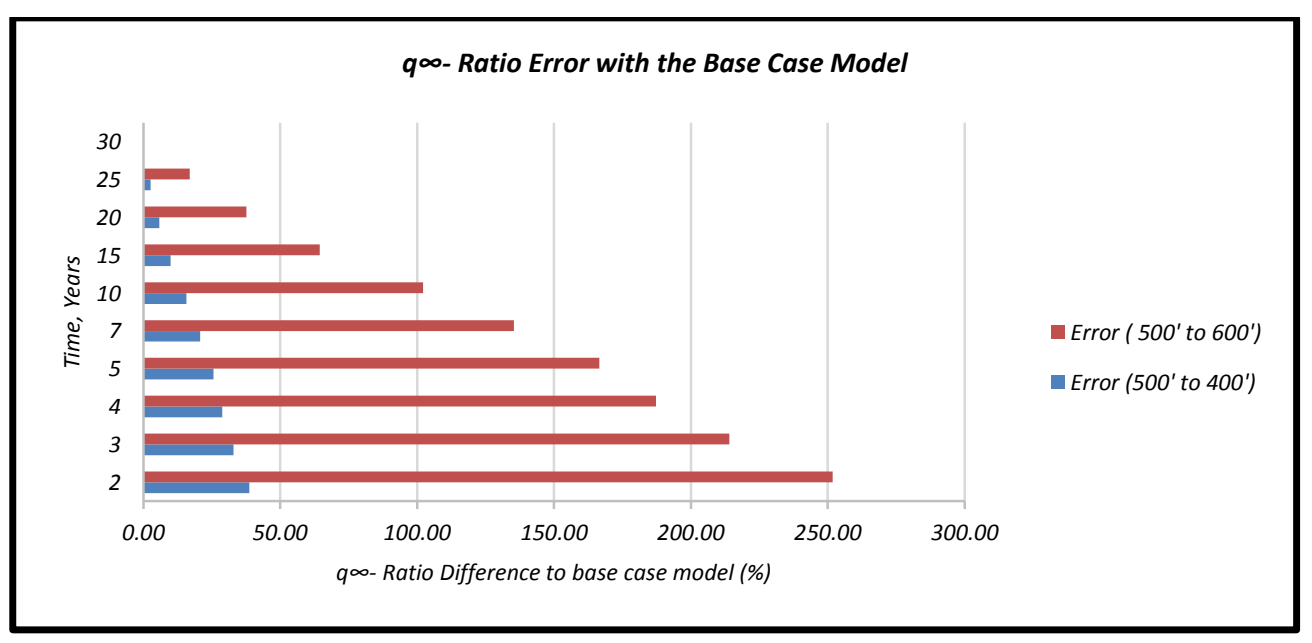

Figure 4-28: $q_{\infty}$ - Ratio Error with the Base Case Model - Fracture Half length - 7 Stages

According to Figure 4-29 through Figure 4-32, underestimating permeability causes a larger error in calculating the Duong model constants; particularly for initial and infinite flow rates. However, after 15 years the effect of permeability will be diminished and there is not much difference in errors compared to the base case model (less than $0.5 \%$ for $\boldsymbol{a}$ and $\boldsymbol{m}$; and $10 \%$ for $\boldsymbol{q}_{1}$ and $\boldsymbol{q}_{\infty}$ ). 


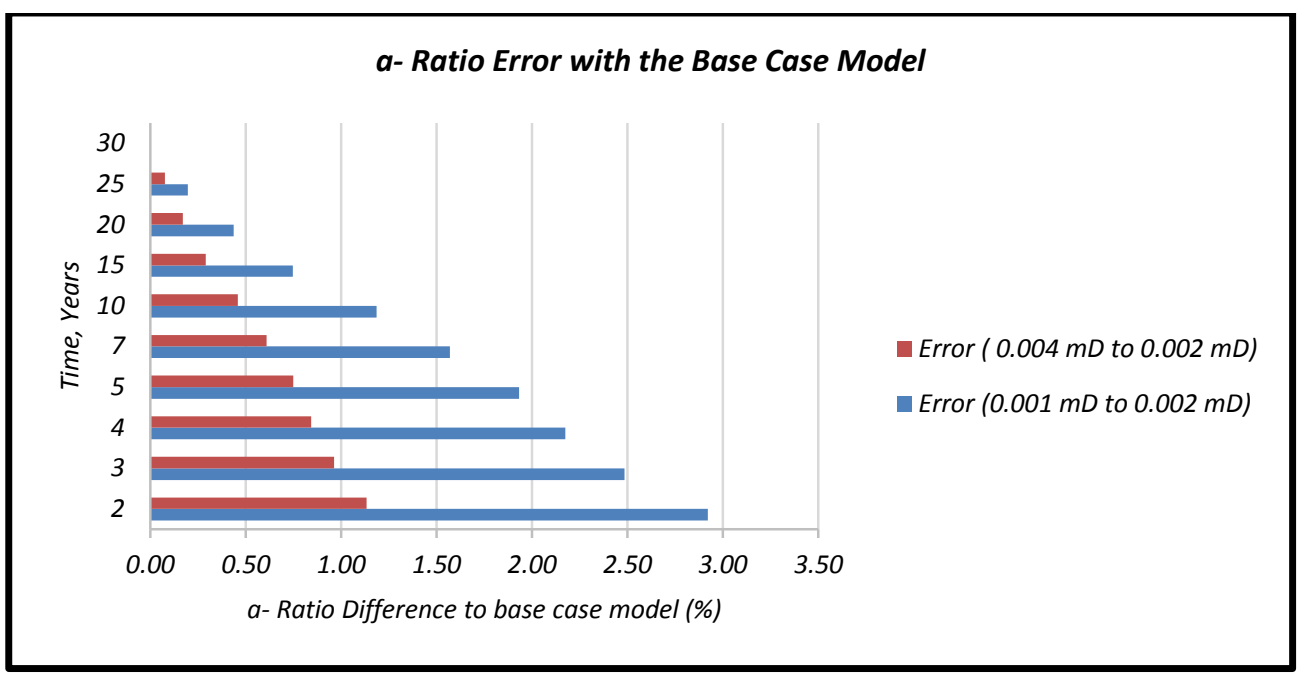

Figure 4-29: a- Ratio Error with the Base Case Model- Permeability - 7 Stages

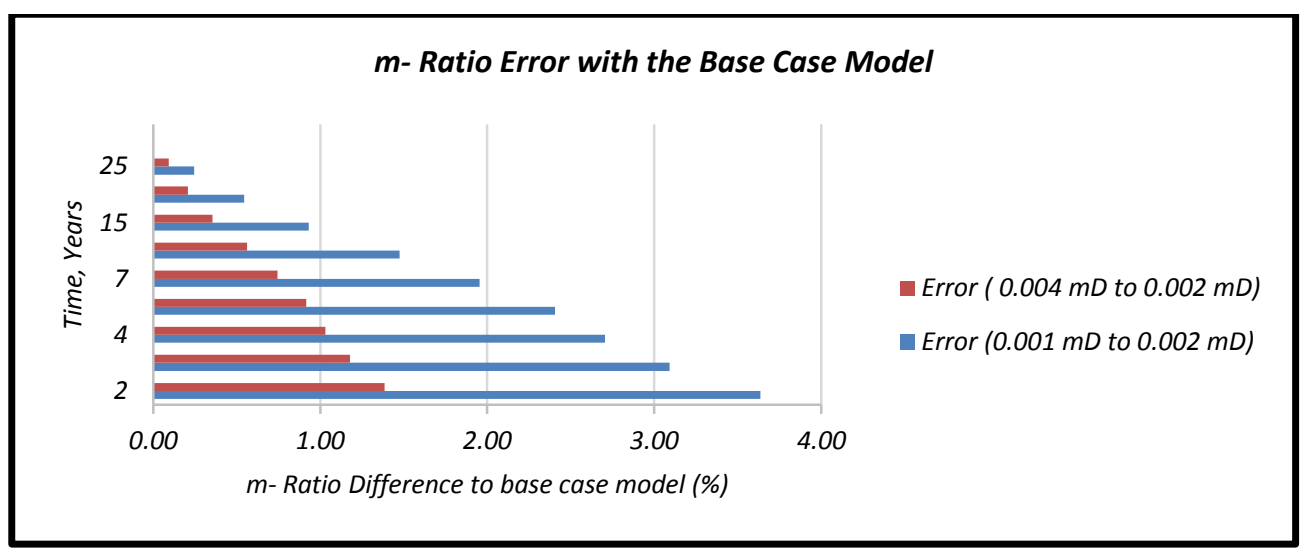

Figure 4-30: m- Ratio Error with the Base Case Model- Permeability - 7 Stages

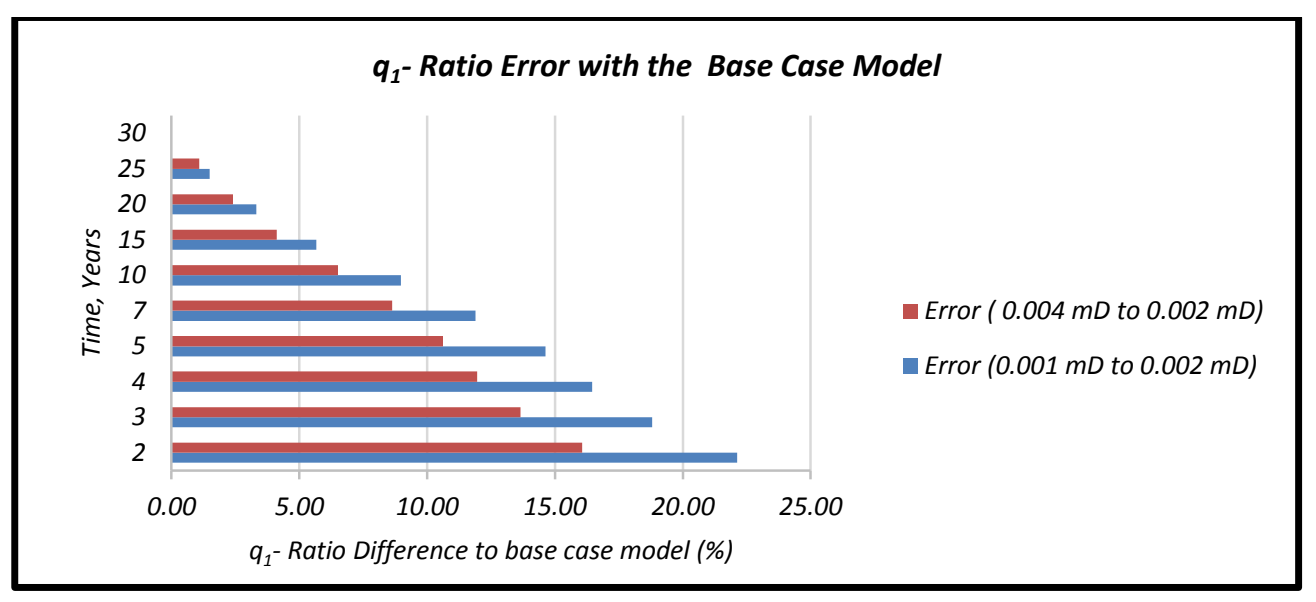

Figure 4-31: $q_{1}$ - Ratio Error with the Base Case Model- Permeability - 7 Stages 


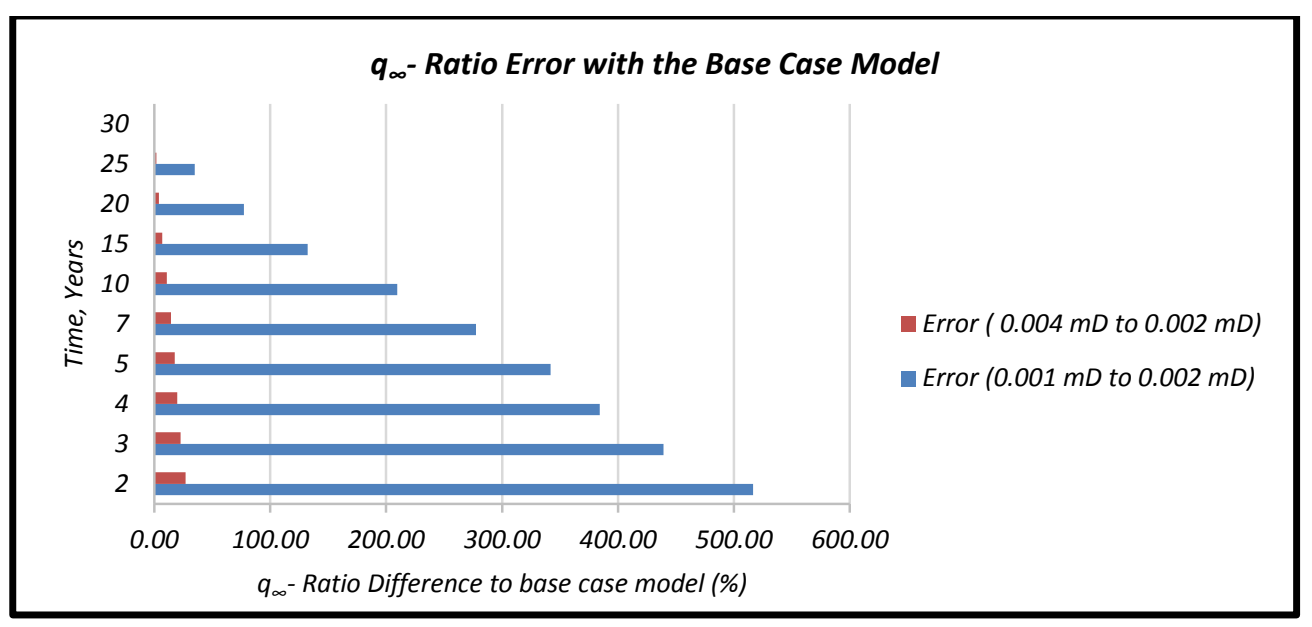

Figure 4-32: $q_{\infty}$ - Ratio Error with the Base Case Model- Permeability - 7 Stages

\subsubsection{Thirteen Stages Model}

\subsubsection{Arps decline Curve Analysis}

According to Figure 4-33 through Figure 4-35, underestimating the fracture half-length results in a larger error in calculating the Arps model constants, particularly for initial decline rate $\left(\boldsymbol{d}_{\boldsymbol{i}}\right)$ values. However, as hydraulic fractures are spaced closely and the BDF period happens earlier with 13 stages, the errors are very minimal in compare to the seven stages scenario (Nelson, 2014).

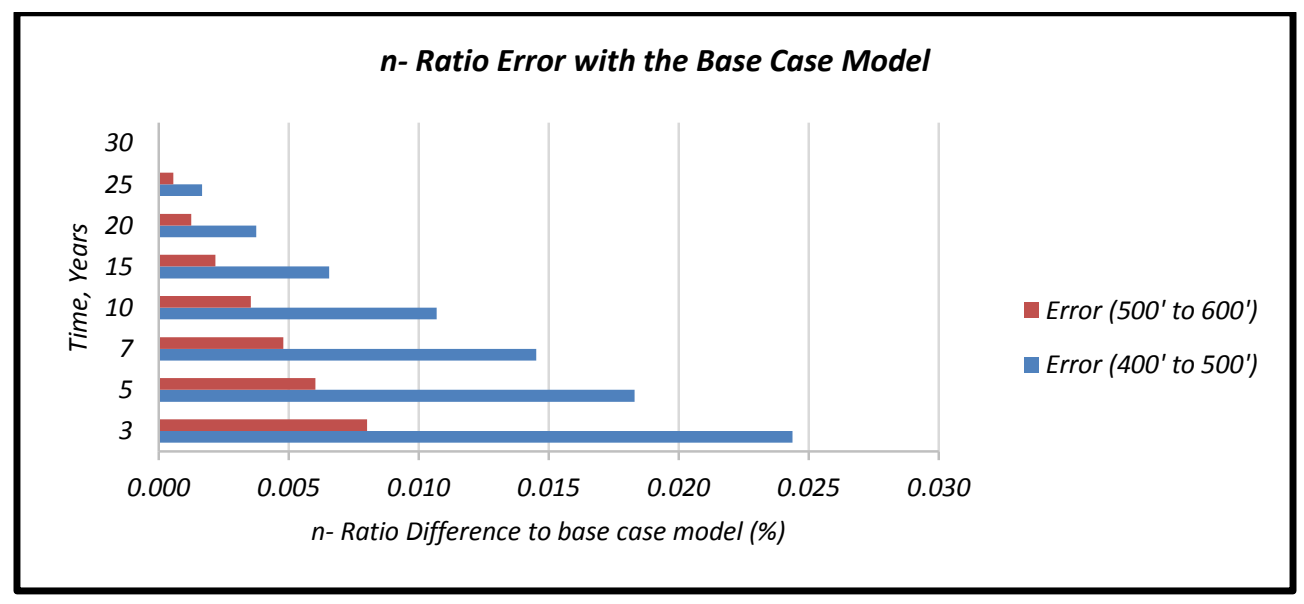

Figure 4-33: n- Ratio Error with the Base Case Model - Fracture Half length - 13 Stages 


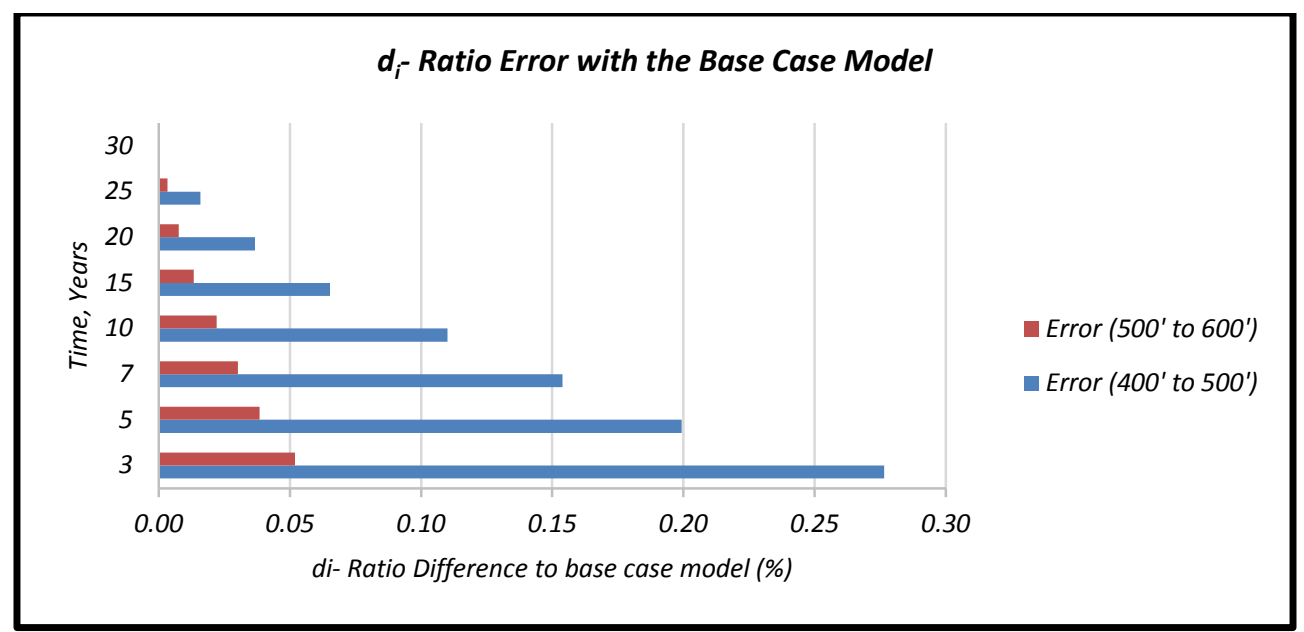

Figure 4-34: $d_{i^{-}}$Ratio Error with the Base Case Model - Fracture Half length- 13 Stages

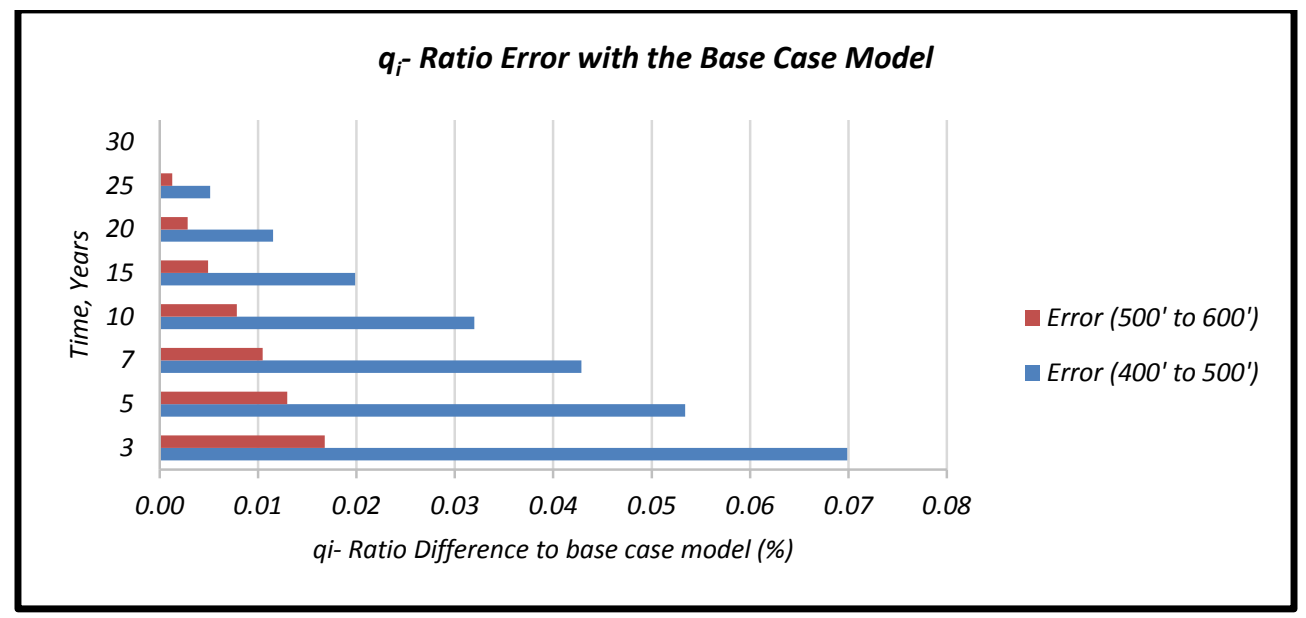

Figure 4-35: $q_{i}$ - Ratio Error with the Base Case Model- Fracture Half Length - 13 Stages

According to Figure 4-36 through Figure 4-38, underestimating the natural fracture permeability results in a larger error in calculating the Arps model constants, except for initial flow rate $\left(\boldsymbol{q}_{\boldsymbol{i}}\right)$ values. However, after 15 years the effect of permeability will be diminished and there is not much difference in errors compared to the base case model (less than $1 \%$ for $\boldsymbol{n}$ and $\boldsymbol{d}_{\boldsymbol{i}}$; and $0.2 \%$ for $\boldsymbol{q}_{\boldsymbol{i}}$ ). 


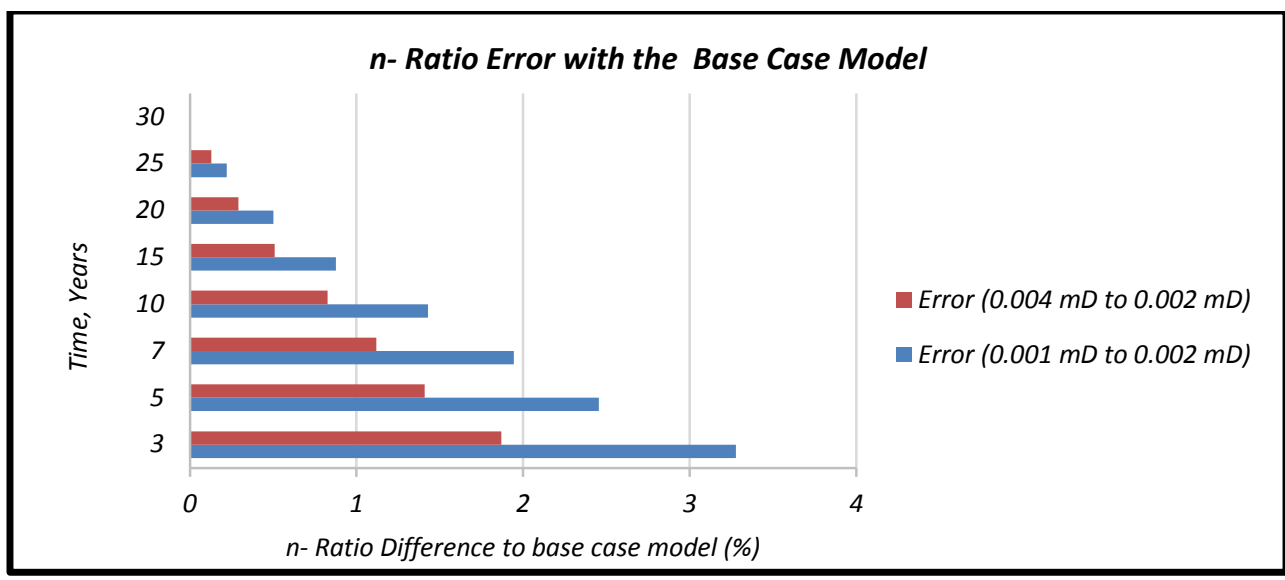

Figure 4-36: n- Ratio Error with the Base Case Model - Permeability - 13 Stages

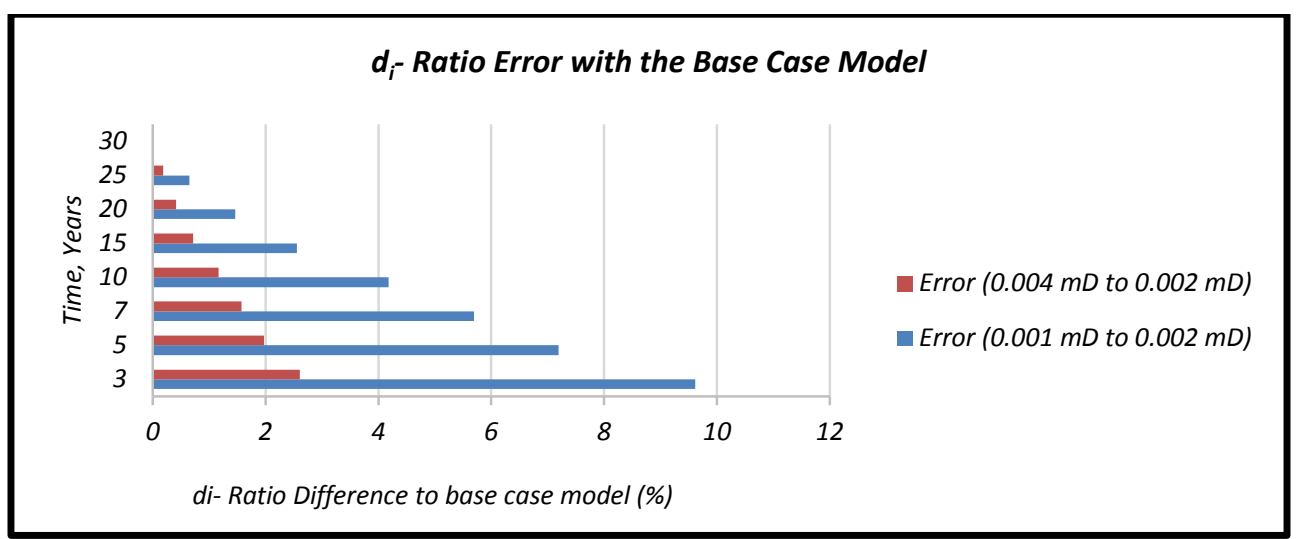

Figure 4-37: $d_{i-}$ - Ratio Error with the Base Case Model - Permeability - 13 Stages

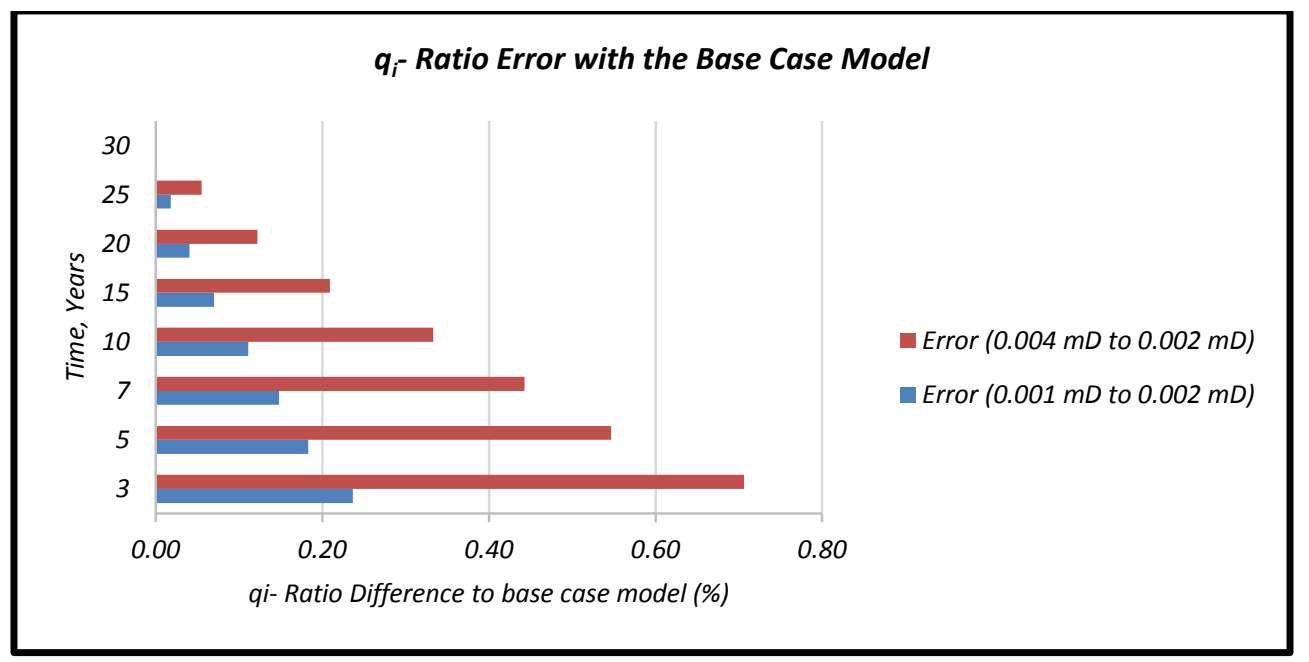

Figure 4-38: $q_{i-}$ Ratio Error with the Base Case Model - Permeability - 13 Stages 
According to Figure 4-39 through Figure 4-41, underestimating the porosity results in a larger error in calculating the Arps model constants, except for initial flow rate $\left(\boldsymbol{q}_{i}\right)$ values. However, after 15 years the effect of porosity will be diminished and there is not much difference in errors compared to the base case model (less than $1 \%$ for $\boldsymbol{n}$ and $\boldsymbol{d}_{i}$; and $0.2 \%$ for $\boldsymbol{q}_{i}$ ). Yet, the errors are very minimal compared to seven stages scenario, particularly for initial flow rate $\left(\boldsymbol{q}_{i}\right)$.

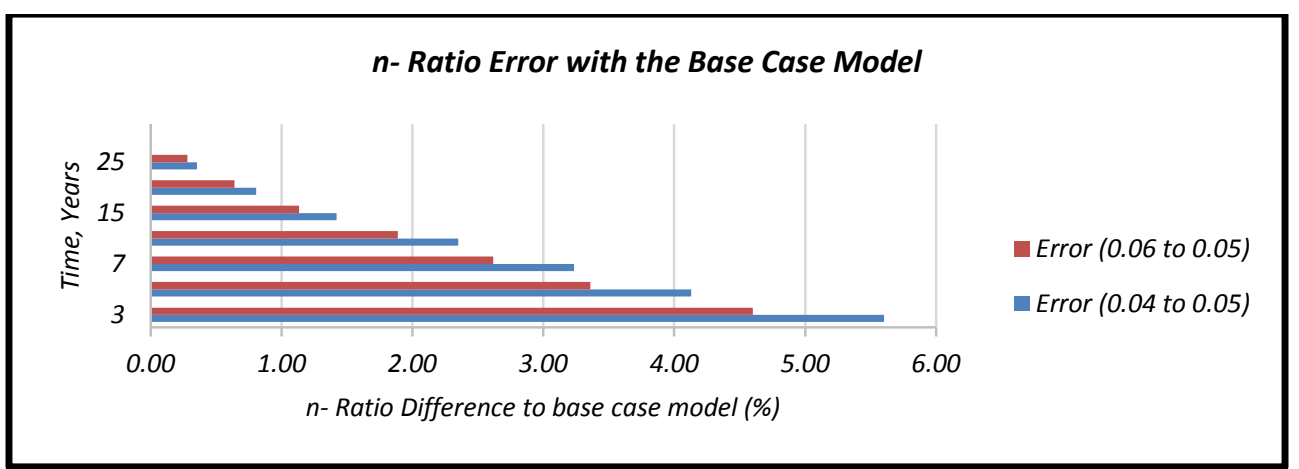

Figure 4-39: n- Ratio Error with the Base Case Model - Porosity - 13 Stages

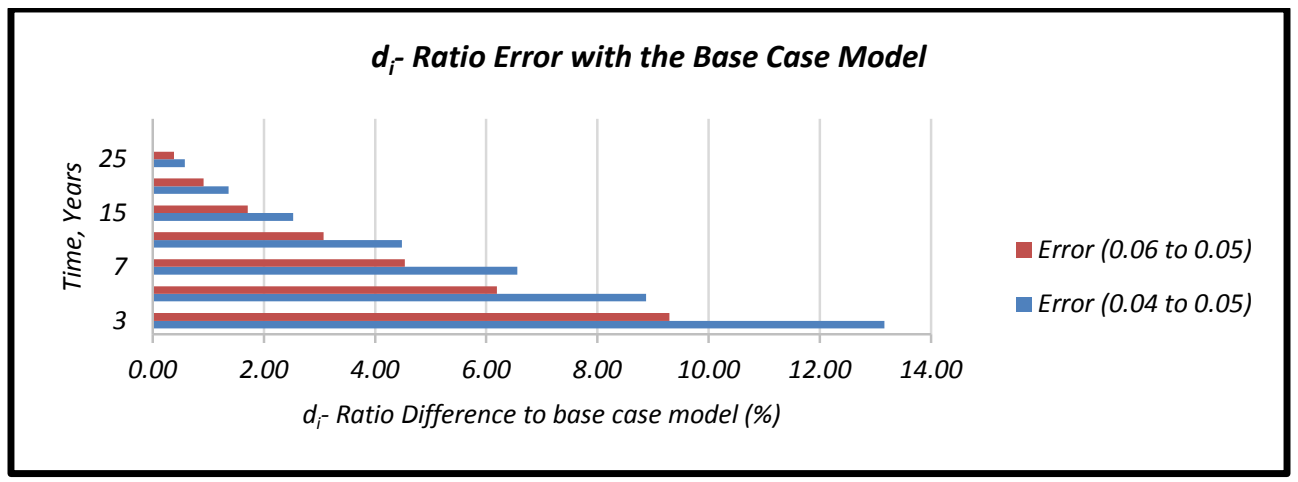

Figure 4-40: di- Ratio Error with the Base Case Model - Porosity - 13 Stages

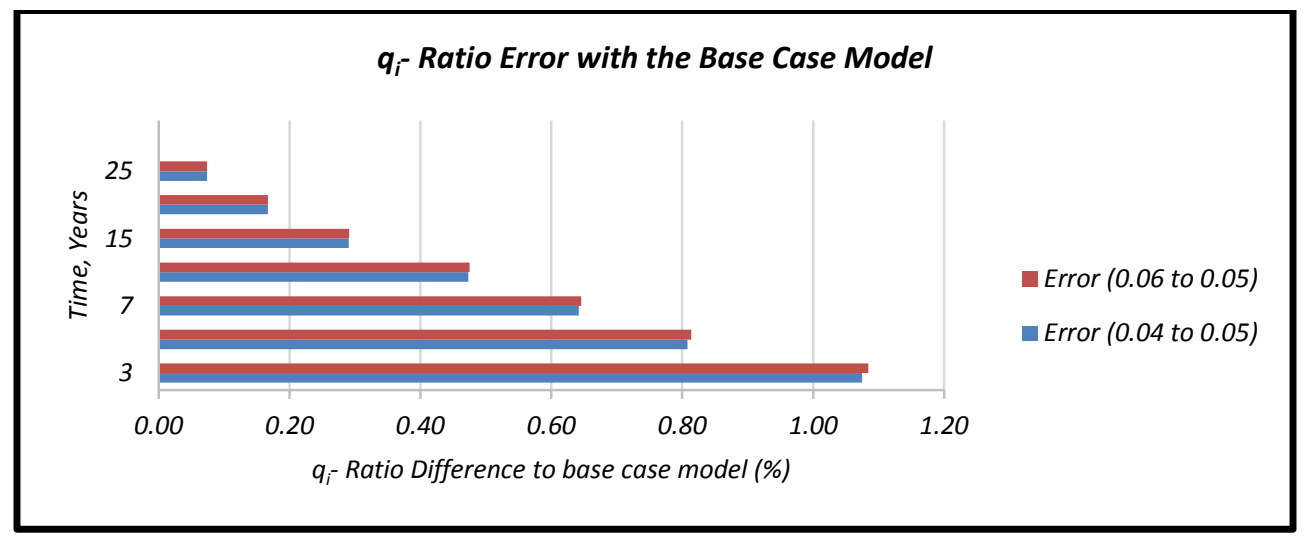

Figure 4-41: $q_{i}$ - Ratio Error with the Base Case Model - Porosity - 13 Stages 


\subsubsection{Duong Decline Curve Analysis}

As it is shown in Figure 4-42 through Figure 4-45, overestimating the fracture half- length generates a significant error in calculating the Duong model constants; particularly for initial and infinite flow rates. However, underestimating the fracture half-length value does not have much effect on Duong model constants (less than $2 \%$ error in all the constants). Unlike Arps model, even after 15 or 20 years, a higher fracture half-length value will deflect from the base model with a large error.

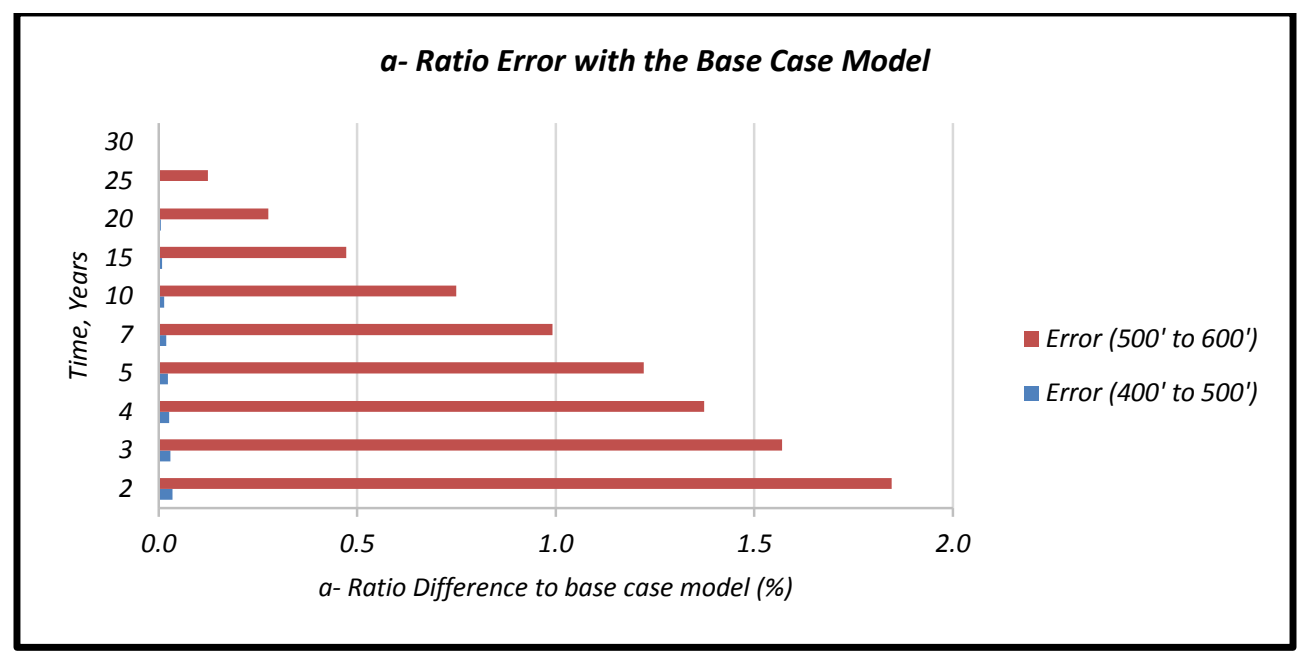

Figure 4-42: a- Ratio Error with the Base Case Model - Fracture Half length - 13 Stages

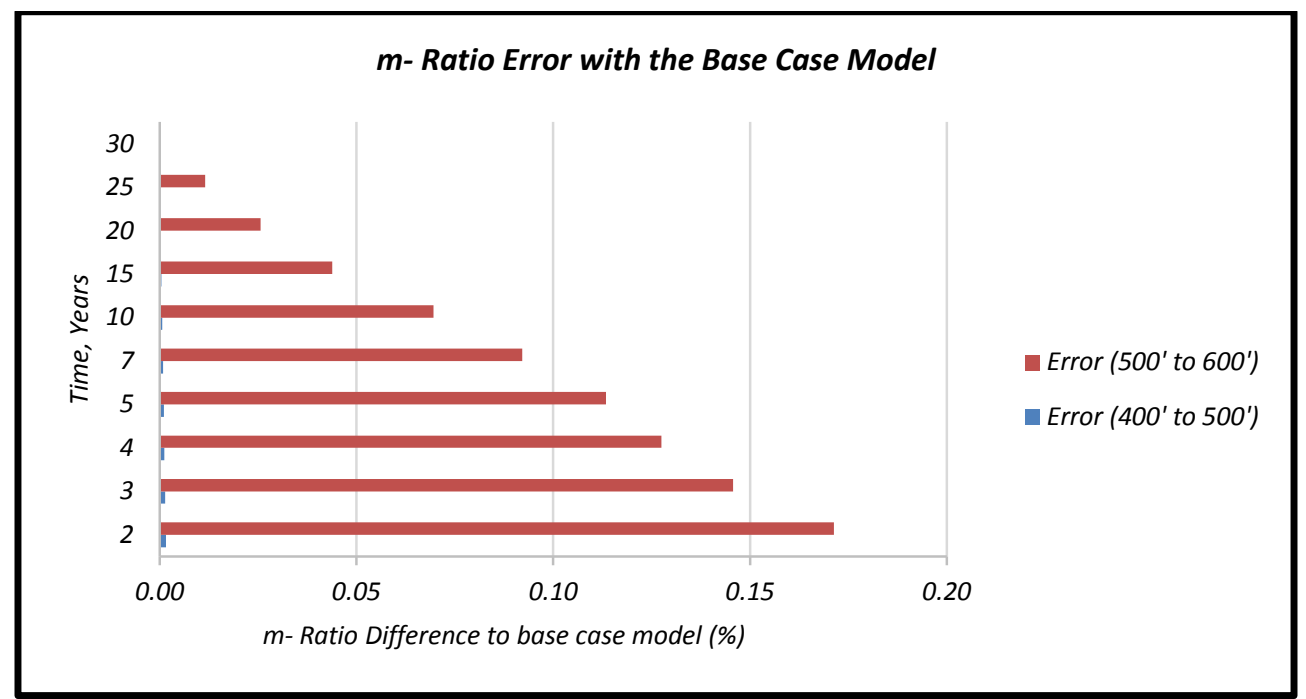

Figure 4-43: m- Ratio Error with the Base Case Model - Fracture Half length - 13 Stages 


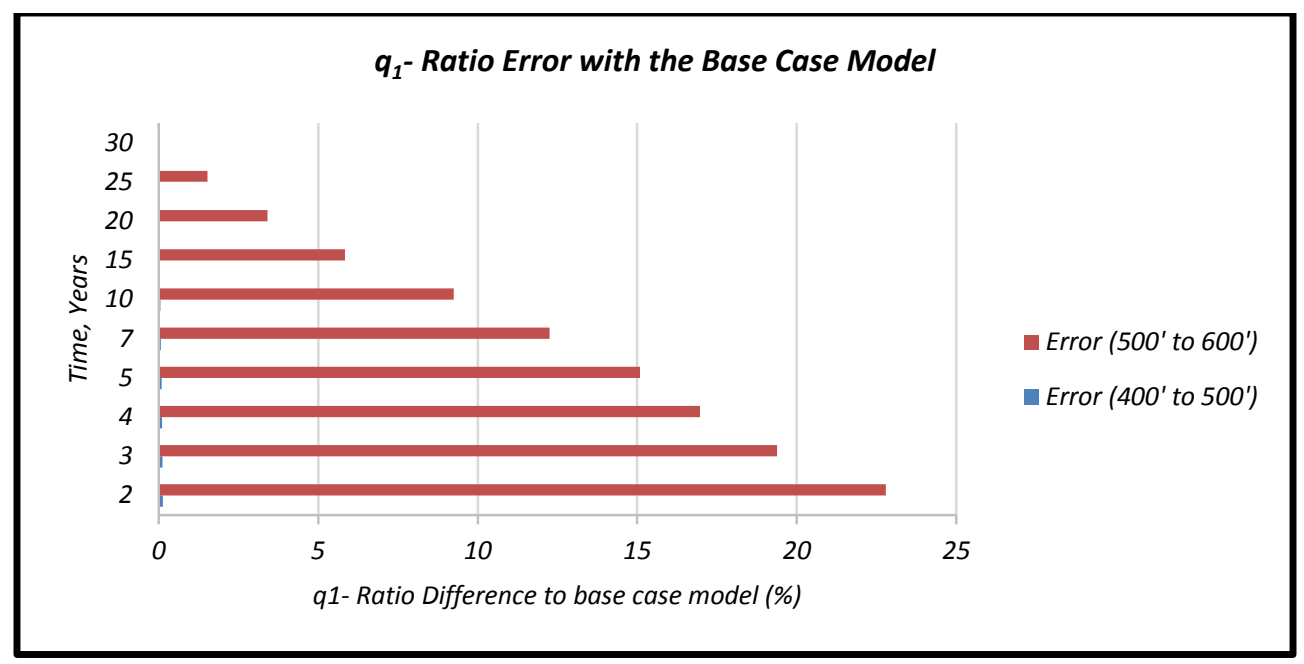

Figure 4-44: $q_{1}$ - Ratio Error with the Base Case Model - Fracture Half length - 13 Stages

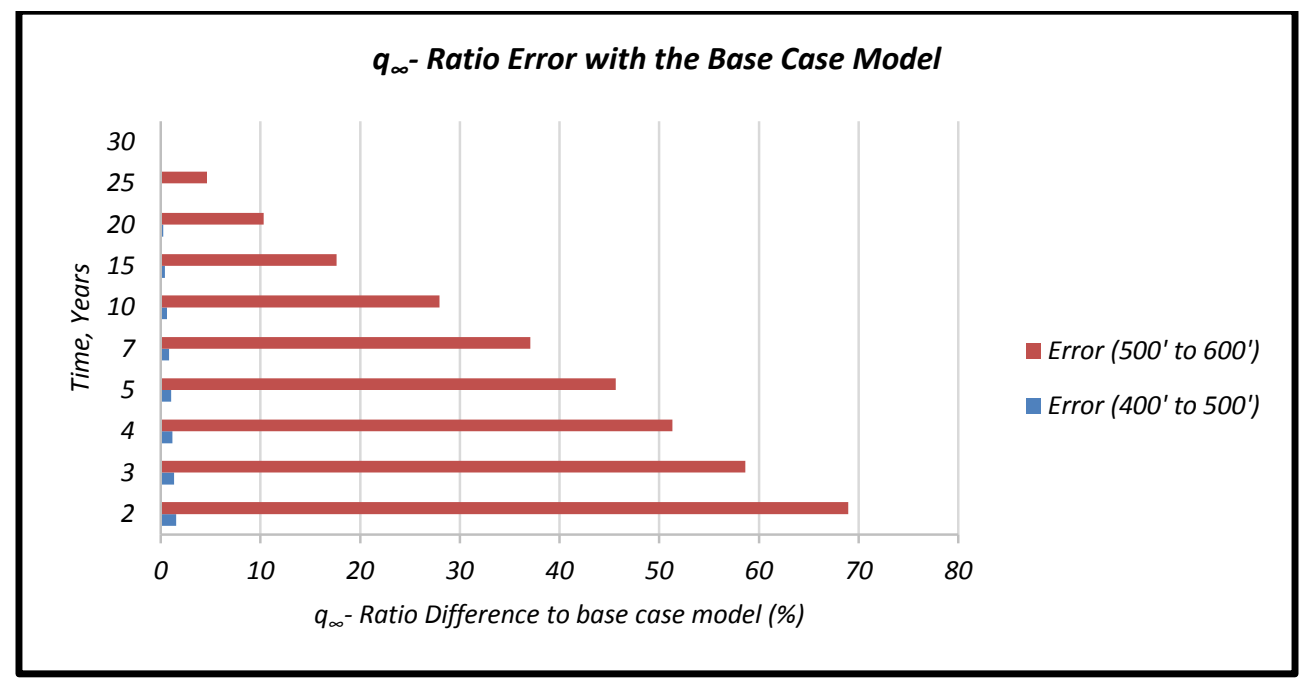

Figure 4-45: $q_{\infty}$ - Ratio Error with the Base Case Model - Fracture Half length - 13 Stages

As it is shown in Figure 4-46 through Figure 4-49, overestimating permeability causes a larger error in calculating the $(\boldsymbol{a})$ and $\left(\boldsymbol{q}_{1}\right)$ constants and adversely affected the $(\boldsymbol{m})$ and $\left(\boldsymbol{q}_{\infty}\right)$ constants. However, after 20 years of production the effect of permeability reduces, and there is not much difference in errors compared to the base case model (less than $0.3 \%$ for $\boldsymbol{a}$ and $\boldsymbol{m}$; and $10 \%$ for $\boldsymbol{q}_{\boldsymbol{i}}$ ), except for infinite flow rate values. 


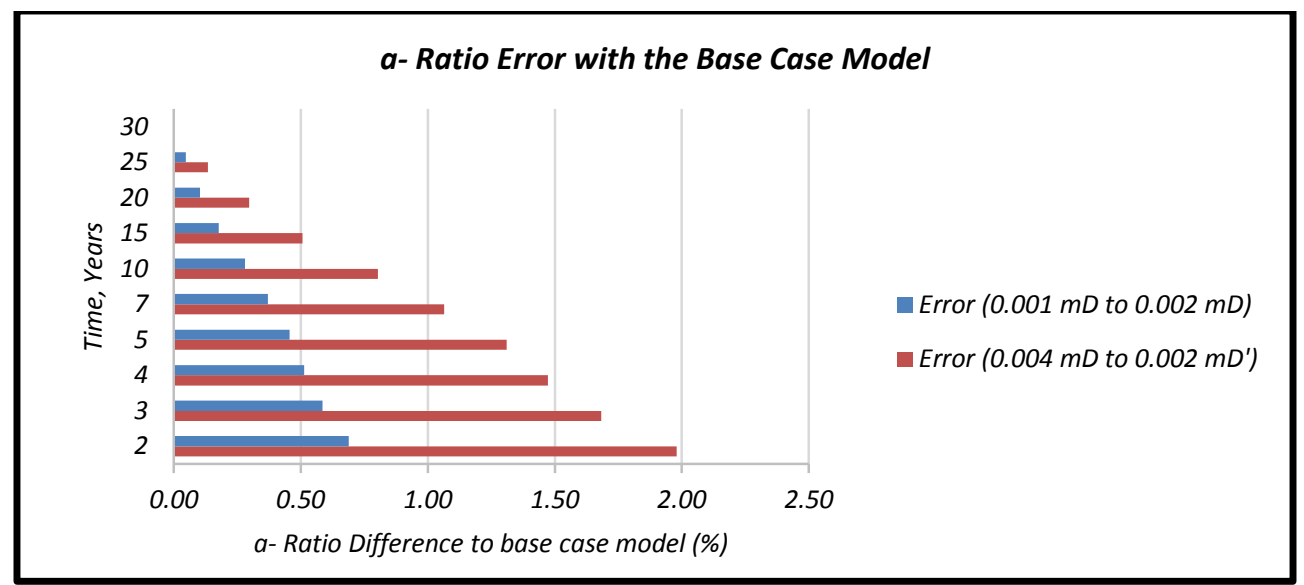

Figure 4-46: a- Ratio Error with the Base Case Model - Permeability- 13 Stages

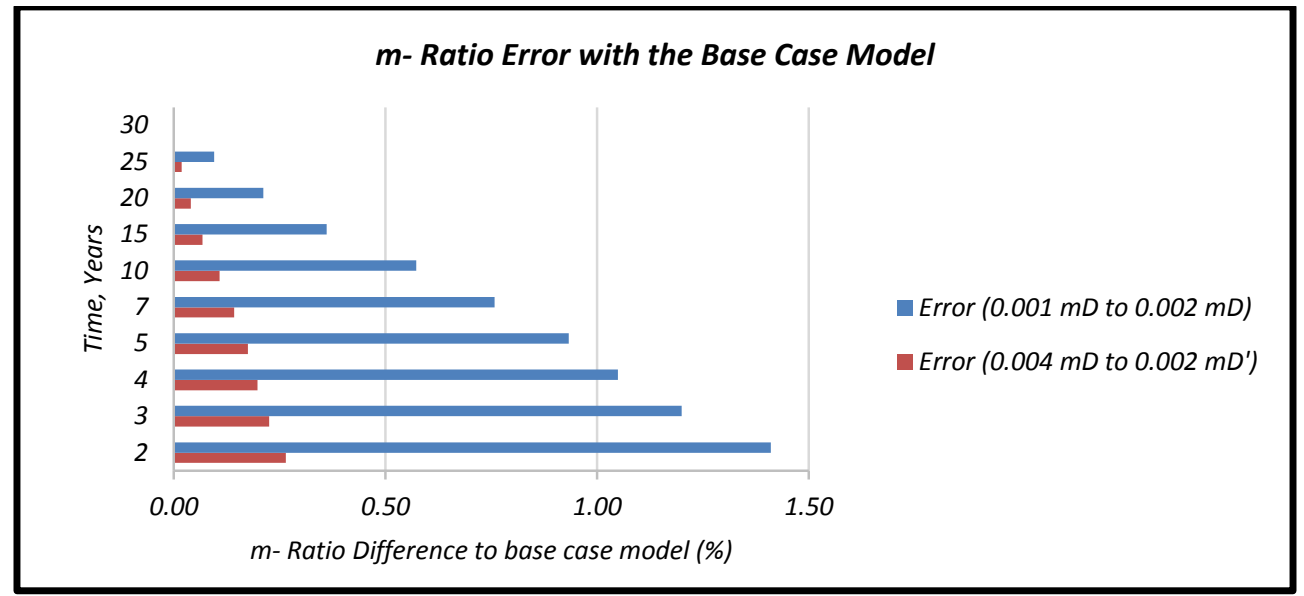

Figure 4-47: m- Ratio Error with the Base Case Model - Permeability- 13 Stages

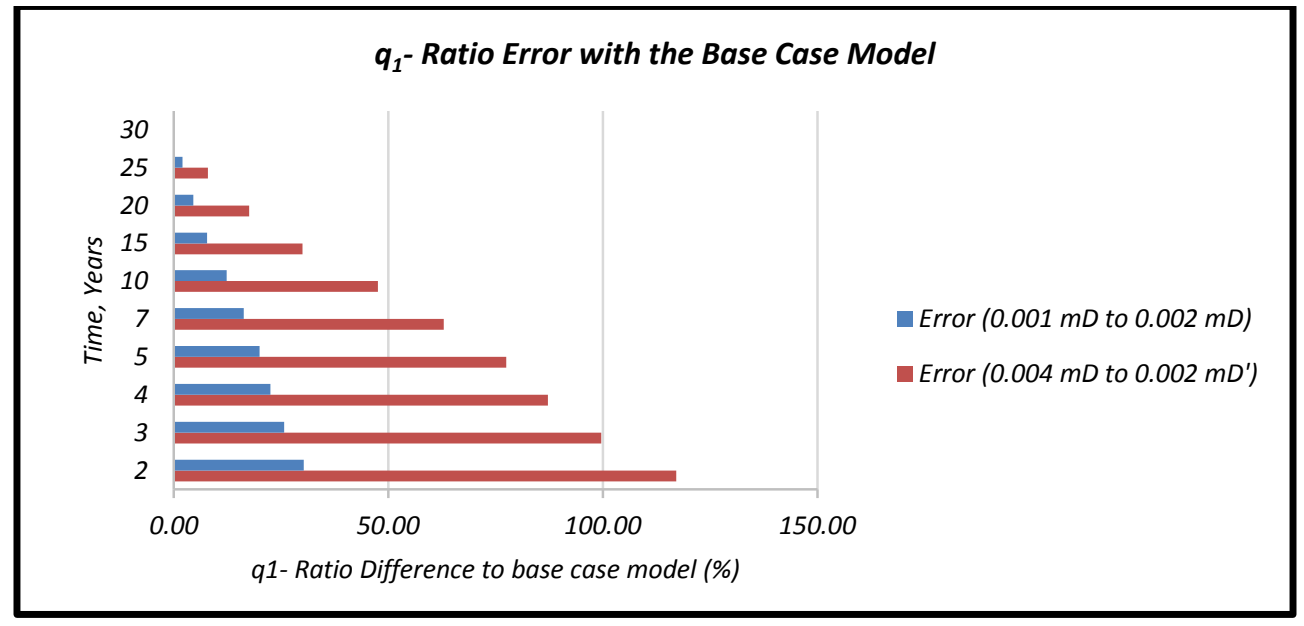

Figure 4-48: $q_{1}$ - Ratio Error with the Base Case Model - Permeability- 13 Stages 


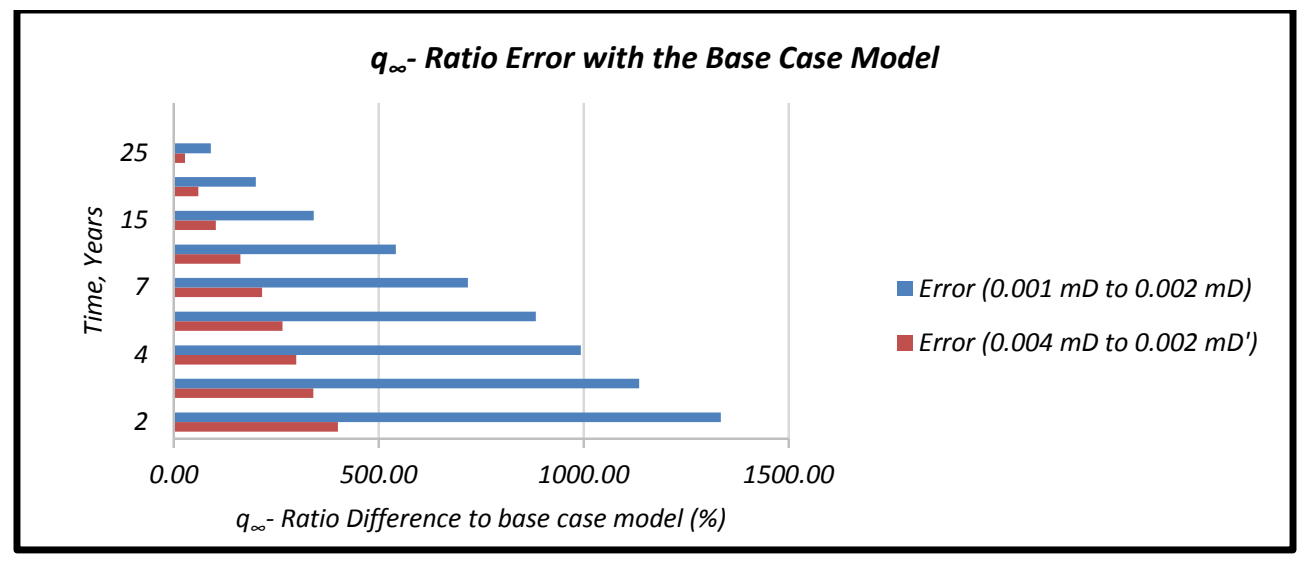

Figure 4-49: $q_{\infty}$ - Ratio Error with the Base Case Model - Permeability- 13 Stages

As it is shown in Figure 4-50 through Figure 4-53, overestimating porosity causes a larger error in calculating the $\left(\boldsymbol{q}_{1}\right)$ and $\left(\boldsymbol{q}_{\infty}\right)$ constants and adversely affected the (a) and (m) constants. However, after 15 years of production the effect of porosity reduces, and there is not much difference in errors compared to the base case model (less than $0.5 \%$ for $\boldsymbol{a}, \boldsymbol{m}$, and $\boldsymbol{q}$; and $30 \%$ for $\boldsymbol{q}_{\infty}$ ). Unlike other properties, incorrect estimation of porosity does not have a significant error on Duong models.

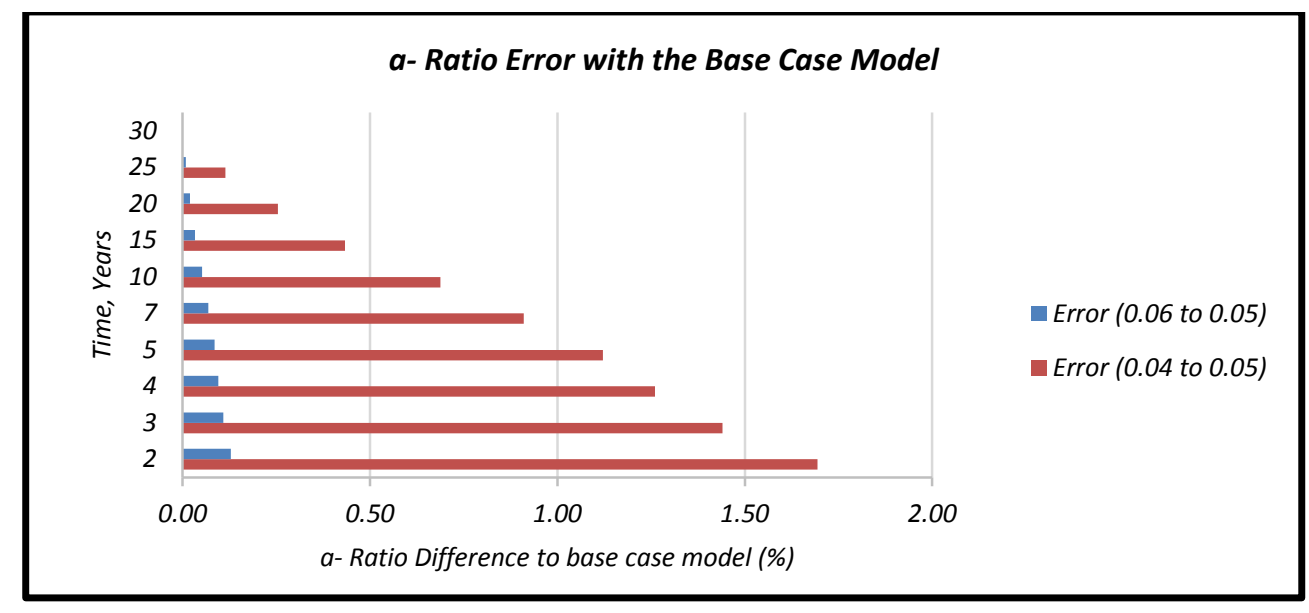

Figure 4-50: a- Ratio Error with the Base Case Model - Porosity-13 Stages 


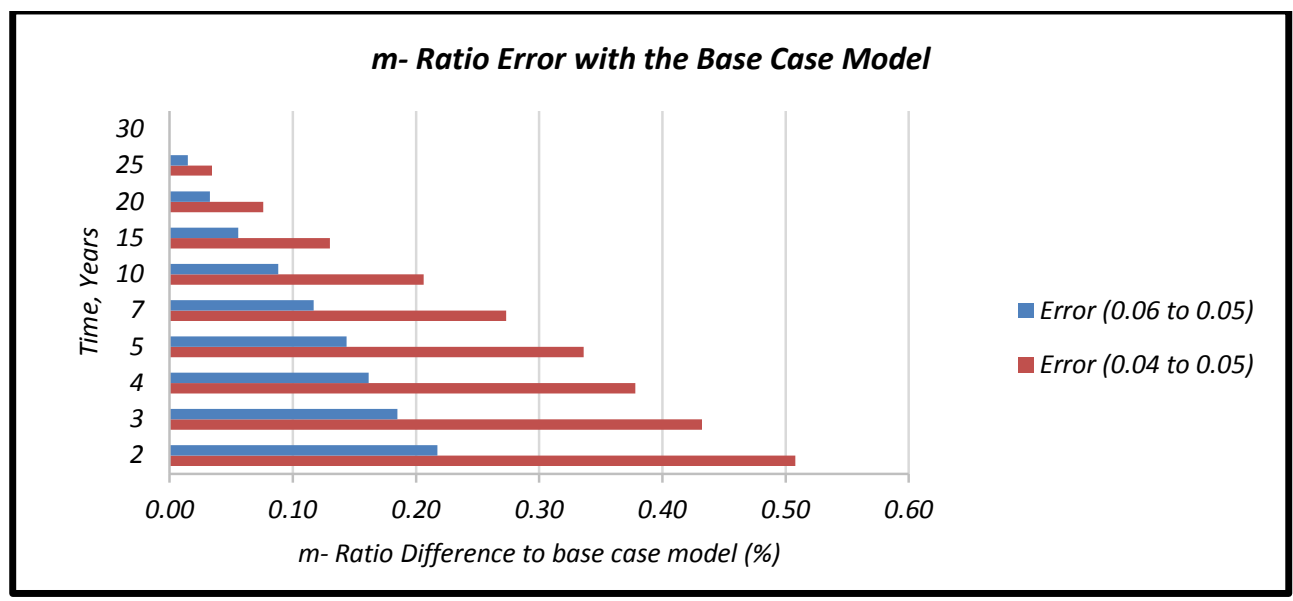

Figure 4-51: m- Ratio Error with the Base Case Model - Porosity- 13 Stages

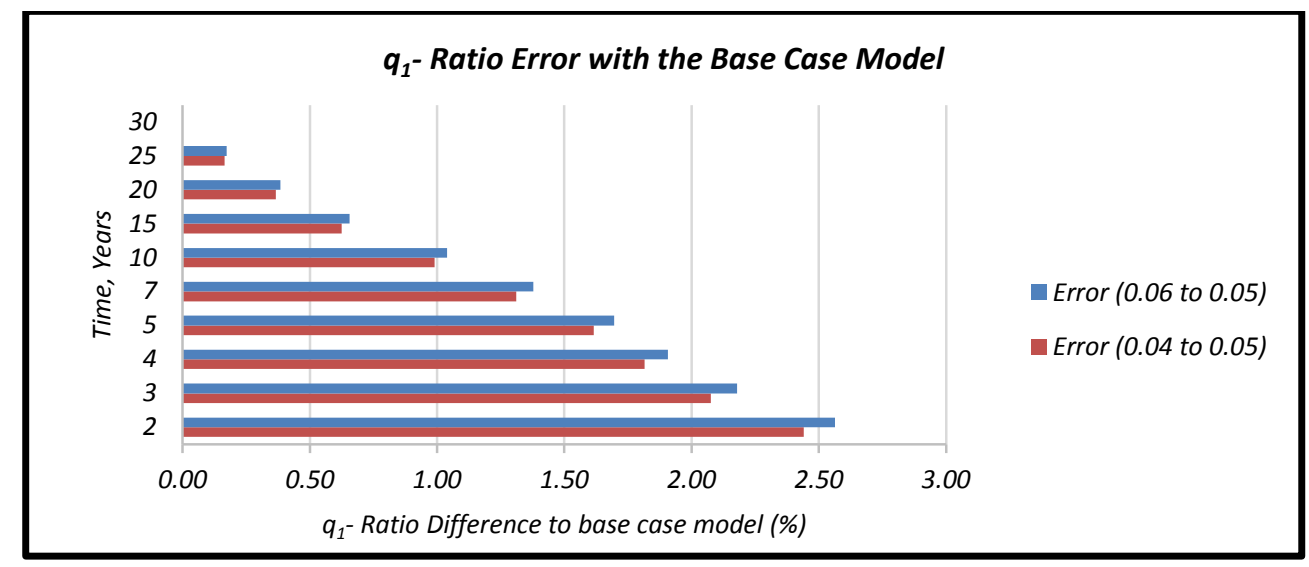

Figure 4-52: $q_{1}$ - Ratio Error with the Base Case Model - Porosity- 13 Stages

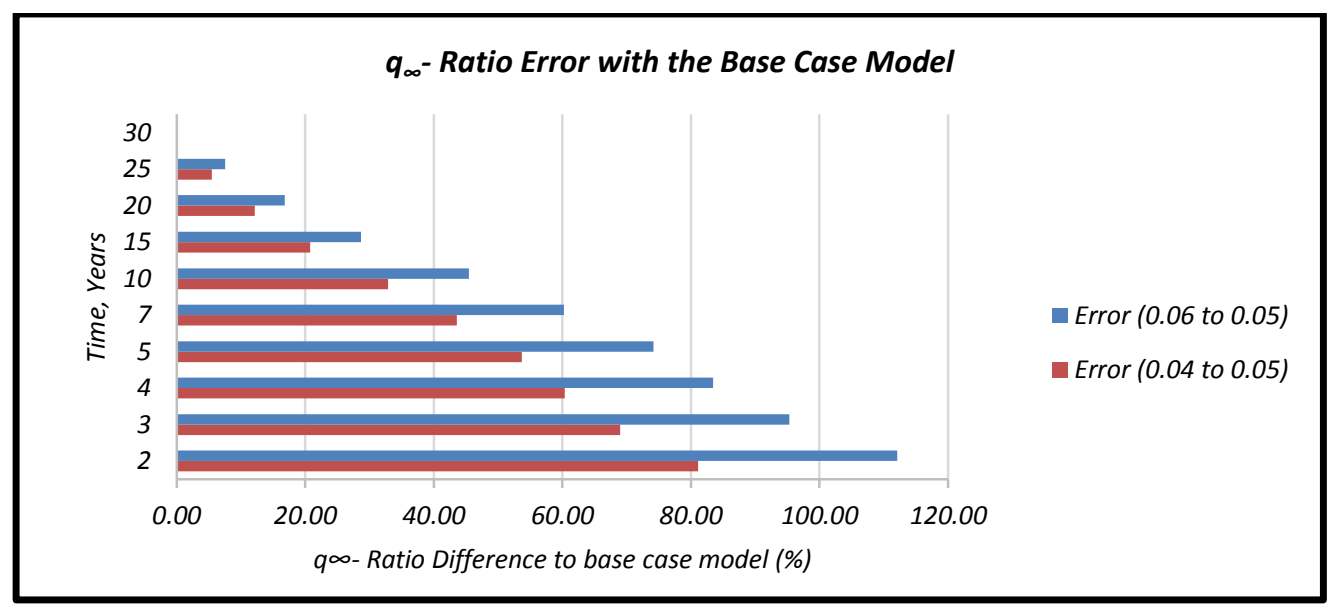

Figure 4-53: $q_{\infty}$ - Ratio Error with the Base Case Model - Porosity- 13 Stages 


\subsection{Confirmation with Field Data}

Well 1 production data and the corresponding Fekete (Fast Evolution) history match for 3.5 years as well as the simulator prediction for 30 years is shown in Figure 4-54 and Figure 4-55, respectively.

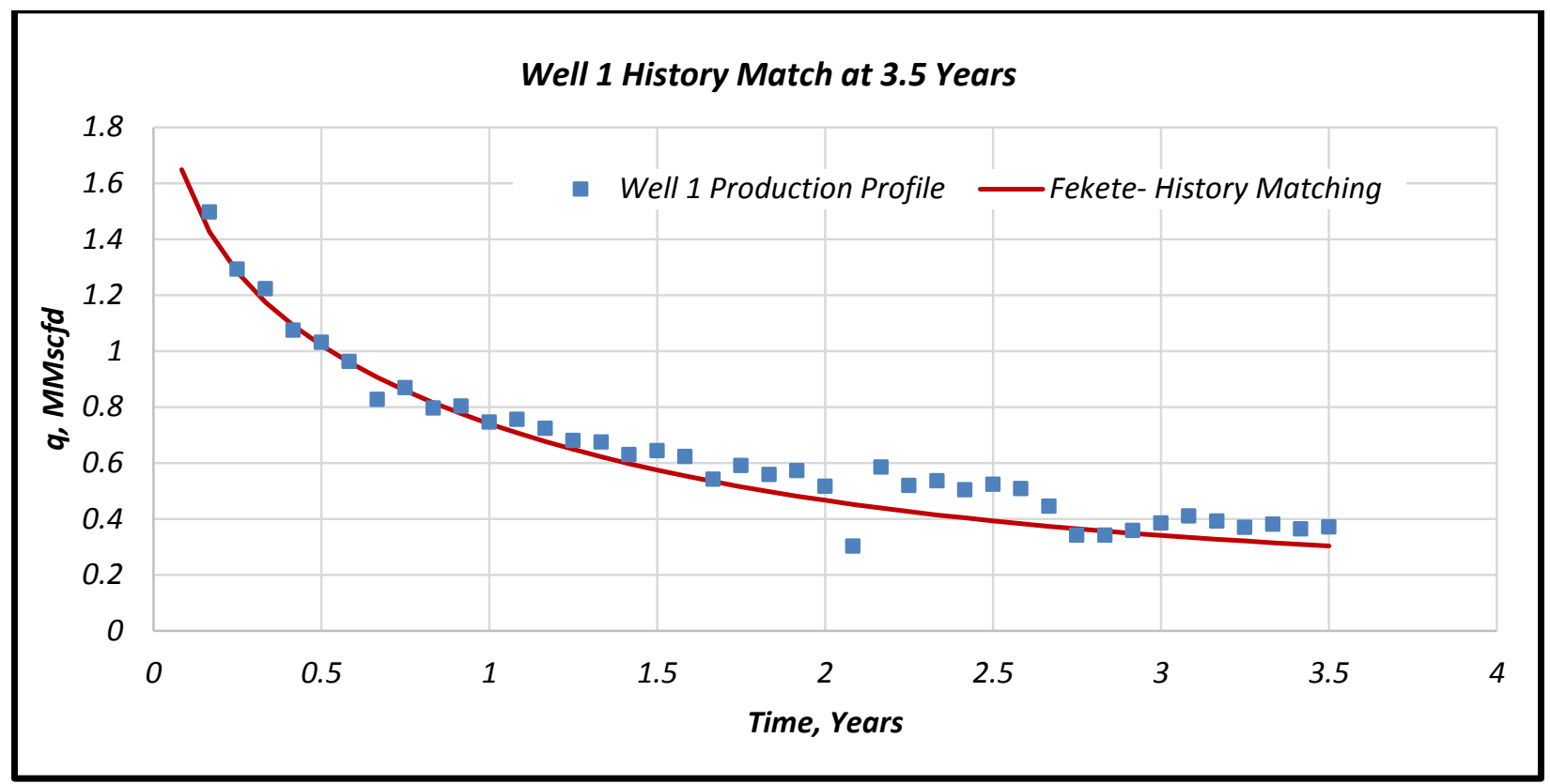

Figure 4-54: Well 1 Production History Match at 3.5 years (By the Fekete Simulator)

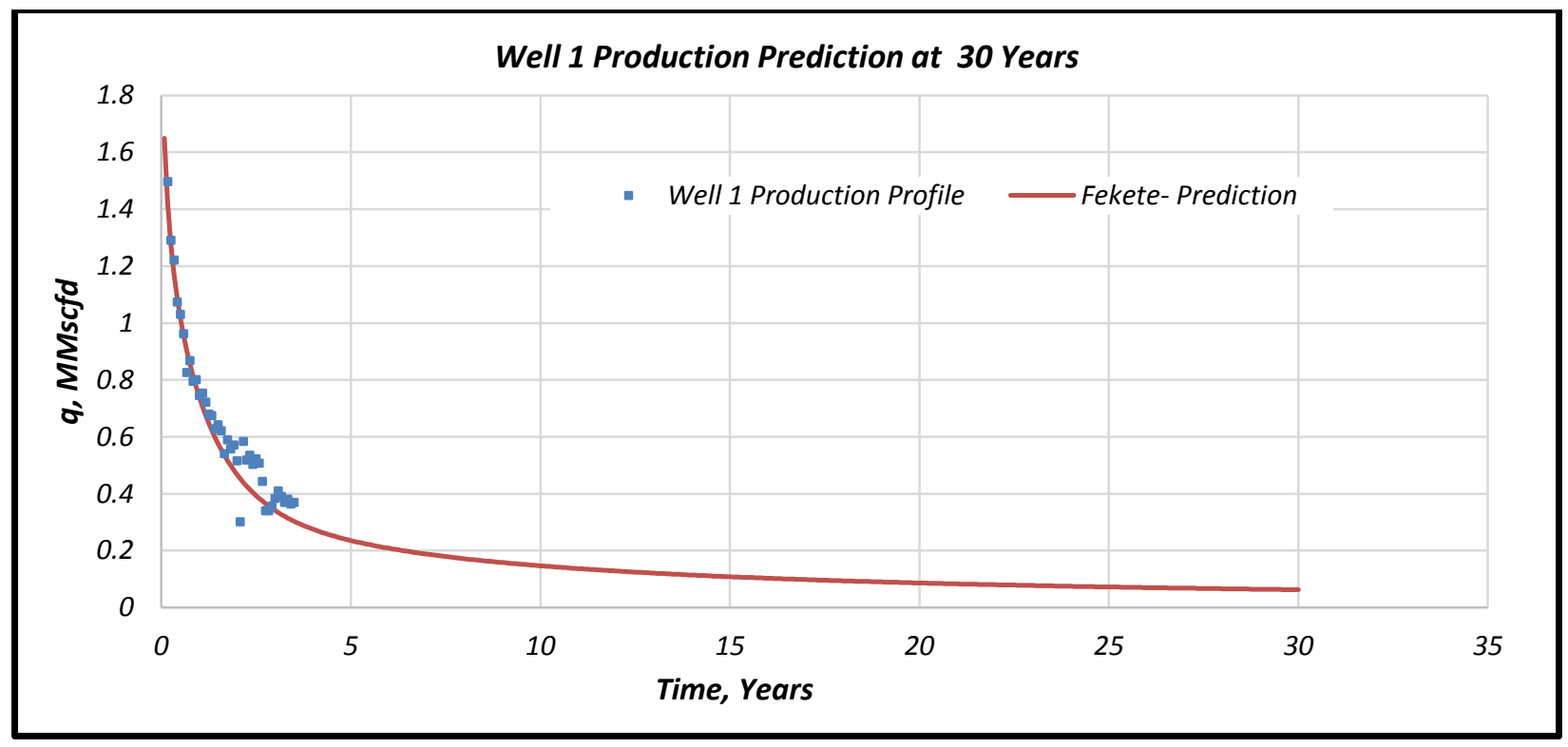

Figure 4-55: Well 1 Production Prediction for 360 Months (By the Fekete Simulator) 
Figure 4-56 and Figure 4-57 illustrate the Arps and Duong DCA models fitting to the same 3.5 years of monthly production rate for well 1 .

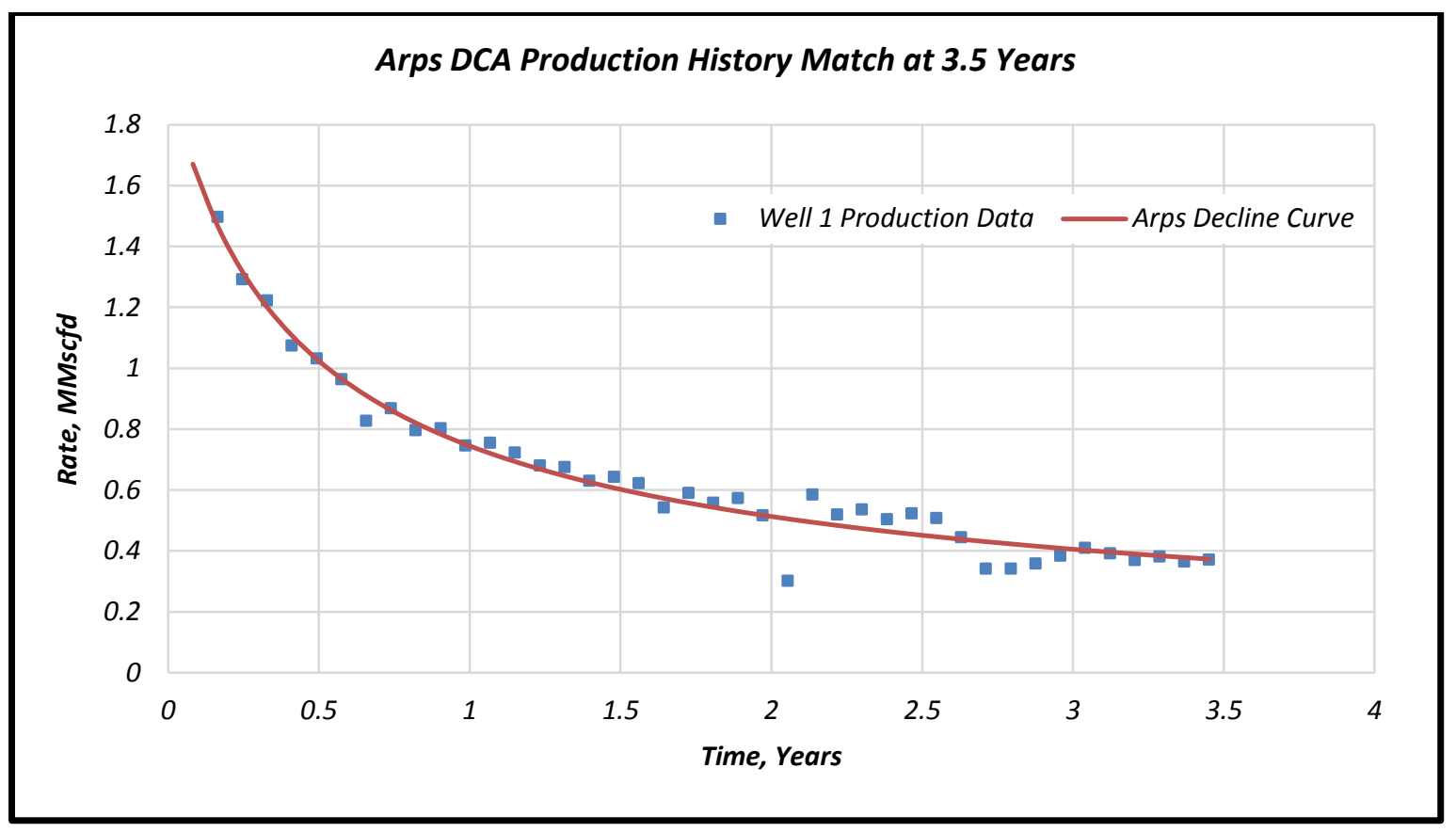

Figure 4-56: Arps DCA Production History Match at 3.5 Years

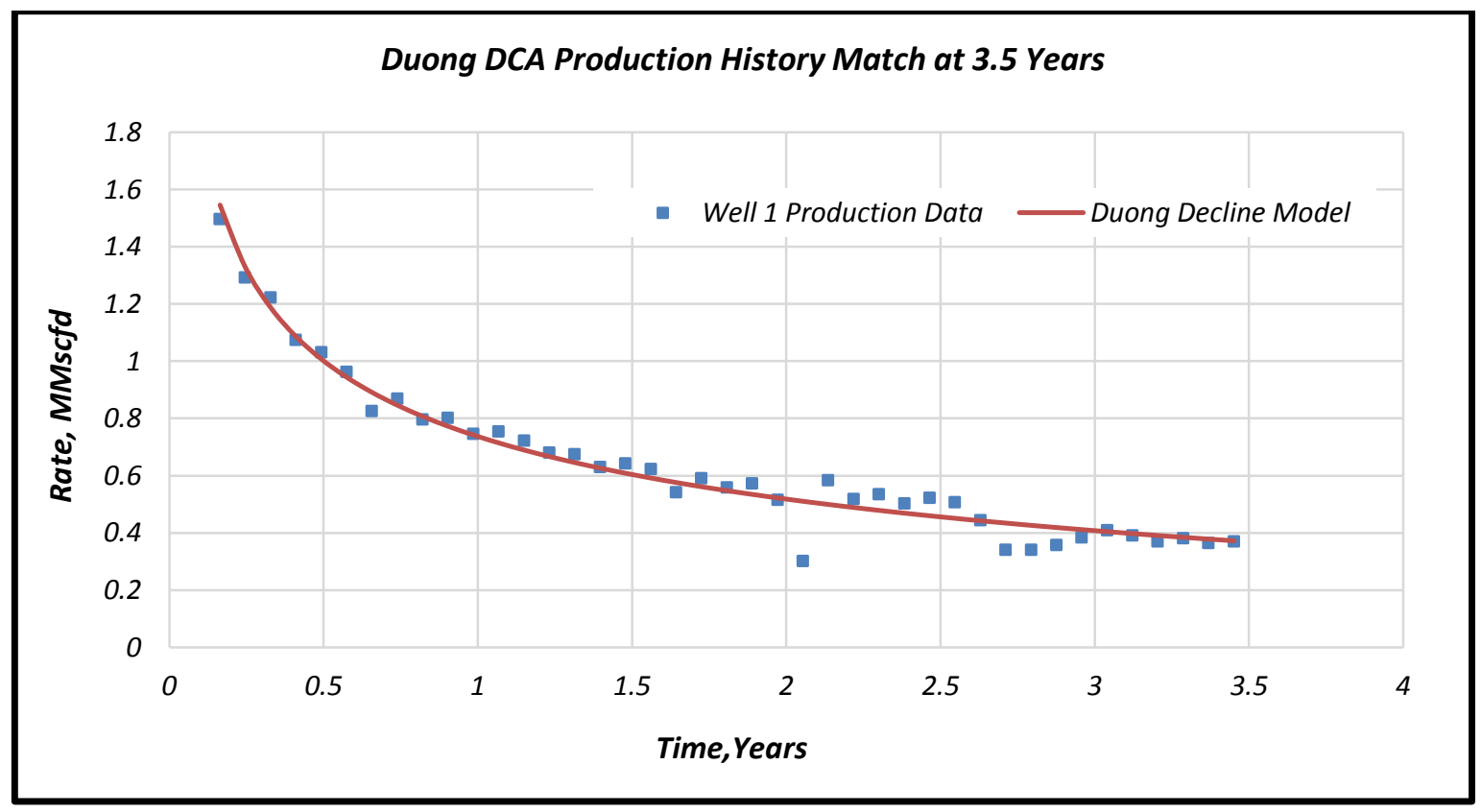

Figure 4-57: Duong DCA Production History Match at 3.5 Years 
Arps and Duong models fit the production history data with high $\boldsymbol{R}^{2}$ values $\left(\boldsymbol{R}^{2}=\mathbf{0 . 9 6 6}\right)$.

The final reservoir parameters after history matching are 350-ft fracture half-length, $0.002 \mathrm{~m}-\mathrm{D}$ natural fracture permeability, and $4.5 \%$ matrix porosity. Therefore, the comparison has been done with 400-ft fracture half-length, $0.002 \mathrm{~m}-\mathrm{D}$ natural fracture permeability, and 5\% matrix porosity, for both seven and thirteen fracture stages.

The constants ratios obtained in section 4.4 for each DCA model plotted versus time; and the correlation was then derived for each DCA constants. By inserting the production history of Well-1 (3.5 years production time) into these correlations, a value of the ratio at this point in time was calculated. Actual Well 1 value of the constant obtained via the nonlinear-regression method (Microsoft ExcelSolver) at 3.5 years was then divided by the value of the ratio at 3.5 years. So, future reservoir performance (at 30 years) can be determined by applying predicted constant values to DCA models (Nelson, 2013). The results were shown in Table G-1 through Table G-8.

In order to confirm the obtained results via ratio method for well 1 with five fracture stages (453$\mathrm{ft}$ spacing), the well 1 history match data generated from Fekete (Fast Evolution). Arps and Duong models were then compared with the simulated data to determine which DCA model matches most closely. Figure 4-58 compares these two DCA models prediction for well 1, with respect to stage spacing, against the simulator data for both seven (500-ft spacing) and thirteen (250-ft spacing) stage cases from 3.5 years until 30 years of production history.

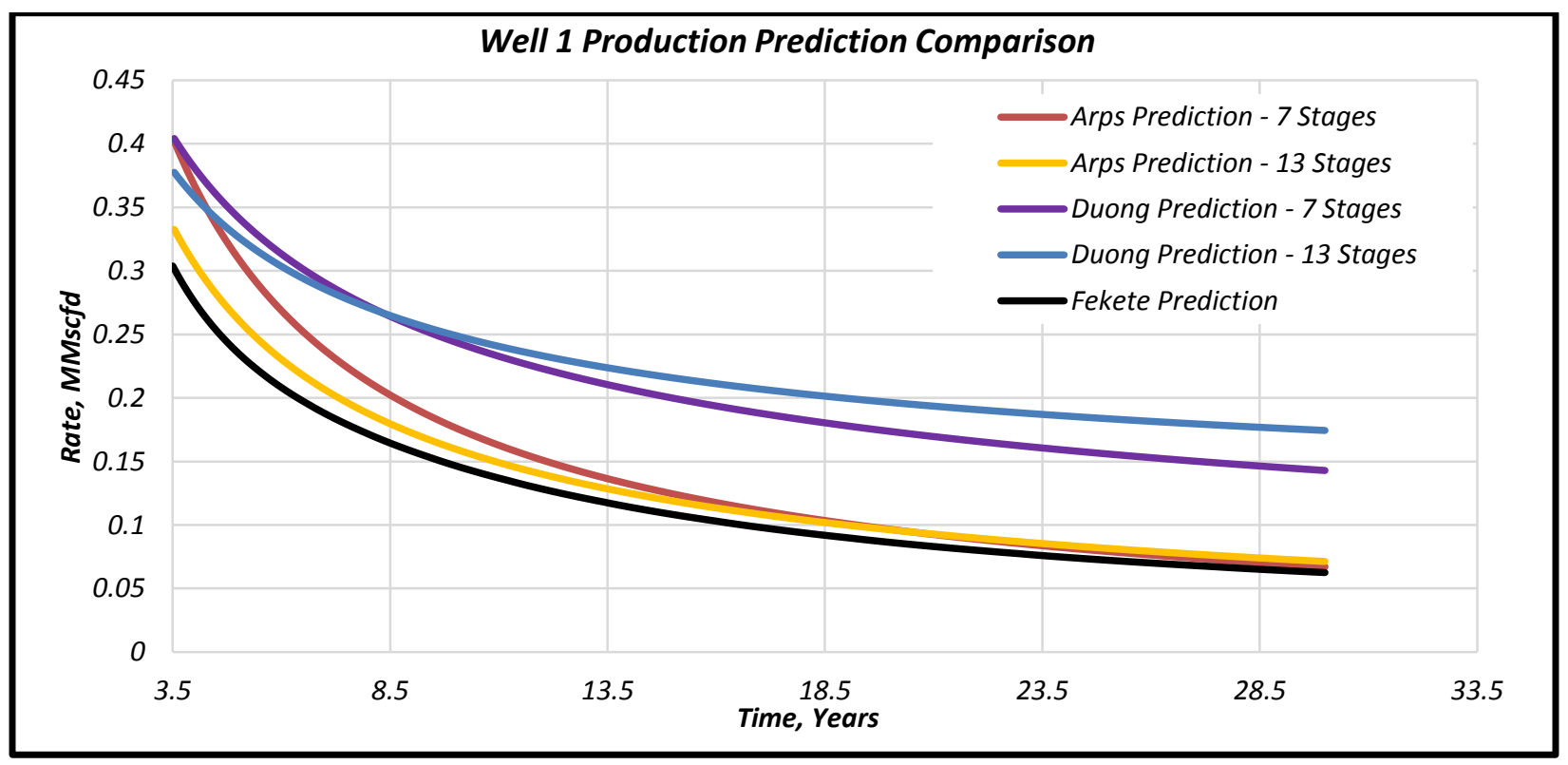

Figure 4-58: Well 1 Production Prediction Comparison 
As it can be observed, Arps DCA model prediction is close to the predicted data obtained from Fekete simulator, especially in the case of 13 stages. On the contrary, Duong appears to overestimate the rates, particularly at later production time. The decrease in spacing between stages results in earlier BDF period which makes Arps prediction more accurate in case of 13 stages (250-ft spacing).

As stated previously, the predicted DCA model constants' values were derived from 400-ft fracture half-length, $0.002 \mathrm{~m}$-D natural fracture permeability, and $5 \%$ matrix porosity horizontal well in order to forecast the Well 1 production performance.

In order to confirm the reliability of the results regarding to the effect of underestimating or overestimating the fracture half-length, permeability, and porosity on the accuracy of the DCA models, the higher and lower values of the Well 1 history matched corresponding properties were considered (Table 4-34).

Table 4-34: Comparison Cases

\begin{tabular}{|c|c|c|}
\hline Lower Value Case & Well \#1 History Matched Properties & Higher Value Case \\
\hline \multicolumn{3}{|c|}{ Fracture Half-Length $(f t)}$. \\
\hline 300 & 350 & 500 \\
\hline \multicolumn{3}{|c|}{ Natural Fracture Permeability in $x$-direction $(\boldsymbol{m}-\mathrm{D})$} \\
\hline 0.001 & 0.002 & 0.004 \\
\hline \multicolumn{3}{|c|}{ Matrix Porosity (\%) } \\
\hline 4
\end{tabular}

Firstly, the generated production data (at 3.5 years) by Fekete simulator, for each case, were matched to Well 1 production history at 3.5 years. As it is shown in Figure G-1 through Figure G-3, the simulated production data matches the Well 1 production history to some extent of accuracy. However, the case of $0.001-\mathrm{mD}$ permeability is not well-matched. Therefore, 0.001-m-D has not been applied for future prediction in the next step.

Figure 4-59 through Figure 4-61 illustrate that Arps model predicts the future production more accurately in the case of overestimating the fracture half-length value (400-ft compared to 300-ft) after 10 years of production; and permeability value ( $0.004 \mathrm{~m}-\mathrm{D}$ compared to $0.002 \mathrm{~m}-\mathrm{D})$ during the early years; as well as underestimating the porosity value (4\% compared to $6 \%$ ).

On the Other hand, Duong model seems to be more precise when the fracture half-length value is underestimated (300-ft compared to $400-\mathrm{ft}$ ) only during the very short time; and the porosity value is 
overestimated (6\% compared to $4 \%$ ). It should be noted that as the lower value permeability $(0.001-\mathrm{mD})$ history match was not achieved, it would be difficult to confirm the results in this case.

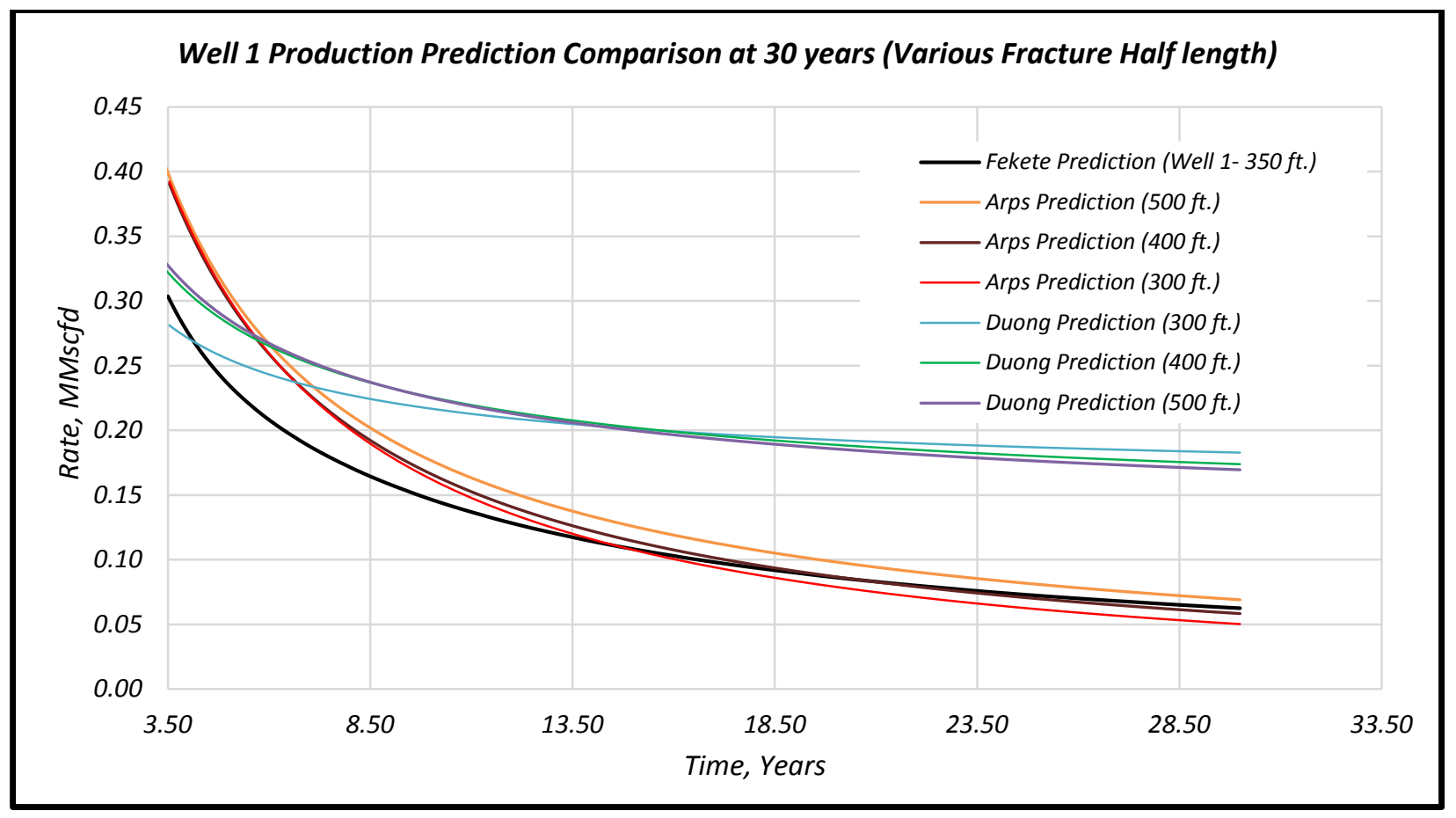

Figure 4-59: Well 1 Production Prediction Comparison at 30 years (Various Fracture Half length)

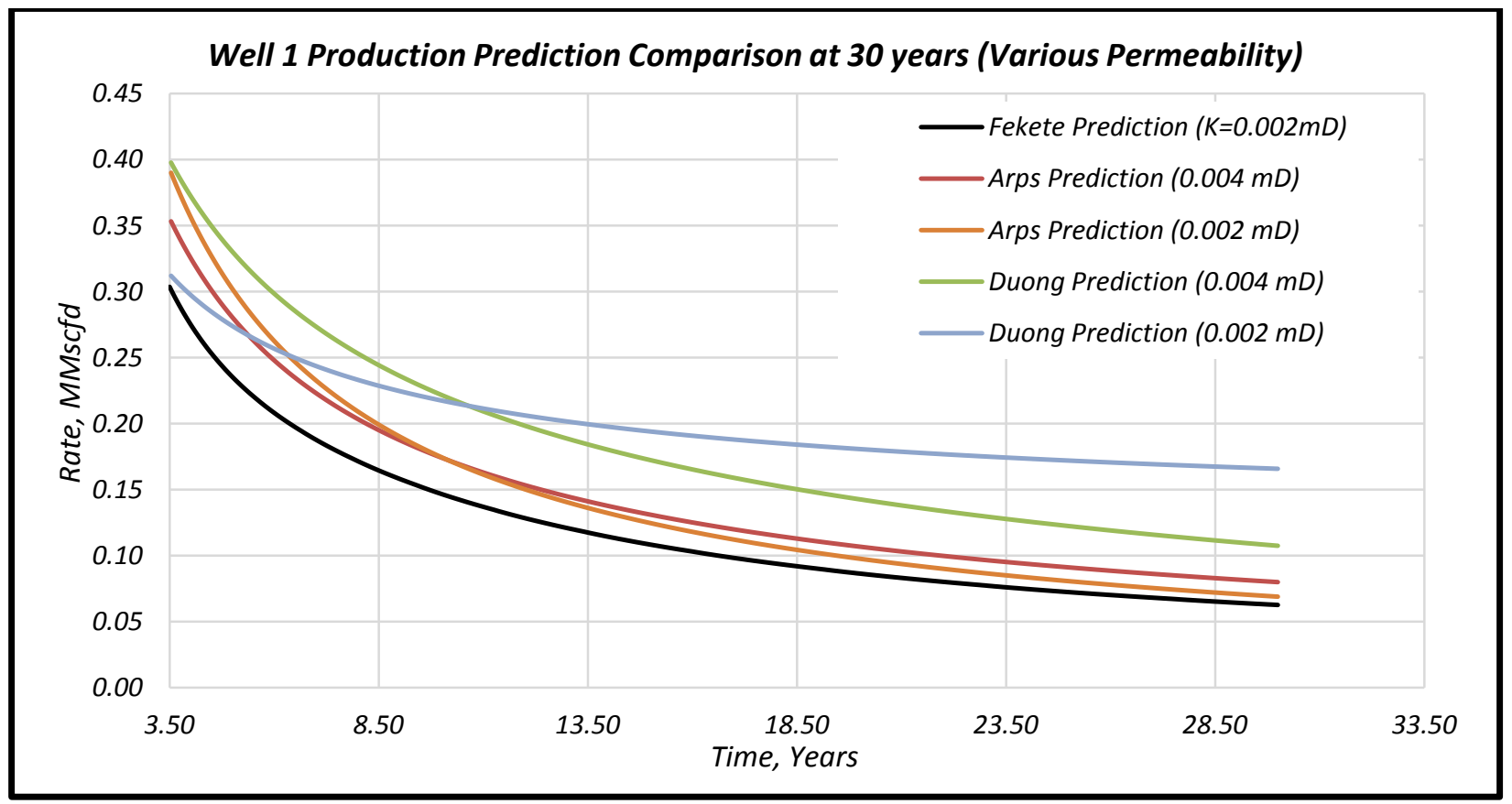

Figure 4-60: Well 1 Production Prediction Comparison at 30 years (Various Permeability) 


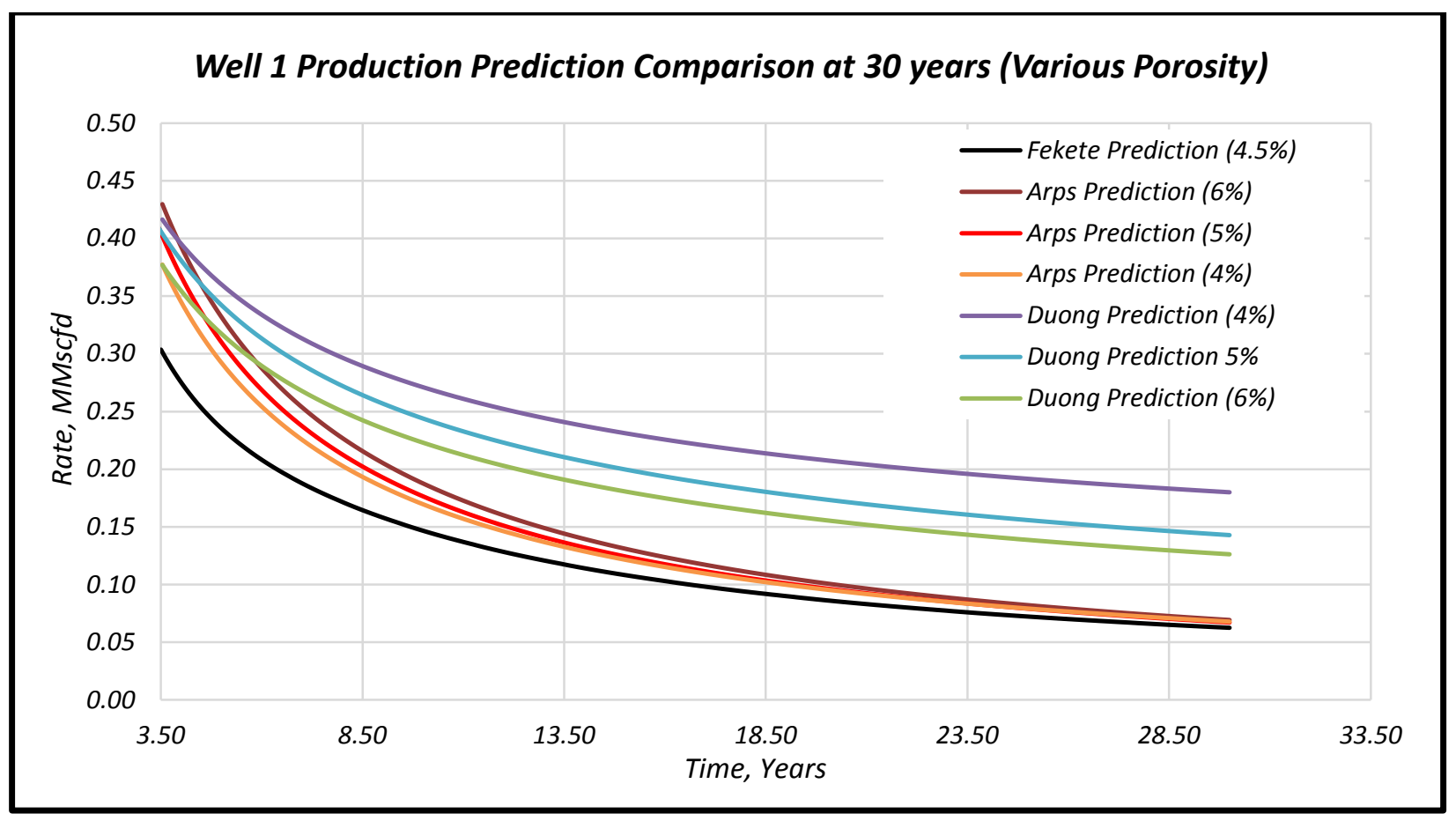

Figure 4-61: Well 1 Production Prediction Comparison at 30 years (Various Porosity) 


\section{Conclusions}

- The three DCA models (Arps, PLE, and Duong) can provide equally good fits to the single porosity simulated production history of a horizontal well with multiple hydraulic fractures in a Marcellus shale formation.

- Developing a DCA model constants correlation based on a single porosity simulated production history shows that Arps and Duong models appear to have a better trend for their constants over 30 years of production time than PLE model.

- Comparing Arps and Duong models at various fracture half length, permeability, and porosity indicates that for both cases of seven and thirteen stage:

$\checkmark$ Duong model is more accurate at lower ranges of fracture half length, permeability and higher ranges of porosity.

$\checkmark$ Aprs model predicts with higher precession at higher ranges of fracture half length, permeability and lower ranges of porosity

- The impact of formation and fracture properties was found to be small on $(\boldsymbol{a})$ and $(\boldsymbol{m})$ constants in Duong model; while $\left(\boldsymbol{q}_{1}\right)$ and $\left(\boldsymbol{q}_{\infty}\right)$ seem to get more effected particularly by fracture half-length and natural fracture permeability changes.

- The loss ratio $\left(\boldsymbol{d}_{\boldsymbol{i}}\right)$ in Arps model get impacted significantly by the changes in formation and fracture properties compare to initial flow rate $\left(\boldsymbol{q}_{\boldsymbol{i}}\right)$ and derivative of loss ratio $(\boldsymbol{n})$.

- Generally, the effect of changes in fracture half-length and permeability are more substantial on DCA model constants compared to matrix porosity.

- Underestimating the fracture half-length, natural fracture permeability, and matrix porosity values results in a larger error in calculating the Arps models constants.

- Overestimating the fracture half-length, natural fracture permeability, and matrix porosity values results in a larger error in calculating the Duong models constants.

- The effect of formation and fracture properties on DCA models constants will be diminished after fifteen or twenty years of production time.

- Incorrect estimation of the fracture half length, permeability, and porosity will result in smaller error in DCA models constants in case of 13 stages rather than 7 stages.

- The applicability of the method of ratios to the limited production data in order to predict the future production has been confirmed in this study.

- The Arps hyperbolic decline curve provides a more reliable production prediction for a limited Well 1 Marcellus data with five fracture stages compare to Duong model. 


\section{Recommendations}

- It is recommended to investigate the effect of other reservoir and formation properties such as drainage area, desorption, lateral length, and reservoir thickness on decline curve models constants as well as hydraulic fractures characteristics like fracture conductivity and width of the fracture.

- Future research should be conducted with other simulators to test the results, particularly for dual porosity reservoirs.

- Additional research is needed to be done to obtain a more accurate numerical optimization method.

- Further analysis can be performed if a longer production history of a Marcellus horizontal well would be available. 


\section{References}

Belvalkar, R. and Oyewole, S. Development of Marcellus Shale in Pennsylvania. Paper 134852-MS presented at the SPE Annual Technical Conference and Exhibition, Florence, Italy, 19-22 September 2010. DOI: 10.2118/134852-MS.

Belyadi, A et. al. 2010. Performance of the Hydraulically Fractured Horizontal Wells in Low Permeability Formation. Paper 139082-MS presented at the SPE Eastern Regional Meeting, Morgantown, West Virginia, USA, 12-14 October 2010. DOI: 10.2118/139082-MS.

Belyadi, F et. al. 2012. Analysis of Production Performance of the Hydraulically Fractured Horizontal Wells. Paper 16348-MS presented at the SPE Eastern Regional Meeting, Lexington, Kentucky, USA, 3-5 October 2012.

Duong, A.N. 2011. Rate-Decline Analysis for Fracture-Dominated Shale Reservoirs. SPE Reservoir Evaluation \& Engineering (3): pp. 377-387. DOI: 10.2118/137748-PA.

El Sgher, M. (2013). Analysis of Production Data from Marcellus Shale Horizontal Wells in WV. Master's Thesis, West Virginia University, Morgantown, WV.

Ilk, D. et. al. 2008. Exponential vs. Hyperbolic Decline in Tight Gas Sands: Understanding the Origin and Implications for Reserve Estimates Using Arps' Decline Curves. Paper 116731-MS presented at the SPE Annual Technical Conference and Exhibition, Denver, Colorado, USA, 21-24 September 2008. DOI: 10.2118/116731-MS.

Joshi, K. and Lee, J. 2013. Comparison of Various Deterministic Forecasting Techniques in Shale Gas Reservoirs. Paper 163870-MS presented at the 2013 SPE Hydraulic Fracturing Technology Conference, The Woodlands, Texas, USA, 04-06 February 2013. DOI: 10.2118/163870-MS.

Kanfar, M.S. and Wattenbarger, R.A. 2012. Comparison of Empirical Decline Curve Methods for Shale Wells. Paper SPE 162648-MS presented at the SPE Canadian Unconventional Resources Conference, Calgary, Alberta, Canada, 30 October-01 November 2012. DOI: 10.2118/162648MS.

Kanfar, M.S. and Wattenbarger, R.A. 2013. Modeling Guidelines for Analyzing and Forecasting Shale Well Performance. Paper SPE 165698-MS presented at the Eastern Regional Meeting, Pittsburgh, Pennsylvania, USA, 20-22 August 2013.

Mishra, S. 2012. A New Approach to Reserves Estimation in Shale Gas Reservoirs Using Multiple Decline Curve Analysis Models. Paper 161092-MS presented at the SPE Eastern Regional Meeting, Lexington, Kentucky, USA, 03-05 October 2012. DOI: 10.2118/161092-MS.

Nelson, B. (2013). Analysis of Shale Production Performance Using Decline Curve Methods. Master's Thesis, West Virginia University, Morgantown, WV.

Nelson, B. et. al. 2014. Predicting Long-term Production Behavior of the Marcellus Shale. Paper 169489-MS presented at the Western North American and Rocky Mountain Joint Meeting, Denver, Colorado, 17-18 April 2014. DOI: 10.2118/169489-MS 
Nobakht, M. 2011. Effect of Heterogeneity in a Horizontal Well with Multiple Fractures on the LongTerm Forecast in Shale Gas Reservoirs. Paper 149400-MS presented at the Canadian Unconventional Resources Conference, Calgary, Alberta, Canada, 15 -17 November 2011.

Okouma, V. et. al. 2012. Practical Considerations for Decline Curve Analysis in Unconventional Reservoirs --- Application of Recently Developed Rate-Time Relations. Paper 162910-MS presented at the SPE Hydrocarbon Economics and Evaluation Symposium, Calgary, Alberta, Canada, 24-25 September 2012. DOI: 10.2118/162910-MS.

Seshadri, J. and Mattar, L. 2010. Comparison of Power Law and Modified Hyperbolic Decline Methods. Paper 137320-MS presented at the Canadian Unconventional Resources and International Petroleum Conference, Calgary, Alberta, Canada, 19-21 October 2010. DOI: 10.2118/137320MS.

Towler, Brian F. 2002. Fundamental Principles of Reservoir Engineering. Richardson, Texas: Henry L. Doherty Memorial Fund of AIME, Society of Petroleum Engineers.

Valko, P.P. and Lee, W.J. 2010. A Better Way to Forecast Production from Unconventional Gas Wells. Paper SPE 134231 presented at the SPE Annual Technical Conference and Exhibition, Florence, Italy, 19-22 September. DOI: 10.2118/134231-MS. 


\section{Appendix}

\section{A. Application of Decline Curve Analysis to Simulated Data Using Excel- Solve Method}

Towler (2002) introduced a non-linear regression technique using Excel- Solver for decline curve parameters determination. The technique is presented as follows.

A spreadsheet was set up containing cells for each parameter of every DCA model. For every model, a column with the appropriate production rate equation, $\boldsymbol{q}^{\prime}$, the errors squared, $\left(\boldsymbol{q}-\boldsymbol{q}^{\mathbf{}}\right)^{2}$, and total errors

squared, $\left(\boldsymbol{q}-\boldsymbol{q}_{\text {average }}\right)^{2}$, was then generated, where $\boldsymbol{q}$ corresponds to the flow rate from simulated production data. A cell for the sum of errors squared, $S_{S E}$, and total errors squared, $S_{S T}$, was also created. The regression coefficient was also generated in a cell by using the following formula:

$$
R^{2}=1-\frac{S_{S E}}{S_{S T}} \ldots \ldots \ldots \ldots \ldots \ldots
$$

The Solver works by optimizing $\boldsymbol{R}^{2}$ with non-linear equations to indicate the best curve fit to production history of a well; while varying only each DCA model parameters (Nelson, 2013).

\section{B. Development of a Marcellus Shale Reservoir Model}

Various models were generated for the two scenarios of seven and thirteen stages (for various permeability and porosity values) based on the ranges which were given in Table 3-1. 


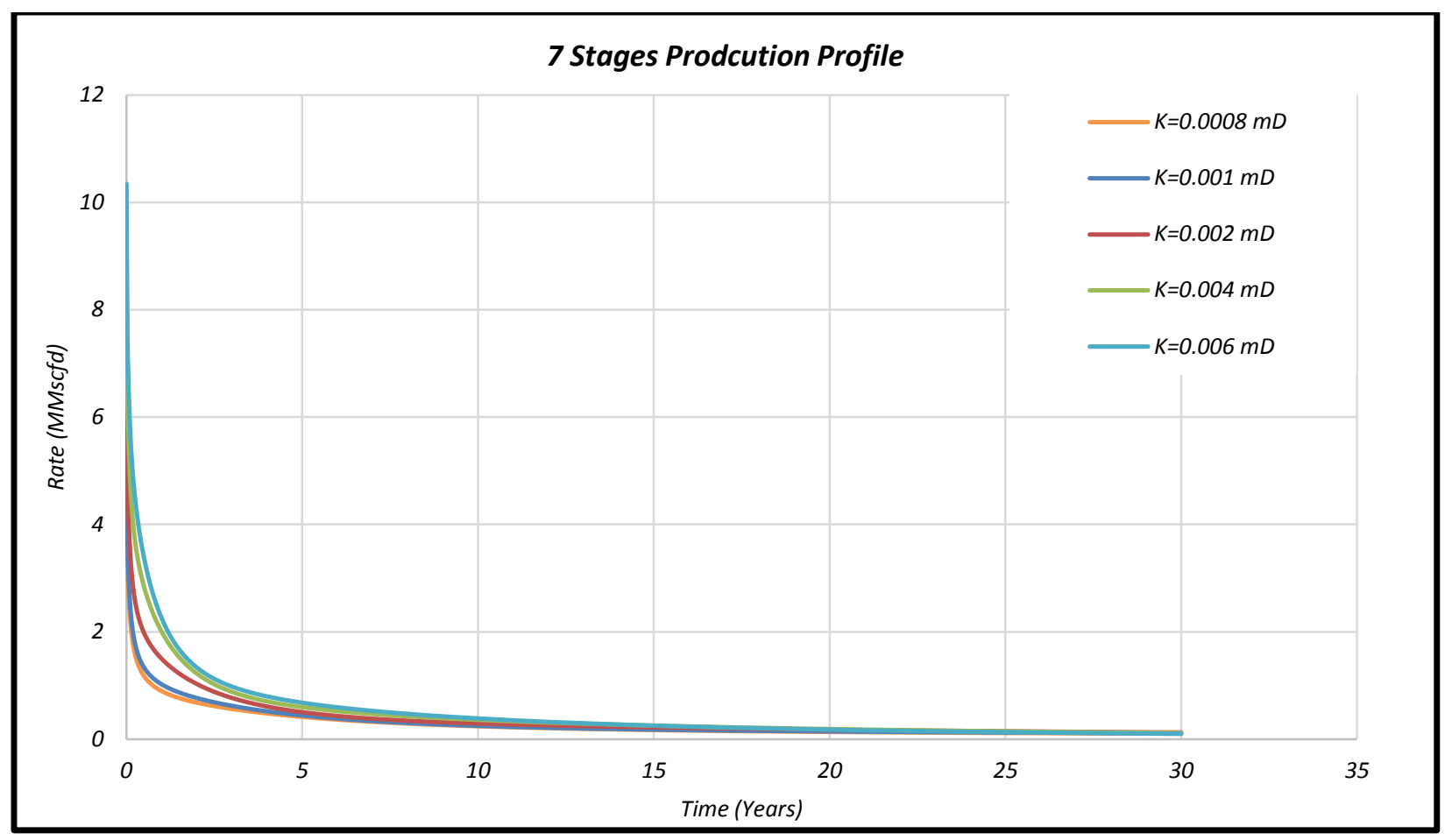

Figure B-1: 7 Stages Production Profile- Various Permeability

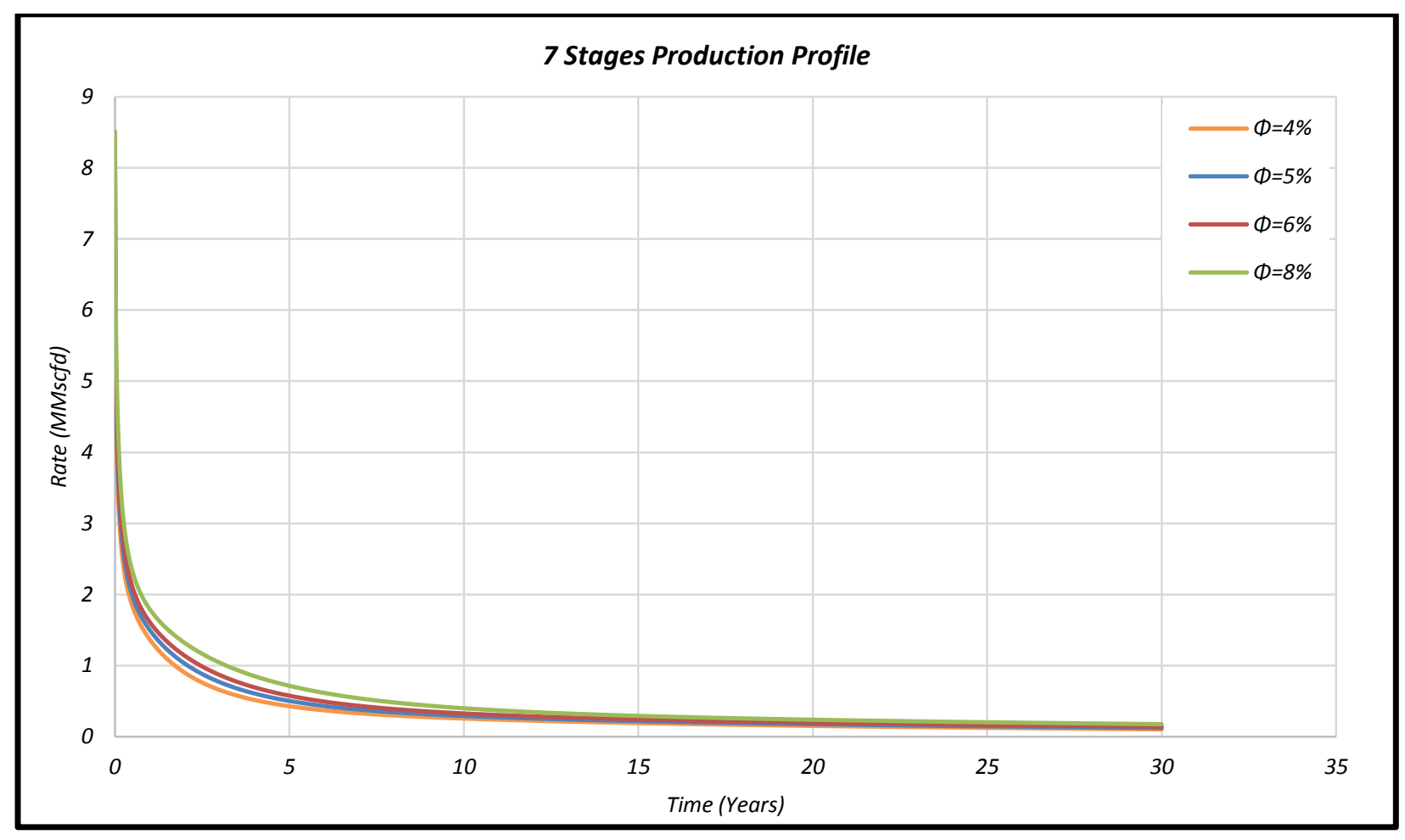

Figure B-2: 7 Stages Production Profile- Various Porosity 


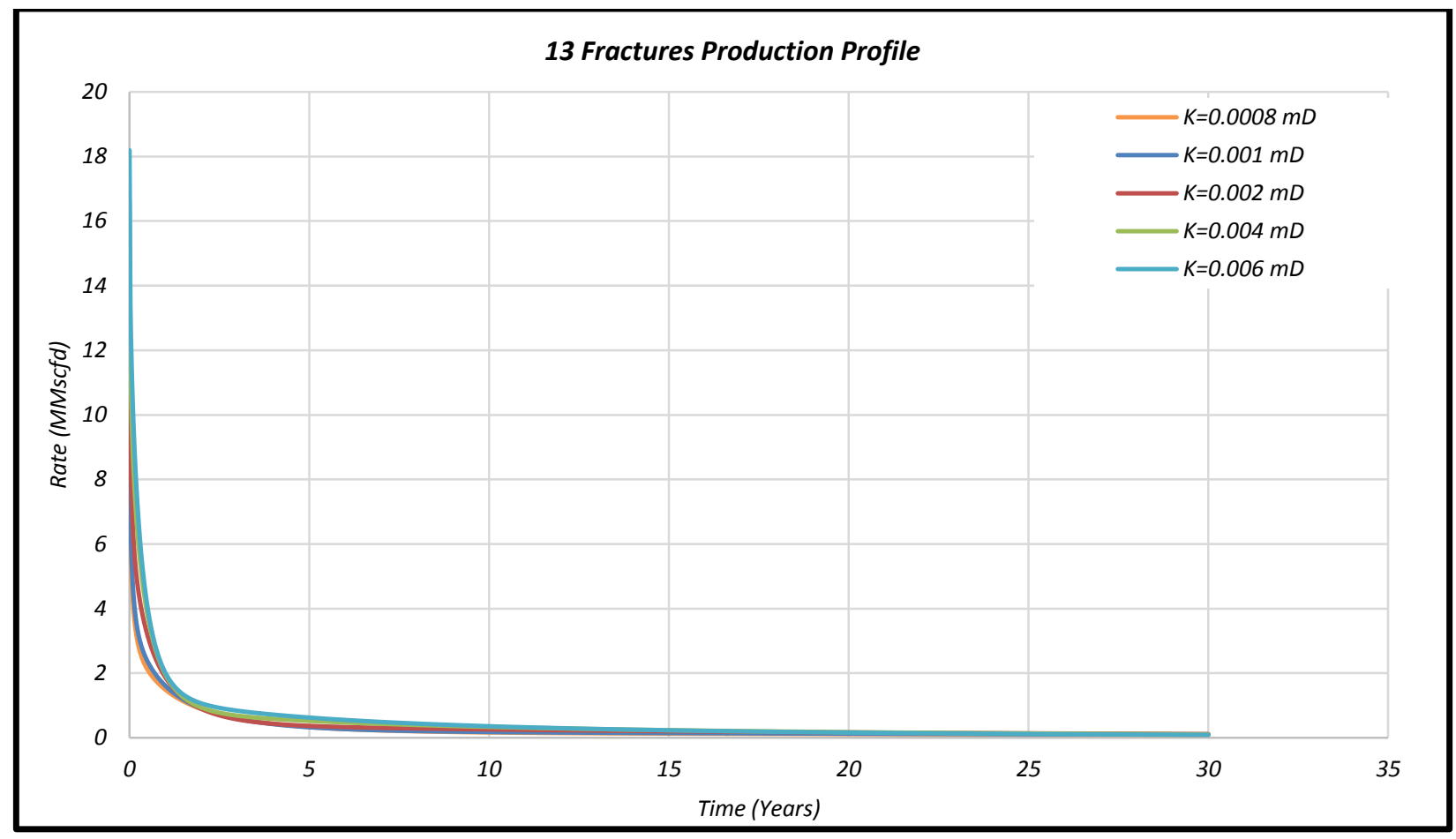

Figure B-3: 13 Stages Production Profile- Various Permeability

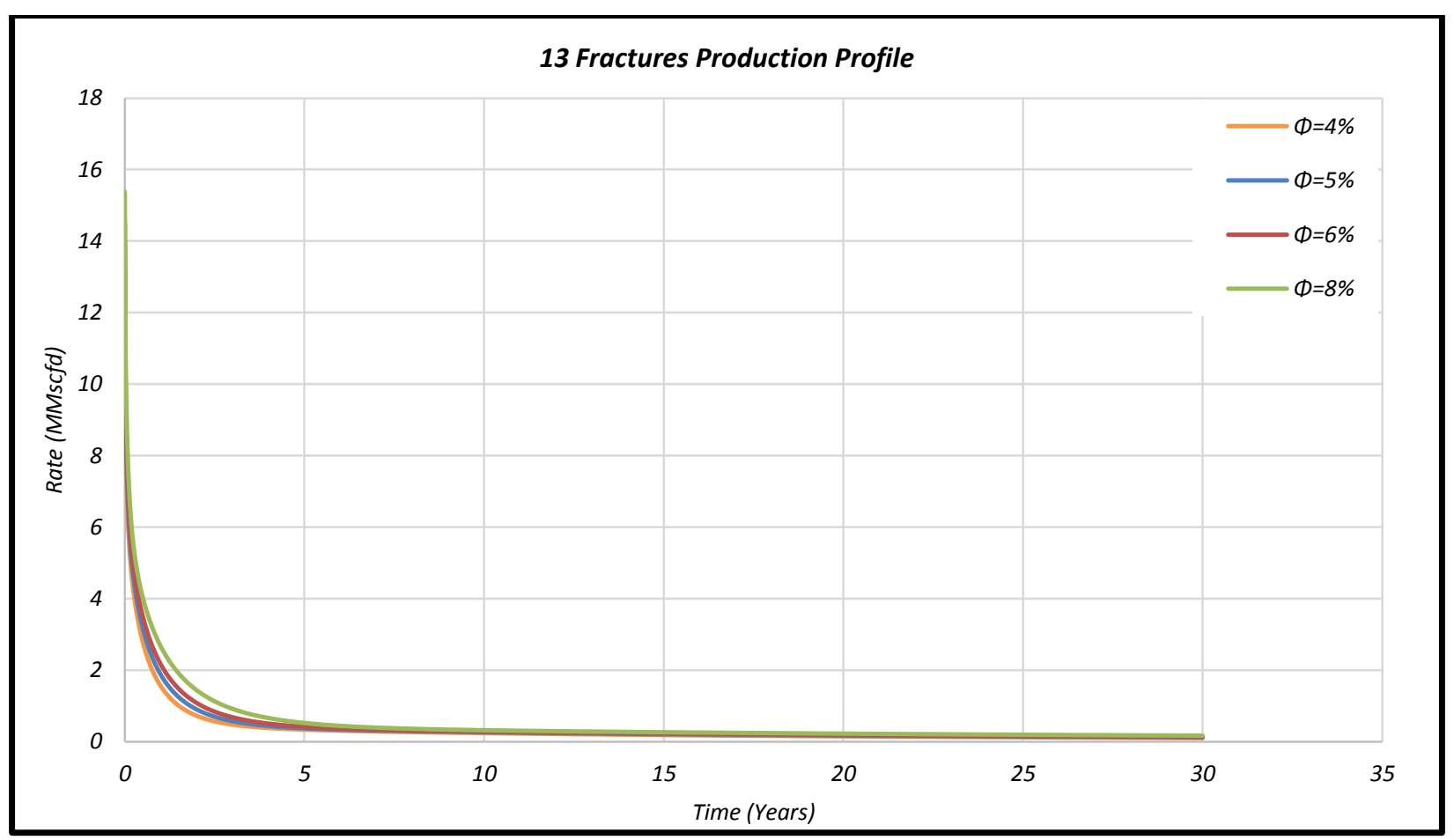

Figure B-4: 13 Stages Production Profile- Various Porosity 


\section{Application of Selected DCA Models to All Simulated Data}

Matching Arps, PLE, and Duong DCA models to all simulated production history yielded the results presented below for thirteen-stage case (Base Model).

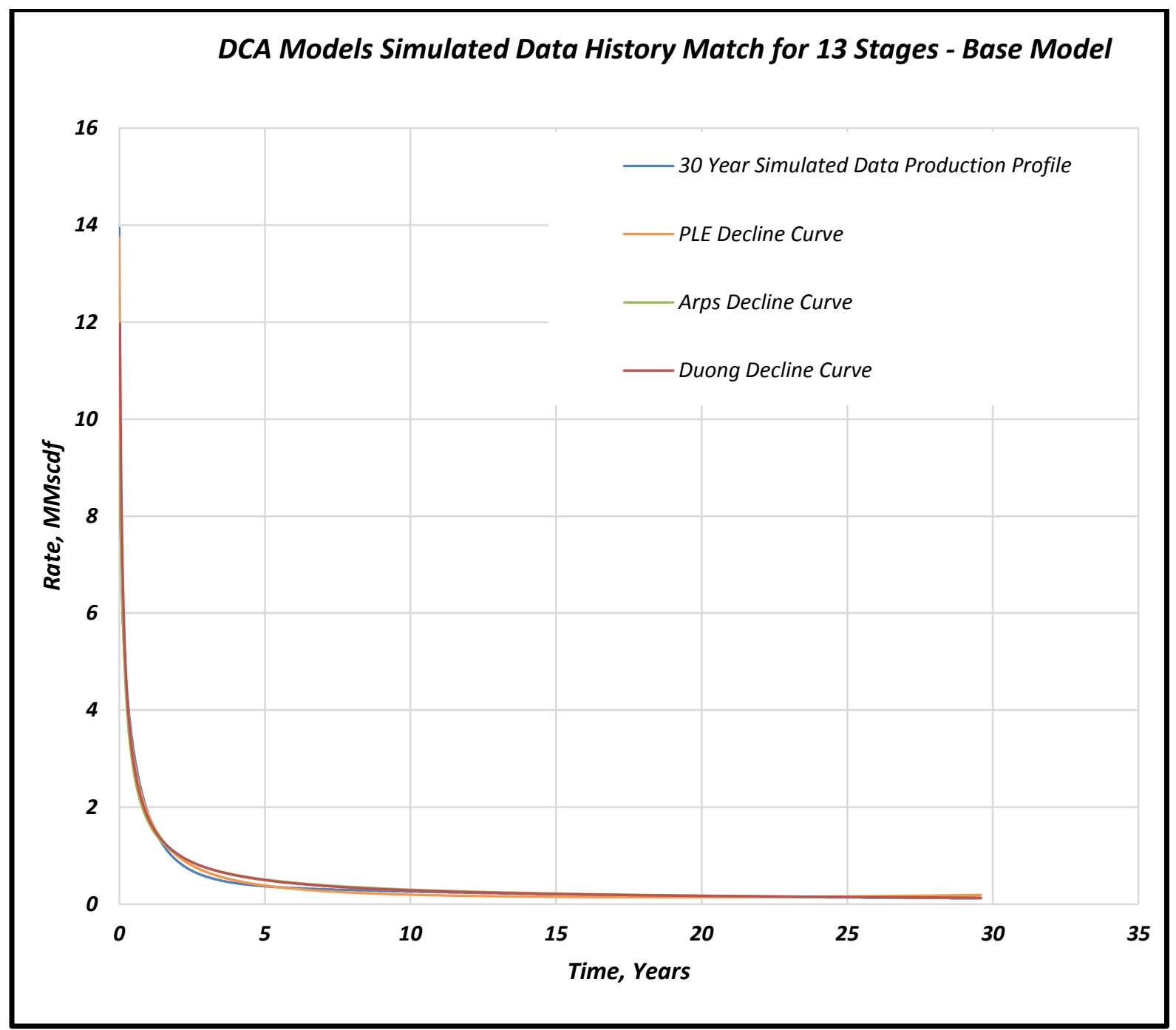

Figure C-1: Arps, PLE, and Duong DCA Models Simulated Data History Match - Thirteen Stages 


\section{DCA Models Constants Correlations}

For both seven and thirteen stage cases with various fracture half-lengths, permeability, and porosity, the DCA models constants over two, five, seven, ten, eleven, twelve, fifteen, twenty, twenty-five, and thirty years of production time are shown in the following tables.

\section{D.1. Seven Stages Model}

Table D-1: 7 Stages (300 ft.) - Arps

\begin{tabular}{|c|c|c|c|c|}
\hline \multicolumn{5}{|c|}{ 7 Fractures (300 ft.)- Arps } \\
\hline Years & $n$ & di & qi & $R^{2}$ \\
\hline 3 & 2.1669 & 0.0436 & 5.0052 & 0.9928 \\
\hline 5 & 1.8742 & 0.0247 & 4.3838 & 0.9951 \\
\hline 7 & 1.6453 & 0.0154 & 3.9078 & 0.9958 \\
\hline 10 & 1.4477 & 0.0100 & 3.4948 & 0.9904 \\
\hline 15 & 1.2704 & 0.0065 & 3.0975 & 0.9744 \\
\hline 20 & 1.1807 & 0.0051 & 2.8748 & 0.9594 \\
\hline 25 & 1.1270 & 0.0043 & 2.7301 & 0.9474 \\
\hline 30 & 1.0795 & 0.0038 & 2.6105 & 0.9363 \\
\hline
\end{tabular}

Table D-2: 7 Stages (300 ft.) - PLE

\begin{tabular}{|c|c|c|c|c|c|}
\hline \multicolumn{7}{|c|}{ 7 Fractures (300 ft.)-PLE } \\
\hline Years & $\boldsymbol{D}_{\infty}$ & $\boldsymbol{n}$ & $\boldsymbol{q}_{\boldsymbol{i}}$ & $\boldsymbol{D}_{\boldsymbol{1}}$ & $\boldsymbol{R}^{\mathbf{2}}$ \\
\hline 2 & -0.00056 & 0.32722 & 6.88861 & 0.10258 & 0.99943 \\
\hline 3 & -0.00034 & 0.31392 & 6.90018 & 0.10266 & 0.99926 \\
\hline 4 & -0.00025 & 0.30712 & 6.90898 & 0.10296 & 0.99926 \\
\hline 5 & -0.00023 & 0.30590 & 6.90989 & 0.10284 & 0.99930 \\
\hline 7 & -0.00023 & 0.30557 & 6.89710 & 0.10272 & 0.99938 \\
\hline 10 & -0.00023 & 0.30510 & 6.90718 & 0.10292 & 0.99945 \\
\hline 15 & -0.00021 & 0.30401 & 6.92042 & 0.10303 & 0.99946 \\
\hline 20 & -0.00019 & 0.29906 & 6.90695 & 0.10343 & 0.99925 \\
\hline 25 & -0.00016 & 0.29361 & 6.90687 & 0.10408 & 0.99881 \\
\hline 30 & -0.00014 & 0.28892 & 6.90722 & 0.10465 & 0.99754 \\
\hline
\end{tabular}

Table D-3: 7 Stages (300 ft.) - Duong

\begin{tabular}{|c|c|c|c|c|c|}
\hline \multicolumn{6}{|c|}{ 7 Fractures (300 ft.)- Duong } \\
\hline Years & $a$ & $m$ & $q_{1}$ & $q_{\infty}$ & $R^{2}$ \\
\hline 2 & 0.8370 & 0.9883 & 11.4065 & -4.5662 & 0.9997 \\
\hline 3 & 0.8116 & 0.9874 & 10.4424 & -3.4514 & 0.9997 \\
\hline 4 & 0.7944 & 0.9878 & 9.7563 & -2.7111 & 0.9994 \\
\hline 5 & 0.7671 & 0.9880 & 9.2240 & -1.9608 & 0.9988 \\
\hline 7 & 0.7377 & 1.0007 & 8.4220 & -0.7879 & 0.9974 \\
\hline 10 & 0.7992 & 1.0331 & 7.5720 & -0.2725 & 0.9964 \\
\hline 15 & 0.9062 & 1.0656 & 6.6051 & -0.0834 & 0.9962 \\
\hline 20 & 0.9884 & 1.0846 & 5.9190 & -0.0243 & 0.9968 \\
\hline 25 & 1.0540 & 1.0972 & 5.3870 & 0.0011 & 0.9974 \\
\hline 30 & 1.0774 & 1.1014 & 5.2052 & 0.0079 & 0.9977 \\
\hline
\end{tabular}



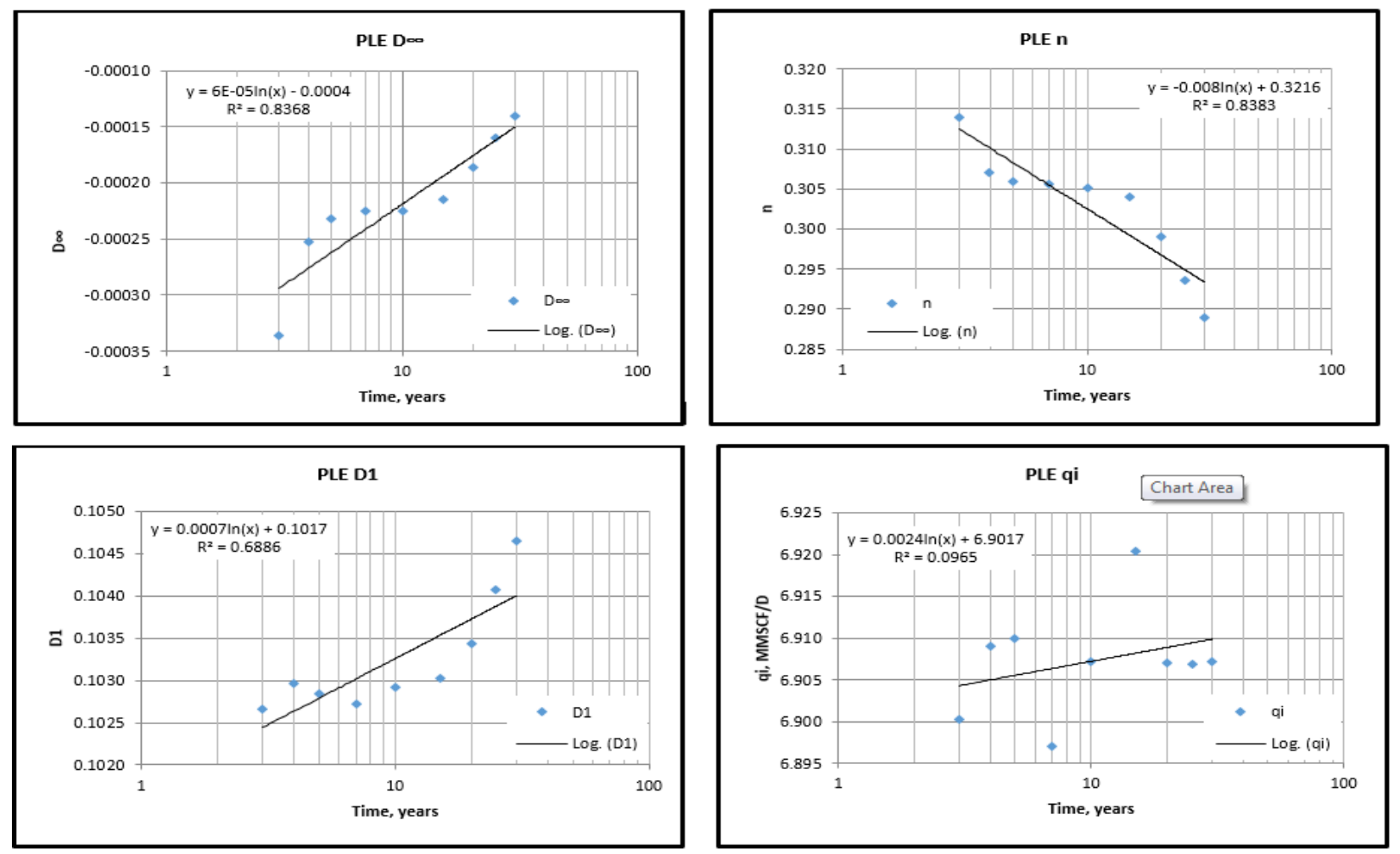

Figure D-1: 7 Stages - PLE Constants Correlations (300ft.)
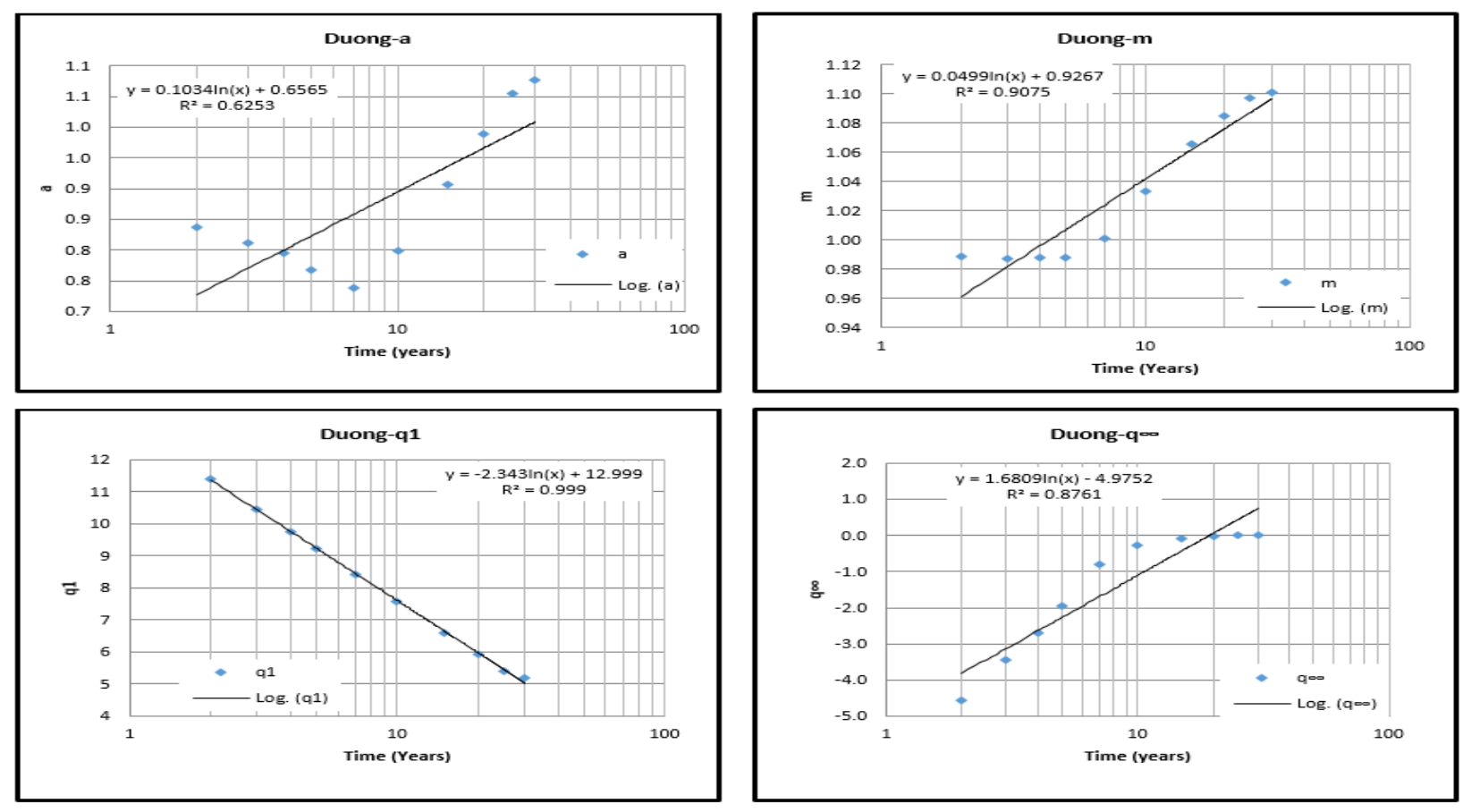

Figure D-2: 7 Stages - Duong Constants Correlations (300ft.) 

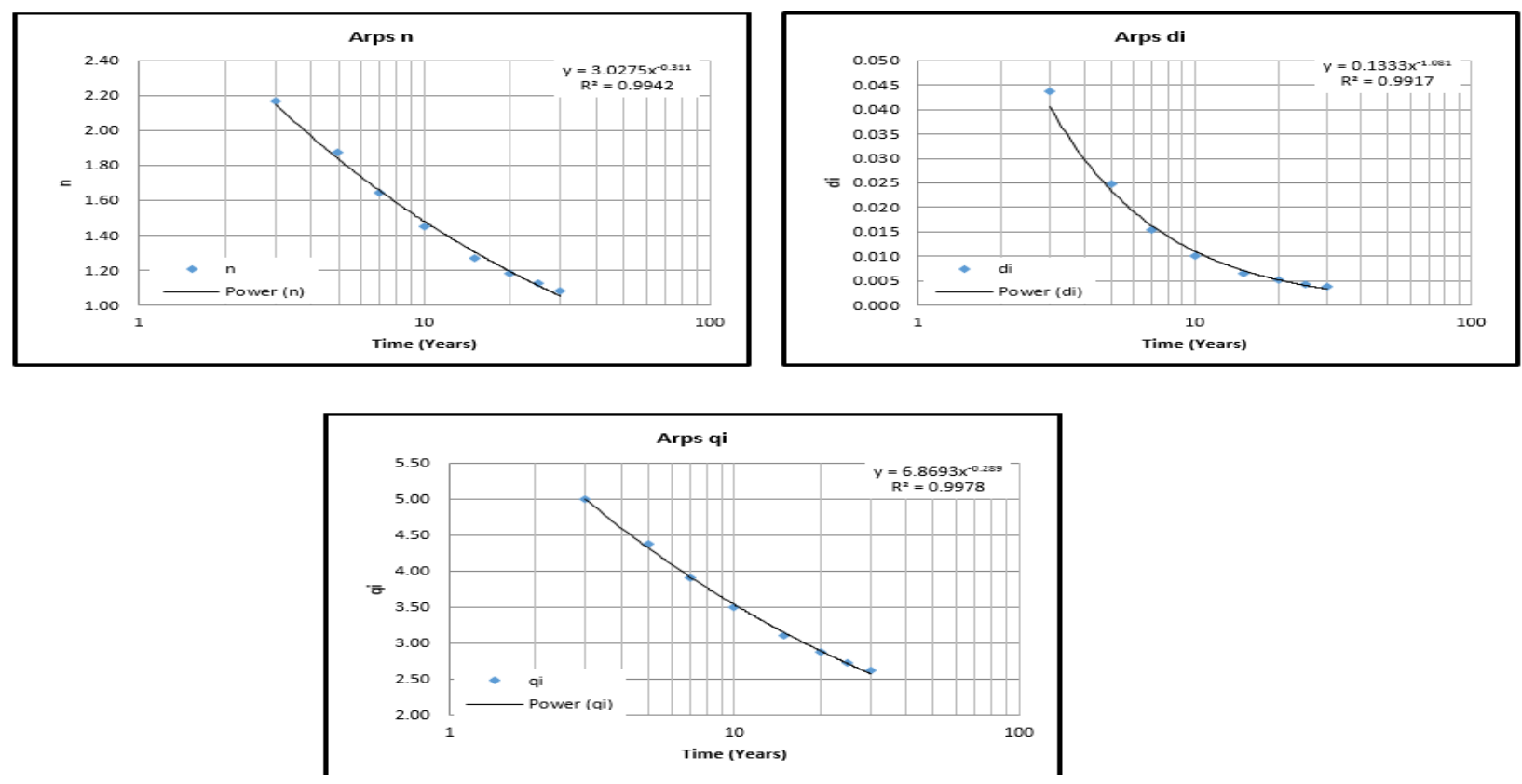

Figure D-3: 7 Stages - Arps Constants Correlations (300ft.) 
Table D-4: 7 Stages (400 ft.) - Arps

\begin{tabular}{|c|c|c|c|c|}
\hline \multicolumn{5}{|c|}{ 7 Fractures (400 ft.)- Arps } \\
\hline Years & $n$ & di & qi & $R^{2}$ \\
\hline 3 & 2.1317 & 0.0349 & 5.7257 & 0.9930 \\
\hline 5 & 1.8148 & 0.0203 & 5.0730 & 0.9910 \\
\hline 7 & 1.6213 & 0.0143 & 4.6758 & 0.9913 \\
\hline 10 & 1.4605 & 0.0105 & 4.3258 & 0.9913 \\
\hline 15 & 1.3394 & 0.0080 & 4.0284 & 0.9891 \\
\hline 20 & 1.2832 & 0.0070 & 3.8694 & 0.9865 \\
\hline 25 & 1.2501 & 0.0063 & 3.7674 & 0.9842 \\
\hline 30 & 1.2278 & 0.0060 & 3.6982 & 0.9825 \\
\hline
\end{tabular}

Table D-5: 7 Stages (400 ft.) - PLE

\begin{tabular}{|c|c|c|c|c|c|}
\hline \multicolumn{7}{|c|}{ 7 Fractures (400 ft.)- PLE } \\
\hline Years & $\boldsymbol{D}_{\infty}$ & $\boldsymbol{n}$ & $\boldsymbol{q}_{\boldsymbol{i}}$ & $\boldsymbol{D}_{\mathbf{1}}$ & $\boldsymbol{R}^{\mathbf{2}}$ \\
\hline 2 & -0.00076 & 0.35784 & 7.58525 & 0.09139 & 0.99843 \\
\hline 3 & -0.00035 & 0.33202 & 7.59484 & 0.09181 & 0.99790 \\
\hline 4 & -0.00019 & 0.31973 & 7.59416 & 0.09210 & 0.99785 \\
\hline 5 & -0.00014 & 0.31482 & 7.61079 & 0.09241 & 0.99796 \\
\hline 7 & -0.00012 & 0.31342 & 7.59811 & 0.09232 & 0.99823 \\
\hline 10 & -0.00015 & 0.31760 & 7.59367 & 0.09189 & 0.99841 \\
\hline 15 & -0.00017 & 0.31946 & 7.58652 & 0.09175 & 0.99855 \\
\hline 20 & -0.00017 & 0.31946 & 7.58652 & 0.09175 & 0.99865 \\
\hline 25 & -0.00015 & 0.31653 & 7.58643 & 0.09213 & 0.99862 \\
\hline 30 & -0.00014 & 0.31314 & 7.58639 & 0.09259 & 0.99848 \\
\hline
\end{tabular}

Table D-6: 7 Stages (400 ft.) - Duong

\begin{tabular}{|c|c|c|c|c|c|}
\hline \multicolumn{7}{|c|}{ 7 Fractures (400 ft.)-Duong } \\
\hline Years & $\boldsymbol{a}$ & $\boldsymbol{m}$ & $\boldsymbol{q}_{\mathbf{1}}$ & $\boldsymbol{q}_{\infty}$ & $\boldsymbol{R}^{2}$ \\
\hline 2 & 0.8075 & 0.9904 & 11.5016 & -3.2483 & 0.9996 \\
\hline 3 & 0.8082 & 0.9959 & 10.5101 & -2.4452 & 0.9997 \\
\hline 4 & 0.8104 & 1.0023 & 9.7481 & -1.8054 & 0.9997 \\
\hline 5 & 0.8165 & 1.0099 & 9.1861 & -1.3209 & 0.9996 \\
\hline 7 & 0.8498 & 1.0281 & 8.3380 & -0.7414 & 0.9990 \\
\hline 10 & 0.9226 & 1.0540 & 7.4454 & -0.3634 & 0.9979 \\
\hline 15 & 1.0356 & 1.0835 & 6.4180 & -0.1491 & 0.9967 \\
\hline 20 & 1.1255 & 1.1022 & 5.6940 & -0.0714 & 0.9964 \\
\hline 25 & 1.1985 & 1.1149 & 5.1320 & -0.0364 & 0.9966 \\
\hline 30 & 1.2611 & 1.1245 & 4.6720 & -0.0185 & 0.9968 \\
\hline
\end{tabular}



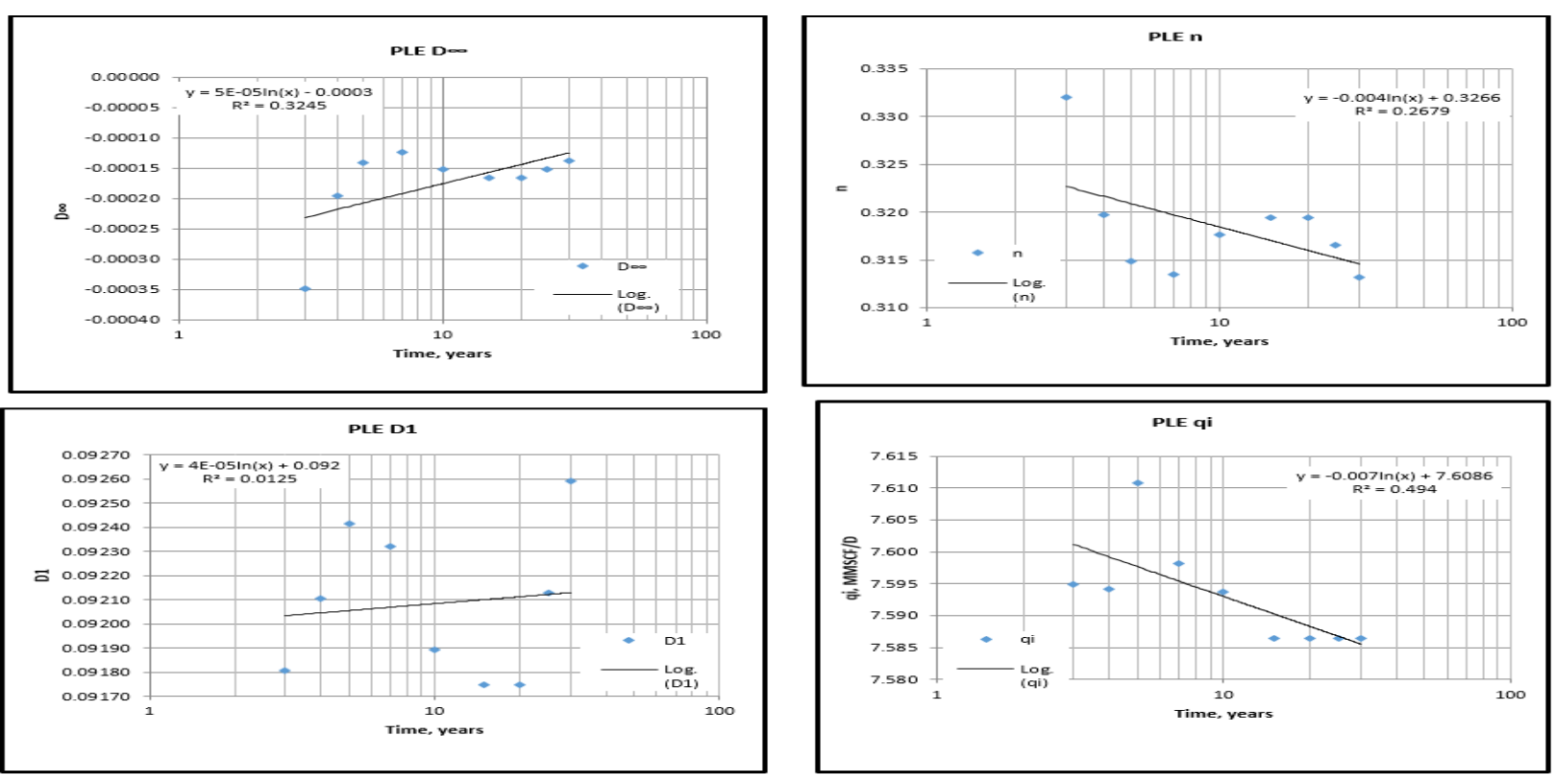

Figure D-4: 7 Stages - PLE Constants Correlations (400ft.)
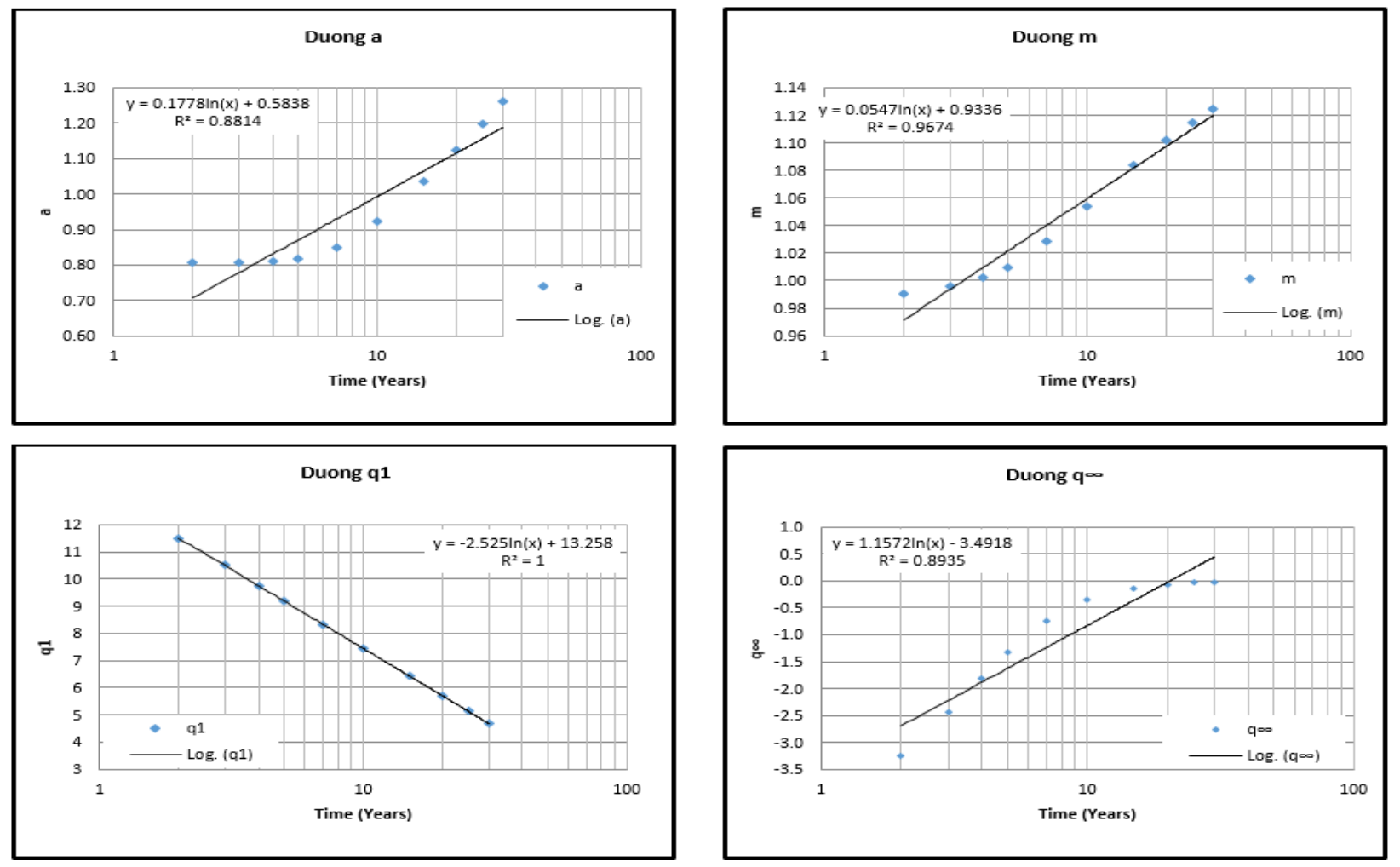

Figure D-5: 7 Stages - Duong Constants Correlations (400ft.) 

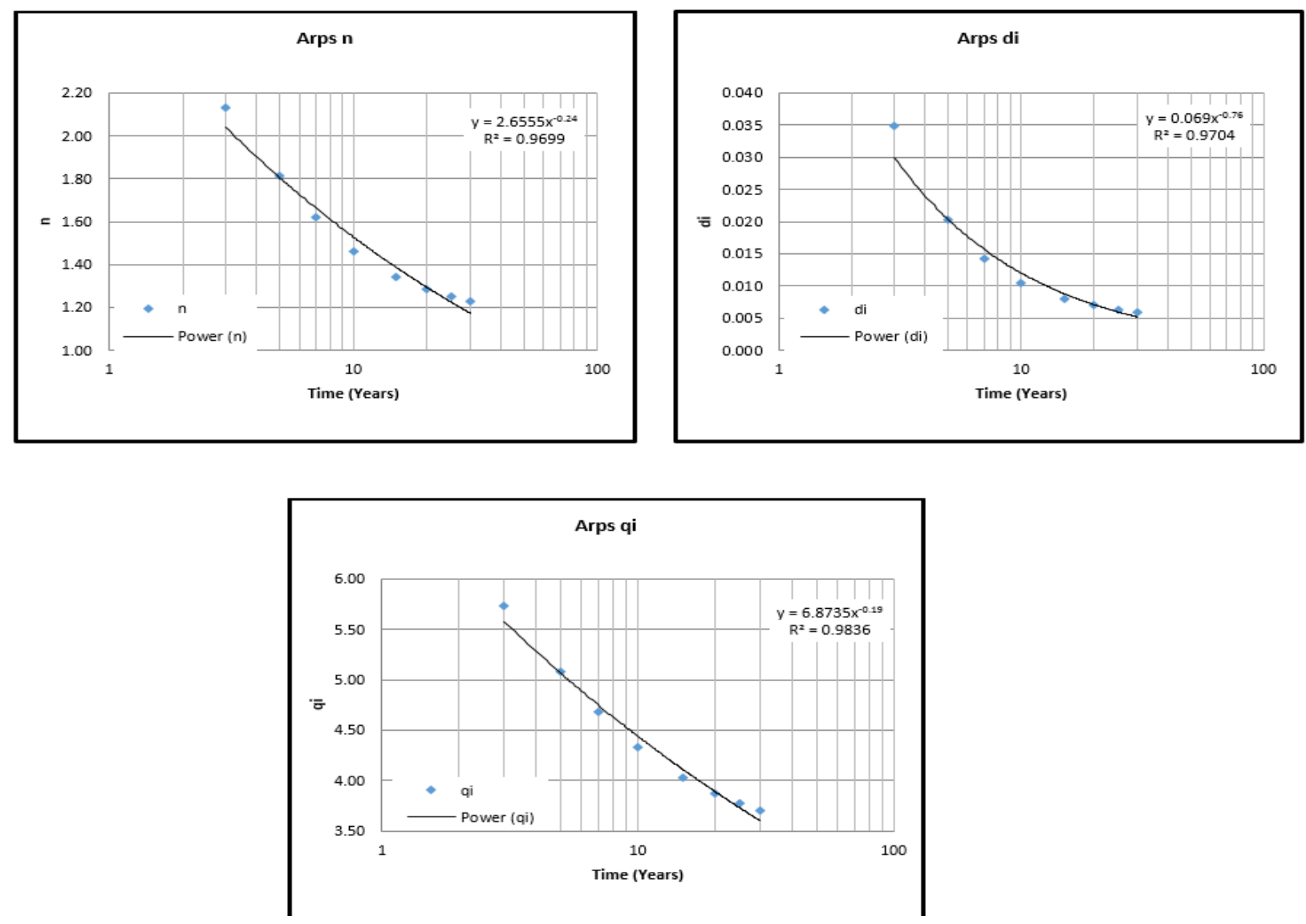

Figure D-6: 7 Stages - Arps Constants Correlations (400ft.) 
Table D-77: 7 Stages (500ft.) - Arps

\begin{tabular}{|c|c|c|c|c|}
\hline \multicolumn{5}{|c|}{ 7 Fractures (500 ft.)- Arps } \\
\hline Years & $n$ & $\boldsymbol{d}_{\boldsymbol{i}}$ & $\boldsymbol{q}_{\boldsymbol{i}}$ & $\boldsymbol{R}^{2}$ \\
\hline 3 & 2.1055 & 0.0259 & 6.0292 & 0.9950 \\
\hline 5 & 1.7534 & 0.0149 & 5.3604 & 0.9902 \\
\hline 7 & 1.5965 & 0.0118 & 5.0889 & 0.9885 \\
\hline 10 & 1.4858 & 0.0099 & 4.8918 & 0.9885 \\
\hline 15 & 1.4195 & 0.0089 & 4.7677 & 0.9895 \\
\hline 20 & 1.3931 & 0.0085 & 4.7153 & 0.9903 \\
\hline 25 & 1.3769 & 0.0083 & 4.6821 & 0.9909 \\
\hline 30 & 1.3647 & 0.0081 & 4.6569 & 0.9912 \\
\hline
\end{tabular}

Table D-8 : 7 Stages (500ft.) - PLE

\begin{tabular}{|c|c|c|c|c|c|}
\hline \multicolumn{7}{|c|}{ 7 Fractures (500 ft.)-PLE } \\
\hline Years & $D_{\infty}$ & $n$ & $\boldsymbol{q}_{\boldsymbol{i}}$ & $\boldsymbol{D}_{\mathbf{1}}$ & $\boldsymbol{R}^{\mathbf{2}}$ \\
\hline 2 & -0.000994 & 0.397486 & 7.754779 & 0.077834 & 0.998041 \\
\hline 3 & -0.000460 & 0.362622 & 7.766450 & 0.078970 & 0.997015 \\
\hline 4 & -0.000242 & 0.343609 & 7.778605 & 0.079894 & 0.996721 \\
\hline 5 & -0.000141 & 0.333277 & 7.788613 & 0.080465 & 0.996772 \\
\hline 7 & -0.000077 & 0.325283 & 7.801243 & 0.081104 & 0.997153 \\
\hline 10 & -0.000081 & 0.326343 & 7.806431 & 0.080959 & 0.997574 \\
\hline 15 & -0.000100 & 0.329156 & 7.806475 & 0.080775 & 0.997838 \\
\hline 20 & -0.000116 & 0.333219 & 7.788616 & 0.080075 & 0.997987 \\
\hline 25 & -0.000118 & 0.333970 & 7.788459 & 0.079975 & 0.998105 \\
\hline 30 & -0.000114 & 0.332869 & 7.789941 & 0.080144 & 0.998170 \\
\hline
\end{tabular}

Table D-9: 7 Stages (500ft.) - Duong

\begin{tabular}{|c|c|c|c|c|c|}
\hline \multicolumn{7}{|c|}{ 7 Fractures (500 ft.)- Duong } \\
\hline Years & $\boldsymbol{a}$ & $\boldsymbol{m}$ & $\boldsymbol{q}_{\mathbf{1}}$ & $\boldsymbol{q}_{\infty}$ & $\boldsymbol{R}^{\mathbf{2}}$ \\
\hline 2 & 0.808 & 0.989 & 12.151 & -3.519 & 0.970 \\
\hline 3 & 0.812 & 0.992 & 11.050 & -2.853 & 0.973 \\
\hline 4 & 0.850 & 1.011 & 9.802 & -1.851 & 0.994 \\
\hline 5 & 0.891 & 1.029 & 8.870 & -1.109 & 0.999 \\
\hline 7 & 0.940 & 1.044 & 8.021 & -0.776 & 0.999 \\
\hline 10 & 1.022 & 1.066 & 7.025 & -0.461 & 0.998 \\
\hline 15 & 1.117 & 1.089 & 6.175 & -0.247 & 0.997 \\
\hline 20 & 1.202 & 1.106 & 5.501 & -0.151 & 0.996 \\
\hline 25 & 1.261 & 1.122 & 5.074 & -0.061 & 0.988 \\
\hline 30 & 1.320 & 1.130 & 4.650 & -0.035 & 0.991 \\
\hline
\end{tabular}



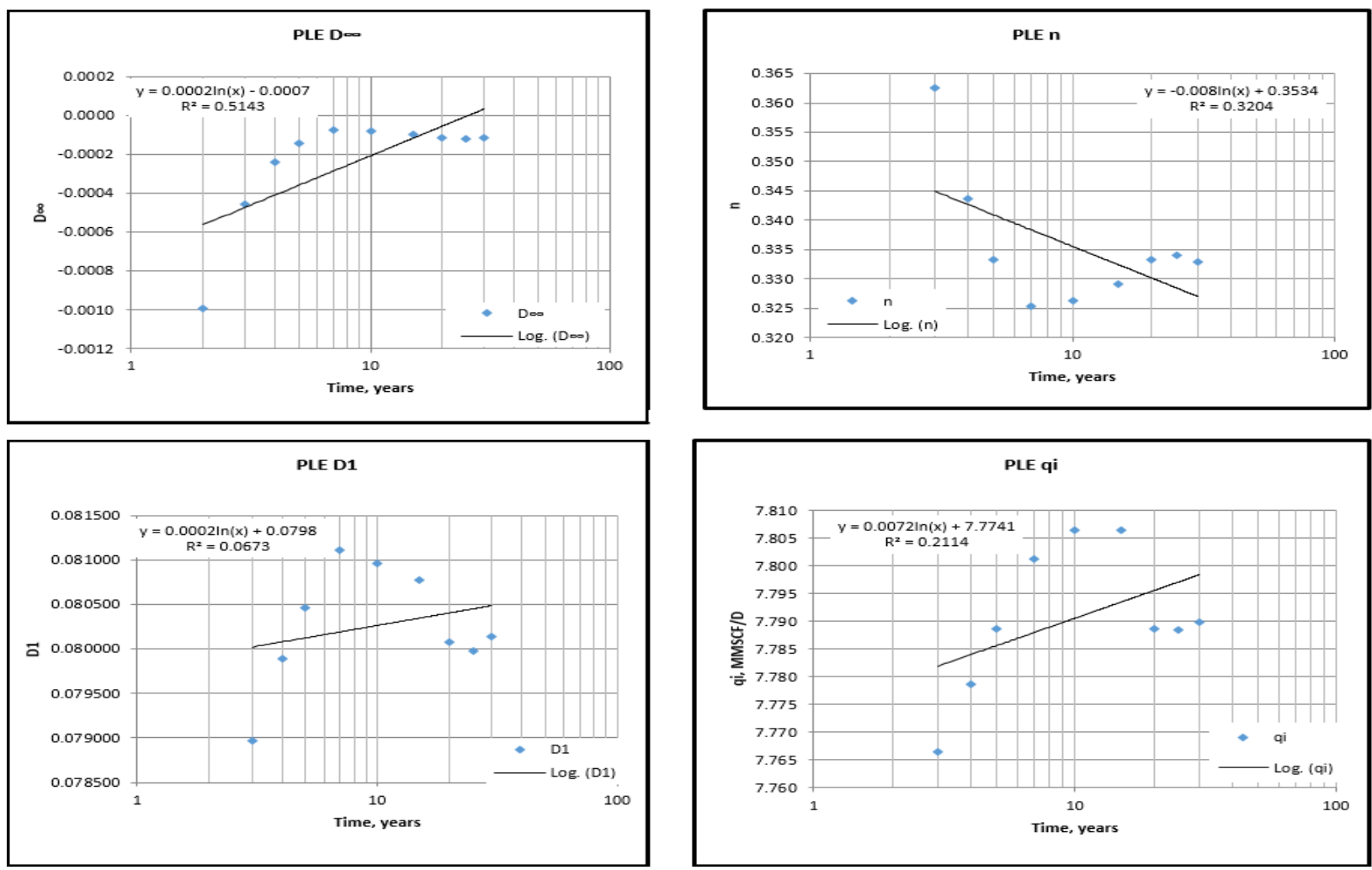

Figure D-7: 7 Stages - PLE Constants Correlations (500ft.)
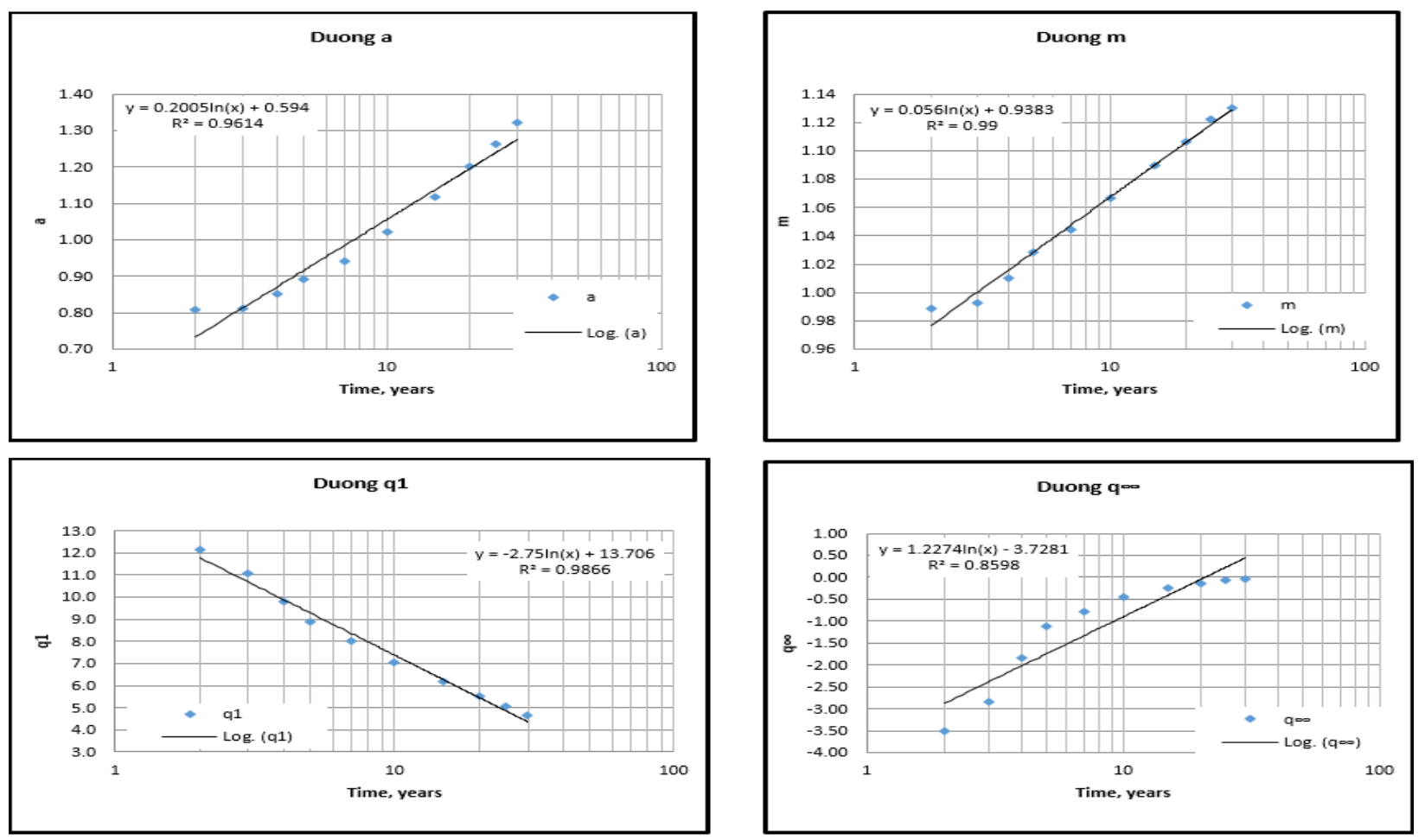

Figure D-8: 7 Stages - Duong Constants Correlations (500ft.) 

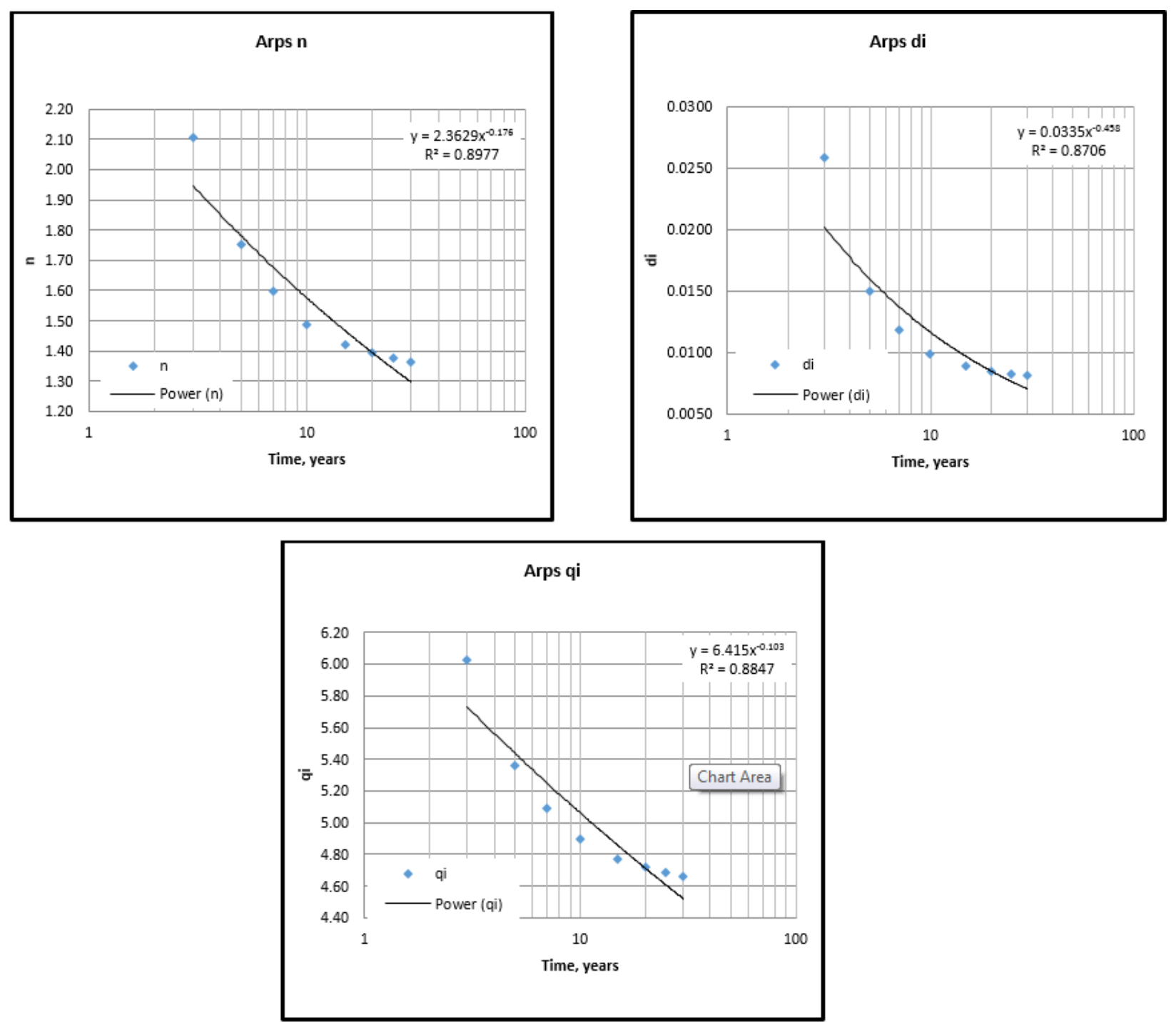

Figure D-9: 7 Stages - Arps Constants Correlations (500ft.) 
Table D-10: 7 Stages (600 ft.) - Arps

\begin{tabular}{|l|l|l|l|l|}
\hline \multicolumn{5}{|c|}{ 7 Fractures (600 ft.)-Arps } \\
\hline Years & $n$ & $d_{i}$ & $q_{i}$ & $R^{2}$ \\
\hline 3 & 2.0700 & 0.0181 & 6.0055 & 0.9963 \\
\hline 5 & 1.9707 & 0.0175 & 6.0129 & 0.9897 \\
\hline 7 & 1.8060 & 0.0142 & 5.7744 & 0.9860 \\
\hline 10 & 1.7032 & 0.0128 & 5.6735 & 0.9826 \\
\hline 15 & 1.6397 & 0.0124 & 5.6647 & 0.9792 \\
\hline 20 & 1.5905 & 0.0118 & 5.6180 & 0.9783 \\
\hline 25 & 1.5702 & 0.0117 & 5.6271 & 0.9770 \\
\hline 30 & 1.5601 & 0.0118 & 5.6488 & 0.9756 \\
\hline
\end{tabular}

Table D-11: 7 Stages (600 ft.) - PLE

\begin{tabular}{|c|c|c|c|c|c|}
\hline \multicolumn{7}{|c|}{ 7 Fractures (600 ft.)-PLE } \\
\hline Years & $D_{\infty}$ & $n$ & $\boldsymbol{q}_{\boldsymbol{i}}$ & $\boldsymbol{D}_{\mathbf{1}}$ & $\boldsymbol{R}^{\mathbf{2}}$ \\
\hline 2 & -0.001210 & 0.441118 & 7.605094 & 0.064286 & 0.998296 \\
\hline 3 & -0.000560 & 0.393394 & 7.653150 & 0.066939 & 0.997020 \\
\hline 4 & -0.000309 & 0.370971 & 7.652832 & 0.067932 & 0.996492 \\
\hline 5 & -0.000175 & 0.356099 & 7.657943 & 0.068790 & 0.996384 \\
\hline 7 & -0.000074 & 0.342357 & 7.675244 & 0.069826 & 0.996650 \\
\hline 10 & -0.000044 & 0.340433 & 7.617607 & 0.069180 & 0.997148 \\
\hline 15 & -0.000048 & 0.341435 & 7.616927 & 0.069063 & 0.997627 \\
\hline 20 & -0.000055 & 0.341618 & 7.658626 & 0.069477 & 0.997854 \\
\hline 25 & -0.000067 & 0.344964 & 7.659044 & 0.069041 & 0.997970 \\
\hline 30 & -0.000066 & 0.344877 & 7.622074 & 0.068830 & 0.998069 \\
\hline
\end{tabular}

Table D-12: 7 Stages (600 ft.) - Duong

\begin{tabular}{|c|c|c|c|c|c|}
\hline \multicolumn{7}{|c|}{ 7 Fractures (600 ft.)-Duong } \\
\hline Years & $\boldsymbol{a}$ & $\boldsymbol{m}$ & $\boldsymbol{q}_{\mathbf{1}}$ & $\boldsymbol{q}_{\infty}$ & $\boldsymbol{R}^{2}$ \\
\hline 2 & 0.812 & 0.983 & 14.655 & -5.219 & 0.973 \\
\hline 3 & 0.831 & 1.000 & 12.084 & -2.788 & 0.998 \\
\hline 4 & 0.855 & 1.008 & 11.062 & -2.294 & 0.999 \\
\hline 5 & 0.881 & 1.018 & 10.065 & -1.720 & 0.999 \\
\hline 7 & 0.922 & 1.032 & 9.015 & -1.219 & 0.999 \\
\hline 10 & 0.980 & 1.049 & 8.022 & -0.798 & 0.999 \\
\hline 15 & 1.081 & 1.074 & 7.015 & -0.575 & 0.978 \\
\hline 20 & 1.221 & 1.111 & 6.060 & -0.213 & 0.973 \\
\hline 25 & 1.330 & 1.121 & 5.205 & -0.211 & 0.991 \\
\hline 30 & 1.410 & 1.130 & 4.709 & -0.217 & 0.981 \\
\hline
\end{tabular}



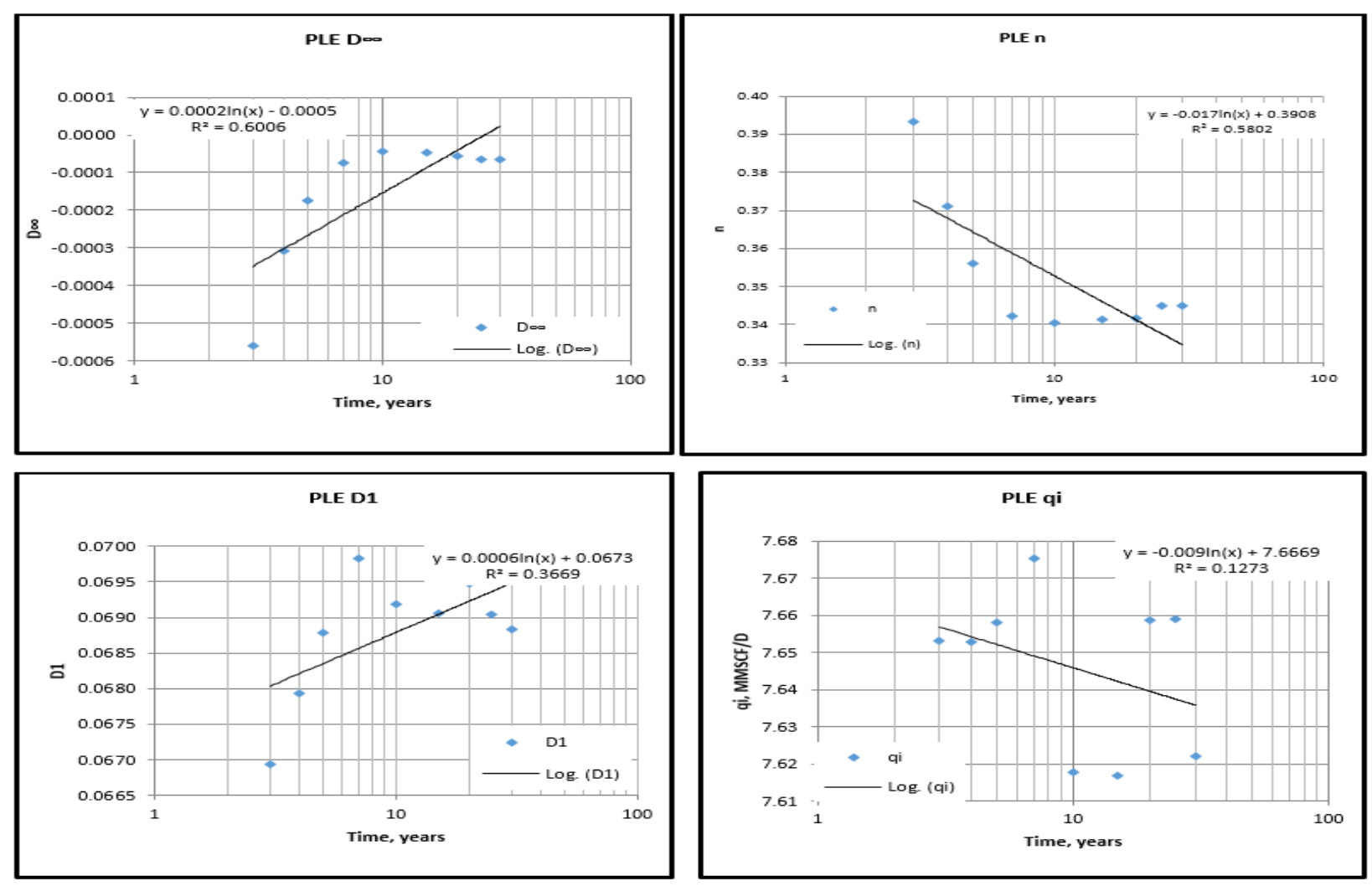

Figure D-10: 7 Stages - PLE Constants Correlations (600ft.)
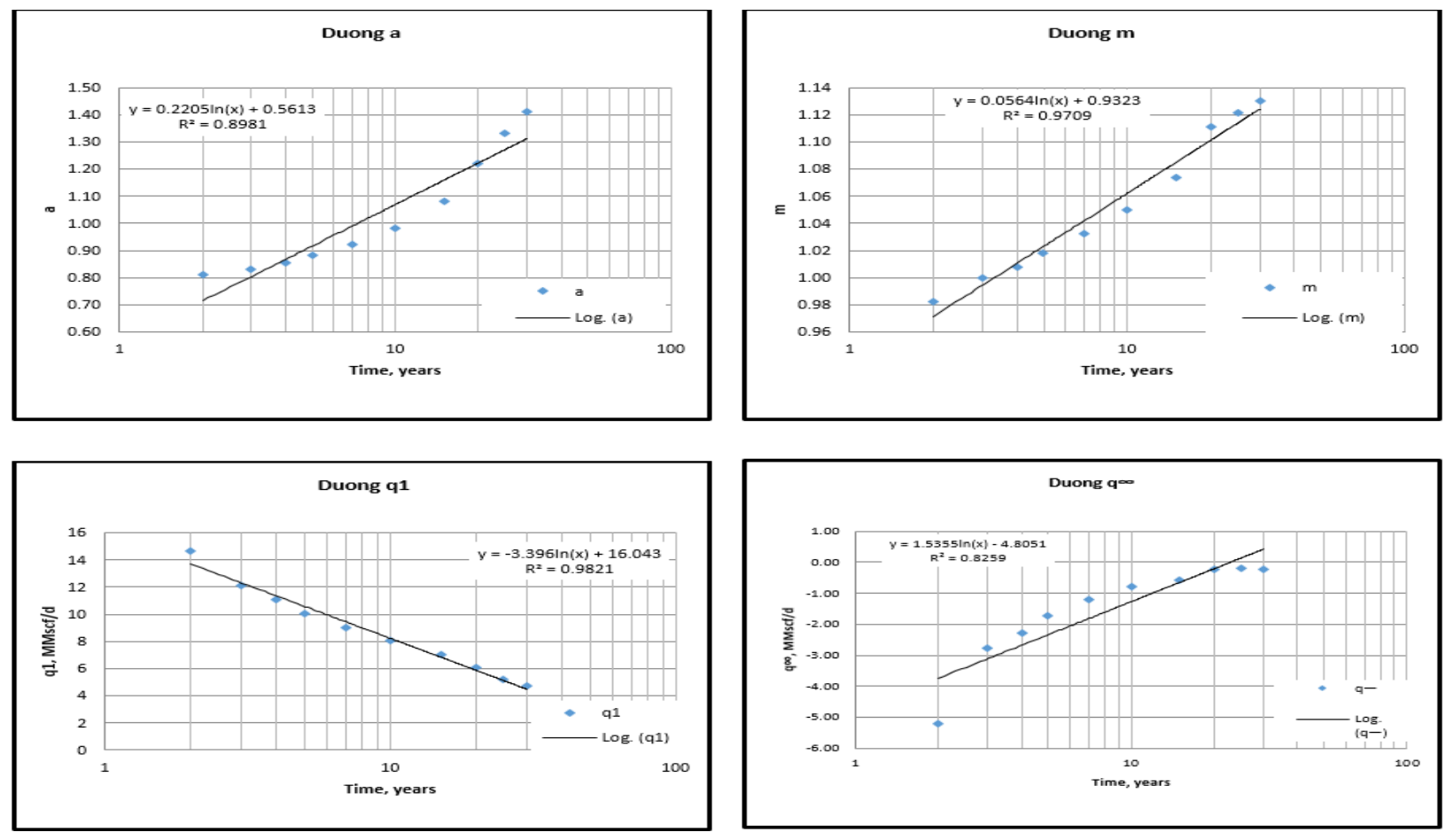

Figure D-11: 7 Stages - Duong Constants Correlations (600ft.) 

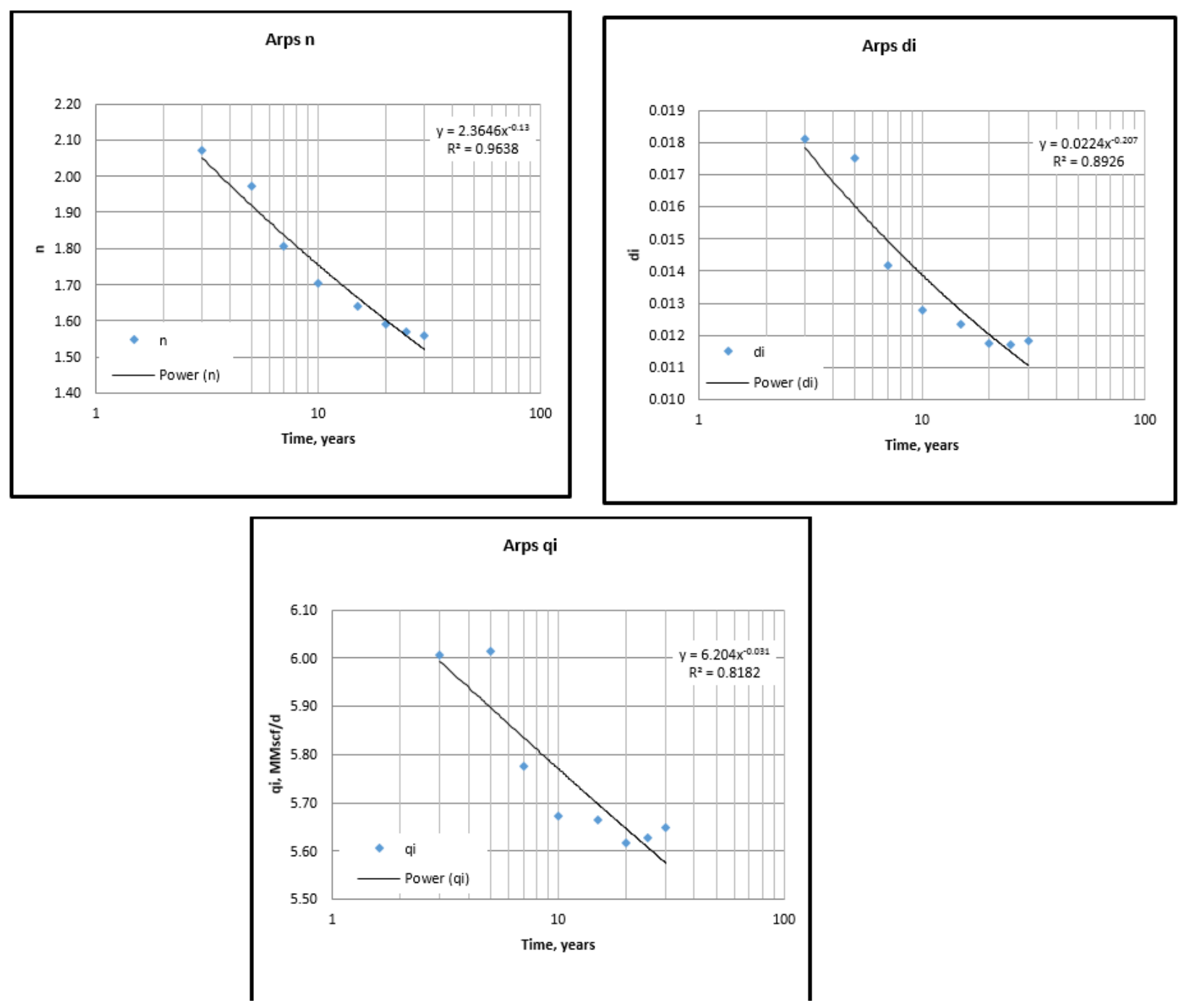

Figure D-12: 7 Stages - Arps Constants Correlations (600ft.) 
Table D-13: 7 Stages (700 ft.)- Arps

\begin{tabular}{|c|c|c|c|c|}
\hline \multicolumn{5}{|c|}{ 7 Fractures (700 ft.)-Arps } \\
\hline Years & $n$ & $\boldsymbol{d}_{\boldsymbol{i}}$ & $\boldsymbol{q}_{\boldsymbol{i}}$ & $\boldsymbol{R}^{\mathbf{2}}$ \\
\hline 3 & 1.9283 & 0.0118 & 5.7419 & 0.9930 \\
\hline 5 & 1.8589 & 0.0112 & 5.7172 & 0.9919 \\
\hline 7 & 1.8021 & 0.0106 & 5.6887 & 0.9877 \\
\hline 10 & 1.7065 & 0.0100 & 5.6524 & 0.9821 \\
\hline 15 & 1.6045 & 0.0093 & 5.5957 & 0.9790 \\
\hline 20 & 1.5561 & 0.0091 & 5.5946 & 0.9730 \\
\hline 25 & 1.5124 & 0.0087 & 5.5612 & 0.9712 \\
\hline 30 & 1.4896 & 0.0086 & 5.5577 & 0.9696 \\
\hline
\end{tabular}

Table D-14: 7 Stages (700 ft.)- PLE

\begin{tabular}{|c|c|c|c|c|c|}
\hline \multicolumn{7}{|c|}{ 7 Fractures (700 ft.)-PLE } \\
\hline Years & $\boldsymbol{D}_{\infty}$ & $\boldsymbol{n}$ & $\boldsymbol{q}_{\boldsymbol{i}}$ & $\boldsymbol{D}_{\mathbf{1}}$ & $\boldsymbol{R}^{\mathbf{2}}$ \\
\hline 2 & -0.001320 & 0.479142 & 7.308632 & 0.052714 & 0.998766 \\
\hline 3 & -0.000661 & 0.433825 & 7.247723 & 0.053863 & 0.997449 \\
\hline 4 & -0.000376 & 0.404813 & 7.266815 & 0.055553 & 0.996813 \\
\hline 5 & -0.000215 & 0.379885 & 7.380440 & 0.058351 & 0.996635 \\
\hline 7 & -0.000078 & 0.360111 & 7.398304 & 0.059706 & 0.996692 \\
\hline 10 & -0.000014 & 0.348555 & 7.411853 & 0.060621 & 0.997109 \\
\hline 15 & 0.000009 & 0.343733 & 7.421391 & 0.061089 & 0.997659 \\
\hline 20 & 0.000010 & 0.342378 & 7.411506 & 0.061315 & 0.997954 \\
\hline 25 & 0.000003 & 0.345321 & 7.411598 & 0.060867 & 0.998108 \\
\hline 30 & -0.000006 & 0.348579 & 7.411705 & 0.060474 & 0.998183 \\
\hline
\end{tabular}

Table D-15: 7 Stages (700 ft.)- Duong

\begin{tabular}{|c|c|c|c|c|c|}
\hline \multicolumn{7}{|c|}{ 7 Fractures (700 ft.)-Duong } \\
\hline Years & $\boldsymbol{a}$ & $\boldsymbol{m}$ & $\boldsymbol{q}_{1}$ & $\boldsymbol{q}_{\infty}$ & $\boldsymbol{R}^{2}$ \\
\hline 2 & 0.889 & 0.996 & 16.505 & -7.556 & 0.997 \\
\hline 3 & 0.839 & 0.995 & 14.451 & -4.487 & 0.974 \\
\hline 4 & 0.846 & 1.000 & 12.541 & -3.305 & 0.977 \\
\hline 5 & 0.876 & 1.010 & 11.207 & -2.570 & 0.981 \\
\hline 7 & 0.905 & 1.019 & 10.000 & -1.939 & 0.999 \\
\hline 10 & 0.944 & 1.032 & 9.054 & -1.371 & 0.999 \\
\hline 15 & 1.033 & 1.050 & 8.051 & -1.099 & 0.974 \\
\hline 20 & 1.151 & 1.100 & 7.051 & -0.124 & 0.981 \\
\hline 25 & 1.222 & 1.110 & 6.014 & -0.123 & 0.975 \\
\hline 30 & 1.346 & 1.129 & 4.890 & -0.102 & 0.953 \\
\hline
\end{tabular}



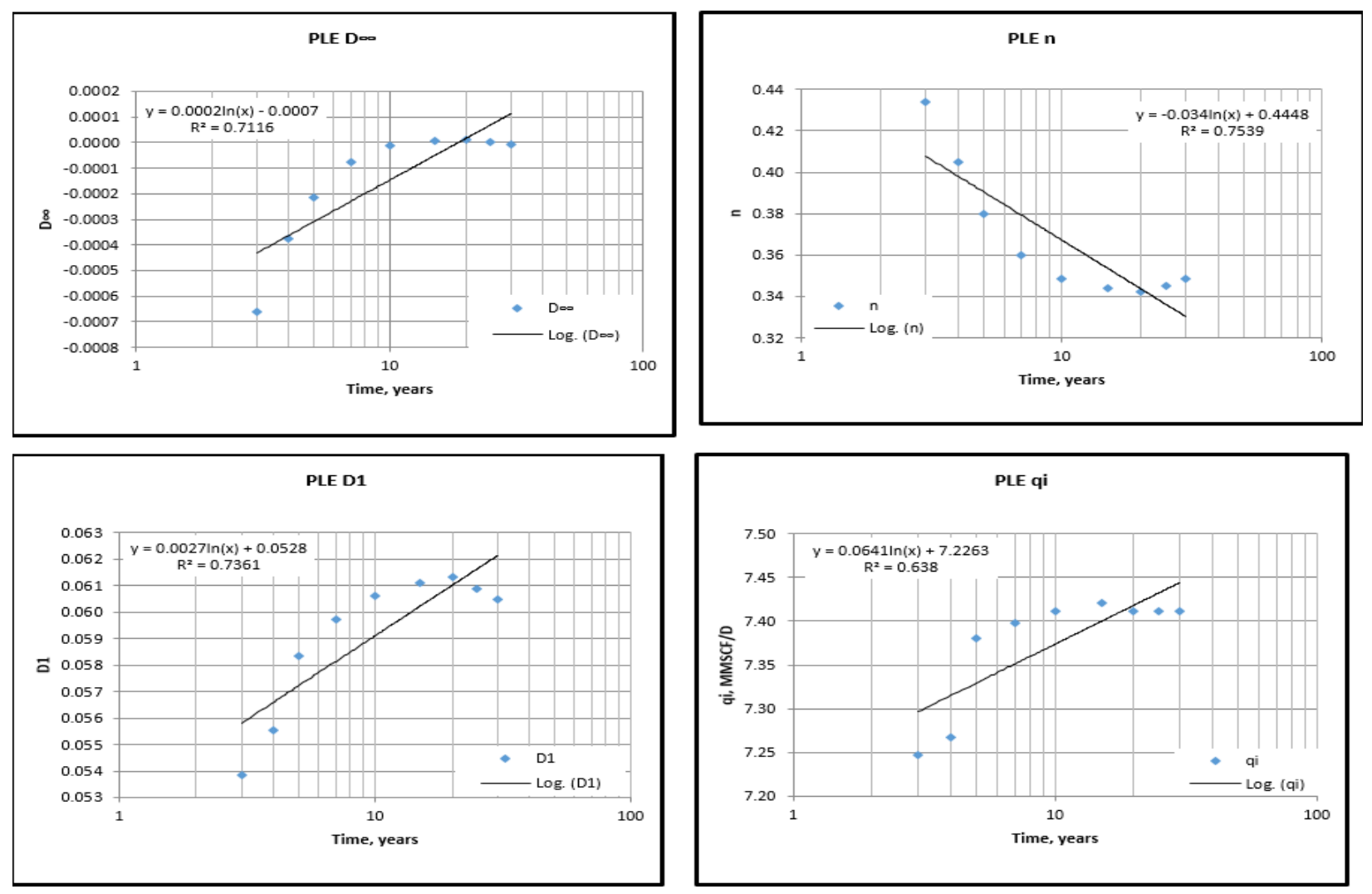

Figure D-13: 7 Stages - PLE Constants Correlations (700ft.)
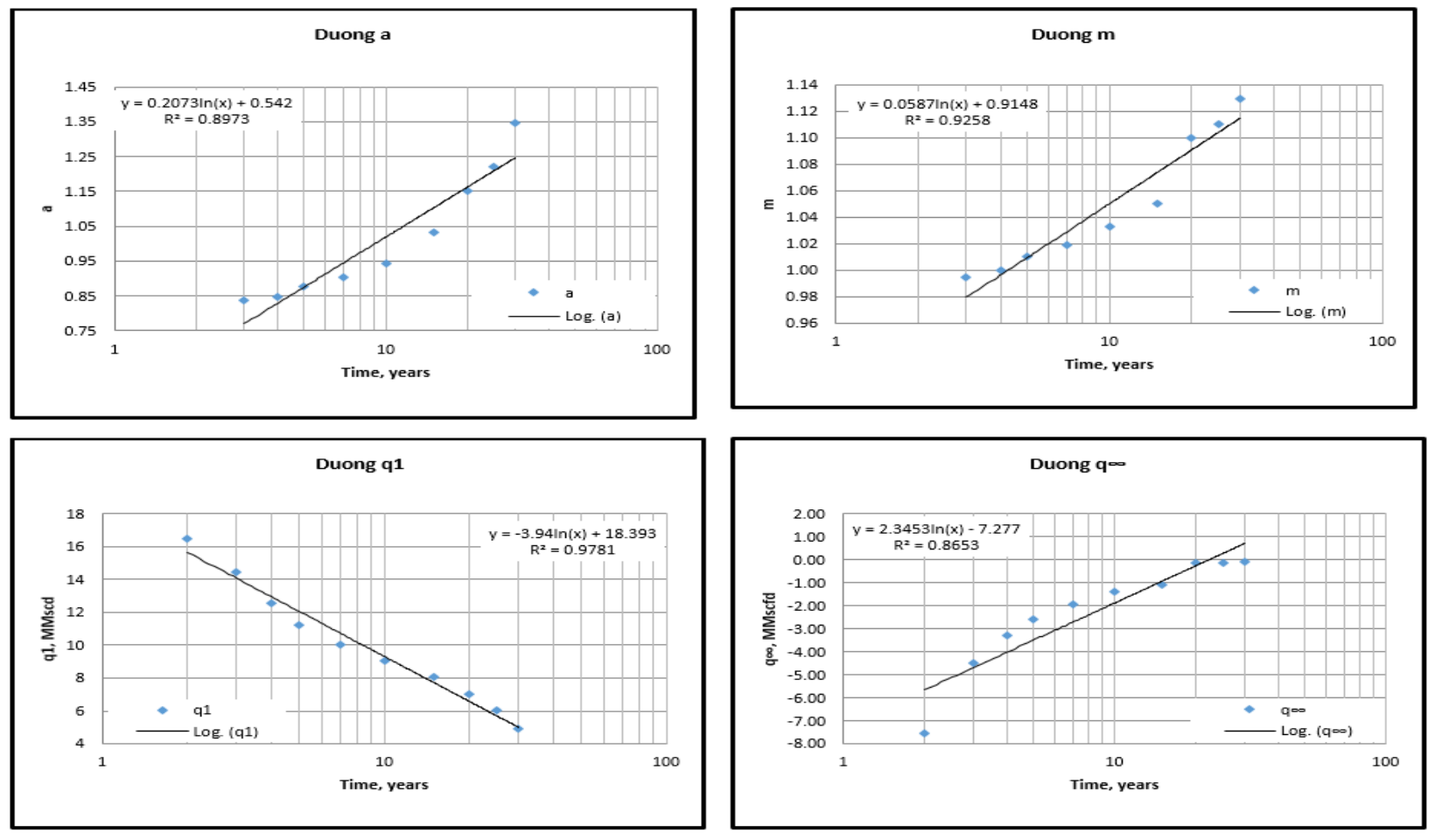

Figure D-14: 7 Stages - Duong Constants Correlations (700ft.) 

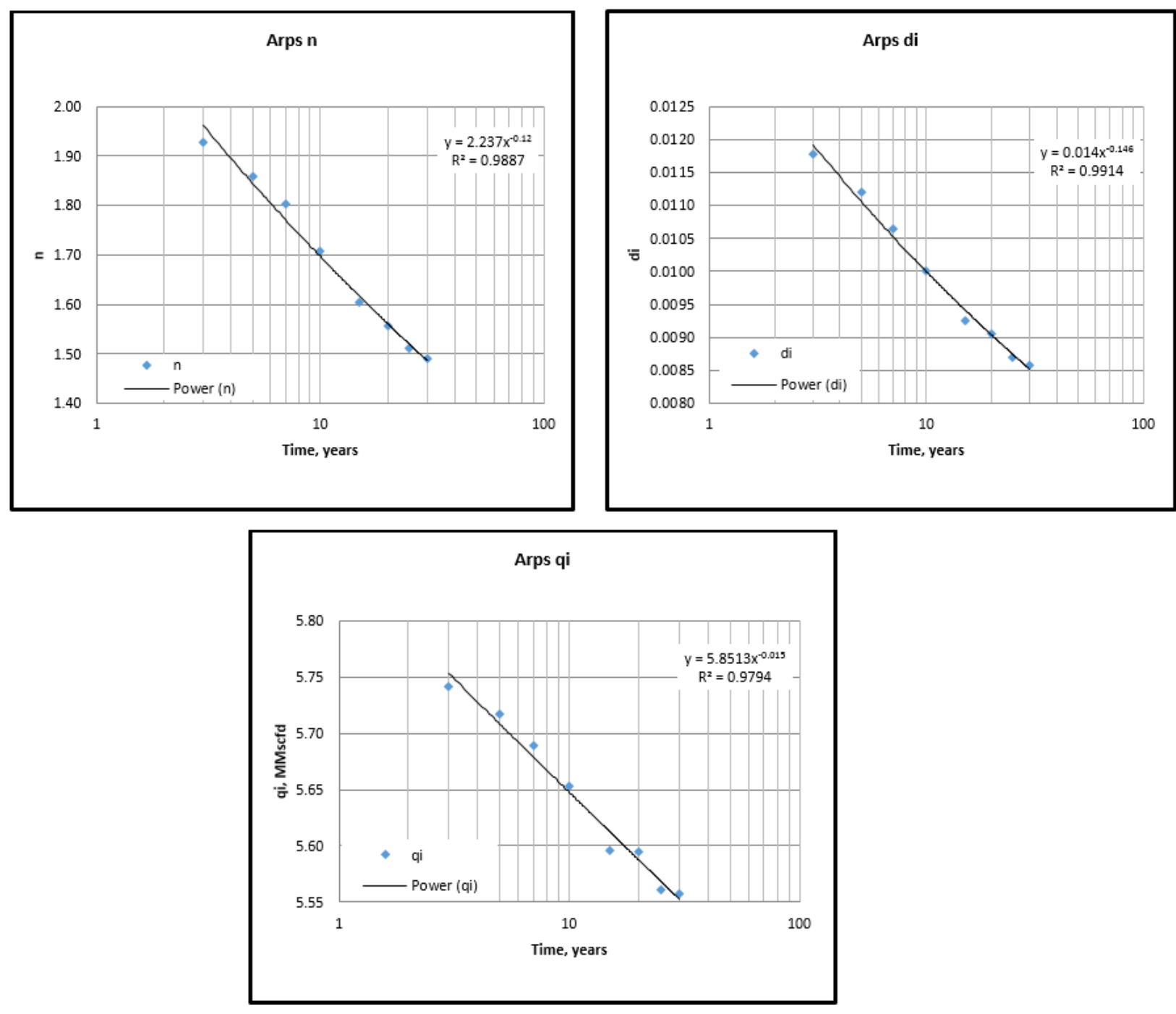

Figure D-15: 7 Stages - Arps Constants Correlations (700ft.) 
Table D-16: 7 Stages (0.0008 md) - Arps

\begin{tabular}{|c|c|c|c|c|}
\hline \multicolumn{5}{|c|}{ 7 Fractures $(0.0008 \mathrm{md}$ )-Arps } \\
\hline Years & $n$ & $\boldsymbol{d}_{i}$ & $\boldsymbol{q}_{\boldsymbol{i}}$ & $\boldsymbol{R}^{2}$ \\
\hline 3 & 2.377 & 0.076 & 5.240 & 0.999 \\
\hline 5 & 2.299 & 0.061 & 4.945 & 0.999 \\
\hline 7 & 2.195 & 0.046 & 4.605 & 0.996 \\
\hline 10 & 2.056 & 0.033 & 4.228 & 0.991 \\
\hline 15 & 1.895 & 0.023 & 3.854 & 0.986 \\
\hline 20 & 1.796 & 0.018 & 3.643 & 0.983 \\
\hline 25 & 1.733 & 0.016 & 3.511 & 0.982 \\
\hline 30 & 1.693 & 0.014 & 3.430 & 0.981 \\
\hline
\end{tabular}

Table D-17: 7 Stages (0.0008 md) - PLE

\begin{tabular}{|c|c|c|c|c|c|}
\hline \multicolumn{7}{|c|}{ 7 Fractures $(0.0008 \mathrm{md})$ - PLE } \\
\hline Years & $\boldsymbol{D}_{\infty}$ & $\boldsymbol{n}$ & $\boldsymbol{q}_{\boldsymbol{i}}$ & $\boldsymbol{D}_{\mathbf{1}}$ & $\boldsymbol{R}^{\mathbf{2}}$ \\
\hline 2 & -0.0017599 & 0.4041707 & 5.8630480 & 0.0951762 & 0.9987945 \\
\hline 3 & -0.0010798 & 0.3673193 & 5.8842922 & 0.0970671 & 0.9972487 \\
\hline 4 & -0.0007545 & 0.3450723 & 5.8879911 & 0.0981314 & 0.9957509 \\
\hline 5 & -0.0005413 & 0.3269072 & 5.8970867 & 0.0992108 & 0.9944219 \\
\hline 7 & -0.0003101 & 0.3024638 & 5.9140685 & 0.1007829 & 0.9925840 \\
\hline 10 & -0.0001595 & 0.2823156 & 5.9306075 & 0.1020690 & 0.9913864 \\
\hline 15 & -0.0000733 & 0.2677478 & 5.9434058 & 0.1030337 & 0.9913360 \\
\hline 20 & -0.0000473 & 0.2622412 & 5.9431991 & 0.1034574 & 0.9918924 \\
\hline 25 & -0.0000386 & 0.2594209 & 5.9552019 & 0.1039534 & 0.9924197 \\
\hline 30 & -0.0000389 & 0.2603138 & 5.9476042 & 0.1036524 & 0.9927936 \\
\hline
\end{tabular}

Table D-18: 7 Stages (0.0008 md) - Duong

\begin{tabular}{|c|c|c|c|c|c|}
\hline \multicolumn{7}{|c|}{ 7 Fractures $(\mathbf{0 . 0 0 0 8} \mathbf{m d}$ )-Duong } \\
\hline Years & $\boldsymbol{a}$ & $\boldsymbol{m}$ & $\boldsymbol{q}_{1}$ & $\boldsymbol{q}_{\infty}$ & $\boldsymbol{R}^{2}$ \\
\hline 2 & 0.814 & 1.052 & 6.500 & 0.110 & 0.9941 \\
\hline 3 & 0.876 & 1.070 & 6.000 & 0.138 & 0.9990 \\
\hline 4 & 0.965 & 1.088 & 5.300 & 0.154 & 0.9989 \\
\hline 5 & 0.983 & 1.087 & 5.100 & 0.115 & 0.9982 \\
\hline 7 & 1.034 & 1.090 & 4.605 & 0.057 & 0.9962 \\
\hline 10 & 1.067 & 1.089 & 4.228 & -0.013 & 0.9940 \\
\hline 15 & 1.105 & 1.090 & 3.854 & -0.064 & 0.9928 \\
\hline 20 & 1.157 & 1.096 & 3.500 & -0.064 & 0.9923 \\
\hline 25 & 1.237 & 1.108 & 3.060 & -0.048 & 0.9912 \\
\hline 30 & 1.270 & 1.113 & 2.900 & -0.042 & 0.9911 \\
\hline
\end{tabular}



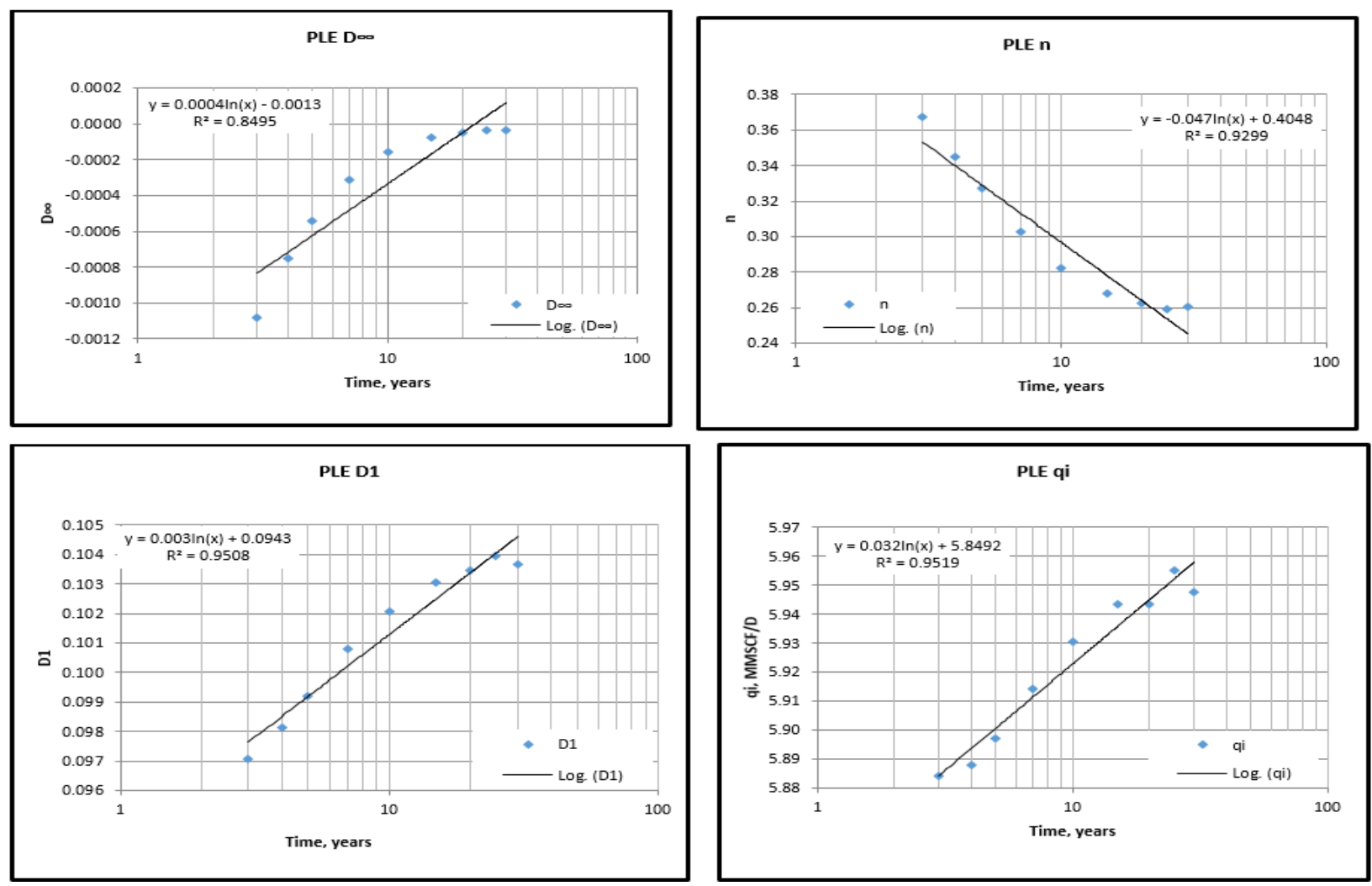

Figure D-16: 7 Stages - PLE Constants Correlations (0.0008 m-D)
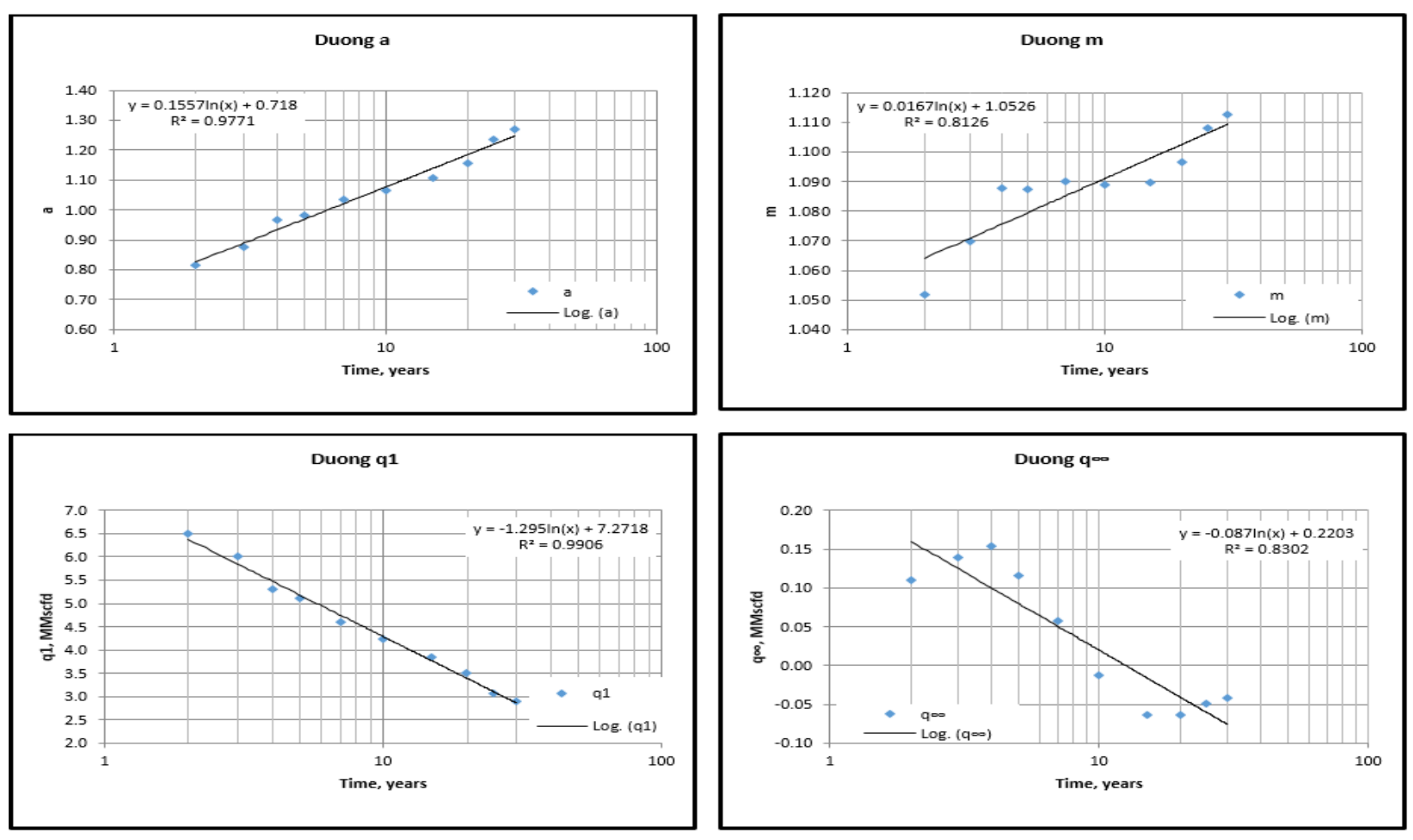

Figure D-17: 7 Stages - Duong Constants Correlations (0.0008 m-D) 

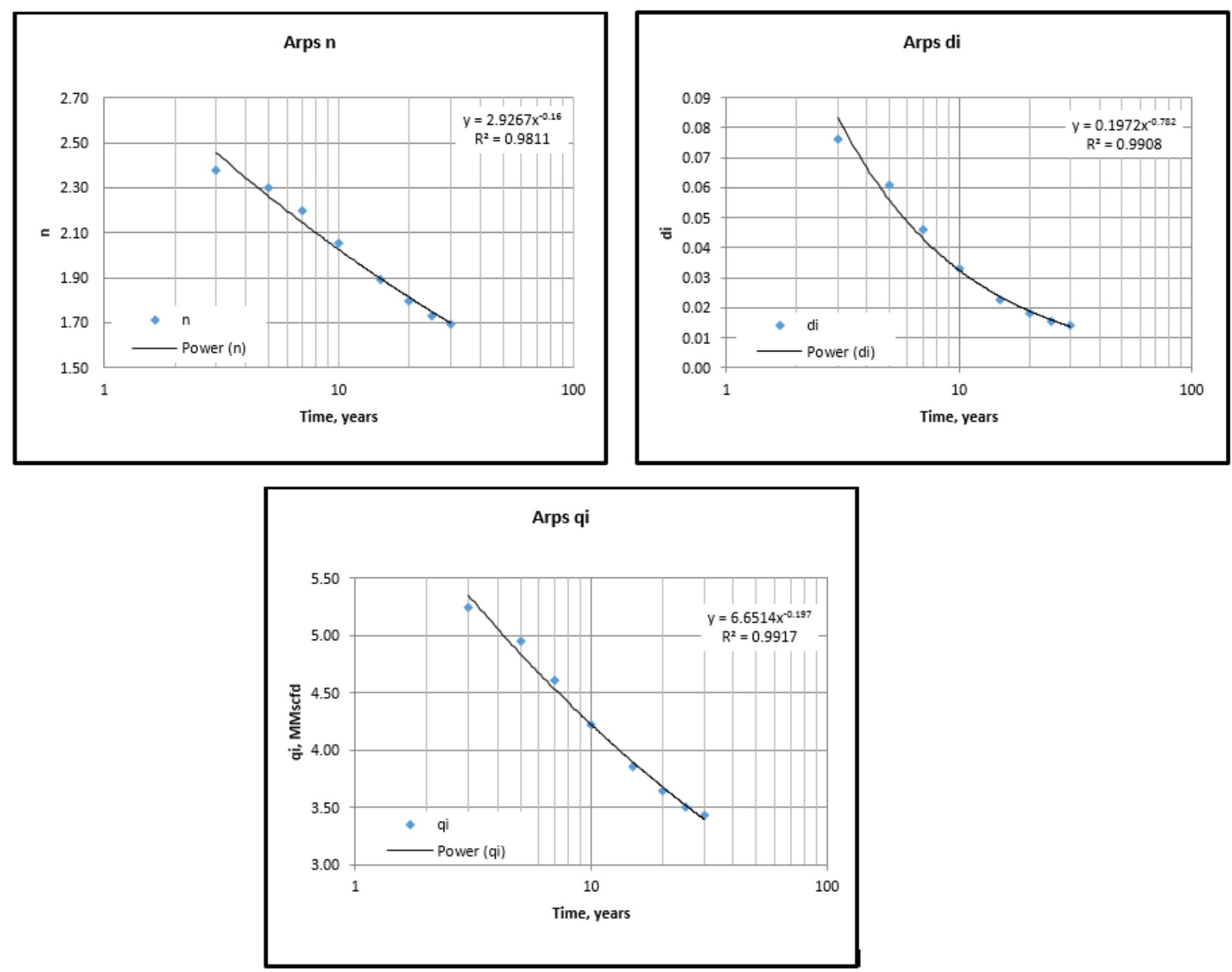

Figure D-18: 7 Stages - Arps Constants Correlations (0.0008 m-D) 
Table D-19: 7 Stages (0.001 md) - Arps

\begin{tabular}{|c|c|c|c|c|}
\hline \multicolumn{5}{|c|}{ 7 Fractures (0.001 $\mathbf{m d}$ )-Arps } \\
\hline Years & $n$ & $d i$ & $q i$ & $\boldsymbol{R}^{2}$ \\
\hline 3 & 2.2579 & 0.0607 & 5.4598 & 0.9907 \\
\hline 5 & 2.1343 & 0.0431 & 5.0242 & 0.9915 \\
\hline 7 & 1.9900 & 0.0302 & 4.6638 & 0.9904 \\
\hline 10 & 1.9027 & 0.0231 & 4.3044 & 0.9877 \\
\hline 15 & 1.7674 & 0.0166 & 3.9711 & 0.9842 \\
\hline 20 & 1.6800 & 0.0138 & 3.7939 & 0.9829 \\
\hline 25 & 1.6292 & 0.0124 & 3.6905 & 0.9828 \\
\hline 30 & 1.5980 & 0.0116 & 3.6266 & 0.9829 \\
\hline
\end{tabular}

Table D-20: 7 Stages (0.001 md) - PLE

\begin{tabular}{|c|c|c|c|c|c|}
\hline \multicolumn{7}{|c|}{ 7 Fractures $(0.001 \mathrm{md})$ - PLE } \\
\hline Years & $\boldsymbol{D}_{\infty}$ & $\boldsymbol{n}$ & $\boldsymbol{q}_{\boldsymbol{i}}$ & \multicolumn{1}{c|}{$\boldsymbol{D}_{\boldsymbol{1}}$} & \multicolumn{1}{c|}{$\boldsymbol{R}^{\mathbf{2}}$} \\
\hline 2 & -0.0016583 & 0.4049781 & 6.3078249 & 0.0913779 & 0.9985639 \\
\hline 3 & -0.0009749 & 0.3674505 & 6.3117454 & 0.0929166 & 0.9968762 \\
\hline 4 & -0.0006447 & 0.3433544 & 6.3281281 & 0.0942091 & 0.9954338 \\
\hline 5 & -0.0004511 & 0.3262473 & 6.3384936 & 0.0951939 & 0.9943143 \\
\hline 7 & -0.0002410 & 0.3035609 & 6.3505370 & 0.0964695 & 0.9930946 \\
\hline 10 & -0.0001180 & 0.2870777 & 6.3502003 & 0.0973312 & 0.9927224 \\
\hline 15 & -0.0000583 & 0.2760628 & 6.3829838 & 0.0985132 & 0.9932919 \\
\hline 20 & -0.0000461 & 0.2737594 & 6.3855497 & 0.0986443 & 0.9939106 \\
\hline 25 & -0.0000461 & 0.2739570 & 6.3851936 & 0.0985882 & 0.9943316 \\
\hline 30 & -0.0000471 & 0.2739408 & 6.3900587 & 0.0987206 & 0.9946006 \\
\hline
\end{tabular}

Table D-21: 7 Stages (0.001 md) - Duong

\begin{tabular}{|c|c|c|c|c|c|}
\hline \multicolumn{7}{|c|}{ 7 Fractures $(0.001 \mathrm{md})$ - Duong } \\
\hline Years & $\boldsymbol{a}$ & $\boldsymbol{m}$ & $\boldsymbol{q 1}$ & $\boldsymbol{q}^{\infty}$ & $\boldsymbol{R}^{2}$ \\
\hline 2 & 0.812 & 1.046 & 6.800 & 0.200 & 0.951 \\
\hline 3 & 0.876 & 1.062 & 6.500 & 0.185 & 0.959 \\
\hline 4 & 0.929 & 1.071 & 6.000 & 0.131 & 0.978 \\
\hline 5 & 0.982 & 1.079 & 5.500 & 0.098 & 0.979 \\
\hline 7 & 1.025 & 1.080 & 5.050 & -0.021 & 0.994 \\
\hline 10 & 1.136 & 1.096 & 4.160 & -0.061 & 0.994 \\
\hline 15 & 1.180 & 1.099 & 3.800 & -0.089 & 0.993 \\
\hline 20 & 1.230 & 1.107 & 3.700 & -0.132 & 0.984 \\
\hline 25 & 1.268 & 1.113 & 3.600 & -0.154 & 0.957 \\
\hline 30 & 1.299 & 1.117 & 3.550 & -0.154 & 0.943 \\
\hline
\end{tabular}



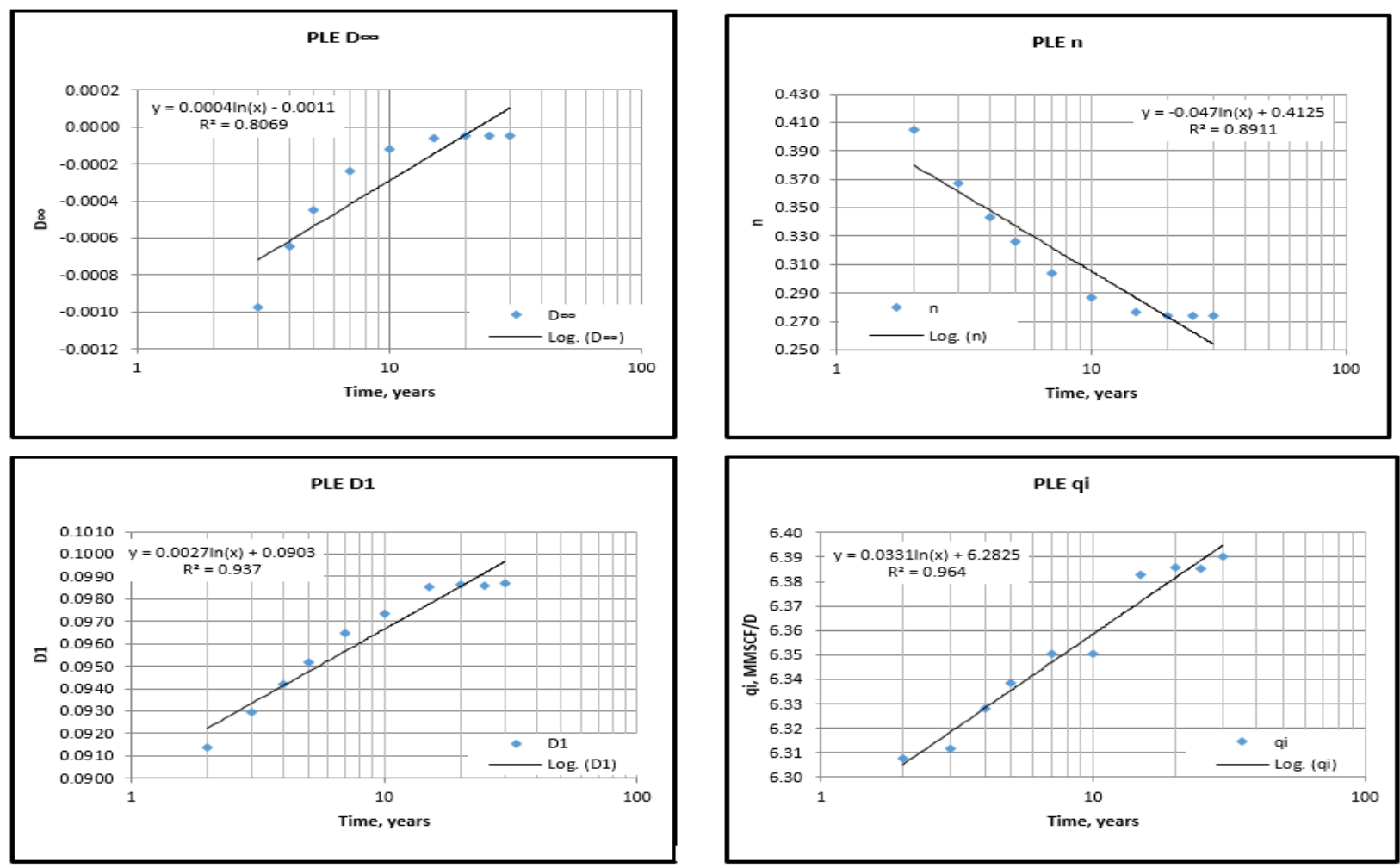

Figure D-19: 7 Stages - PLE Constants Correlations (0.001 m-D)
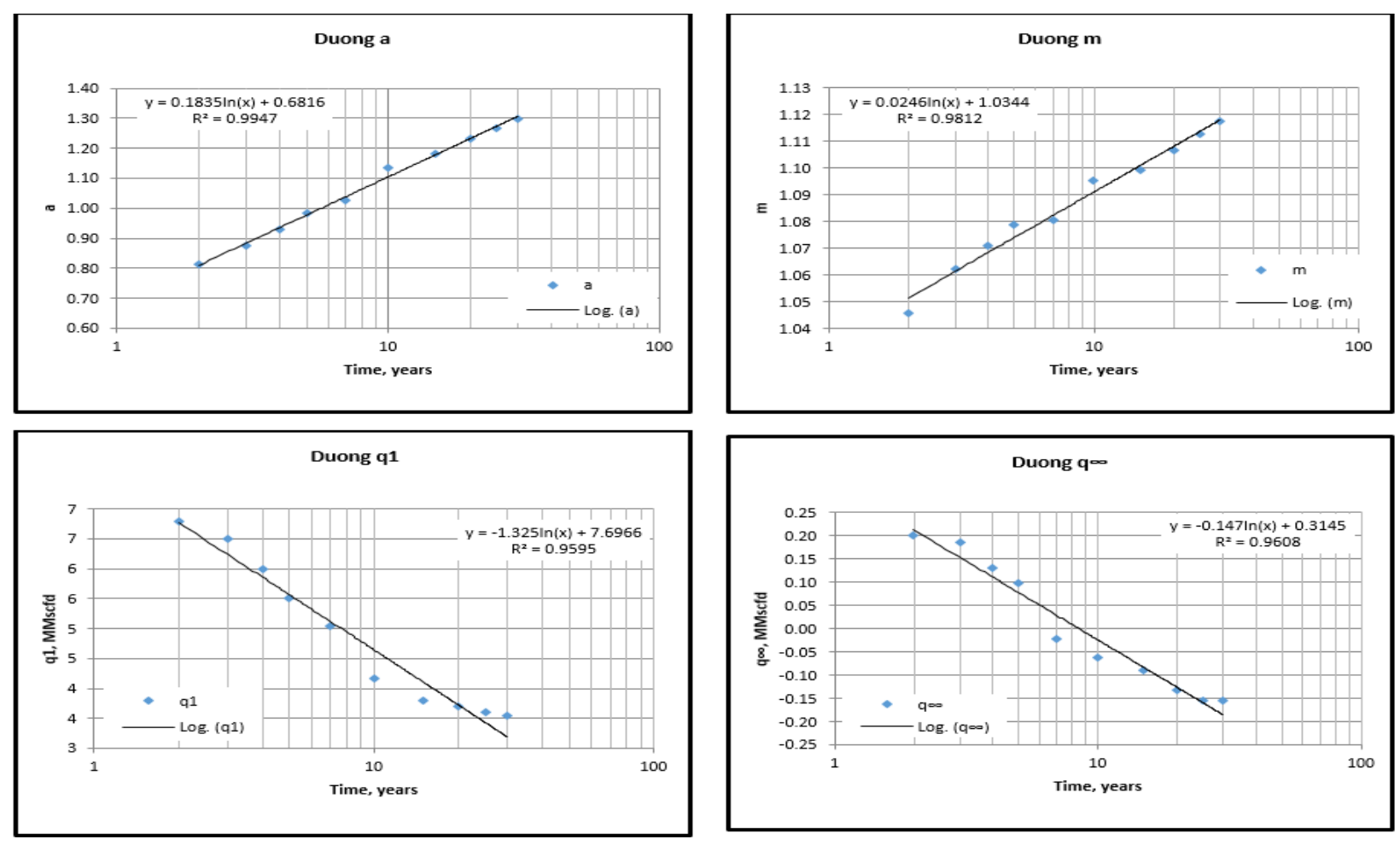

Figure D-20: 7 Stages - Duong Constants Correlations (0.001 m-D) 

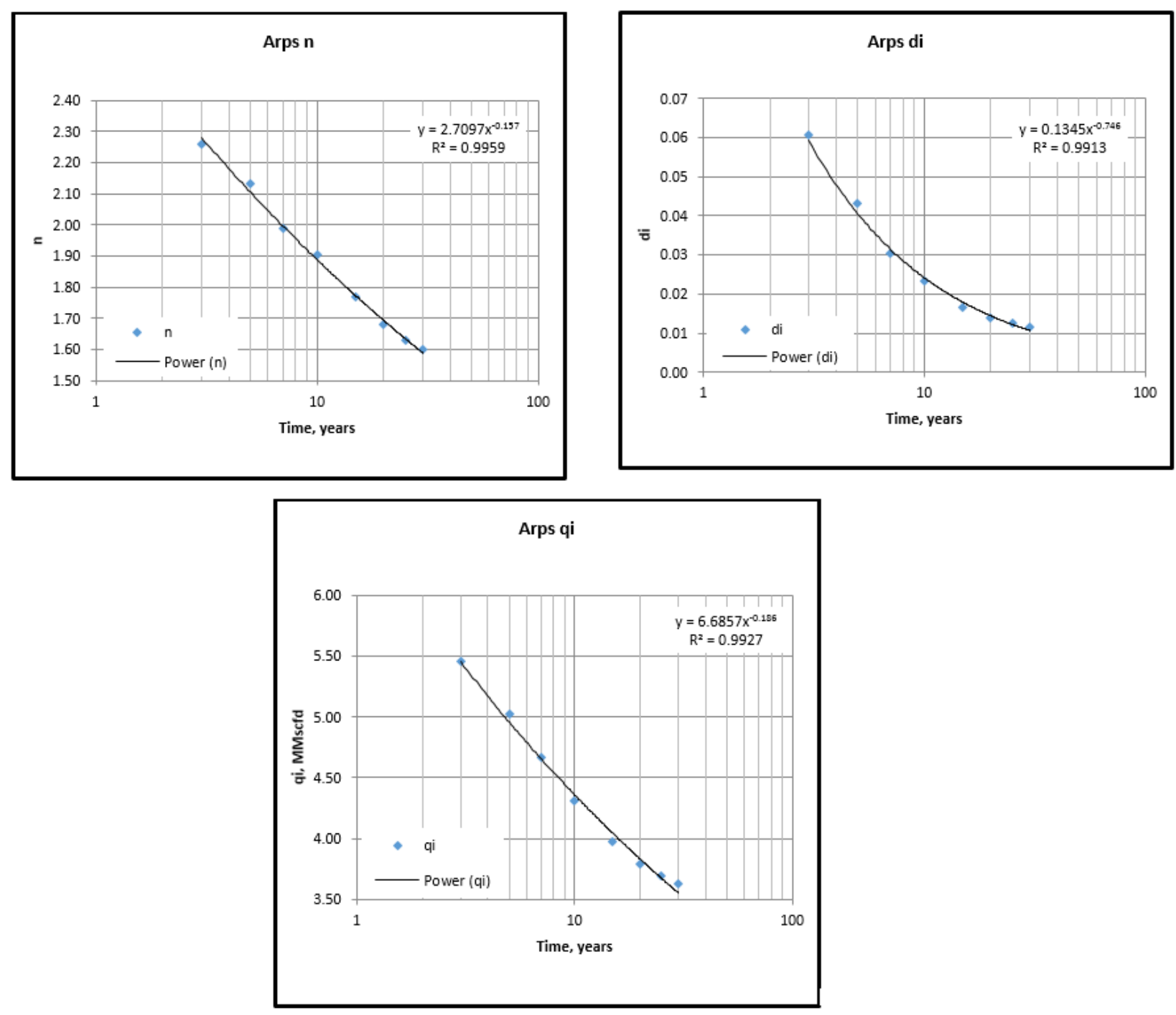

Figure D-21: 7 Stages - Arps Constants Correlations (0.001 m-D) 
Table D-22: 7 Stages (0.002 md) - Arps

\begin{tabular}{|c|c|c|c|c|}
\hline \multicolumn{5}{|c|}{7 Fractures (0.002 md) - Arps } \\
\hline Years & $n$ & di & qi & $R^{2}$ \\
\hline 3 & 2.0494 & 0.0231 & 5.8789 & 0.9951 \\
\hline 5 & 1.7531 & 0.0149 & 5.3601 & 0.9902 \\
\hline 7 & 1.5962 & 0.0118 & 5.0870 & 0.9885 \\
\hline 10 & 1.4851 & 0.0099 & 4.8906 & 0.9885 \\
\hline 15 & 1.4190 & 0.0089 & 4.7662 & 0.9895 \\
\hline 20 & 1.3929 & 0.0085 & 4.7148 & 0.9903 \\
\hline 25 & 1.3769 & 0.0083 & 4.6826 & 0.9909 \\
\hline 30 & 1.3646 & 0.0081 & 4.6567 & 0.9912 \\
\hline
\end{tabular}

Table D-23: 7 Stages (0.002 md) - PLE

\begin{tabular}{|c|c|c|c|c|c|}
\hline \multicolumn{7}{|c|}{ 7 Fractures $(\mathbf{0 . 0 0 2} \mathbf{~ m d )}$ PLE } \\
\hline Years & $\boldsymbol{D}_{\infty}$ & $\boldsymbol{n}$ & $\boldsymbol{q}_{\boldsymbol{i}}$ & $\boldsymbol{D}_{\mathbf{1}}$ & $\boldsymbol{R}^{\mathbf{2}}$ \\
\hline 2 & -0.000995 & 0.397612 & 7.753027 & 0.077808 & 0.998041 \\
\hline 3 & -0.000459 & 0.362615 & 7.765285 & 0.078960 & 0.997015 \\
\hline 4 & -0.000242 & 0.343634 & 7.777479 & 0.079884 & 0.996721 \\
\hline 5 & -0.000141 & 0.333309 & 7.787229 & 0.080450 & 0.996773 \\
\hline 7 & -0.000077 & 0.325932 & 7.791395 & 0.080849 & 0.997153 \\
\hline 10 & -0.000078 & 0.326346 & 7.774932 & 0.080706 & 0.997577 \\
\hline 15 & -0.000109 & 0.332615 & 7.770000 & 0.079955 & 0.997830 \\
\hline 20 & -0.000113 & 0.335953 & 7.756657 & 0.079415 & 0.997657 \\
\hline 25 & -0.000120 & 0.335184 & 7.737065 & 0.079441 & 0.998099 \\
\hline 30 & -0.000111 & 0.331992 & 7.789662 & 0.080253 & 0.998176 \\
\hline
\end{tabular}

Table D-24: 7 Stages (0.002 md) - Duong

\begin{tabular}{|c|c|c|c|c|c|}
\hline \multicolumn{7}{|c|}{ 7 Fractures $(\mathbf{0 . 0 0 2} \mathbf{m d}$ )-Duong } \\
\hline Years & $\boldsymbol{a}$ & $\boldsymbol{m}$ & $\boldsymbol{q 1}$ & $\boldsymbol{q}^{\infty}$ & $\boldsymbol{R}^{\mathbf{2}}$ \\
\hline 2 & 0.894 & 1.040 & 9.300 & -0.877 & 0.960 \\
\hline 3 & 0.952 & 1.051 & 8.000 & -0.791 & 0.941 \\
\hline 4 & 1.043 & 1.070 & 6.750 & -0.584 & 0.960 \\
\hline 5 & 1.090 & 1.078 & 6.250 & -0.421 & 0.998 \\
\hline 7 & 1.213 & 1.100 & 5.150 & -0.294 & 0.997 \\
\hline 10 & 1.261 & 1.109 & 4.800 & -0.233 & 0.997 \\
\hline 15 & 1.390 & 1.130 & 4.000 & -0.012 & 0.957 \\
\hline 20 & 1.432 & 1.137 & 3.800 & 0.026 & 0.951 \\
\hline 25 & 1.456 & 1.142 & 3.700 & 0.010 & 0.973 \\
\hline 30 & 1.465 & 1.143 & 3.670 & 0.008 & 0.978 \\
\hline
\end{tabular}



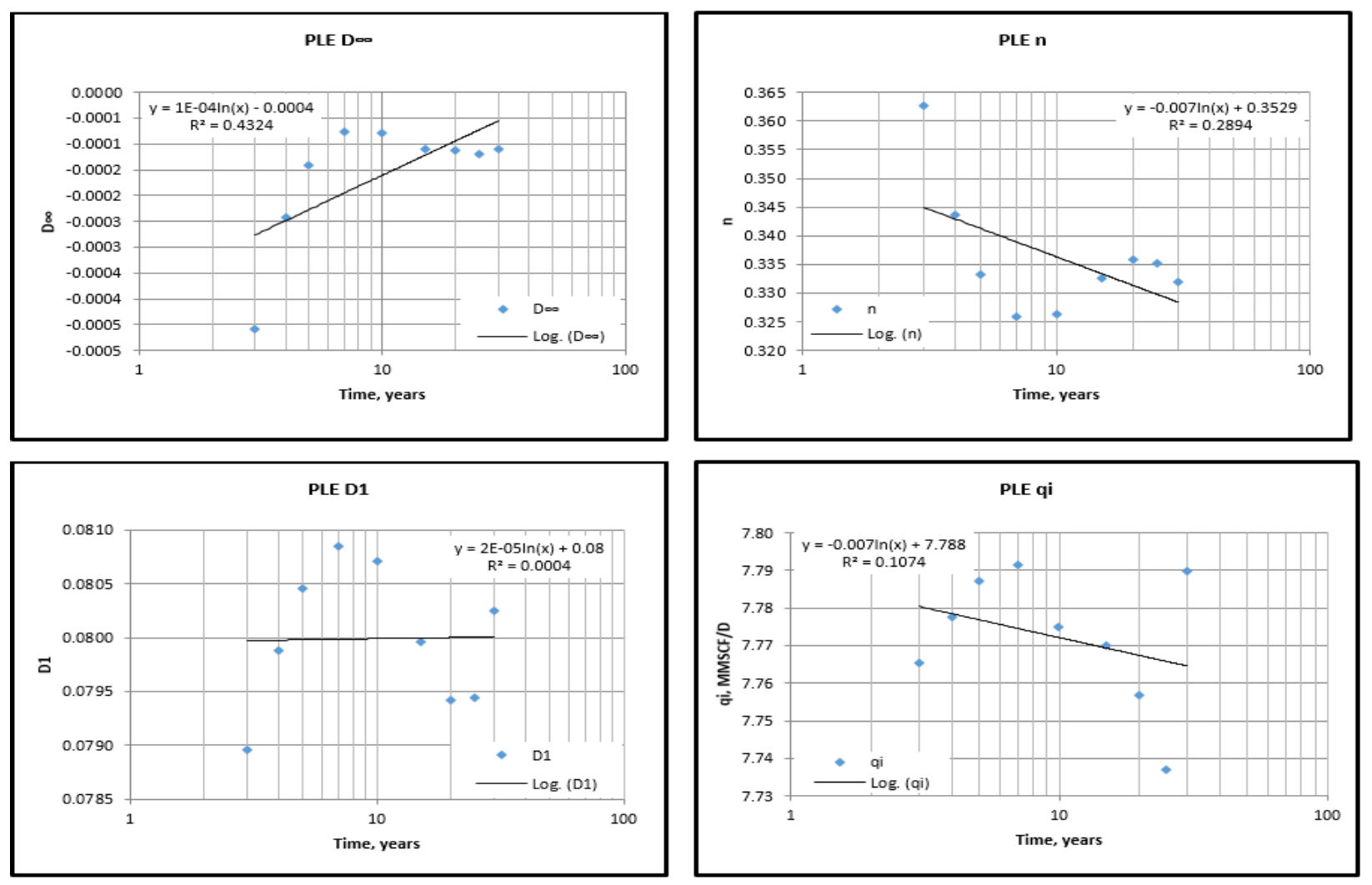

Figure D-22: 7 Stages - PLE Constants Correlations (0.002 m-D)
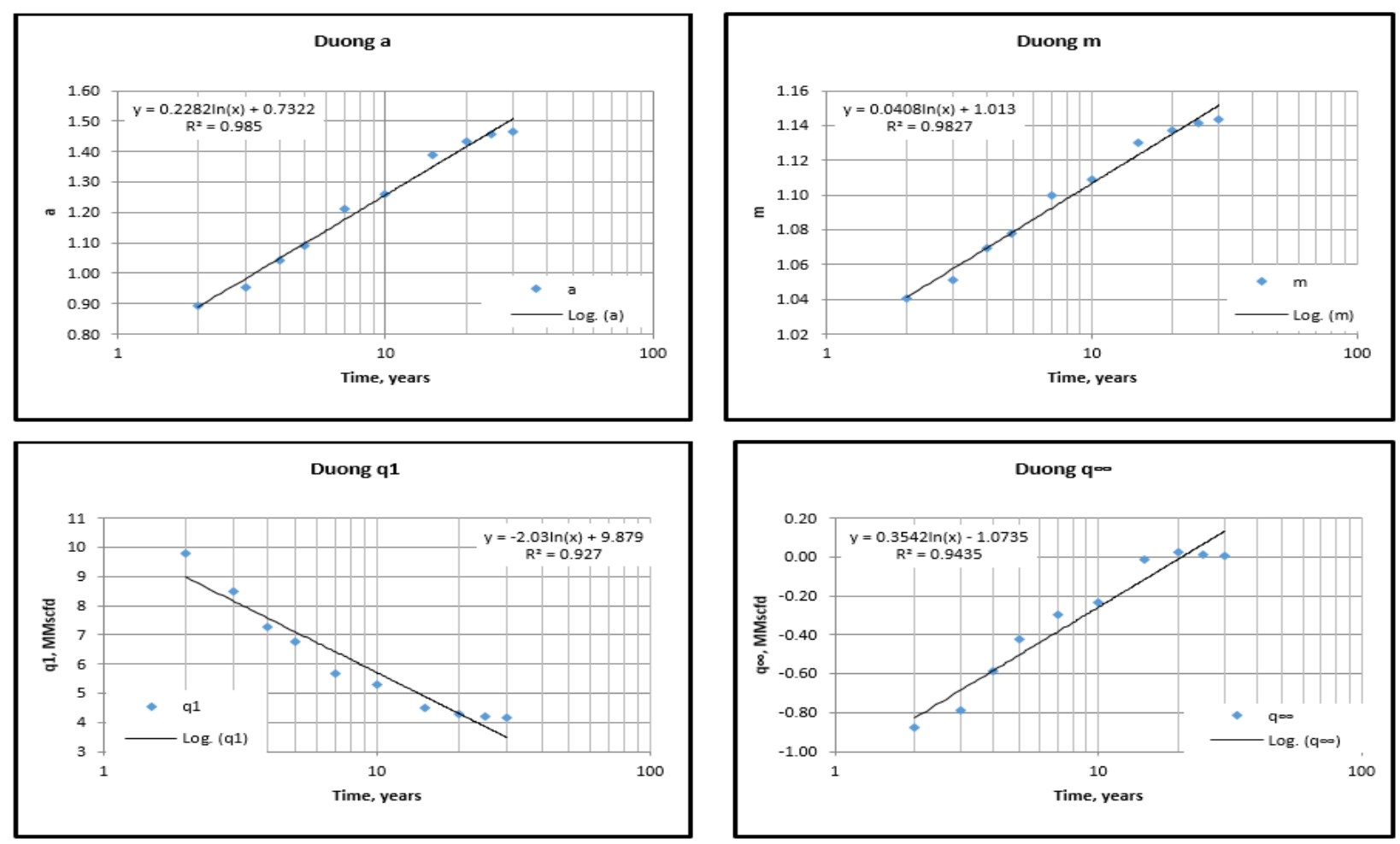

Figure D-23: 7 Stages - Duong Constants Correlations (0.002 m-D) 

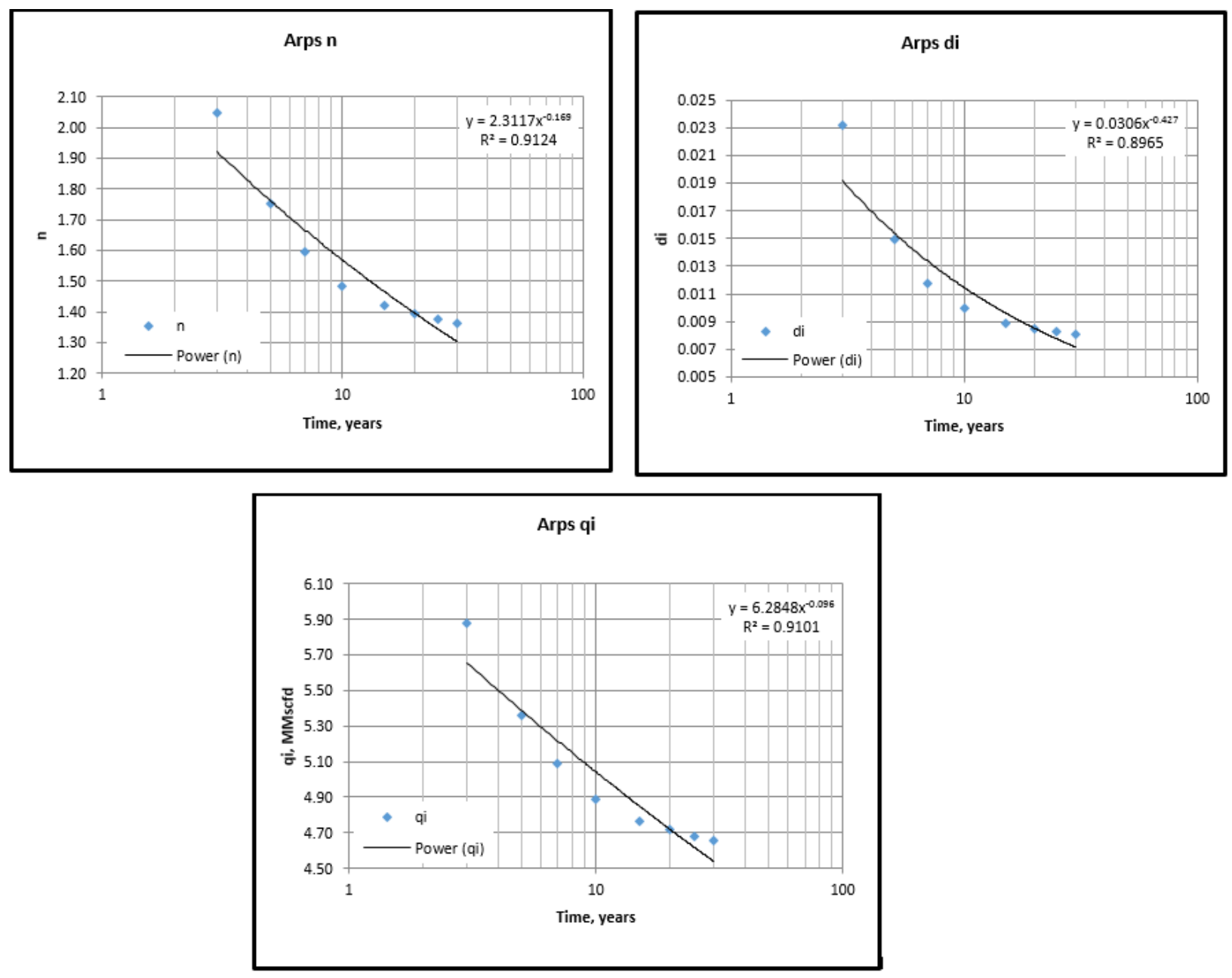

Figure D-24: 7 Stages - Arps Constants Correlations (0.002 m-D) 
Table D-25: 7 Stages (0.004 md) - Arps

\begin{tabular}{|c|c|c|c|c|}
\hline \multicolumn{5}{|c|}{ 7 Fractures $(0.004$ md)- Arps } \\
\hline Years & $n$ & di & qi & $R^{2}$ \\
\hline 3 & 1.4226 & 0.0097 & 6.6927 & 0.9939 \\
\hline 5 & 1.2860 & 0.0083 & 6.4906 & 0.9947 \\
\hline 7 & 1.2603 & 0.0080 & 6.4478 & 0.9955 \\
\hline 10 & 1.2553 & 0.0080 & 6.4386 & 0.9962 \\
\hline 15 & 1.2482 & 0.0079 & 6.4238 & 0.9968 \\
\hline 20 & 1.2355 & 0.0077 & 6.3942 & 0.9970 \\
\hline 25 & 1.2203 & 0.0076 & 6.3577 & 0.9970 \\
\hline 30 & 1.2071 & 0.0074 & 6.3261 & 0.9969 \\
\hline
\end{tabular}

Table D-26: 7 Stages (0.004 md) - PLE

\begin{tabular}{|c|c|c|c|c|c|}
\hline \multicolumn{7}{|c|}{ 7 Fractures $(\mathbf{0 . 0 0 4} \mathbf{m d})$ - PLE } \\
\hline Years & $\boldsymbol{D}_{\infty}$ & $\boldsymbol{n}$ & $\boldsymbol{q}_{\boldsymbol{i}}$ & $\boldsymbol{D}_{\boldsymbol{1}}$ & $\boldsymbol{R}^{2}$ \\
\hline 2 & -0.00015 & 0.39455 & 9.34784 & 0.06228 & 0.99911 \\
\hline 3 & -0.00004 & 0.38593 & 9.34969 & 0.06255 & 0.99929 \\
\hline 4 & -0.00008 & 0.39036 & 9.34302 & 0.06216 & 0.99938 \\
\hline 5 & -0.00014 & 0.39683 & 9.35595 & 0.06189 & 0.99936 \\
\hline 7 & -0.00027 & 0.41293 & 9.30001 & 0.06029 & 0.99923 \\
\hline 10 & -0.00033 & 0.42337 & 9.25717 & 0.05888 & 0.99922 \\
\hline 15 & -0.00030 & 0.41868 & 9.25710 & 0.05948 & 0.99929 \\
\hline 20 & -0.00026 & 0.41149 & 9.25690 & 0.06032 & 0.99913 \\
\hline 25 & -0.00023 & 0.40444 & 9.25688 & 0.06115 & 0.99883 \\
\hline 30 & -0.00020 & 0.39852 & 9.25688 & 0.06190 & 0.99851 \\
\hline
\end{tabular}

Table D-27: 7 Stages (0.004 md) - Duong

\begin{tabular}{|c|c|c|c|c|c|}
\hline \multicolumn{7}{|c|}{ 7 Fractures (0.004)-Duong } \\
\hline Years & $\boldsymbol{a}$ & $\boldsymbol{m}$ & $\boldsymbol{q}_{\mathbf{1}}$ & $\boldsymbol{q}_{\infty}$ & $\boldsymbol{R}^{2}$ \\
\hline 2 & 1.039 & 1.053 & 9.900 & -2.019 & 0.989 \\
\hline 3 & 1.090 & 1.066 & 8.900 & -1.543 & 0.991 \\
\hline 4 & 1.146 & 1.081 & 8.000 & -1.100 & 0.988 \\
\hline 5 & 1.212 & 1.095 & 7.300 & -0.794 & 0.999 \\
\hline 7 & 1.252 & 1.106 & 6.950 & -0.527 & 0.998 \\
\hline 10 & 1.381 & 1.131 & 5.850 & -0.268 & 0.997 \\
\hline 15 & 1.462 & 1.145 & 5.300 & -0.148 & 0.997 \\
\hline 20 & 1.647 & 1.168 & 4.030 & -0.013 & 0.989 \\
\hline 25 & 1.674 & 1.171 & 3.880 & -0.012 & 0.991 \\
\hline 30 & 1.700 & 1.173 & 3.820 & -0.053 & 0.991 \\
\hline
\end{tabular}



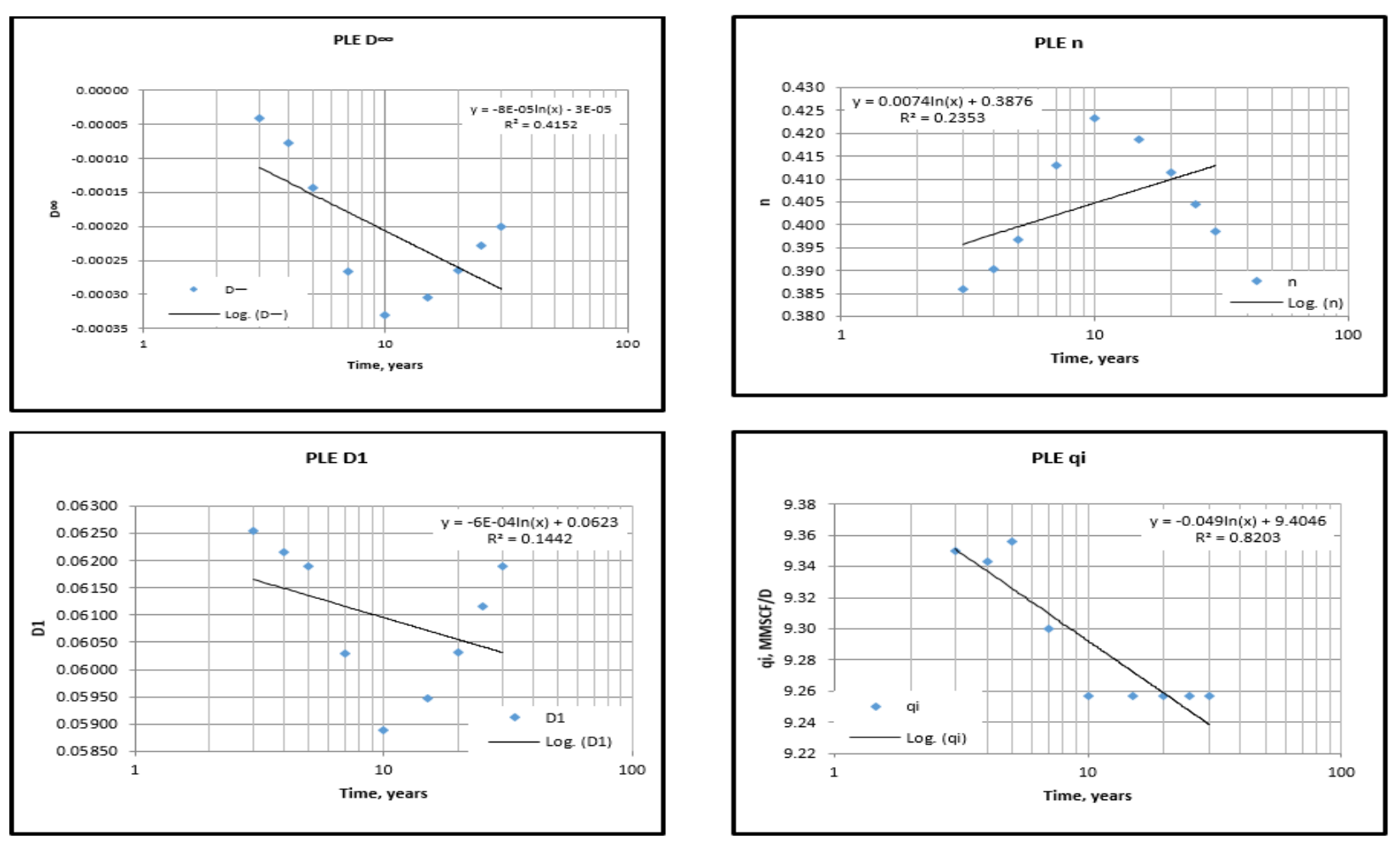

Figure D-25: 7 Stages - PLE Constants Correlations (0.004 m-D)
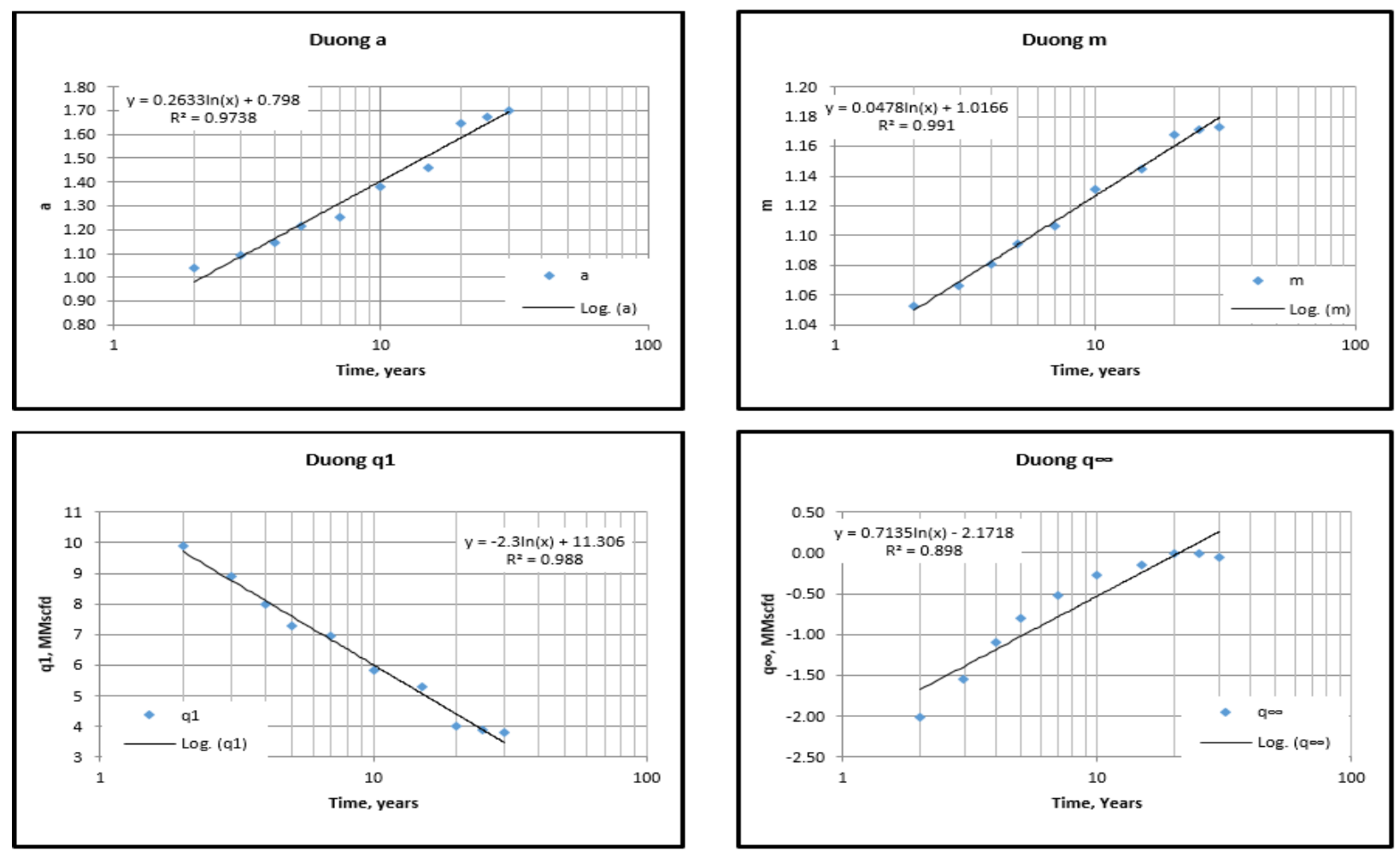

Figure D-26: 7 Stages - Duong Constants Correlations (0.004 m-D) 

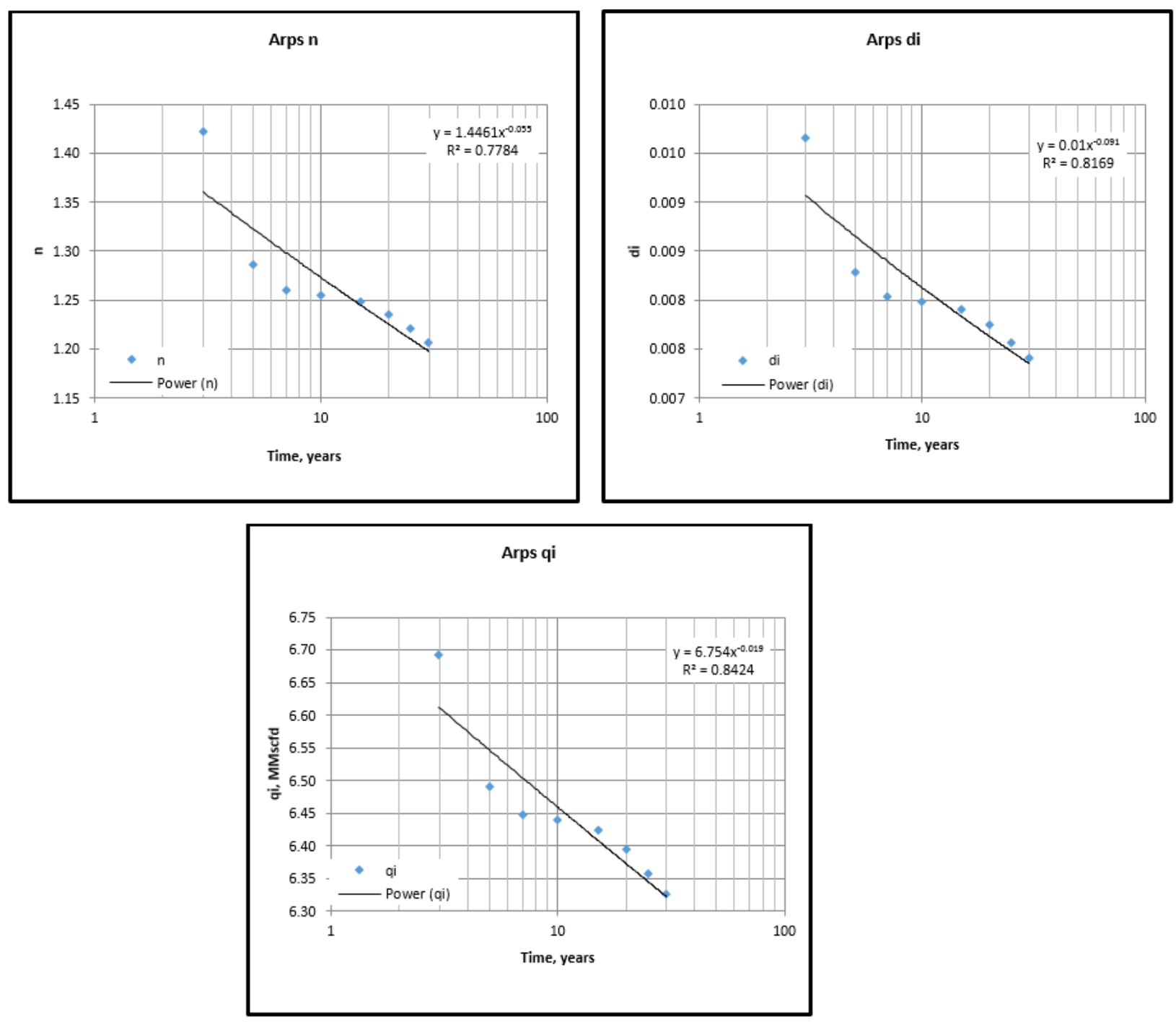

Figure D-27: 7 Stages - Arps Constants Correlations (0.004 m-D) 
Table D-28: 7 Stages (0.006 md) - Arps

\begin{tabular}{|c|c|c|c|c|}
\hline \multicolumn{5}{|c|}{ 7 Fractures $(0.006$ md)- Arps } \\
\hline Years & $n$ & di & qi & $R^{2}$ \\
\hline 3 & 1.2020 & 0.0081 & 7.7187 & 0.9972 \\
\hline 5 & 1.1908 & 0.0081 & 7.7039 & 0.9980 \\
\hline 7 & 1.2009 & 0.0082 & 7.7231 & 0.9983 \\
\hline 10 & 1.2038 & 0.0082 & 7.7289 & 0.9985 \\
\hline 15 & 1.1885 & 0.0080 & 7.6917 & 0.9987 \\
\hline 20 & 1.1671 & 0.0078 & 7.6365 & 0.9985 \\
\hline 25 & 1.1471 & 0.0075 & 7.5823 & 0.9982 \\
\hline 30 & 1.1307 & 0.0073 & 7.5361 & 0.9978 \\
\hline
\end{tabular}

Table D-29: 7 Stages (0.006 md) - PLE

\begin{tabular}{|c|c|c|c|c|c|}
\hline \multicolumn{7}{|c|}{ 7 Fractures $(0.006 \mathrm{md})$ - PLE } \\
\hline Years & $\boldsymbol{D}_{\infty}$ & $\boldsymbol{n}$ & $\boldsymbol{q}_{\boldsymbol{i}}$ & $\boldsymbol{D}_{\boldsymbol{1}}$ & $\boldsymbol{R}^{2}$ \\
\hline 2 & 0.00009 & 0.42243 & 10.35337 & 0.05241 & 0.99981 \\
\hline 3 & -0.00017 & 0.44563 & 10.31848 & 0.05117 & 0.99968 \\
\hline 4 & -0.00038 & 0.46432 & 10.29341 & 0.05007 & 0.99948 \\
\hline 5 & -0.00056 & 0.48445 & 10.23376 & 0.04823 & 0.99935 \\
\hline 7 & -0.00063 & 0.49091 & 10.25994 & 0.04792 & 0.99937 \\
\hline 10 & -0.00058 & 0.48603 & 10.24710 & 0.04821 & 0.99940 \\
\hline 15 & -0.00045 & 0.46876 & 10.24625 & 0.04987 & 0.99901 \\
\hline 20 & -0.00036 & 0.45438 & 10.24649 & 0.05126 & 0.99842 \\
\hline 25 & -0.00027 & 0.43311 & 10.48946 & 0.05502 & 0.99800 \\
\hline 30 & -0.00023 & 0.42474 & 10.48919 & 0.05611 & 0.99760 \\
\hline
\end{tabular}

Table D-30: 7 Stages (0.006 md) - Duong

\begin{tabular}{|c|c|c|c|c|c|}
\hline \multicolumn{7}{|c|}{ 7 Fractures $(0.006 \mathrm{md}$ )-Duong } \\
\hline Years & $\boldsymbol{a}$ & $\boldsymbol{m}$ & $\boldsymbol{q}_{1}$ & $\boldsymbol{q}^{\boldsymbol{1}}$ & $\boldsymbol{R}^{2}$ \\
\hline 2 & 1.0943 & 1.0565 & 11.5000 & -3.2125 & 0.9997 \\
\hline 3 & 1.1183 & 1.0684 & 10.5000 & -2.1135 & 0.9987 \\
\hline 4 & 1.1323 & 1.0772 & 10.1000 & -1.4970 & 0.9973 \\
\hline 5 & 1.1644 & 1.0885 & 9.6000 & -1.0468 & 0.9962 \\
\hline 7 & 1.2213 & 1.1051 & 8.9500 & -0.6195 & 0.9950 \\
\hline 10 & 1.4099 & 1.1382 & 6.9000 & -0.2861 & 0.9960 \\
\hline 15 & 1.5558 & 1.1592 & 5.6400 & -0.1560 & 0.9970 \\
\hline 20 & 1.6885 & 1.1748 & 4.6400 & -0.1050 & 0.9977 \\
\hline 25 & 1.7021 & 1.1764 & 4.5500 & -0.0993 & 0.9979 \\
\hline 30 & 1.7098 & 1.1773 & 4.5000 & -0.0964 & 0.9980 \\
\hline
\end{tabular}



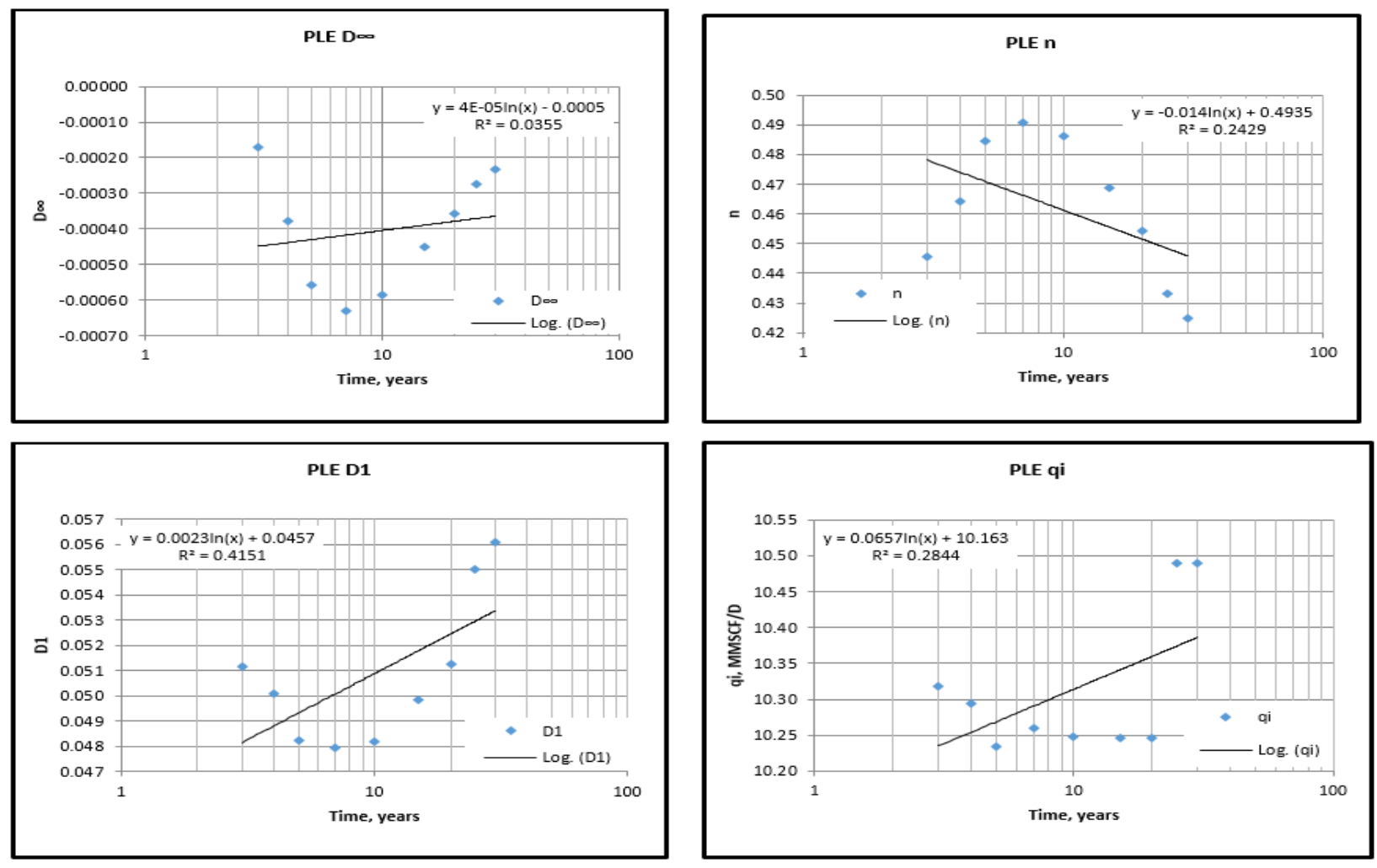

Figure D-28: 7 Stages - PLE Constants Correlations (0.006 m-D)
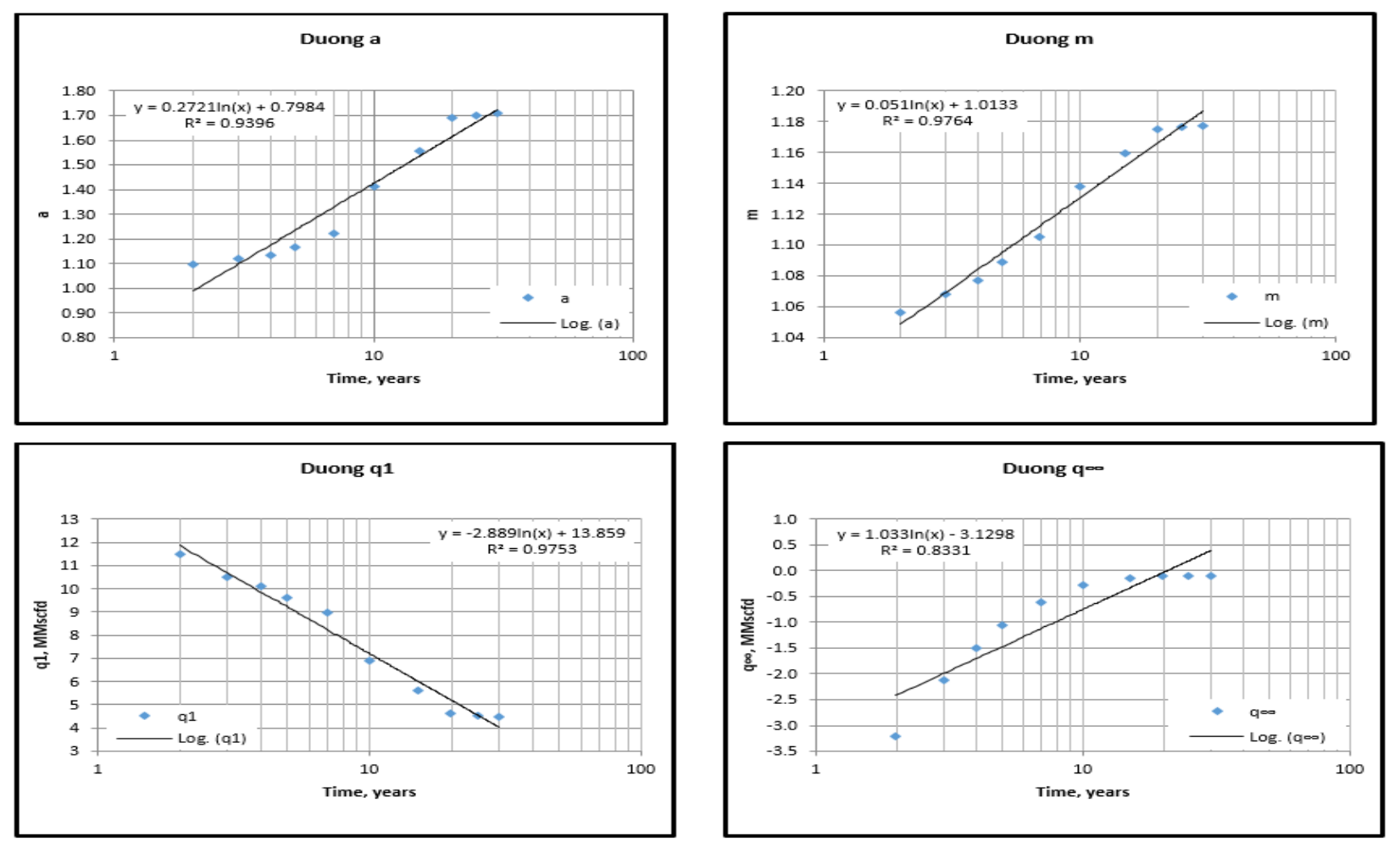

Figure D-29: 7 Stages - Duong Constants Correlations (0.006 m-D) 

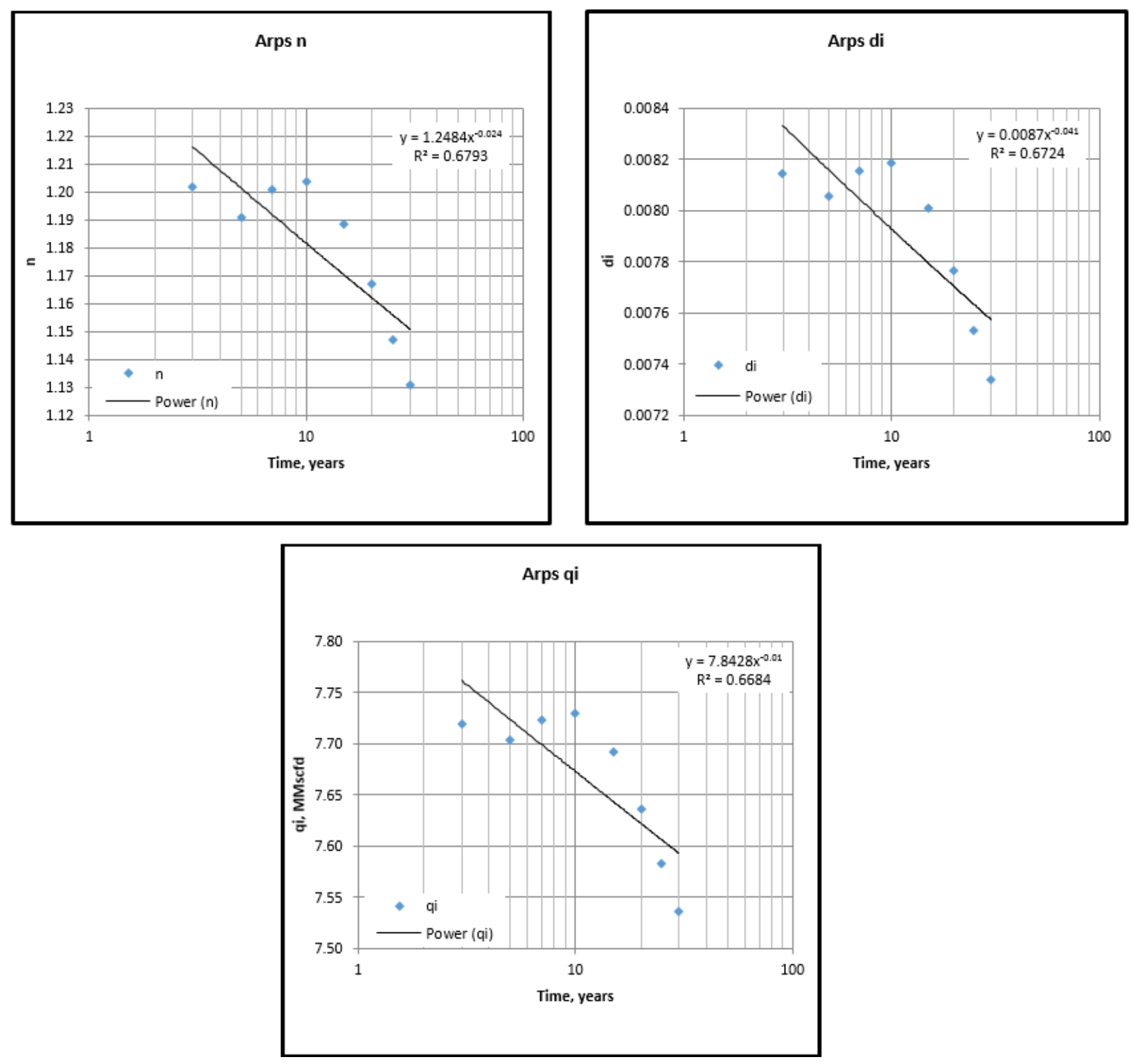

Figure D-30: 7 Stages - Arps Constants Correlations (0.006 m-D) 
Table D-31: 7 Stages (4\%) - Arps

\begin{tabular}{|c|c|c|c|c|}
\hline \multicolumn{5}{|c|}{ 7 Fractures (4\%)-Arps } \\
\hline Years & $n$ & $d i$ & $q i$ & $R^{2}$ \\
\hline 3 & 1.8915 & 0.0198 & 5.3124 & 0.9934 \\
\hline 5 & 1.6118 & 0.0133 & 4.8797 & 0.9899 \\
\hline 7 & 1.4882 & 0.0111 & 4.6859 & 0.9895 \\
\hline 10 & 1.4145 & 0.0099 & 4.5653 & 0.9903 \\
\hline 15 & 1.3751 & 0.0093 & 4.4970 & 0.9914 \\
\hline 20 & 1.3585 & 0.0090 & 4.4656 & 0.9921 \\
\hline 25 & 1.3452 & 0.0088 & 4.4399 & 0.9926 \\
\hline 30 & 1.3341 & 0.0086 & 4.4160 & 0.9928 \\
\hline
\end{tabular}

Table D-32: 7 Stages (4\%) - PLE

\begin{tabular}{|c|c|c|c|c|c|}
\hline \multicolumn{7}{|c|}{ 7 Fractures (4\%)- PLE } \\
\hline Years & $\boldsymbol{D}_{\infty}$ & $\boldsymbol{n}$ & $\boldsymbol{q}_{\boldsymbol{i}}$ & $\boldsymbol{D}_{\boldsymbol{1}}$ & $\boldsymbol{R}^{\mathbf{2}}$ \\
\hline 2 & -0.000785 & 0.382315 & 7.387753 & 0.080651 & 0.998044 \\
\hline 3 & -0.000300 & 0.349959 & 7.393483 & 0.081541 & 0.997443 \\
\hline 4 & -0.000155 & 0.337680 & 7.399518 & 0.082001 & 0.997442 \\
\hline 5 & -0.000097 & 0.332164 & 7.403981 & 0.082281 & 0.997630 \\
\hline 7 & -0.000076 & 0.329848 & 7.417353 & 0.082481 & 0.997985 \\
\hline 10 & -0.000108 & 0.334174 & 7.407473 & 0.082157 & 0.998199 \\
\hline 15 & -0.000145 & 0.340823 & 7.399531 & 0.081305 & 0.998320 \\
\hline 20 & -0.000154 & 0.343527 & 7.372863 & 0.080675 & 0.998438 \\
\hline 25 & -0.000147 & 0.342295 & 7.374503 & 0.080814 & 0.998502 \\
\hline 30 & -0.000132 & 0.338189 & 7.372705 & 0.081450 & 0.998507 \\
\hline
\end{tabular}

Table D-33: 7 Stages (4\%) - Duong

\begin{tabular}{|c|c|c|c|c|c|}
\hline \multicolumn{7}{|c|}{ 7 Fractures (4\%)- Duong } \\
\hline Years & $\boldsymbol{a}$ & $\boldsymbol{m}$ & $\boldsymbol{q 1}$ & $\boldsymbol{q}^{\infty}$ & $\boldsymbol{R}^{\mathbf{2}}$ \\
\hline 2 & 0.885 & 1.032 & 8.300 & -0.863 & 0.999 \\
\hline 3 & 0.955 & 1.048 & 7.400 & -0.735 & 0.999 \\
\hline 4 & 1.033 & 1.066 & 6.500 & -0.571 & 0.999 \\
\hline 5 & 1.116 & 1.083 & 5.700 & -0.431 & 0.998 \\
\hline 7 & 1.201 & 1.099 & 5.000 & -0.312 & 0.998 \\
\hline 10 & 1.324 & 1.121 & 4.200 & -0.179 & 0.997 \\
\hline 15 & 1.439 & 1.141 & 3.600 & -0.056 & 0.996 \\
\hline 20 & 1.489 & 1.149 & 3.380 & -0.056 & 0.996 \\
\hline 25 & 1.510 & 1.152 & 3.300 & -0.014 & 0.992 \\
\hline 30 & 1.532 & 1.155 & 3.200 & -0.034 & 0.996 \\
\hline
\end{tabular}



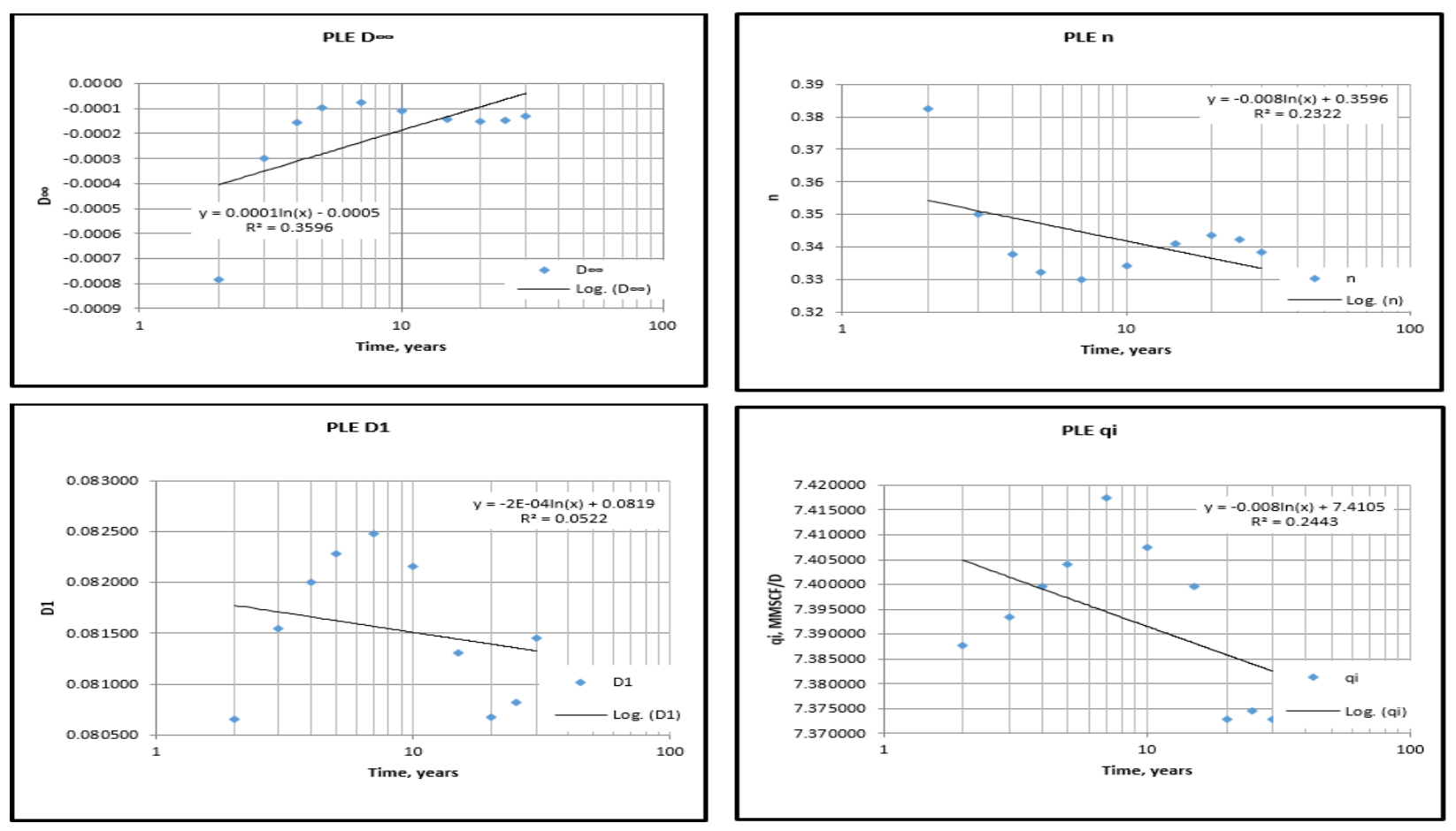

Figure D-31: 7 Stages - PLE Constants Correlations (4\%)
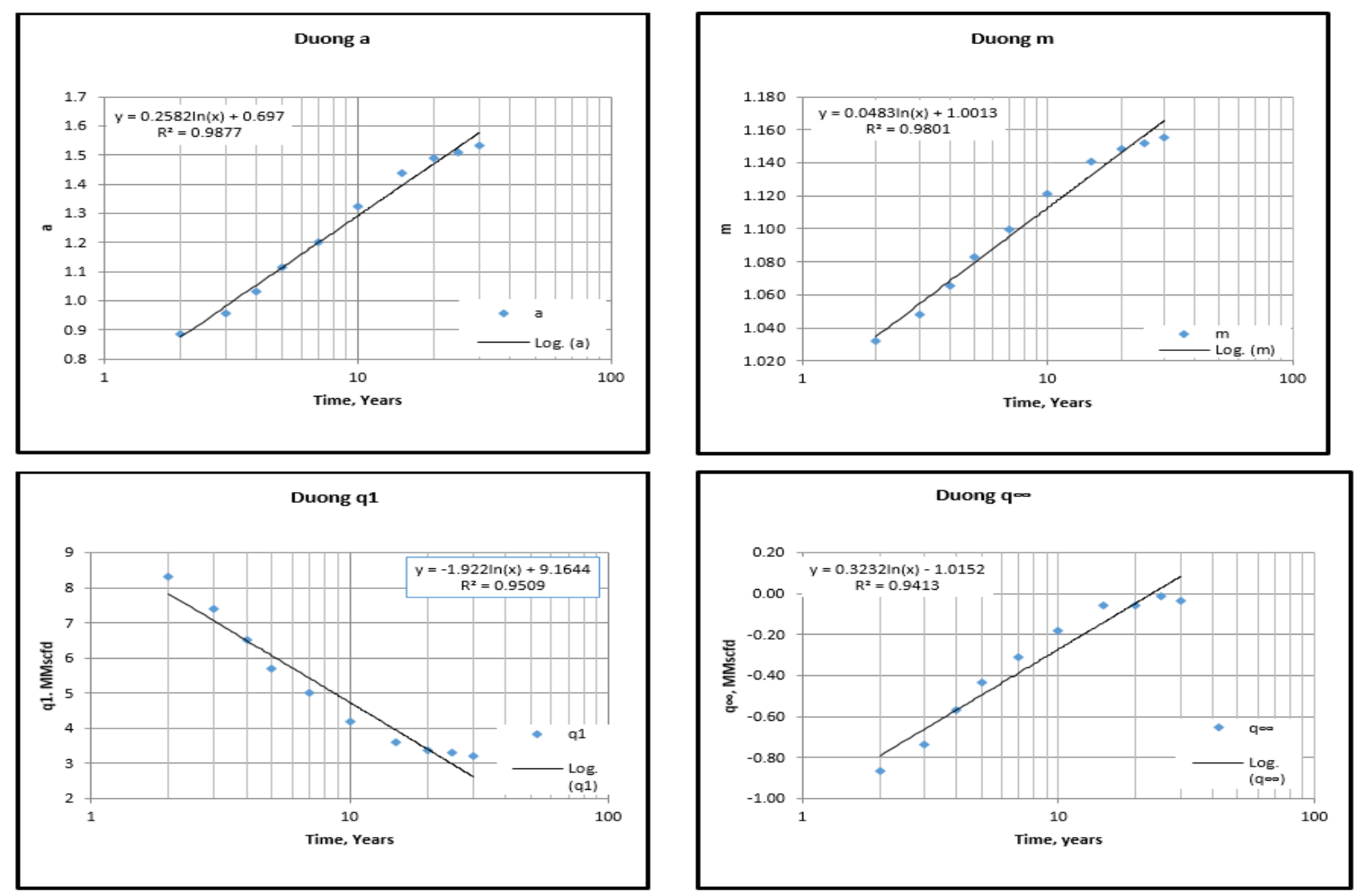

Figure D-32: 7 Stages - Duong Constants Correlations (4\%) 

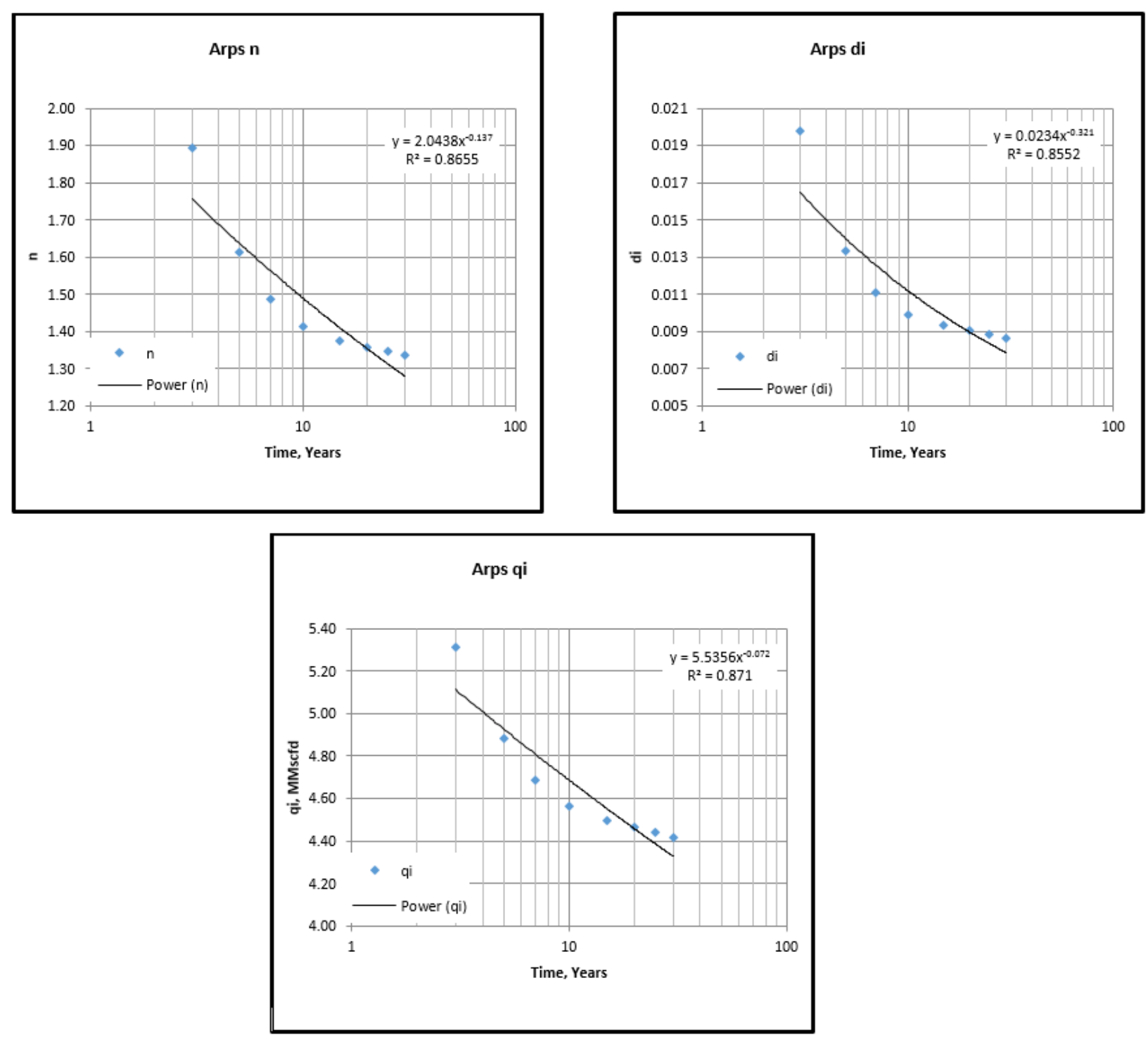

Figure D-33: 7 Stages - Arps Constants Correlations (4\%) 
Table D-34: 7 Stages (5\%) - Arps

\begin{tabular}{|c|c|c|c|c|}
\hline \multicolumn{5}{|c|}{ 7 Fractures (5\%)-Arps } \\
\hline Years & $n$ & $d i$ & $q i$ & $R^{2}$ \\
\hline 3 & 2.0494 & 0.0231 & 5.8798 & 0.9951 \\
\hline 5 & 1.7531 & 0.0149 & 5.3586 & 0.9902 \\
\hline 7 & 1.5968 & 0.0118 & 5.0887 & 0.9885 \\
\hline 10 & 1.4859 & 0.0099 & 4.8925 & 0.9885 \\
\hline 15 & 1.4192 & 0.0089 & 4.7670 & 0.9895 \\
\hline 20 & 1.3931 & 0.0085 & 4.7149 & 0.9903 \\
\hline 25 & 1.3767 & 0.0083 & 4.6806 & 0.9909 \\
\hline 30 & 1.3644 & 0.0081 & 4.6547 & 0.9912 \\
\hline
\end{tabular}

Table D-35: 7 Stages (5\%) - PLE

\begin{tabular}{|c|c|c|c|c|c|}
\hline \multicolumn{6}{|c|}{ 7 Fractures (5\%)-PLE } \\
\hline Years & $\boldsymbol{D}_{\infty}$ & $\boldsymbol{n}$ & $\boldsymbol{q}_{\boldsymbol{i}}$ & $\boldsymbol{D}_{\mathbf{1}}$ & $\boldsymbol{R}^{\mathbf{2}}$ \\
\hline 2 & -0.0010263 & 0.3996857 & 7.7542692 & 0.0777371 & 0.9980356 \\
\hline 3 & -0.0004567 & 0.3622116 & 7.7651826 & 0.0790257 & 0.9970165 \\
\hline 4 & -0.0002323 & 0.3418896 & 7.7922867 & 0.0802047 & 0.9967238 \\
\hline 5 & -0.0001454 & 0.3335663 & 7.7906324 & 0.0805192 & 0.9967706 \\
\hline 7 & -0.0000751 & 0.3253991 & 7.7886584 & 0.0809130 & 0.9971546 \\
\hline 10 & -0.0000803 & 0.3266889 & 7.7902631 & 0.0807726 & 0.9975767 \\
\hline 15 & -0.0001043 & 0.3306330 & 7.7904639 & 0.0804448 & 0.9978375 \\
\hline 20 & -0.0001133 & 0.3321755 & 7.7904542 & 0.0802676 & 0.9979881 \\
\hline 25 & -0.0001145 & 0.3329079 & 7.7911305 & 0.0800973 & 0.9981090 \\
\hline 30 & -0.0001145 & 0.3330758 & 7.7898979 & 0.0801135 & 0.9981683 \\
\hline
\end{tabular}

Table D-36: 7 Stages (5\%) - Duong

\begin{tabular}{|c|c|c|c|c|c|}
\hline \multicolumn{7}{|c|}{ 7 Fractures (5\%)-Duong } \\
\hline Years & $\boldsymbol{a}$ & $\boldsymbol{m}$ & $\boldsymbol{q 1}$ & $\boldsymbol{q}^{\boldsymbol{0}}$ & $\boldsymbol{R}^{\mathbf{2}}$ \\
\hline 2 & 0.8409 & 1.0205 & 9.5000 & -0.9938 & 0.9992 \\
\hline 3 & 0.9044 & 1.0369 & 8.5000 & -0.7985 & 0.9990 \\
\hline 4 & 0.9563 & 1.0485 & 7.7923 & -0.7067 & 0.9987 \\
\hline 5 & 1.0199 & 1.0627 & 7.0000 & -0.5678 & 0.9984 \\
\hline 7 & 1.0946 & 1.0782 & 6.2000 & -0.4359 & 0.9981 \\
\hline 10 & 1.1860 & 1.0966 & 5.4000 & -0.2880 & 0.9976 \\
\hline 15 & 1.2742 & 1.1139 & 4.8000 & -0.1671 & 0.9968 \\
\hline 20 & 1.3695 & 1.1295 & 4.2000 & -0.0986 & 0.9961 \\
\hline 25 & 1.4261 & 1.1380 & 3.8800 & -0.0681 & 0.9958 \\
\hline 30 & 1.4648 & 1.1434 & 3.6700 & -0.0225 & 0.9913 \\
\hline
\end{tabular}



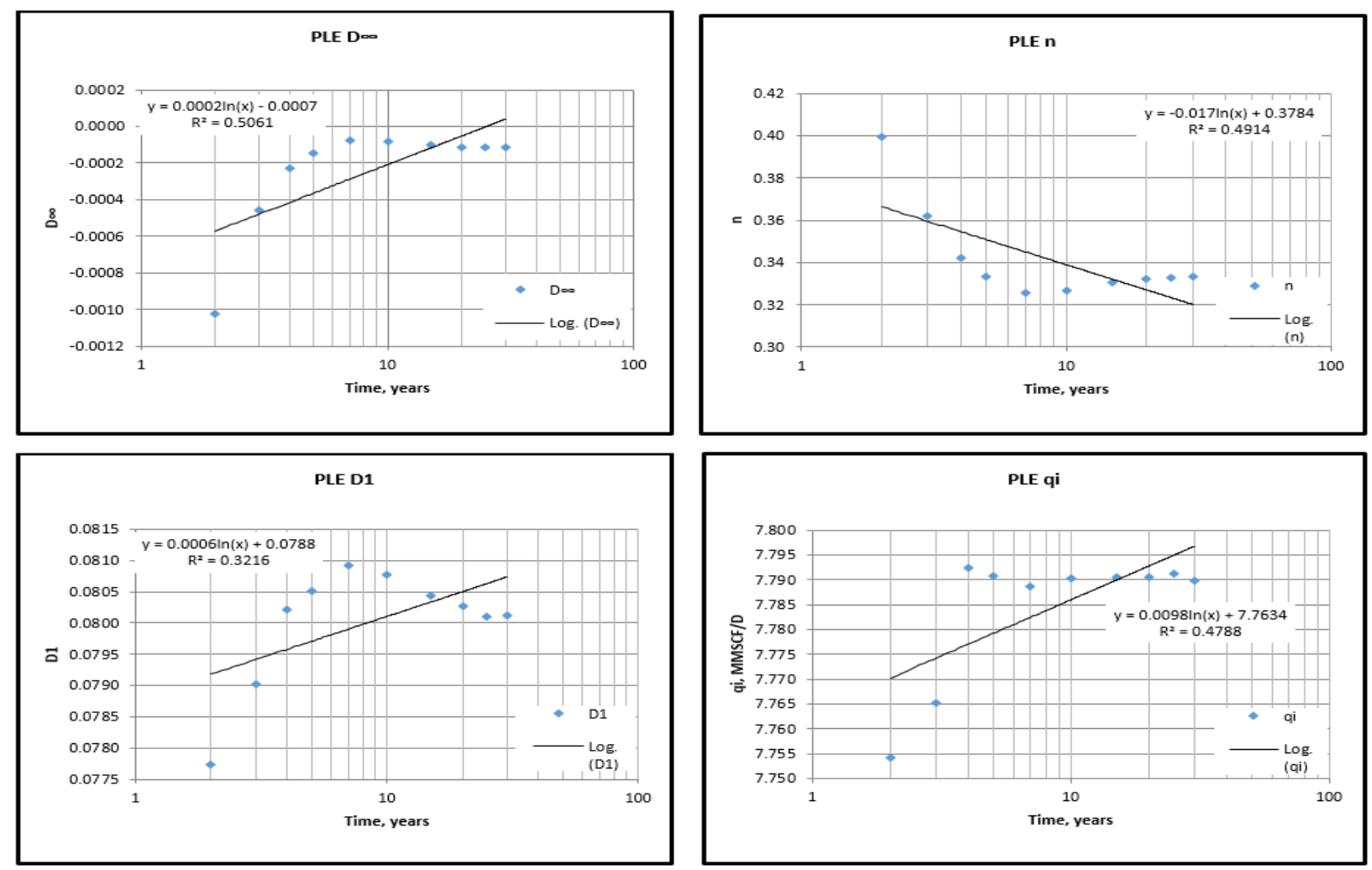

Figure D-34: 7 Stages - PLE Constants Correlations (5\%)
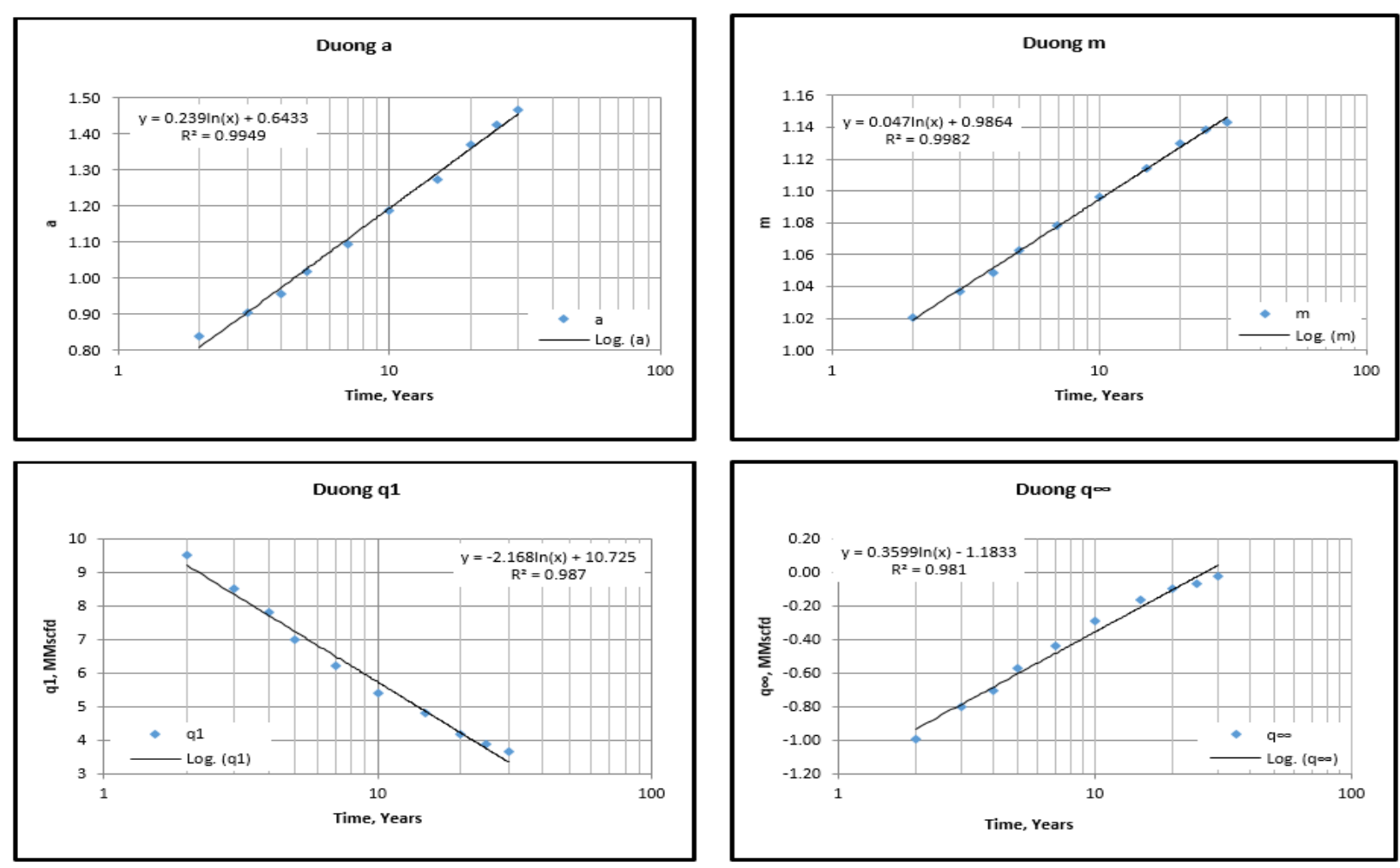
Figure D-35: 7 Stages - Duong Constants Correlations (5\%)
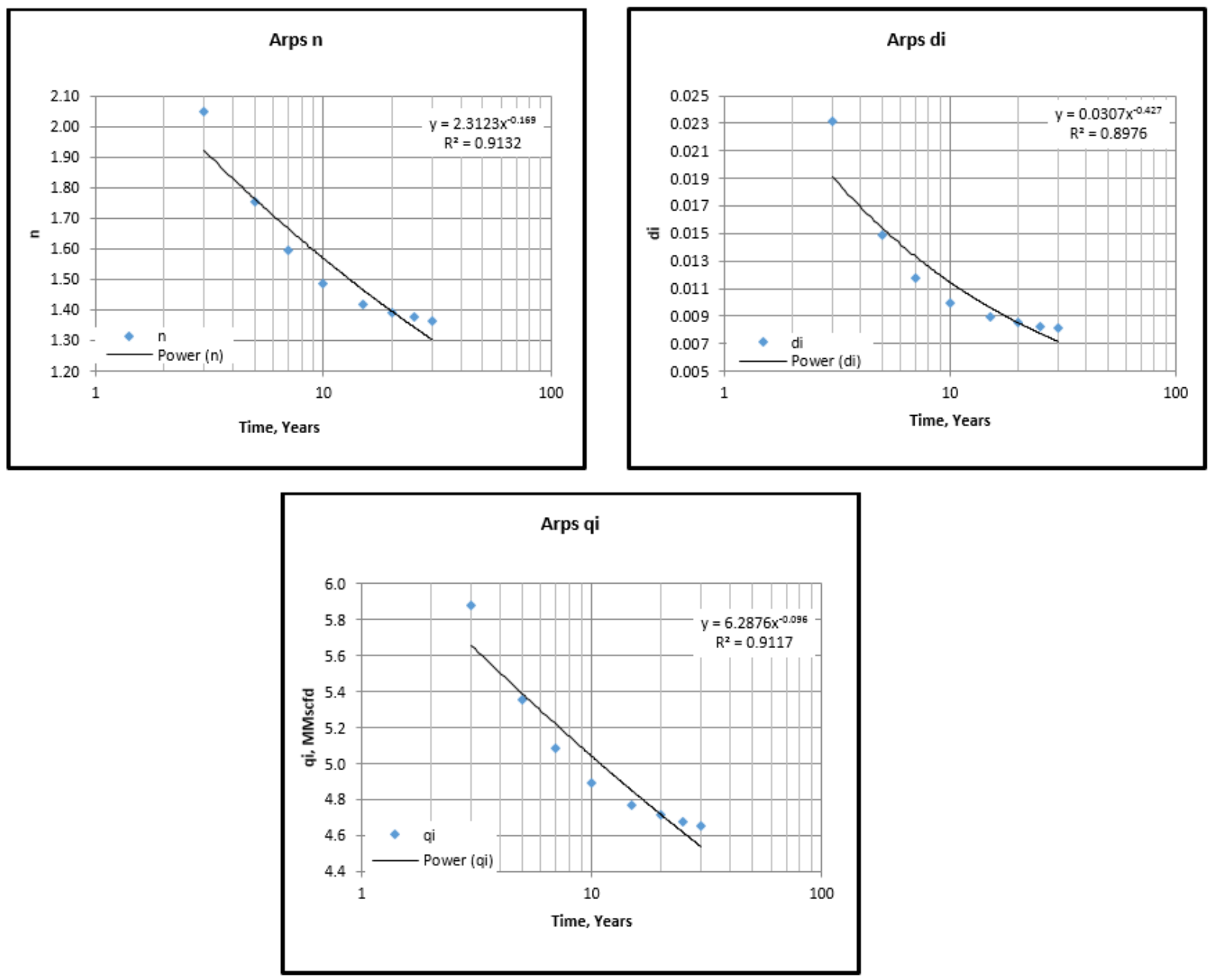

Figure D-36: 7 Stages - Arps Constants Correlations (5\%) 
Table D-37: 7 Stages (6\%) - Arps

\begin{tabular}{|c|c|c|c|c|}
\hline \multicolumn{5}{|c|}{ 7 Fractures (6\%)-Arps } \\
\hline Years & $n$ & $d i$ & $q i$ & $R^{2}$ \\
\hline 3 & 2.16593 & 0.02604 & 6.37471 & 0.9967 \\
\hline 5 & 1.87686 & 0.01673 & 5.81062 & 0.9913 \\
\hline 7 & 1.70174 & 0.01278 & 5.48117 & 0.9885 \\
\hline 10 & 1.56138 & 0.01024 & 5.21353 & 0.9874 \\
\hline 15 & 1.46689 & 0.00876 & 5.02701 & 0.9880 \\
\hline 20 & 1.42918 & 0.00820 & 4.94638 & 0.9888 \\
\hline 25 & 1.40816 & 0.00791 & 4.90262 & 0.9894 \\
\hline 30 & 1.39377 & 0.00770 & 4.87033 & 0.9898 \\
\hline
\end{tabular}

Table D-38: 7 Stages (6\%) - PLE

\begin{tabular}{|c|c|c|c|c|c|}
\hline \multicolumn{7}{|c|}{ 7 Fractures (6\%)-PLE } \\
\hline Years & $\boldsymbol{D}_{\infty}$ & $\boldsymbol{n}$ & $\boldsymbol{q}_{\boldsymbol{i}}$ & $\boldsymbol{D}_{\mathbf{1}}$ & $\boldsymbol{R}^{\mathbf{2}}$ \\
\hline 2 & -0.00118 & 0.41305 & 8.05189 & 0.07497 & 0.99816 \\
\hline 3 & -0.00059 & 0.37403 & 8.07836 & 0.07673 & 0.99685 \\
\hline 4 & -0.00033 & 0.35199 & 8.09137 & 0.07780 & 0.99625 \\
\hline 5 & -0.00020 & 0.33805 & 8.10059 & 0.07860 & 0.99610 \\
\hline 7 & -0.00009 & 0.32480 & 8.12288 & 0.07951 & 0.99635 \\
\hline 10 & -0.00007 & 0.32136 & 8.10653 & 0.07958 & 0.99688 \\
\hline 15 & -0.00008 & 0.32361 & 8.10605 & 0.07934 & 0.99733 \\
\hline 20 & -0.00008 & 0.32361 & 8.12000 & 0.07934 & 0.99748 \\
\hline 25 & -0.00010 & 0.32668 & 8.12288 & 0.07920 & 0.99768 \\
\hline 30 & -0.00009 & 0.32670 & 8.12286 & 0.07918 & 0.99778 \\
\hline
\end{tabular}

Table D-39: 7 Stages (6\%) - Duong

\begin{tabular}{|c|c|c|c|c|c|}
\hline \multicolumn{7}{|c|}{ 7 Fractures (6\%)-Duong } \\
\hline Years & $\boldsymbol{a}$ & $\boldsymbol{m}$ & $\boldsymbol{q 1}$ & $\boldsymbol{q}^{\infty}$ & $\boldsymbol{R}^{\mathbf{2}}$ \\
\hline 2 & 0.815 & 1.013 & 10.500 & -1.195 & 0.996 \\
\hline 3 & 0.866 & 1.028 & 9.500 & -0.945 & 0.987 \\
\hline 4 & 0.924 & 1.042 & 8.600 & -0.711 & 0.999 \\
\hline 5 & 0.952 & 1.047 & 8.200 & -0.702 & 0.999 \\
\hline 7 & 1.021 & 1.062 & 7.300 & -0.554 & 0.998 \\
\hline 10 & 1.093 & 1.078 & 6.500 & -0.400 & 0.998 \\
\hline 15 & 1.173 & 1.095 & 5.800 & -0.247 & 0.997 \\
\hline 20 & 1.241 & 1.108 & 5.300 & -0.106 & 0.986 \\
\hline 25 & 1.356 & 1.126 & 4.450 & -0.060 & 0.990 \\
\hline 30 & 1.371 & 1.129 & 4.380 & -0.045 & 0.990 \\
\hline
\end{tabular}



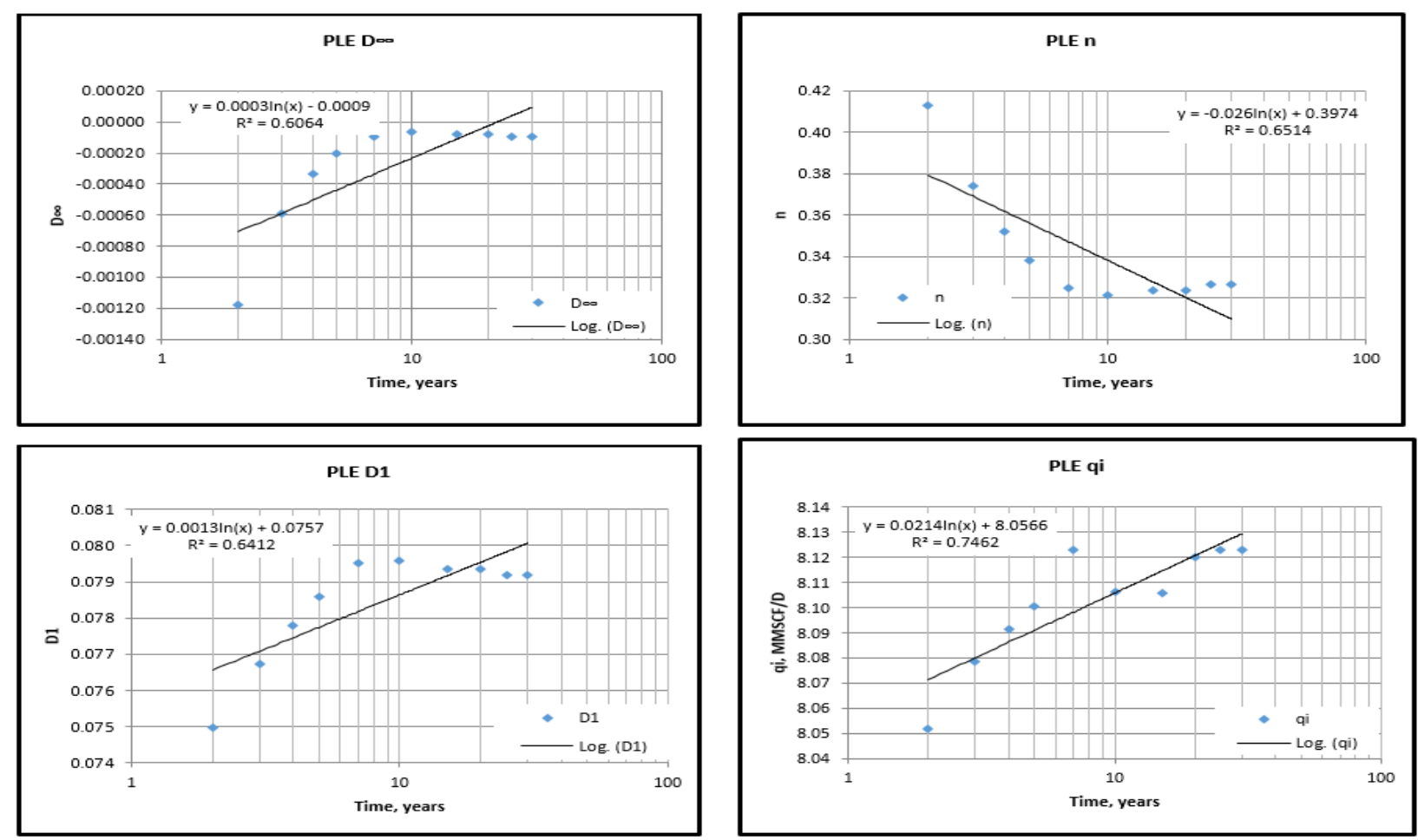

Figure D-37: 7 Stages - PLE Constants Correlations (6\%)
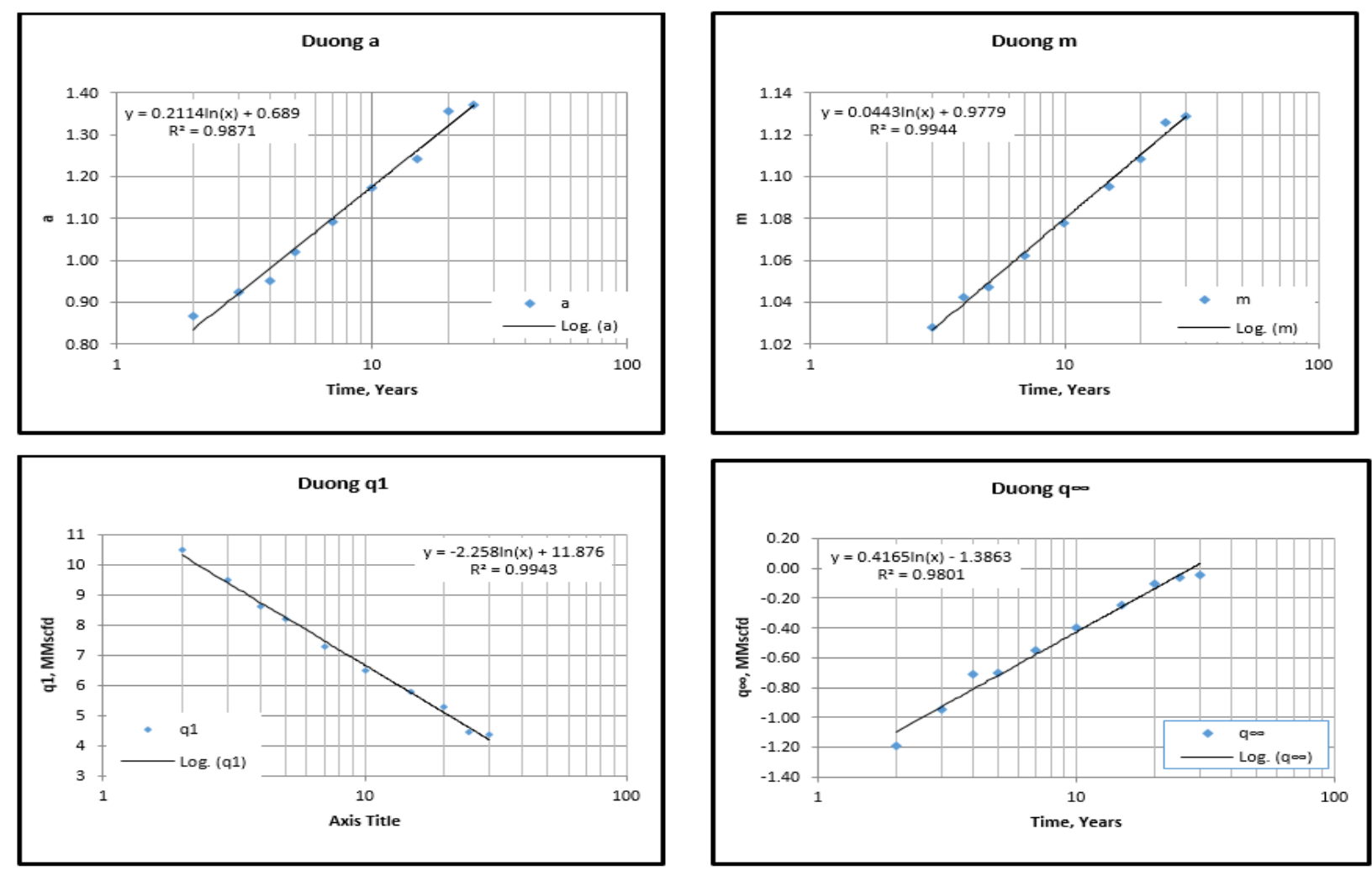

Figure D-38: 7 Stages - Duong Constants Correlations (6\%) 

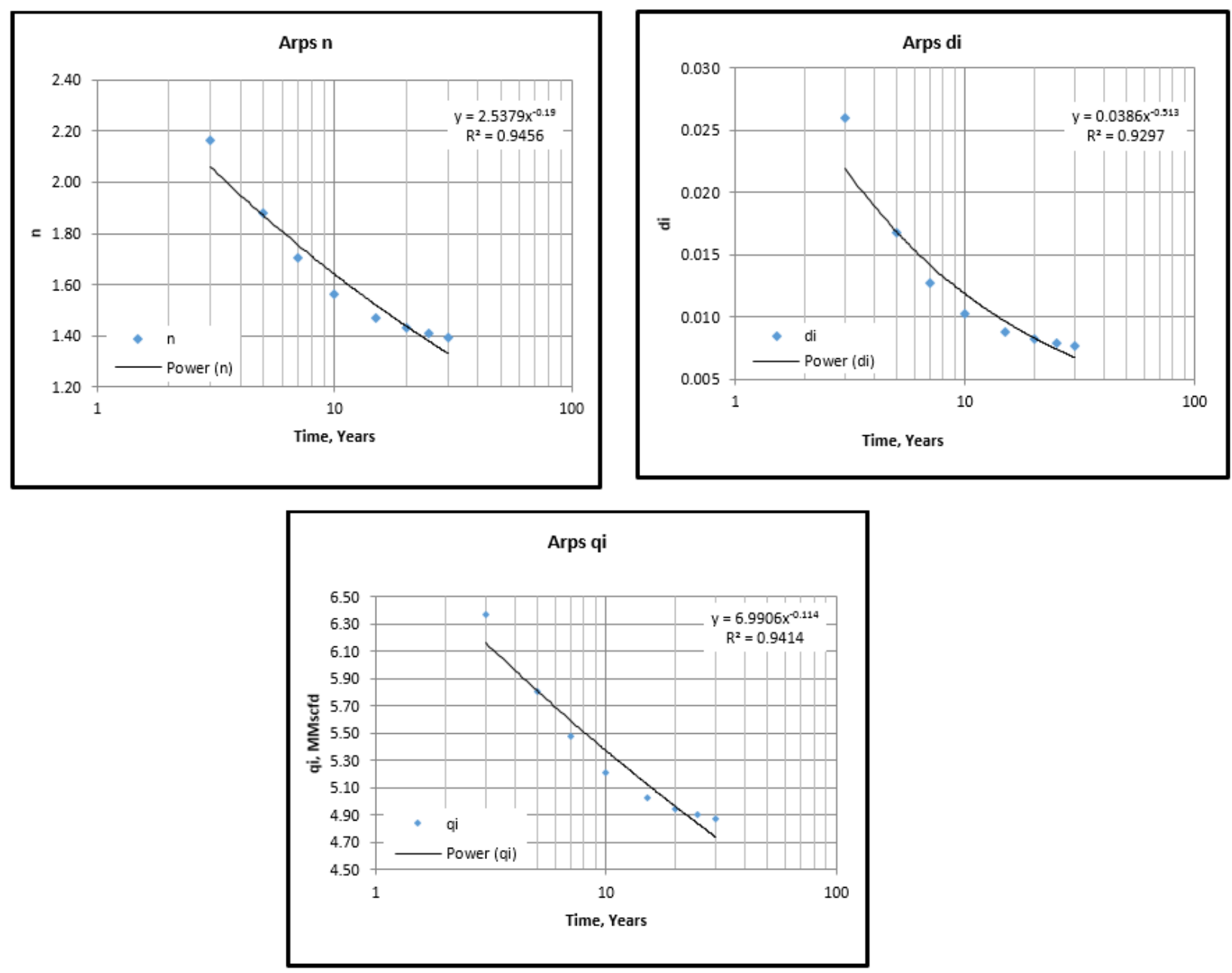

Figure D-39: 7 Stages - Arps Constants Correlations (6\%) 
Table D-40: 7 Stages (8\%) - Arps

\begin{tabular}{|c|c|c|c|c|}
\hline \multicolumn{5}{|c|}{ 7 Fractures (8\%) - Arps } \\
\hline Years & $n$ & $d i$ & $q i$ & $R^{2}$ \\
\hline 3 & 2.3116 & 0.0298 & 7.1613 & 0.9986 \\
\hline 5 & 2.0681 & 0.0201 & 6.6052 & 0.9941 \\
\hline 7 & 1.8845 & 0.0150 & 6.2081 & 0.9901 \\
\hline 10 & 1.7091 & 0.0113 & 5.8304 & 0.9870 \\
\hline 15 & 1.5665 & 0.0089 & 5.5192 & 0.9860 \\
\hline 20 & 1.5029 & 0.0079 & 5.3734 & 0.9864 \\
\hline 25 & 1.4696 & 0.0075 & 5.2974 & 0.9870 \\
\hline 30 & 1.4494 & 0.0072 & 5.2475 & 0.9874 \\
\hline
\end{tabular}

Table D-41: 7 Stages (8\%) - PLE

\begin{tabular}{|c|c|c|c|c|c|}
\hline \multicolumn{6}{|c|}{ 7 Fractures (8\%)-PLE } \\
\hline Years & $\boldsymbol{D}_{\infty}$ & $\boldsymbol{n}$ & $\boldsymbol{q}_{\boldsymbol{i}}$ & $\boldsymbol{D}_{1}$ & $\boldsymbol{R}^{2}$ \\
\hline 2 & -0.0014276 & 0.4373642 & 8.5418185 & 0.0700473 & 0.9985068 \\
\hline 3 & -0.0007734 & 0.3934334 & 8.5773798 & 0.0724611 & 0.9969567 \\
\hline 4 & -0.0004615 & 0.3660959 & 8.5921826 & 0.0739963 & 0.9959223 \\
\hline 5 & -0.0002932 & 0.3469751 & 8.6233565 & 0.0755427 & 0.9953371 \\
\hline 7 & -0.0001445 & 0.3287410 & 8.6250558 & 0.0765437 & 0.9950712 \\
\hline 10 & -0.0000757 & 0.3184932 & 8.6287014 & 0.0772133 & 0.9954898 \\
\hline 15 & -0.0000565 & 0.3150625 & 8.6311078 & 0.0774690 & 0.9962281 \\
\hline 20 & -0.0000689 & 0.3183689 & 8.6320722 & 0.0770969 & 0.9965933 \\
\hline 25 & -0.0000694 & 0.3184869 & 8.6287030 & 0.0770455 & 0.9968308 \\
\hline 30 & -0.0000700 & 0.3182458 & 8.6299384 & 0.0771257 & 0.9969869 \\
\hline
\end{tabular}

Table D-42: 7 Stages (8\%) - Duong

\begin{tabular}{|c|c|c|c|c|c|}
\hline \multicolumn{7}{|c|}{ 7 Fractures (8\%)-Duong } \\
\hline Years & $\boldsymbol{a}$ & $\boldsymbol{m}$ & $\boldsymbol{q 1}$ & $\boldsymbol{q}^{\infty}$ & $\boldsymbol{R}^{\mathbf{2}}$ \\
\hline 2 & 0.7961 & 0.9998 & 12.5002 & -1.9834 & 0.9979 \\
\hline 3 & 0.7984 & 1.0034 & 12.1001 & -1.6560 & 0.9985 \\
\hline 4 & 0.8141 & 1.0102 & 11.5440 & -1.4846 & 0.9769 \\
\hline 5 & 0.8487 & 1.0212 & 10.6869 & -1.0469 & 0.9971 \\
\hline 7 & 0.9037 & 1.0352 & 9.7614 & -0.8557 & 0.9969 \\
\hline 10 & 0.9037 & 1.0352 & 9.6140 & -0.7681 & 0.9839 \\
\hline 15 & 0.9666 & 1.0535 & 8.6569 & -0.4529 & 0.9847 \\
\hline 20 & 1.1037 & 1.0819 & 6.9500 & -0.2087 & 0.9807 \\
\hline 25 & 1.1899 & 1.0976 & 6.1000 & -0.0912 & 0.9657 \\
\hline 30 & 1.2034 & 1.1010 & 6.0300 & -0.0911 & 0.9797 \\
\hline
\end{tabular}



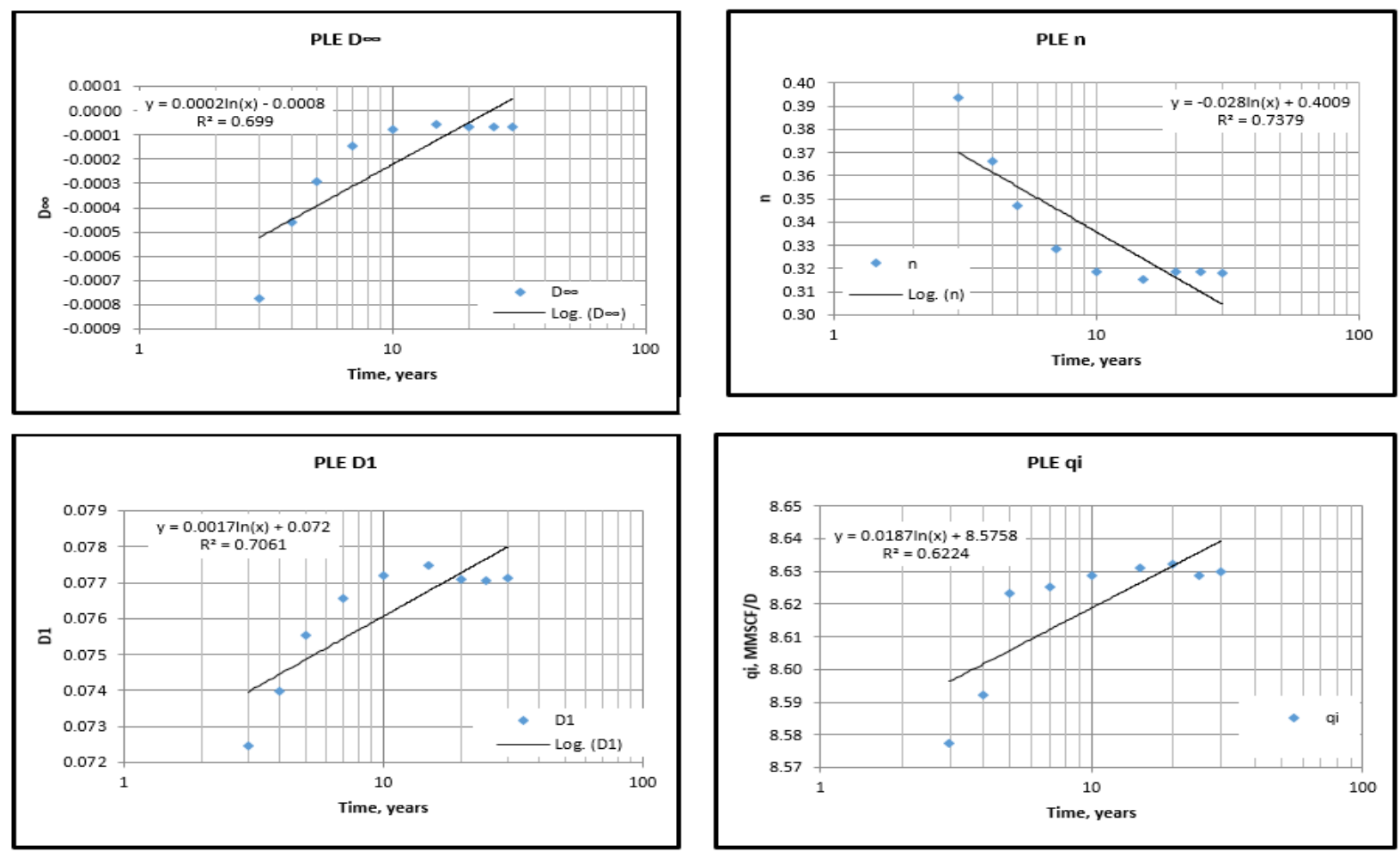

Figure D-40: 7 Stages - PLE Constants Correlations (8\%)
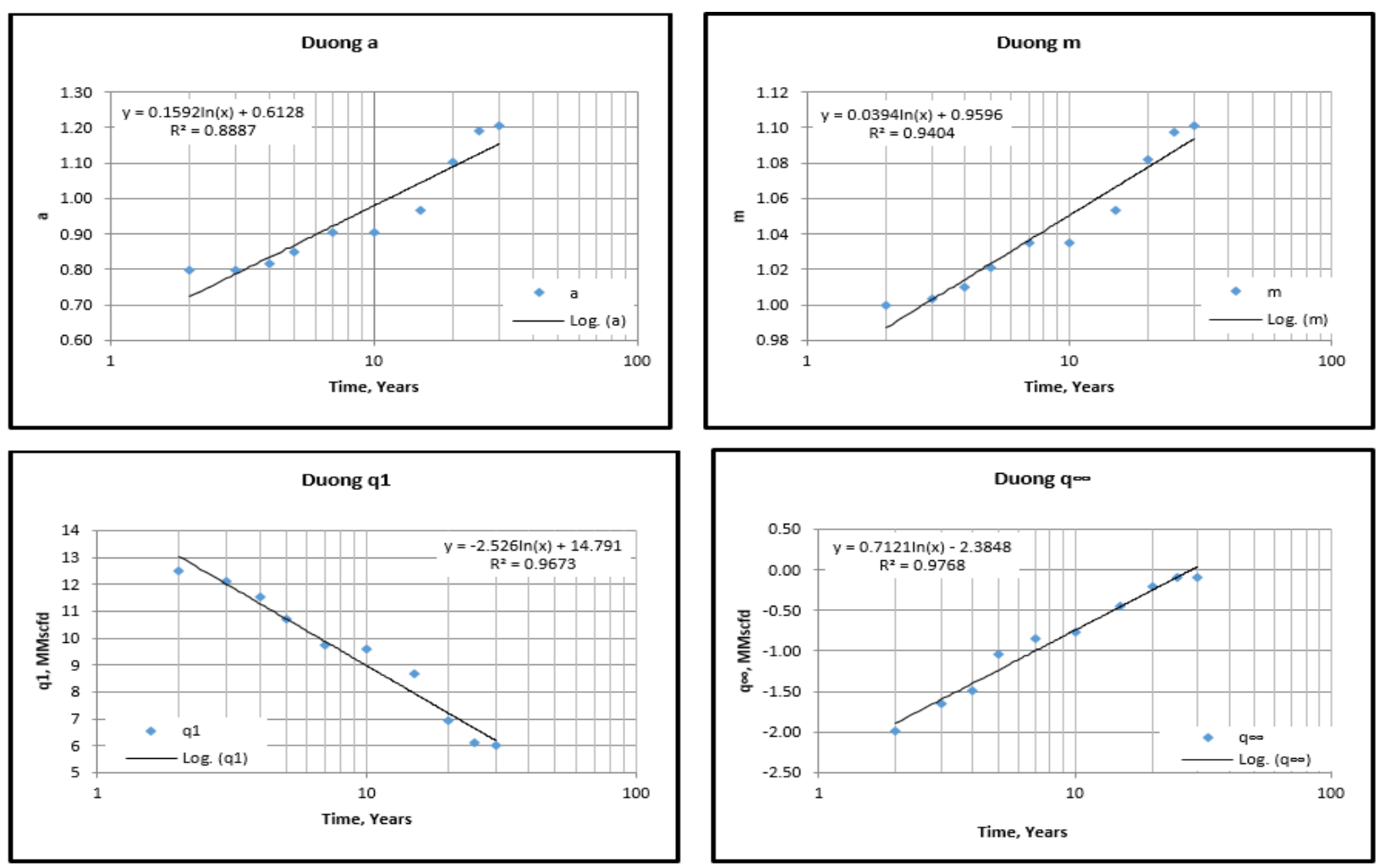

Figure D-41: 7 Stages - Duong Constants Correlations (8\%) 

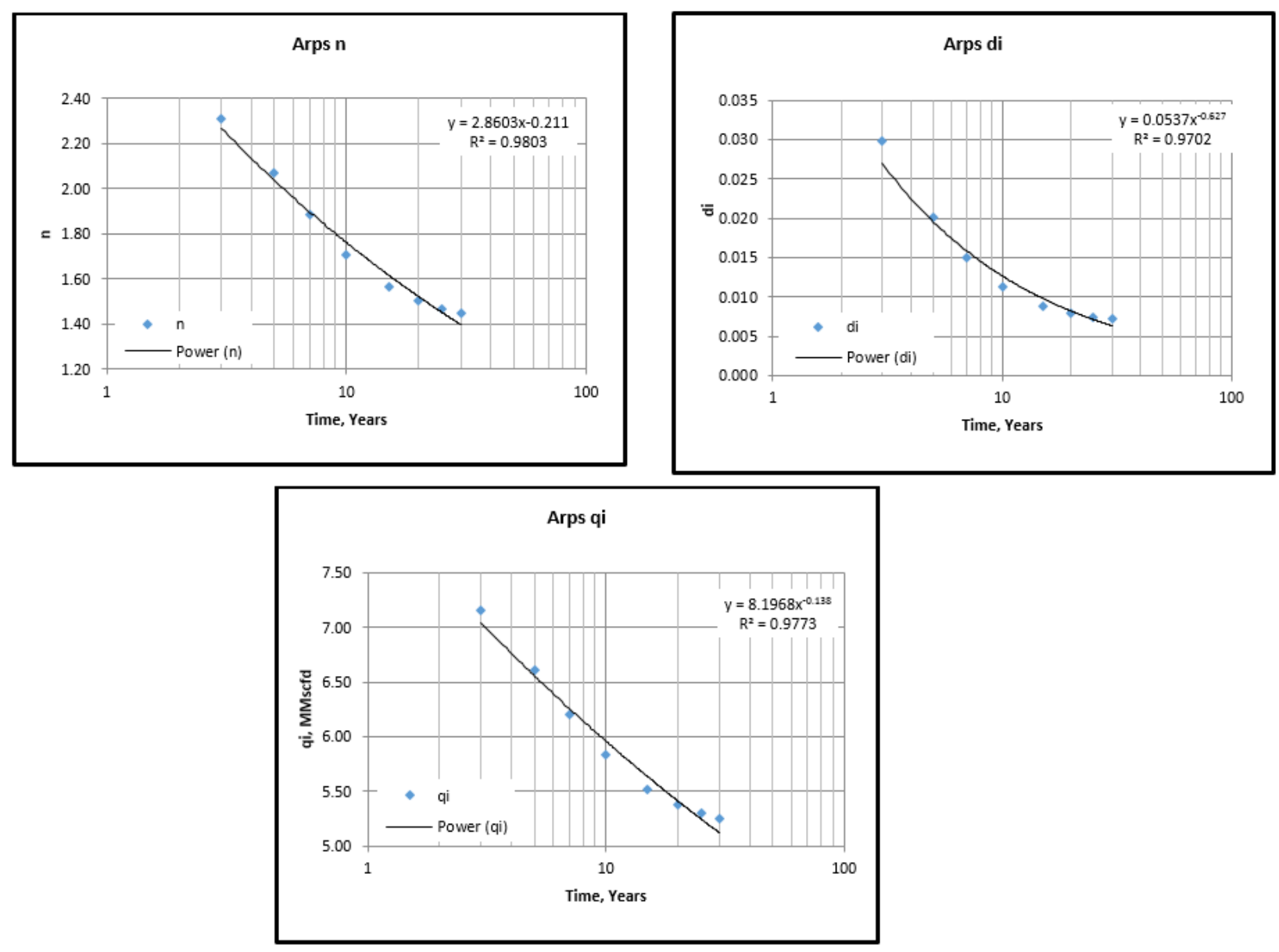

Figure D-42: 7 Stages - Arps Constants Correlations (8\%) 


\section{D.2. Thirteen Stages Model}

Table D-43: 13 Stages (300 ft.)- Arps

\begin{tabular}{|c|c|c|c|c|}
\hline \multicolumn{5}{|c|}{13 Fractures (300 ft.)- Arps } \\
\hline Years & $n$ & $d_{i}$ & $q_{i}$ & $R^{2}$ \\
\hline 3 & 1.422 & 0.032 & 8.748 & 0.974 \\
\hline 5 & 1.325 & 0.027 & 8.443 & 0.982 \\
\hline 7 & 1.278 & 0.025 & 8.206 & 0.987 \\
\hline 10 & 1.226 & 0.022 & 7.899 & 0.988 \\
\hline 15 & 1.209 & 0.020 & 7.717 & 0.986 \\
\hline 20 & 1.194 & 0.019 & 7.571 & 0.983 \\
\hline 25 & 1.180 & 0.018 & 7.452 & 0.980 \\
\hline 30 & 1.178 & 0.018 & 7.406 & 0.978 \\
\hline
\end{tabular}

Table D-44: 13 Stages (300 ft.)- PLE

\begin{tabular}{|c|c|c|c|c|c|}
\hline \multicolumn{7}{|c|}{ 13 Fractures (300 ft.)-PLE } \\
\hline Years & $D_{\infty}$ & $\boldsymbol{n}$ & $\boldsymbol{q}_{\boldsymbol{i}}$ & $\boldsymbol{D}_{\mathbf{1}}$ & $\boldsymbol{R}^{\mathbf{2}}$ \\
\hline 2 & 0.00108 & 0.31242 & 12.40479 & 0.09891 & 0.99956 \\
\hline 3 & 0.00039 & 0.34859 & 12.38347 & 0.09934 & 0.99849 \\
\hline 4 & -0.00018 & 0.38027 & 12.34272 & 0.09822 & 0.99724 \\
\hline 5 & -0.00018 & 0.38027 & 12.34272 & 0.09822 & 0.99559 \\
\hline 7 & -0.00094 & 0.42481 & 12.26754 & 0.09468 & 0.99595 \\
\hline 10 & -0.00096 & 0.42618 & 12.27122 & 0.09445 & 0.99610 \\
\hline 15 & -0.00077 & 0.40981 & 12.31815 & 0.09686 & 0.99533 \\
\hline 20 & -0.00059 & 0.38989 & 12.41823 & 0.10050 & 0.99344 \\
\hline 25 & -0.00049 & 0.37774 & 12.46526 & 0.10256 & 0.99110 \\
\hline 30 & -0.00040 & 0.36136 & 12.65075 & 0.10718 & 0.98874 \\
\hline
\end{tabular}

Table D-45: 13 Stages (300 ft.)- Duong

\begin{tabular}{|c|c|c|c|c|c|}
\hline \multicolumn{7}{|c|}{ 13 Fractures (300 ft.)- Duong } \\
\hline Years & $\boldsymbol{a}$ & $\boldsymbol{m}$ & $\boldsymbol{q}_{\mathbf{1}}$ & $\boldsymbol{q}_{\infty}$ & $\boldsymbol{R}^{2}$ \\
\hline 2 & 0.908 & 1.024 & 14.505 & -3.934 & 0.997 \\
\hline 3 & 0.855 & 1.032 & 14.205 & -1.972 & 0.991 \\
\hline 4 & 0.881 & 1.057 & 13.650 & -0.977 & 0.985 \\
\hline 5 & 0.935 & 1.082 & 13.010 & -0.558 & 0.982 \\
\hline 7 & 1.008 & 1.109 & 12.400 & -0.245 & 0.978 \\
\hline 10 & 1.065 & 1.130 & 12.040 & -0.082 & 0.974 \\
\hline 15 & 1.122 & 1.146 & 11.608 & 0.040 & 0.973 \\
\hline 20 & 1.162 & 1.155 & 11.208 & 0.040 & 0.974 \\
\hline 25 & 1.215 & 1.164 & 10.500 & 0.055 & 0.976 \\
\hline 30 & 1.249 & 1.170 & 10.040 & 0.060 & 0.977 \\
\hline
\end{tabular}



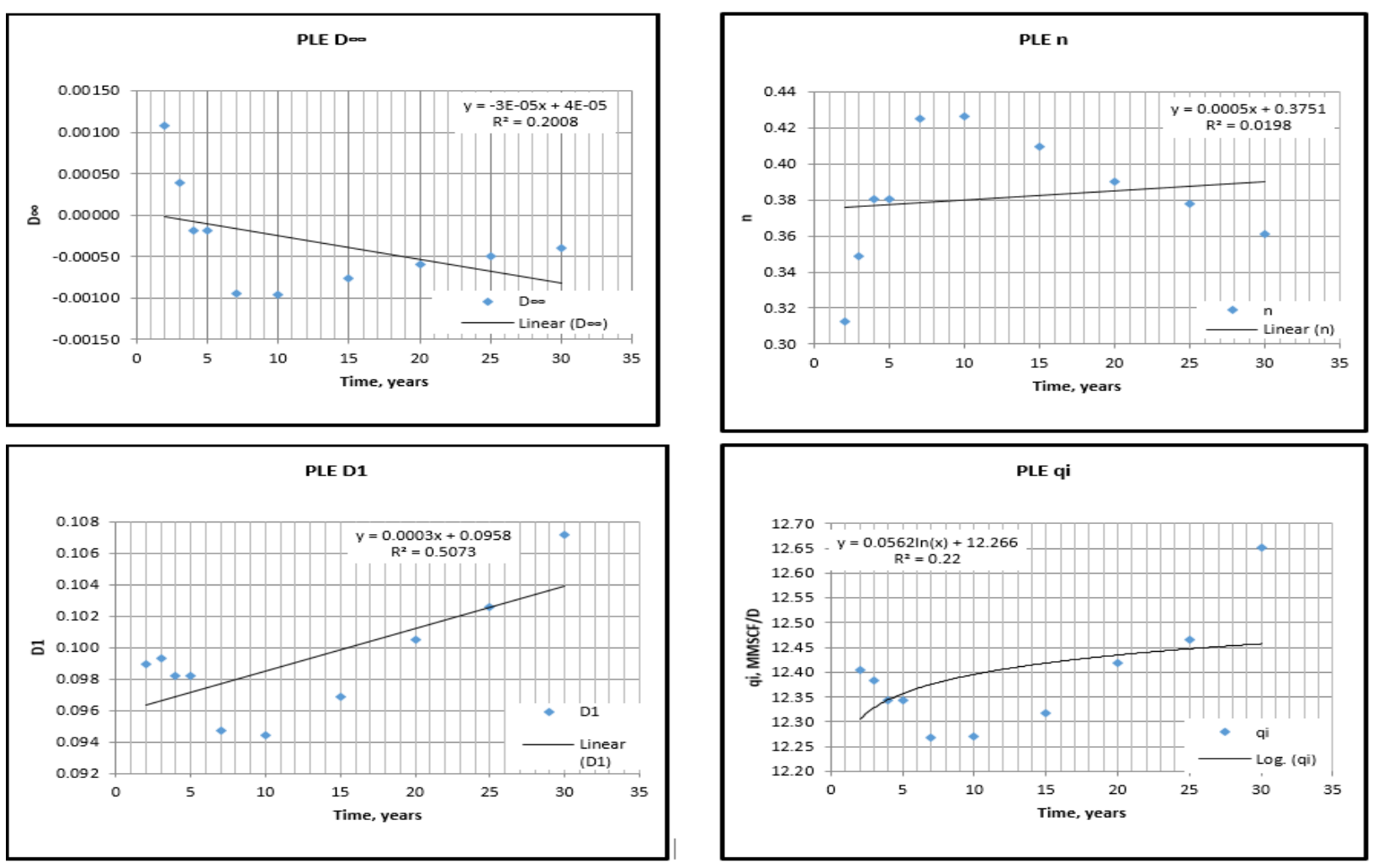

Figure D-43: 13 Stages - PLE Constants Correlation (300ft.)
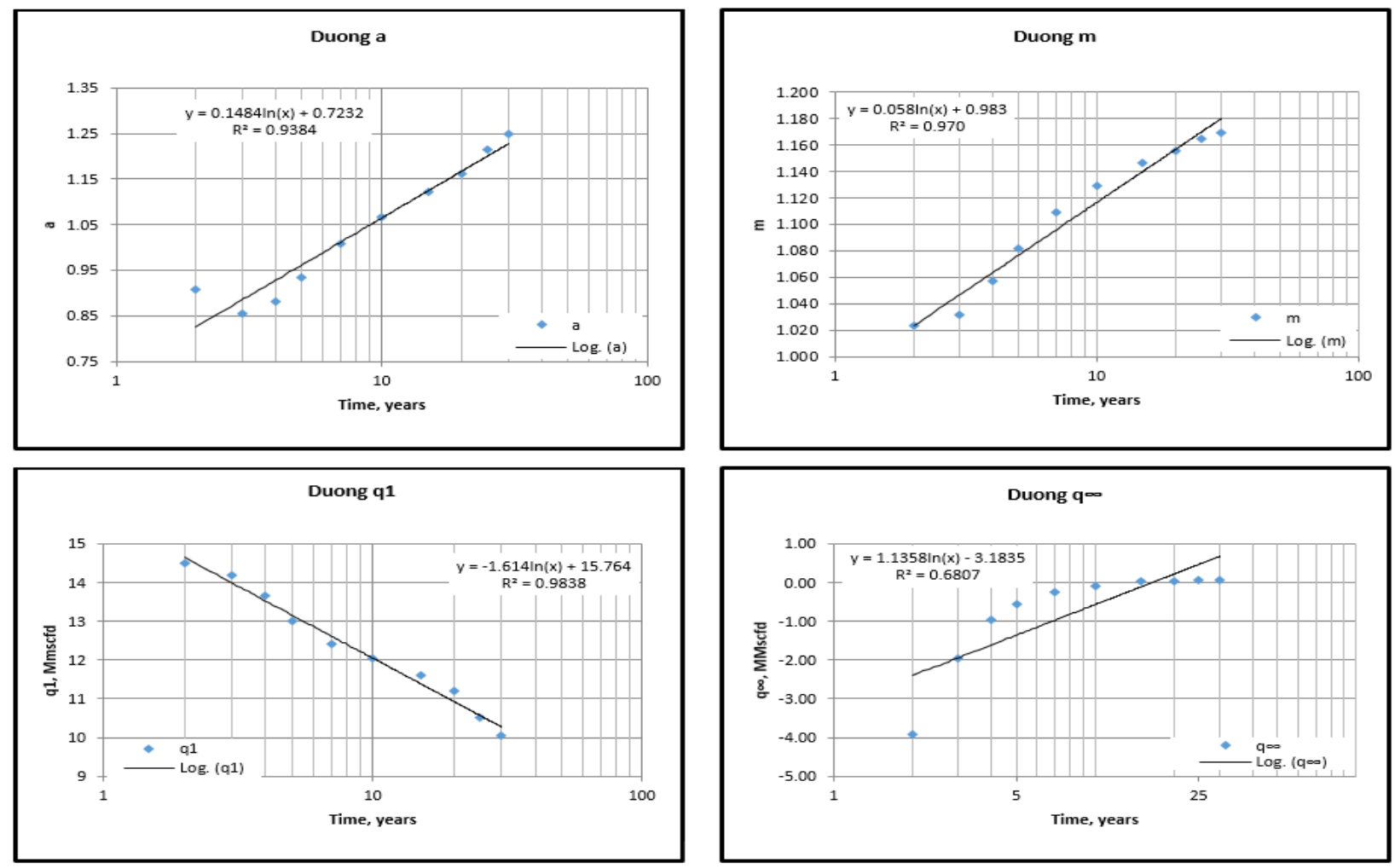

Figure D-44: 13 Stages - Duong Constants Correlation (300ft.) 

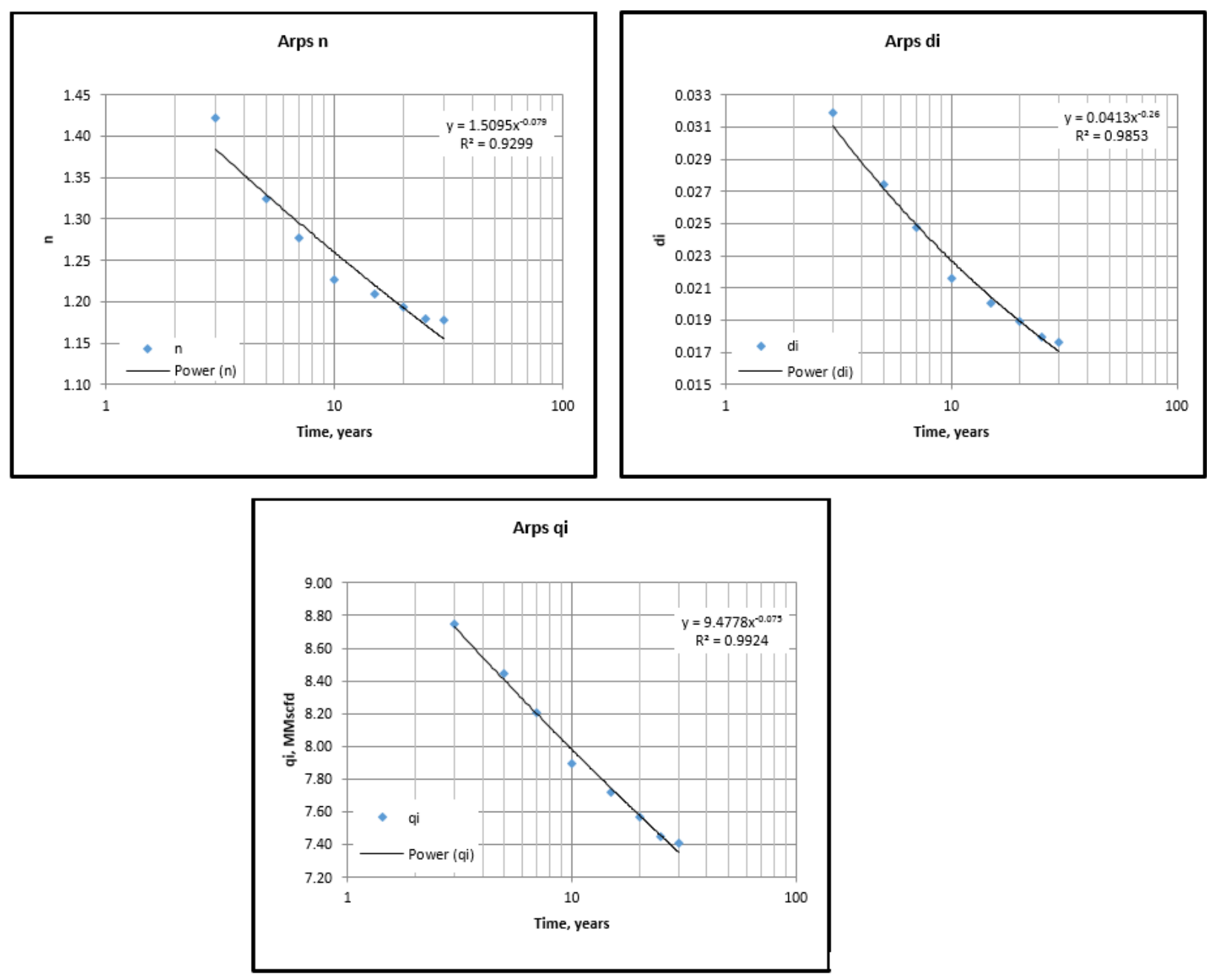

Figure D-45: 13 Stages - Arps Constants Correlation (300ft.) 
Table D-46: 13 Stages (400 ft.)- Arps

\begin{tabular}{|c|c|c|c|c|}
\hline \multicolumn{5}{|c|}{ 13 Fractures (400 ft.)- Arps } \\
\hline Years & $n$ & di & qi & $R^{2}$ \\
\hline 3 & 1.485 & 0.033 & 10.781 & 0.968 \\
\hline 5 & 1.405 & 0.031 & 10.714 & 0.970 \\
\hline 7 & 1.345 & 0.028 & 10.444 & 0.977 \\
\hline 10 & 1.305 & 0.026 & 10.217 & 0.981 \\
\hline 15 & 1.287 & 0.024 & 10.070 & 0.984 \\
\hline 20 & 1.271 & 0.023 & 9.928 & 0.985 \\
\hline 25 & 1.250 & 0.022 & 9.764 & 0.986 \\
\hline 30 & 1.240 & 0.021 & 9.680 & 0.986 \\
\hline
\end{tabular}

Table D-47: 13 Stages (400 ft.)- PLE

\begin{tabular}{|c|c|c|c|c|c|}
\hline \multicolumn{7}{|c|}{ 13 Fractures (400 ft.)- PLE } \\
\hline Years & $\boldsymbol{D}_{\infty}$ & $\boldsymbol{n}$ & $\boldsymbol{q}_{\boldsymbol{i}}$ & $\boldsymbol{D}_{\mathbf{1}}$ & $\boldsymbol{R}^{\mathbf{2}}$ \\
\hline 2 & 0.00080 & 0.34496 & 13.67353 & 0.08701 & 0.99958 \\
\hline 3 & 0.00049 & 0.36265 & 13.66283 & 0.08684 & 0.99937 \\
\hline 4 & 0.00013 & 0.38490 & 13.63423 & 0.08602 & 0.99873 \\
\hline 5 & -0.00021 & 0.40703 & 13.60437 & 0.08463 & 0.99795 \\
\hline 7 & -0.00070 & 0.43970 & 13.52472 & 0.08163 & 0.99692 \\
\hline 10 & -0.00093 & 0.45725 & 13.45377 & 0.07947 & 0.99672 \\
\hline 15 & -0.00084 & 0.44949 & 13.48119 & 0.08054 & 0.99667 \\
\hline 20 & -0.00069 & 0.43334 & 13.58492 & 0.08325 & 0.99571 \\
\hline 25 & -0.00057 & 0.42064 & 13.58613 & 0.08509 & 0.99420 \\
\hline 30 & -0.00049 & 0.41009 & 13.58668 & 0.08682 & 0.99261 \\
\hline
\end{tabular}

Table D-48: 13 Stages (400 ft.)- Duong

\begin{tabular}{|c|c|c|c|c|c|}
\hline \multicolumn{7}{|c|}{13 Fractures (400 ft.)-Duong } \\
\hline Years & $\boldsymbol{a}$ & $\boldsymbol{m}$ & $\boldsymbol{q}_{\mathbf{1}}$ & $\boldsymbol{q}_{\infty}$ & $\boldsymbol{R}^{2}$ \\
\hline 2 & 0.973 & 1.043 & 15.050 & -3.557 & 0.999 \\
\hline 3 & 0.965 & 1.055 & 14.501 & -2.142 & 0.996 \\
\hline 4 & 0.998 & 1.075 & 13.850 & -1.292 & 0.993 \\
\hline 5 & 1.058 & 1.097 & 13.020 & -0.815 & 0.990 \\
\hline 7 & 1.137 & 1.123 & 12.254 & -0.413 & 0.985 \\
\hline 10 & 1.216 & 1.146 & 11.600 & -0.183 & 0.981 \\
\hline 15 & 1.276 & 1.163 & 11.202 & -0.054 & 0.978 \\
\hline 20 & 1.316 & 1.172 & 10.860 & -0.006 & 0.978 \\
\hline 25 & 1.347 & 1.178 & 10.530 & 0.015 & 0.978 \\
\hline 30 & 1.572 & 1.218 & 10.232 & 0.071 & 0.976 \\
\hline
\end{tabular}



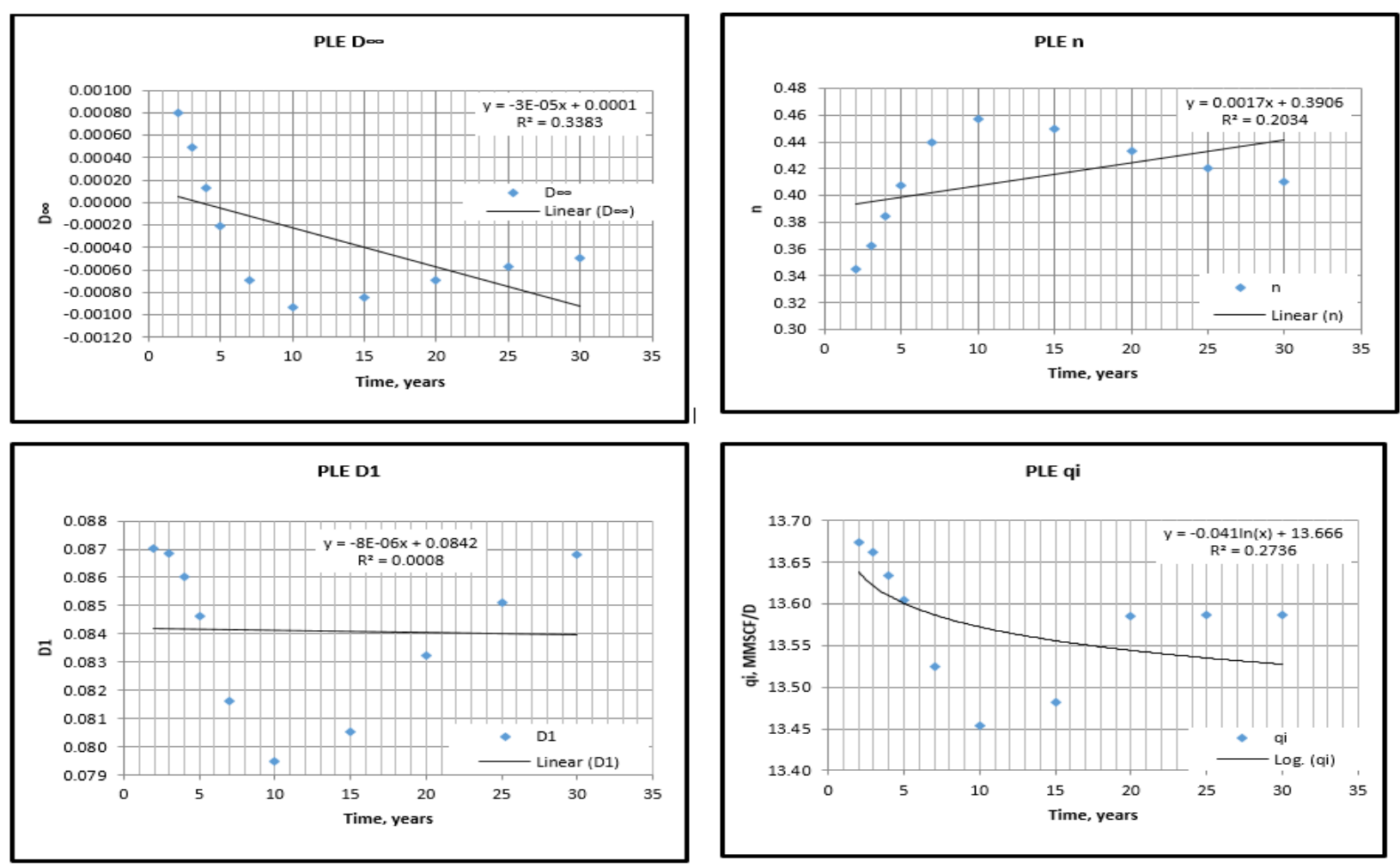

Figure D-46: 13 Stages - PLE Constants Correlation (400ft.)
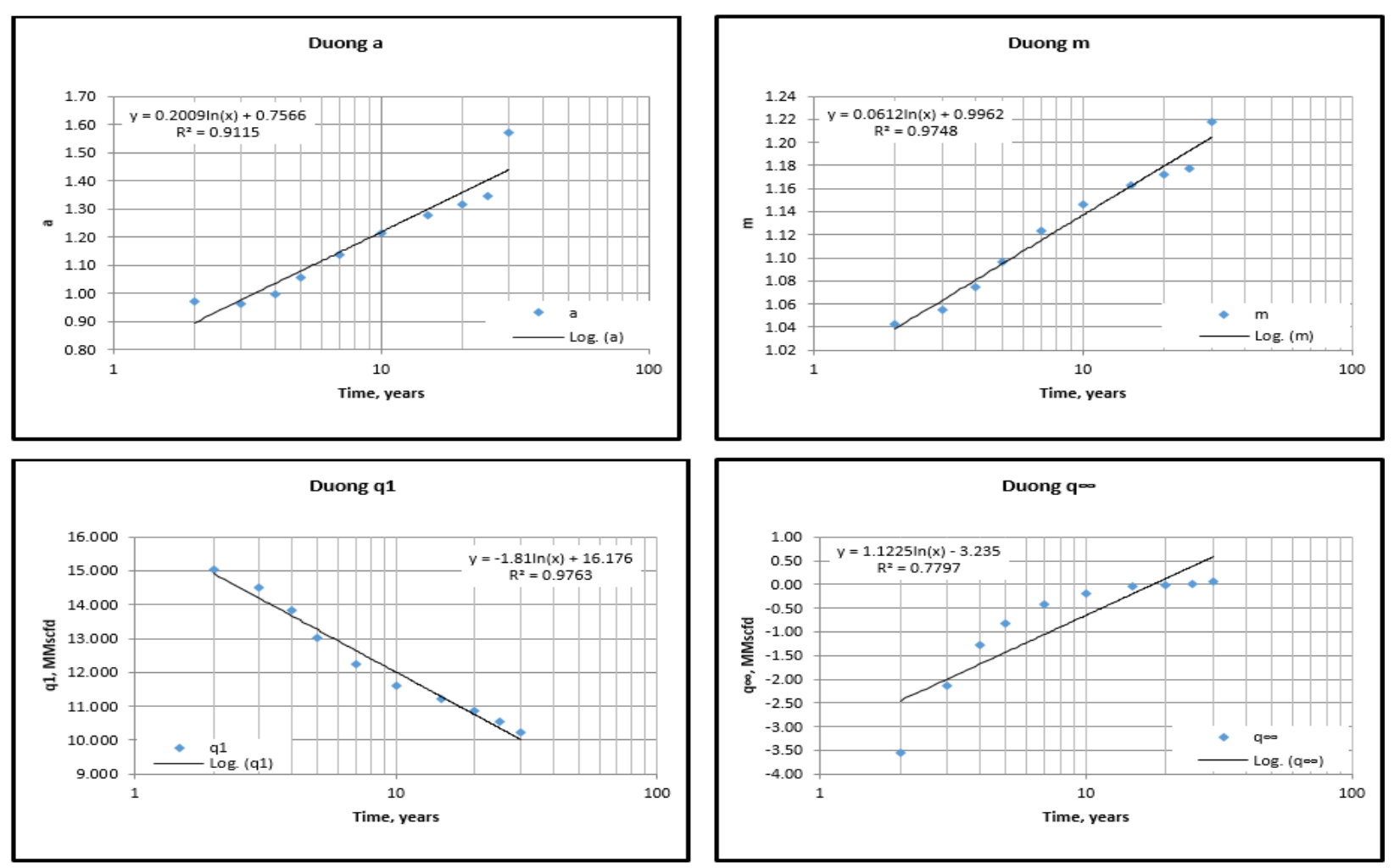

Figure D-47:13 Stages - Duong Constants Correlation (400ft.) 

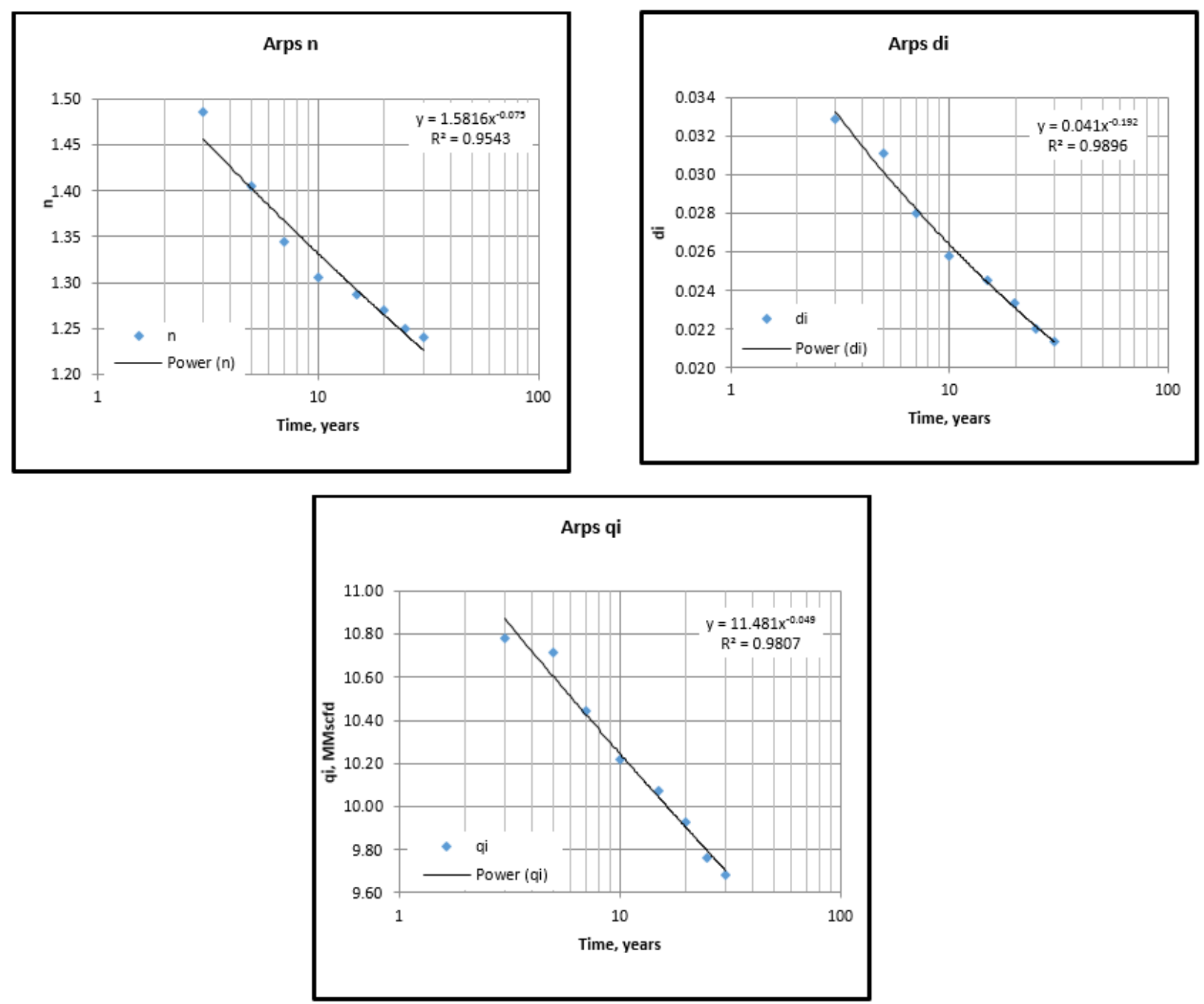

Figure D-48: 13 Stages - Arps Constants Correlation (400ft.) 
Table D-49: 13 Stages (500 ft.)- Arps

\begin{tabular}{|c|c|c|c|c|}
\hline \multicolumn{5}{|c|}{13 Fractures (500 ft.)- Arps } \\
\hline Years & $n$ & di & qi & $\boldsymbol{R}^{\mathbf{2}}$ \\
\hline 3 & 1.5027 & 0.0281 & 11.76 & 0.971 \\
\hline 5 & 1.4045 & 0.0265 & 11.71 & 0.971 \\
\hline 7 & 1.3575 & 0.0252 & 11.61 & 0.974 \\
\hline 10 & 1.3221 & 0.0240 & 11.48 & 0.978 \\
\hline 15 & 1.3046 & 0.0233 & 11.41 & 0.980 \\
\hline 20 & 1.2946 & 0.0229 & 11.35 & 0.982 \\
\hline 25 & 1.2800 & 0.0221 & 11.25 & 0.984 \\
\hline 30 & 1.2765 & 0.0220 & 11.23 & 0.984 \\
\hline
\end{tabular}

Table D-50: 13 Stages (500 ft.)- PLE

\begin{tabular}{|c|c|c|c|c|c|}
\hline \multicolumn{7}{|c|}{ 13 Fractures (500 ft.)- PLE } \\
\hline Years & $\boldsymbol{D}_{\infty}$ & $\boldsymbol{n}$ & $\boldsymbol{q}_{\boldsymbol{i}}$ & $\boldsymbol{D}_{\mathbf{1}}$ & $\boldsymbol{R}^{\mathbf{2}}$ \\
\hline 2 & 0.00043 & 0.38974 & 13.96094 & 0.07301 & 0.99967 \\
\hline 3 & 0.00031 & 0.39698 & 13.96372 & 0.07287 & 0.99968 \\
\hline 4 & 0.00007 & 0.41378 & 13.93370 & 0.07191 & 0.99946 \\
\hline 5 & -0.00014 & 0.42864 & 13.91210 & 0.07096 & 0.99909 \\
\hline 7 & -0.00052 & 0.45740 & 13.83536 & 0.06846 & 0.99837 \\
\hline 10 & -0.00083 & 0.48304 & 13.74054 & 0.06558 & 0.99797 \\
\hline 15 & -0.00084 & 0.48344 & 13.73831 & 0.06556 & 0.99803 \\
\hline 20 & -0.00073 & 0.47279 & 13.73751 & 0.06678 & 0.99765 \\
\hline 25 & -0.00063 & 0.46149 & 13.73848 & 0.06819 & 0.99680 \\
\hline 30 & -0.00055 & 0.45262 & 13.74003 & 0.06942 & 0.99581 \\
\hline
\end{tabular}

Table D-51: 13 Stages (500 ft.)- Duong

\begin{tabular}{|c|c|c|c|c|c|}
\hline \multicolumn{7}{|c|}{ 13 Fractures (500 ft.)-Duong } \\
\hline Years & $\boldsymbol{a}$ & $\boldsymbol{m}$ & $\boldsymbol{q}_{\mathbf{1}}$ & $\boldsymbol{q}_{\infty}$ & $\boldsymbol{R}^{2}$ \\
\hline 2 & 0.946 & 1.049 & 16.1 & -2.577 & 0.954 \\
\hline 3 & 0.986 & 1.051 & 15.0 & -2.556 & 0.982 \\
\hline 4 & 1.063 & 1.081 & 14.0 & -1.591 & 0.996 \\
\hline 5 & 1.118 & 1.099 & 13.2 & -1.081 & 0.994 \\
\hline 7 & 1.199 & 1.124 & 12.3 & -0.609 & 0.990 \\
\hline 10 & 1.262 & 1.143 & 11.8 & -0.324 & 0.986 \\
\hline 15 & 1.340 & 1.162 & 11.2 & -0.144 & 0.983 \\
\hline 20 & 1.399 & 1.181 & 10.9 & -0.038 & 0.977 \\
\hline 25 & 1.465 & 1.185 & 10.2 & -0.024 & 0.980 \\
\hline 30 & 1.650 & 1.220 & 9.8 & 0.050 & 0.963 \\
\hline
\end{tabular}



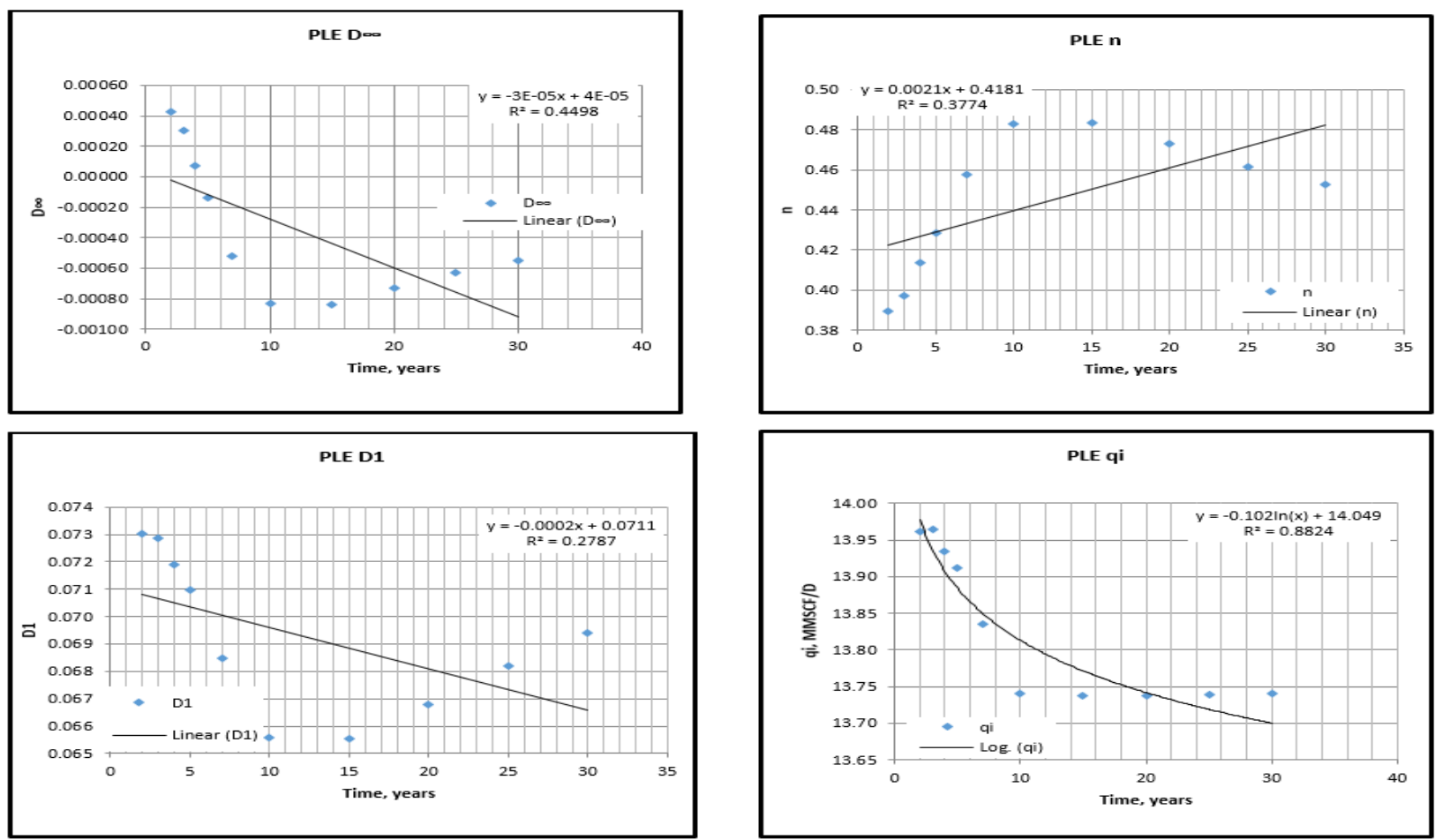

Figure D-49: 13 Stages - PLE Constants Correlation (500ft.)
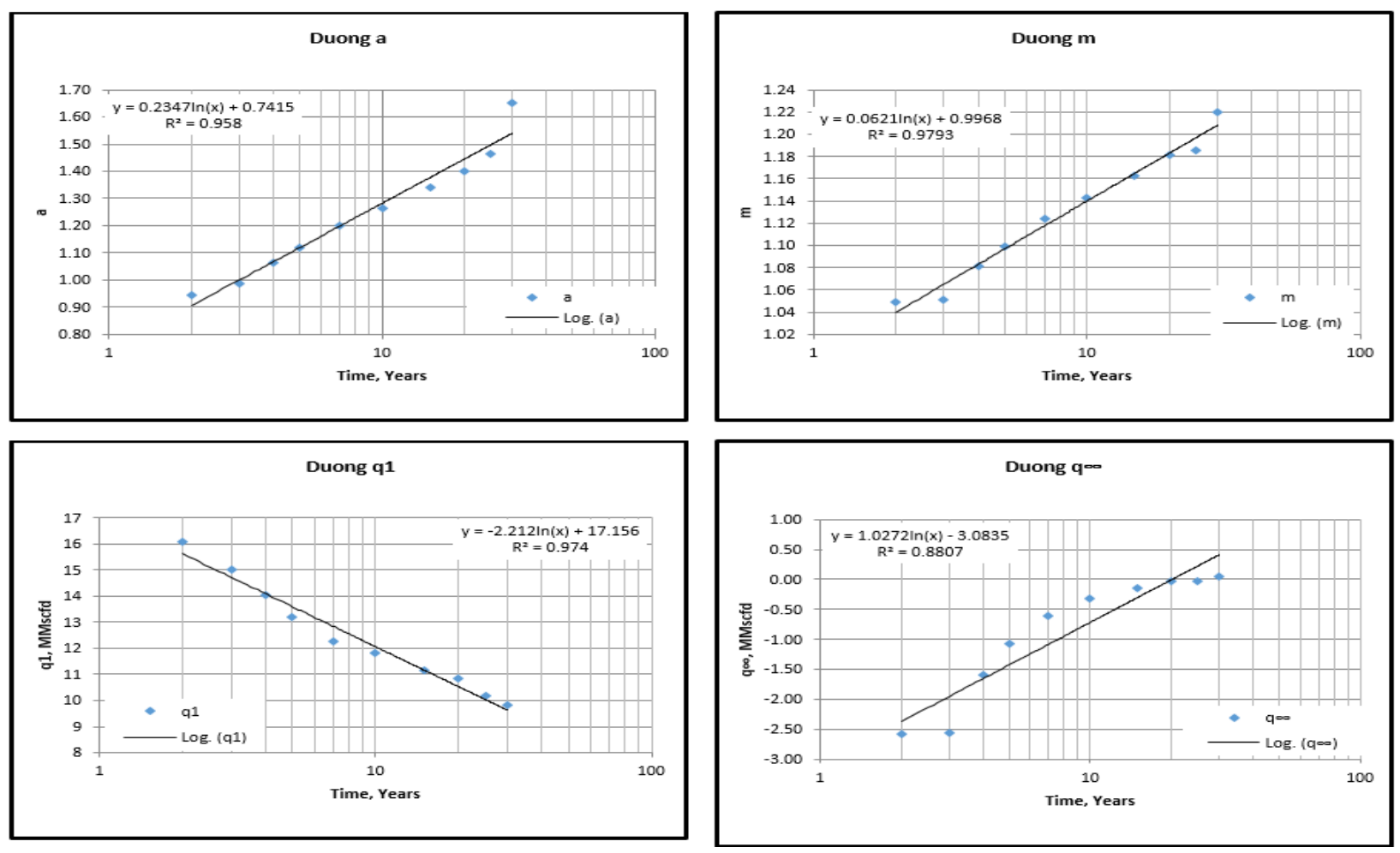

Figure D-50: 13 Stages - Duong Constants Correlation (500ft.) 

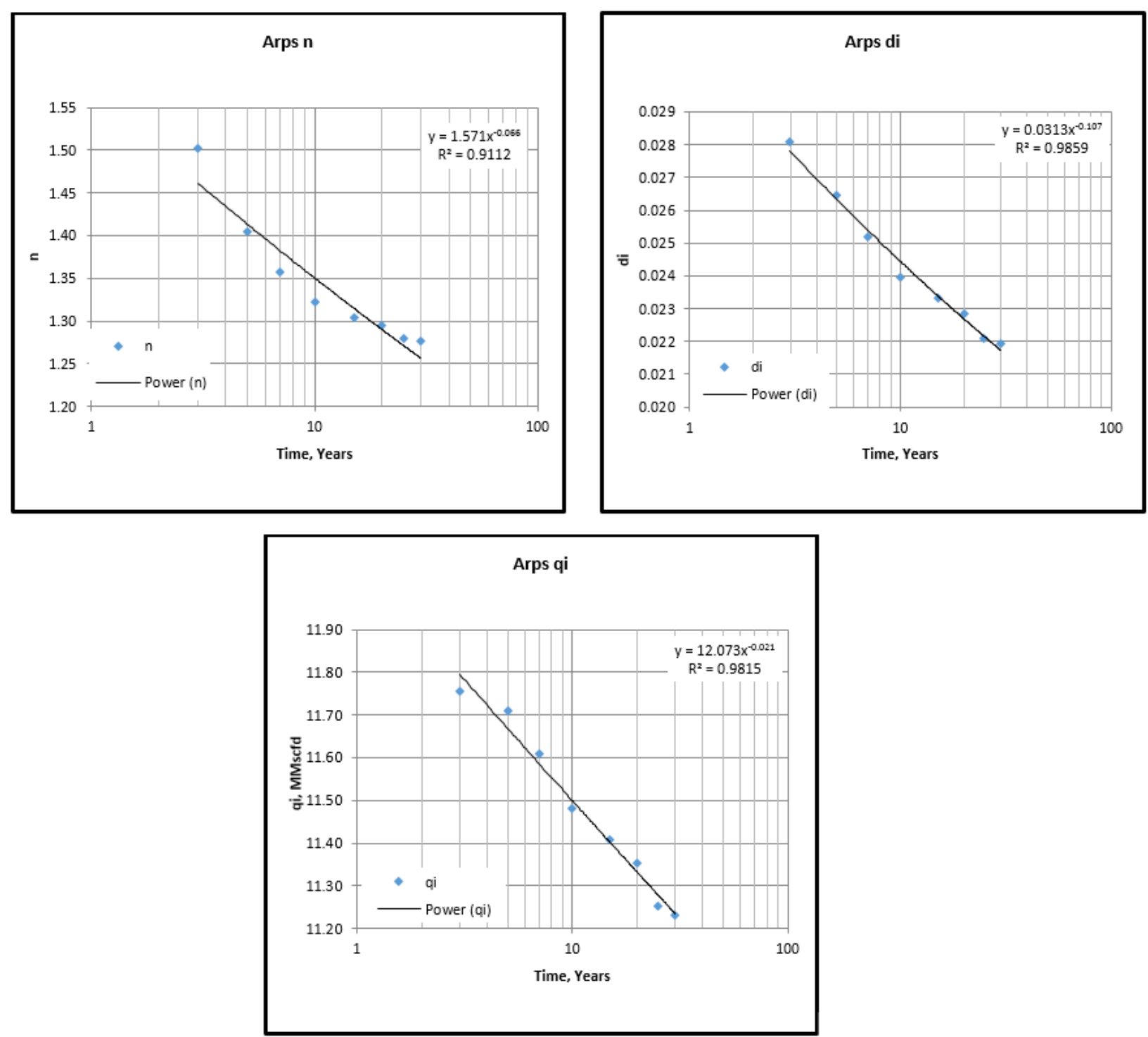

Figure D-51: 13 Stages - Arps Constants Correlation (500ft.) 
Table D-52: 13 Stages (600 ft.)- Arps

\begin{tabular}{|c|c|c|c|c|}
\hline \multicolumn{5}{|c|}{13 Fractures (600 ft.)-Arps } \\
\hline Years & $\boldsymbol{n}$ & $\boldsymbol{d}_{\boldsymbol{i}}$ & $\boldsymbol{q}_{\boldsymbol{i}}$ & $\boldsymbol{R}^{\mathbf{2}}$ \\
\hline 3 & 1.4450 & 0.0224 & 12.0700 & 0.9779 \\
\hline 5 & 1.4031 & 0.0214 & 12.0418 & 0.9739 \\
\hline 7 & 1.3678 & 0.0210 & 12.0225 & 0.9737 \\
\hline 10 & 1.3229 & 0.0200 & 11.9181 & 0.9767 \\
\hline 15 & 1.3027 & 0.0198 & 11.9095 & 0.9785 \\
\hline 20 & 1.2795 & 0.0190 & 11.8087 & 0.9810 \\
\hline 25 & 1.2648 & 0.0186 & 11.7405 & 0.9825 \\
\hline 30 & 1.2538 & 0.0182 & 11.6853 & 0.9836 \\
\hline
\end{tabular}

Table D-53: 13 Stages (600 ft.)- PLE

\begin{tabular}{|c|c|c|c|c|c|}
\hline \multicolumn{7}{|c|}{13 Fractures (600 ft.)- PLE } \\
\hline Years & $D_{\infty}$ & $n$ & $\boldsymbol{q}_{\boldsymbol{i}}$ & $\boldsymbol{D}_{1}$ & $\boldsymbol{R}^{2}$ \\
\hline 2 & 0.00022 & 0.42758 & 13.69827 & 0.05990 & 0.99983 \\
\hline 3 & 0.00007 & 0.43851 & 13.67661 & 0.05928 & 0.99983 \\
\hline 4 & -0.00009 & 0.45032 & 13.65668 & 0.05860 & 0.99973 \\
\hline 5 & -0.00026 & 0.46464 & 13.61662 & 0.05747 & 0.99957 \\
\hline 7 & -0.00052 & 0.48787 & 13.54504 & 0.05542 & 0.99924 \\
\hline 10 & -0.00073 & 0.50604 & 13.46277 & 0.05359 & 0.99902 \\
\hline 15 & -0.00075 & 0.50428 & 13.60774 & 0.05453 & 0.99903 \\
\hline 20 & -0.00068 & 0.49576 & 13.67713 & 0.05575 & 0.99893 \\
\hline 25 & -0.00061 & 0.48764 & 13.67656 & 0.05662 & 0.99862 \\
\hline 30 & -0.00055 & 0.48126 & 13.67509 & 0.05725 & 0.99817 \\
\hline
\end{tabular}

Table D-54: 13 Stages (600 ft.)- Duong

\begin{tabular}{|c|c|c|c|c|c|}
\hline \multicolumn{7}{|c|}{ 13 Fractures (600 ft.)-Duong } \\
\hline Years & $\boldsymbol{a}$ & $\boldsymbol{m}$ & $\boldsymbol{q 1}$ & $\boldsymbol{q}^{\infty}$ & $\boldsymbol{R}^{2}$ \\
\hline 2 & 1.021 & 1.041 & 16.507 & -5.493 & 0.963 \\
\hline 3 & 1.034 & 1.051 & 15.500 & -4.020 & 0.985 \\
\hline 4 & 1.085 & 1.078 & 14.540 & -1.983 & 0.996 \\
\hline 5 & 1.138 & 1.094 & 13.540 & -1.390 & 0.995 \\
\hline 7 & 1.213 & 1.116 & 12.541 & -0.837 & 0.992 \\
\hline 10 & 1.303 & 1.139 & 11.640 & -0.479 & 0.988 \\
\hline 15 & 1.395 & 1.159 & 10.750 & -0.253 & 0.986 \\
\hline 20 & 1.505 & 1.181 & 9.970 & -0.121 & 0.984 \\
\hline 25 & 1.565 & 1.200 & 9.520 & -0.020 & 0.976 \\
\hline 30 & 1.606 & 1.199 & 9.020 & -0.032 & 0.984 \\
\hline
\end{tabular}



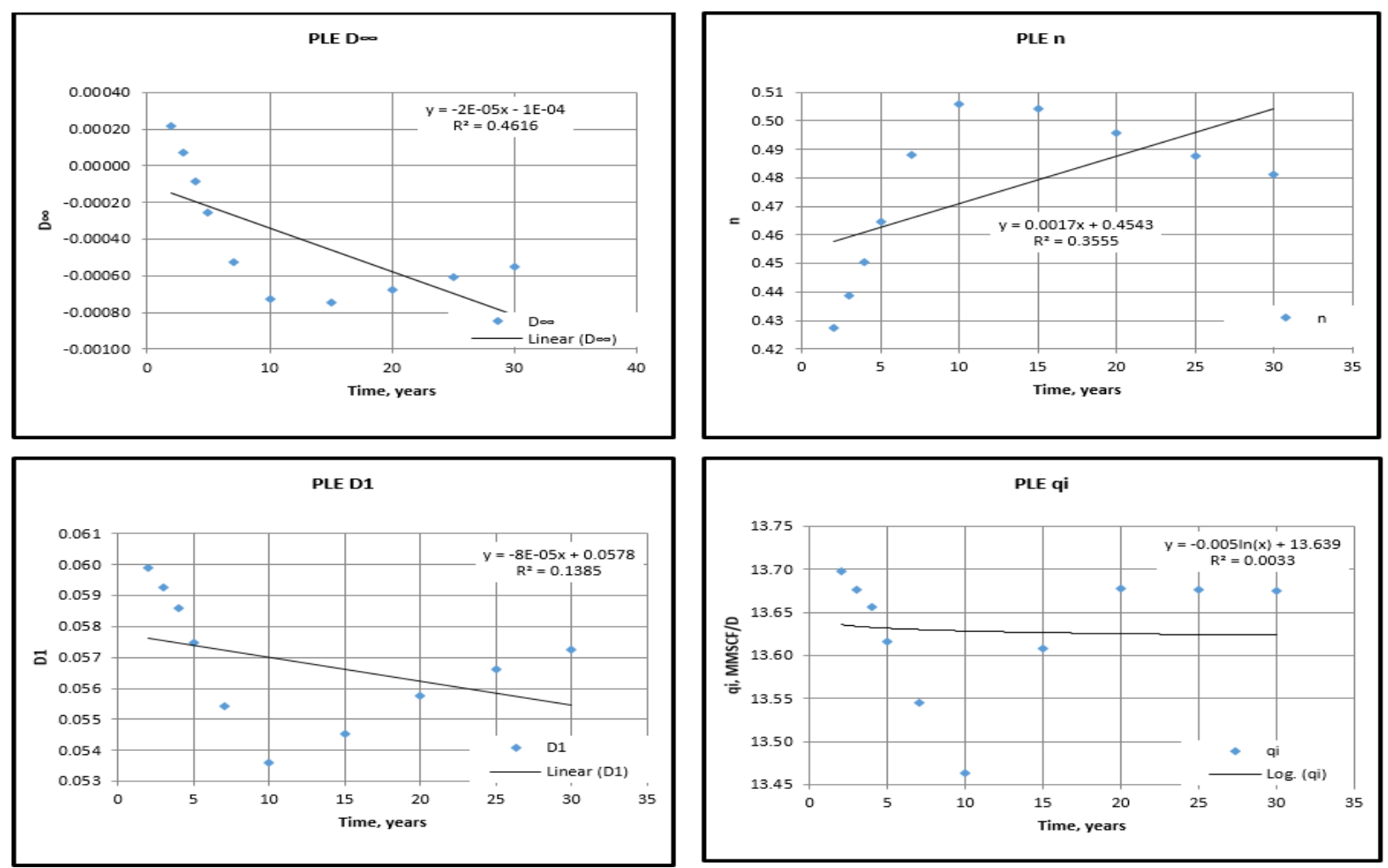

Figure D-52: 13 Stages - PLE Constants Correlation (600ft.)
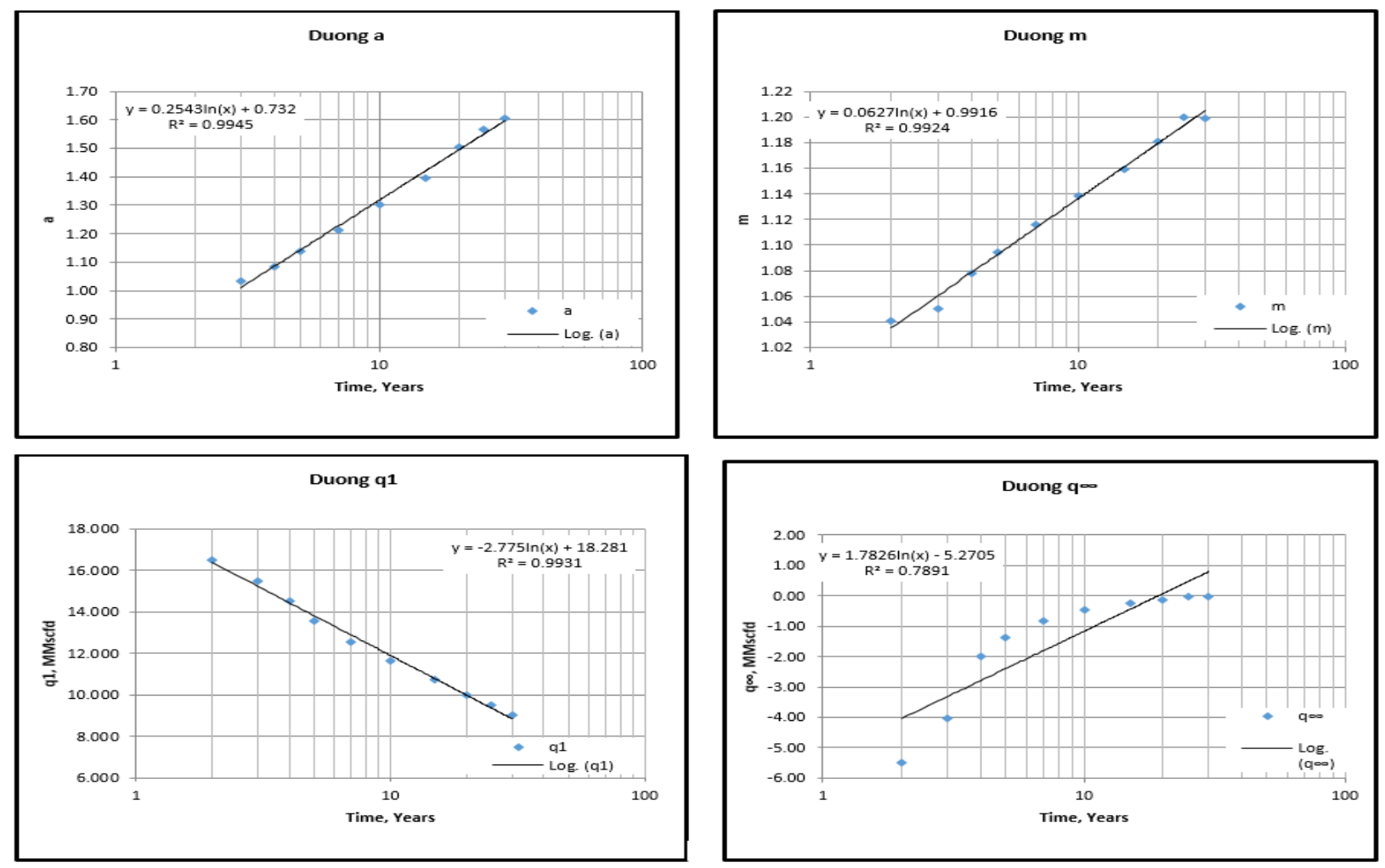

Figure D-53: 13 Stages - Duong Constants Correlation (600ft.) 

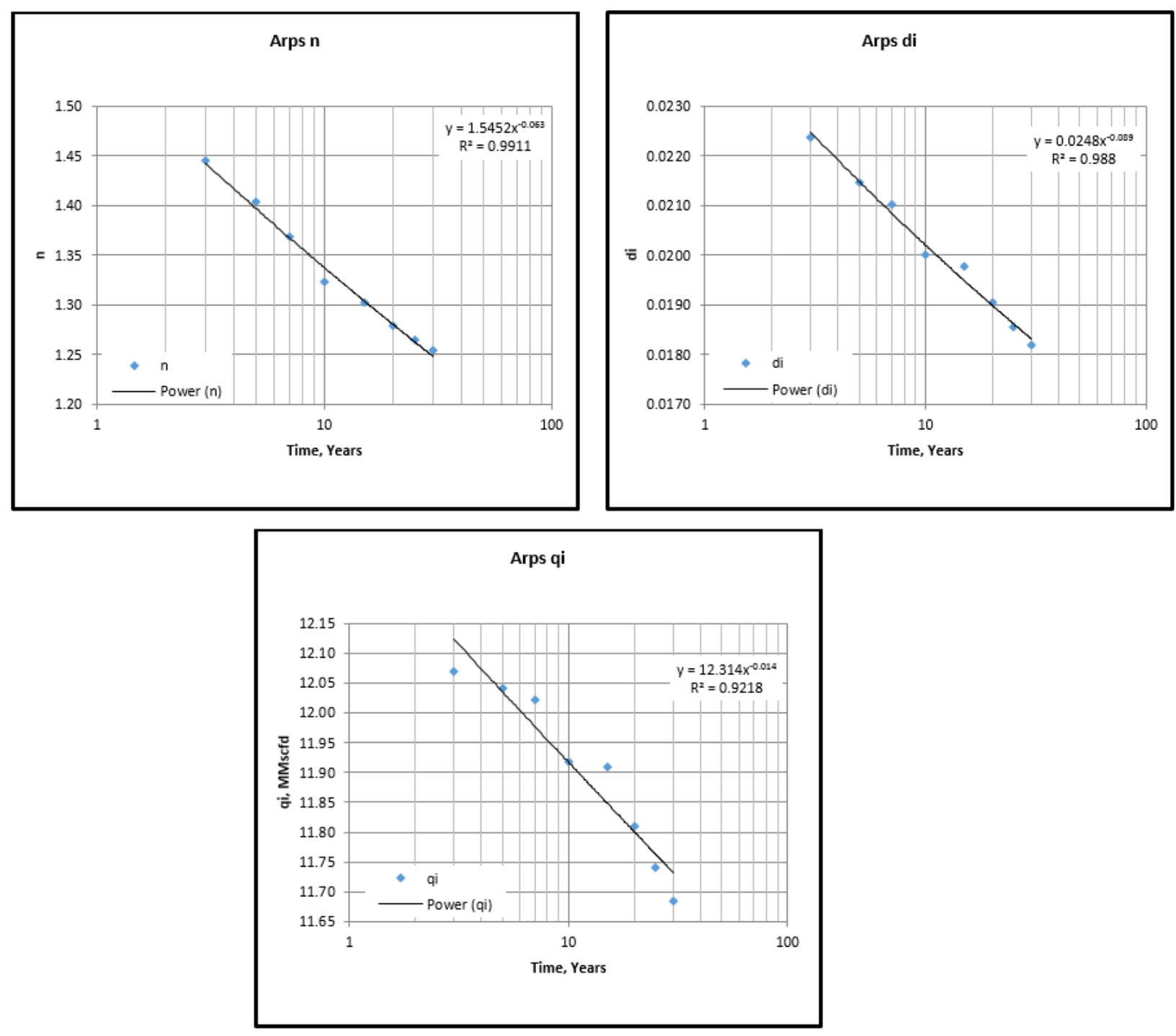

Figure D-54: 13 Stages - Arps Constants Correlation (600ft.) 
Table D-55: 13 Stages (700 ft.)- Arps

\begin{tabular}{|c|c|c|c|c|}
\hline \multicolumn{5}{|c|}{ 13 Fractures (700 ft.)- Arps } \\
\hline Years & $n$ & di & qi & $\boldsymbol{R}^{2}$ \\
\hline 3 & 1.46852 & 0.01906 & 12.22260 & 0.97786 \\
\hline 5 & 1.44685 & 0.01902 & 12.18208 & 0.97294 \\
\hline 7 & 1.42000 & 0.01770 & 12.06787 & 0.97043 \\
\hline 10 & 1.38458 & 0.01694 & 12.00566 & 0.96882 \\
\hline 15 & 1.36408 & 0.01649 & 11.97663 & 0.96604 \\
\hline 20 & 1.32989 & 0.01631 & 11.97121 & 0.96935 \\
\hline 25 & 1.30288 & 0.01621 & 11.95697 & 0.97233 \\
\hline 30 & 1.29766 & 0.01606 & 11.93092 & 0.97197 \\
\hline
\end{tabular}

Table D-56: 13 Stages (700 ft.)- PLE

\begin{tabular}{|c|c|c|c|c|c|}
\hline \multicolumn{7}{|c|}{ 13 Fractures (700 ft.)- PLE } \\
\hline Years & $D_{\infty}$ & $n$ & $\boldsymbol{q}_{\boldsymbol{i}}$ & $\boldsymbol{D}_{\mathbf{1}}$ & $\boldsymbol{R}^{\mathbf{2}}$ \\
\hline 2 & 0.00009 & 0.46229 & 13.11657 & 0.04833 & 0.99991 \\
\hline 3 & -0.00005 & 0.47230 & 13.10195 & 0.04792 & 0.99988 \\
\hline 4 & -0.00021 & 0.48640 & 13.06952 & 0.04703 & 0.99980 \\
\hline 5 & -0.00035 & 0.49873 & 13.06428 & 0.04634 & 0.99972 \\
\hline 7 & -0.00049 & 0.51175 & 13.02549 & 0.04534 & 0.99962 \\
\hline 10 & -0.00063 & 0.52632 & 12.98356 & 0.04403 & 0.99958 \\
\hline 15 & -0.00067 & 0.53208 & 12.92281 & 0.04323 & 0.99961 \\
\hline 20 & -0.00063 & 0.52686 & 12.92406 & 0.04374 & 0.99960 \\
\hline 25 & -0.00058 & 0.52271 & 12.88195 & 0.04396 & 0.99949 \\
\hline 30 & -0.00053 & 0.51545 & 12.90238 & 0.04482 & 0.99935 \\
\hline
\end{tabular}

Table D-57: 13 Stages (700 ft.)- Duong

\begin{tabular}{|c|c|c|c|c|c|}
\hline \multicolumn{7}{|c|}{ 13 Fractures (700 ft.)-Duong } \\
\hline Years & $\boldsymbol{a}$ & $\boldsymbol{m}$ & $\boldsymbol{q}_{1}$ & $\boldsymbol{q}_{\infty}$ & $\boldsymbol{R}^{2}$ \\
\hline 2 & 1.023 & 1.036 & 18.500 & -7.214 & 0.947 \\
\hline 3 & 1.020 & 1.045 & 17.420 & -4.633 & 0.997 \\
\hline 4 & 1.071 & 1.065 & 15.142 & -2.765 & 0.996 \\
\hline 5 & 1.118 & 1.081 & 14.014 & -1.890 & 0.995 \\
\hline 7 & 1.180 & 1.101 & 13.015 & -1.169 & 0.993 \\
\hline 10 & 1.252 & 1.121 & 12.125 & -0.725 & 0.991 \\
\hline 15 & 1.353 & 1.139 & 11.405 & -0.474 & 0.972 \\
\hline 20 & 1.495 & 1.185 & 10.458 & -0.063 & 0.966 \\
\hline 25 & 1.606 & 1.196 & 9.700 & -0.091 & 0.979 \\
\hline 30 & 1.653 & 1.197 & 8.790 & -0.022 & 0.977 \\
\hline
\end{tabular}



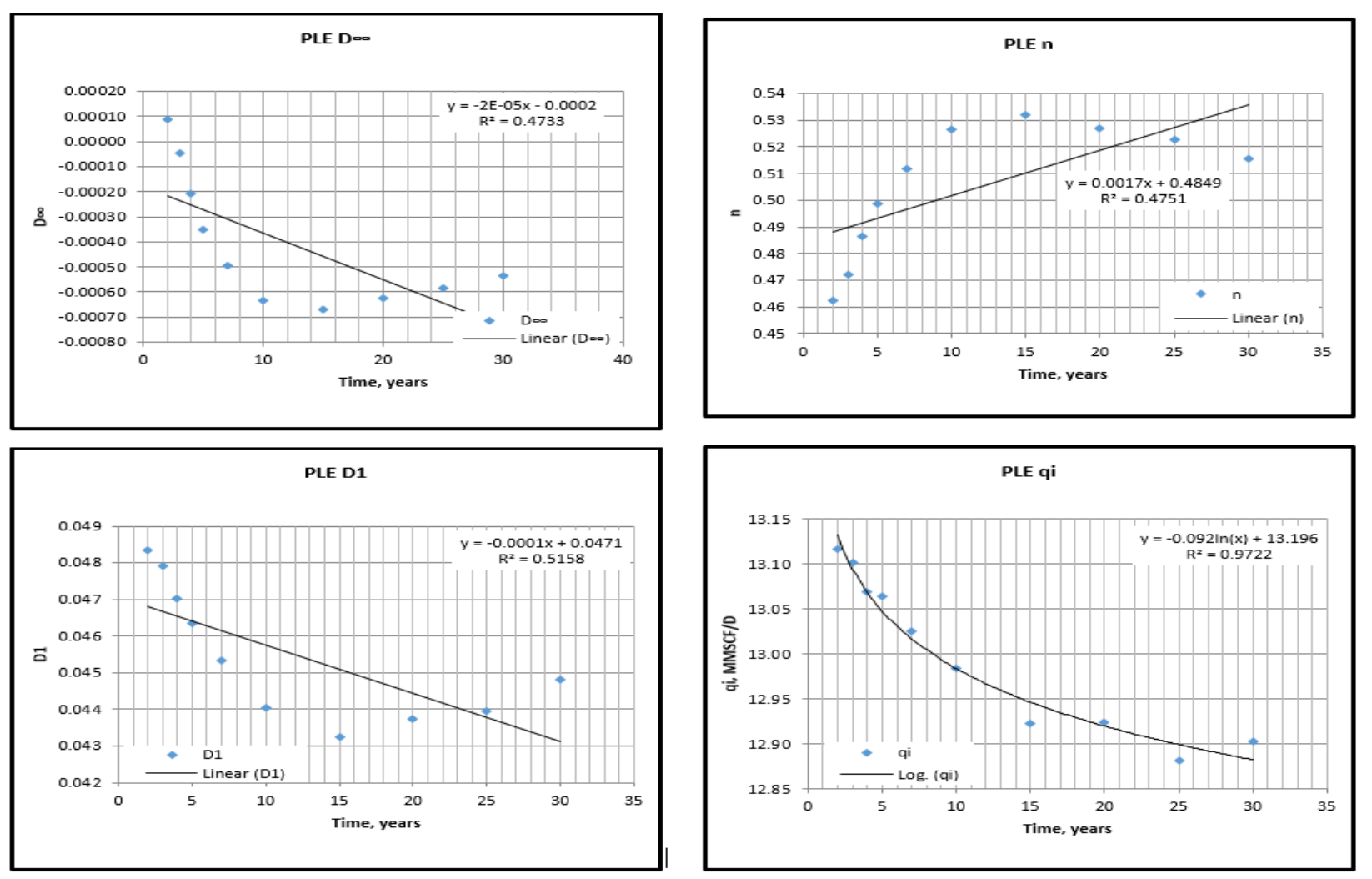

Figure D-55: 13 Stages - PLE Constants Correlation (700ft.)
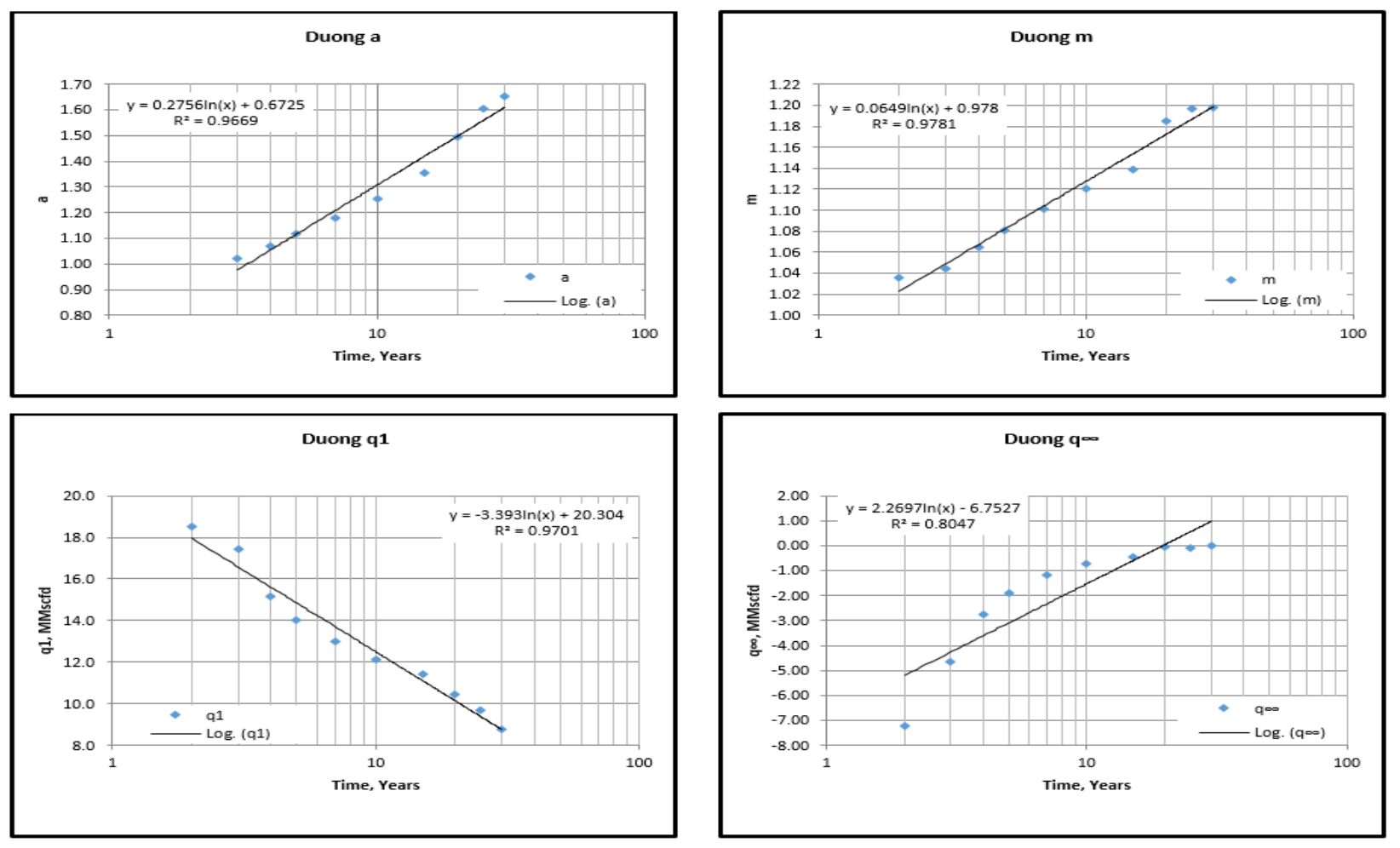

Figure D-56: 13 Stages - Duong Constants Correlation (700ft.) 

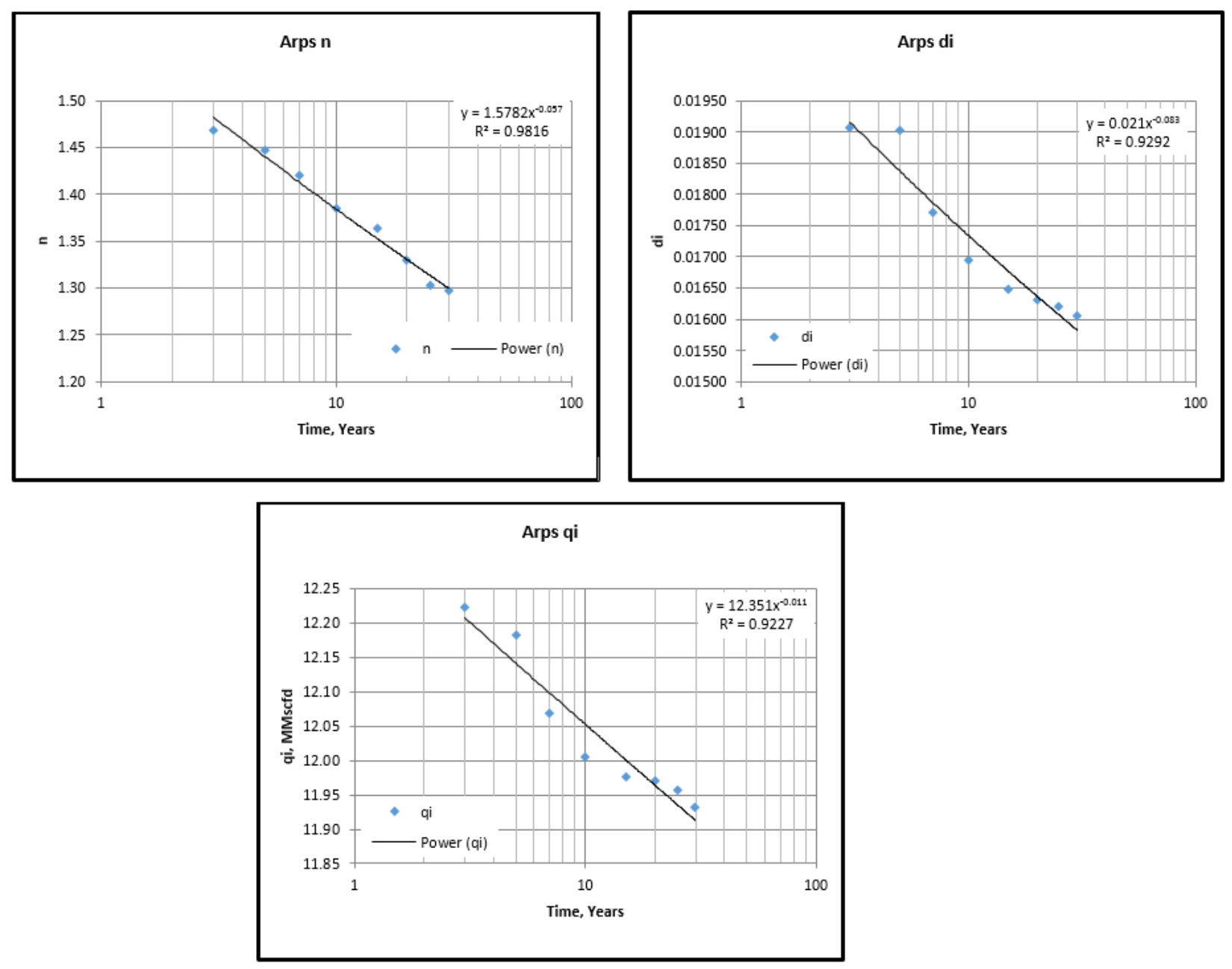

Figure D-57: 13 Stages - Arps Constants Correlation (700ft.) 
Table D-58: 13 Stages (0.0008 md) - Arps

\begin{tabular}{|c|c|c|c|c|}
\hline \multicolumn{5}{|c|}{ 13 Fractures (0.0008 md)-Arps } \\
\hline Years & $n$ & $d_{i}$ & $q_{i}$ & $R^{2}$ \\
\hline 3 & 1.7081 & 0.0279 & 7.6043 & 0.9914 \\
\hline 5 & 1.6072 & 0.0266 & 7.5911 & 0.9822 \\
\hline 7 & 1.5350 & 0.0249 & 7.5138 & 0.9776 \\
\hline 10 & 1.4861 & 0.0242 & 7.4964 & 0.9744 \\
\hline 15 & 1.4426 & 0.0232 & 7.4440 & 0.9742 \\
\hline 20 & 1.4236 & 0.0227 & 7.4178 & 0.9751 \\
\hline 25 & 1.4126 & 0.0224 & 7.3962 & 0.9762 \\
\hline 30 & 1.4055 & 0.0222 & 7.3783 & 0.9770 \\
\hline
\end{tabular}

Table D-59: 13 Stages (0.0008 md) - PLE

\begin{tabular}{|c|c|c|c|c|c|}
\hline \multicolumn{7}{|c|}{ 13 Fractures $(0.0008 \mathrm{md})$ - PLE } \\
\hline Years & $\boldsymbol{D}_{\infty}$ & $\boldsymbol{n}$ & $\boldsymbol{q}_{\boldsymbol{i}}$ & $\boldsymbol{D}_{1}$ & $\boldsymbol{R}^{\mathbf{2}}$ \\
\hline 2 & -0.00079 & 0.37450 & 10.71868 & 0.09489 & 0.99830 \\
\hline 3 & -0.00027 & 0.34598 & 10.72667 & 0.09543 & 0.99772 \\
\hline 4 & -0.00009 & 0.33348 & 10.73402 & 0.09582 & 0.99763 \\
\hline 5 & -0.00001 & 0.32773 & 10.74286 & 0.09596 & 0.99772 \\
\hline 7 & 0.00003 & 0.32376 & 10.75309 & 0.09623 & 0.99797 \\
\hline 10 & 0.00000 & 0.32810 & 10.74030 & 0.09585 & 0.99814 \\
\hline 15 & -0.00009 & 0.33908 & 10.71571 & 0.09473 & 0.99788 \\
\hline 20 & -0.00016 & 0.34824 & 10.68225 & 0.09349 & 0.99754 \\
\hline 25 & -0.00020 & 0.35350 & 10.66887 & 0.09286 & 0.99738 \\
\hline 30 & -0.00021 & 0.35676 & 10.64840 & 0.09224 & 0.99737 \\
\hline
\end{tabular}

Table D-60: 13 Stages (0.0008 md) - Duong

\begin{tabular}{|c|c|c|c|c|c|}
\hline \multicolumn{7}{|c|}{ 13 Fractures $(0.0008$ md)-Duong } \\
\hline Years & $\boldsymbol{a}$ & $\boldsymbol{m}$ & $\boldsymbol{q}_{\mathbf{1}}$ & $\boldsymbol{q}_{\infty}$ & $\boldsymbol{R}^{\mathbf{2}}$ \\
\hline 2 & 0.96 & 1.07 & 10.50 & -0.90 & 0.97 \\
\hline 3 & 1.00 & 1.07 & 9.50 & -0.73 & 1.00 \\
\hline 4 & 1.05 & 1.08 & 8.80 & -0.69 & 1.00 \\
\hline 5 & 1.11 & 1.09 & 8.00 & -0.59 & 1.00 \\
\hline 7 & 1.19 & 1.11 & 7.20 & -0.45 & 1.00 \\
\hline 10 & 1.27 & 1.13 & 6.50 & -0.31 & 1.00 \\
\hline 15 & 1.37 & 1.15 & 5.87 & -0.18 & 0.99 \\
\hline 20 & 1.50 & 1.17 & 5.00 & -0.04 & 0.98 \\
\hline 25 & 1.58 & 1.18 & 4.55 & -0.02 & 0.99 \\
\hline 30 & 1.61 & 1.18 & 4.45 & -0.01 & 0.99 \\
\hline
\end{tabular}



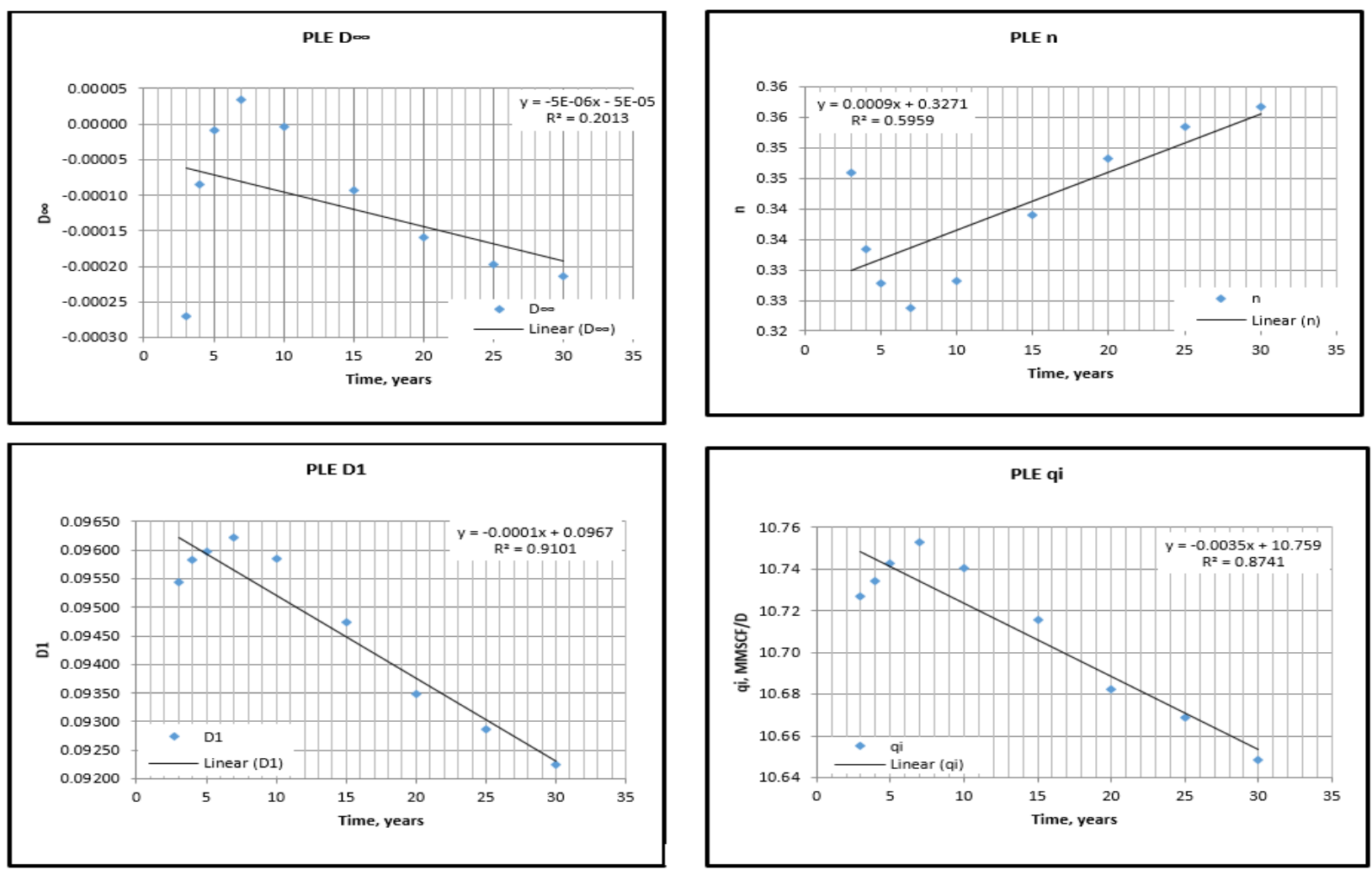

Figure D-58: 13 Stages - PLE Constants Correlation (0.0008 m-D)
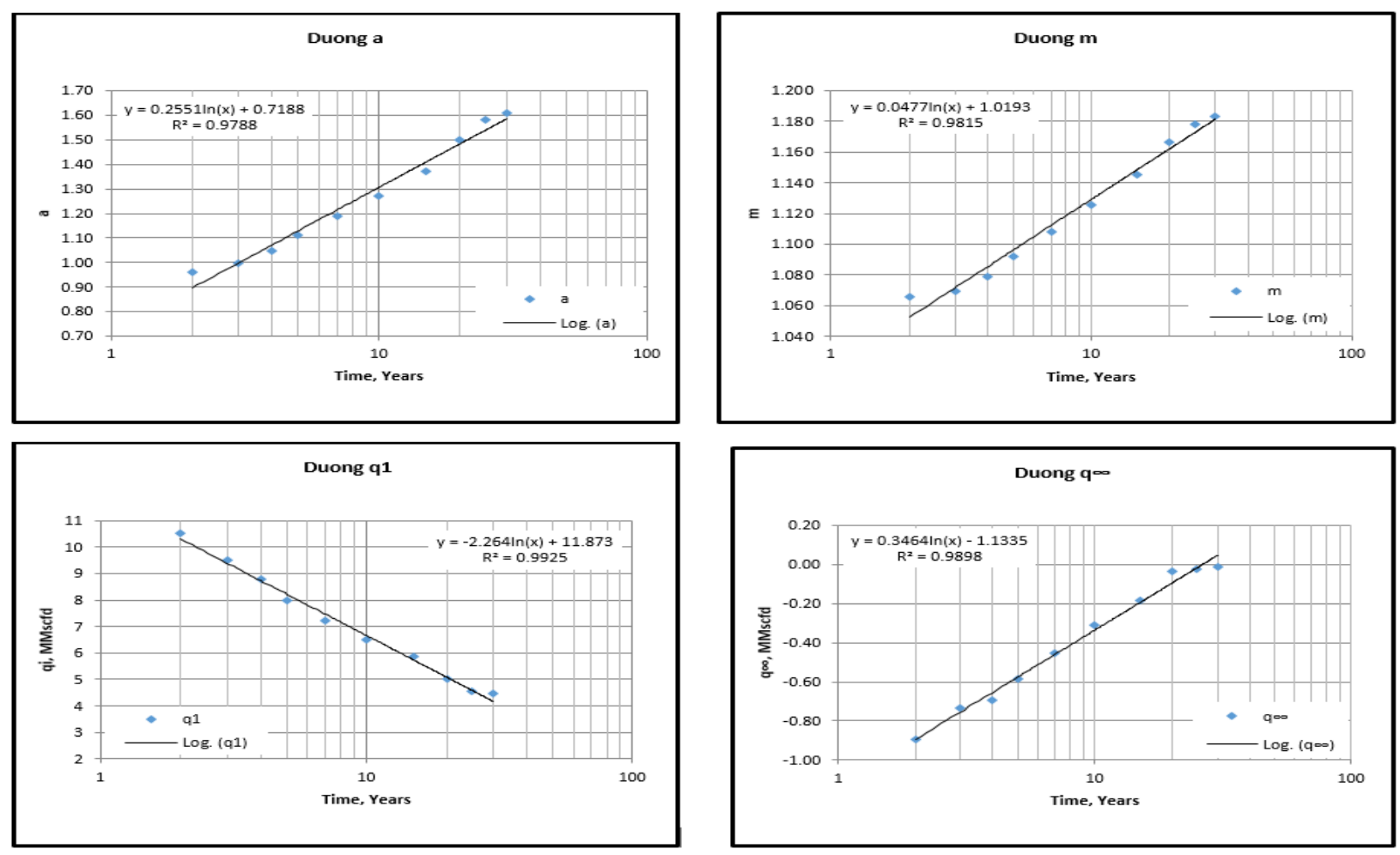

Figure D-59: 13 Stages - Duong Constants Correlation (0.0008 m-D) 

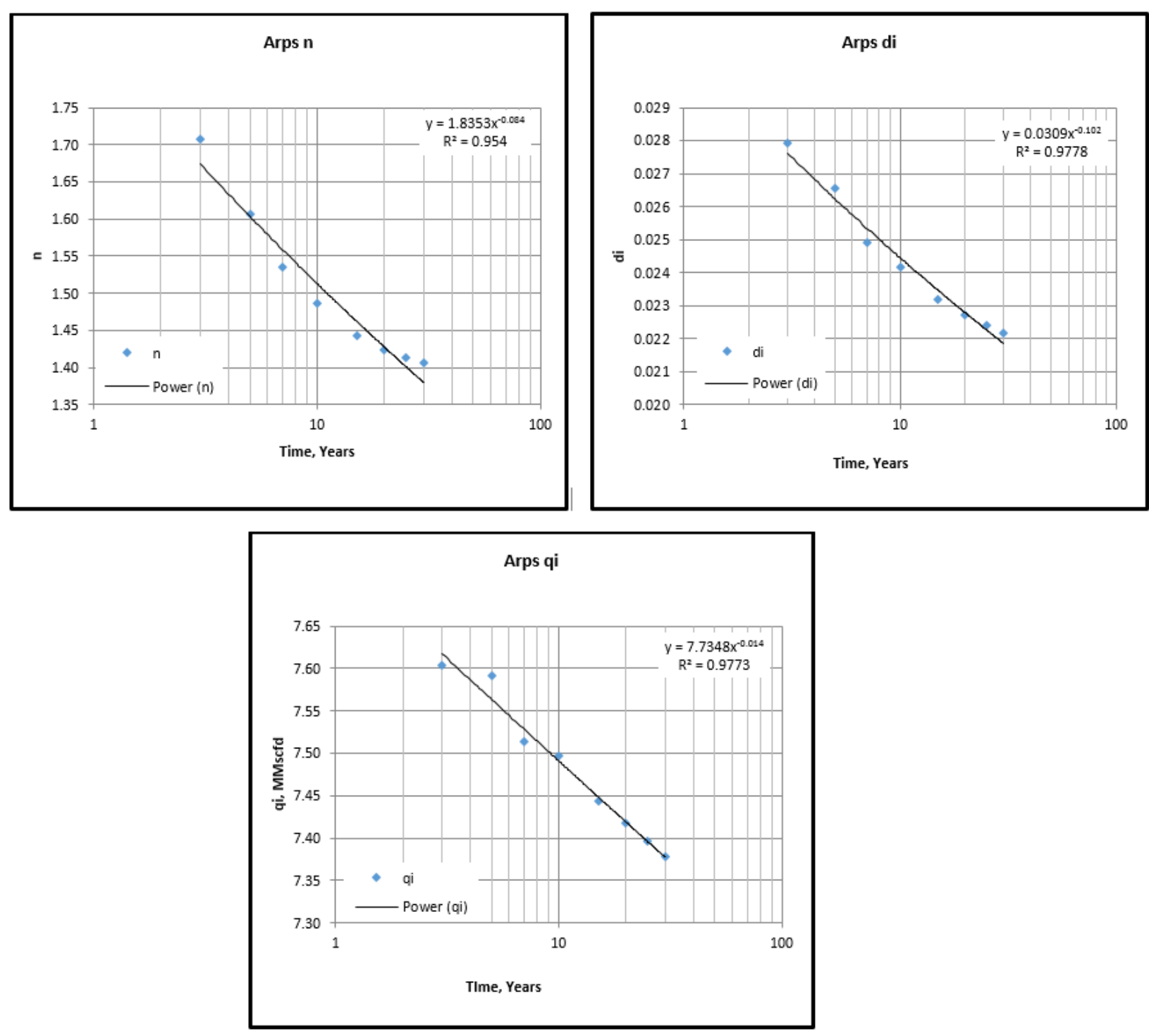

Figure D-60: 13 Stages - Arps Constants Correlation (0.0008 m-D) 
Table D-61: 13 Stages (0.001 md) - Arps

\begin{tabular}{|c|c|c|c|c|}
\hline \multicolumn{5}{|c|}{13 Fractures $(0.001$ md)-Arps } \\
\hline Years & $n$ & $d_{i}$ & $q_{i}$ & $R^{2}$ \\
\hline 3 & 1.71228 & 0.03078 & 8.68725 & 0.98508 \\
\hline 5 & 1.59603 & 0.02896 & 8.66456 & 0.97525 \\
\hline 7 & 1.53583 & 0.02796 & 8.64567 & 0.97119 \\
\hline 10 & 1.48984 & 0.02717 & 8.62811 & 0.96961 \\
\hline 15 & 1.45077 & 0.02612 & 8.56997 & 0.97098 \\
\hline 20 & 1.43475 & 0.02569 & 8.54586 & 0.97242 \\
\hline 25 & 1.41867 & 0.02491 & 8.48038 & 0.97430 \\
\hline 30 & 1.41237 & 0.02467 & 8.46194 & 0.97520 \\
\hline
\end{tabular}

Table D-62: 13 Stages (0.001 md) - PLE

\begin{tabular}{|c|c|c|c|c|c|}
\hline \multicolumn{7}{|c|}{ 13 Fractures $(0.001 \mathrm{md})$ - PLE } \\
\hline Years & $\boldsymbol{D}_{\infty}$ & $\boldsymbol{n}$ & $\boldsymbol{q}_{\boldsymbol{i}}$ & $\boldsymbol{D}_{1}$ & $\boldsymbol{R}^{2}$ \\
\hline 2 & -0.000474 & 0.372956 & 11.478445 & 0.089993 & 0.998487 \\
\hline 3 & -0.000075 & 0.350434 & 11.488406 & 0.090392 & 0.998288 \\
\hline 4 & 0.000036 & 0.342631 & 11.497691 & 0.090685 & 0.998382 \\
\hline 5 & 0.000069 & 0.339972 & 11.498864 & 0.090782 & 0.998524 \\
\hline 7 & 0.000037 & 0.343018 & 11.497754 & 0.090579 & 0.998670 \\
\hline 10 & -0.000056 & 0.352353 & 11.482352 & 0.089846 & 0.998505 \\
\hline 15 & -0.000204 & 0.369531 & 11.437436 & 0.087887 & 0.997936 \\
\hline 20 & -0.000278 & 0.379788 & 11.391280 & 0.086325 & 0.997675 \\
\hline 25 & -0.000301 & 0.383195 & 11.375149 & 0.085816 & 0.997677 \\
\hline 30 & -0.000298 & 0.382883 & 11.362997 & 0.085791 & 0.997719 \\
\hline
\end{tabular}

Table D-63: 13 Stages (0.001 md) - Duong

\begin{tabular}{|c|c|c|c|c|c|}
\hline \multicolumn{7}{|c|}{ 13 Fractures $(0.001 \mathrm{md})$ - Duong } \\
\hline Years & $\boldsymbol{a}$ & $\boldsymbol{m}$ & $\boldsymbol{q}_{\mathbf{1}}$ & $\boldsymbol{q}_{\infty}$ & $\boldsymbol{R}^{2}$ \\
\hline 2 & 0.99 & 1.06 & 10.80 & -1.06 & 1.00 \\
\hline 3 & 1.07 & 1.08 & 9.50 & -0.92 & 1.00 \\
\hline 4 & 1.18 & 1.10 & 8.10 & -0.71 & 1.00 \\
\hline 5 & 1.25 & 1.12 & 7.40 & -0.59 & 1.00 \\
\hline 7 & 1.30 & 1.13 & 7.02 & -0.46 & 1.00 \\
\hline 10 & 1.42 & 1.15 & 6.02 & -0.28 & 1.00 \\
\hline 15 & 1.52 & 1.17 & 5.50 & -0.15 & 0.99 \\
\hline 20 & 1.73 & 1.20 & 4.20 & -0.07 & 0.99 \\
\hline 25 & 1.77 & 1.20 & 4.02 & -0.04 & 0.99 \\
\hline 30 & 1.80 & 1.21 & 3.90 & -0.02 & 0.99 \\
\hline
\end{tabular}



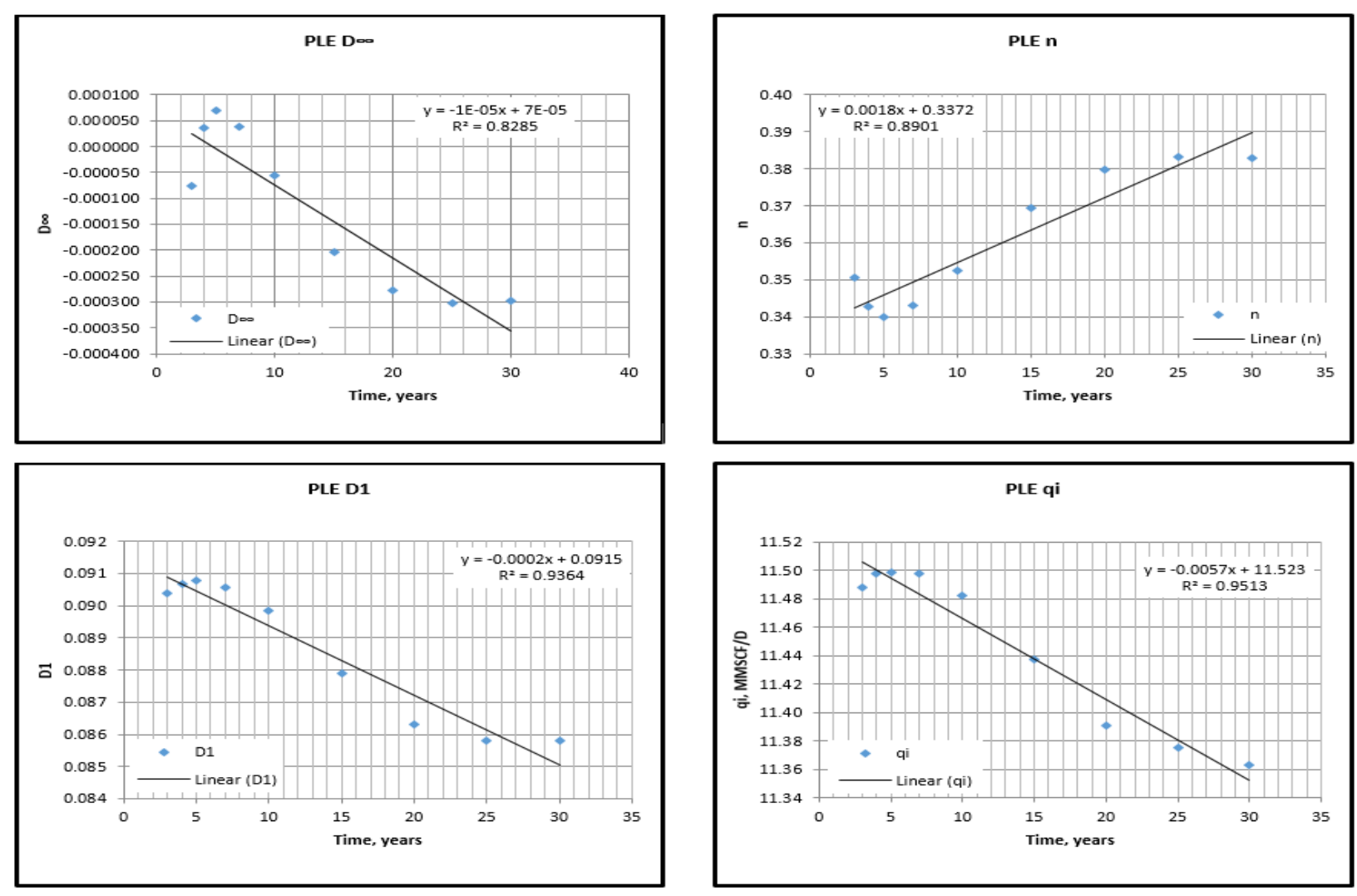

Figure D-61: 13 Stages - PLE Constants Correlation (0.001 m-D)
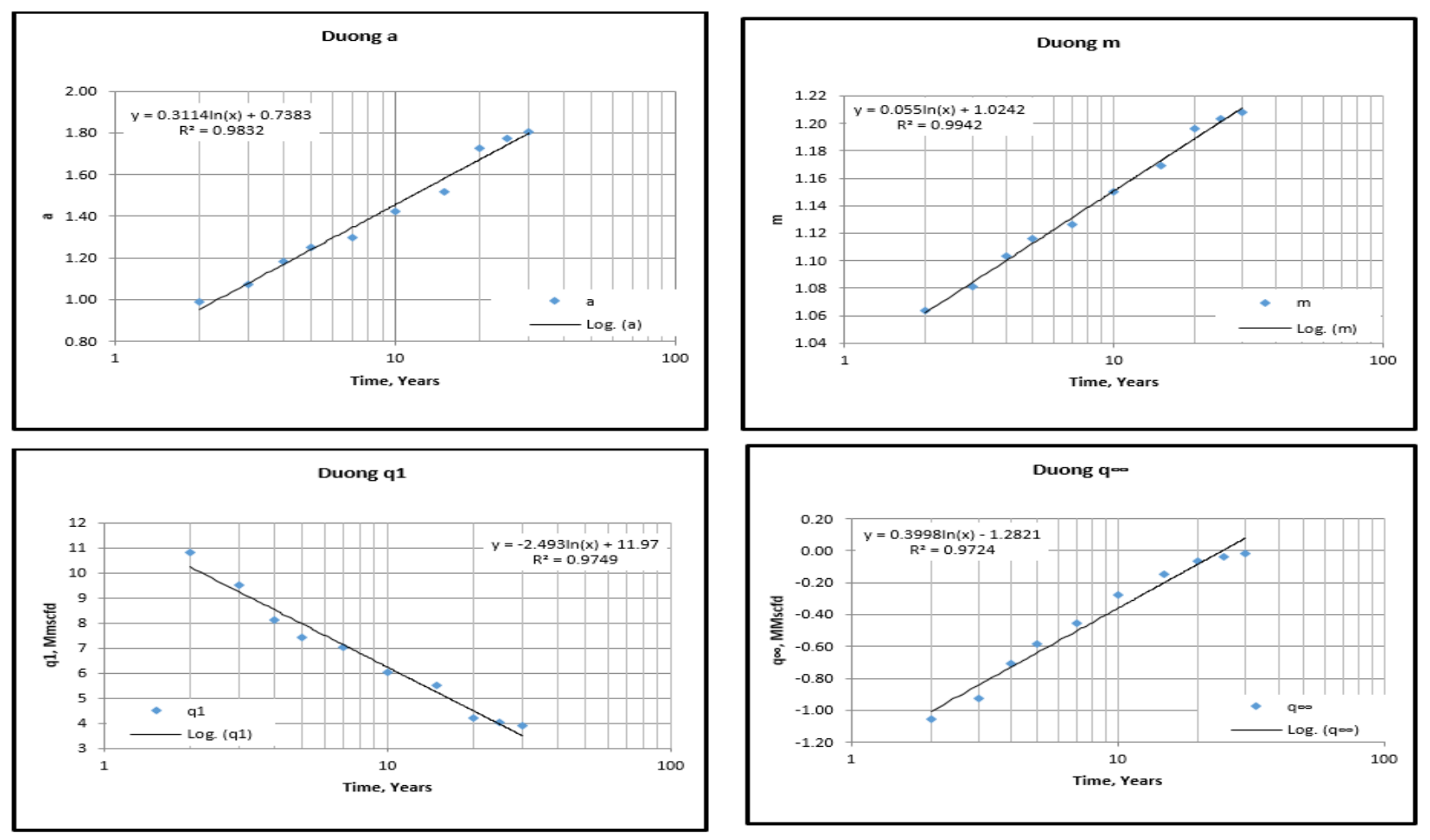

Figure D-62: 13 Stages - Duong Constants Correlation (0.001 m-D) 

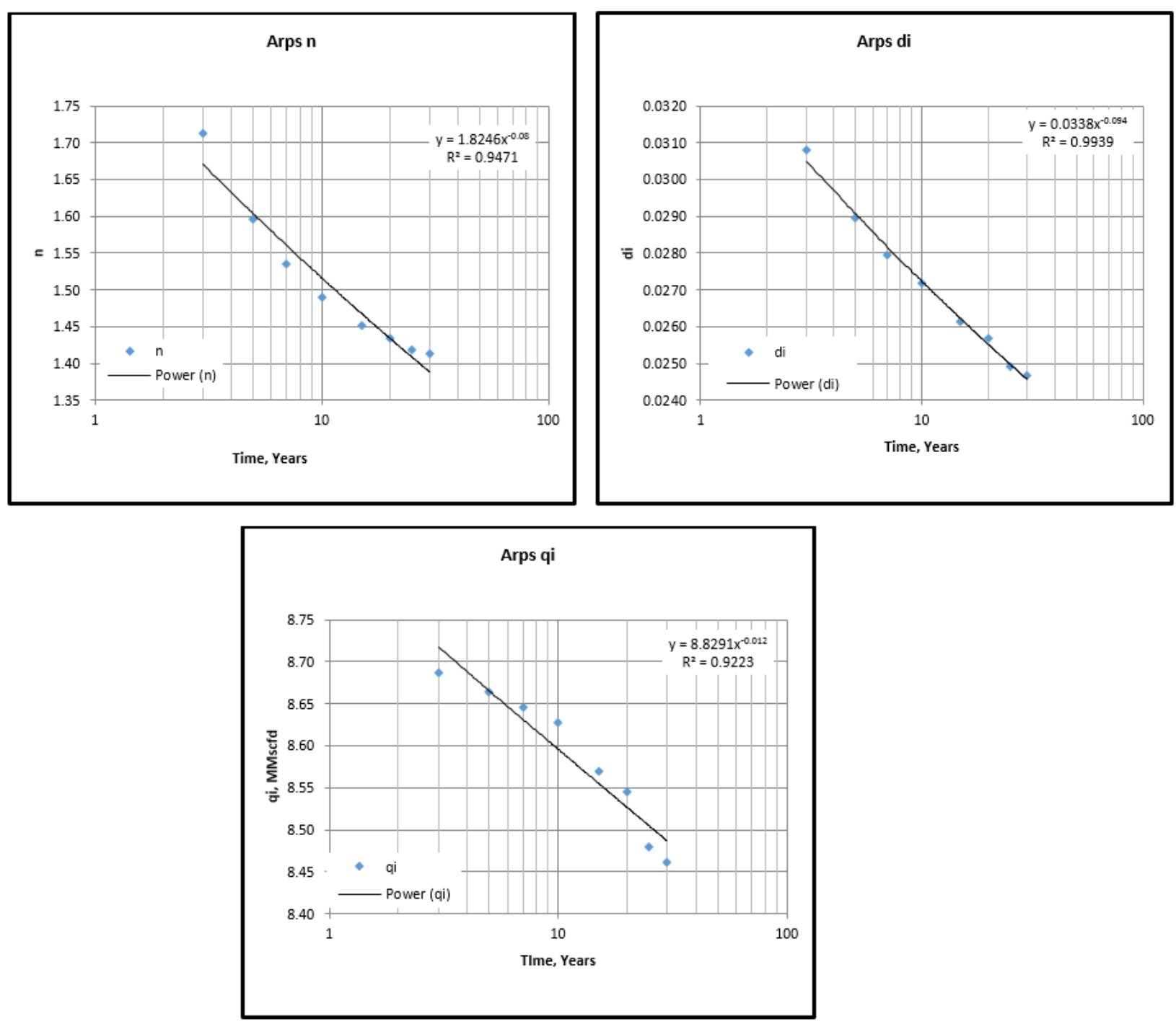

Figure D-63: 13 Stages - Arps Constants Correlation (0.001 m-D) 
Table D-64: 13 Stages (0.002 md) - Arps

\begin{tabular}{|c|c|c|c|c|}
\hline \multicolumn{5}{|c|}{13 Fractures (0.002 md)-Arps } \\
\hline Years & $n$ & $d_{i}$ & $q_{i}$ & $R^{2}$ \\
\hline 3 & 1.7204 & 0.0432 & 13.2629 & 0.9511 \\
\hline 5 & 1.6219 & 0.0424 & 13.2042 & 0.9472 \\
\hline 7 & 1.5506 & 0.0412 & 13.1656 & 0.9518 \\
\hline 10 & 1.5202 & 0.0394 & 13.1046 & 0.9548 \\
\hline 15 & 1.4899 & 0.0390 & 13.0411 & 0.9590 \\
\hline 20 & 1.4711 & 0.0384 & 12.9876 & 0.9618 \\
\hline 25 & 1.4602 & 0.0382 & 12.9649 & 0.9634 \\
\hline 30 & 1.4502 & 0.0381 & 12.9520 & 0.9646 \\
\hline
\end{tabular}

Table D-65: 13 Stages (0.002 md) - PLE

\begin{tabular}{|c|c|c|c|c|c|}
\hline \multicolumn{7}{|c|}{ 13Fractures $(0.002 \mathrm{md})$ - PLE } \\
\hline Years & $D_{\infty}$ & $n$ & $\boldsymbol{q}_{\boldsymbol{i}}$ & $\boldsymbol{D}_{1}$ & $\boldsymbol{R}^{2}$ \\
\hline 2 & 0.0004 & 0.3897 & 13.9609 & 0.0730 & 0.9997 \\
\hline 3 & 0.0003 & 0.3970 & 13.9637 & 0.0729 & 0.9997 \\
\hline 4 & 0.0001 & 0.4138 & 13.9337 & 0.0719 & 0.9995 \\
\hline 5 & -0.0001 & 0.4286 & 13.9121 & 0.0710 & 0.9991 \\
\hline 7 & -0.0005 & 0.4574 & 13.8354 & 0.0685 & 0.9984 \\
\hline 10 & -0.0008 & 0.4816 & 13.7358 & 0.0657 & 0.9980 \\
\hline 15 & -0.0008 & 0.4838 & 13.7626 & 0.0656 & 0.9980 \\
\hline 20 & -0.0007 & 0.4677 & 13.8786 & 0.0682 & 0.9977 \\
\hline 25 & -0.0006 & 0.4585 & 13.8818 & 0.0693 & 0.9968 \\
\hline 30 & -0.0005 & 0.4476 & 13.9559 & 0.0711 & 0.9959 \\
\hline
\end{tabular}

Table D-66: 13 Stages (0.002 md) - Duong

\begin{tabular}{|c|c|c|c|c|c|}
\hline \multicolumn{7}{|c|}{ 13Fractures $(0.002 \mathrm{md})$ - Duong } \\
\hline Years & $\boldsymbol{a}$ & $\boldsymbol{m}$ & $\boldsymbol{q}_{1}$ & $\boldsymbol{q}_{\infty}$ & $\boldsymbol{R}^{2}$ \\
\hline 2 & 1.112 & 1.091 & 11.850 & -1.001 & 0.980 \\
\hline 3 & 1.192 & 1.108 & 10.850 & -1.009 & 0.990 \\
\hline 4 & 1.324 & 1.132 & 9.500 & -0.824 & 0.995 \\
\hline 5 & 1.431 & 1.151 & 8.500 & -0.696 & 0.996 \\
\hline 7 & 1.543 & 1.174 & 7.600 & -0.395 & 0.994 \\
\hline 10 & 1.692 & 1.199 & 6.500 & -0.183 & 0.991 \\
\hline 15 & 1.821 & 1.218 & 5.704 & -0.056 & 0.989 \\
\hline 20 & 1.919 & 1.231 & 5.100 & -0.006 & 0.989 \\
\hline 25 & 2.003 & 1.240 & 4.600 & 0.002 & 0.989 \\
\hline 30 & 2.083 & 1.247 & 4.140 & 0.001 & 0.989 \\
\hline
\end{tabular}



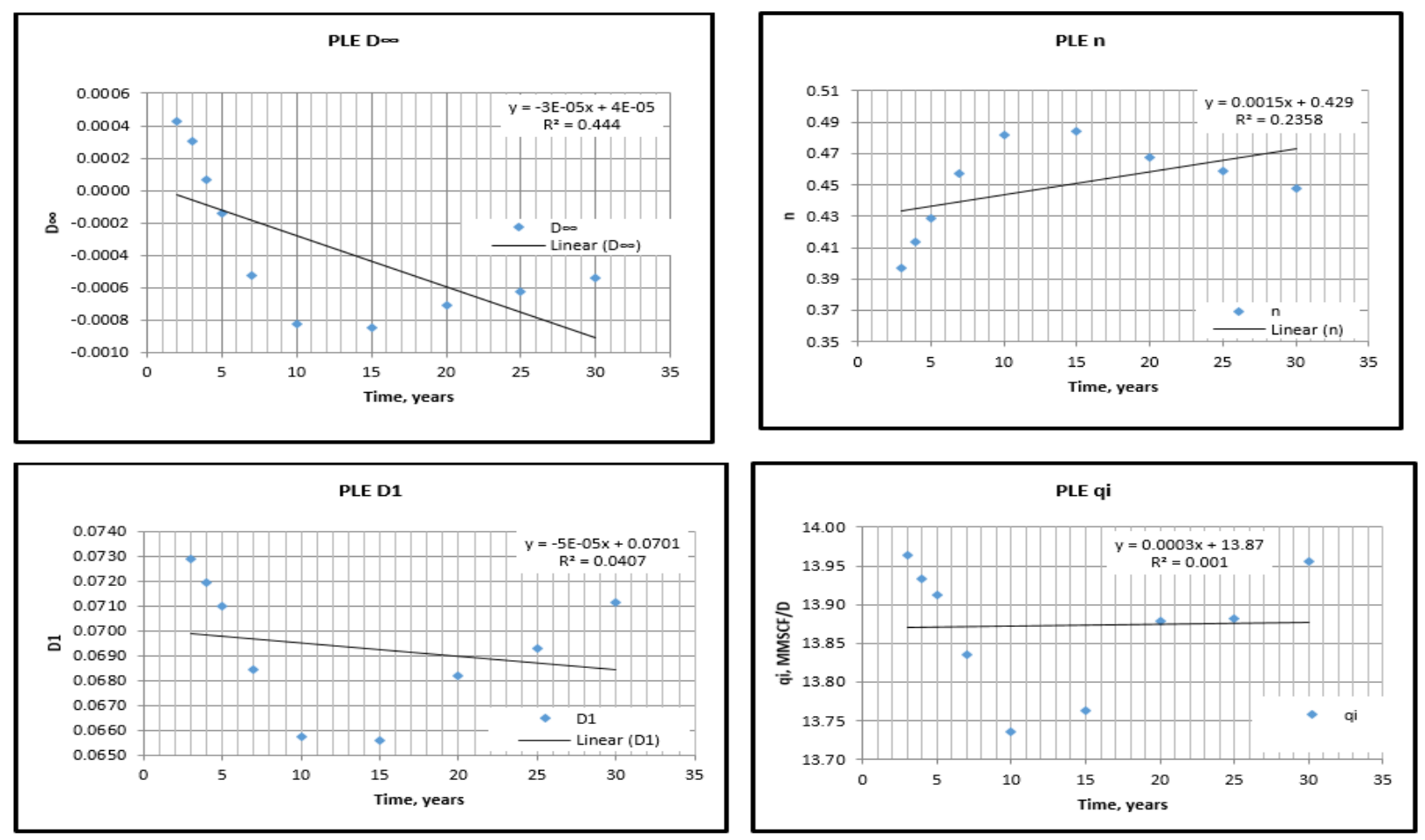

Figure D-64: 13 Stages - PLE Constants Correlation (0.002 m-D)
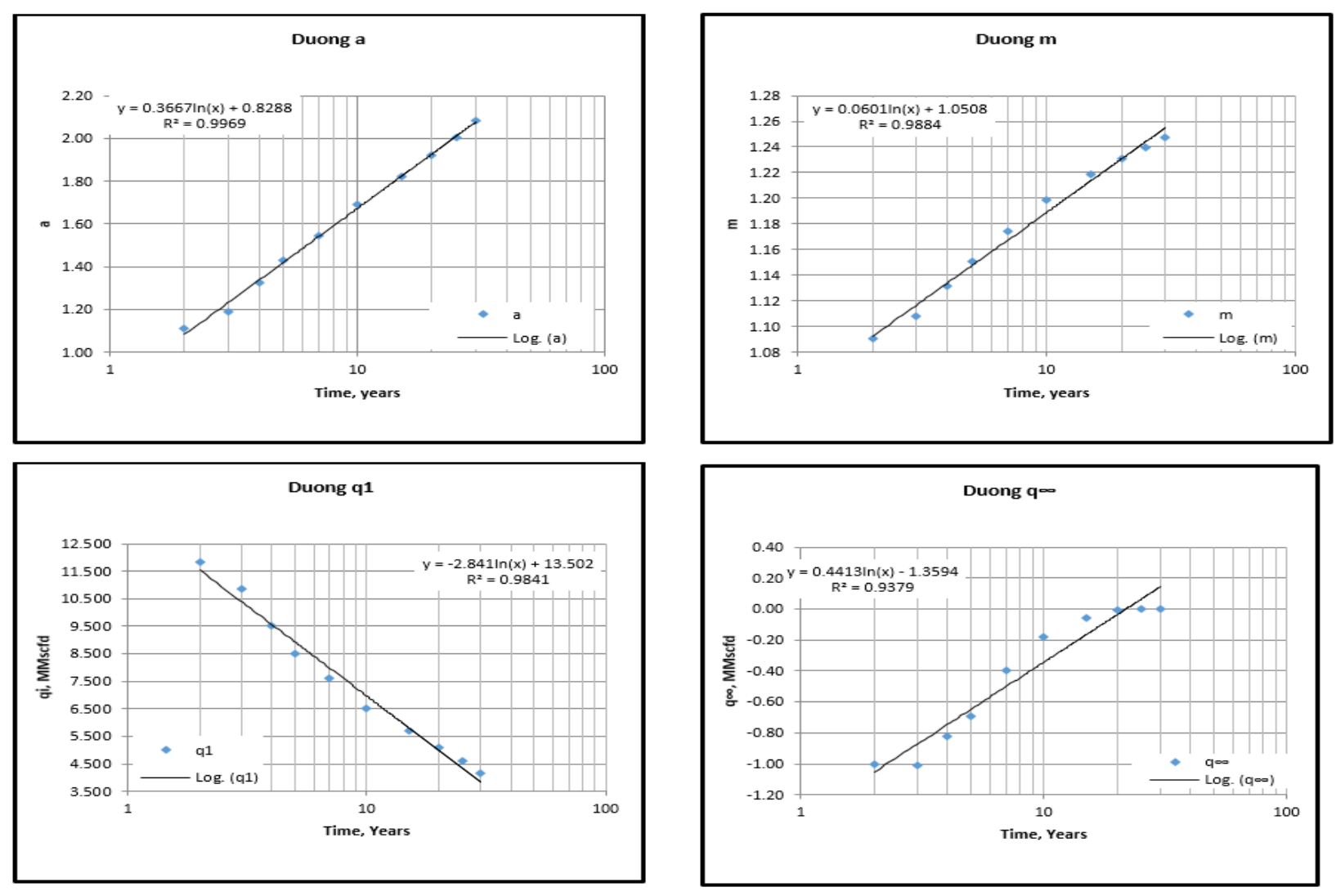

Figure D-65: 13 Stages - Duong Constants Correlation (0.002 m-D) 

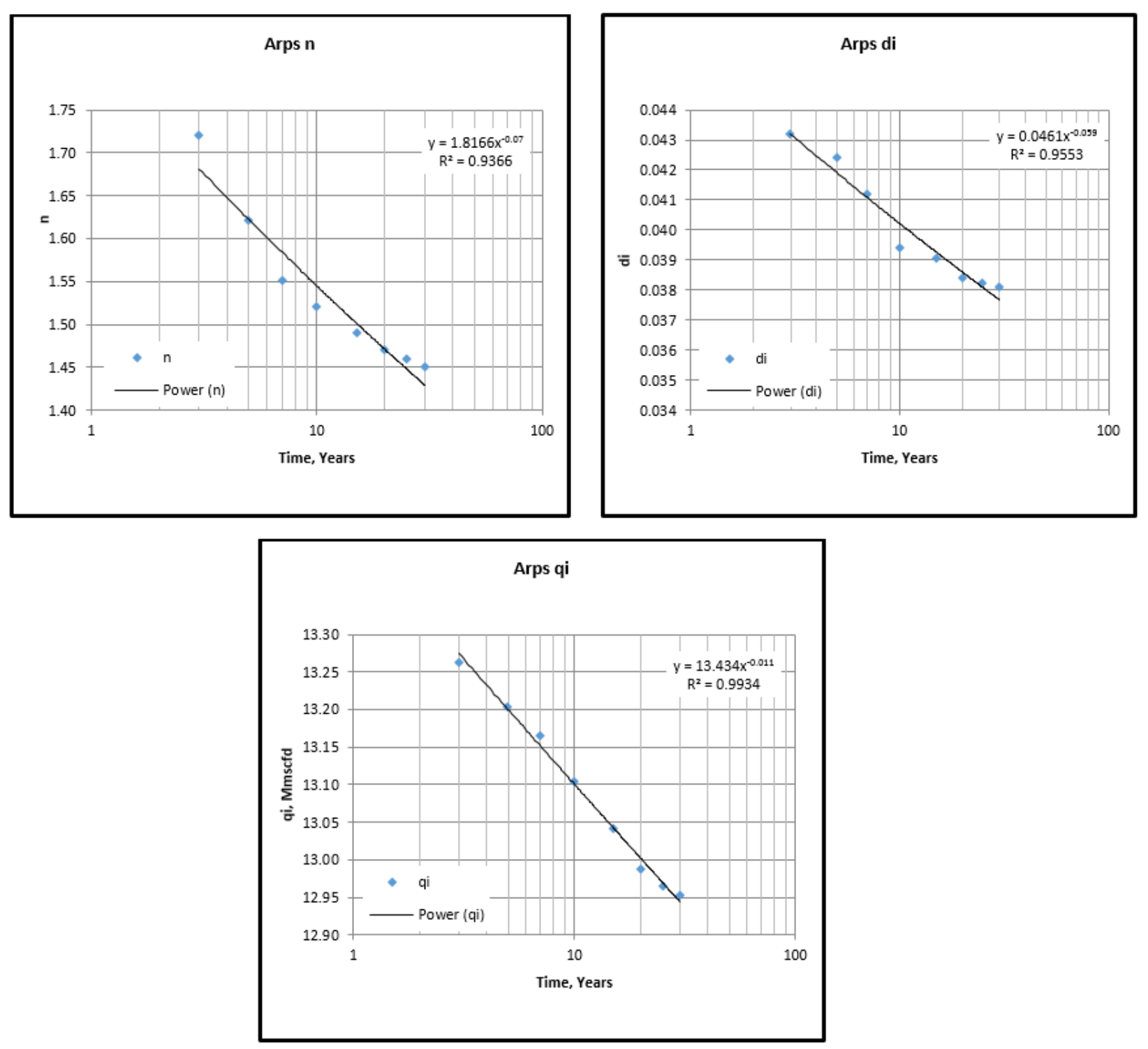

Figure D-66: 13 Stages - Arps Constants Correlation (0.002 m-D) 
Table D-67: 13 Stages (0.004 md) - Arps

\begin{tabular}{|c|c|c|c|c|}
\hline \multicolumn{5}{|c|}{ 13 Fractures (0.004 md)-Arps } \\
\hline Years & $n$ & $d_{i}$ & $q_{i}$ & $R^{2}$ \\
\hline 3 & 1.4505 & 0.0428 & 17.0135 & 0.9453 \\
\hline 5 & 1.4059 & 0.0418 & 17.0062 & 0.9521 \\
\hline 7 & 1.3851 & 0.0411 & 16.9626 & 0.9563 \\
\hline 10 & 1.3451 & 0.0401 & 16.9083 & 0.9588 \\
\hline 15 & 1.3042 & 0.0391 & 16.8576 & 0.9596 \\
\hline 20 & 1.2874 & 0.0388 & 16.7685 & 0.9588 \\
\hline 25 & 1.2764 & 0.0387 & 16.7524 & 0.9584 \\
\hline 30 & 1.2654 & 0.0386 & 16.7465 & 0.9577 \\
\hline
\end{tabular}

Table D-68: 13 Stages (0.004 md) - PLE

\begin{tabular}{|c|c|c|c|c|c|}
\hline \multicolumn{7}{|c|}{ 13 Fractures $(\mathbf{0 . 0 0 4} \mathbf{m d})-P L E$} \\
\hline Years & $D_{\infty}$ & $\boldsymbol{n}$ & $\boldsymbol{q}_{\boldsymbol{i}}$ & $\boldsymbol{D}_{\mathbf{1}}$ & $\boldsymbol{R}^{\mathbf{2}}$ \\
\hline 2 & 0.00021 & 0.49681 & 16.52229 & 0.05390 & 0.99945 \\
\hline 3 & -0.00119 & 0.56492 & 16.40861 & 0.05096 & 0.99857 \\
\hline 4 & -0.00239 & 0.61786 & 16.25132 & 0.04785 & 0.99808 \\
\hline 5 & -0.00255 & 0.61550 & 16.56712 & 0.04965 & 0.99787 \\
\hline 7 & -0.00251 & 0.61148 & 16.69012 & 0.05039 & 0.99788 \\
\hline 10 & -0.00199 & 0.58632 & 16.69210 & 0.05221 & 0.99734 \\
\hline 15 & -0.00138 & 0.54895 & 16.66632 & 0.05539 & 0.99491 \\
\hline 20 & -0.00069 & 0.48187 & 17.06158 & 0.06432 & 0.98844 \\
\hline 25 & -0.00081 & 0.49566 & 17.02566 & 0.06251 & 0.99592 \\
\hline 30 & -0.00069 & 0.48187 & 17.06158 & 0.06432 & 0.98789 \\
\hline
\end{tabular}

Table D-69: 13 Stages (0.004 md) - Duong

\begin{tabular}{|c|c|c|c|c|c|}
\hline \multicolumn{7}{|c|}{ 13 Fractures $(0.004 \mathrm{md})$ - Duong } \\
\hline Years & $\boldsymbol{a}$ & $\boldsymbol{m}$ & $\boldsymbol{q}_{\mathbf{1}}$ & $\boldsymbol{q}_{\infty}$ & $\boldsymbol{R}^{2}$ \\
\hline 2 & 1.285 & 1.114 & 14.100 & -2.803 & 0.997 \\
\hline 3 & 1.387 & 1.145 & 12.500 & -1.426 & 0.994 \\
\hline 4 & 1.509 & 1.172 & 11.000 & -0.809 & 0.991 \\
\hline 5 & 1.618 & 1.192 & 9.840 & -0.486 & 0.989 \\
\hline 7 & 1.765 & 1.217 & 8.500 & -0.199 & 0.988 \\
\hline 10 & 1.920 & 1.239 & 7.200 & -0.038 & 0.988 \\
\hline 15 & 2.077 & 1.256 & 6.000 & 0.040 & 0.989 \\
\hline 20 & 2.220 & 1.269 & 5.000 & 0.062 & 0.991 \\
\hline 25 & 2.360 & 1.281 & 4.150 & 0.069 & 0.992 \\
\hline 30 & 2.487 & 1.290 & 3.500 & 0.071 & 0.993 \\
\hline
\end{tabular}



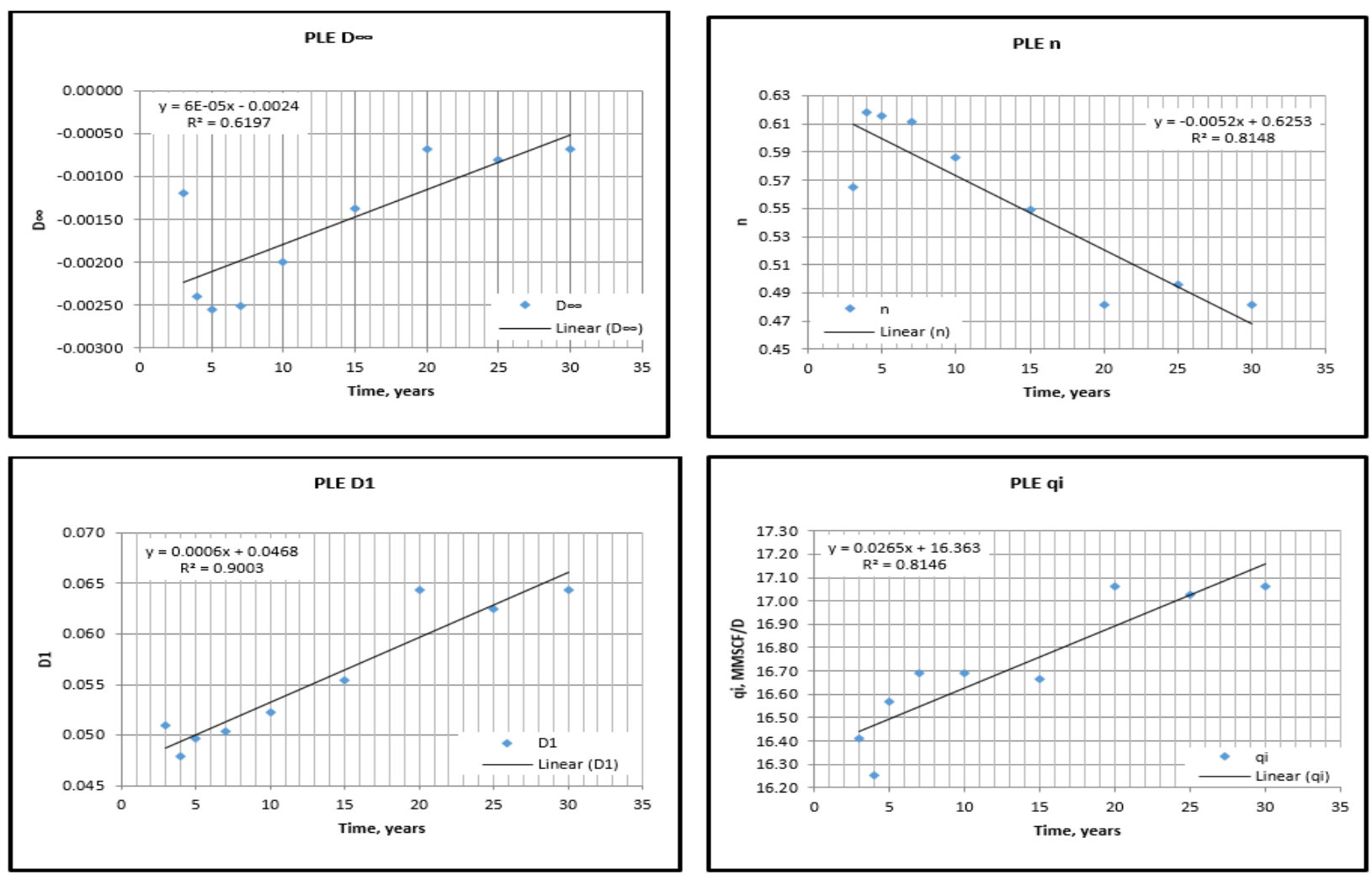

Figure D-67: 13 Stages - PLE Constants Correlation (0.004 m-D)
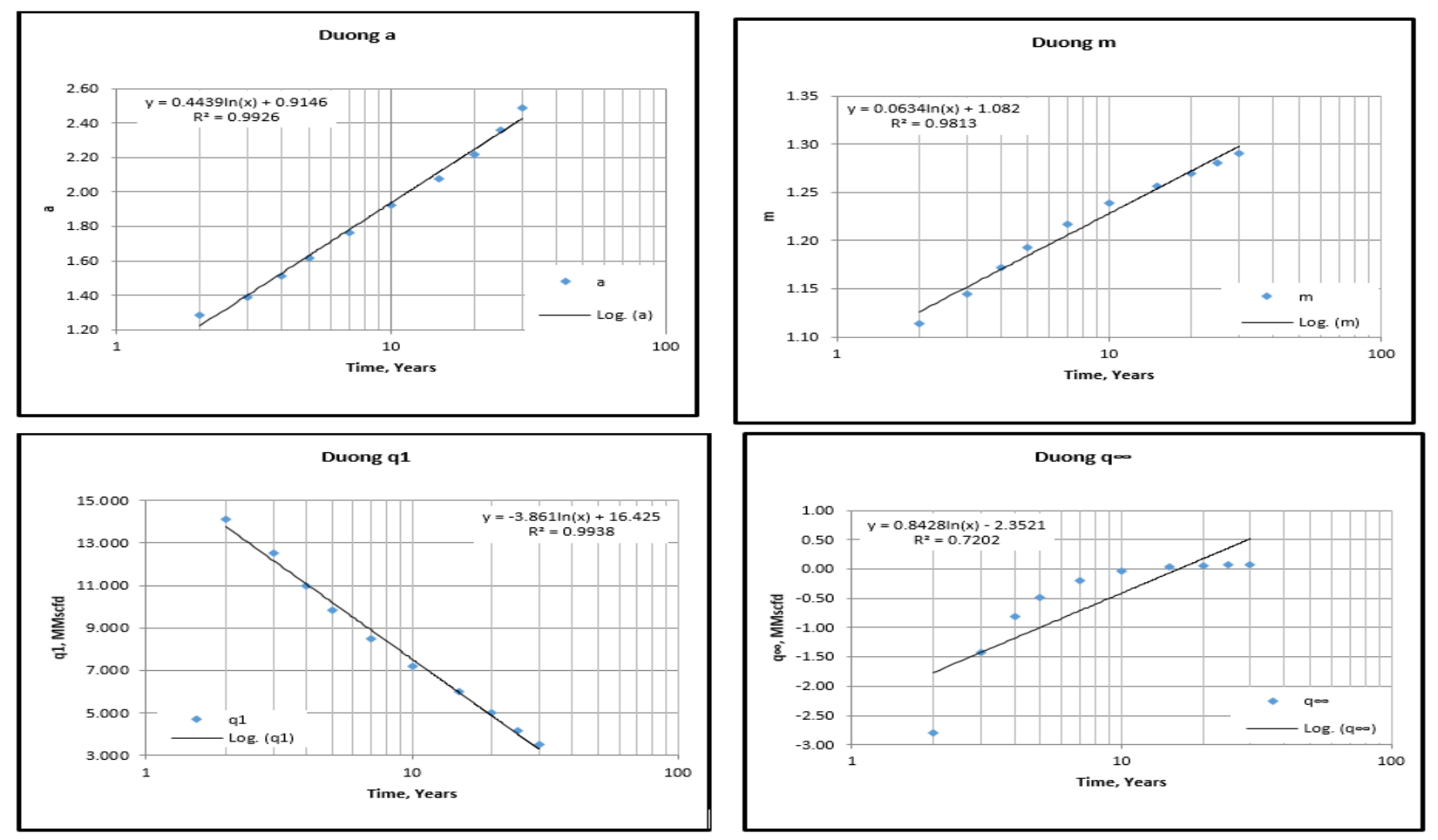

Figure D-68: 13 Stages - Duong Constants Correlation (0.004 m-D) 

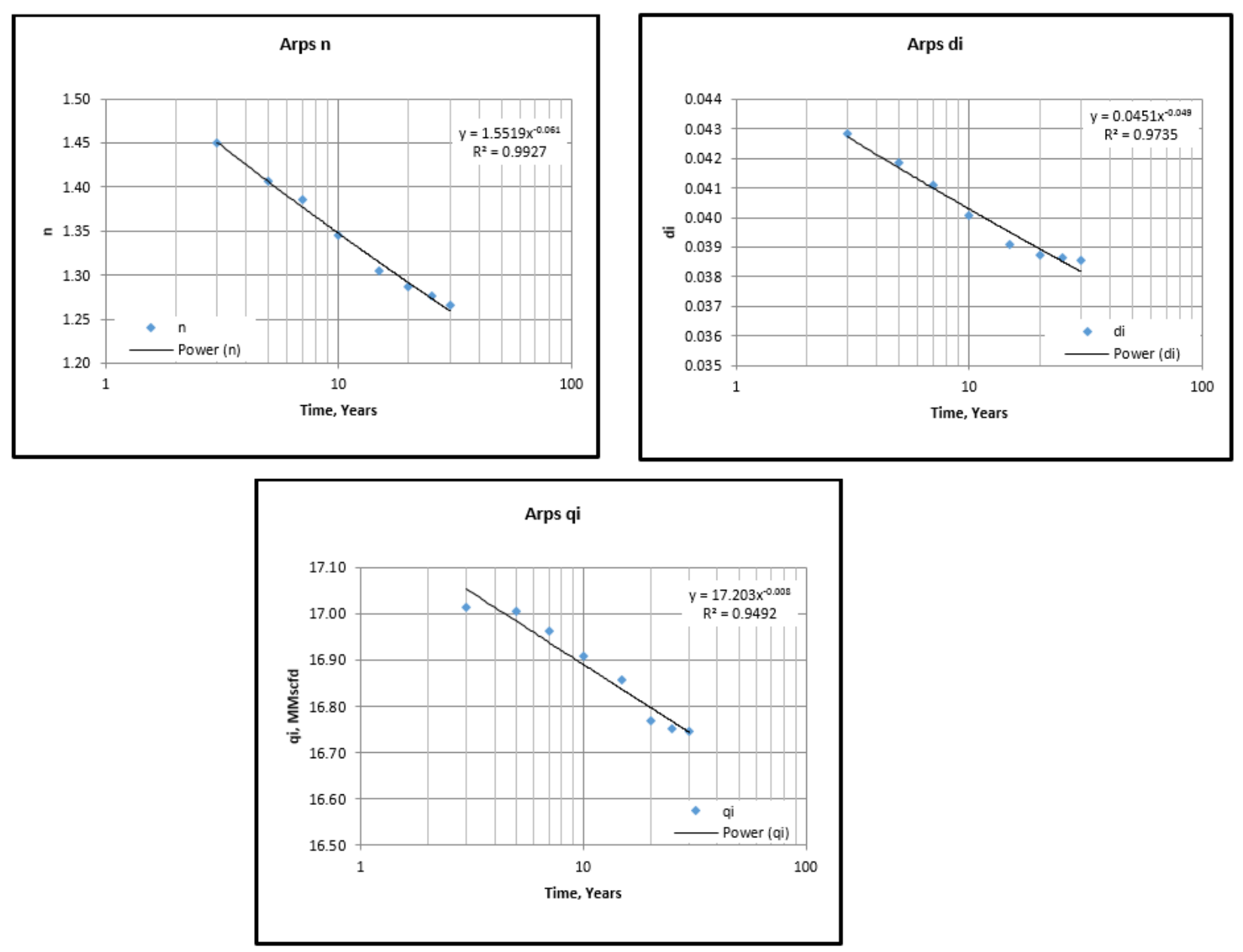

Figure D-69: 13 Stages - Arps Constants Correlation (0.004 m-D) 
Table D-70: 13 Stages (0.006 md) - Arps

\begin{tabular}{|c|c|c|c|c|}
\hline \multicolumn{5}{|c|}{ 13 Fractures (0.006 $\mathrm{md}$ )-Arps } \\
\hline Years & $\boldsymbol{n}$ & $\boldsymbol{d}_{\boldsymbol{i}}$ & $\boldsymbol{q}_{\boldsymbol{i}}$ & $\boldsymbol{R}^{\mathbf{2}}$ \\
\hline 3 & 1.670760 & 0.067481 & 23.046770 & 0.932476 \\
\hline 5 & 1.630571 & 0.068697 & 23.005184 & 0.937313 \\
\hline 7 & 1.584310 & 0.067430 & 23.001984 & 0.943918 \\
\hline 10 & 1.560853 & 0.066324 & 22.980259 & 0.947709 \\
\hline 15 & 1.534700 & 0.065168 & 22.894356 & 0.950518 \\
\hline 20 & 1.514508 & 0.064501 & 22.785205 & 0.951413 \\
\hline 25 & 1.490434 & 0.064057 & 22.694780 & 0.951903 \\
\hline 30 & 1.482164 & 0.063557 & 22.684934 & 0.951872 \\
\hline
\end{tabular}

Table D-71: 13 Stages (0.006 md) - PLE

\begin{tabular}{|c|c|c|c|c|c|}
\hline \multicolumn{7}{|c|}{ 13 Fractures $(0.006 \mathrm{md})$ - PLE } \\
\hline Years & $\boldsymbol{D}_{\infty}$ & $\boldsymbol{n}$ & $\boldsymbol{q}_{\boldsymbol{i}}$ & $\boldsymbol{D}_{1}$ & $\boldsymbol{R}^{2}$ \\
\hline 2 & -0.00244 & 0.64996 & 17.97412 & 0.04281 & 0.99868 \\
\hline 3 & -0.00602 & 0.73628 & 17.80197 & 0.04149 & 0.99826 \\
\hline 4 & -0.00703 & 0.75759 & 17.64590 & 0.04081 & 0.99835 \\
\hline 5 & -0.00575 & 0.72998 & 17.82385 & 0.04168 & 0.99832 \\
\hline 7 & -0.00418 & 0.68948 & 17.97193 & 0.04310 & 0.99730 \\
\hline 10 & -0.00279 & 0.61914 & 18.00000 & 0.05290 & 0.98016 \\
\hline 15 & -0.00146 & 0.55660 & 18.70211 & 0.05457 & 0.99080 \\
\hline 20 & -0.00103 & 0.51952 & 18.99970 & 0.05942 & 0.98755 \\
\hline 25 & -0.00083 & 0.50188 & 18.99947 & 0.06136 & 0.98509 \\
\hline 30 & -0.00071 & 0.48995 & 19.00348 & 0.06274 & 0.98330 \\
\hline
\end{tabular}

Table D-72: 13 Stages (0.006 md) - Duong

\begin{tabular}{|c|c|c|c|c|c|}
\hline \multicolumn{7}{|c|}{ 13 Fractures $(0.006$ md)-Duong } \\
\hline Years & $\boldsymbol{a}$ & $\boldsymbol{m}$ & $\boldsymbol{q}_{\mathbf{1}}$ & $\boldsymbol{q}_{\infty}$ & $\boldsymbol{R}^{2}$ \\
\hline 2 & 1.252 & 1.115 & 17.531 & -2.965 & 0.993 \\
\hline 3 & 1.369 & 1.145 & 15.500 & -1.584 & 0.981 \\
\hline 4 & 1.495 & 1.180 & 13.700 & -0.659 & 0.986 \\
\hline 5 & 1.621 & 1.202 & 12.000 & -0.349 & 0.986 \\
\hline 7 & 1.776 & 1.226 & 10.200 & -0.101 & 0.986 \\
\hline 10 & 1.919 & 1.245 & 8.700 & 0.017 & 0.988 \\
\hline 15 & 2.067 & 1.260 & 7.250 & 0.061 & 0.990 \\
\hline 20 & 2.211 & 1.272 & 6.000 & 0.069 & 0.992 \\
\hline 25 & 2.338 & 1.282 & 5.050 & 0.068 & 0.993 \\
\hline 30 & 2.511 & 1.299 & 4.013 & 0.100 & 0.989 \\
\hline
\end{tabular}



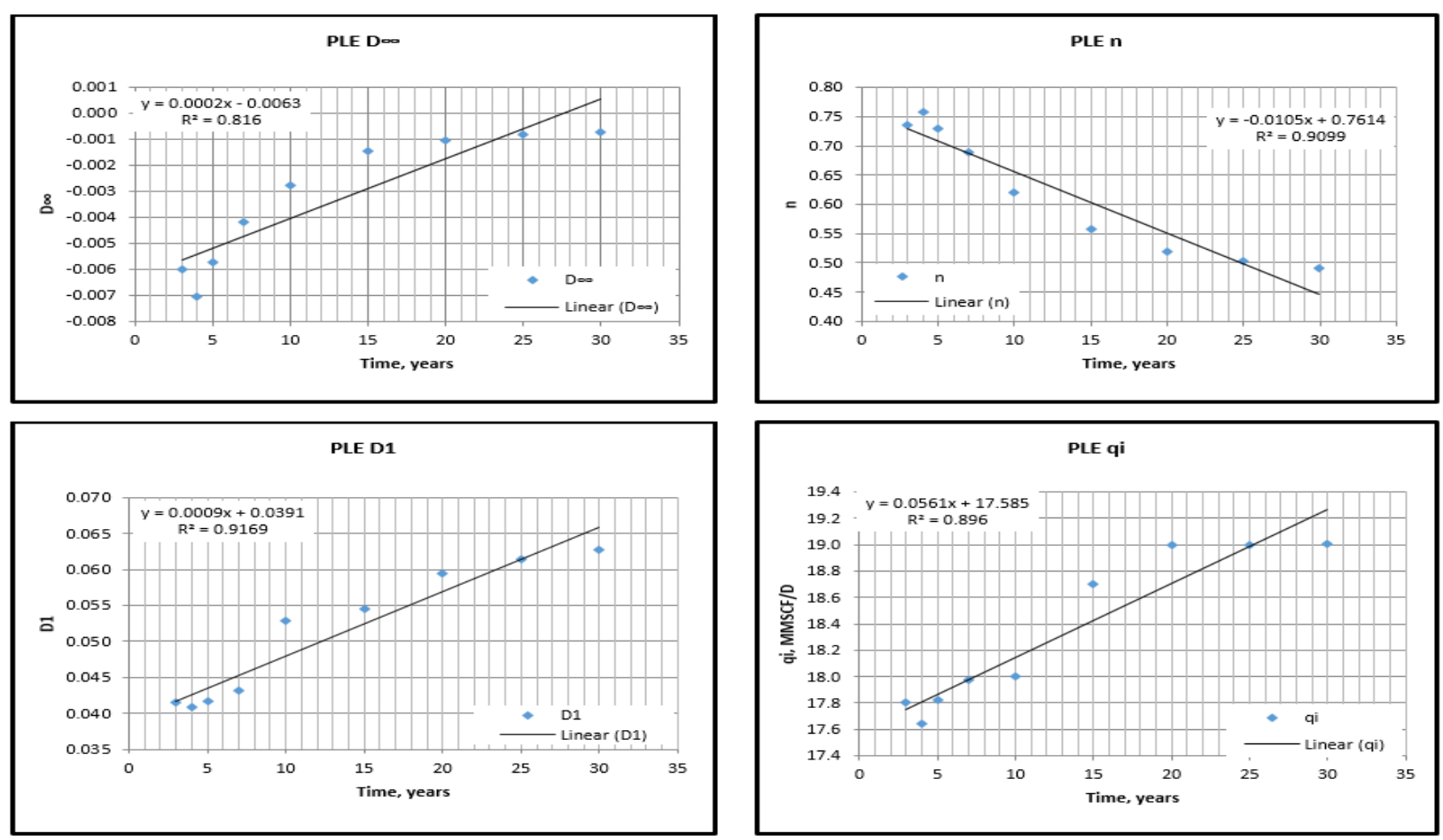

Figure D-70: 13 Stages - PLE Constants Correlation (0.006 m-D)
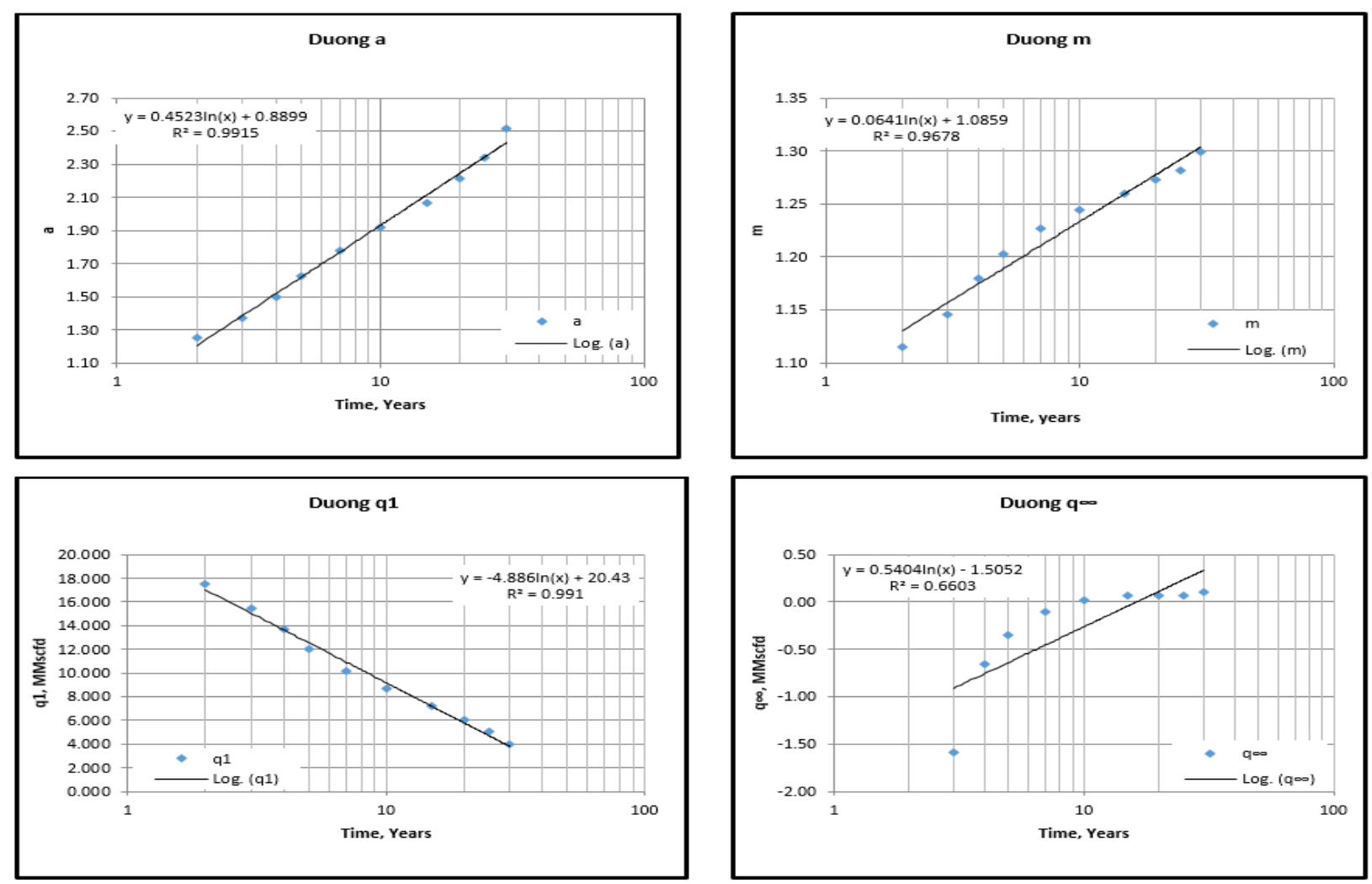

Figure D-71: 13 Stages - Duong Constants Correlation (0.006 m-D) 

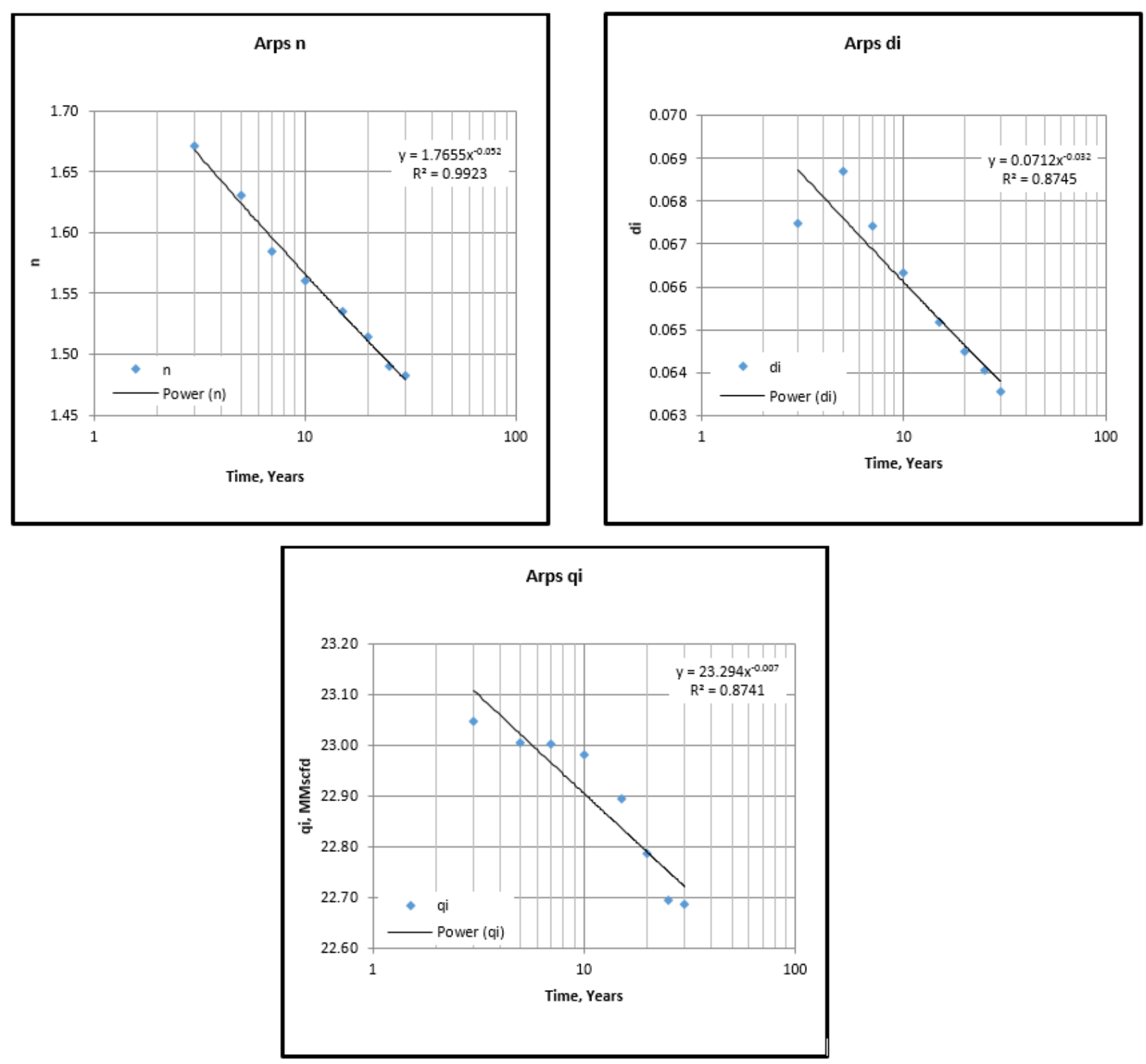

Figure D-72: 13 Stages - Arps Constants Correlation (0.006 m-D) 
Table D-73: 13 Stages (4\%) - Arps

\begin{tabular}{|c|c|c|c|c|}
\hline \multicolumn{5}{|c|}{13 Fractures (4\%) - Arps } \\
\hline Years & $n$ & di & qi & $\boldsymbol{R}^{2}$ \\
\hline 3 & 1.7081 & 0.0570 & 13.3167 & 0.9439 \\
\hline 5 & 1.6020 & 0.0528 & 13.2247 & 0.9451 \\
\hline 7 & 1.5292 & 0.0466 & 12.8230 & 0.9525 \\
\hline 10 & 1.4691 & 0.0412 & 12.4245 & 0.9605 \\
\hline 15 & 1.4210 & 0.0371 & 12.0791 & 0.9678 \\
\hline 20 & 1.3910 & 0.0345 & 11.8450 & 0.9722 \\
\hline 25 & 1.3710 & 0.0329 & 11.6904 & 0.9749 \\
\hline 30 & 1.3651 & 0.0325 & 11.6599 & 0.9759 \\
\hline
\end{tabular}

Table D-74: 13 Stages (4\%) - PLE

\begin{tabular}{|c|c|c|c|c|c|}
\hline \multicolumn{7}{|c|}{ 13Fractures $(\phi=4 \%)$ - PLE } \\
\hline years & $D_{\infty}$ & $n$ & $q_{i}$ & $D_{1}$ & $R^{2}$ \\
\hline 2 & 0.0006 & 0.3932 & 13.3007 & 0.0750 & 0.9998 \\
\hline 3 & 0.0002 & 0.4131 & 13.2775 & 0.0744 & 0.9996 \\
\hline 4 & -0.0002 & 0.4369 & 13.2433 & 0.0730 & 0.9992 \\
\hline 5 & -0.0005 & 0.4584 & 13.2024 & 0.0714 & 0.9987 \\
\hline 7 & -0.0009 & 0.4876 & 13.1329 & 0.0687 & 0.9981 \\
\hline 10 & -0.0011 & 0.5006 & 13.0790 & 0.0672 & 0.9980 \\
\hline 15 & -0.0010 & 0.4879 & 13.1193 & 0.0688 & 0.9978 \\
\hline 20 & -0.0008 & 0.4646 & 13.2900 & 0.0731 & 0.9969 \\
\hline 25 & -0.0007 & 0.4529 & 13.3916 & 0.0746 & 0.9956 \\
\hline 30 & -0.0006 & 0.4422 & 13.3910 & 0.0762 & 0.9943 \\
\hline
\end{tabular}

Table D-75: 13 Stages (4\%) - Duong

\begin{tabular}{|c|c|c|c|c|c|}
\hline \multicolumn{7}{|c|}{ 13 Fractures $(\phi=4 \%)$ - Duong } \\
\hline Years & $a$ & $m$ & $q_{1}$ & $q_{\infty}$ & $R^{2}$ \\
\hline 2 & 1.087 & 1.074 & 13.000 & -2.560 & 0.999 \\
\hline 3 & 1.113 & 1.091 & 12.400 & -1.592 & 0.997 \\
\hline 4 & 1.161 & 1.109 & 11.800 & -1.039 & 0.994 \\
\hline 5 & 1.223 & 1.127 & 11.100 & -0.701 & 0.992 \\
\hline 7 & 1.298 & 1.149 & 10.500 & -0.386 & 0.988 \\
\hline 10 & 1.385 & 1.170 & 9.800 & -0.186 & 0.985 \\
\hline 15 & 1.458 & 1.186 & 9.278 & -0.025 & 0.983 \\
\hline 20 & 1.512 & 1.195 & 8.800 & -0.025 & 0.983 \\
\hline 25 & 1.525 & 1.198 & 8.750 & -0.008 & 0.984 \\
\hline 30 & 1.533 & 1.200 & 8.700 & 0.000 & 0.984 \\
\hline
\end{tabular}



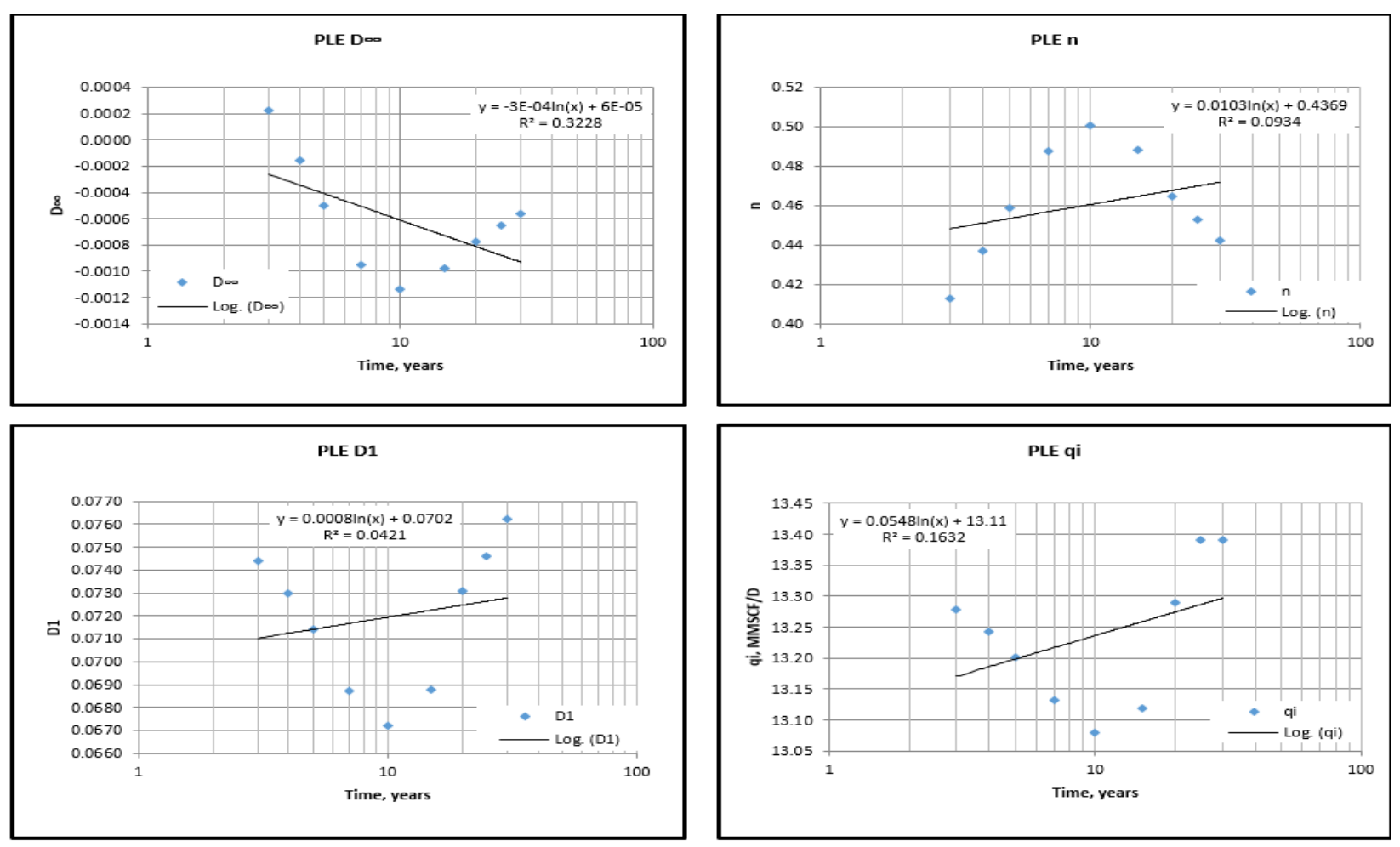

Figure D-73: 13 Stages - PLE Constants Correlation (4\%)
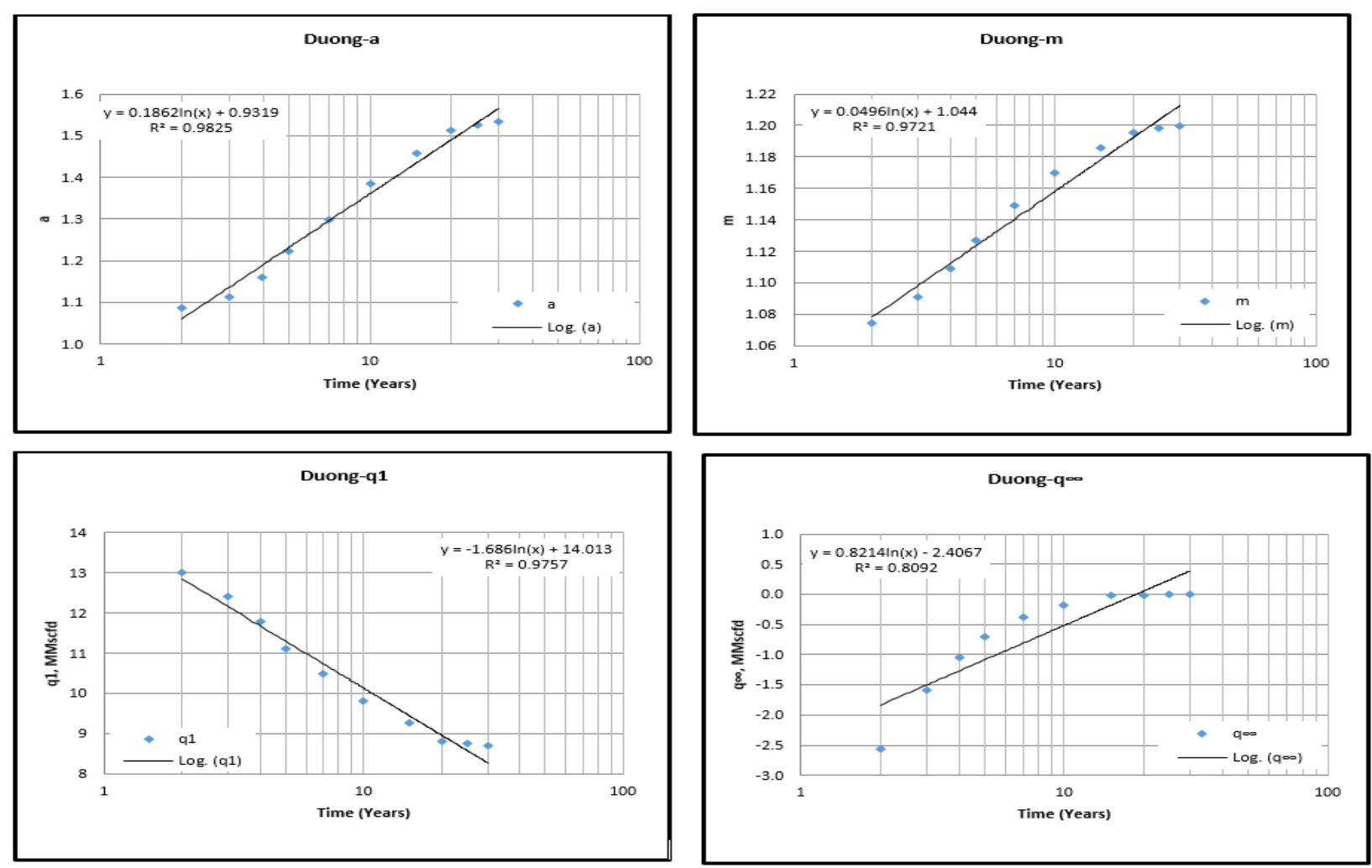

Figure D-74: 13 Stages - Duong Constants Correlation (4\%) 

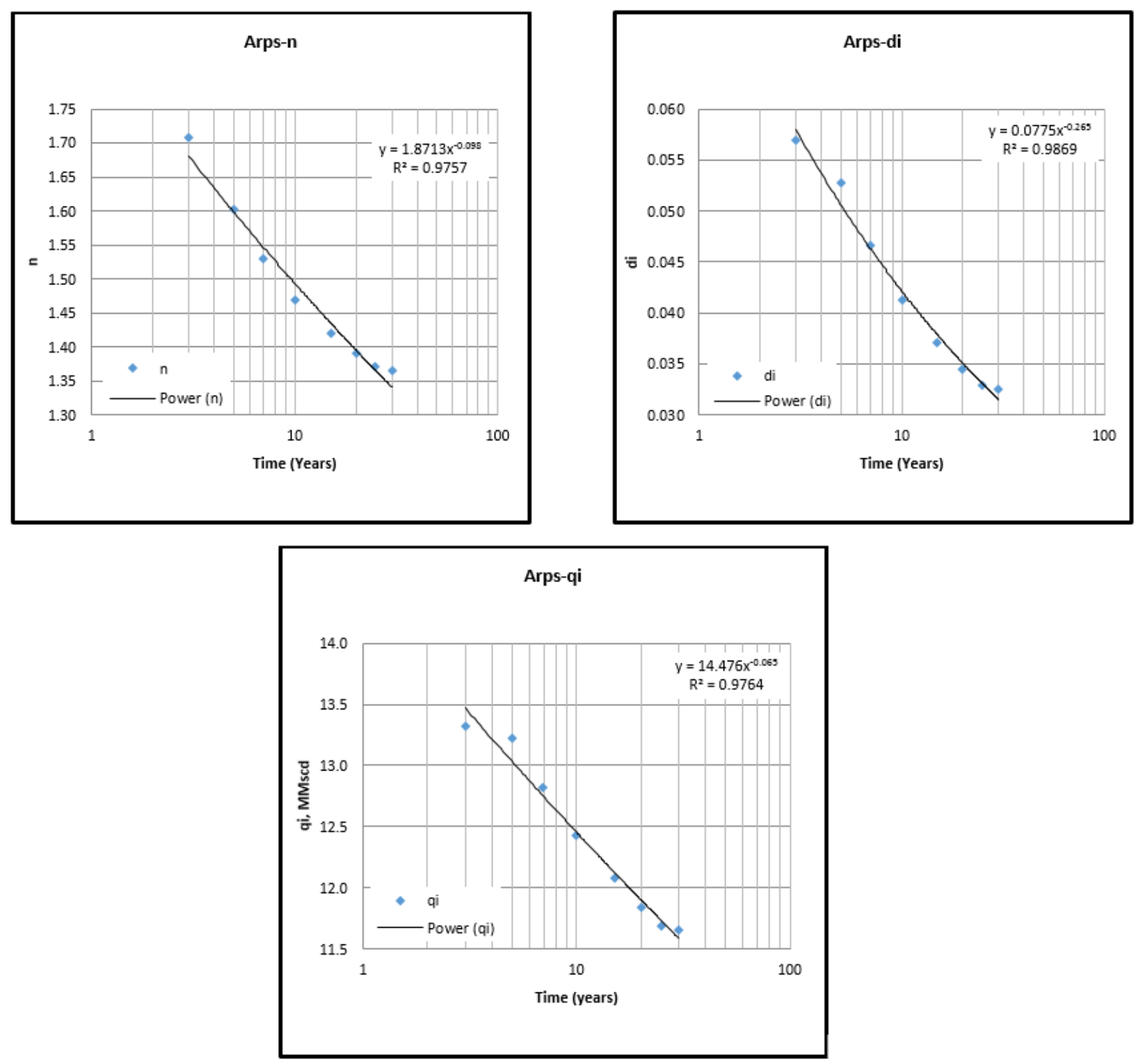

Figure D-75: 13 Stages - Arps Constants Correlation (4\%) 
Table D-76: 13 Stages (5\%) - Arps

\begin{tabular}{|c|c|c|c|c|}
\hline \multicolumn{5}{|c|}{13 Fractures (5\%) - Arps } \\
\hline Years & $n$ & $d i$ & qi & $\boldsymbol{R}^{\mathbf{2}}$ \\
\hline 3 & 1.7421 & 0.0475 & 13.4537 & 0.9498 \\
\hline 5 & 1.6410 & 0.0467 & 13.6124 & 0.9449 \\
\hline 7 & 1.5517 & 0.0405 & 13.1748 & 0.9518 \\
\hline 10 & 1.4807 & 0.0355 & 12.7633 & 0.9600 \\
\hline 15 & 1.4107 & 0.0305 & 12.2690 & 0.9694 \\
\hline 20 & 1.3765 & 0.0282 & 12.0222 & 0.9741 \\
\hline 25 & 1.3523 & 0.0266 & 11.8401 & 0.9772 \\
\hline 30 & 1.3452 & 0.0263 & 11.7978 & 0.9783 \\
\hline
\end{tabular}

Table D-77: 13 Stages (5\%) - PLE

\begin{tabular}{|c|c|c|c|c|c|}
\hline \multicolumn{7}{|c|}{ 13 Fractures $(\boldsymbol{\phi}=5 \%)$ - PLE } \\
\hline Years & $D_{\infty}$ & $n$ & $\boldsymbol{q}_{\boldsymbol{i}}$ & $\boldsymbol{D}_{\mathbf{1}}$ & $\boldsymbol{R}^{2}$ \\
\hline 2 & 0.0004 & 0.3896 & 13.9740 & 0.0731 & 0.9997 \\
\hline 3 & 0.0003 & 0.3981 & 13.9621 & 0.0728 & 0.9997 \\
\hline 4 & 0.0001 & 0.4135 & 13.9369 & 0.0720 & 0.9995 \\
\hline 5 & -0.0001 & 0.4286 & 13.9203 & 0.0710 & 0.9991 \\
\hline 7 & -0.0005 & 0.4578 & 13.8467 & 0.0685 & 0.9984 \\
\hline 10 & -0.0008 & 0.4829 & 13.7437 & 0.0656 & 0.9980 \\
\hline 15 & -0.0009 & 0.4855 & 13.7134 & 0.0651 & 0.9980 \\
\hline 20 & -0.0007 & 0.4713 & 13.8168 & 0.0674 & 0.9977 \\
\hline 25 & -0.0006 & 0.4602 & 13.8203 & 0.0688 & 0.9968 \\
\hline 30 & -0.0005 & 0.4475 & 13.9572 & 0.0711 & 0.9959 \\
\hline
\end{tabular}

Table D-78: 13 Stages (5\%) - Duong

\begin{tabular}{|c|c|c|c|c|c|}
\hline \multicolumn{7}{|c|}{ 13 Fractures ( $\phi=5 \%)$ - Duong } \\
\hline Years & $\boldsymbol{a}$ & $\boldsymbol{m}$ & $\boldsymbol{q}_{\mathbf{1}}$ & $\boldsymbol{q}_{\infty}$ & $\boldsymbol{R}^{2}$ \\
\hline 2 & 1.086 & 1.071 & 13.700 & -2.801 & 1.000 \\
\hline 3 & 1.126 & 1.087 & 12.700 & -1.875 & 0.999 \\
\hline 4 & 1.189 & 1.106 & 11.700 & -1.257 & 0.997 \\
\hline 5 & 1.243 & 1.122 & 11.050 & -0.893 & 0.995 \\
\hline 7 & 1.309 & 1.141 & 10.500 & -0.526 & 0.992 \\
\hline 10 & 1.380 & 1.160 & 10.000 & -0.278 & 0.988 \\
\hline 15 & 1.449 & 1.172 & 9.561 & -0.120 & 0.975 \\
\hline 20 & 1.488 & 1.185 & 9.300 & -0.059 & 0.984 \\
\hline 25 & 1.515 & 1.190 & 9.100 & -0.030 & 0.984 \\
\hline 30 & 1.529 & 1.193 & 9.000 & -0.016 & 0.984 \\
\hline
\end{tabular}



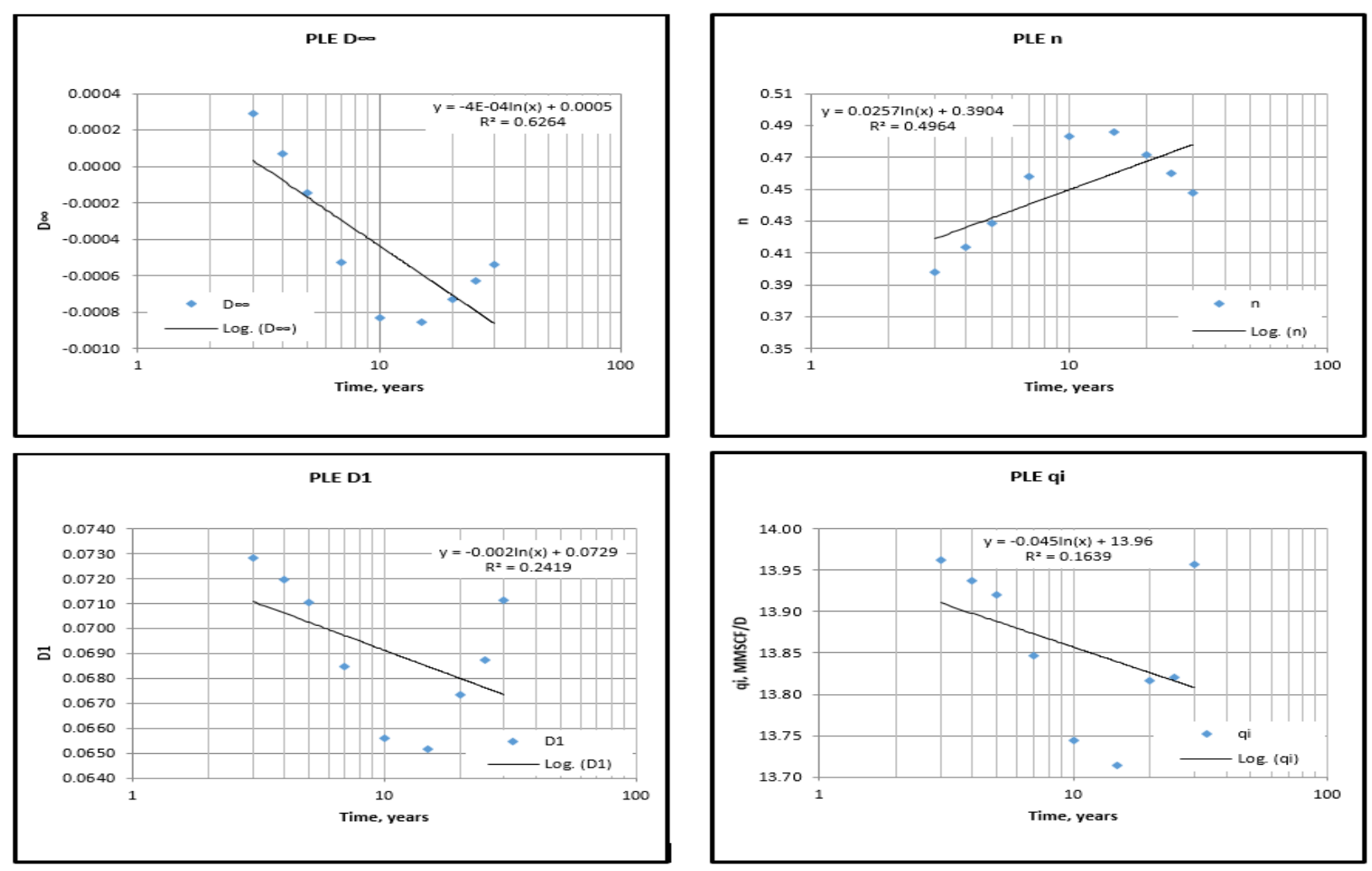

Figure D-76: 13 Stages - PLE Constants Correlation (5\%)

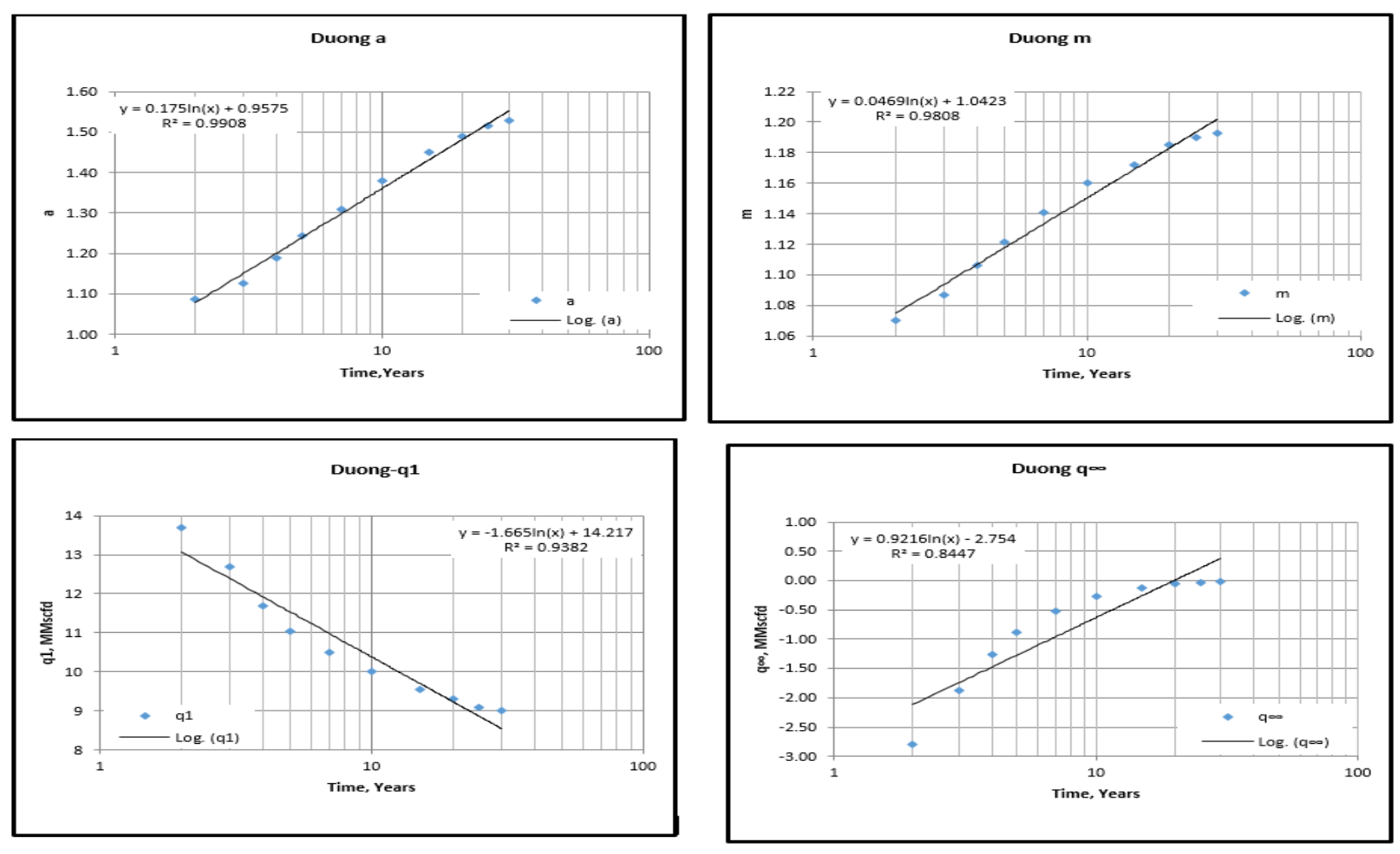

Figure D-77: 13 Stages - Duong Constants Correlation (5\%) 

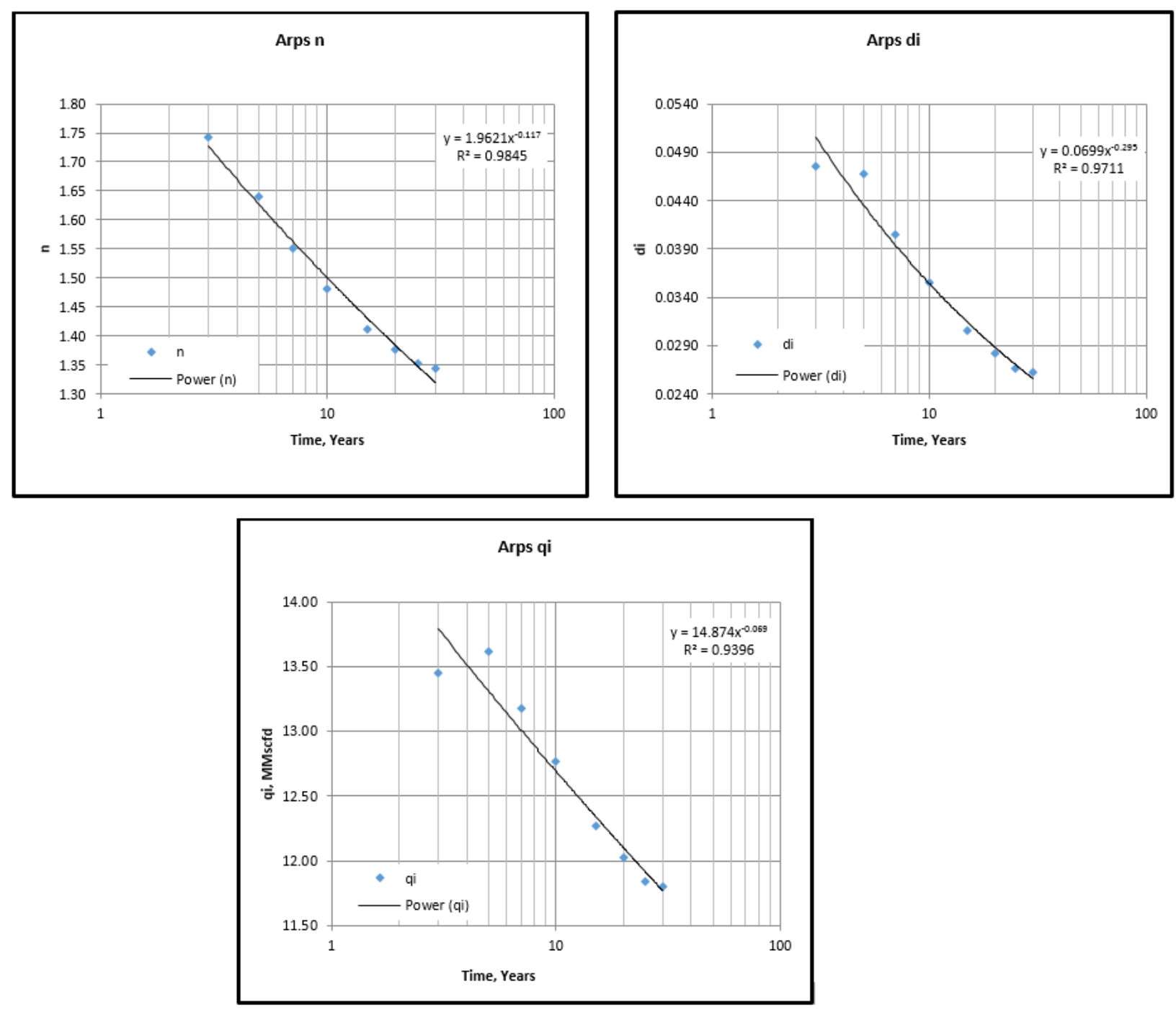

Figure D-78: 13 Stages - Arps Constants Correlation (5\%) 
Table D-79: 13 Stages (6\%) - Arps

\begin{tabular}{|c|c|c|c|c|}
\hline \multicolumn{5}{|c|}{ 13 Fractures (6\%) - Arps } \\
\hline Years & $n$ & di & qi & $R^{2}$ \\
\hline 3 & 1.8065 & 0.0444 & 13.8793 & 0.9528 \\
\hline 5 & 1.6359 & 0.0379 & 13.7552 & 0.9504 \\
\hline 7 & 1.5368 & 0.0329 & 13.1509 & 0.9564 \\
\hline 10 & 1.4502 & 0.0283 & 12.6930 & 0.9648 \\
\hline 15 & 1.4039 & 0.0261 & 12.4598 & 0.9706 \\
\hline 20 & 1.3625 & 0.0238 & 12.1694 & 0.9759 \\
\hline 25 & 1.3404 & 0.0226 & 12.0141 & 0.9787 \\
\hline 30 & 1.3209 & 0.0216 & 11.8694 & 0.9809 \\
\hline
\end{tabular}

Table D-80: 13 Stages (6\%) - PLE

\begin{tabular}{|c|c|c|c|c|c|}
\hline \multicolumn{7}{|c|}{ 13 Fractures $(\phi=6 \%)-P L E$} \\
\hline Years & $D_{\infty}$ & $n$ & $\boldsymbol{q}_{\boldsymbol{i}}$ & $\boldsymbol{D}_{1}$ & $\boldsymbol{R}^{2}$ \\
\hline 2 & 0.00028 & 0.38915 & 14.53514 & 0.07150 & 0.99946 \\
\hline 3 & 0.00029 & 0.38869 & 14.53413 & 0.07149 & 0.99957 \\
\hline 4 & 0.00016 & 0.39894 & 14.51876 & 0.07090 & 0.99953 \\
\hline 5 & 0.00001 & 0.41162 & 14.47904 & 0.06995 & 0.99932 \\
\hline 7 & -0.00028 & 0.43504 & 14.43713 & 0.06808 & 0.99870 \\
\hline 10 & -0.00059 & 0.46575 & 14.25055 & 0.06440 & 0.99804 \\
\hline 15 & -0.00070 & 0.47362 & 14.30886 & 0.06398 & 0.99797 \\
\hline 20 & -0.00064 & 0.46715 & 14.34853 & 0.06495 & 0.99793 \\
\hline 25 & -0.00058 & 0.46031 & 14.34864 & 0.06571 & 0.99749 \\
\hline 30 & -0.00051 & 0.45007 & 14.40841 & 0.06729 & 0.99686 \\
\hline
\end{tabular}

Table D-81: 13 Stages (6\%) - Duong

\begin{tabular}{|c|c|c|c|c|c|}
\hline \multicolumn{7}{|c|}{ 13 Fractures $(\phi=6 \%)$ - Duong } \\
\hline Years & $\boldsymbol{a}$ & $\boldsymbol{m}$ & $\boldsymbol{q}_{\mathbf{1}}$ & $\boldsymbol{q}_{\infty}$ & $\boldsymbol{R}^{2}$ \\
\hline 2 & 1.057 & 1.062 & 15.000 & -3.184 & 1.000 \\
\hline 3 & 1.075 & 1.071 & 14.300 & -2.394 & 0.999 \\
\hline 4 & 1.114 & 1.086 & 13.450 & -1.704 & 0.998 \\
\hline 5 & 1.145 & 1.098 & 13.000 & -1.268 & 0.996 \\
\hline 7 & 1.218 & 1.120 & 12.100 & -0.752 & 0.993 \\
\hline 10 & 1.283 & 1.139 & 11.600 & -0.418 & 0.989 \\
\hline 15 & 1.359 & 1.158 & 11.000 & -0.197 & 0.985 \\
\hline 20 & 1.414 & 1.169 & 10.500 & -0.107 & 0.983 \\
\hline 25 & 1.441 & 1.175 & 10.300 & -0.065 & 0.983 \\
\hline 30 & 1.455 & 1.178 & 10.200 & -0.043 & 0.983 \\
\hline
\end{tabular}



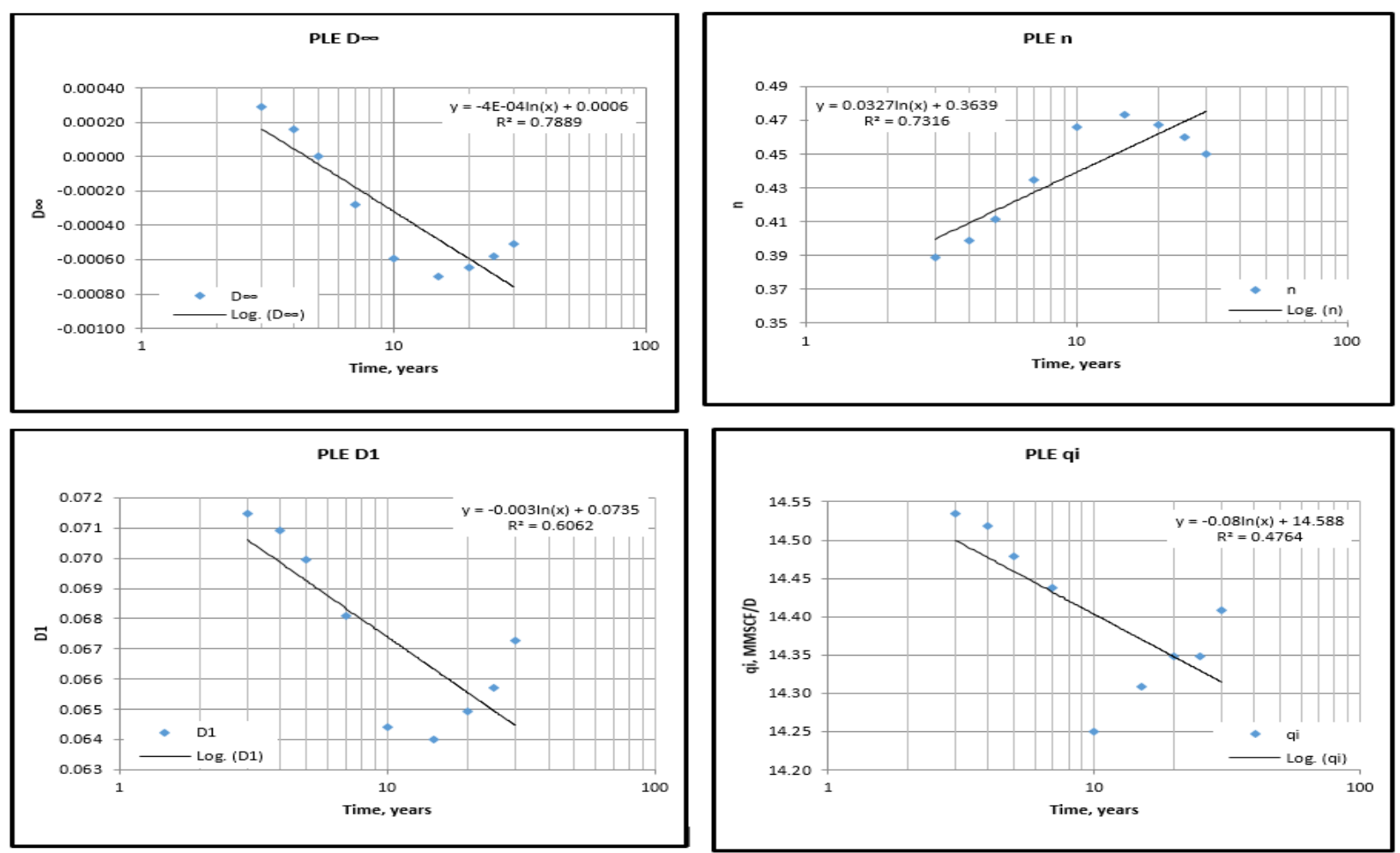

Figure D-79: 13 Stages - PLE Constants Correlation (6\%)
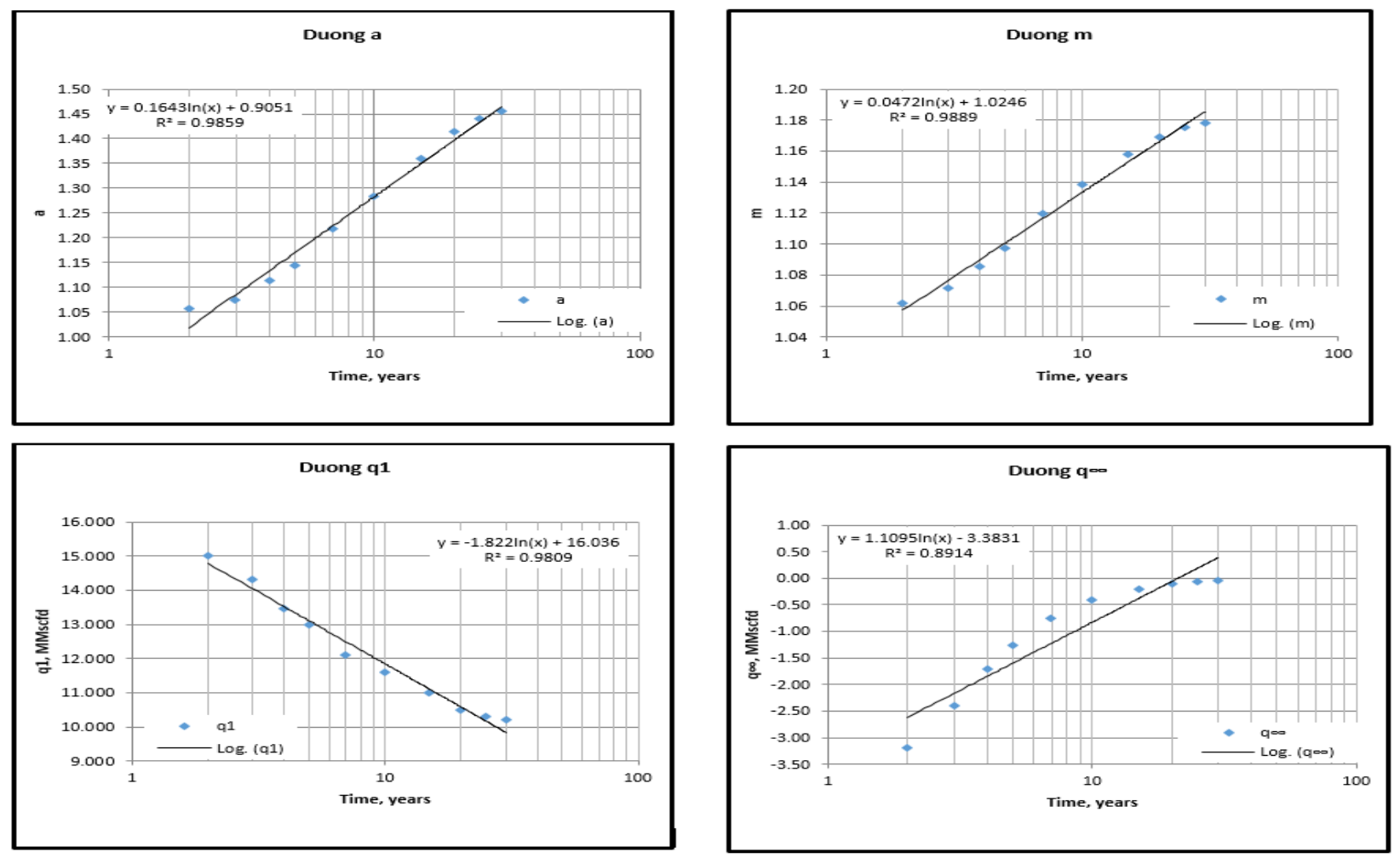

Figure D-80: 13 Stages - Duong Constants Correlation (6\%) 


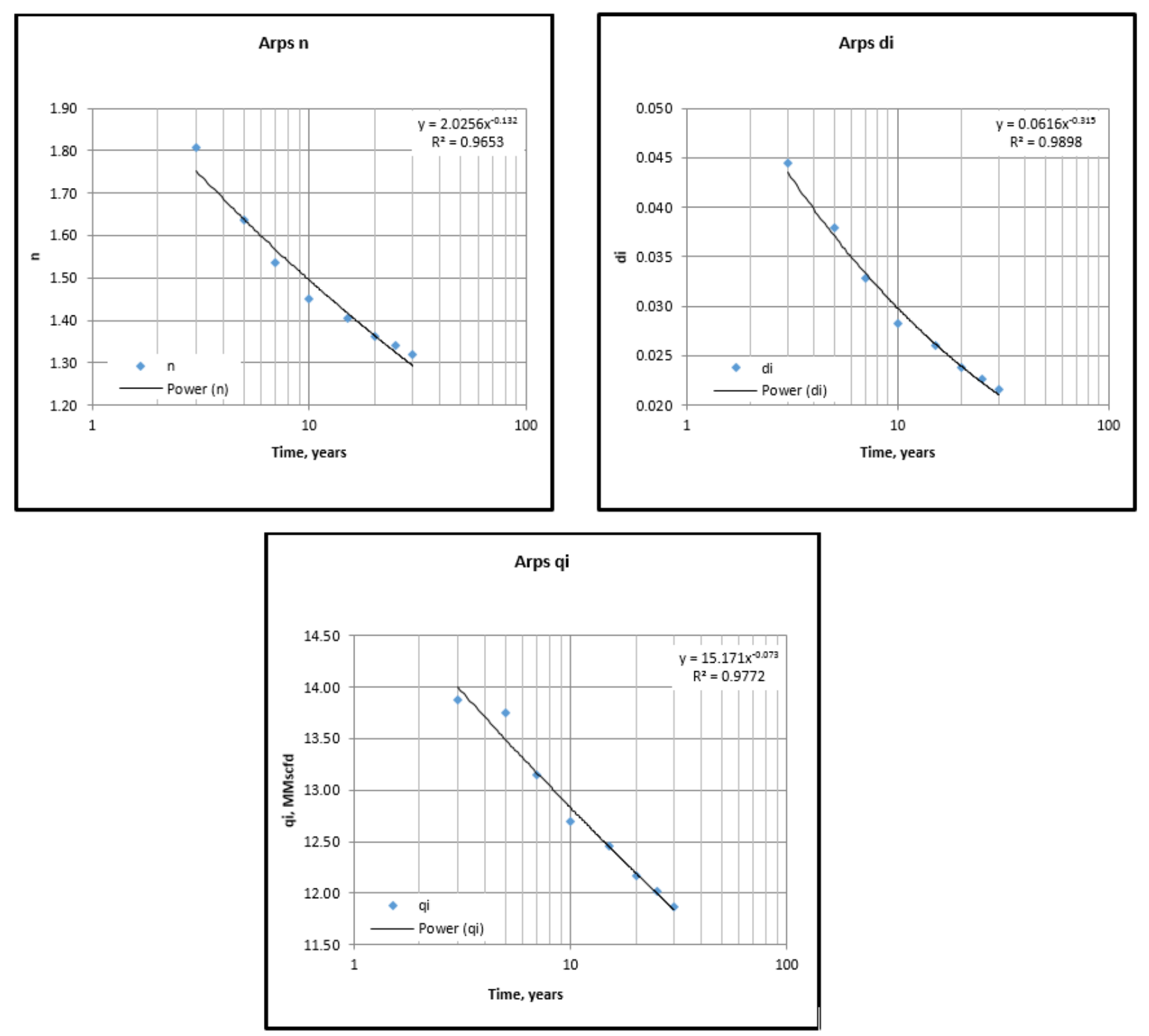

Figure D-81: 13 Stages - Arps Constants Correlation (6\%) 
Table D-82: 13 Stages (8\%) - Arps

\begin{tabular}{|c|c|c|c|c|}
\hline \multicolumn{5}{|c|}{ 13 Fractures (8\%) - Arps } \\
\hline Years & $n$ & di & qi & $\boldsymbol{R}^{2}$ \\
\hline 3 & 1.9041 & 0.0387 & 14.4732 & 0.9610 \\
\hline 5 & 1.7050 & 0.0326 & 14.1389 & 0.9542 \\
\hline 7 & 1.5960 & 0.0264 & 13.5263 & 0.9549 \\
\hline 10 & 1.5045 & 0.0252 & 13.4493 & 0.9612 \\
\hline 15 & 1.4325 & 0.0223 & 13.0902 & 0.9684 \\
\hline 20 & 1.3515 & 0.0187 & 12.5148 & 0.9773 \\
\hline 25 & 1.3024 & 0.0167 & 12.1619 & 0.9823 \\
\hline 30 & 1.2834 & 0.0160 & 12.0275 & 0.9841 \\
\hline
\end{tabular}

Table D-83: 13 Stages (8\%) - PLE

\begin{tabular}{|c|c|c|c|c|c|}
\hline \multicolumn{7}{|c|}{ 13Fractures $(\phi=8 \%)$ - PLE } \\
\hline Years & $\boldsymbol{D}_{\infty}$ & $\boldsymbol{n}$ & $\boldsymbol{q}_{\boldsymbol{i}}$ & $\boldsymbol{D}_{\mathbf{1}}$ & $\boldsymbol{R}^{\mathbf{2}}$ \\
\hline 2 & -0.00005 & 0.39867 & 15.42605 & 0.06837 & 0.99907 \\
\hline 3 & 0.00015 & 0.38618 & 15.43693 & 0.06860 & 0.99917 \\
\hline 4 & 0.00016 & 0.38510 & 15.43725 & 0.06869 & 0.99929 \\
\hline 5 & 0.00013 & 0.38955 & 15.37688 & 0.06806 & 0.99932 \\
\hline 7 & -0.00004 & 0.40579 & 15.37621 & 0.06701 & 0.99908 \\
\hline 10 & -0.00026 & 0.42954 & 15.28329 & 0.06462 & 0.99841 \\
\hline 15 & -0.00047 & 0.45512 & 15.18778 & 0.06162 & 0.99785 \\
\hline 20 & -0.00051 & 0.46111 & 15.08417 & 0.06053 & 0.99788 \\
\hline 25 & -0.00048 & 0.45725 & 15.11713 & 0.06108 & 0.99788 \\
\hline 30 & -0.00045 & 0.45225 & 15.17413 & 0.06192 & 0.99768 \\
\hline
\end{tabular}

Table D-84: 13 Stages (8\%) - Duong

\begin{tabular}{|c|c|c|c|c|c|}
\hline \multicolumn{7}{|c|}{ 13Fractures $(\phi=8 \%)$ - Duong } \\
\hline Years & $\boldsymbol{a}$ & $\boldsymbol{m}$ & $\boldsymbol{q}_{1}$ & $\boldsymbol{q}_{\infty}$ & $\boldsymbol{R}^{\mathbf{2}}$ \\
\hline 2 & 1.07 & 1.06 & 15.42 & -2.99 & 0.99 \\
\hline 3 & 1.08 & 1.07 & 15.00 & -2.79 & 0.99 \\
\hline 4 & 1.11 & 1.08 & 14.20 & -2.08 & 1.00 \\
\hline 5 & 1.15 & 1.09 & 13.40 & -1.61 & 1.00 \\
\hline 7 & 1.21 & 1.11 & 12.60 & -1.06 & 1.00 \\
\hline 10 & 1.28 & 1.13 & 11.90 & -0.63 & 0.99 \\
\hline 15 & 1.36 & 1.15 & 11.22 & -0.32 & 0.99 \\
\hline 20 & 1.40 & 1.16 & 10.92 & -0.19 & 0.99 \\
\hline 25 & 1.43 & 1.16 & 10.70 & -0.09 & 0.98 \\
\hline 30 & 1.45 & 1.17 & 10.62 & -0.07 & 0.98 \\
\hline
\end{tabular}



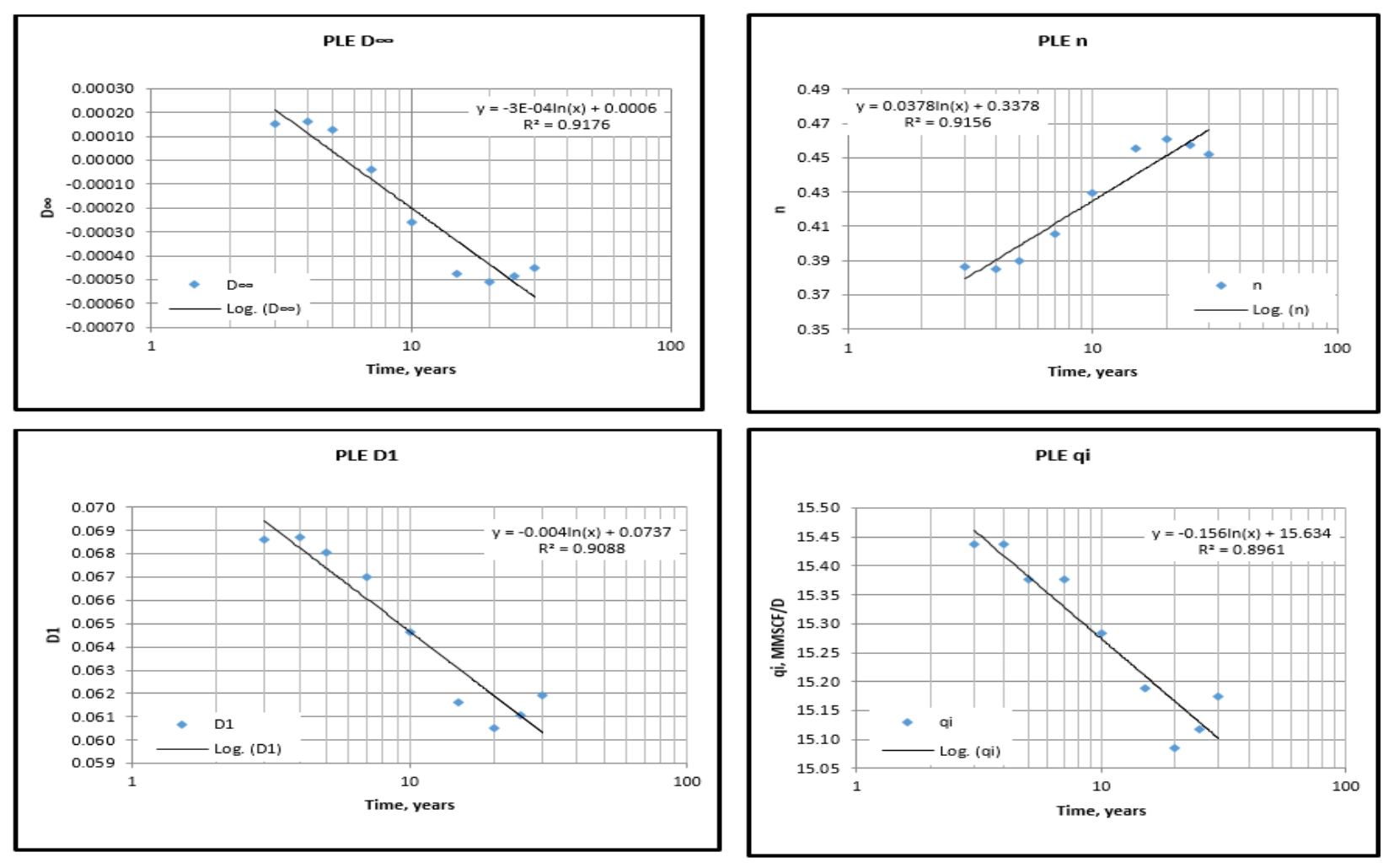

Figure D-82: 13 Stages - PLE Constants Correlation (8\%)
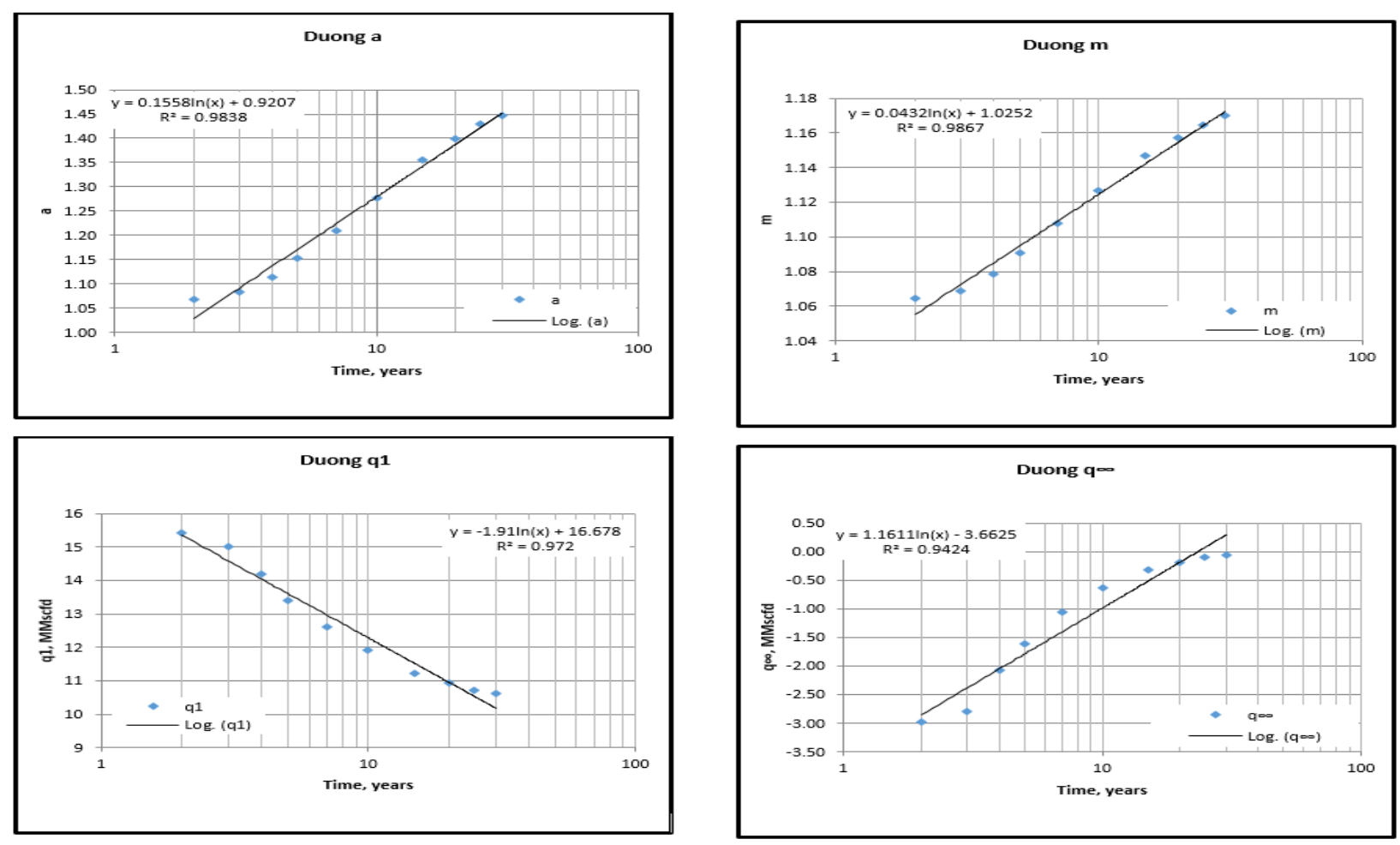

Figure D-83: 13 Stages - Duong Constants Correlation (8\%) 

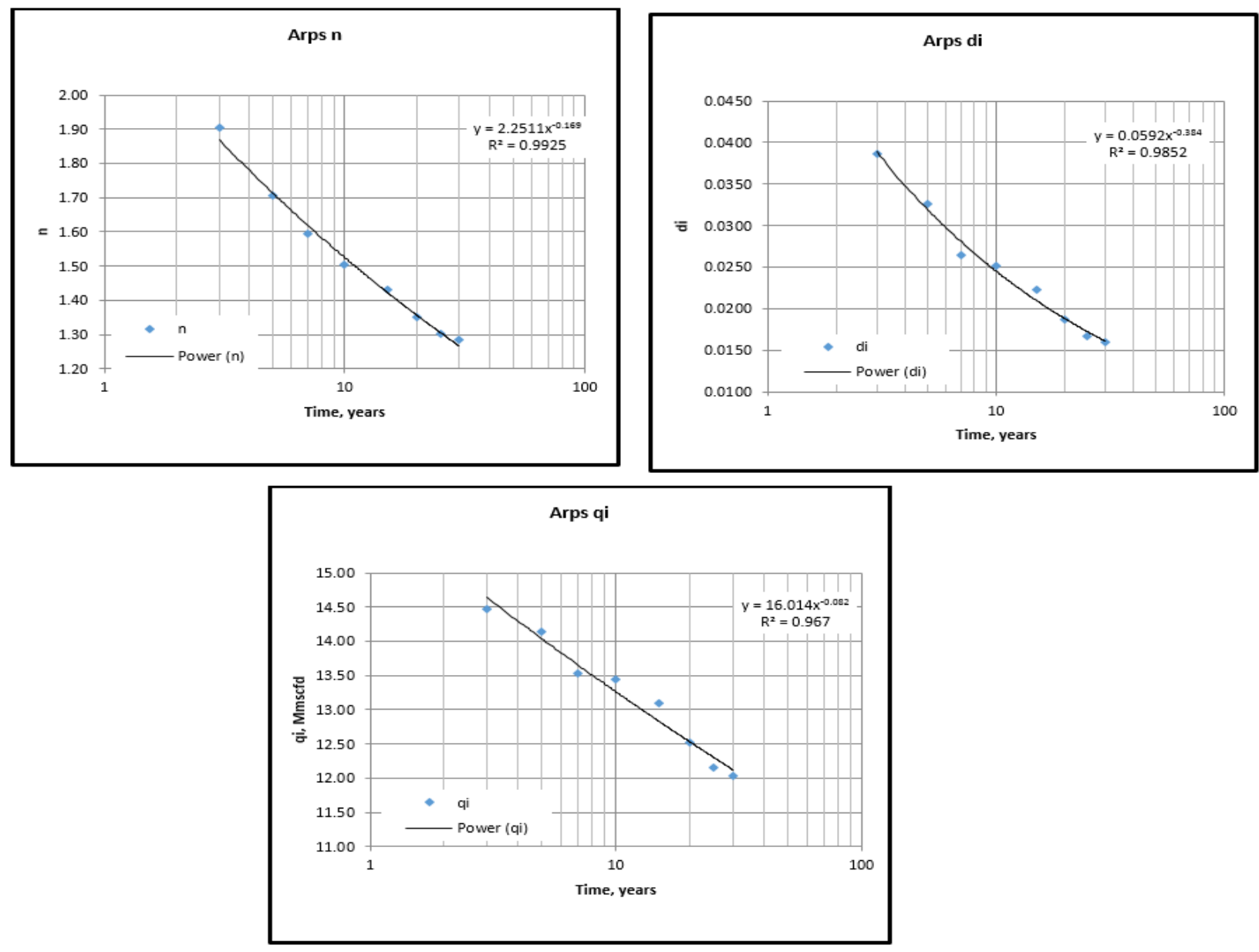

Figure D-84: 13 Stages - Arps Constants Correlation (8\%) 


\section{E. DCA Models Constants Ratios}

The results for re-calculated Arps and Duong constants and their ratios were summarized in the following tables, for both seven and thirteen stages.

\section{E.1. Seven Stages Model}

Table E-1: 7 Stages (300 ft.) - Arps- Recalculated Constants

\begin{tabular}{|c|c|c|c|c|c|c|}
\hline \multicolumn{7}{|c|}{ 7 Fractures (300 ft.)-Arps } \\
\hline Years & $n$ & $n($ Eq.) & di & di(Eq.) & qi & qi(Eq.) \\
\hline 3 & 2.1669 & 2.1513 & 0.0436 & 0.0407 & 5.0052 & 5.0006 \\
\hline 5 & 1.8742 & 1.8353 & 0.0247 & 0.0234 & 4.3838 & 4.3143 \\
\hline 7 & 1.6453 & 1.6529 & 0.0154 & 0.0163 & 3.9078 & 3.9145 \\
\hline 10 & 1.4477 & 1.4794 & 0.0100 & 0.0111 & 3.4948 & 3.5311 \\
\hline 15 & 1.2704 & 1.3041 & 0.0065 & 0.0071 & 3.0975 & 3.1407 \\
\hline 20 & 1.1807 & 1.1925 & 0.0051 & 0.0052 & 2.8748 & 2.8901 \\
\hline 25 & 1.1270 & 1.1126 & 0.0043 & 0.0041 & 2.7301 & 2.7096 \\
\hline 30 & 1.0795 & 1.0512 & 0.0038 & 0.0034 & 2.6105 & 2.5705 \\
\hline
\end{tabular}

Table E-2: 7 Stages (300 ft.) - Duong- Recalculated Constants

\begin{tabular}{|c|c|c|c|c|c|c|c|c|}
\hline \multicolumn{9}{|c|}{ 7 Fractures (300 ft.)- Duong } \\
\hline Years & $a$ & $a(E q)$. & $m$ & $m(E q)$. & $q_{1}$ & $q_{1}$ (Eq.) & $q_{\infty}$ & $q_{\infty}$ (Eq.) \\
\hline 2 & 0.8370 & 0.7282 & 0.9883 & 0.9613 & 11.4065 & 11.3750 & -4.5662 & -3.8101 \\
\hline 3 & 0.8116 & 0.7701 & 0.9874 & 0.9815 & 10.4424 & 10.4250 & -3.4514 & -3.1285 \\
\hline 4 & 0.7944 & 0.7998 & 0.9878 & 0.9959 & 9.7563 & 9.7509 & -2.7111 & -2.6450 \\
\hline 5 & 0.7671 & 0.8229 & 0.9880 & 1.0070 & 9.2240 & 9.2281 & -1.9608 & -2.2699 \\
\hline 7 & 0.7377 & 0.8577 & 1.0007 & 1.0238 & 8.4220 & 8.4397 & -0.7879 & -1.7043 \\
\hline 10 & 0.7992 & 0.8946 & 1.0331 & 1.0416 & 7.5720 & 7.6040 & -0.2725 & -1.1048 \\
\hline 15 & 0.9062 & 0.9365 & 1.0656 & 1.0618 & 6.6051 & 6.6540 & -0.0834 & -0.4232 \\
\hline 20 & 0.9884 & 0.9663 & 1.0846 & 1.0762 & 5.9190 & 5.9800 & -0.0243 & 0.0603 \\
\hline 25 & 1.0540 & 0.9893 & 1.0972 & 1.0873 & 5.3870 & 5.4572 & 0.0011 & 0.4354 \\
\hline 30 & 1.0774 & 1.0082 & 1.1014 & 1.0964 & 5.2052 & 5.0300 & 0.0079 & 0.7419 \\
\hline
\end{tabular}

Table E-3: 7 Stages (400 ft.) - Arps- Recalculated Constants

\begin{tabular}{|c|c|c|c|c|c|c|}
\hline \multicolumn{7}{|c|}{ 7 Fractures (400 ft.)-Arps } \\
\hline Years & $n$ & $n(E q)$. & $d i$ & di(Eq.) & $q i$ & $q i(E q)$. \\
\hline 3 & 2.1317 & 2.0400 & 0.0349 & 0.0299 & 5.7257 & 5.5786 \\
\hline 5 & 1.8148 & 1.8047 & 0.0203 & 0.0203 & 5.0730 & 5.0626 \\
\hline 7 & 1.6213 & 1.6646 & 0.0143 & 0.0157 & 4.6758 & 4.7491 \\
\hline 10 & 1.4605 & 1.5281 & 0.0105 & 0.0120 & 4.3258 & 4.4379 \\
\hline 15 & 1.3394 & 1.3864 & 0.0080 & 0.0088 & 4.0284 & 4.1089 \\
\hline 20 & 1.2832 & 1.2939 & 0.0070 & 0.0071 & 3.8694 & 3.8903 \\
\hline 25 & 1.2501 & 1.2264 & 0.0063 & 0.0060 & 3.7674 & 3.7288 \\
\hline 30 & 1.2278 & 1.1739 & 0.0060 & 0.0052 & 3.6982 & 3.6018 \\
\hline
\end{tabular}


Table E-4: 7 Stages (400 ft.) - Duong - Recalculated Constants

\begin{tabular}{|c|c|c|c|c|c|c|c|c|}
\hline \multicolumn{9}{|c|}{ 7 Fractures (400 ft.)- Duong } \\
\hline Years & $\boldsymbol{a}$ & $\boldsymbol{a}$ (Eq.) & $\boldsymbol{m}$ & $\boldsymbol{m}$ (Eq.) & $\boldsymbol{q}_{1}$ & $\boldsymbol{q}_{1}$ (Eq.) & $\boldsymbol{q}_{\infty}$ & $\boldsymbol{q}_{\infty}$ (Eq.) \\
\hline 2 & 0.808 & 0.707 & 0.990 & 0.972 & 11.502 & 11.508 & -3.248 & -2.690 \\
\hline 3 & 0.808 & 0.779 & 0.996 & 0.994 & 10.510 & 10.484 & -2.445 & -2.220 \\
\hline 4 & 0.810 & 0.830 & 1.002 & 1.009 & 9.748 & 9.758 & -1.805 & -1.888 \\
\hline 5 & 0.816 & 0.870 & 1.010 & 1.022 & 9.186 & 9.194 & -1.321 & -1.629 \\
\hline 7 & 0.850 & 0.930 & 1.028 & 1.040 & 8.338 & 8.345 & -0.741 & -1.240 \\
\hline 10 & 0.923 & 0.993 & 1.054 & 1.060 & 7.445 & 7.444 & -0.363 & -0.827 \\
\hline 15 & 1.036 & 1.065 & 1.083 & 1.082 & 6.418 & 6.420 & -0.149 & -0.358 \\
\hline 20 & 1.125 & 1.116 & 1.102 & 1.097 & 5.694 & 5.694 & -0.071 & -0.025 \\
\hline 25 & 1.198 & 1.156 & 1.115 & 1.110 & 5.132 & 5.130 & -0.036 & 0.233 \\
\hline 30 & 1.261 & 1.189 & 1.124 & 1.120 & 4.672 & 4.670 & -0.018 & 0.444 \\
\hline
\end{tabular}

Table E-5: 7 Stages (500 ft.) - Arps- Recalculated Constants

\begin{tabular}{|c|c|c|c|c|c|c|}
\hline \multicolumn{7}{|c|}{ 7 Fractures (500 ft.)-Arps } \\
\hline Years & $n$ & $n(E q)$. & di & di(Eq.) & qi & qi(Eq.) \\
\hline 3 & 2.1055 & 1.9475 & 0.0259 & 0.0203 & 6.0292 & 5.7287 \\
\hline 5 & 1.7534 & 1.7800 & 0.0149 & 0.0160 & 5.3604 & 5.4350 \\
\hline 7 & 1.5965 & 1.6777 & 0.0118 & 0.0137 & 5.0889 & 5.2499 \\
\hline 10 & 1.4858 & 1.5756 & 0.0099 & 0.0117 & 4.8918 & 5.0605 \\
\hline 15 & 1.4195 & 1.4671 & 0.0089 & 0.0097 & 4.7677 & 4.8535 \\
\hline 20 & 1.3931 & 1.3946 & 0.0085 & 0.0085 & 4.7153 & 4.7118 \\
\hline 25 & 1.3769 & 1.3409 & 0.0083 & 0.0077 & 4.6821 & 4.6048 \\
\hline 30 & 1.3647 & 1.2986 & 0.0081 & 0.0071 & 4.6569 & 4.5191 \\
\hline
\end{tabular}

Table E-6: 7 Stages (500 ft.) - Duong- Recalculated Constants

\begin{tabular}{|c|c|c|c|c|c|c|c|c|}
\hline \multicolumn{9}{|c|}{7 Fractures (500 ft.)- Duong } \\
\hline Years & $a$ & $a(E q)$. & $m$ & $m(E q)$. & $q 1$ & $q 1$ (Eq.) & $q \infty$ & $q \infty$ (Eq.) \\
\hline 2 & 0.808 & 0.733 & 0.989 & 0.979 & 12.151 & 11.800 & -3.519 & -2.877 \\
\hline 3 & 0.812 & 0.814 & 0.992 & 1.001 & 11.050 & 10.685 & -2.853 & -2.380 \\
\hline 4 & 0.850 & 0.872 & 1.011 & 1.017 & 9.802 & 9.894 & -1.851 & -2.027 \\
\hline 5 & 0.891 & 0.917 & 1.029 & 1.030 & 8.870 & 9.280 & -1.109 & -1.753 \\
\hline 7 & 0.940 & 0.984 & 1.044 & 1.049 & 8.021 & 8.355 & -0.776 & -1.340 \\
\hline 10 & 1.022 & 1.056 & 1.066 & 1.069 & 7.025 & 7.374 & -0.461 & -0.902 \\
\hline 15 & 1.117 & 1.137 & 1.089 & 1.091 & 6.175 & 6.259 & -0.247 & -0.404 \\
\hline 20 & 1.202 & 1.195 & 1.106 & 1.108 & 5.501 & 5.468 & -0.151 & -0.051 \\
\hline 25 & 1.261 & 1.239 & 1.122 & 1.120 & 5.074 & 4.854 & -0.061 & 0.223 \\
\hline 30 & 1.320 & 1.276 & 1.130 & 1.130 & 4.650 & 4.353 & -0.035 & 0.447 \\
\hline
\end{tabular}


Table E-7: 7 Stages (600 ft.) - Arps- Recalculated Constants

\begin{tabular}{|c|c|c|c|c|c|c|}
\hline \multicolumn{7}{|c|}{ 7 Fractures (600 ft.)-Arps } \\
\hline Years & $n$ & $n(E q)$. & $d i$ & di(Eq.) & $q i$ & qi(Eq.) \\
\hline 3 & 2.0700 & 2.0499 & 0.0181 & 0.0178 & 6.0055 & 5.9963 \\
\hline 5 & 1.9707 & 1.9182 & 0.0175 & 0.0161 & 6.0129 & 5.9021 \\
\hline 7 & 1.8060 & 1.8361 & 0.0142 & 0.0150 & 5.7744 & 5.8408 \\
\hline 10 & 1.7032 & 1.7529 & 0.0128 & 0.0139 & 5.6735 & 5.7766 \\
\hline 15 & 1.6397 & 1.6629 & 0.0124 & 0.0128 & 5.6647 & 5.7044 \\
\hline 20 & 1.5905 & 1.6019 & 0.0118 & 0.0120 & 5.6180 & 5.6538 \\
\hline 25 & 1.5702 & 1.5561 & 0.0117 & 0.0115 & 5.6271 & 5.6148 \\
\hline 30 & 1.5601 & 1.5196 & 0.0118 & 0.0111 & 5.6488 & 5.5832 \\
\hline
\end{tabular}

Table E-8: 7 Stages (600 ft.) - Duong- Recalculated Constants

\begin{tabular}{|c|c|c|c|c|c|c|c|c|}
\hline \multicolumn{9}{|c|}{7 Fractures (600 ft.)- Duong } \\
\hline Years & $a$ & $a(E q)$. & $m$ & $m(E q)$. & $q 1$ & $q 1$ (Eq.) & $q \infty$ & $q \infty$ (Eq.) \\
\hline 2 & 0.812 & 0.714 & 0.983 & 0.971 & 14.655 & 13.689 & -5.219 & -3.741 \\
\hline 3 & 0.831 & 0.804 & 1.000 & 0.994 & 12.084 & 12.312 & -2.788 & -3.118 \\
\hline 4 & 0.855 & 0.867 & 1.008 & 1.010 & 11.062 & 11.335 & -2.294 & -2.676 \\
\hline 5 & 0.881 & 0.916 & 1.018 & 1.023 & 10.065 & 10.577 & -1.720 & -2.334 \\
\hline 7 & 0.922 & 0.990 & 1.032 & 1.042 & 9.015 & 9.435 & -1.219 & -1.817 \\
\hline 10 & 0.980 & 1.069 & 1.049 & 1.062 & 8.022 & 8.223 & -0.798 & -1.269 \\
\hline 15 & 1.081 & 1.158 & 1.074 & 1.085 & 7.015 & 6.846 & -0.575 & -0.647 \\
\hline 20 & 1.221 & 1.222 & 1.111 & 1.101 & 6.060 & 5.869 & -0.213 & -0.205 \\
\hline 25 & 1.330 & 1.271 & 1.121 & 1.114 & 5.205 & 5.112 & -0.211 & 0.137 \\
\hline 30 & 1.410 & 1.311 & 1.130 & 1.124 & 4.709 & 4.493 & -0.217 & 0.417 \\
\hline
\end{tabular}

Table E-9: 7 Stages (700 ft.) - Arps- Recalculated Constants

\begin{tabular}{|c|c|c|c|c|c|c|}
\hline \multicolumn{7}{|c|}{ 7 Fractures (700 ft.)-Arps } \\
\hline Years & $n$ & $n(E q)$. & $d i$ & di(Eq.) & $q i$ & qi(Eq.) \\
\hline 3 & 1.9283 & 1.9607 & 0.0118 & 0.0119 & 5.7419 & 5.7557 \\
\hline 5 & 1.8589 & 1.8441 & 0.0112 & 0.0111 & 5.7172 & 5.7117 \\
\hline 7 & 1.8021 & 1.7711 & 0.0106 & 0.0105 & 5.6887 & 5.6830 \\
\hline 10 & 1.7065 & 1.6969 & 0.0100 & 0.0100 & 5.6524 & 5.6527 \\
\hline 15 & 1.6045 & 1.6163 & 0.0093 & 0.0094 & 5.5957 & 5.6184 \\
\hline 20 & 1.5561 & 1.5615 & 0.0091 & 0.0090 & 5.5946 & 5.5942 \\
\hline 25 & 1.5124 & 1.5202 & 0.0087 & 0.0088 & 5.5612 & 5.5755 \\
\hline 30 & 1.4896 & 1.4873 & 0.0086 & 0.0085 & 5.5577 & 5.5603 \\
\hline
\end{tabular}


Table E-10: 7 Stages (700 ft.) - Duong- Recalculated Constants

\begin{tabular}{|c|c|c|c|c|c|c|c|c|}
\hline \multicolumn{9}{|c|}{7 Fractures (700 ft.)- Duong } \\
\hline Years & $a$ & $a(E q)$. & $m$ & $m(E q)$. & $q 1$ & $q 1$ (Eq.) & $q \infty$ & $q \infty$ (Eq.) \\
\hline 2 & 0.889 & 0.686 & 0.996 & 0.955 & 16.505 & 15.662 & -7.556 & -5.651 \\
\hline 3 & 0.839 & 0.770 & 0.995 & 0.979 & 14.451 & 14.064 & -4.487 & -4.700 \\
\hline 4 & 0.846 & 0.829 & 1.000 & 0.996 & 12.541 & 12.931 & -3.305 & -4.026 \\
\hline 5 & 0.876 & 0.876 & 1.010 & 1.009 & 11.207 & 12.052 & -2.570 & -3.502 \\
\hline 7 & 0.905 & 0.945 & 1.019 & 1.029 & 10.000 & 10.726 & -1.939 & -2.713 \\
\hline 10 & 0.944 & 1.019 & 1.032 & 1.050 & 9.054 & 9.321 & -1.371 & -1.877 \\
\hline 15 & 1.033 & 1.103 & 1.050 & 1.074 & 8.051 & 7.723 & -1.099 & -0.926 \\
\hline 20 & 1.151 & 1.163 & 1.100 & 1.091 & 7.051 & 6.590 & -0.124 & -0.251 \\
\hline 25 & 1.222 & 1.209 & 1.110 & 1.104 & 6.014 & 5.711 & -0.123 & 0.272 \\
\hline 30 & 1.346 & 1.247 & 1.129 & 1.114 & 4.890 & 4.992 & -0.102 & 0.700 \\
\hline
\end{tabular}

Table E-11: 7 Stages (0.0008 m-D) - Arps- Recalculated Constants

\begin{tabular}{|c|c|c|c|c|c|c|}
\hline \multicolumn{7}{|c|}{ 7 Fractures (0.0008 m-D)-Arps } \\
\hline Years & $n$ & $n$ (Eq.) & di & di(Eq.) & qi & qi(Eq.) \\
\hline 3 & 2.3770 & 2.4549 & 0.0762 & 0.0835 & 5.2399 & 5.3574 \\
\hline 5 & 2.2994 & 2.2623 & 0.0610 & 0.0560 & 4.9447 & 4.8445 \\
\hline 7 & 2.1953 & 2.1437 & 0.0462 & 0.0431 & 4.6050 & 4.5338 \\
\hline 10 & 2.0564 & 2.0248 & 0.0328 & 0.0326 & 4.2277 & 4.2262 \\
\hline 15 & 1.8951 & 1.8976 & 0.0226 & 0.0237 & 3.8544 & 3.9017 \\
\hline 20 & 1.7957 & 1.8122 & 0.0181 & 0.0189 & 3.6427 & 3.6867 \\
\hline 25 & 1.7325 & 1.7487 & 0.0157 & 0.0159 & 3.5110 & 3.5282 \\
\hline 30 & 1.6930 & 1.6984 & 0.0143 & 0.0138 & 3.4299 & 3.4037 \\
\hline
\end{tabular}

Table E-12: 7 Stages (0.0008 m-D) - Duong- Recalculated Constants

\begin{tabular}{|c|c|c|c|c|c|c|c|c|}
\hline \multicolumn{9}{|c|}{7 Fractures $(0.0008 \mathrm{~m}-\mathrm{D})$ - Duong } \\
\hline Years & $a$ & $a(E q)$. & $m$ & $m(E q)$. & $q 1$ & $q 1$ (Eq.) & $q \infty$ & $q \infty(E q)$. \\
\hline 2 & 0.8135 & 0.8259 & 1.0520 & 1.0643 & 6.50 & 6.3742 & 0.1098 & 0.1600 \\
\hline 3 & 0.8763 & 0.8891 & 1.0698 & 1.0710 & 6.00 & 5.8491 & 0.1385 & 0.1247 \\
\hline 4 & 0.9649 & 0.9338 & 1.0878 & 1.0759 & 5.30 & 5.4765 & 0.1538 & 0.0997 \\
\hline 5 & 0.9825 & 0.9686 & 1.0873 & 1.0796 & 5.10 & 5.1876 & 0.1153 & 0.0803 \\
\hline 7 & 1.0339 & 1.0210 & 1.0902 & 1.0852 & 4.60 & 4.7518 & 0.0571 & 0.0510 \\
\hline 10 & 1.0668 & 1.0765 & 1.0887 & 1.0912 & 4.23 & 4.2900 & -0.0133 & 0.0200 \\
\hline 15 & 1.1050 & 1.1396 & 1.0896 & 1.0979 & 3.85 & 3.7649 & -0.0643 & -0.0153 \\
\hline 20 & 1.1571 & 1.1844 & 1.0964 & 1.1027 & 3.50 & 3.3923 & -0.0643 & -0.0403 \\
\hline 25 & 1.2370 & 1.2192 & 1.1080 & 1.1065 & 3.06 & 3.1034 & -0.0484 & -0.0597 \\
\hline 30 & 1.2696 & 1.2476 & 1.1126 & 1.1095 & 2.90 & 2.8672 & -0.0416 & -0.0756 \\
\hline
\end{tabular}


Table E-13: 7 Stages (0.001 m-D) - Arps- Recalculated Constants

\begin{tabular}{|c|c|c|c|c|c|c|}
\hline \multicolumn{7}{|c|}{ 7 Fractures (0.001 m-D)-Arps } \\
\hline Years & $n$ & $n(E q)$. & $d i$ & di(Eq.) & $q i$ & $q i(E q)$. \\
\hline 3 & 2.2579 & 2.2804 & 0.0607 & 0.0593 & 5.4598 & 5.4501 \\
\hline 5 & 2.1343 & 2.1047 & 0.0431 & 0.0405 & 5.0242 & 4.9561 \\
\hline 7 & 1.9900 & 1.9964 & 0.0302 & 0.0315 & 4.6638 & 4.6554 \\
\hline 10 & 1.9027 & 1.8876 & 0.0231 & 0.0241 & 4.3044 & 4.3566 \\
\hline 15 & 1.7674 & 1.7712 & 0.0166 & 0.0178 & 3.9711 & 4.0401 \\
\hline 20 & 1.6800 & 1.6930 & 0.0138 & 0.0144 & 3.7939 & 3.8296 \\
\hline 25 & 1.6292 & 1.6347 & 0.0124 & 0.0122 & 3.6905 & 3.6739 \\
\hline 30 & 1.5980 & 1.5886 & 0.0116 & 0.0106 & 3.6266 & 3.5514 \\
\hline
\end{tabular}

Table E-14: 7 Stages (0.001 m-D) - Duong- Recalculated Constants

\begin{tabular}{|c|c|c|c|c|c|c|c|c|}
\hline \multicolumn{9}{|c|}{7 Fractures (0.001 m-D)- Duong } \\
\hline Years & $a$ & $a(E q)$. & $m$ & $m(E q)$. & $q 1$ & $q 1$ (Eq.) & $q \infty$ & $q \infty(E q)$. \\
\hline 2 & 0.8117 & 0.8091 & 1.0458 & 1.0515 & 6.8000 & 6.9782 & 0.2000 & 0.2126 \\
\hline 3 & 0.8763 & 0.8835 & 1.0624 & 1.0614 & 6.5000 & 6.3676 & 0.1851 & 0.1530 \\
\hline 4 & 0.9285 & 0.9363 & 1.0710 & 1.0685 & 6.0000 & 5.9343 & 0.1310 & 0.1107 \\
\hline 5 & 0.9823 & 0.9772 & 1.0787 & 1.0740 & 5.5000 & 5.5983 & 0.0983 & 0.0779 \\
\hline 7 & 1.0245 & 1.0390 & 1.0804 & 1.0823 & 5.0500 & 5.0915 & -0.0212 & 0.0285 \\
\hline 10 & 1.1360 & 1.1044 & 1.0955 & 1.0910 & 4.1600 & 4.5544 & -0.0613 & -0.0240 \\
\hline 15 & 1.1804 & 1.1788 & 1.0994 & 1.1010 & 3.8000 & 3.9438 & -0.0885 & -0.0836 \\
\hline 20 & 1.2299 & 1.2316 & 1.1066 & 1.1081 & 3.7000 & 3.5105 & -0.1321 & -0.1259 \\
\hline 25 & 1.2684 & 1.2726 & 1.1127 & 1.1136 & 3.6000 & 3.1745 & -0.1542 & -0.1587 \\
\hline 30 & 1.2986 & 1.3060 & 1.1174 & 1.1181 & 3.5500 & 2.8999 & -0.1535 & -0.1855 \\
\hline
\end{tabular}

Table E-15: 7 Stages (0.002 m-D) - Arps- Recalculated Constants

\begin{tabular}{|c|c|c|c|c|c|c|}
\hline \multicolumn{7}{|c|}{ 7 Fractures $(\mathbf{0 . 0 0 2}$ m-D)-Arps } \\
\hline Years & $n$ & $n(E q)$. & $d i$ & di(Eq.) & qi & qi(Eq.) \\
\hline 3 & 2.0494 & 1.8041 & 0.0231 & 0.0191 & 5.8789 & 5.6557 \\
\hline 5 & 1.7531 & 1.6864 & 0.0149 & 0.0154 & 5.3601 & 5.3851 \\
\hline 7 & 1.5962 & 1.6132 & 0.0118 & 0.0133 & 5.0870 & 5.2139 \\
\hline 10 & 1.4851 & 1.5390 & 0.0099 & 0.0114 & 4.8906 & 5.0384 \\
\hline 15 & 1.4190 & 1.4588 & 0.0089 & 0.0096 & 4.7662 & 4.8460 \\
\hline 20 & 1.3929 & 1.4044 & 0.0085 & 0.0085 & 4.7148 & 4.7140 \\
\hline 25 & 1.3769 & 1.3637 & 0.0083 & 0.0077 & 4.6826 & 4.6141 \\
\hline 30 & 1.3646 & 1.3312 & 0.0081 & 0.0072 & 4.6567 & 4.5341 \\
\hline
\end{tabular}


Table E-16: 7 Stages (0.002 m-D) - Duong- Recalculated Constants

\begin{tabular}{|c|c|c|c|c|c|c|c|c|}
\hline \multicolumn{9}{|c|}{7 Fractures $(0.002 \mathrm{~m}-\mathrm{D})$ - Duong } \\
\hline Years & $a$ & $a(E q)$. & $m$ & $m(E q)$. & $q 1$ & $q 1$ (Eq.) & $q \infty$ & $q \infty(E q)$. \\
\hline 2 & 0.8937 & 0.8904 & 1.0404 & 1.0413 & 9.3000 & 8.1230 & -0.8769 & -0.8280 \\
\hline 3 & 0.9522 & 0.9829 & 1.0511 & 1.0578 & 8.0000 & 7.3697 & -0.7907 & -0.6844 \\
\hline 4 & 1.0426 & 1.0486 & 1.0698 & 1.0696 & 6.7500 & 6.8352 & -0.5840 & -0.5825 \\
\hline 5 & 1.0902 & 1.0995 & 1.0779 & 1.0787 & 6.2500 & 6.4206 & -0.4212 & -0.5034 \\
\hline 7 & 1.2132 & 1.1763 & 1.0999 & 1.0924 & 5.1500 & 5.7954 & -0.2945 & -0.3843 \\
\hline 10 & 1.2615 & 1.2576 & 1.1088 & 1.1069 & 4.8000 & 5.1327 & -0.2333 & -0.2579 \\
\hline 15 & 1.3897 & 1.3502 & 1.1301 & 1.1235 & 4.0000 & 4.3793 & -0.0123 & -0.1143 \\
\hline 20 & 1.4321 & 1.4158 & 1.1375 & 1.1352 & 3.8000 & 3.8448 & 0.0259 & -0.0124 \\
\hline 25 & 1.4556 & 1.4667 & 1.1416 & 1.1443 & 3.7000 & 3.4302 & 0.0100 & 0.0666 \\
\hline 30 & 1.4652 & 1.5084 & 1.1435 & 1.1518 & 3.6700 & 3.0915 & 0.0081 & 0.1312 \\
\hline
\end{tabular}

Table E-17: 7 Stages (0.004 m-D) - Arps- Recalculated Constants

\begin{tabular}{|c|c|c|c|c|c|c|}
\hline \multicolumn{7}{|c|}{ 7 Fractures $(\mathbf{0 . 0 0 4}$ m-D)-Arps } \\
\hline Years & $n$ & $n$ (Eq.) & di & di(Eq.) & qi & qi(Eq.) \\
\hline 3 & 1.4226 & 1.3613 & 0.0097 & 0.0090 & 6.6927 & 6.6145 \\
\hline 5 & 1.2860 & 1.3236 & 0.0083 & 0.0086 & 6.4906 & 6.5506 \\
\hline 7 & 1.2603 & 1.2993 & 0.0080 & 0.0084 & 6.4478 & 6.5088 \\
\hline 10 & 1.2553 & 1.2741 & 0.0080 & 0.0081 & 6.4386 & 6.4649 \\
\hline 15 & 1.2482 & 1.2460 & 0.0079 & 0.0078 & 6.4238 & 6.4153 \\
\hline 20 & 1.2355 & 1.2264 & 0.0077 & 0.0076 & 6.3942 & 6.3803 \\
\hline 25 & 1.2203 & 1.2115 & 0.0076 & 0.0075 & 6.3577 & 6.3533 \\
\hline 30 & 1.2071 & 1.1994 & 0.0074 & 0.0073 & 6.3261 & 6.3313 \\
\hline
\end{tabular}

Table E-18: 7 Stages (0.004 m-D) - Duong- Recalculated Constants

\begin{tabular}{|c|c|c|c|c|c|c|c|c|}
\hline \multicolumn{9}{|c|}{7 Fractures $(0.004 \mathrm{~m}-\mathrm{D})$ - Duong } \\
\hline Years & $a$ & $a(E q)$. & $m$ & $m(E q)$. & $q 1$ & $q 1$ (Eq.) & $q \infty$ & $q \infty(E q)$. \\
\hline 2 & 1.0394 & 0.9805 & 1.0525 & 1.0497 & 9.9000 & 9.7118 & -2.0193 & -1.6772 \\
\hline 3 & 1.0903 & 1.0873 & 1.0660 & 1.0691 & 8.9000 & 8.7792 & -1.5433 & -1.3879 \\
\hline 4 & 1.1460 & 1.1630 & 1.0810 & 1.0829 & 8.0000 & 8.1175 & -1.1003 & -1.1827 \\
\hline 5 & 1.2122 & 1.2218 & 1.0947 & 1.0935 & 7.3000 & 7.6043 & -0.7940 & -1.0235 \\
\hline 7 & 1.2521 & 1.3104 & 1.1064 & 1.1096 & 6.9500 & 6.8304 & -0.5266 & -0.7834 \\
\hline 10 & 1.3810 & 1.4043 & 1.1307 & 1.1267 & 5.8500 & 6.0101 & -0.2680 & -0.5289 \\
\hline 15 & 1.4622 & 1.5110 & 1.1451 & 1.1460 & 5.3000 & 5.0775 & -0.1481 & -0.2396 \\
\hline 20 & 1.6475 & 1.5868 & 1.1681 & 1.1598 & 4.0300 & 4.4158 & -0.0126 & -0.0343 \\
\hline 25 & 1.6741 & 1.6455 & 1.1713 & 1.1705 & 3.8800 & 3.9026 & -0.0123 & 0.1249 \\
\hline 30 & 1.7000 & 1.6935 & 1.1725 & 1.1792 & 3.8200 & 3.4832 & -0.0526 & 0.2550 \\
\hline
\end{tabular}


Table E-19: 7 Stages (0.006 m-D) - Arps- Recalculated Constants

\begin{tabular}{|c|c|c|c|c|c|c|}
\hline \multicolumn{7}{|c|}{ 7 Fractures $(0.006$ m-D)-Arps } \\
\hline Years & $n$ & $n(E q)$. & $d i$ & di(Eq.) & $q i$ & $q i(E q)$. \\
\hline 3 & 1.2020 & 1.2159 & 0.0081 & 0.0083 & 7.7187 & 7.7571 \\
\hline 5 & 1.1908 & 1.2011 & 0.0081 & 0.0081 & 7.7039 & 7.7176 \\
\hline 7 & 1.2009 & 1.1914 & 0.0082 & 0.0080 & 7.7231 & 7.6917 \\
\hline 10 & 1.2038 & 1.1813 & 0.0082 & 0.0079 & 7.7289 & 7.6643 \\
\hline 15 & 1.1885 & 1.1698 & 0.0080 & 0.0078 & 7.6917 & 7.6333 \\
\hline 20 & 1.1671 & 1.1618 & 0.0078 & 0.0077 & 7.6365 & 7.6113 \\
\hline 25 & 1.1471 & 1.1556 & 0.0075 & 0.0076 & 7.5823 & 7.5944 \\
\hline 30 & 1.1307 & 1.1505 & 0.0073 & 0.0076 & 7.5361 & 7.5805 \\
\hline
\end{tabular}

Table E-20: 7 Stages (0.006 m-D) - Duong- Recalculated Constants

\begin{tabular}{|c|c|c|c|c|c|c|c|c|}
\hline \multicolumn{9}{|c|}{7 Fractures (0.006 m-D)- Duong } \\
\hline Years & $a$ & $a(E q)$. & $m$ & $m(E q)$. & $q 1$ & $q 1$ (Eq.) & $q \infty$ & $q \infty$ (Eq.) \\
\hline 2 & 1.0943 & 0.9870 & 1.0565 & 1.0487 & 11.5000 & 11.8565 & -3.2125 & -2.4138 \\
\hline 3 & 1.1183 & 1.0973 & 1.0684 & 1.0693 & 10.5000 & 10.6851 & -2.1135 & -1.9949 \\
\hline 4 & 1.1323 & 1.1756 & 1.0772 & 1.0840 & 10.1000 & 9.8540 & -1.4970 & -1.6978 \\
\hline 5 & 1.1644 & 1.2363 & 1.0885 & 1.0954 & 9.6000 & 9.2093 & -1.0468 & -1.4673 \\
\hline 7 & 1.2213 & 1.3279 & 1.1051 & 1.1125 & 8.9500 & 8.2373 & -0.6195 & -1.1197 \\
\hline 10 & 1.4099 & 1.4249 & 1.1382 & 1.1307 & 6.9000 & 7.2068 & -0.2861 & -0.7512 \\
\hline 15 & 1.5558 & 1.5353 & 1.1592 & 1.1514 & 5.6400 & 6.0354 & -0.1560 & -0.3324 \\
\hline 20 & 1.6885 & 1.6135 & 1.1748 & 1.1661 & 4.6400 & 5.2043 & -0.1050 & -0.0352 \\
\hline 25 & 1.7021 & 1.6743 & 1.1764 & 1.1775 & 4.5500 & 4.5597 & -0.0993 & 0.1953 \\
\hline 30 & 1.7098 & 1.7239 & 1.1773 & 1.1868 & 4.5000 & 4.0329 & -0.0964 & 0.3836 \\
\hline
\end{tabular}

Table E-21: 7 Stages (4\%) - Arps- Recalculated Constants

\begin{tabular}{|c|c|c|c|c|c|c|}
\hline \multicolumn{7}{|c|}{ 7 Fractures (4\%)-Arps } \\
\hline Years & $n$ & $n(E q)$. & di & di(Eq.) & qi & qi(Eq.) \\
\hline 3 & 1.8915 & 1.7582 & 0.0198 & 0.0164 & 5.3124 & 5.1146 \\
\hline 5 & 1.6118 & 1.6394 & 0.0133 & 0.0140 & 4.8797 & 4.9299 \\
\hline 7 & 1.4882 & 1.5655 & 0.0111 & 0.0125 & 4.6859 & 4.8119 \\
\hline 10 & 1.4145 & 1.4909 & 0.0099 & 0.0112 & 4.5653 & 4.6899 \\
\hline 15 & 1.3751 & 1.4103 & 0.0093 & 0.0098 & 4.4970 & 4.5550 \\
\hline 20 & 1.3585 & 1.3558 & 0.0090 & 0.0089 & 4.4656 & 4.4616 \\
\hline 25 & 1.3452 & 1.3150 & 0.0088 & 0.0083 & 4.4399 & 4.3905 \\
\hline 30 & 1.3341 & 1.2825 & 0.0086 & 0.0079 & 4.4160 & 4.3332 \\
\hline
\end{tabular}


Table E-22: 7 Stages (4\%) - Duong - Recalculated Constants

\begin{tabular}{|c|c|c|c|c|c|c|c|c|}
\hline \multicolumn{9}{|c|}{7 Fractures (4\%)- Duong } \\
\hline Years & $a$ & $a(E q)$. & $m$ & $m(E q)$. & $q 1$ & $q 1$ (Eq.) & $q \infty$ & $q \infty$ (Eq.) \\
\hline 2 & 0.8853 & 0.8760 & 1.0319 & 1.0348 & 8.3000 & 7.8322 & -0.8628 & -0.7912 \\
\hline 3 & 0.9550 & 0.9807 & 1.0481 & 1.0544 & 7.4000 & 7.0529 & -0.7345 & -0.6601 \\
\hline 4 & 1.0331 & 1.0549 & 1.0656 & 1.0683 & 6.5000 & 6.4999 & -0.5706 & -0.5671 \\
\hline 5 & 1.1156 & 1.1126 & 1.0828 & 1.0790 & 5.7000 & 6.0711 & -0.4313 & -0.4950 \\
\hline 7 & 1.2013 & 1.1994 & 1.0994 & 1.0953 & 5.0000 & 5.4244 & -0.3116 & -0.3863 \\
\hline 10 & 1.3235 & 1.2915 & 1.1215 & 1.1125 & 4.2000 & 4.7388 & -0.1788 & -0.2710 \\
\hline 15 & 1.4386 & 1.3962 & 1.1406 & 1.1321 & 3.6000 & 3.9595 & -0.0556 & -0.1400 \\
\hline 20 & 1.4891 & 1.4705 & 1.1487 & 1.1460 & 3.3800 & 3.4066 & -0.0556 & -0.0470 \\
\hline 25 & 1.5102 & 1.5281 & 1.1521 & 1.1568 & 3.3000 & 2.9777 & -0.0142 & 0.0251 \\
\hline 30 & 1.5325 & 1.5752 & 1.1552 & 1.1656 & 3.2000 & 2.6273 & -0.0340 & 0.0841 \\
\hline
\end{tabular}

Table E-23: 7 Stages (5\%) - Arps- Recalculated Constants

\begin{tabular}{|c|c|c|c|c|c|c|}
\hline \multicolumn{7}{|c|}{ 7 Fractures (5\%)-Arps } \\
\hline Years & $n$ & $n($ Eq.) & di & di(Eq.) & qi & qi(Eq.) \\
\hline 3 & 2.0494 & 1.9205 & 0.0231 & 0.0192 & 5.8798 & 5.6582 \\
\hline 5 & 1.7531 & 1.7616 & 0.0149 & 0.0154 & 5.3586 & 5.3875 \\
\hline 7 & 1.5968 & 1.6643 & 0.0118 & 0.0134 & 5.0887 & 5.2162 \\
\hline 10 & 1.4859 & 1.5669 & 0.0099 & 0.0115 & 4.8925 & 5.0406 \\
\hline 15 & 1.4192 & 1.4631 & 0.0089 & 0.0097 & 4.7670 & 4.8482 \\
\hline 20 & 1.3931 & 1.3937 & 0.0085 & 0.0085 & 4.7149 & 4.7161 \\
\hline 25 & 1.3767 & 1.3421 & 0.0083 & 0.0078 & 4.6806 & 4.6162 \\
\hline 30 & 1.3644 & 1.3014 & 0.0081 & 0.0072 & 4.6547 & 4.5361 \\
\hline
\end{tabular}

Table E-24: 7 Stages (5\%) - Duong- Recalculated Constants

\begin{tabular}{|c|c|c|c|c|c|c|c|c|}
\hline \multicolumn{9}{|c|}{7 Fractures (5\%)- Duong } \\
\hline Years & $a$ & $a(E q)$. & $m$ & $m(E q)$. & $q 1$ & $q 1$ (Eq.) & $q \infty$ & $q \infty$ (Eq.) \\
\hline 2 & 0.8409 & 0.8090 & 1.0205 & 1.0190 & 9.5000 & 9.2223 & -0.9938 & -0.9338 \\
\hline 3 & 0.9044 & 0.9059 & 1.0369 & 1.0380 & 8.5000 & 8.3432 & -0.7985 & -0.7879 \\
\hline 4 & 0.9563 & 0.9746 & 1.0485 & 1.0516 & 7.7923 & 7.7195 & -0.7067 & -0.6844 \\
\hline 5 & 1.0199 & 1.0280 & 1.0627 & 1.0620 & 7.0000 & 7.2357 & -0.5678 & -0.6041 \\
\hline 7 & 1.0946 & 1.1084 & 1.0782 & 1.0779 & 6.2000 & 6.5063 & -0.4359 & -0.4830 \\
\hline 10 & 1.1860 & 1.1936 & 1.0966 & 1.0946 & 5.4000 & 5.7330 & -0.2880 & -0.3546 \\
\hline 15 & 1.2742 & 1.2905 & 1.1139 & 1.1137 & 4.8000 & 4.8539 & -0.1671 & -0.2087 \\
\hline 20 & 1.3695 & 1.3593 & 1.1295 & 1.1272 & 4.2000 & 4.2303 & -0.0986 & -0.1051 \\
\hline 25 & 1.4261 & 1.4126 & 1.1380 & 1.1377 & 3.8800 & 3.7465 & -0.0681 & -0.0248 \\
\hline 30 & 1.4648 & 1.4562 & 1.1434 & 1.1463 & 3.6700 & 3.3512 & -0.0225 & 0.0408 \\
\hline
\end{tabular}


Table E-25: 7 Stages (6\%) - Arps- Recalculated Constants

\begin{tabular}{|c|c|c|c|c|c|c|}
\hline \multicolumn{7}{|c|}{ 7 Fractures (6\%)-Arps } \\
\hline Years & $n$ & $n(E q)$. & di & di(Eq.) & qi & qi(Eq.) \\
\hline 3 & 2.1659 & 2.0598 & 0.0260 & 0.0220 & 6.3747 & 6.1677 \\
\hline 5 & 1.8769 & 1.8693 & 0.0167 & 0.0169 & 5.8106 & 5.8188 \\
\hline 7 & 1.7017 & 1.7535 & 0.0128 & 0.0142 & 5.4812 & 5.5998 \\
\hline 10 & 1.5614 & 1.6386 & 0.0102 & 0.0118 & 5.2135 & 5.3767 \\
\hline 15 & 1.4669 & 1.5171 & 0.0088 & 0.0096 & 5.0270 & 5.1338 \\
\hline 20 & 1.4292 & 1.4364 & 0.0082 & 0.0083 & 4.9464 & 4.9682 \\
\hline 25 & 1.4082 & 1.3768 & 0.0079 & 0.0074 & 4.9026 & 4.8434 \\
\hline 30 & 1.3938 & 1.3299 & 0.0077 & 0.0067 & 4.8703 & 4.7438 \\
\hline
\end{tabular}

Table E-26: 7 Stages (6\%) - Duong- Recalculated Constants

\begin{tabular}{|c|c|c|c|c|c|c|c|c|}
\hline \multicolumn{9}{|c|}{ 7 Fractures (6\%)- Duong } \\
\hline Years & $\boldsymbol{a}$ & $\boldsymbol{a}$ (Eq.) & $\boldsymbol{m}$ & $\boldsymbol{m}$ (Eq.) & $\boldsymbol{q} \mathbf{1}$ & $\boldsymbol{q}$ (Eq.) & $q^{\infty}$ & $\boldsymbol{q}$ (Eq.) \\
\hline 2 & 0.8152 & 0.8355 & 1.0128 & 1.0086 & 10.5000 & 10.3109 & -1.1949 & -1.0976 \\
\hline 3 & 0.8663 & 0.9212 & 1.0282 & 1.0266 & 9.5000 & 9.3953 & -0.9451 & -0.9287 \\
\hline 4 & 0.9240 & 0.9821 & 1.0422 & 1.0393 & 8.6000 & 8.7457 & -0.7110 & -0.8089 \\
\hline 5 & 0.9520 & 1.0292 & 1.0474 & 1.0492 & 8.2000 & 8.2419 & -0.7019 & -0.7160 \\
\hline 7 & 1.0208 & 1.1004 & 1.0624 & 1.0641 & 7.3000 & 7.4821 & -0.5542 & -0.5758 \\
\hline 10 & 1.0930 & 1.1758 & 1.0780 & 1.0799 & 6.5000 & 6.6768 & -0.4004 & -0.4273 \\
\hline 15 & 1.1735 & 1.2615 & 1.0953 & 1.0979 & 5.8000 & 5.7612 & -0.2471 & -0.2584 \\
\hline 20 & 1.2407 & 1.3223 & 1.1083 & 1.1106 & 5.3000 & 5.1116 & -0.1062 & -0.1386 \\
\hline 25 & 1.3562 & 1.3695 & 1.1259 & 1.1205 & 4.4500 & 4.6078 & -0.0598 & -0.0456 \\
\hline 30 & 1.3714 & 1.4080 & 1.1288 & 1.1286 & 4.3800 & 4.1961 & -0.0453 & 0.0303 \\
\hline
\end{tabular}

Table E-27: 7 Stages (8\%) - Arps- Recalculated Constants

\begin{tabular}{|c|c|c|c|c|c|c|}
\hline \multicolumn{7}{|c|}{ 7 Fractures (8\%)-Arps } \\
\hline Years & $n$ & $n$ (Eq.) & di & di(Eq.) & qi & qi(Eq.) \\
\hline 3 & 2.3116 & 2.2685 & 0.0298 & 0.0270 & 7.1613 & 7.0437 \\
\hline 5 & 2.0681 & 2.0367 & 0.0201 & 0.0196 & 6.6052 & 6.5643 \\
\hline 7 & 1.8845 & 1.8971 & 0.0150 & 0.0159 & 6.2081 & 6.2664 \\
\hline 10 & 1.7091 & 1.7596 & 0.0113 & 0.0127 & 5.8304 & 5.9655 \\
\hline 15 & 1.5665 & 1.6153 & 0.0089 & 0.0098 & 5.5192 & 5.6408 \\
\hline 20 & 1.5029 & 1.5202 & 0.0079 & 0.0082 & 5.3734 & 5.4213 \\
\hline 25 & 1.4696 & 1.4503 & 0.0075 & 0.0071 & 5.2974 & 5.2569 \\
\hline 30 & 1.4494 & 1.3955 & 0.0072 & 0.0064 & 5.2475 & 5.1263 \\
\hline
\end{tabular}


Table E-28: 7 Stages (8\%) - Duong- Recalculated Constants

\begin{tabular}{|c|c|c|c|c|c|c|c|c|}
\hline \multicolumn{9}{|c|}{7 Fractures (8\%)- Duong } \\
\hline Years & $a$ & $a(E q)$. & $m$ & $m(E q)$. & $q 1$ & $q 1$ (Eq.) & $q \infty$ & $q \infty$ (Eq.) \\
\hline 2 & 0.7961 & 0.7231 & 0.9998 & 0.9869 & 12.5002 & 13.0401 & -1.9834 & -1.8912 \\
\hline 3 & 0.7984 & 0.7877 & 1.0034 & 1.0029 & 12.1001 & 12.0159 & -1.6560 & -1.6025 \\
\hline 4 & 0.8141 & 0.8335 & 1.0102 & 1.0142 & 11.5440 & 11.2892 & -1.4846 & -1.3976 \\
\hline 5 & 0.8487 & 0.8690 & 1.0212 & 1.0230 & 10.6869 & 10.7256 & -1.0469 & -1.2387 \\
\hline 7 & 0.9037 & 0.9226 & 1.0352 & 1.0363 & 9.7614 & 9.8756 & -0.8557 & -0.9991 \\
\hline 10 & 0.9037 & 0.9794 & 1.0352 & 1.0503 & 9.6140 & 8.9747 & -0.7681 & -0.7451 \\
\hline 15 & 0.9666 & 1.0439 & 1.0535 & 1.0663 & 8.6569 & 7.9505 & -0.4529 & -0.4564 \\
\hline 20 & 1.1037 & 1.0897 & 1.0819 & 1.0776 & 6.9500 & 7.2238 & -0.2087 & -0.2515 \\
\hline 25 & 1.1899 & 1.1252 & 1.0976 & 1.0864 & 6.1000 & 6.6601 & -0.0912 & -0.0926 \\
\hline 30 & 1.2034 & 1.1543 & 1.1010 & 1.0936 & 6.0300 & 6.1996 & -0.0911 & 0.0372 \\
\hline
\end{tabular}

Table E-29: 7 Stages (300 ft.)- Arps- Table of Ratios

\begin{tabular}{|c|c|c|c|}
\hline \multicolumn{5}{|c|}{7 Fractures (300 ft.)- Arps- Table of Ratios } \\
\hline Years & n-Ratio & di-Ratio & qi-Ratio \\
\hline 3 & 2.046445 & 12.05036 & 1.94536 \\
\hline 5 & 1.745842 & 6.937157 & 1.678362 \\
\hline 7 & 1.572386 & 4.821888 & 1.522842 \\
\hline 10 & 1.407294 & 3.279201 & 1.373688 \\
\hline 15 & 1.240567 & 2.115502 & 1.221793 \\
\hline 20 & 1.134395 & 1.550082 & 1.124321 \\
\hline 25 & 1.05834 & 1.217853 & 1.054104 \\
\hline 30 & 1 & 1 & 1 \\
\hline
\end{tabular}

Table E-30: 7 Stages (300 ft.)- Duong- Table of Ratios

\begin{tabular}{|c|c|c|c|c|}
\hline \multicolumn{5}{|c|}{ 7 Fractures (300 ft.)- Duong- Table of Ratios } \\
\hline Years & a-Ratio & m-Ratio & $\boldsymbol{q}_{1}$ - Ratio & $q_{\infty}$-Ratio \\
\hline 2 & 0.722260576 & 0.876752 & 2.261425 & -5.13577 \\
\hline 3 & 0.763845346 & 0.895205 & 2.072557 & -4.21709 \\
\hline 4 & 0.79335021 & 0.908298 & 1.938553 & -3.56527 \\
\hline 5 & 0.816235961 & 0.918454 & 1.834612 & -3.05968 \\
\hline 7 & 0.850744776 & 0.933767 & 1.677881 & -2.29732 \\
\hline 10 & 0.887325595 & 0.95 & 1.51174 & -1.48918 \\
\hline 15 & 0.928910366 & 0.968454 & 1.322872 & -0.5705 \\
\hline 20 & 0.95841523 & 0.981547 & 1.188868 & 0.081316 \\
\hline 25 & 0.98130098 & 0.991702 & 1.084926 & 0.586904 \\
\hline 30 & 1 & 1 & 1 & 1 \\
\hline
\end{tabular}


Table E-31: 7 Stages (400 ft.)- Arps- Table of Ratios

\begin{tabular}{|c|c|c|c|}
\hline \multicolumn{4}{|c|}{7 Fractures (400 ft.)- Arps- Table of Ratios } \\
\hline Years & n-Ratio & di- Ratio & qi-Ratio \\
\hline 3 & 1.737801 & 5.754399 & 1.548817 \\
\hline 5 & 1.537292 & 3.902968 & 1.405558 \\
\hline 7 & 1.41803 & 3.022301 & 1.318513 \\
\hline 10 & 1.301695 & 2.304688 & 1.23212 \\
\hline 15 & 1.180993 & 1.693491 & 1.140764 \\
\hline 20 & 1.102204 & 1.36091 & 1.080084 \\
\hline 25 & 1.044729 & 1.148624 & 1.035248 \\
\hline 30 & 1 & 1 & 1 \\
\hline
\end{tabular}

Table E-32: 7 Stages (400 ft.)- Duong- Table of Ratios

\begin{tabular}{|c|c|c|c|c|}
\hline \multicolumn{5}{|c|}{ 7 Fractures (400 ft.)-Duong-Table of Ratios } \\
\hline Years & $a-$-Ratio & m-Ratio & $q_{1}$-Ratio & $q_{\infty}$ - Ratio \\
\hline 2 & 0.594886 & 0.867699 & 2.46421 & -6.05697 \\
\hline 3 & 0.655542 & 0.887508 & 2.24498 & -5.00036 \\
\hline 4 & 0.698578 & 0.901562 & 2.089434 & -4.25068 \\
\hline 5 & 0.73196 & 0.912464 & 1.968783 & -3.66918 \\
\hline 7 & 0.782295 & 0.928902 & 1.786856 & -2.79236 \\
\hline 10 & 0.835652 & 0.946328 & 1.594006 & -1.8629 \\
\hline 15 & 0.896308 & 0.966136 & 1.374776 & -0.80629 \\
\hline 20 & 0.939344 & 0.980191 & 1.21923 & -0.05661 \\
\hline 25 & 0.972725 & 0.991093 & 1.098579 & 0.524884 \\
\hline 30 & 1 & 1 & 1 & 1 \\
\hline
\end{tabular}

Table E-33: 7 Stages (500 ft.)- Arps- Table of Ratios

\begin{tabular}{|c|c|c|c|}
\hline \multicolumn{4}{|c|}{7 Fractures (500 ft.)- Arps- Table of Ratios } \\
\hline Years & n-Ratio & di- Ratio & qi-Ratio \\
\hline 3 & 1.499685 & 2.870781 & 1.267652 \\
\hline 5 & 1.370739 & 2.271921 & 1.202679 \\
\hline 7 & 1.291921 & 1.947451 & 1.161712 \\
\hline 10 & 1.213314 & 1.653947 & 1.119808 \\
\hline 15 & 1.129747 & 1.373636 & 1.074004 \\
\hline 20 & 1.07397 & 1.204065 & 1.042647 \\
\hline 25 & 1.032609 & 1.087089 & 1.018957 \\
\hline 30 & 1 & 1 & 1 \\
\hline
\end{tabular}


Table E-34: 7 Stages (500 ft.)- Duong- Table of Ratios

\begin{tabular}{|c|c|c|c|c|}
\hline \multicolumn{5}{|c|}{7 Fractures (500 ft.)- Duong- Table of Ratios } \\
\hline Years & a-Ratio & m-Ratio & q1- Ratio & qo - Ratio \\
\hline 2 & 0.57446 & 0.865827 & 2.710921 & -6.4437626 \\
\hline 3 & 0.638174 & 0.885917 & 2.454752 & -5.3292389 \\
\hline 4 & 0.68338 & 0.90017 & 2.272997 & -4.5384718 \\
\hline 5 & 0.718445 & 0.911226 & 2.132017 & -3.9251052 \\
\hline 7 & 0.771318 & 0.927897 & 1.919437 & -3.0002259 \\
\hline 10 & 0.827365 & 0.945568 & 1.694093 & -2.0198144 \\
\hline 15 & 0.89108 & 0.965657 & 1.437924 & -0.9052908 \\
\hline 20 & 0.936286 & 0.979911 & 1.256169 & -0.1145237 \\
\hline 25 & 0.97135 & 0.990967 & 1.115189 & 0.49884298 \\
\hline 30 & 1 & 1 & 1 & 1 \\
\hline
\end{tabular}

Table E-35: 7 Stages (600 ft.)- Arps- Table of Ratios

\begin{tabular}{|c|c|c|c|}
\hline \multicolumn{4}{|c|}{7 Fractures (600 ft.)- Arps- Table of Ratios } \\
\hline Years & n-Ratio & di-Ratio & qi-Ratio \\
\hline 3 & 1.348963 & 1.610646 & 1.073989 \\
\hline 5 & 1.262292 & 1.44903 & 1.057116 \\
\hline 7 & 1.208267 & 1.35154 & 1.046147 \\
\hline 10 & 1.153522 & 1.255348 & 1.034644 \\
\hline 15 & 1.094294 & 1.154285 & 1.02172 \\
\hline 20 & 1.054124 & 1.087554 & 1.012649 \\
\hline 25 & 1.023985 & 1.038462 & 1.005668 \\
\hline 30 & 1 & 1 & 1 \\
\hline
\end{tabular}

Table E-36: 7 Stages (600 ft.)- Duong- Table of Ratios

\begin{tabular}{|c|c|c|c|c|}
\hline \multicolumn{5}{|c|}{ 7 Fractures (600 ft.)-Duong-Table of Ratios } \\
\hline Years & a-Ratio & m-Ratio & q1-Ratio & qo - Ratio \\
\hline 2 & 0.544619 & 0.864131 & 3.047072 & -8.9612525 \\
\hline 3 & 0.612801 & 0.884474 & 2.740572 & -7.4697955 \\
\hline 4 & 0.661177 & 0.898908 & 2.523107 & -6.41159 \\
\hline 5 & 0.698701 & 0.910103 & 2.354428 & -5.590782 \\
\hline 7 & 0.755281 & 0.926985 & 2.100082 & -4.3531074 \\
\hline 10 & 0.815259 & 0.94488 & 1.830464 & -3.0411195 \\
\hline 15 & 0.883442 & 0.965223 & 1.523964 & -1.5496625 \\
\hline 20 & 0.931818 & 0.979657 & 1.3065 & -0.491457 \\
\hline 25 & 0.969341 & 0.990853 & 1.137821 & 0.32935104 \\
\hline 30 & 1 & 1 & 1 & 1 \\
\hline
\end{tabular}


Table E-37: 7 Stages (700 ft.)- Arps- Table of Ratios

\begin{tabular}{|c|c|c|c|}
\hline \multicolumn{4}{|c|}{7 Fractures (700 ft.)- Arps- Table of Ratios } \\
\hline Years & n-Ratio & di-Ratio & qi-Ratio \\
\hline 3 & 1.318257 & 1.399587 & 1.035142 \\
\hline 5 & 1.239876 & 1.299003 & 1.027241 \\
\hline 7 & 1.190811 & 1.236731 & 1.022069 \\
\hline 10 & 1.140918 & 1.173977 & 1.016616 \\
\hline 15 & 1.086735 & 1.106497 & 1.010451 \\
\hline 20 & 1.049859 & 1.060985 & 1.006101 \\
\hline 25 & 1.02212 & 1.026976 & 1.002739 \\
\hline 30 & 1 & 1 & 1 \\
\hline
\end{tabular}

Table E-38: 7 Stages (700 ft.)- Duong- Table of Ratios

\begin{tabular}{|c|c|c|c|c|}
\hline \multicolumn{5}{|c|}{ 7 Fractures (700 ft.)- Duong- Table of Ratios } \\
\hline Years & a-Ratio & m-Ratio & q1-Ratio & q - Ratio \\
\hline 2 & 0.549841 & 0.857362 & 3.137242 & -8.0753559 \\
\hline 3 & 0.617242 & 0.878719 & 2.817242 & -6.7165405 \\
\hline 4 & 0.665063 & 0.893872 & 2.590198 & -5.7524457 \\
\hline 5 & 0.702156 & 0.905625 & 2.414089 & -5.0046357 \\
\hline 7 & 0.758088 & 0.923348 & 2.148539 & -3.8770328 \\
\hline 10 & 0.817378 & 0.942134 & 1.867045 & -2.6817255 \\
\hline 15 & 0.884778 & 0.963491 & 1.547044 & -1.3229102 \\
\hline 20 & 0.9326 & 0.978643 & 1.32 & -0.3588153 \\
\hline 25 & 0.969693 & 0.990397 & 1.143891 & 0.38899471 \\
\hline 30 & 1 & 1 & 1 & 1 \\
\hline
\end{tabular}

Table E-39: 7 Stages (0.0008 m-D) - Arps- Table of Ratios

\begin{tabular}{|c|c|c|c|}
\hline \multicolumn{4}{|c|}{7 Fractures (0.0008 } \\
\hline mears & D)-Arps- Table of Ratios \\
\hline 3 & 1.44544 & 6.053409 & 1.573983 \\
\hline 5 & 1.332 & 4.05989 & 1.423298 \\
\hline 7 & 1.262187 & 3.120629 & 1.332013 \\
\hline 10 & 1.192173 & 2.36107 & 1.241632 \\
\hline 15 & 1.117287 & 1.719513 & 1.146312 \\
\hline 20 & 1.067025 & 1.373104 & 1.083153 \\
\hline 25 & 1.029601 & 1.15324 & 1.03657 \\
\hline 30 & 1 & 1 & 1 \\
\hline
\end{tabular}


Table E-40: 7 Stages (0.0008 m-D) - Duong- Table of Ratios

\begin{tabular}{|c|c|c|c|c|}
\hline \multicolumn{5}{|c|}{ 7 Fractures (0.0008 m-D)-Duong-Table of Ratios } \\
\hline Years & a-Ratio & m-Ratio & q1-Ratio & qo - Ratio \\
\hline 2 & 0.662027 & 0.959239 & 2.223097 & -2.116235 \\
\hline 3 & 0.712631 & 0.965342 & 2.039968 & -1.6496541 \\
\hline 4 & 0.748534 & 0.969672 & 1.910036 & -1.3186096 \\
\hline 5 & 0.776383 & 0.973031 & 1.809252 & -1.0618316 \\
\hline 7 & 0.818376 & 0.978095 & 1.657284 & -0.6746429 \\
\hline 10 & 0.86289 & 0.983464 & 1.496191 & -0.2642063 \\
\hline 15 & 0.913493 & 0.989567 & 1.313062 & 0.20237464 \\
\hline 20 & 0.949397 & 0.993897 & 1.183129 & 0.53341908 \\
\hline 25 & 0.977246 & 0.997256 & 1.082346 & 0.79019709 \\
\hline 30 & 1 & 1 & 1 & 1 \\
\hline
\end{tabular}

Table E-41: 7 Stages (0.001 m-D) - Arps- Table of Ratios

\begin{tabular}{|c|c|c|c|}
\hline \multicolumn{4}{|c|}{ 7 Fractures (0.001 m-D)-Arps- Table of Ratios } \\
\hline Years & n-Ratio & di-Ratio & qi-Ratio \\
\hline 3 & 1.435489 & 5.571857 & 1.534616983 \\
\hline 5 & 1.324859 & 3.806281 & 1.395520217 \\
\hline 7 & 1.256689 & 2.961347 & 1.31086002 \\
\hline 10 & 1.188251 & 2.269512 & 1.226717479 \\
\hline 15 & 1.114966 & 1.677136 & 1.137605228 \\
\hline 20 & 1.065728 & 1.353207 & 1.078333194 \\
\hline 25 & 1.029038 & 1.145696 & 1.03449337 \\
\hline 30 & 1 & 1 & 1 \\
\hline
\end{tabular}

Table E-42: 7 Stages (0.001 m-D) - Duong- Table of Ratios

\begin{tabular}{|c|c|c|c|c|}
\hline \multicolumn{5}{|c|}{ 7 Fractures (0.001 m-D)- Duong-Table of Ratios } \\
\hline Years & a-Ratio & m-Ratio & q1-Ratio & qo - Ratio \\
\hline 2 & 0.61951 & 0.940417 & 2.406373 & -1.1462796 \\
\hline 3 & 0.676479 & 0.949338 & 2.195803 & -0.824926 \\
\hline 4 & 0.7169 & 0.955668 & 2.046401 & -0.5969221 \\
\hline 5 & 0.748252 & 0.960577 & 1.930516 & -0.4200685 \\
\hline 7 & 0.795527 & 0.96798 & 1.755775 & -0.1533956 \\
\hline 10 & 0.845641 & 0.975828 & 1.570543 & 0.129289 \\
\hline 15 & 0.902611 & 0.984749 & 1.359973 & 0.45064252 \\
\hline 20 & 0.943031 & 0.991079 & 1.21057 & 0.67864648 \\
\hline 25 & 0.974383 & 0.995989 & 1.094685 & 0.85550008 \\
\hline 30 & 1 & 1 & 1 & 1 \\
\hline
\end{tabular}


Table E-43: 7 Stages (0.002 m-D) - Arps- Table of Ratios

\begin{tabular}{|c|c|c|c|}
\hline \multicolumn{4}{|c|}{7 Fractures (0.002 m-D)-Arps- Table of Ratios } \\
\hline Years & n-Ratio & di-Ratio & qi-Ratio \\
\hline 3 & 1.355189 & 2.673006 & 1.247384 \\
\hline 5 & 1.266823 & 2.149169 & 1.187688 \\
\hline 7 & 1.211789 & 1.861547 & 1.149937 \\
\hline 10 & 1.156059 & 1.598567 & 1.111229 \\
\hline 15 & 1.095812 & 1.344435 & 1.068806 \\
\hline 20 & 1.05498 & 1.189025 & 1.039692 \\
\hline 25 & 1.024358 & 1.080962 & 1.017657 \\
\hline 30 & 1 & 1 & 1 \\
\hline
\end{tabular}

Table E-44: 7 Stages (0.002 m-D) - Duong- Table of Ratios

\begin{tabular}{|c|c|c|c|c|}
\hline \multicolumn{5}{|c|}{ 7 Fractures (0.002 m-D)-Duong-Table of Ratios } \\
\hline Years & a-Ratio & m-Ratio & q1-Ratio & qo - Ratio \\
\hline 2 & 0.590297 & 0.904071 & 2.627559 & -6.3106808 \\
\hline 3 & 0.65164 & 0.918434 & 2.383871 & -5.2160829 \\
\hline 4 & 0.695164 & 0.928625 & 2.210972 & -4.4394534 \\
\hline 5 & 0.728923 & 0.936529 & 2.076861 & -3.8370527 \\
\hline 7 & 0.779828 & 0.948448 & 1.874639 & -2.9287087 \\
\hline 10 & 0.83379 & 0.961083 & 1.660274 & -1.9658253 \\
\hline 15 & 0.895133 & 0.975446 & 1.416587 & -0.8712274 \\
\hline 20 & 0.938657 & 0.985637 & 1.243688 & -0.0945979 \\
\hline 25 & 0.972416 & 0.993541 & 1.109577 & 0.50780281 \\
\hline 30 & 1 & 1 & 1 & 1 \\
\hline
\end{tabular}

Table E-45: 7 Stages (0.004 m-D) - Arps- Table of Ratios

\begin{tabular}{|c|c|c|c|}
\hline \multicolumn{4}{|c|}{7 Fractures (0.004 m-D)-Arps- Table of Ratios } \\
\hline Years & n-Ratio & di-Ratio & qi-Ratio \\
\hline 3 & 1.135011 & 1.233105 & 1.04472 \\
\hline 5 & 1.103566 & 1.177096 & 1.03463 \\
\hline 7 & 1.083331 & 1.1416 & 1.028036 \\
\hline 10 & 1.062287 & 1.105142 & 1.021093 \\
\hline 15 & 1.038859 & 1.065108 & 1.013257 \\
\hline 20 & 1.022551 & 1.037586 & 1.007734 \\
\hline 25 & 1.010078 & 1.01673 & 1.00347 \\
\hline 30 & 1 & 1 & 1 \\
\hline
\end{tabular}


Table E-46: 7 Stages (0.004 m-D) - Duong- Table of Ratios

\begin{tabular}{|c|c|c|c|c|}
\hline \multicolumn{5}{|c|}{ 7 Fractures (0.004 m-D)- Duong-Table of Ratios } \\
\hline Years & a-Ratio & m-Ratio & q1-Ratio & qo-Ratio \\
\hline 2 & 0.57897 & 0.890224 & 2.788135 & -6.5785879 \\
\hline 3 & 0.642009 & 0.906661 & 2.520405 & -5.4438774 \\
\hline 4 & 0.686736 & 0.918322 & 2.330448 & -4.6387875 \\
\hline 5 & 0.721429 & 0.927368 & 2.183105 & -4.0143113 \\
\hline 7 & 0.773741 & 0.941007 & 1.960931 & -3.0726801 \\
\hline 10 & 0.829195 & 0.955466 & 1.725418 & -2.0745109 \\
\hline 15 & 0.892234 & 0.971902 & 1.457688 & -0.9398004 \\
\hline 20 & 0.936961 & 0.983564 & 1.26773 & -0.1347105 \\
\hline 25 & 0.971654 & 0.992609 & 1.120388 & 0.48976576 \\
\hline 30 & 1 & 1 & 1 & 1 \\
\hline
\end{tabular}

Table E-47: 7 Stages (0.006 m-D) - Arps- Table of Ratios

\begin{tabular}{|c|c|c|c|}
\hline \multicolumn{4}{|c|}{7 Fractures (0.006 m-D)-Arps- Table of Ratios } \\
\hline Years & $n$-Ratio & di-Ratio & qi-Ratio \\
\hline 3 & 1.056818 & 1.099006 & 1.023293 \\
\hline 5 & 1.04394 & 1.076228 & 1.018079 \\
\hline 7 & 1.035544 & 1.061483 & 1.014659 \\
\hline 10 & 1.026717 & 1.046073 & 1.011047 \\
\hline 15 & 1.016775 & 1.028827 & 1.006956 \\
\hline 20 & 1.009779 & 1.016763 & 1.004063 \\
\hline 25 & 1.004385 & 1.007503 & 1.001825 \\
\hline 30 & 1 & 1 & 1 \\
\hline
\end{tabular}

Table E-48: 7 Stages (0.006 m-D) - Duong- Table of Ratios

\begin{tabular}{|c|c|c|c|c|}
\hline \multicolumn{5}{|c|}{ 7 Fractures $(0.006$ m-D)- Duong- Table of Ratios } \\
\hline Years & a-Ratio & m-Ratio & q1-Ratio & qo - Ratio \\
\hline 2 & 0.572553 & 0.883624 & 2.939914 & -6.2918322 \\
\hline 3 & 0.636553 & 0.901048 & 2.649458 & -5.2000564 \\
\hline 4 & 0.681962 & 0.913411 & 2.443377 & -4.4254292 \\
\hline 5 & 0.717183 & 0.923001 & 2.283528 & -3.8245817 \\
\hline 7 & 0.770293 & 0.93746 & 2.042496 & -2.9185796 \\
\hline 10 & 0.826592 & 0.952788 & 1.786992 & -1.9581787 \\
\hline 15 & 0.890592 & 0.970213 & 1.496536 & -0.866403 \\
\hline 20 & 0.936 & 0.982575 & 1.290455 & -0.0917757 \\
\hline 25 & 0.971222 & 0.992165 & 1.130606 & 0.50907181 \\
\hline 30 & 1 & 1 & 1 & 1 \\
\hline
\end{tabular}


Table E-49: 7 Stages (4\%) - Arps- Table of Ratios

\begin{tabular}{|c|c|c|c|}
\hline \multicolumn{4}{|c|}{ 7 Fractures (4\%)-Arps- Table of Ratios } \\
\hline Years & n-Ratio & di-Ratio & qi-Ratio \\
\hline 3 & 1.370882 & 2.094112 & 1.180321 \\
\hline 5 & 1.278223 & 1.777406 & 1.137698 \\
\hline 7 & 1.220639 & 1.595436 & 1.110467 \\
\hline 10 & 1.162427 & 1.42284 & 1.082313 \\
\hline 15 & 1.099616 & 1.249196 & 1.051173 \\
\hline 20 & 1.057121 & 1.139004 & 1.029624 \\
\hline 25 & 1.025293 & 1.060272 & 1.013214 \\
\hline 30 & 1 & 1 & 1 \\
\hline
\end{tabular}

Table E-50: 7 Stages (4\%) - Duong- Table of Ratios

\begin{tabular}{|c|c|c|c|c|}
\hline \multicolumn{5}{|c|}{ 7 Fractures (4\%)- Duong- Table of Ratios } \\
\hline Years & a-Ratio & m-Ratio & q1-Ratio & q - Ratio \\
\hline 2 & 0.556105 & 0.887782 & 2.981074 & -9.4112421 \\
\hline 3 & 0.622568 & 0.9045839 & 2.684456 & -7.8524101 \\
\hline 4 & 0.669724 & 0.9165051 & 2.474002 & -6.7464011 \\
\hline 5 & 0.7063 & 0.9257519 & 2.310761 & -5.888514 \\
\hline 7 & 0.761454 & 0.9396948 & 2.064615 & -4.5949287 \\
\hline 10 & 0.819919 & 0.954475 & 1.80369 & -3.223673 \\
\hline 15 & 0.886382 & 0.9712769 & 1.507072 & -1.664841 \\
\hline 20 & 0.933537 & 0.9831981 & 1.296618 & -0.558832 \\
\hline 25 & 0.970114 & 0.9924448 & 1.133377 & 0.29905514 \\
\hline 30 & 1 & 1 & 1 & 1 \\
\hline
\end{tabular}

Table E-51: 7 Stages (5\%) - Arps- Table of Ratios

\begin{tabular}{|c|c|c|c|}
\hline \multicolumn{4}{|c|}{7 Fractures (5\%)- Arps- Table of Ratios } \\
\hline Years & n-Ratio & di- Ratio & qi-Ratio \\
\hline 3 & 1.475707 & 2.673006 & 1.247384 \\
\hline 5 & 1.353654 & 2.149169 & 1.187688 \\
\hline 7 & 1.278827 & 1.861547 & 1.149937 \\
\hline 10 & 1.204019 & 1.598567 & 1.111229 \\
\hline 15 & 1.124279 & 1.344435 & 1.068806 \\
\hline 20 & 1.070926 & 1.189025 & 1.039692 \\
\hline 25 & 1.031292 & 1.080962 & 1.017657 \\
\hline 30 & 1 & 1 & 1 \\
\hline
\end{tabular}


Table E-52: 7 Stages (5\%) - Duong- Table of Ratios

\begin{tabular}{|c|c|c|c|c|}
\hline \multicolumn{5}{|c|}{ 7 Fractures (5\%)- Duong- Table of Ratios } \\
\hline Years & a-Ratio & m-Ratio & q1-Ratio & q - Ratio \\
\hline 2 & 0.555535 & 0.8889617 & 2.751923 & -22.89323 \\
\hline 3 & 0.622083 & 0.905587 & 2.489615 & -19.315796 \\
\hline 4 & 0.669299 & 0.9173828 & 2.303505 & -16.777566 \\
\hline 5 & 0.705923 & 0.9265324 & 2.159146 & -14.808762 \\
\hline 7 & 0.761148 & 0.9403288 & 1.941471 & -11.840055 \\
\hline 10 & 0.819688 & 0.9549535 & 1.710727 & -8.6930982 \\
\hline 15 & 0.886236 & 0.9715789 & 1.448419 & -5.115664 \\
\hline 20 & 0.933452 & 0.9833747 & 1.262308 & -2.5774341 \\
\hline 25 & 0.970076 & 0.9925243 & 1.11795 & -0.6086301 \\
\hline 30 & 1 & 1 & 1 & 1 \\
\hline
\end{tabular}

Table E-53: 7 Stages (6\%) - Arps- Table of Ratios

\begin{tabular}{|c|c|c|c|}
\hline \multicolumn{4}{|c|}{7 Fractures (6\%)-Arps- Table of Ratios } \\
\hline Years & n-Ratio & di-Ratio & qi- Ratio \\
\hline 3 & 1.548817 & 3.258367 & 1.30017 \\
\hline 5 & 1.405558 & 2.507215 & 1.226618 \\
\hline 7 & 1.318513 & 2.109735 & 1.180458 \\
\hline 10 & 1.23212 & 1.756965 & 1.133422 \\
\hline 15 & 1.140764 & 1.427015 & 1.082225 \\
\hline 20 & 1.080084 & 1.231218 & 1.047308 \\
\hline 25 & 1.035248 & 1.098045 & 1.021002 \\
\hline 30 & 1 & 1 & 1 \\
\hline
\end{tabular}

Table E-54: 7 Stages (6\%) - Duong- Table of Ratios

\begin{tabular}{|c|c|c|c|c|}
\hline \multicolumn{5}{|c|}{7 Fractures (6\%)- Duong- Table of Ratios } \\
\hline Years & a-Ratio & m-Ratio & q1-Ratio & qo - Ratio \\
\hline 2 & 0.593412 & 0.8937006 & 2.457254 & -36.226104 \\
\hline 3 & 0.654288 & 0.9096164 & 2.239065 & -30.652394 \\
\hline 4 & 0.697481 & 0.9209088 & 2.084258 & -26.697784 \\
\hline 5 & 0.730984 & 0.9296679 & 1.96418 & -23.63035 \\
\hline 7 & 0.781502 & 0.9428755 & 1.783118 & -19.005048 \\
\hline 10 & 0.835054 & 0.9568761 & 1.591184 & -14.10203 \\
\hline 15 & 0.89593 & 0.9727918 & 1.372996 & -8.52832 \\
\hline 20 & 0.939123 & 0.9840842 & 1.218189 & -4.5737099 \\
\hline 25 & 0.972626 & 0.9928433 & 1.098111 & -1.506276 \\
\hline 30 & 1 & 1 & 1 & 1 \\
\hline
\end{tabular}


Table E-55: 7 Stages (8\%) - Arps- Table of Ratios

\begin{tabular}{|c|c|c|c|}
\hline \multicolumn{4}{|c|}{7 Fractures (8\%)- Arps- Table of Ratios } \\
\hline Years & n-Ratio & di-Ratio & qi-Ratio \\
\hline 3 & 1.625549 & 4.23643 & 1.374042 \\
\hline 5 & 1.459452 & 3.075395 & 1.280516 \\
\hline 7 & 1.35943 & 2.490454 & 1.222417 \\
\hline 10 & 1.260877 & 1.991384 & 1.163705 \\
\hline 15 & 1.15749 & 1.54435 & 1.100379 \\
\hline 20 & 1.089319 & 1.289464 & 1.057549 \\
\hline 25 & 1.039219 & 1.121106 & 1.02548 \\
\hline 30 & 1 & 1 & 1 \\
\hline
\end{tabular}

Table E-56: 7 Stages (8\%) - Duong- Table of Ratios

\begin{tabular}{|c|c|c|c|c|}
\hline \multicolumn{5}{|c|}{ 7 Fractures (8\%)-Duong- Table of Ratios } \\
\hline Years & a-Ratio & m-Ratio & q1-Ratio & qo-Ratio \\
\hline 2 & 0.626499 & 0.9024356 & 2.103388 & -50.849015 \\
\hline 3 & 0.682421 & 0.9170435 & 1.938182 & -43.085877 \\
\hline 4 & 0.722099 & 0.927408 & 1.820967 & -37.577843 \\
\hline 5 & 0.752876 & 0.9354473 & 1.730047 & -33.305481 \\
\hline 7 & 0.799283 & 0.9475695 & 1.592953 & -26.863298 \\
\hline 10 & 0.848477 & 0.9604197 & 1.447627 & -20.034309 \\
\hline 15 & 0.904399 & 0.9750276 & 1.282421 & -12.271171 \\
\hline 20 & 0.944077 & 0.9853921 & 1.165206 & -6.7631376 \\
\hline 25 & 0.974854 & 0.9934314 & 1.074286 & -2.4907747 \\
\hline 30 & 1 & 1 & 1 & 1 \\
\hline
\end{tabular}




\section{E.2. Thirteen Stages Model}

Table E-57: 13 Stages (300 ft.) - Arps- Recalculated Constants

\begin{tabular}{|c|c|c|c|c|c|c|}
\hline \multicolumn{7}{|c|}{ 13 Fractures (300 ft.)-Arps } \\
\hline Years & $n$ & $n$ (Eq.) & $\boldsymbol{d}_{i}$ & $\boldsymbol{d}_{\boldsymbol{i}}$ (Eq.) & $\boldsymbol{q} \mathbf{i}$ & $\boldsymbol{q}$ (Eq.) \\
\hline 3 & 1.4221 & 1.3840 & 0.0319 & 0.0310 & 8.7480 & 8.7282 \\
\hline 5 & 1.3251 & 1.3293 & 0.0274 & 0.0272 & 8.4425 & 8.4001 \\
\hline 7 & 1.2777 & 1.2944 & 0.0247 & 0.0249 & 8.2065 & 8.1908 \\
\hline 10 & 1.2260 & 1.2584 & 0.0216 & 0.0227 & 7.8986 & 7.9746 \\
\hline 15 & 1.2087 & 1.2188 & 0.0201 & 0.0204 & 7.7170 & 7.7357 \\
\hline 20 & 1.1936 & 1.1914 & 0.0189 & 0.0190 & 7.5712 & 7.5706 \\
\hline 25 & 1.1800 & 1.1706 & 0.0180 & 0.0179 & 7.4521 & 7.4450 \\
\hline 30 & 1.1784 & 1.1538 & 0.0177 & 0.0171 & 7.4063 & 7.3438 \\
\hline
\end{tabular}

Table E-58: 13 Stages (300 ft.) - Duong- Recalculated Constants

\begin{tabular}{|c|c|c|c|c|c|c|c|c|}
\hline \multicolumn{9}{|c|}{13 Fractures (300 ft.)- Duong } \\
\hline Years & $a$ & $a(E q)$. & $m$ & $m(E q)$. & $q 1$ & q1 (Eq.) & $q \infty$ & $q \infty$ (Eq.) \\
\hline 2 & 0.908 & 0.826 & 1.024 & 1.023 & 14.505 & 14.645 & -3.934 & -2.396 \\
\hline 3 & 0.855 & 0.886 & 1.032 & 1.047 & 14.205 & 13.991 & -1.972 & -1.936 \\
\hline 4 & 0.881 & 0.929 & 1.057 & 1.063 & 13.650 & 13.527 & -0.977 & -1.609 \\
\hline 5 & 0.935 & 0.962 & 1.082 & 1.076 & 13.010 & 13.166 & -0.558 & -1.356 \\
\hline 7 & 1.008 & 1.012 & 1.109 & 1.096 & 12.400 & 12.623 & -0.245 & -0.973 \\
\hline 10 & 1.065 & 1.065 & 1.130 & 1.117 & 12.040 & 12.048 & -0.082 & -0.568 \\
\hline 15 & 1.122 & 1.125 & 1.146 & 1.140 & 11.608 & 11.393 & 0.040 & -0.108 \\
\hline 20 & 1.162 & 1.168 & 1.155 & 1.157 & 11.208 & 10.929 & 0.040 & 0.219 \\
\hline 25 & 1.215 & 1.201 & 1.164 & 1.170 & 10.500 & 10.569 & 0.055 & 0.472 \\
\hline 30 & 1.249 & 1.228 & 1.170 & 1.180 & 10.040 & 10.274 & 0.060 & 0.680 \\
\hline
\end{tabular}

Table E-59: 13 Stages (400 ft.) - Arps- Recalculated Constants

\begin{tabular}{|c|c|c|c|c|c|c|}
\hline \multicolumn{7}{|c|}{ 13 Fractures (400 ft.)-Arps } \\
\hline Years & $n$ & $n(E q)$. & $d_{i}$ & $d_{i}$ (Eq.) & $q i$ & $q i(E q)$. \\
\hline 3 & 1.4853 & 1.4565 & 0.0329 & 0.0332 & 10.7806 & 10.8793 \\
\hline 5 & 1.4045 & 1.4018 & 0.0311 & 0.0301 & 10.7141 & 10.6104 \\
\hline 7 & 1.3446 & 1.3668 & 0.0280 & 0.0282 & 10.4438 & 10.4369 \\
\hline 10 & 1.3052 & 1.3308 & 0.0258 & 0.0264 & 10.2169 & 10.2560 \\
\hline 15 & 1.2869 & 1.2909 & 0.0245 & 0.0244 & 10.0698 & 10.0543 \\
\hline 20 & 1.2705 & 1.2633 & 0.0233 & 0.0231 & 9.9284 & 9.9136 \\
\hline 25 & 1.2500 & 1.2424 & 0.0220 & 0.0221 & 9.7641 & 9.8057 \\
\hline 30 & 1.2400 & 1.2255 & 0.0214 & 0.0213 & 9.6799 & 9.7185 \\
\hline
\end{tabular}


Table E-60: 13 Stages (400 ft.) - Duong- Recalculated Constants

\begin{tabular}{|c|c|c|c|c|c|c|c|c|}
\hline \multicolumn{9}{|c|}{ 13 Fractures (400 ft.)- Duong } \\
\hline Years & $\boldsymbol{a}$ & $\boldsymbol{a}(\mathrm{Eq}$.) & $\boldsymbol{m}$ & $\boldsymbol{m}$ (Eq.) & $\boldsymbol{q 1}$ & $\boldsymbol{q 1}$ (Eq.) & $\boldsymbol{q} \mathbf{}$ & $\boldsymbol{q}^{\infty}$ (Eq.) \\
\hline 2 & 0.9725 & 0.8959 & 1.0430 & 1.0386 & 15.0501 & 14.9214 & -3.5566 & -2.4569 \\
\hline 3 & 0.9647 & 0.9773 & 1.0552 & 1.0634 & 14.5010 & 14.1875 & -2.1417 & -2.0018 \\
\hline 4 & 0.9976 & 1.0351 & 1.0750 & 1.0810 & 13.8504 & 13.6668 & -1.2916 & -1.6789 \\
\hline 5 & 1.0576 & 1.0799 & 1.0967 & 1.0947 & 13.0200 & 13.2629 & -0.8145 & -1.4284 \\
\hline 7 & 1.1370 & 1.1475 & 1.1231 & 1.1153 & 12.2540 & 12.6539 & -0.4128 & -1.0507 \\
\hline 10 & 1.2155 & 1.2192 & 1.1458 & 1.1371 & 11.6000 & 12.0083 & -0.1834 & -0.6503 \\
\hline 15 & 1.2763 & 1.3006 & 1.1626 & 1.1619 & 11.2020 & 11.2744 & -0.0539 & -0.1952 \\
\hline 20 & 1.3162 & 1.3584 & 1.1717 & 1.1795 & 10.8601 & 10.7537 & -0.0061 & 0.1277 \\
\hline 25 & 1.3474 & 1.4033 & 1.1775 & 1.1932 & 10.5303 & 10.3498 & 0.0153 & 0.3782 \\
\hline 30 & 1.5718 & 1.4399 & 1.2182 & 1.2044 & 10.2320 & 10.0198 & 0.0708 & 0.5828 \\
\hline
\end{tabular}

Table E-61: 13 Stages (500 ft.) - Arps- Recalculated Constants

\begin{tabular}{|c|c|c|c|c|c|c|}
\hline \multicolumn{7}{|c|}{ 13 Fractures (500 ft.)-Arps } \\
\hline Years & $n$ & $n(E q)$. & $d_{i}$ & $d_{i}$ (Eq.) & $q i$ & qi(Eq.) \\
\hline 3 & 1.5027 & 1.4611 & 0.0281 & 0.0278 & 11.7560 & 11.7977 \\
\hline 5 & 1.4045 & 1.4127 & 0.0265 & 0.0263 & 11.7097 & 11.6718 \\
\hline 7 & 1.3575 & 1.3817 & 0.0252 & 0.0254 & 11.6079 & 11.5896 \\
\hline 10 & 1.3221 & 1.3495 & 0.0240 & 0.0245 & 11.4800 & 11.5031 \\
\hline 15 & 1.3046 & 1.3139 & 0.0233 & 0.0234 & 11.4094 & 11.4056 \\
\hline 20 & 1.2946 & 1.2892 & 0.0229 & 0.0227 & 11.3525 & 11.3369 \\
\hline 25 & 1.2800 & 1.2703 & 0.0221 & 0.0222 & 11.2519 & 11.2839 \\
\hline 30 & 1.2765 & 1.2551 & 0.0220 & 0.0218 & 11.2320 & 11.2408 \\
\hline
\end{tabular}

Table E-62: 13 Stages (500 ft.) - Duong- Recalculated Constants

\begin{tabular}{|c|c|c|c|c|c|c|c|c|}
\hline \multicolumn{9}{|c|}{13 Fractures (500 ft.)- Duong } \\
\hline Years & $a$ & $a(E q)$. & $m$ & $m(E q)$. & $q 1$ & $q 1$ (Eq.) & $q \infty$ & $q \infty$ (Eq.) \\
\hline 2 & 0.9457 & 0.9042 & 1.0494 & 1.0398 & 16.0602 & 15.6228 & -2.5770 & -2.3715 \\
\hline 3 & 0.9859 & 0.9993 & 1.0506 & 1.0650 & 15.0210 & 14.7259 & -2.5563 & -1.9550 \\
\hline 4 & 1.0626 & 1.0669 & 1.0809 & 1.0829 & 14.0400 & 14.0895 & -1.5909 & -1.6595 \\
\hline 5 & 1.1180 & 1.1192 & 1.0992 & 1.0967 & 13.1801 & 13.5959 & -1.0808 & -1.4303 \\
\hline 7 & 1.1985 & 1.1982 & 1.1236 & 1.1176 & 12.2501 & 12.8516 & -0.6089 & -1.0847 \\
\hline 10 & 1.2621 & 1.2819 & 1.1430 & 1.1398 & 11.8010 & 12.0627 & -0.3241 & -0.7183 \\
\hline 15 & 1.3396 & 1.3771 & 1.1621 & 1.1650 & 11.1505 & 11.1658 & -0.1441 & -0.3018 \\
\hline 20 & 1.3988 & 1.4446 & 1.1808 & 1.1828 & 10.8500 & 10.5294 & -0.0376 & -0.0063 \\
\hline 25 & 1.4654 & 1.4970 & 1.1851 & 1.1967 & 10.1590 & 10.0358 & -0.0240 & 0.2229 \\
\hline 30 & 1.6505 & 1.5398 & 1.2199 & 1.2080 & 9.8000 & 9.6326 & 0.0500 & 0.4102 \\
\hline
\end{tabular}


Table E-63: 13 Stages (600 ft.) - Arps- Recalculated Constants

\begin{tabular}{|c|c|c|c|c|c|c|}
\hline \multicolumn{7}{|c|}{ 13 Fractures (600 ft.)-Arps } \\
\hline Years & $n$ & $n(E q)$. & $d_{i}$ & $d_{i}$ (Eq.) & $q i$ & $q i(E q)$. \\
\hline 3 & 1.4450 & 1.4419 & 0.0224 & 0.0225 & 12.0700 & 12.1261 \\
\hline 5 & 1.4031 & 1.3962 & 0.0214 & 0.0215 & 12.0418 & 12.0396 \\
\hline 7 & 1.3678 & 1.3669 & 0.0210 & 0.0209 & 12.0225 & 11.9831 \\
\hline 10 & 1.3229 & 1.3365 & 0.0200 & 0.0202 & 11.9181 & 11.9234 \\
\hline 15 & 1.3027 & 1.3028 & 0.0198 & 0.0195 & 11.9095 & 11.8559 \\
\hline 20 & 1.2795 & 1.2794 & 0.0190 & 0.0190 & 11.8087 & 11.8082 \\
\hline 25 & 1.2648 & 1.2616 & 0.0186 & 0.0186 & 11.7405 & 11.7714 \\
\hline 30 & 1.2538 & 1.2472 & 0.0182 & 0.0183 & 11.6853 & 11.7414 \\
\hline
\end{tabular}

Table E-64: 13 Stages (600 ft.) - Duong- Recalculated Constants

\begin{tabular}{|c|c|c|c|c|c|c|c|c|}
\hline \multicolumn{9}{|c|}{13 Fractures (600 ft.)- Duong } \\
\hline Years & $a$ & $a(E q)$. & $m$ & $m(E q)$. & $q 1$ & $q 1$ (Eq.) & $q \infty$ & $q \infty$ (Eq.) \\
\hline 2 & 1.0207 & 0.9083 & 1.0409 & 1.0351 & 16.5065 & 16.3575 & -5.4934 & -4.0349 \\
\hline 3 & 1.0341 & 1.0114 & 1.0506 & 1.0605 & 15.5000 & 15.2324 & -4.0200 & -3.3121 \\
\hline 4 & 1.0848 & 1.0845 & 1.0775 & 1.0785 & 14.5404 & 14.4340 & -1.9835 & -2.7993 \\
\hline 5 & 1.1384 & 1.1413 & 1.0943 & 1.0925 & 13.5400 & 13.8148 & -1.3903 & -2.4015 \\
\hline 7 & 1.2131 & 1.2268 & 1.1163 & 1.1136 & 12.5405 & 12.8811 & -0.8371 & -1.8017 \\
\hline 10 & 1.3027 & 1.3175 & 1.1386 & 1.1360 & 11.6400 & 11.8913 & -0.4788 & -1.1659 \\
\hline 15 & 1.3954 & 1.4207 & 1.1590 & 1.1614 & 10.7500 & 10.7662 & -0.2525 & -0.4431 \\
\hline 20 & 1.5050 & 1.4938 & 1.1808 & 1.1794 & 9.9700 & 9.9678 & -0.1206 & 0.0697 \\
\hline 25 & 1.5652 & 1.5506 & 1.1998 & 1.1934 & 9.5200 & 9.3486 & -0.0200 & 0.4675 \\
\hline 30 & 1.6060 & 1.5969 & 1.1986 & 1.2049 & 9.0200 & 8.8427 & -0.0320 & 0.7925 \\
\hline
\end{tabular}

Table E-65: 13 Stages (700 ft.) - Arps- Recalculated Constants

\begin{tabular}{|c|c|c|c|c|c|c|}
\hline \multicolumn{7}{|c|}{ 13 Fractures (700 ft.)-Arps } \\
\hline Years & $n$ & $n$ (Eq.) & $d_{i}$ & $d_{\text {i }}$ (Eq.) & qi & qi(Eq.) \\
\hline 3 & 1.4685 & 1.4824 & 0.0191 & 0.01917 & 12.2226 & 12.1671 \\
\hline 5 & 1.4469 & 1.4399 & 0.0190 & 0.01837 & 12.1821 & 12.1480 \\
\hline 7 & 1.4200 & 1.4125 & 0.0177 & 0.01787 & 12.0679 & 12.1031 \\
\hline 10 & 1.3846 & 1.3841 & 0.0169 & 0.01735 & 12.0057 & 12.0557 \\
\hline 15 & 1.3641 & 1.3525 & 0.0165 & 0.01677 & 11.9766 & 12.0021 \\
\hline 20 & 1.3299 & 1.3305 & 0.0163 & 0.01638 & 11.9712 & 11.9642 \\
\hline 25 & 1.3029 & 1.3136 & 0.0162 & 0.01608 & 11.9570 & 11.9348 \\
\hline 30 & 1.2977 & 1.3001 & 0.0161 & 0.01584 & 11.9309 & 11.9109 \\
\hline
\end{tabular}


Table E-66: 13 Stages (700 ft.) - Duong- Recalculated Constants

\begin{tabular}{|c|c|c|c|c|c|c|c|c|}
\hline \multicolumn{9}{|c|}{13 Fractures (700 ft.)- Duong } \\
\hline Years & $a$ & $a(E q)$. & $m$ & $m(E q)$. & $q 1$ & $q 1$ (Eq.) & $q \infty$ & $q \infty$ (Eq.) \\
\hline 2 & 1.0230 & 0.8635 & 1.0359 & 1.0230 & 18.5000 & 17.9522 & -7.2145 & -5.1795 \\
\hline 3 & 1.0204 & 0.9753 & 1.0446 & 1.0493 & 17.4200 & 16.5764 & -4.6330 & -4.2592 \\
\hline 4 & 1.0712 & 1.0546 & 1.0649 & 1.0680 & 15.1420 & 15.6003 & -2.7645 & -3.6062 \\
\hline 5 & 1.1180 & 1.1161 & 1.0812 & 1.0825 & 14.0142 & 14.8432 & -1.8896 & -3.0998 \\
\hline 7 & 1.1803 & 1.2088 & 1.1011 & 1.1043 & 13.0151 & 13.7015 & -1.1692 & -2.3361 \\
\hline 10 & 1.2522 & 1.3071 & 1.1206 & 1.1274 & 12.1250 & 12.4913 & -0.7251 & -1.5265 \\
\hline 15 & 1.3525 & 1.4188 & 1.1386 & 1.1538 & 11.4051 & 11.1156 & -0.4736 & -0.6062 \\
\hline 20 & 1.4950 & 1.4981 & 1.1853 & 1.1724 & 10.4580 & 10.1395 & -0.0630 & 0.0467 \\
\hline 25 & 1.6055 & 1.5596 & 1.1964 & 1.1869 & 9.7000 & 9.3824 & -0.0910 & 0.5532 \\
\hline 30 & 1.6532 & 1.6099 & 1.1974 & 1.1987 & 8.7900 & 8.7637 & -0.0218 & 0.9670 \\
\hline
\end{tabular}

Table E-67: 13 Stages (0.0008 m-D) - Arps- Recalculated Constants

\begin{tabular}{|c|c|c|c|c|c|c|}
\hline \multicolumn{7}{|c|}{ 13 Fractures $(0.0008$ m-D)-Arps } \\
\hline Years & $n$ & $n(E q)$. & $d i$ & $d i(E q)$. & $q i$ & $q i(E q)$. \\
\hline 3 & 1.7081 & 1.6735 & 0.0279 & 0.0276 & 7.6043 & 7.6167 \\
\hline 5 & 1.6072 & 1.6032 & 0.0266 & 0.0262 & 7.5911 & 7.5625 \\
\hline 7 & 1.5350 & 1.5585 & 0.0249 & 0.0253 & 7.5138 & 7.5269 \\
\hline 10 & 1.4861 & 1.5125 & 0.0242 & 0.0244 & 7.4964 & 7.4894 \\
\hline 15 & 1.4426 & 1.4619 & 0.0232 & 0.0234 & 7.4440 & 7.4470 \\
\hline 20 & 1.4236 & 1.4270 & 0.0227 & 0.0228 & 7.4178 & 7.4171 \\
\hline 25 & 1.4126 & 1.4005 & 0.0224 & 0.0223 & 7.3962 & 7.3940 \\
\hline 30 & 1.4055 & 1.3792 & 0.0222 & 0.0218 & 7.3783 & 7.3751 \\
\hline
\end{tabular}

Table E-68: 13 Stages (0.0008 m-D) - Duong- Recalculated Constants

\begin{tabular}{|c|c|c|c|c|c|c|c|c|}
\hline \multicolumn{9}{|c|}{ 13 Fractures (0.0008 $\boldsymbol{m}$-D)-Duong } \\
\hline Years & $\boldsymbol{a}$ & $\boldsymbol{a ( E q . )}$ & $\boldsymbol{m}$ & $\boldsymbol{m}$ (Eq.) & $\boldsymbol{q 1}$ & $\boldsymbol{q 1}$ (Eq.) & $\boldsymbol{q}^{\infty}$ & $\boldsymbol{q}$ (Eq.) \\
\hline 2 & 0.9613 & 0.8956 & 1.0659 & 1.0524 & 10.5000 & 10.3037 & -0.8960 & -0.8934 \\
\hline 3 & 0.9966 & 0.9991 & 1.0690 & 1.0717 & 9.5000 & 9.3857 & -0.7347 & -0.7529 \\
\hline 4 & 1.0467 & 1.0724 & 1.0786 & 1.0854 & 8.8000 & 8.7344 & -0.6917 & -0.6533 \\
\hline 5 & 1.1117 & 1.1294 & 1.0919 & 1.0961 & 8.0000 & 8.2292 & -0.5881 & -0.5760 \\
\hline 7 & 1.1886 & 1.2152 & 1.1079 & 1.1121 & 7.2000 & 7.4675 & -0.4537 & -0.4594 \\
\hline 10 & 1.2727 & 1.3062 & 1.1254 & 1.1291 & 6.5000 & 6.6599 & -0.3139 & -0.3359 \\
\hline 15 & 1.3701 & 1.4096 & 1.1453 & 1.1485 & 5.8650 & 5.7420 & -0.1826 & -0.1954 \\
\hline 20 & 1.5005 & 1.4830 & 1.1660 & 1.1622 & 5.0000 & 5.0907 & -0.0357 & -0.0958 \\
\hline 25 & 1.5811 & 1.5399 & 1.1782 & 1.1728 & 4.5500 & 4.5855 & -0.0246 & -0.0185 \\
\hline 30 & 1.6079 & 1.5864 & 1.1830 & 1.1815 & 4.4500 & 4.1727 & -0.0143 & 0.0447 \\
\hline
\end{tabular}


Table E-69: 13 Stages (0.001 m-D) - Arps- Recalculated Constants

\begin{tabular}{|c|c|c|c|c|c|c|}
\hline \multicolumn{7}{|c|}{13 Fractures (0.001 m-D)-Arps } \\
\hline Years & $n$ & $n(E q)$. & $d i$ & $d i(E q)$. & $q i$ & $q i(E q)$. \\
\hline 3 & 1.7123 & 1.6711 & 0.0308 & 0.0305 & 8.6873 & 8.7135 \\
\hline 5 & 1.5960 & 1.6042 & 0.0290 & 0.0291 & 8.6646 & 8.6602 \\
\hline 7 & 1.5358 & 1.5616 & 0.0280 & 0.0281 & 8.6457 & 8.6253 \\
\hline 10 & 1.4898 & 1.5176 & 0.0272 & 0.0272 & 8.6281 & 8.5885 \\
\hline 15 & 1.4508 & 1.4692 & 0.0261 & 0.0262 & 8.5700 & 8.5468 \\
\hline 20 & 1.4348 & 1.4358 & 0.0257 & 0.0255 & 8.5459 & 8.5173 \\
\hline 25 & 1.4187 & 1.4104 & 0.0249 & 0.0250 & 8.4804 & 8.4946 \\
\hline 30 & 1.4124 & 1.3899 & 0.0247 & 0.0246 & 8.4619 & 8.4760 \\
\hline
\end{tabular}

Table E-70: 13 Stages (0.001 m-D) - Duong- Recalculated Constants

\begin{tabular}{|c|c|c|c|c|c|c|c|c|}
\hline \multicolumn{9}{|c|}{13 Fractures (0.001 m-D)- Duong } \\
\hline Years & $a$ & $a(E q)$. & $m$ & $m(E q)$. & $q 1$ & $q 1$ (Eq.) & $q \infty$ & $q \infty$ (Eq.) \\
\hline 2 & 0.9885 & 0.9541 & 1.0637 & 1.0695 & 10.8000 & 9.8069 & -1.0585 & -0.8994 \\
\hline 3 & 1.0744 & 1.0804 & 1.0813 & 1.0904 & 9.5000 & 8.8821 & -0.9246 & -0.7583 \\
\hline 4 & 1.1836 & 1.1700 & 1.1034 & 1.1052 & 8.1000 & 8.2259 & -0.7052 & -0.6581 \\
\hline 5 & 1.2484 & 1.2395 & 1.1159 & 1.1167 & 7.4000 & 7.7169 & -0.5872 & -0.5805 \\
\hline 7 & 1.2953 & 1.3443 & 1.1267 & 1.1341 & 7.0200 & 6.9494 & -0.4570 & -0.4633 \\
\hline 10 & 1.4233 & 1.4553 & 1.1504 & 1.1525 & 6.0200 & 6.1358 & -0.2781 & -0.3392 \\
\hline 15 & 1.5183 & 1.5816 & 1.1689 & 1.1734 & 5.5000 & 5.2109 & -0.1489 & -0.1980 \\
\hline 20 & 1.7270 & 1.6712 & 1.1963 & 1.1883 & 4.2000 & 4.5547 & -0.0666 & -0.0979 \\
\hline 25 & 1.7728 & 1.7407 & 1.2033 & 1.1998 & 4.0200 & 4.0457 & -0.0364 & -0.0202 \\
\hline 30 & 1.8038 & 1.7974 & 1.2079 & 1.2092 & 3.9000 & 3.6299 & -0.0194 & 0.0433 \\
\hline
\end{tabular}

Table E-71: 13 Stages (0.002 m-D) - Arps- Recalculated Constants

\begin{tabular}{|c|c|c|c|c|c|c|}
\hline \multicolumn{7}{|c|}{13 Fractures $(0.002$ m-D)-Arps } \\
\hline Years & $n$ & $n(E q)$. & $d i$ & $d i(E q)$. & $q i$ & $q i(E q)$. \\
\hline 3 & 1.7204 & 1.6748 & 0.0432 & 0.0432 & 13.2629 & 13.2726 \\
\hline 5 & 1.6219 & 1.6176 & 0.0424 & 0.0419 & 13.2042 & 13.1983 \\
\hline 7 & 1.5506 & 1.5810 & 0.0412 & 0.0411 & 13.1656 & 13.1495 \\
\hline 10 & 1.5202 & 1.5431 & 0.0394 & 0.0402 & 13.1046 & 13.0980 \\
\hline 15 & 1.4899 & 1.5012 & 0.0390 & 0.0393 & 13.0411 & 13.0397 \\
\hline 20 & 1.4711 & 1.4721 & 0.0384 & 0.0386 & 12.9876 & 12.9985 \\
\hline 25 & 1.4602 & 1.4499 & 0.0382 & 0.0381 & 12.9649 & 12.9667 \\
\hline 30 & 1.4502 & 1.4321 & 0.0381 & 0.0377 & 12.9520 & 12.9407 \\
\hline
\end{tabular}


Table E-72: 13 Stages (0.002 m-D) - Duong- Recalculated Constants

\begin{tabular}{|c|c|c|c|c|c|c|c|c|}
\hline \multicolumn{9}{|c|}{13 Fractures (0.002 m-D)- Duong } \\
\hline Years & $a$ & $a(E q)$. & $m$ & $m(E q)$. & $q 1$ & $q 1$ (Eq.) & $q \infty$ & $q \infty$ (Eq.) \\
\hline 2 & 1.1123 & 1.0930 & 1.0908 & 1.0925 & 11.8500 & 11.5328 & -1.0014 & -1.0535 \\
\hline 3 & 1.1920 & 1.2417 & 1.1081 & 1.1168 & 10.8500 & 10.3808 & -1.0091 & -0.8746 \\
\hline 4 & 1.3236 & 1.3472 & 1.1317 & 1.1341 & 9.5000 & 9.5635 & -0.8244 & -0.7476 \\
\hline 5 & 1.4314 & 1.4290 & 1.1512 & 1.1475 & 8.5000 & 8.9296 & -0.6958 & -0.6492 \\
\hline 7 & 1.5432 & 1.5524 & 1.1739 & 1.1677 & 7.6000 & 7.9737 & -0.3947 & -0.5007 \\
\hline 10 & 1.6922 & 1.6832 & 1.1988 & 1.1892 & 6.5000 & 6.9604 & -0.1829 & -0.3433 \\
\hline 15 & 1.8213 & 1.8318 & 1.2185 & 1.2136 & 5.7040 & 5.8084 & -0.0557 & -0.1643 \\
\hline 20 & 1.9194 & 1.9373 & 1.2308 & 1.2308 & 5.1000 & 4.9911 & -0.0063 & -0.0374 \\
\hline 25 & 2.0028 & 2.0192 & 1.2397 & 1.2443 & 4.6000 & 4.3572 & 0.0017 & 0.0611 \\
\hline 30 & 2.0830 & 2.0860 & 1.2474 & 1.2552 & 4.1400 & 3.8392 & 0.0013 & 0.1415 \\
\hline
\end{tabular}

Table E-73: 13 Stages (0.004 m-D) - Arps- Recalculated Constants

\begin{tabular}{|c|c|c|c|c|c|c|}
\hline \multicolumn{7}{|c|}{ 13 Fractures (0.004 m-D)-Arps } \\
\hline Years & $n$ & $n(E q)$. & $d i$ & di(Eq.) & $q i$ & $q i(E q)$. \\
\hline 3 & 1.4505 & 1.4513 & 0.0428 & 0.0427 & 17.0135 & 17.0525 \\
\hline 5 & 1.4059 & 1.4068 & 0.0418 & 0.0417 & 17.0062 & 16.9829 \\
\hline 7 & 1.3851 & 1.3782 & 0.0411 & 0.0410 & 16.9626 & 16.9373 \\
\hline 10 & 1.3451 & 1.3485 & 0.0401 & 0.0403 & 16.9083 & 16.8890 \\
\hline 15 & 1.3042 & 1.3156 & 0.0391 & 0.0395 & 16.8576 & 16.8343 \\
\hline 20 & 1.2874 & 1.2927 & 0.0388 & 0.0389 & 16.7685 & 16.7956 \\
\hline 25 & 1.2764 & 1.2752 & 0.0387 & 0.0385 & 16.7524 & 16.7657 \\
\hline 30 & 1.2654 & 1.2611 & 0.0386 & 0.0382 & 16.7465 & 16.7412 \\
\hline
\end{tabular}

Table E-74: 13 Stages (0.004 m-D) - Duong- Recalculated Constants

\begin{tabular}{|c|c|c|c|c|c|c|c|c|}
\hline \multicolumn{9}{|c|}{13 Fractures $(0.004 m-D)$ - Duong } \\
\hline Years & $a$ & $a(E q)$. & $m$ & $m(E q)$. & $q 1$ & $q 1$ (Eq.) & $q \infty$ & $q \infty$ (Eq.) \\
\hline 2 & 1.2850 & 1.2223 & 1.1144 & 1.1259 & 14.1000 & 13.7488 & -2.8031 & -1.7679 \\
\hline 3 & 1.3870 & 1.4023 & 1.1450 & 1.1517 & 12.5000 & 12.1833 & -1.4261 & -1.4262 \\
\hline 4 & 1.5092 & 1.5300 & 1.1719 & 1.1699 & 11.0000 & 11.0725 & -0.8094 & -1.1837 \\
\hline 5 & 1.6182 & 1.6290 & 1.1924 & 1.1840 & 9.8400 & 10.2110 & -0.4860 & -0.9957 \\
\hline 7 & 1.7648 & 1.7784 & 1.2171 & 1.2054 & 8.5000 & 8.9118 & -0.1985 & -0.7121 \\
\hline 10 & 1.9200 & 1.9367 & 1.2385 & 1.2280 & 7.2000 & 7.5347 & -0.0380 & -0.4115 \\
\hline 15 & 2.0771 & 2.1167 & 1.2563 & 1.2537 & 6.0000 & 5.9692 & 0.0398 & -0.0698 \\
\hline 20 & 2.2197 & 2.2444 & 1.2693 & 1.2719 & 5.0000 & 4.8585 & 0.0622 & 0.1727 \\
\hline 25 & 2.3604 & 2.3435 & 1.2805 & 1.2861 & 4.1500 & 3.9969 & 0.0695 & 0.3608 \\
\hline 30 & 2.4872 & 2.4244 & 1.2898 & 1.2976 & 3.5000 & 3.2930 & 0.0710 & 0.5144 \\
\hline
\end{tabular}


Table E-75: 13 Stages (0.006 m-D) - Arps- Recalculated Constants

\begin{tabular}{|c|c|c|c|c|c|c|}
\hline \multicolumn{7}{|c|}{13 Fractures (0.006 m-D)-Arps } \\
\hline Years & $n$ & $n(E q)$. & $d i$ & $d i(E q)$. & $q i$ & $q i(E q)$. \\
\hline 3 & 1.6708 & 1.6675 & 0.0675 & 0.0687 & 23.0468 & 23.1155 \\
\hline 5 & 1.6306 & 1.6238 & 0.0687 & 0.0676 & 23.0052 & 23.0330 \\
\hline 7 & 1.5843 & 1.5956 & 0.0674 & 0.0669 & 23.0020 & 22.9789 \\
\hline 10 & 1.5609 & 1.5663 & 0.0663 & 0.0661 & 22.9803 & 22.9216 \\
\hline 15 & 1.5347 & 1.5336 & 0.0652 & 0.0653 & 22.8944 & 22.8566 \\
\hline 20 & 1.5145 & 1.5108 & 0.0645 & 0.0647 & 22.7852 & 22.8106 \\
\hline 25 & 1.4904 & 1.4934 & 0.0641 & 0.0642 & 22.6948 & 22.7750 \\
\hline 30 & 1.4822 & 1.4793 & 0.0636 & 0.0639 & 22.6849 & 22.7460 \\
\hline
\end{tabular}

Table E-76: 13 Stages (0.006 m-D) - Duong- Recalculated Constants

\begin{tabular}{|c|c|c|c|c|c|c|c|c|}
\hline \multicolumn{9}{|c|}{ 13Fractures (0.006 $m$-D)-Duong } \\
\hline Years & $\boldsymbol{a}$ & $\boldsymbol{a}(\mathrm{Eq}$.) & $\boldsymbol{m}$ & $\boldsymbol{m}$ (Eq.) & $\boldsymbol{q 1}$ & $\boldsymbol{q 1}$ (Eq.) & $q \infty$ & $q \infty$ (Eq.) \\
\hline 2 & 1.2522 & 1.2034 & 1.1154 & 1.1303 & 17.5310 & 17.0433 & -2.9652 & -1.1306 \\
\hline 3 & 1.3691 & 1.3868 & 1.1452 & 1.1563 & 15.5000 & 15.0622 & -1.5843 & -0.9115 \\
\hline 4 & 1.4946 & 1.5169 & 1.1799 & 1.1748 & 13.7000 & 13.6566 & -0.6592 & -0.7560 \\
\hline 5 & 1.6210 & 1.6178 & 1.2023 & 1.1891 & 12.0000 & 12.5663 & -0.3494 & -0.6355 \\
\hline 7 & 1.7764 & 1.7700 & 1.2264 & 1.2106 & 10.2000 & 10.9223 & -0.1013 & -0.4536 \\
\hline 10 & 1.9187 & 1.9314 & 1.2447 & 1.2335 & 8.7000 & 9.1796 & 0.0167 & -0.2609 \\
\hline 15 & 2.0668 & 2.1148 & 1.2600 & 1.2595 & 7.2500 & 7.1985 & 0.0615 & -0.0418 \\
\hline 20 & 2.2106 & 2.2449 & 1.2723 & 1.2779 & 6.0000 & 5.7929 & 0.0694 & 0.1137 \\
\hline 25 & 2.3385 & 2.3458 & 1.2821 & 1.2922 & 5.0500 & 4.7026 & 0.0680 & 0.2343 \\
\hline 30 & 2.5112 & 2.4283 & 1.2995 & 1.3039 & 4.0125 & 3.8117 & 0.0997 & 0.3328 \\
\hline
\end{tabular}

Table E-77: 13 Stages (4\%) - Arps- Recalculated Constants

\begin{tabular}{|c|c|c|c|c|c|c|}
\hline \multicolumn{7}{|c|}{ 13 Fractures (4\%)- Arps } \\
\hline Years & $n$ & $n(E q)$. & $d i$ & di(Eq.) & qi & qi(Eq). \\
\hline 3 & 1.7081 & 1.6803 & 0.0570 & 0.0579 & 13.3167 & 13.4783 \\
\hline 5 & 1.6020 & 1.5982 & 0.0528 & 0.0506 & 13.2247 & 13.0381 \\
\hline 7 & 1.5292 & 1.5464 & 0.0466 & 0.0463 & 12.8230 & 12.7561 \\
\hline 10 & 1.4691 & 1.4933 & 0.0412 & 0.0421 & 12.4245 & 12.4637 \\
\hline 15 & 1.4210 & 1.4351 & 0.0371 & 0.0378 & 12.0791 & 12.1396 \\
\hline 20 & 1.3910 & 1.3952 & 0.0345 & 0.0350 & 11.8450 & 11.9147 \\
\hline 25 & 1.3710 & 1.3650 & 0.0329 & 0.0330 & 11.6904 & 11.7431 \\
\hline 30 & 1.3651 & 1.3409 & 0.0325 & 0.0315 & 11.6599 & 11.6047 \\
\hline
\end{tabular}


Table E-78: 13 Stages (4\%) - Duong- Recalculated Constants

\begin{tabular}{|c|c|c|c|c|c|c|c|c|}
\hline \multicolumn{9}{|c|}{13 Fractures (4\%)- Duong } \\
\hline Years & $a$ & $a(E q)$. & $m$ & $m(E q)$. & $q 1$ & $q 1$ (Eq.) & $q \infty$ & $q \infty(E q)$. \\
\hline 2 & 1.0875 & 1.0610 & 1.0742 & 1.0784 & 13.0000 & 12.8444 & -2.5596 & -1.8373 \\
\hline 3 & 1.1131 & 1.1365 & 1.0908 & 1.0985 & 12.4000 & 12.1607 & -1.5919 & -1.5043 \\
\hline 4 & 1.1605 & 1.1900 & 1.1090 & 1.1128 & 11.8000 & 11.6757 & -1.0387 & -1.2680 \\
\hline 5 & 1.2235 & 1.2316 & 1.1273 & 1.1238 & 11.1000 & 11.2995 & -0.7009 & -1.0847 \\
\hline 7 & 1.2984 & 1.2942 & 1.1488 & 1.1405 & 10.5000 & 10.7322 & -0.3861 & -0.8083 \\
\hline 10 & 1.3853 & 1.3606 & 1.1696 & 1.1582 & 9.8000 & 10.1308 & -0.1860 & -0.5154 \\
\hline 15 & 1.4579 & 1.4361 & 1.1857 & 1.1783 & 9.2783 & 9.4472 & -0.0251 & -0.1823 \\
\hline 20 & 1.5124 & 1.4897 & 1.1953 & 1.1926 & 8.8000 & 8.9622 & -0.0251 & 0.0540 \\
\hline 25 & 1.5248 & 1.5313 & 1.1982 & 1.2037 & 8.7500 & 8.5860 & -0.0079 & 0.2373 \\
\hline 30 & 1.5331 & 1.5652 & 1.1999 & 1.2127 & 8.7000 & 8.2786 & 0.0000 & 0.3870 \\
\hline
\end{tabular}

Table E-79: 13 Stages (5\%) - Arps- Recalculated Constants

\begin{tabular}{|c|c|c|c|c|c|c|}
\hline \multicolumn{7}{|c|}{13 Fractures (5\%)-Arps } \\
\hline Years & $n$ & $n(E q)$. & $d i$ & di(Eq.) & $q i$ & qi(Eq). \\
\hline 3 & 1.7421 & 1.7254 & 0.0475 & 0.0506 & 13.4537 & 13.7882 \\
\hline 5 & 1.6410 & 1.6253 & 0.0467 & 0.0435 & 13.6124 & 13.3106 \\
\hline 7 & 1.5517 & 1.5626 & 0.0405 & 0.0394 & 13.1748 & 13.0052 \\
\hline 10 & 1.4807 & 1.4987 & 0.0355 & 0.0354 & 12.7633 & 12.6890 \\
\hline 15 & 1.4107 & 1.4293 & 0.0305 & 0.0314 & 12.2690 & 12.3389 \\
\hline 20 & 1.3765 & 1.3820 & 0.0282 & 0.0289 & 12.0222 & 12.0964 \\
\hline 25 & 1.3523 & 1.3464 & 0.0266 & 0.0270 & 11.8401 & 11.9116 \\
\hline 30 & 1.3452 & 1.3179 & 0.0263 & 0.0256 & 11.7978 & 11.7627 \\
\hline
\end{tabular}

Table E-80: 13 Stages (5\%) - Duong- Recalculated Constants

\begin{tabular}{|c|c|c|c|c|c|c|c|c|}
\hline \multicolumn{9}{|c|}{ 13Fractures (5\%)- Duong } \\
\hline Years & $a$ & $a(E q)$. & $m$ & $m(E q)$. & $q 1$ & $q 1$ (Eq.) & $q \infty$ & $q \infty$ (Eq.) \\
\hline 2 & 1.0862 & 1.0788 & 1.0705 & 1.0748 & 13.7000 & 13.0629 & -2.8015 & -2.1152 \\
\hline 3 & 1.1260 & 1.1498 & 1.0869 & 1.0938 & 12.7000 & 12.3878 & -1.8750 & -1.7415 \\
\hline 4 & 1.1887 & 1.2001 & 1.1062 & 1.1073 & 11.7000 & 11.9088 & -1.2571 & -1.4764 \\
\hline 5 & 1.2427 & 1.2392 & 1.1217 & 1.1178 & 11.0500 & 11.5373 & -0.8933 & -1.2707 \\
\hline 7 & 1.3090 & 1.2980 & 1.1411 & 1.1336 & 10.5000 & 10.9771 & -0.5259 & -0.9606 \\
\hline 10 & 1.3804 & 1.3605 & 1.1600 & 1.1503 & 10.0000 & 10.3832 & -0.2776 & -0.6319 \\
\hline 15 & 1.4489 & 1.4314 & 1.1716 & 1.1693 & 9.5611 & 9.7081 & -0.1199 & -0.2583 \\
\hline 20 & 1.4882 & 1.4818 & 1.1848 & 1.1828 & 9.3000 & 9.2291 & -0.0589 & 0.0069 \\
\hline 25 & 1.5146 & 1.5208 & 1.1899 & 1.1933 & 9.1000 & 8.8576 & -0.0302 & 0.2125 \\
\hline 30 & 1.5286 & 1.5527 & 1.1926 & 1.2018 & 9.0000 & 8.5540 & -0.0162 & 0.3805 \\
\hline
\end{tabular}


Table E-81: 13 Stages (6\%) - Arps- Recalculated Constants

\begin{tabular}{|c|c|c|c|c|c|c|}
\hline \multicolumn{7}{|c|}{13 Fractures (6\%)-Arps } \\
\hline Years & $n$ & $n(E q)$. & $d i$ & $d i(E q)$. & $q i$ & $q i(E q)$. \\
\hline 3 & 1.8065 & 1.7522 & 0.0444 & 0.0436 & 13.8793 & 14.0018 \\
\hline 5 & 1.6359 & 1.6379 & 0.0379 & 0.0371 & 13.7552 & 13.4893 \\
\hline 7 & 1.5368 & 1.5668 & 0.0329 & 0.0334 & 13.1509 & 13.1620 \\
\hline 10 & 1.4502 & 1.4947 & 0.0283 & 0.0298 & 12.6930 & 12.8237 \\
\hline 15 & 1.4039 & 1.4168 & 0.0261 & 0.0262 & 12.4598 & 12.4497 \\
\hline 20 & 1.3625 & 1.3640 & 0.0238 & 0.0240 & 12.1694 & 12.1910 \\
\hline 25 & 1.3404 & 1.3244 & 0.0226 & 0.0223 & 12.0141 & 11.9940 \\
\hline 30 & 1.3209 & 1.2929 & 0.0216 & 0.0211 & 11.8694 & 11.8354 \\
\hline
\end{tabular}

Table E-82: 13 Stages (6\%) - Duong - Recalculated Constants

\begin{tabular}{|c|c|c|c|c|c|c|c|c|}
\hline \multicolumn{9}{|c|}{ 13 Fractures (6\%)- Duong } \\
\hline Years & $\boldsymbol{a}$ & $\boldsymbol{a}(\mathrm{Eq}$.) & $\boldsymbol{m}$ & $\boldsymbol{m}$ (Eq.) & $\mathbf{q 1}$ & $\boldsymbol{q} \mathbf{1}$ (Eq.) & $\mathbf{q}^{\infty}$ & $\mathbf{q}$ (Eq.) \\
\hline 2 & 1.0571 & 1.0190 & 1.0616 & 1.0573 & 15.0000 & 14.7731 & -3.1843 & -2.6143 \\
\hline 3 & 1.0752 & 1.0856 & 1.0714 & 1.0765 & 14.3000 & 14.0343 & -2.3936 & -2.1643 \\
\hline 4 & 1.1137 & 1.1329 & 1.0858 & 1.0900 & 13.4500 & 13.5102 & -1.7041 & -1.8450 \\
\hline 5 & 1.1446 & 1.1695 & 1.0975 & 1.1006 & 13.0000 & 13.1036 & -1.2677 & -1.5973 \\
\hline 7 & 1.2183 & 1.2248 & 1.1196 & 1.1164 & 12.1000 & 12.4906 & -0.7515 & -1.2238 \\
\hline 10 & 1.2827 & 1.2834 & 1.1387 & 1.1333 & 11.6000 & 11.8407 & -0.4184 & -0.8280 \\
\hline 15 & 1.3587 & 1.3500 & 1.1579 & 1.1524 & 11.0000 & 11.1019 & -0.1971 & -0.3779 \\
\hline 20 & 1.4137 & 1.3973 & 1.1694 & 1.1660 & 10.5000 & 10.5778 & -0.1069 & -0.0586 \\
\hline 25 & 1.4406 & 1.4340 & 1.1752 & 1.1765 & 10.3000 & 10.1712 & -0.0647 & 0.1890 \\
\hline 30 & 1.4555 & 1.4639 & 1.1784 & 1.1851 & 10.2000 & 9.8390 & -0.0432 & 0.3914 \\
\hline
\end{tabular}

Table E-83: 13 Stages (8\%) - Arps- Recalculated Constants

\begin{tabular}{|c|c|c|c|c|c|c|}
\hline \multicolumn{7}{|c|}{ 13 Fractures (8\%)-Arps } \\
\hline Years & $n$ & $n(E q)$. & di & di(Eq.) & $q i$ & $q i(E q)$. \\
\hline 3 & 1.9041 & 1.8697 & 0.0387 & 0.0388 & 14.4732 & 14.6344 \\
\hline 5 & 1.7050 & 1.7150 & 0.0326 & 0.0319 & 14.1389 & 14.0341 \\
\hline 7 & 1.5960 & 1.6202 & 0.0264 & 0.0280 & 13.5263 & 13.6522 \\
\hline 10 & 1.5045 & 1.5254 & 0.0252 & 0.0245 & 13.4493 & 13.2587 \\
\hline 15 & 1.4325 & 1.4244 & 0.0223 & 0.0209 & 13.0902 & 12.8251 \\
\hline 20 & 1.3515 & 1.3568 & 0.0187 & 0.0187 & 12.5148 & 12.5261 \\
\hline 25 & 1.3024 & 1.3066 & 0.0167 & 0.0172 & 12.1619 & 12.2990 \\
\hline 30 & 1.2834 & 1.2670 & 0.0160 & 0.0160 & 12.0275 & 12.1165 \\
\hline
\end{tabular}


Table E-84: 13 Stages (8\%) - Duong - Recalculated Constants

\begin{tabular}{|c|c|c|c|c|c|c|c|c|}
\hline \multicolumn{9}{|c|}{ 13 Fractures (8\%)- Duong } \\
\hline Years & $\boldsymbol{a}$ & $\boldsymbol{a}$ (Eq.) & $\boldsymbol{m}$ & $\boldsymbol{m}$ (Eq.) & $\boldsymbol{q} \mathbf{1}$ & $\boldsymbol{q 1}$ (Eq.) & $\boldsymbol{q}^{\infty}$ & $\boldsymbol{q}$ (Eq.) \\
\hline 2 & 1.0689 & 1.0287 & 1.0645 & 1.0553 & 15.4200 & 15.3541 & -2.9859 & -2.8577 \\
\hline 3 & 1.0830 & 1.0919 & 1.0688 & 1.0727 & 15.0000 & 14.5797 & -2.7861 & -2.3869 \\
\hline 4 & 1.1138 & 1.1367 & 1.0788 & 1.0851 & 14.2000 & 14.0302 & -2.0824 & -2.0529 \\
\hline 5 & 1.1534 & 1.1715 & 1.0905 & 1.0946 & 13.4000 & 13.6040 & -1.6133 & -1.7938 \\
\hline 7 & 1.2091 & 1.2239 & 1.1075 & 1.1091 & 12.6000 & 12.9613 & -1.0579 & -1.4031 \\
\hline 10 & 1.2765 & 1.2794 & 1.1266 & 1.1244 & 11.9000 & 12.2801 & -0.6278 & -0.9890 \\
\hline 15 & 1.3553 & 1.3426 & 1.1465 & 1.1418 & 11.2200 & 11.5056 & -0.3203 & -0.5182 \\
\hline 20 & 1.3994 & 1.3874 & 1.1573 & 1.1541 & 10.9200 & 10.9562 & -0.1906 & -0.1842 \\
\hline 25 & 1.4300 & 1.4222 & 1.1643 & 1.1637 & 10.7000 & 10.5299 & -0.0910 & 0.0749 \\
\hline 30 & 1.4459 & 1.4506 & 1.1698 & 1.1715 & 10.6200 & 10.1817 & -0.0679 & 0.2866 \\
\hline
\end{tabular}

Table E-85: 13 Stages (300 ft.)- Arps- Table of Ratios

\begin{tabular}{|c|c|c|c|}
\hline \multicolumn{4}{|c|}{ 13Fractures (300 ft.)-Arps- Table of Ratios } \\
\hline Years & $n$ - Ratio & di- Ratio & qi- Ratio \\
\hline & & & \\
\hline$s 3$ & 1.199499 & 1.819701 & 1.188502 \\
\hline 5 & 1.152057 & 1.59338 & 1.14383 \\
\hline 7 & 1.121837 & 1.45991 & 1.115326 \\
\hline 10 & 1.090668 & 1.330612 & 1.085886 \\
\hline 15 & 1.056286 & 1.197479 & 1.053361 \\
\hline 20 & 1.03255 & 1.111178 & 1.030877 \\
\hline 25 & 1.014508 & 1.048545 & 1.013768 \\
\hline 30 & 1 & 1 & 1 \\
\hline
\end{tabular}

Table E-86: 13 Stages (300 ft.)- Duong- Table of Ratios

\begin{tabular}{|c|c|c|c|c|}
\hline \multicolumn{5}{|c|}{ 13Fractures (300 ft.)- Duong-Table of Ratios } \\
\hline Years & a-Ratio & m-Ratio & $q_{1}$-Ratio & $q_{\infty}$-Ratio \\
\hline 2 & 0.672724 & 0.866923 & 1.425403 & -3.52604 \\
\hline 3 & 0.721726 & 0.886848 & 1.361709 & -2.84837 \\
\hline 4 & 0.756493 & 0.900985 & 1.316518 & -2.36756 \\
\hline 5 & 0.78346 & 0.911951 & 1.281465 & -1.99461 \\
\hline 7 & 0.824124 & 0.928485 & 1.228609 & -1.43226 \\
\hline 10 & 0.867229 & 0.946013 & 1.172579 & -0.83614 \\
\hline 15 & 0.916231 & 0.965938 & 1.108885 & -0.15848 \\
\hline 20 & 0.950998 & 0.980075 & 1.063694 & 0.322335 \\
\hline 25 & 0.977966 & 0.99104 & 1.028641 & 0.695281 \\
\hline 30 & 1 & 1 & 1 & 1 \\
\hline
\end{tabular}


Table E-87: 13 Stages (400 ft.)- Arps- Table of Ratios

\begin{tabular}{|c|c|c|c|}
\hline \multicolumn{4}{|c|}{ 13Fractures (400 ft.)-Arps- Table of Ratios } \\
\hline Years & $n$ - Ratio & di-Ratio & qi- Ratio \\
\hline 3 & 1.188502 & 1.555966 & 1.119438 \\
\hline 5 & 1.14383 & 1.410604 & 1.091766 \\
\hline 7 & 1.115326 & 1.322356 & 1.073913 \\
\hline 10 & 1.085886 & 1.23483 & 1.055307 \\
\hline 15 & 1.053361 & 1.142346 & 1.034548 \\
\hline 20 & 1.030877 & 1.08096 & 1.020066 \\
\hline 25 & 1.013768 & 1.035626 & 1.008974 \\
\hline 30 & 1 & 1 & 1 \\
\hline
\end{tabular}

Table E-88: 13 Stages (400 ft.)- Duong- Table of Ratios

\begin{tabular}{|c|c|c|c|c|}
\hline \multicolumn{5}{|c|}{ 13 Fractures (400 ft.)- Duong-Table of Ratios } \\
\hline Years & a-Ratio & m-Ratio & $\boldsymbol{q}_{\mathbf{1}}$-Ratio & $\boldsymbol{q}_{\infty}$-Ratio \\
\hline 2 & 0.622163 & 0.862389 & 1.489187 & -4.21544 \\
\hline 3 & 0.678735 & 0.882993 & 1.415943 & -3.43455 \\
\hline 4 & 0.718874 & 0.897611 & 1.363976 & -2.8805 \\
\hline 5 & 0.750007 & 0.908951 & 1.323667 & -2.45075 \\
\hline 7 & 0.796953 & 0.926049 & 1.262886 & -1.80274 \\
\hline 10 & 0.846718 & 0.944173 & 1.198455 & -1.11582 \\
\hline 15 & 0.90329 & 0.964777 & 1.125211 & -0.33493 \\
\hline 20 & 0.943428 & 0.979396 & 1.073244 & 0.219114 \\
\hline 25 & 0.974562 & 0.990735 & 1.032935 & 0.648867 \\
\hline 30 & 1 & 1 & 1 & 1 \\
\hline
\end{tabular}

Table E-89: 13 Stages (500 ft.)- Arps- Table of Ratios

\begin{tabular}{|c|c|c|c|}
\hline \multicolumn{4}{|c|}{ 13Fractures (500 ft.)-Arps- Table of Ratios } \\
\hline Years & $n$ - Ratio & di-Ratio & qi- Ratio \\
\hline 3 & 1.164126 & 1.279381 & 1.049542 \\
\hline 5 & 1.125532 & 1.211329 & 1.038344 \\
\hline 7 & 1.100813 & 1.168494 & 1.031033 \\
\hline 10 & 1.075202 & 1.12474 & 1.023339 \\
\hline 15 & 1.04681 & 1.076986 & 1.014663 \\
\hline 20 & 1.027122 & 1.04434 & 1.008551 \\
\hline 25 & 1.012106 & 1.0197 & 1.003836 \\
\hline 30 & 1 & 1 & 1 \\
\hline
\end{tabular}


Table E-90: 13 Stages (500 ft.)- Duong- Table of Ratios

\begin{tabular}{|c|c|c|c|c|}
\hline \multicolumn{5}{|c|}{ 13 Fractures (500 ft.)- Duong-Table of Ratios } \\
\hline Years & a-Ratio & m-Ratio & $\boldsymbol{q}_{1}$-Ratio & $\boldsymbol{q}_{\infty}$ - Ratio \\
\hline 2 & 0.587222 & 0.860788 & 1.621871 & -5.781184 \\
\hline 3 & 0.649026 & 0.881632 & 1.528761 & -4.7658655 \\
\hline 4 & 0.692876 & 0.896421 & 1.462698 & -4.0454856 \\
\hline 5 & 0.726889 & 0.907892 & 1.411456 & -3.4867155 \\
\hline 7 & 0.778176 & 0.925189 & 1.334189 & -2.6441609 \\
\hline 10 & 0.832543 & 0.943524 & 1.252283 & -1.751017 \\
\hline 15 & 0.894346 & 0.964368 & 1.159173 & -0.7356985 \\
\hline 20 & 0.938196 & 0.979156 & 1.09311 & -0.0153185 \\
\hline 25 & 0.972209 & 0.990627 & 1.041868 & 0.54345158 \\
\hline 30 & 1 & 1 & 1 & 1 \\
\hline
\end{tabular}

Table E-91: 13 Stages (600 ft.)- Arps- Table of Ratios

\begin{tabular}{|c|c|c|c|}
\hline \multicolumn{4}{|c|}{ 13Fractures (600 ft.)-Arps- Table of Ratios } \\
\hline Years & n-Ratio & di- Ratio & qi- Ratio \\
\hline 3 & 1.156112 & 1.227439 & 1.032761 \\
\hline 5 & 1.119499 & 1.172885 & 1.025402 \\
\hline 7 & 1.096017 & 1.138283 & 1.020583 \\
\hline 10 & 1.071664 & 1.102716 & 1.015499 \\
\hline 15 & 1.044636 & 1.063633 & 1.009751 \\
\hline 20 & 1.025873 & 1.036745 & 1.005693 \\
\hline 25 & 1.011552 & 1.016359 & 1.002556 \\
\hline 30 & 1 & 1 & 1 \\
\hline
\end{tabular}

Table E-92: 13 Stages (600 ft.)- Duong- Table of Ratios

\begin{tabular}{|c|c|c|c|c|}
\hline \multicolumn{5}{|c|}{13 Fractures (600 ft.)- Duong- Table of Ratios } \\
\hline Years & a-Ratio & m-Ratio & $q_{1}$-Ratio & $q_{\infty}$ - Ratio \\
\hline 2 & 0.56876 & 0.859075 & 1.849838 & -5.0915153 \\
\hline 3 & 0.633328 & 0.880175 & 1.722595 & -4.1794581 \\
\hline 4 & 0.67914 & 0.895146 & 1.632315 & -3.5323431 \\
\hline 5 & 0.714674 & 0.906758 & 1.562288 & -3.0304018 \\
\hline 7 & 0.768255 & 0.924268 & 1.456697 & -2.2735377 \\
\hline 10 & 0.825053 & 0.942829 & 1.344765 & -1.4712295 \\
\hline 15 & 0.889621 & 0.963929 & 1.217523 & -0.5591722 \\
\hline 20 & 0.935432 & 0.9789 & 1.127243 & 0.08794271 \\
\hline 25 & 0.970966 & 0.990512 & 1.057216 & 0.58988406 \\
\hline 30 & 1 & 1 & 1 & 1 \\
\hline
\end{tabular}


Table E-93: 13 Stages (700 ft.)- Arps- Table of Ratios

\begin{tabular}{|c|c|c|c|}
\hline \multicolumn{4}{|c|}{ 13Fractures (700 ft.)- Arps- Table of Ratios } \\
\hline Years & $n$ - Ratio & di- Ratio & qi- Ratio \\
\hline 3 & 1.14025 & 1.210598 & 1.021505 \\
\hline 5 & 1.107528 & 1.160343 & 1.019905 \\
\hline 7 & 1.086489 & 1.128387 & 1.016137 \\
\hline 10 & 1.064623 & 1.095471 & 1.012158 \\
\hline 15 & 1.0403 & 1.059218 & 1.007654 \\
\hline 20 & 1.023381 & 1.034226 & 1.00447 \\
\hline 25 & 1.010447 & 1.015248 & 1.002008 \\
\hline 30 & 1 & 1 & 1 \\
\hline
\end{tabular}

Table E-94: 13 Stages (700 ft.)- Duong- Table of Ratios

\begin{tabular}{|c|c|c|c|c|}
\hline \multicolumn{5}{|c|}{13 Fractures (700 ft.)- Duong-Table of Ratios } \\
\hline Years & a-Ratio & m-Ratio & $q_{1}$-Ratio & $q_{\infty}$-Ratio \\
\hline 2 & 0.536398 & 0.853385 & 2.048458 & -5.3562318 \\
\hline 3 & 0.605811 & 0.875337 & 1.891477 & -4.4045396 \\
\hline 4 & 0.655061 & 0.890913 & 1.780097 & -3.7293033 \\
\hline 5 & 0.693262 & 0.902994 & 1.693704 & -3.2055493 \\
\hline 7 & 0.750864 & 0.92121 & 1.563434 & -2.4157945 \\
\hline 10 & 0.811924 & 0.940521 & 1.425343 & -1.5786207 \\
\hline 15 & 0.881337 & 0.962473 & 1.268361 & -0.6269285 \\
\hline 20 & 0.930587 & 0.978048 & 1.156981 & 0.04830781 \\
\hline 25 & 0.968788 & 0.990129 & 1.070588 & 0.57206182 \\
\hline 30 & 1 & 1 & 1 & 1 \\
\hline
\end{tabular}

Table E-95: 13 Stages (0.0008 m-D) - Arps-Table of Ratios

\begin{tabular}{|c|c|c|c|}
\hline \multicolumn{4}{|c|}{ 13Fractures (0.0008 m-D)-Arps-Table of Ratios } \\
\hline Years & $n$ - Ratio & di-Ratio & qi- Ratio \\
\hline 3 & 1.213389 & 1.264736 & 1.032761 \\
\hline 5 & 1.162424 & 1.200526 & 1.025402 \\
\hline 7 & 1.13003 & 1.160022 & 1.020583 \\
\hline 10 & 1.096676 & 1.118578 & 1.015499 \\
\hline 15 & 1.059953 & 1.07326 & 1.009751 \\
\hline 20 & 1.034646 & 1.042225 & 1.005693 \\
\hline 25 & 1.015433 & 1.018771 & 1.002556 \\
\hline 30 & 1 & 1 & 1 \\
\hline
\end{tabular}


Table E-96: 13 Stages (0.0008 m-D) - Duong -Table of Ratios

\begin{tabular}{|c|c|c|c|c|}
\hline \multicolumn{5}{|c|}{13 Fractures $(0.0008 \mathrm{~m}$-D)- Duong-Table of Ratios } \\
\hline Years & $\boldsymbol{a}$-Ratio & m-Ratio & $\boldsymbol{q}_{1}$-Ratio & $\boldsymbol{q}_{\infty}$ - Ratio \\
\hline 2 & 0.564546 & 0.890673 & 2.469322 & -19.997725 \\
\hline 3 & 0.629745 & 0.907042 & 2.249327 & -16.853823 \\
\hline 4 & 0.676004 & 0.918656 & 2.093238 & -14.623189 \\
\hline 5 & 0.711886 & 0.927665 & 1.972165 & -12.892974 \\
\hline 7 & 0.76599 & 0.941248 & 1.789604 & -10.28403 \\
\hline 10 & 0.823343 & 0.955648 & 1.59608 & -7.5184383 \\
\hline 15 & 0.888542 & 0.972017 & 1.376085 & -4.3745362 \\
\hline 20 & 0.934801 & 0.983631 & 1.219996 & -2.1439021 \\
\hline 25 & 0.970683 & 0.992639 & 1.098923 & -0.4136879 \\
\hline 30 & 1 & 1 & 1 & 1 \\
\hline
\end{tabular}

Table E-97: 13 Stages (0.001 m-D) - Arps -Table of Ratios

\begin{tabular}{|c|c|c|c|}
\hline \multicolumn{4}{|c|}{ 13Fractures (0.001 m-D)-Arps-Table of Ratios } \\
\hline Years & $n$-Ratio & di-Ratio & qi-Ratio \\
\hline 3 & 1.202264 & 1.241652 & 1.028016 \\
\hline 5 & 1.154123 & 1.18344 & 1.021734 \\
\hline 7 & 1.123471 & 1.146595 & 1.017617 \\
\hline 10 & 1.091867 & 1.10879 & 1.013271 \\
\hline 15 & 1.057018 & 1.067325 & 1.008352 \\
\hline 20 & 1.032969 & 1.038849 & 1.004877 \\
\hline 25 & 1.014693 & 1.017286 & 1.00219 \\
\hline 30 & 1 & 1 & 1 \\
\hline
\end{tabular}

Table E-98: 13 Stages (0.001 m-D) - Duong -Table of Ratios

\begin{tabular}{|c|c|c|c|c|}
\hline \multicolumn{5}{|c|}{13 Fractures $(0.001$ m-D)- Duong-Table of Ratios } \\
\hline Years & a-Ratio & m-Ratio & $q_{1}$-Ratio & $q_{\infty}$ - Ratio \\
\hline 2 & 0.530838 & 0.88444 & 2.701732 & -20.79246 \\
\hline 3 & 0.601084 & 0.901742 & 2.446938 & -17.529566 \\
\hline 4 & 0.650924 & 0.914018 & 2.26616 & -15.214505 \\
\hline 5 & 0.689583 & 0.923541 & 2.125937 & -13.418805 \\
\hline 7 & 0.747876 & 0.937899 & 1.914499 & -10.711116 \\
\hline 10 & 0.809669 & 0.953119 & 1.690365 & -7.8408496 \\
\hline 15 & 0.879914 & 0.970421 & 1.435572 & -4.577955 \\
\hline 20 & 0.929754 & 0.982698 & 1.254793 & -2.2628945 \\
\hline 25 & 0.968413 & 0.99222 & 1.11457 & -0.4671941 \\
\hline 30 & 1 & 1 & 1 & 1 \\
\hline
\end{tabular}


Table E-99: 13 Stages (0.002 m-D) - Arps -Table of Ratios

\begin{tabular}{|c|c|c|c|}
\hline \multicolumn{4}{|c|}{ 13Fractures (0.002 m-D)-Arps-Table of Ratios } \\
\hline Years & $n$ - Ratio & di-Ratio & qi- Ratio \\
\hline 3 & 1.169499 & 1.145513 & 1.025652 \\
\hline 5 & 1.129573 & 1.111504 & 1.019905 \\
\hline 7 & 1.104022 & 1.089656 & 1.016137 \\
\hline 10 & 1.077567 & 1.066965 & 1.012158 \\
\hline 15 & 1.048262 & 1.041743 & 1.007654 \\
\hline 20 & 1.027955 & 1.024211 & 1.00447 \\
\hline 25 & 1.012475 & 1.010815 & 1.002008 \\
\hline 30 & 1 & 1 & 1 \\
\hline
\end{tabular}

Table E-100: 13 Stages (0.002 m-D) - Duong -Table of Ratios

\begin{tabular}{|c|c|c|c|c|}
\hline \multicolumn{5}{|c|}{ 13 Fractures $(\mathbf{0 . 0 0 2} \boldsymbol{m}$-D)-Duong-Table of Ratios } \\
\hline Years & $a$-Ratio & m-Ratio & $q_{1}$-Ratio & $q_{\infty}$-Ratio \\
\hline 2 & 0.523954 & 0.870338 & 3.003952 & -7.4427836 \\
\hline 3 & 0.59523 & 0.889751 & 2.703909 & -6.1786807 \\
\hline 4 & 0.645801 & 0.903526 & 2.491025 & -5.2817854 \\
\hline 5 & 0.685028 & 0.91421 & 2.325899 & -4.5860994 \\
\hline 7 & 0.744176 & 0.93032 & 2.07691 & -3.5370929 \\
\hline 10 & 0.806876 & 0.947398 & 1.812971 & -2.4251011 \\
\hline 15 & 0.878152 & 0.966812 & 1.512928 & -1.1609982 \\
\hline 20 & 0.928724 & 0.980586 & 1.300043 & -0.2641029 \\
\hline 25 & 0.96795 & 0.99127 & 1.134918 & 0.43158312 \\
\hline 30 & 1 & 1 & 1 & 1 \\
\hline
\end{tabular}

Table E-101: 13 Stages (0.004 m-D) - Arps -Table of Ratios

\begin{tabular}{|c|c|c|c|}
\hline \multicolumn{4}{|c|}{ 13Fractures (0.004 m-D)-Arps-Table of Ratios } \\
\hline Years & $n$ - Ratio & di- Ratio & qi- Ratio \\
\hline 3 & 1.1508 & 1.119438 & 1.018591 \\
\hline 5 & 1.115494 & 1.091766 & 1.014437 \\
\hline 7 & 1.092832 & 1.073913 & 1.01171 \\
\hline 10 & 1.069312 & 1.055307 & 1.008828 \\
\hline 15 & 1.043189 & 1.034548 & 1.005561 \\
\hline 20 & 1.025042 & 1.020066 & 1.003249 \\
\hline 25 & 1.011184 & 1.008974 & 1.00146 \\
\hline 30 & 1 & 1 & 1 \\
\hline
\end{tabular}


Table E-102: 13 Stages (0.004 m-D) - Duong -Table of Ratios

\begin{tabular}{|c|c|c|c|c|}
\hline \multicolumn{5}{|c|}{ 13 Fractures $(\mathbf{0 . 0 0 4} \boldsymbol{m}$-D)-Duong-Table of Ratios } \\
\hline Years & $a$-Ratio & $m$-Ratio & $q_{1}$-Ratio & $q_{\infty}$-Ratio \\
\hline 2 & 0.504163 & 0.86769 & 4.175176 & -3.4366551 \\
\hline 3 & 0.578402 & 0.8875 & 3.69977 & -2.7723731 \\
\hline 4 & 0.631076 & 0.901556 & 3.362464 & -2.3010576 \\
\hline 5 & 0.671933 & 0.912458 & 3.10083 & -1.9354769 \\
\hline 7 & 0.733541 & 0.928897 & 2.706317 & -1.3842274 \\
\hline 10 & 0.798847 & 0.946324 & 2.288118 & -0.7998794 \\
\hline 15 & 0.873086 & 0.966134 & 1.812712 & -0.1355975 \\
\hline 20 & 0.92576 & 0.98019 & 1.475406 & 0.33571807 \\
\hline 25 & 0.966617 & 0.991092 & 1.213771 & 0.70129879 \\
\hline 30 & 1 & 1 & 1 & 1 \\
\hline
\end{tabular}

Table E-103: 13 Stages (0.006 m-D) - Arps -Table of Ratios

\begin{tabular}{|c|c|c|c|}
\hline \multicolumn{4}{|c|}{ 13Fractures (0.006 m-D)-Arps-Table of Ratios } \\
\hline Years & $n$ - Ratio & di-Ratio & qi-Ratio \\
\hline 3 & 1.127197 & 1.076465 & 1.016249 \\
\hline 5 & 1.09765 & 1.059012 & 1.012621 \\
\hline 7 & 1.078612 & 1.047671 & 1.010239 \\
\hline 10 & 1.058791 & 1.035781 & 1.00772 \\
\hline 15 & 1.036701 & 1.022429 & 1.004864 \\
\hline 20 & 1.021308 & 1.013059 & 1.002842 \\
\hline 25 & 1.009526 & 1.005851 & 1.001277 \\
\hline 30 & 1 & 1 & 1 \\
\hline
\end{tabular}

Table E-104: 13 Stages (0.006 m-D) - Duong -Table of Ratios

\begin{tabular}{|c|c|c|c|c|}
\hline \multicolumn{5}{|c|}{13 Fractures $(0.006$ m-D)-Duong-Table of Ratios } \\
\hline Years & $a$-Ratio & m-Ratio & $\boldsymbol{q}_{1}$-Ratio & $\boldsymbol{q}_{\infty}$-Ratio \\
\hline 2 & 0.495585 & 0.866873 & 4.471249 & -3.3972334 \\
\hline 3 & 0.571109 & 0.886806 & 3.951514 & -2.7388539 \\
\hline 4 & 0.624694 & 0.900948 & 3.582755 & -2.2717262 \\
\hline 5 & 0.666258 & 0.911918 & 3.296724 & -1.9093938 \\
\hline 7 & 0.728931 & 0.928459 & 2.865425 & -1.3630424 \\
\hline 10 & 0.795367 & 0.945993 & 2.40823 & -0.7838867 \\
\hline 15 & 0.870891 & 0.965925 & 1.888494 & -0.1255072 \\
\hline 20 & 0.924476 & 0.980068 & 1.519736 & 0.34162051 \\
\hline 25 & 0.96604 & 0.991037 & 1.233705 & 0.70395289 \\
\hline 30 & 1 & 1 & 1 & 1 \\
\hline
\end{tabular}


Table E-105: 13 Stages (4\%) - Arps-Table of Ratios

\begin{tabular}{|c|c|c|c|}
\hline \multicolumn{4}{|c|}{ 13Fractures (4\%)- Arps-Table of Ratios } \\
\hline Years & $n$ - Ratio & di- Ratio & qi- Ratio \\
\hline 3 & 1.253141 & 1.840772 & 1.161449 \\
\hline 5 & 1.191952 & 1.607719 & 1.123517 \\
\hline 7 & 1.153289 & 1.470572 & 1.099212 \\
\hline 10 & 1.113673 & 1.337942 & 1.074021 \\
\hline 15 & 1.070289 & 1.201636 & 1.046085 \\
\hline 20 & 1.040536 & 1.113433 & 1.026706 \\
\hline 25 & 1.018028 & 1.049501 & 1.011921 \\
\hline 30 & 1 & 1 & 1 \\
\hline
\end{tabular}

Table E-106: 13 Stages (4\%) - Duong -Table of Ratios

\begin{tabular}{|c|c|c|c|c|}
\hline \multicolumn{5}{|c|}{13 Fractures (4\%)- Duong-Table of Ratios } \\
\hline Years & a-Ratio & m-Ratio & $\boldsymbol{q}_{1}$-Ratio & $\boldsymbol{q}_{\infty}$ - Ratio \\
\hline $\mathbf{2}$ & 0.677844 & 0.8892394 & 1.551516 & -4.7471376 \\
\hline 3 & 0.726079 & 0.9058231 & 1.46894 & -3.8866426 \\
\hline 4 & 0.760303 & 0.9175895 & 1.410351 & -3.2761116 \\
\hline 5 & 0.786848 & 0.9267162 & 1.364906 & -2.802547 \\
\hline 7 & 0.826876 & 0.940478 & 1.296381 & -2.0884716 \\
\hline 10 & 0.869307 & 0.9550662 & 1.223741 & -1.331521 \\
\hline 15 & 0.917542 & 0.9716499 & 1.141165 & -0.471026 \\
\hline 20 & 0.951765 & 0.9834163 & 1.082576 & 0.13950495 \\
\hline 25 & 0.978311 & 0.992543 & 1.037131 & 0.61306955 \\
\hline 30 & 1 & 1 & 1 & 1 \\
\hline
\end{tabular}

Table E-107: 13 Stages (5\%) - Arps-Table of Ratios

\begin{tabular}{|c|c|c|c|}
\hline \multicolumn{4}{|c|}{ 13Fractures (5\%)- Arps-Table of Ratios } \\
\hline Years & n- Ratio & di- Ratio & qi- Ratio \\
\hline 3 & 1.309182 & 1.972423 & 1.172195 \\
\hline 5 & 1.233229 & 1.696503 & 1.131599 \\
\hline 7 & 1.185623 & 1.536197 & 1.105629 \\
\hline 10 & 1.137164 & 1.382773 & 1.078751 \\
\hline 15 & 1.084477 & 1.226885 & 1.048989 \\
\hline 20 & 1.048583 & 1.12706 & 1.028372 \\
\hline 25 & 1.021561 & 1.055258 & 1.01266 \\
\hline 30 & 1 & 1 & 1 \\
\hline
\end{tabular}


Table E-108: 13 Stages (5\%) - Duong-Table of Ratios

\begin{tabular}{|c|c|c|c|c|}
\hline \multicolumn{5}{|c|}{ 13 Fractures (5\%)- Duong- Table of Ratios } \\
\hline Years & a-Ratio & m-Ratio & $\boldsymbol{q}_{1}$-Ratio & $\boldsymbol{q}_{\infty}$ - Ratio \\
\hline $\mathbf{2}$ & 0.694786 & 0.8943203 & 1.52711 & -5.5583541 \\
\hline 3 & 0.740484 & 0.9101433 & 1.448188 & -4.576399 \\
\hline 4 & 0.772908 & 0.9213699 & 1.392192 & -3.8796907 \\
\hline 5 & 0.798058 & 0.9300779 & 1.348758 & -3.3392818 \\
\hline 7 & 0.83598 & 0.9432085 & 1.283265 & -2.5244136 \\
\hline 10 & 0.87618 & 0.9571275 & 1.21384 & -1.6606185 \\
\hline 15 & 0.921878 & 0.9729504 & 1.134918 & -0.6786634 \\
\hline 20 & 0.954302 & 0.984177 & 1.078922 & 0.01804488 \\
\hline 25 & 0.979451 & 0.992885 & 1.035488 & 0.55845378 \\
\hline 30 & 1 & 1 & 1 & 1 \\
\hline
\end{tabular}

Table E-109: 13 Stages (6\%) - Arps-Table of Ratios

\begin{tabular}{|c|c|c|c|}
\hline \multicolumn{4}{|c|}{ 13Fractures (6\%)- Arps-Table of Ratios } \\
\hline Years & $n$ - Ratio & di-Ratio & qi-Ratio \\
\hline 3 & 1.355189 & 2.06538 & 1.183042 \\
\hline 5 & 1.266823 & 1.7584 & 1.139738 \\
\hline 7 & 1.211789 & 1.581566 & 1.112084 \\
\hline 10 & 1.156059 & 1.413491 & 1.083502 \\
\hline 15 & 1.095812 & 1.244012 & 1.051902 \\
\hline 20 & 1.05498 & 1.136237 & 1.030041 \\
\hline 25 & 1.024358 & 1.059112 & 1.013398 \\
\hline 30 & 1 & 1 & 1 \\
\hline
\end{tabular}

Table E-110: 13 Stages (6\%) - Duong -Table of Ratios

\begin{tabular}{|c|c|c|c|c|}
\hline \multicolumn{5}{|c|}{13 Fractures (6\%)- Duong-Table of Ratios } \\
\hline Years & a-Ratio & m-Ratio & $\boldsymbol{q}_{1}$-Ratio & $\boldsymbol{q}_{\infty}$-Ratio \\
\hline $\mathbf{2}$ & 0.696067 & 0.8921475 & 1.50148 & -6.6794829 \\
\hline 3 & 0.741574 & 0.9082958 & 1.426395 & -5.5296658 \\
\hline 4 & 0.773861 & 0.9197532 & 1.373122 & -4.7138576 \\
\hline 5 & 0.798905 & 0.9286402 & 1.3318 & -4.0810676 \\
\hline 7 & 0.836669 & 0.9420408 & 1.269492 & -3.1269004 \\
\hline 10 & 0.876699 & 0.956246 & 1.203442 & -2.1154423 \\
\hline 15 & 0.922206 & 0.9723943 & 1.128358 & -0.9656253 \\
\hline 20 & 0.954493 & 0.9838517 & 1.075084 & -0.1498171 \\
\hline 25 & 0.979537 & 0.9927387 & 1.033763 & 0.48297293 \\
\hline 30 & 1 & 1 & 1 & 1 \\
\hline
\end{tabular}


Table E-111: 13 Stages (8\%) - Arps-Table of Ratios

\begin{tabular}{|c|c|c|c|}
\hline \multicolumn{4}{|c|}{ 13Fractures (8\%)- Arps-Table of Ratios } \\
\hline Years & n-Ratio & di-Ratio & qi-Ratio \\
\hline 3 & 1.475707 & 2.421029 & 1.207814 \\
\hline 5 & 1.353654 & 1.989803 & 1.158266 \\
\hline 7 & 1.278827 & 1.748626 & 1.126746 \\
\hline 10 & 1.204019 & 1.524806 & 1.094269 \\
\hline 15 & 1.124279 & 1.304955 & 1.058484 \\
\hline 20 & 1.070926 & 1.168474 & 1.033807 \\
\hline 25 & 1.031292 & 1.07252 & 1.015063 \\
\hline 30 & 1 & 1 & 1 \\
\hline
\end{tabular}

Table E-112: 13 Stages (8\%) - Duong -Table of Ratios

\begin{tabular}{|c|c|c|c|c|}
\hline \multicolumn{5}{|c|}{13 Fractures (8\%)-Duong- Table of Ratios } \\
\hline Years & a-Ratio & m-Ratio & $\boldsymbol{q}_{1}$-Ratio & $\boldsymbol{q}_{\infty}$-Ratio \\
\hline $\mathbf{2}$ & 0.709146 & 0.9008329 & 1.508006 & -9.9699404 \\
\hline 3 & 0.752695 & 0.9156808 & 1.431945 & -8.3274568 \\
\hline 4 & 0.783593 & 0.9262155 & 1.377978 & -7.1620961 \\
\hline 5 & 0.807559 & 0.9343869 & 1.336118 & -6.2581722 \\
\hline 7 & 0.843697 & 0.9467083 & 1.272999 & -4.8951692 \\
\hline 10 & 0.882005 & 0.9597695 & 1.20609 & -3.4503279 \\
\hline 15 & 0.925554 & 0.9746174 & 1.130028 & -1.8078443 \\
\hline 20 & 0.956452 & 0.9851521 & 1.076062 & -0.6424836 \\
\hline 25 & 0.980418 & 0.9933235 & 1.034202 & 0.26144035 \\
\hline 30 & 1 & 1 & 1 & 1 \\
\hline
\end{tabular}




\section{F. Effect of Formation and Hydraulic Fracture Properties on Production Decline Behavior}

The changes of Arps and Duong models' constant ratios with fracture half-length, permeability and porosity at each production time interval were presented in the following figures, for both seven and thirteen stage cases.

\section{F.1. Seven Stages Model}

\section{F.1.1. Arps Decline Curve Analysis}

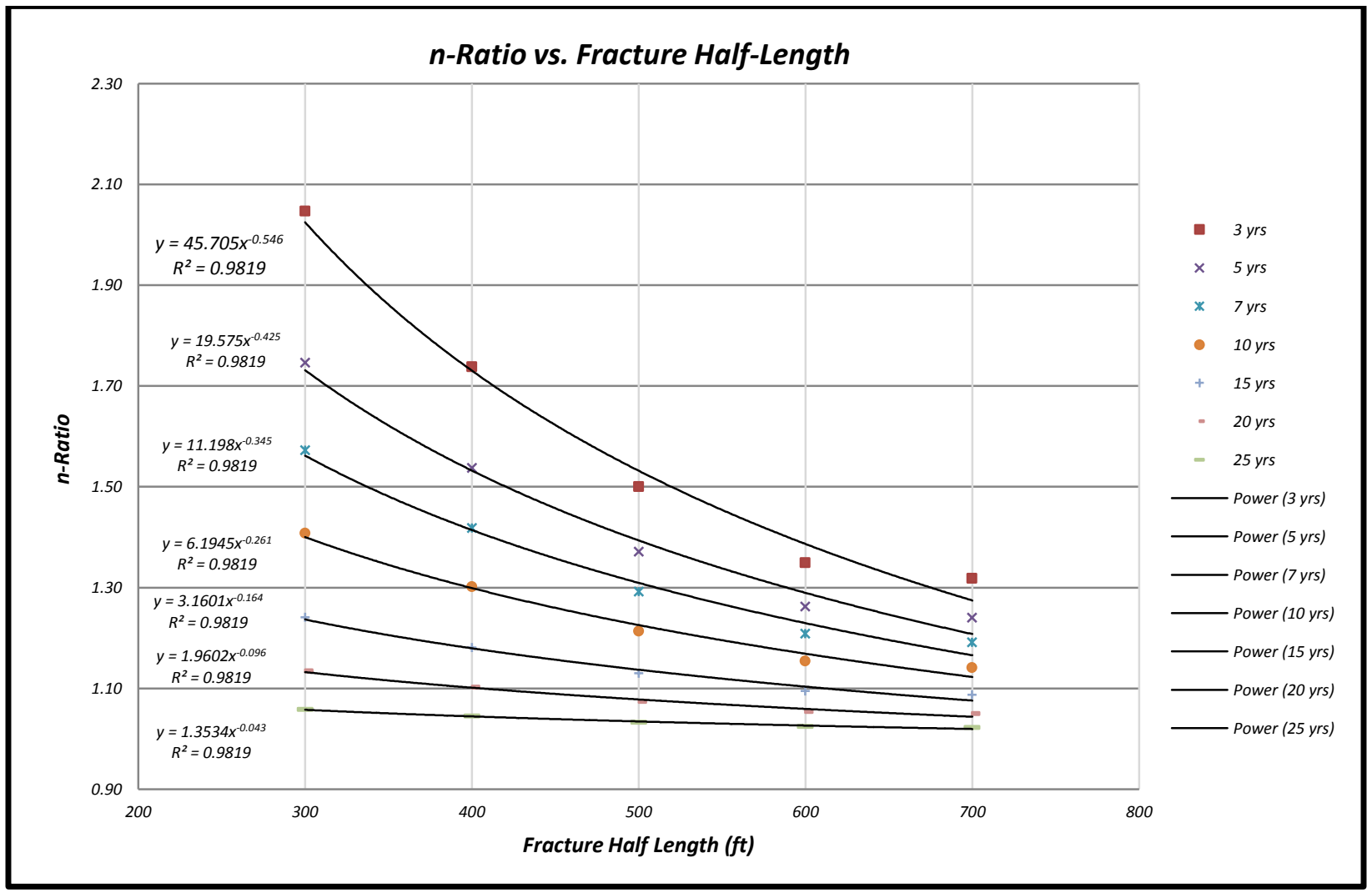

Figure F-1: n-Ratio vs. Fracture Half-length - 7 Stages 


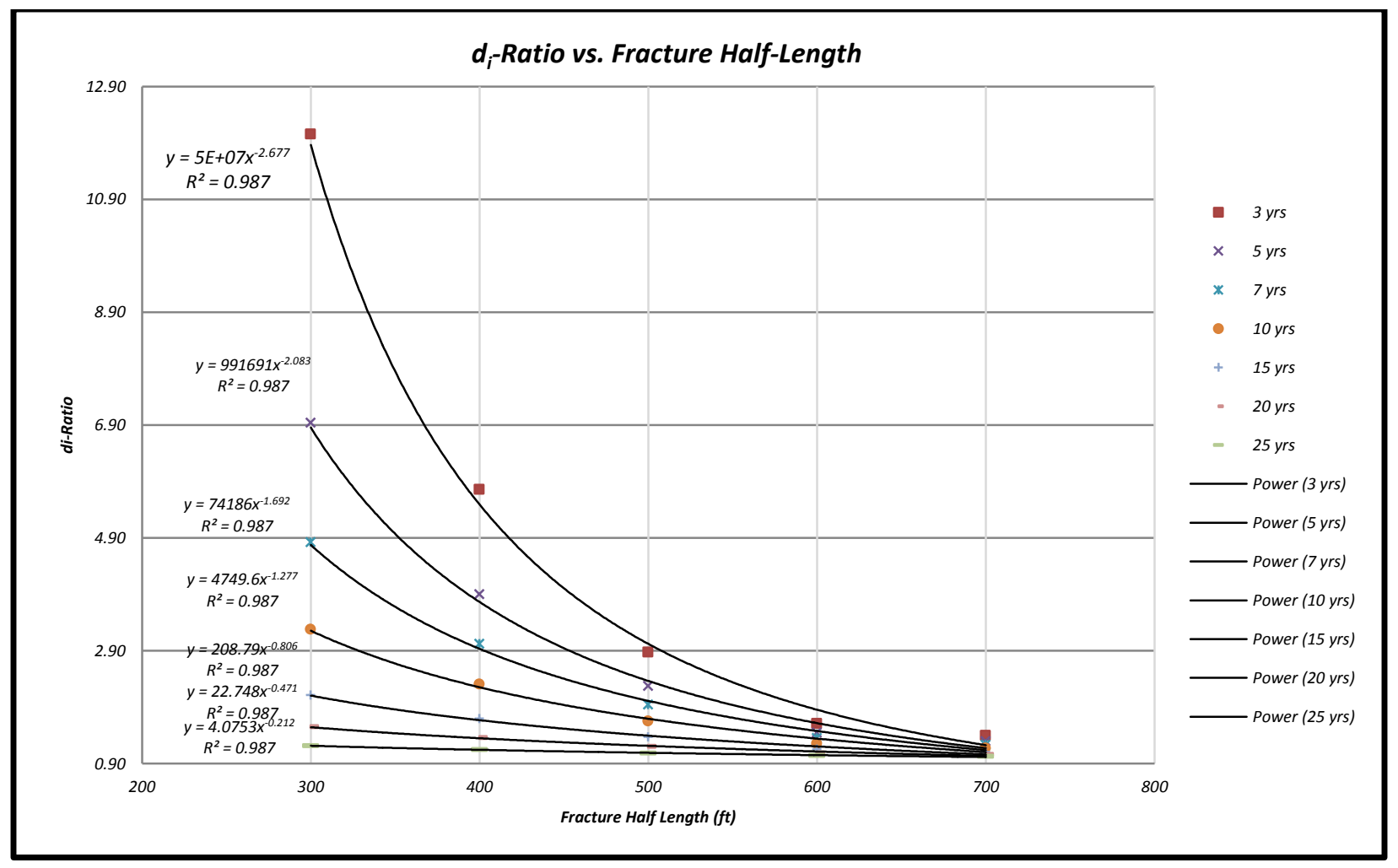

Figure F-2: $d_{i}$-Ratio vs. Fracture Half-length - 7 Stages

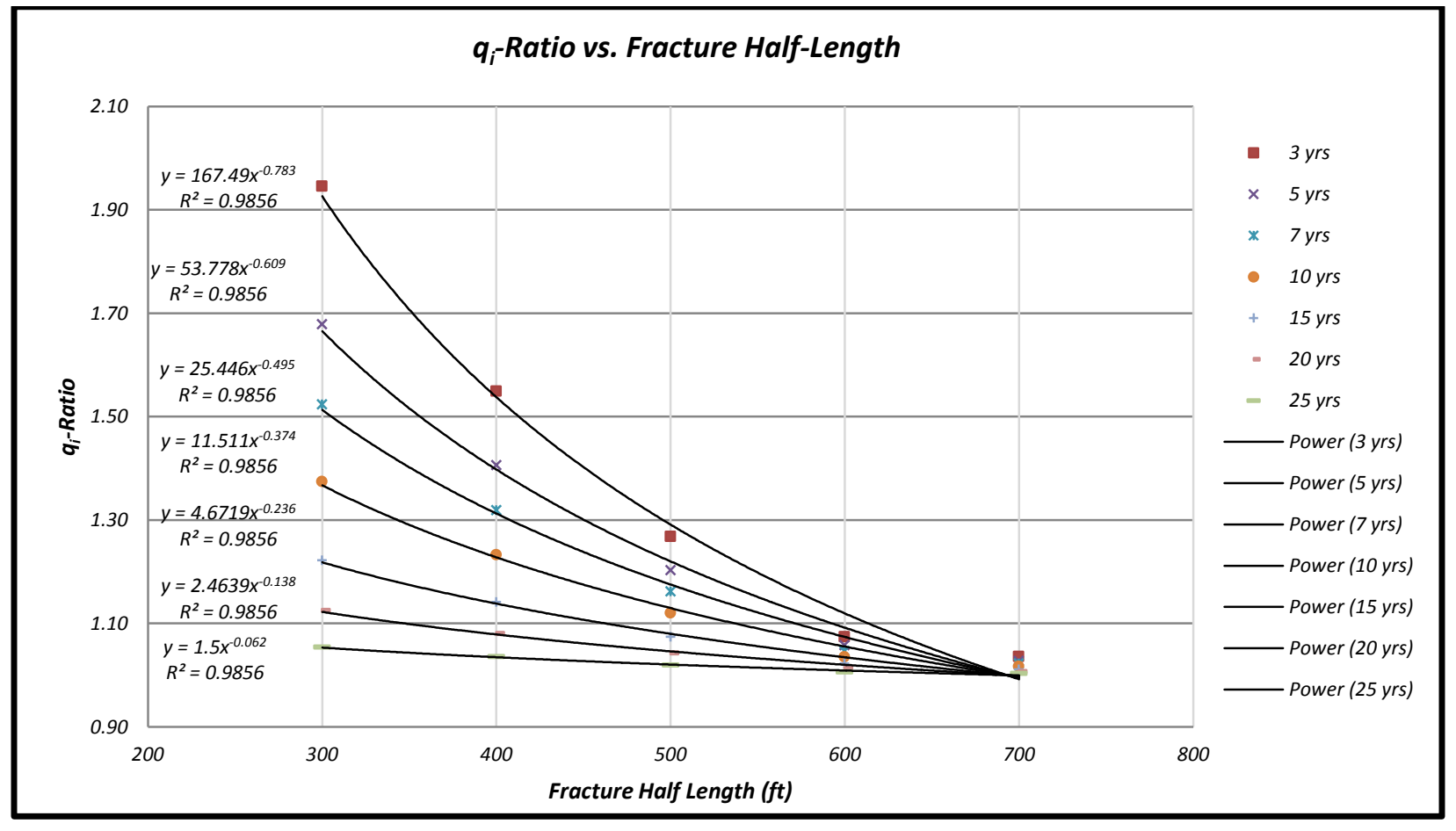

Figure F-3: qi-Ratio vs. Fracture Half-length - 7 Stages 


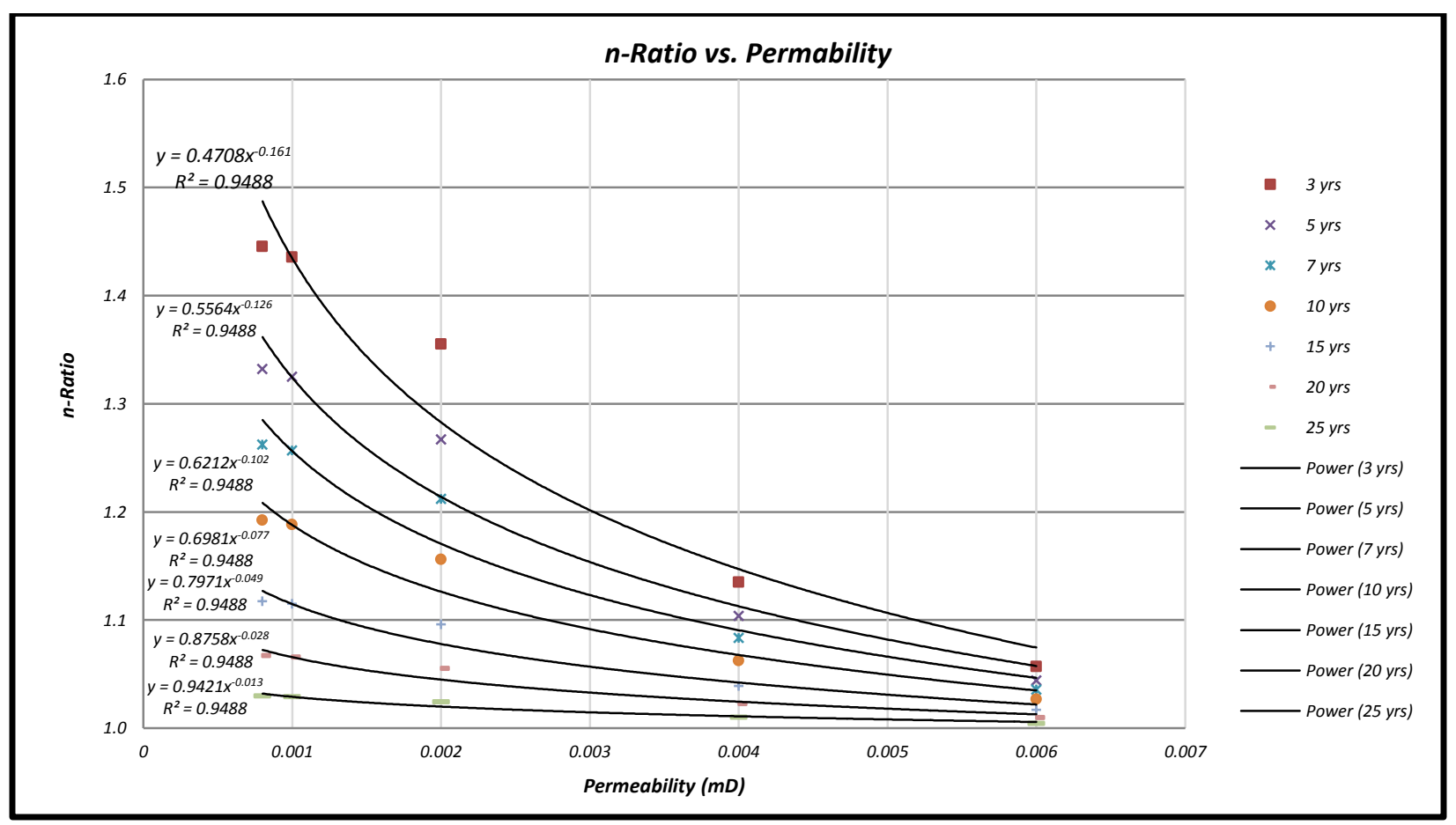

Figure F-4: n-Ratio vs. Permeability- 7 Stages

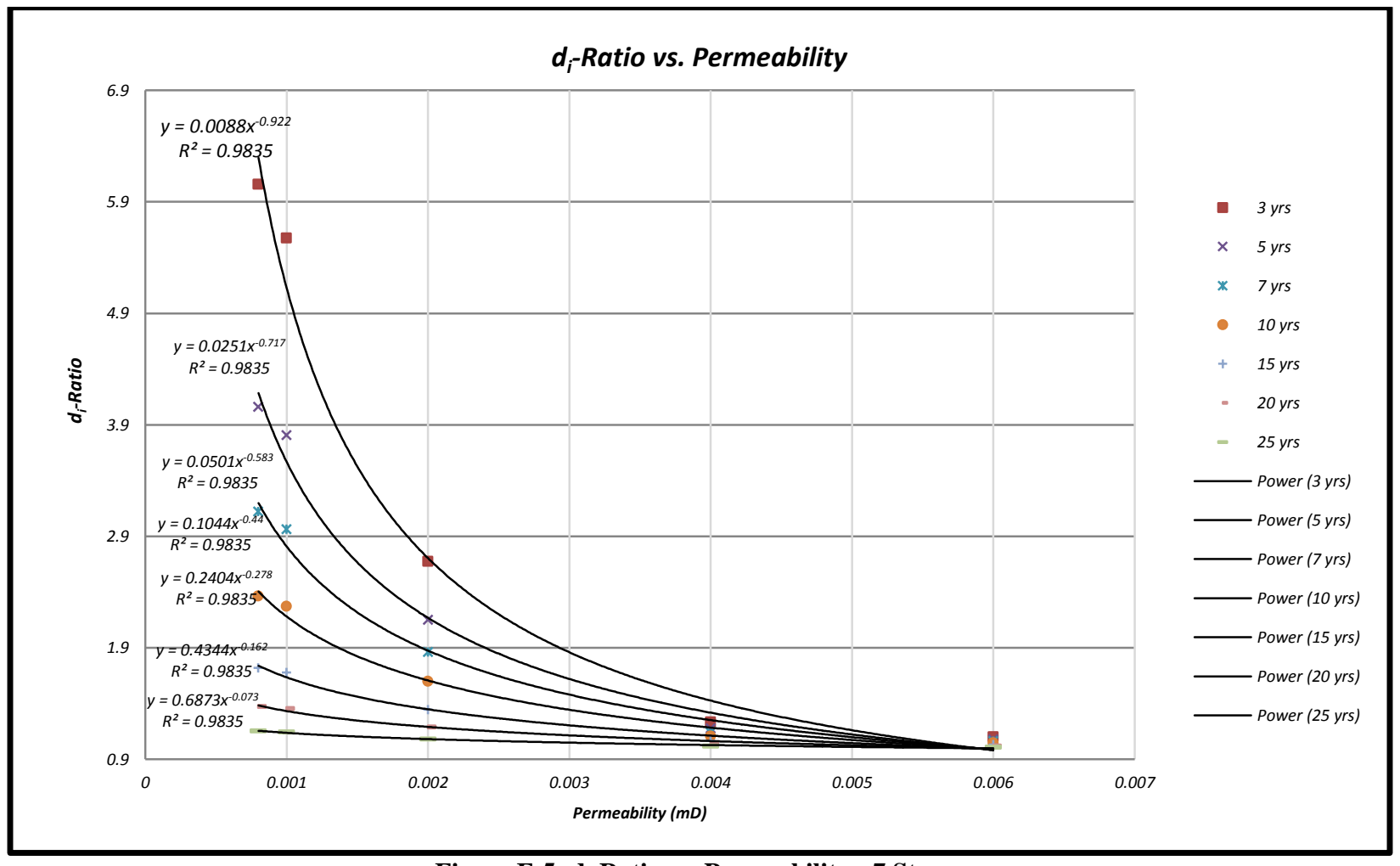

Figure F-5: $d_{i}$-Ratio vs. Permeability - 7 Stages 


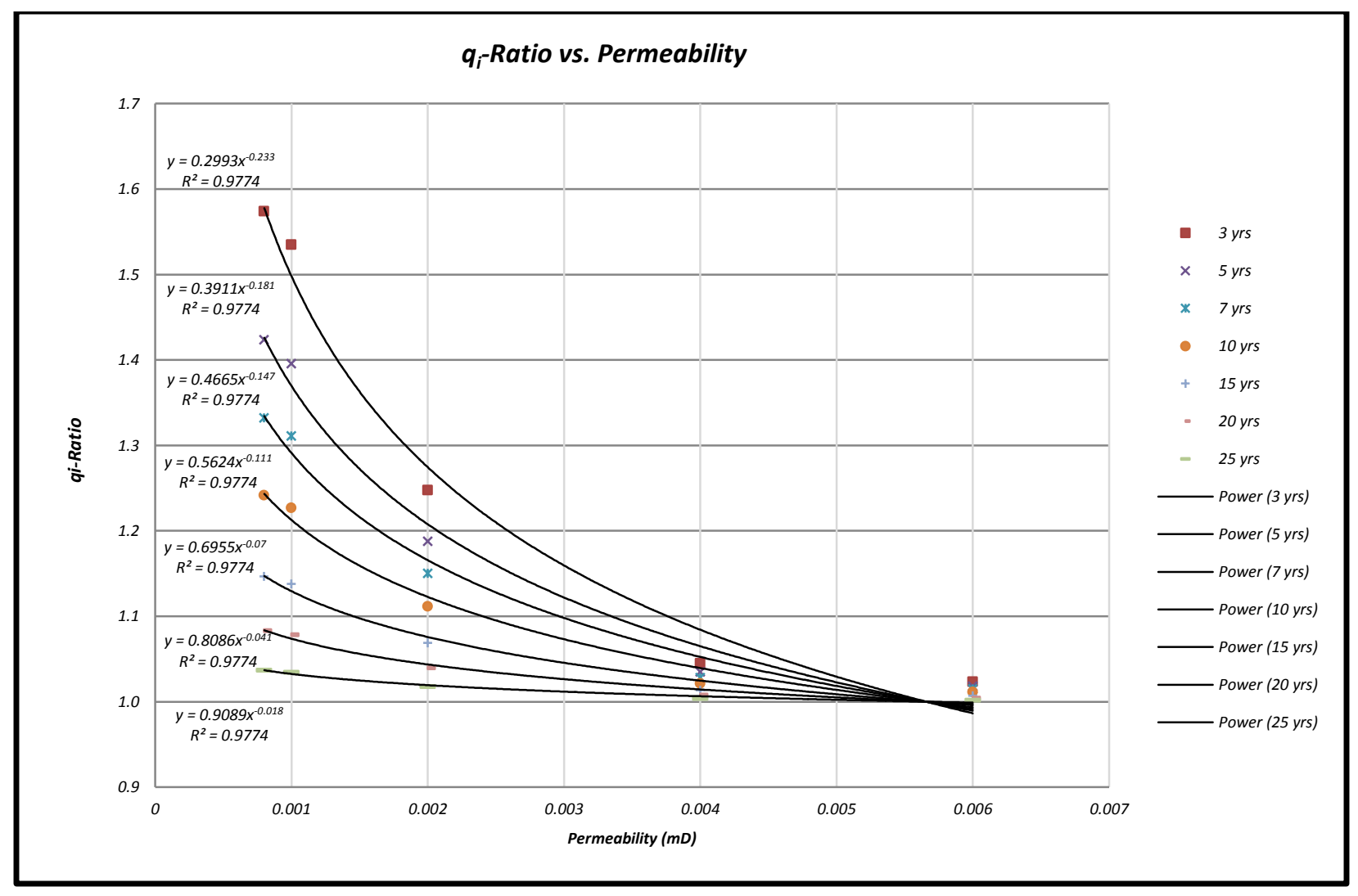

Figure F-6: qi-Ratio vs. Permeability - 7 Stages 


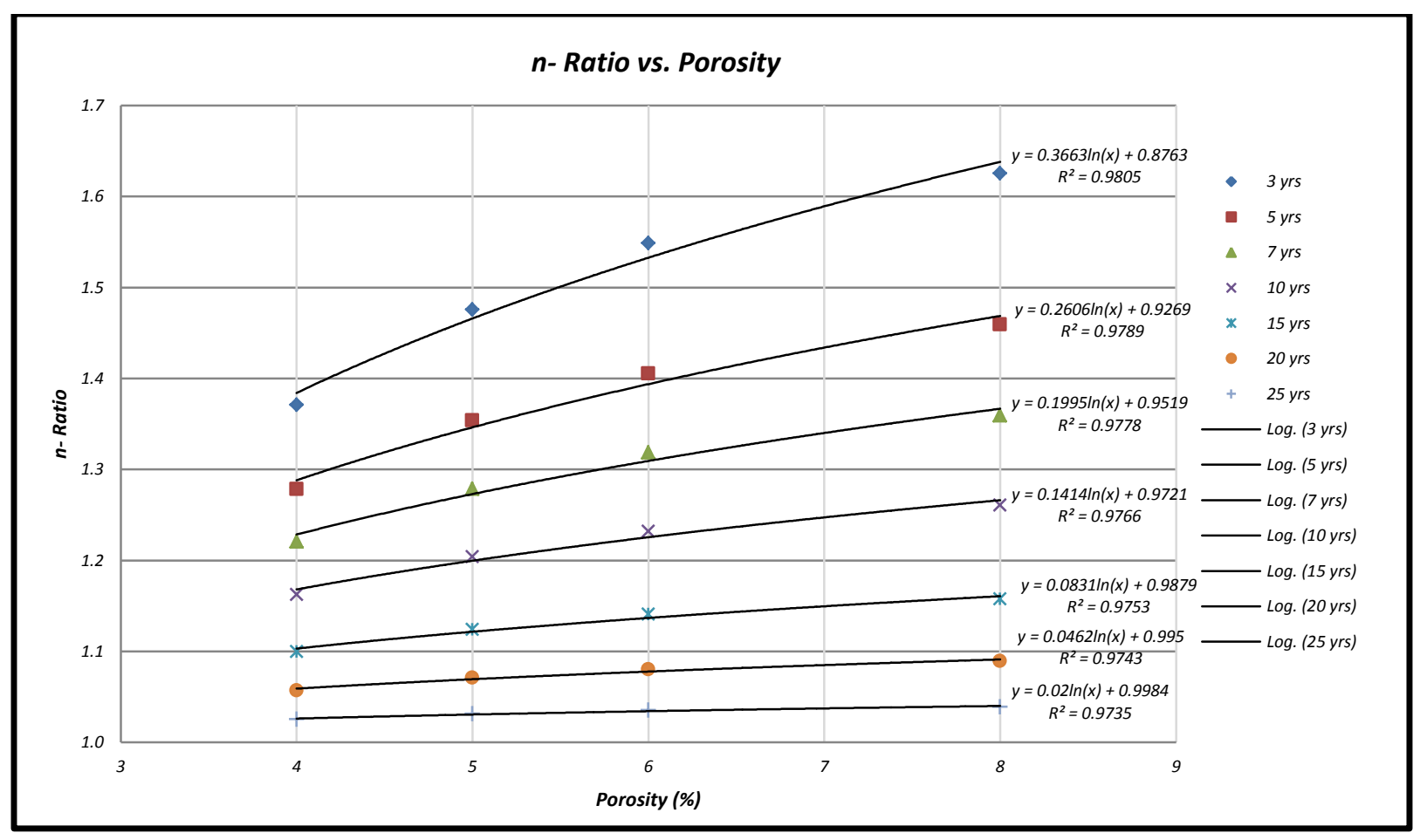

Figure F-7: n-Ratio vs. Porosity- 7 Fractures

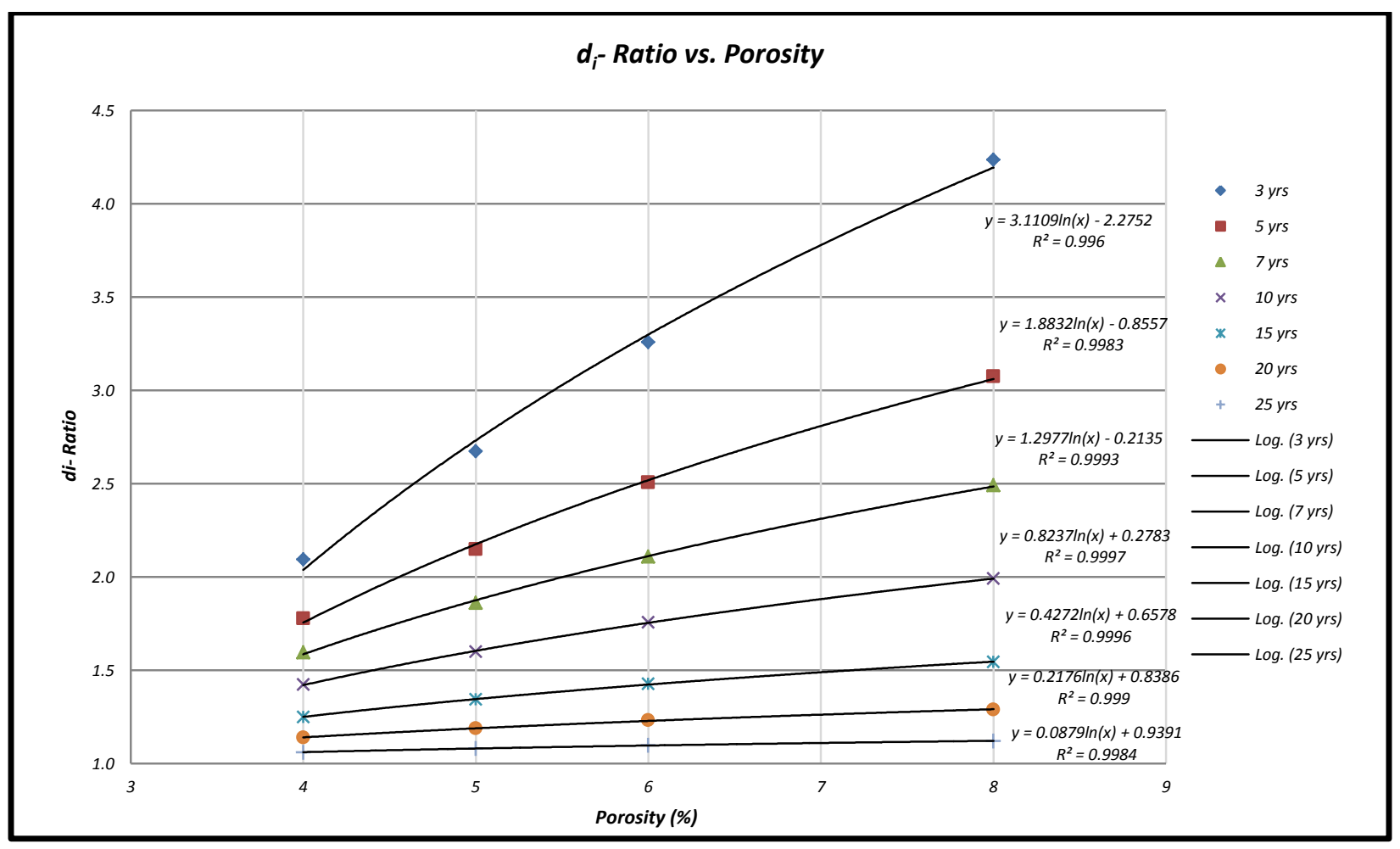

Figure F-8: $d_{i}$-Ratio vs. Porosity-- 7 Fractures 


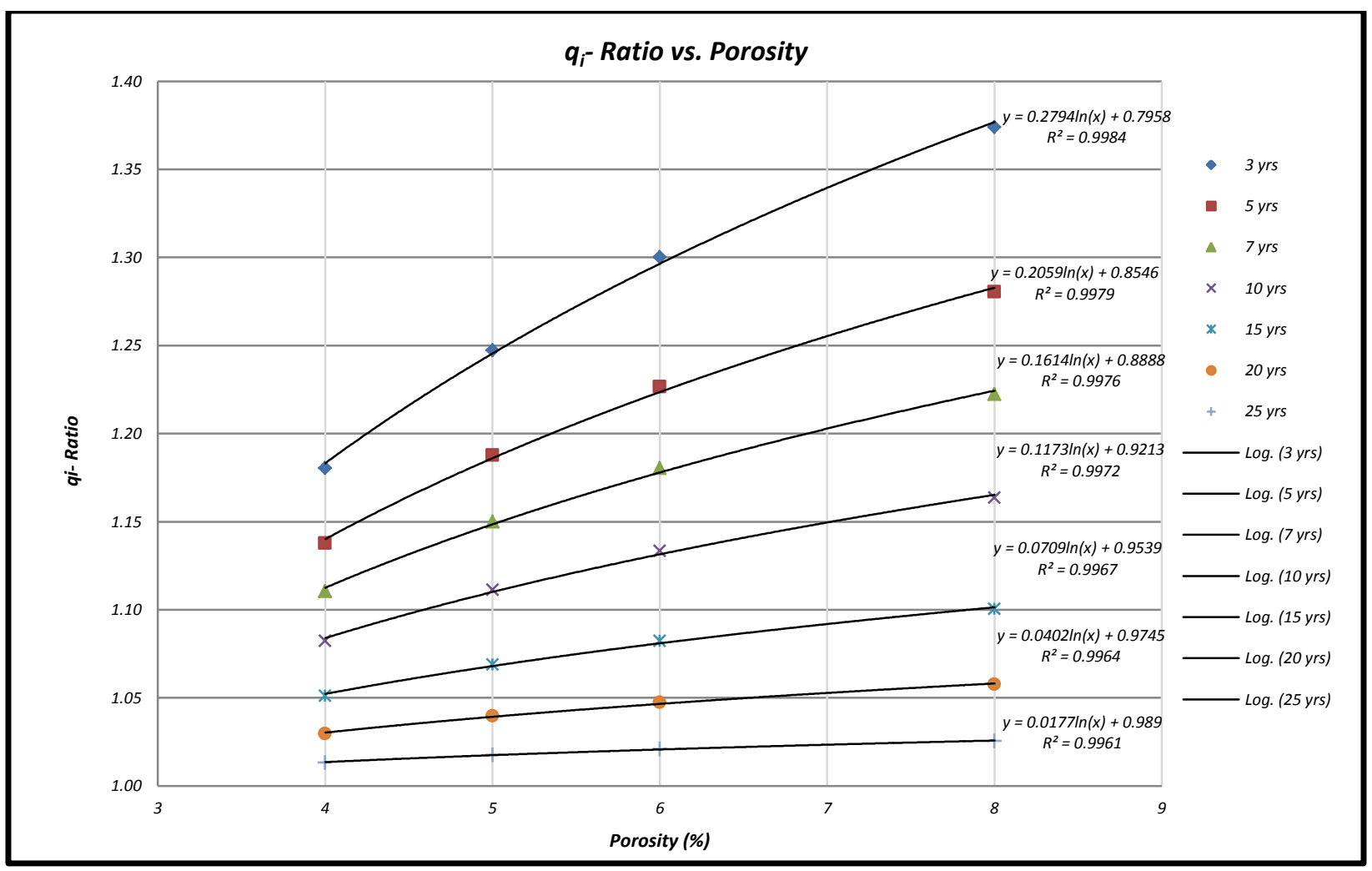

Figure F-9: $q_{i}$-Ratio vs. Porosity - 7 Fractures 


\section{F.1.2. Duong Decline Curve Analysis}

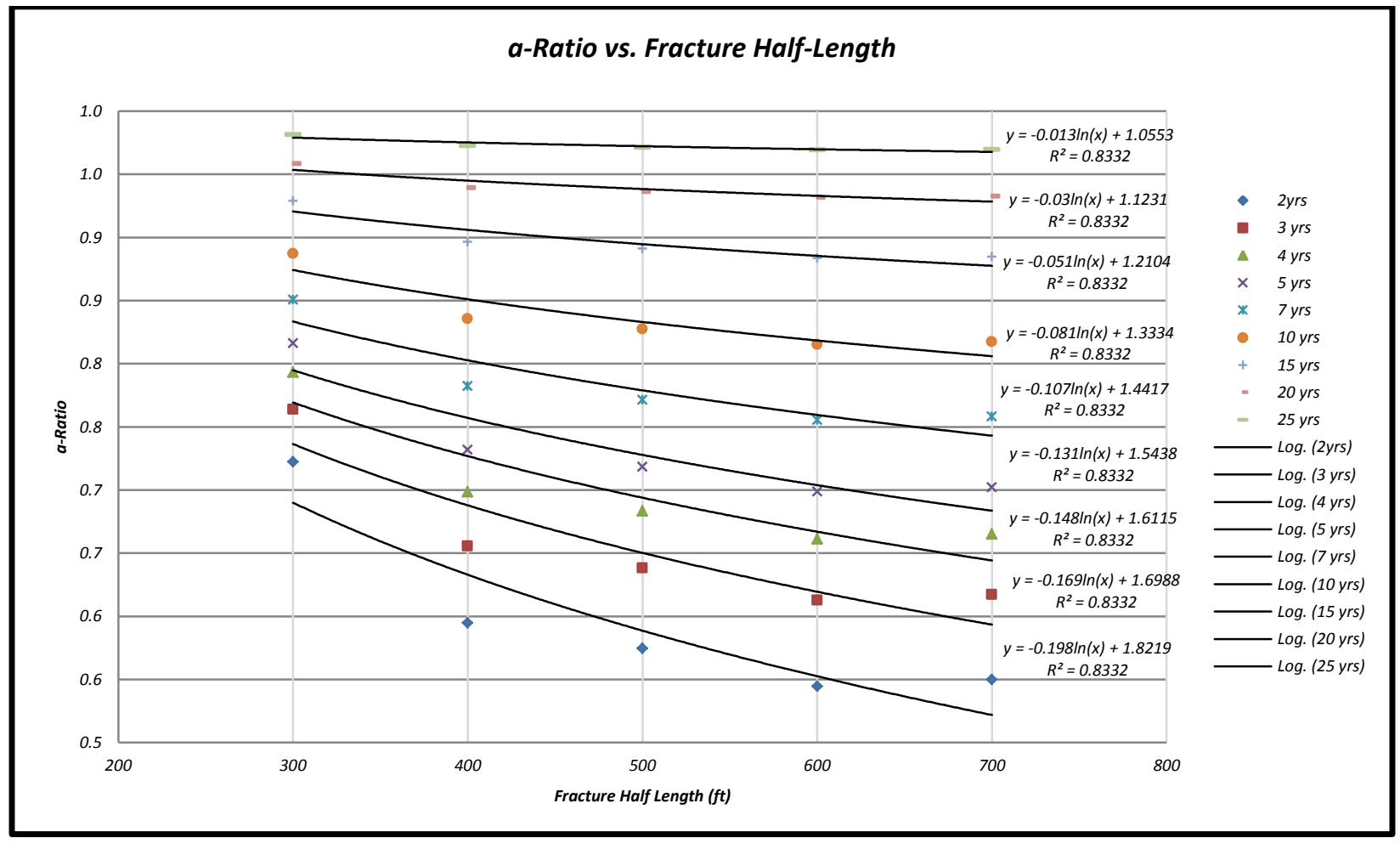

Figure F-10: a-Ratio vs. Fracture Half Length - 7 Stages

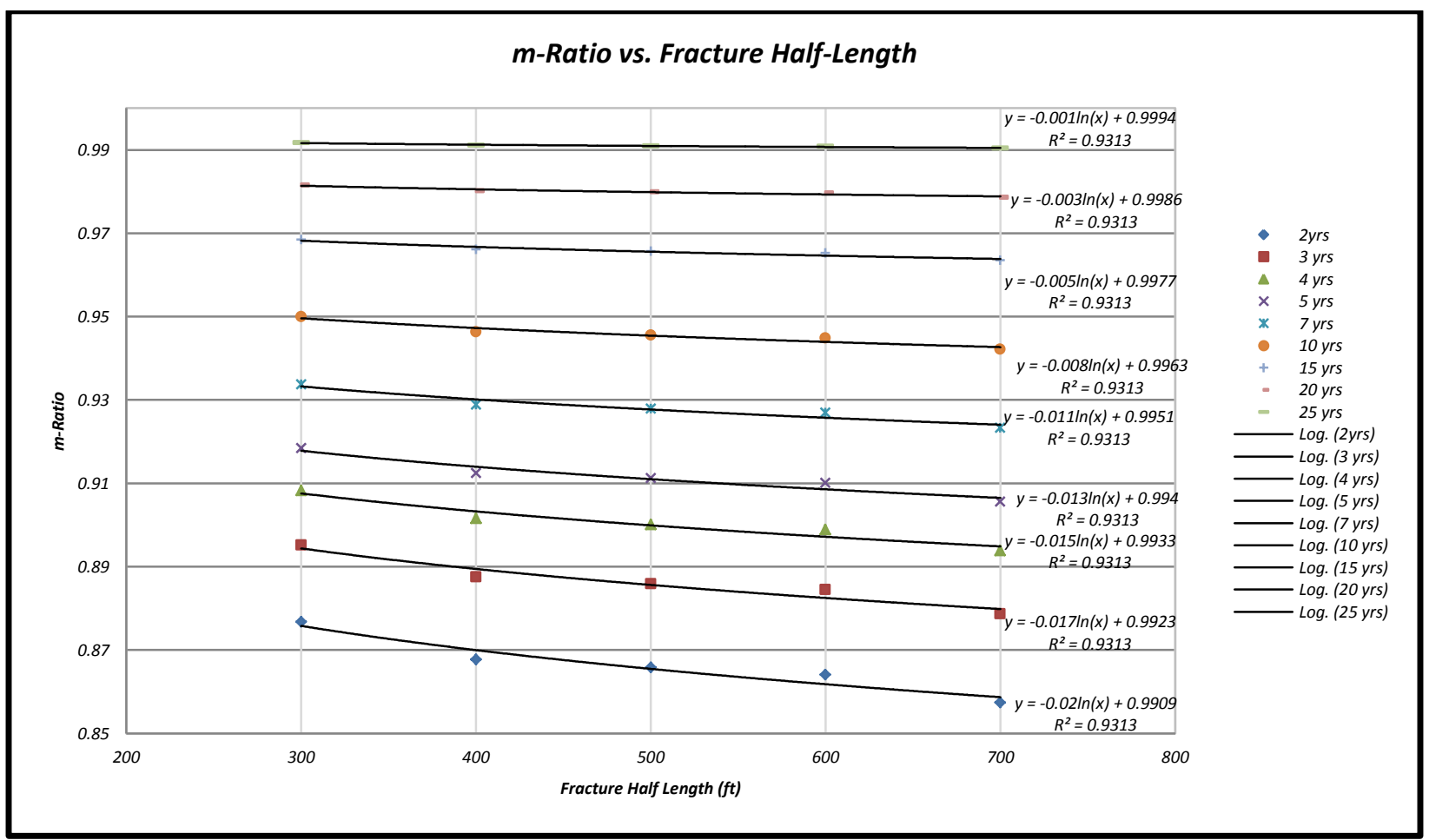

Figure F-11: m-Ratio vs. Fracture half-length- 7 Stages 


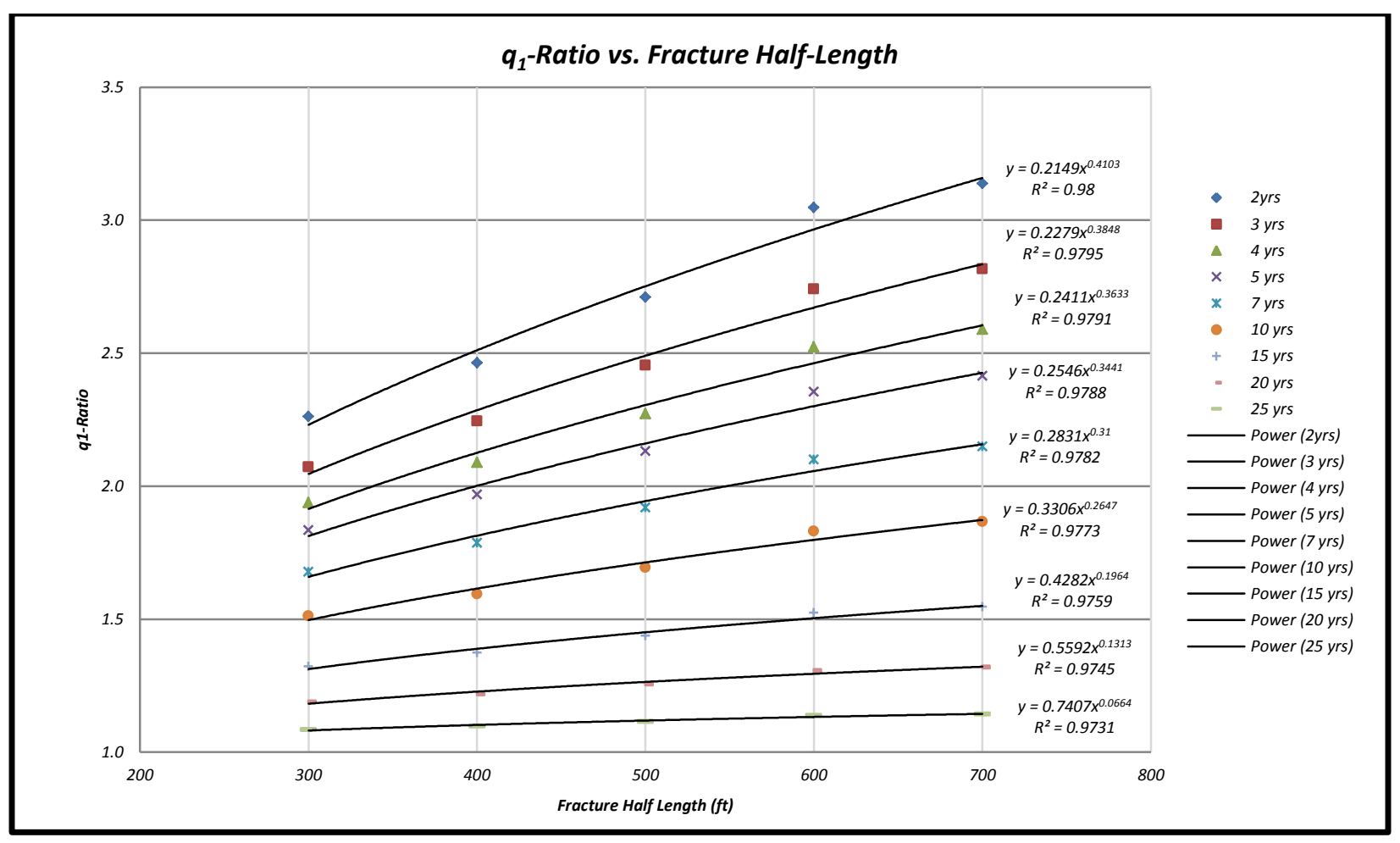

Figure F-12: q1-Ratio vs. Fracture Half Length- 7 Stages

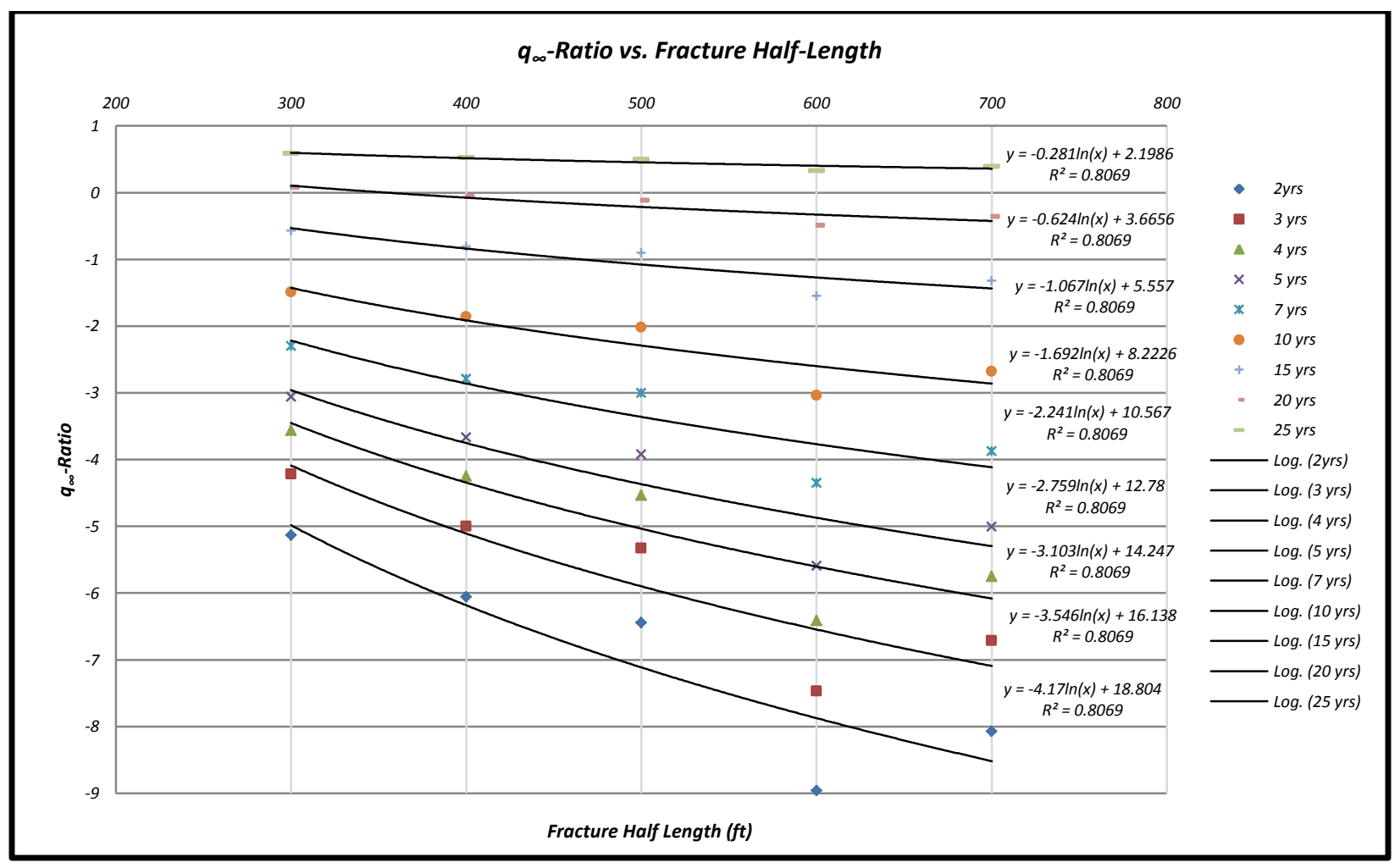

Figure F-13: $q_{\infty}$ vs. Fracture Half Length- 7 Stages 


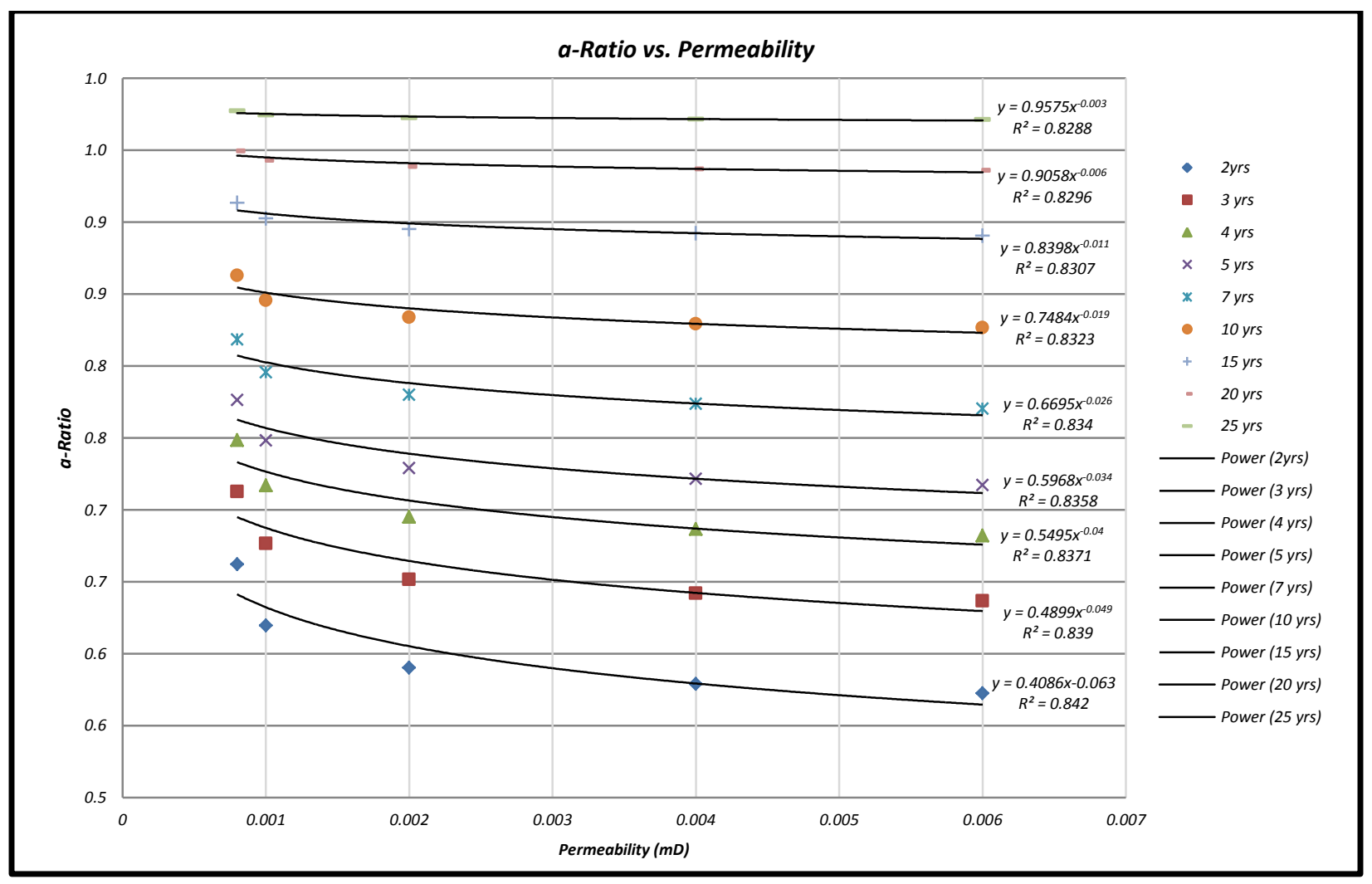

Figure F-14: a-Ratio vs. Permeability - 7 Stages

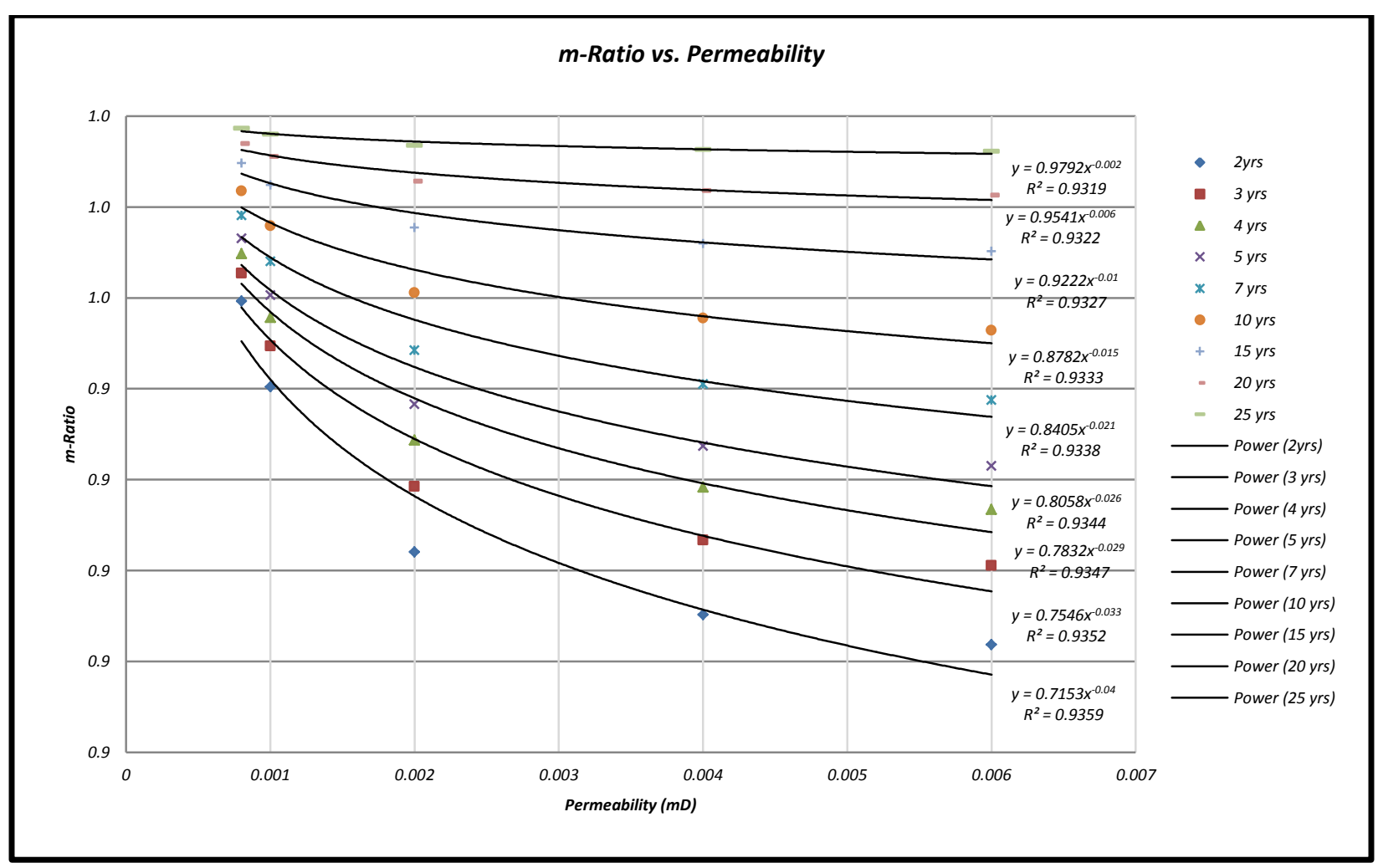

Figure F-15: m-Ratio vs. Permeability - 7 Stages 


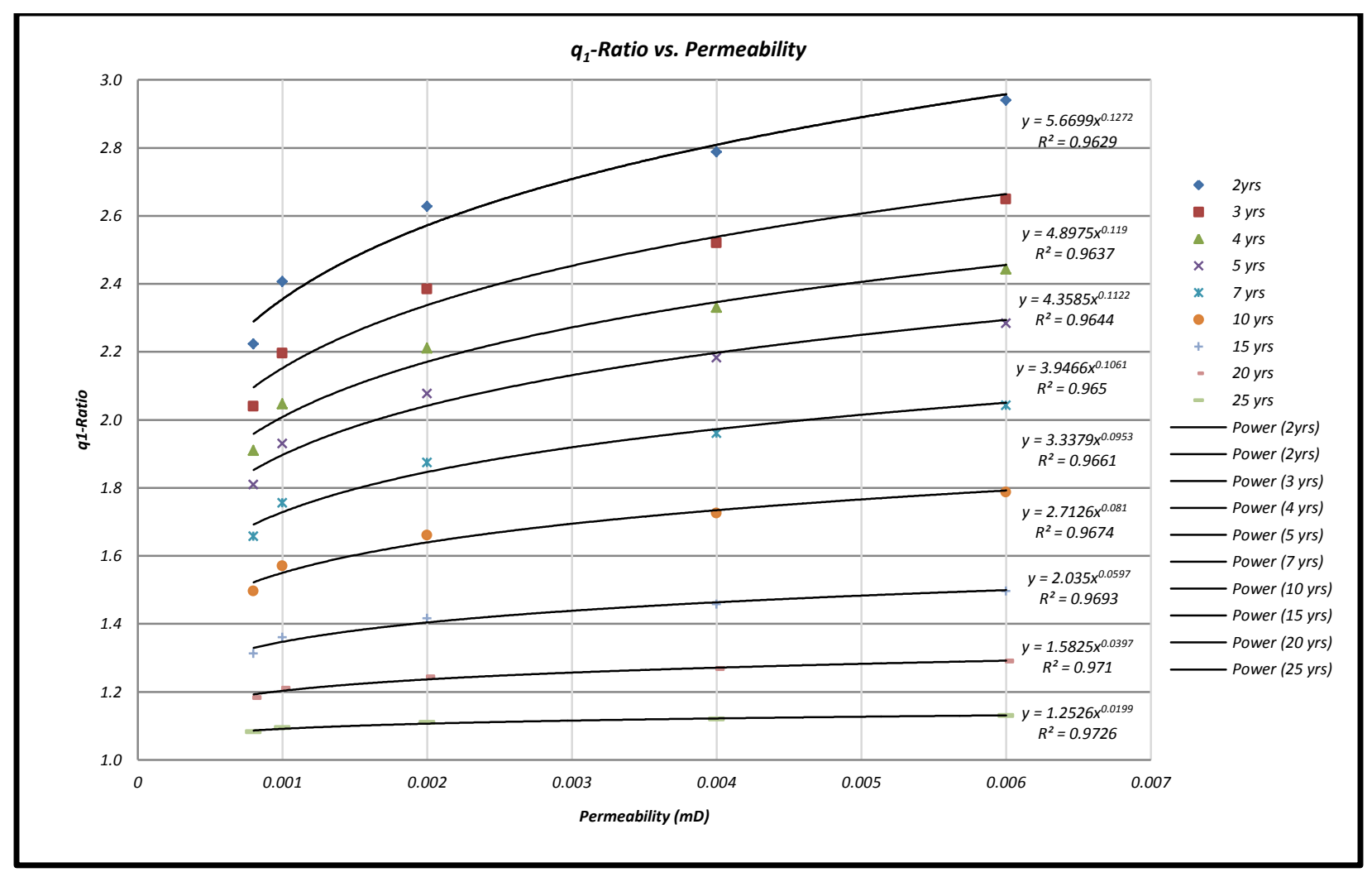

Figure F-16: $q_{1}$-Ratio vs. Permeability - 7 Stages

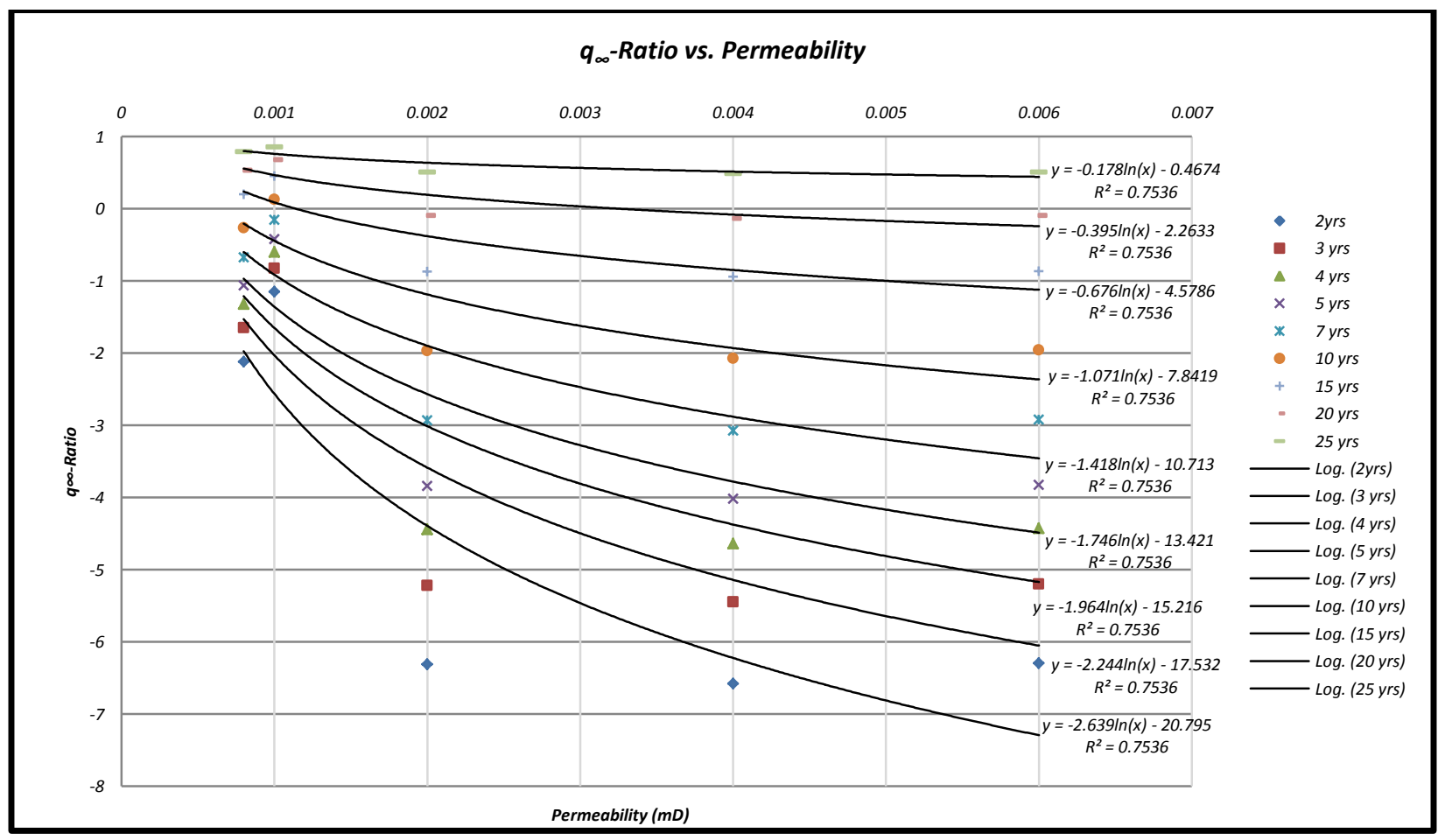

Figure F-17: $q_{\infty}$-Ratio vs. Permeability - 7 Stages 


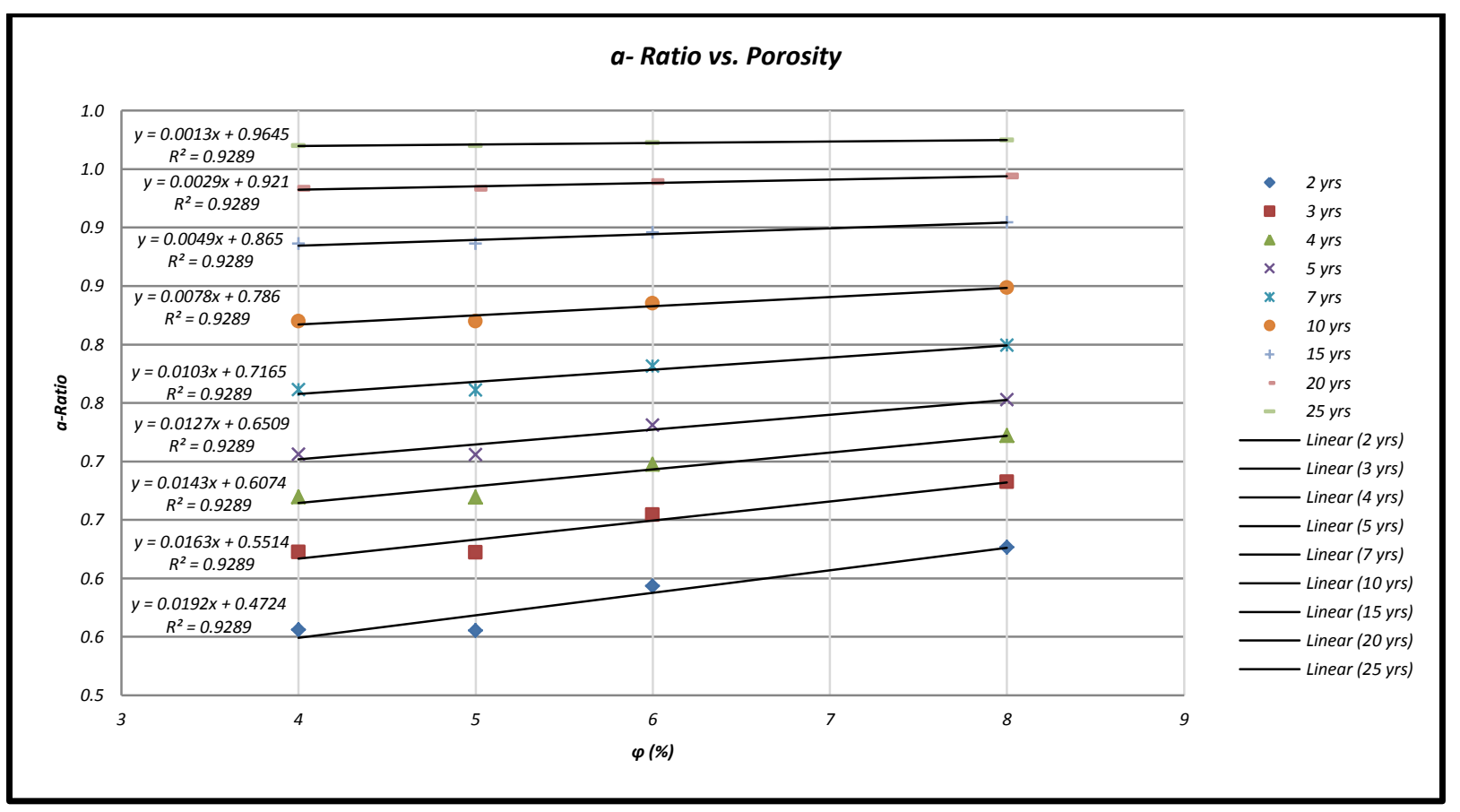

Figure F-18: a-Ratio vs. Porosity - 7 Stages

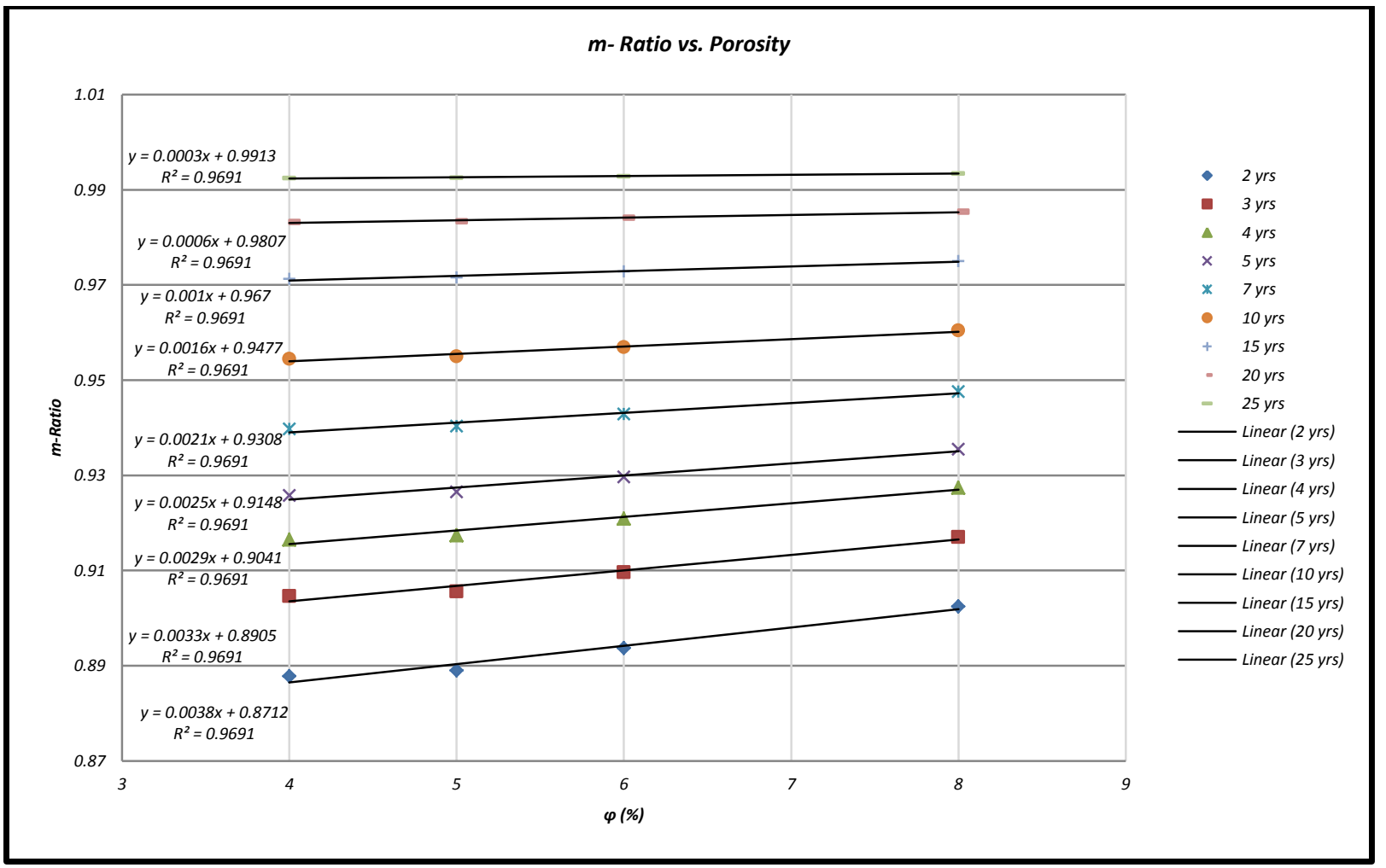

Figure F-19: m-Ratio vs. Porosity - 7 Stages 


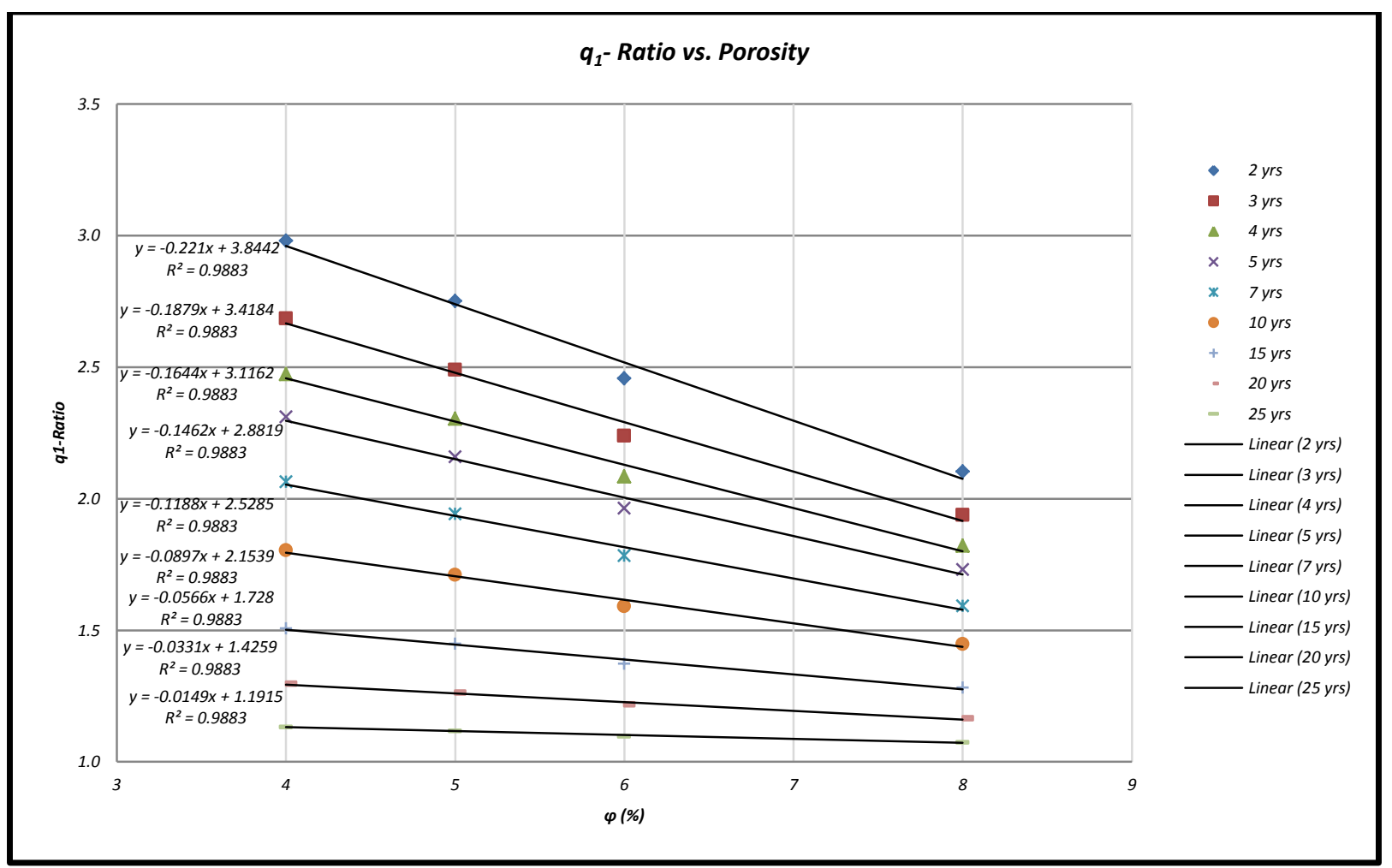

Figure F-20: $q_{1}-$ Ratio vs. Porosity - 7 Stages

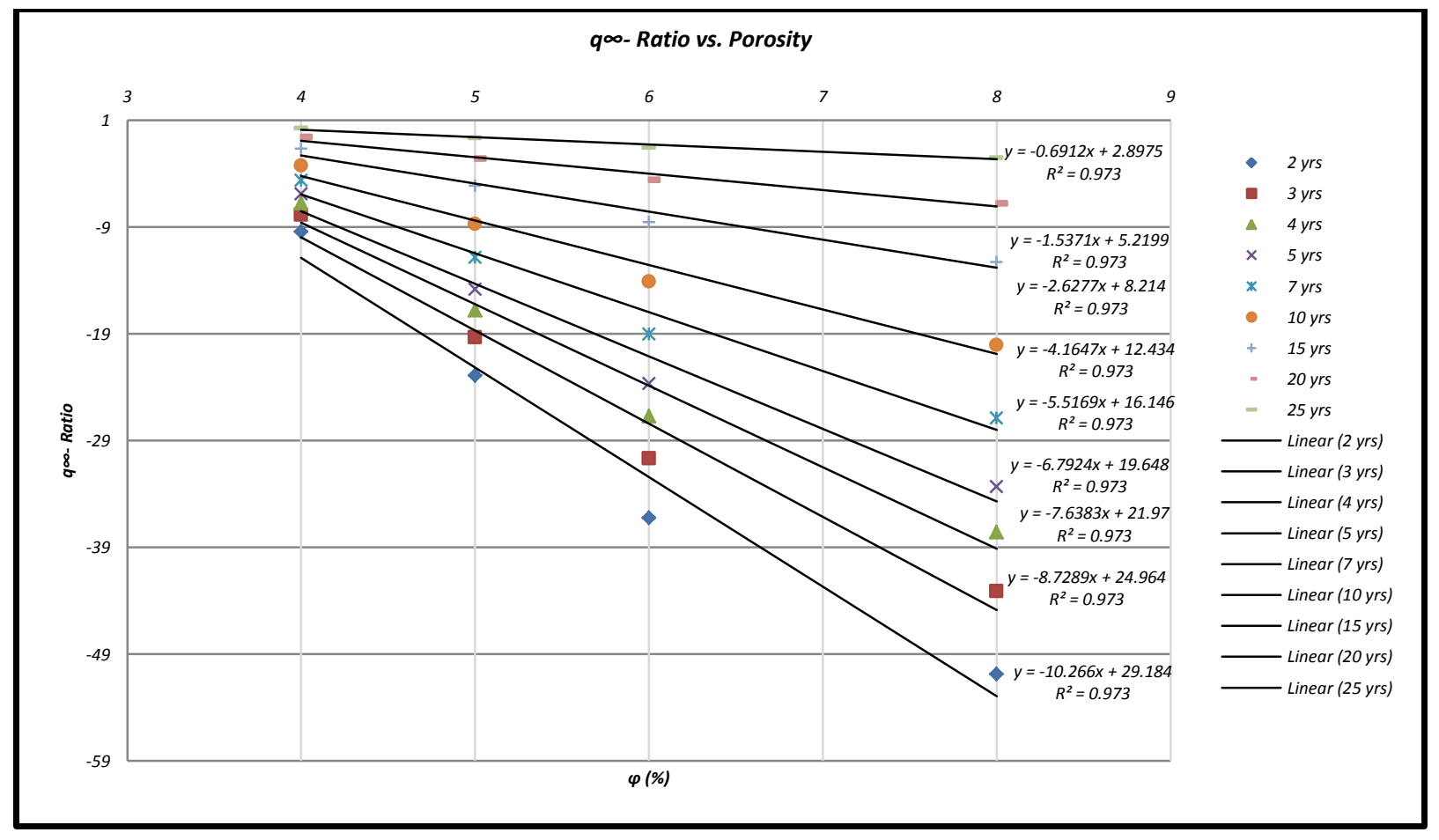

Figure F-21: $q_{\infty}$ - Ratio vs. Porosity - 7 Stages 


\section{F.2. Thirteen Stages Model}

\section{F.2.1. Arps Decline Curve Analysis}

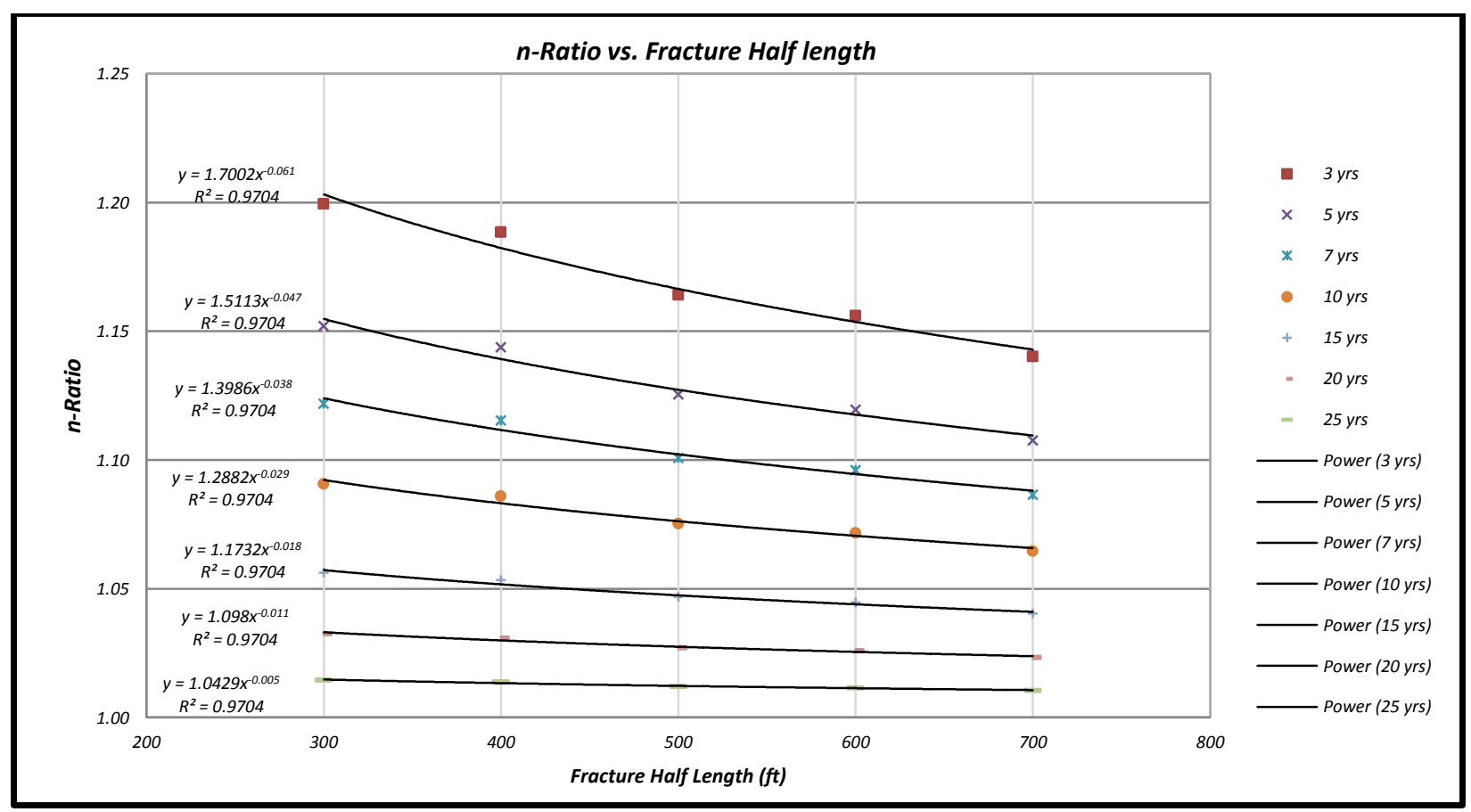

Figure F-22: n-Ratio vs. Fracture Half-length- 13 Stages

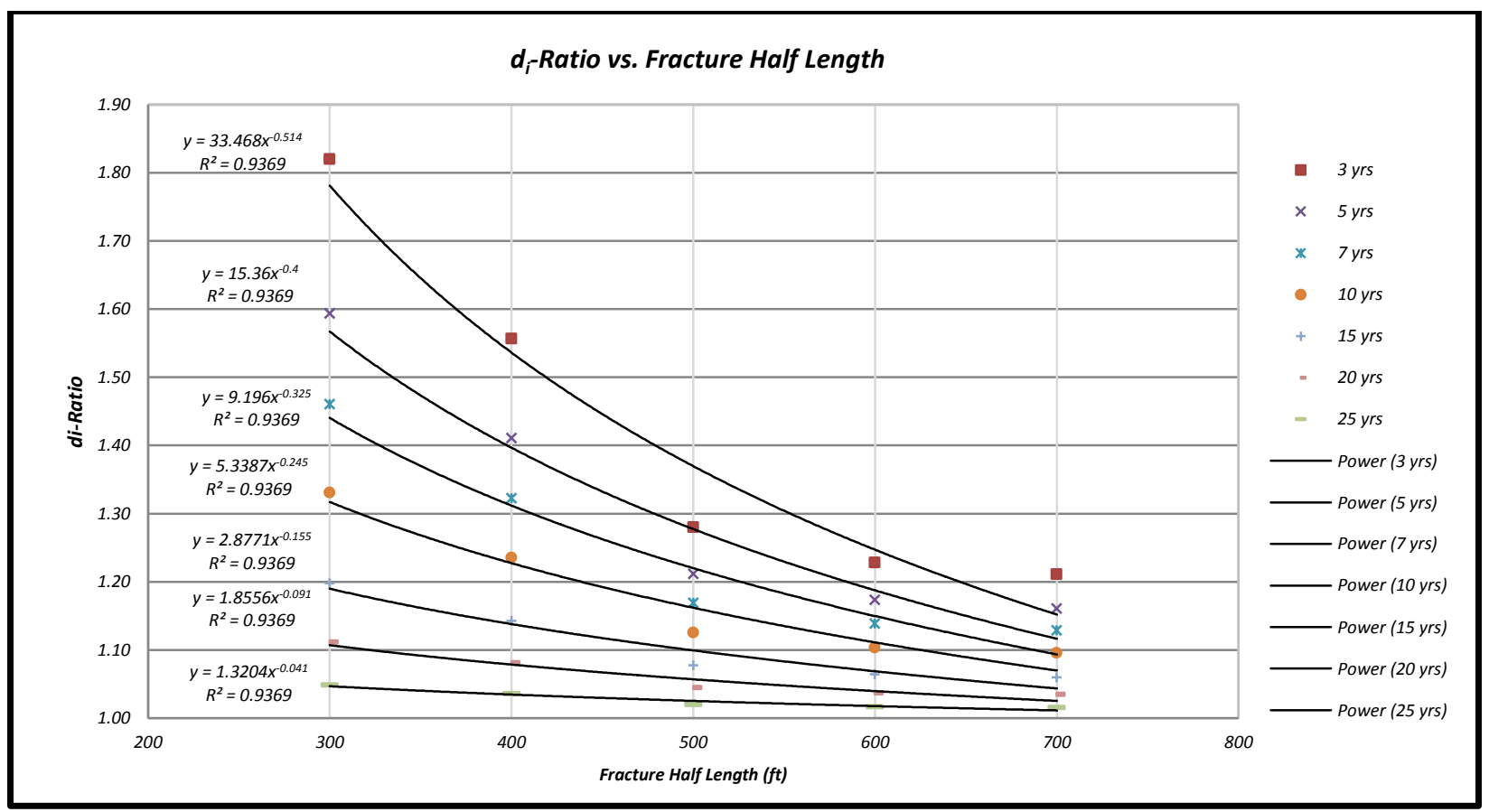

Figure F-23: $d_{i}$-Ratio vs. Fracture Half-length - 13 Stages 


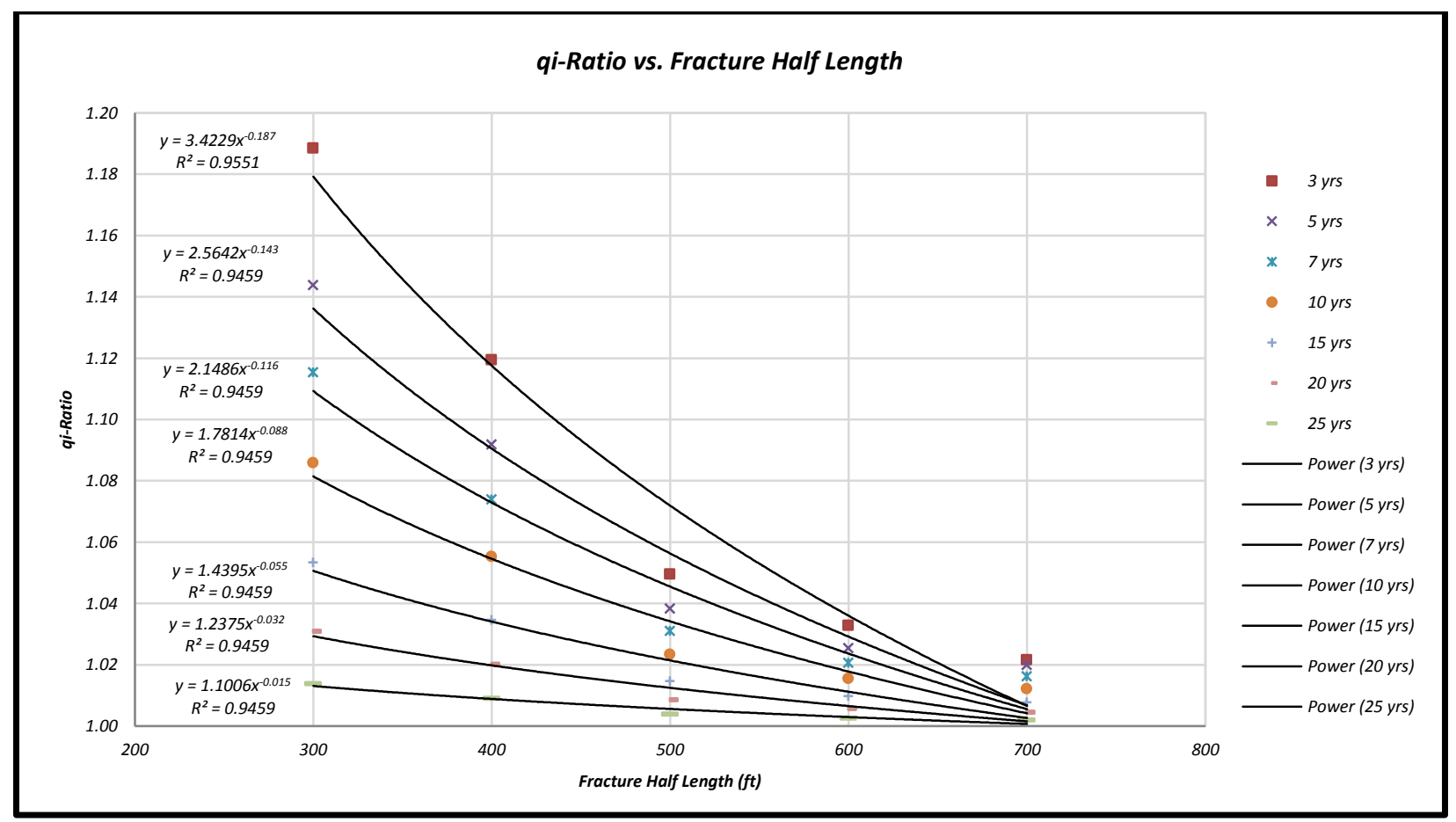

Figure F-24: $q_{i}$-Ratio vs. Fracture Half-length - 13 Stages 


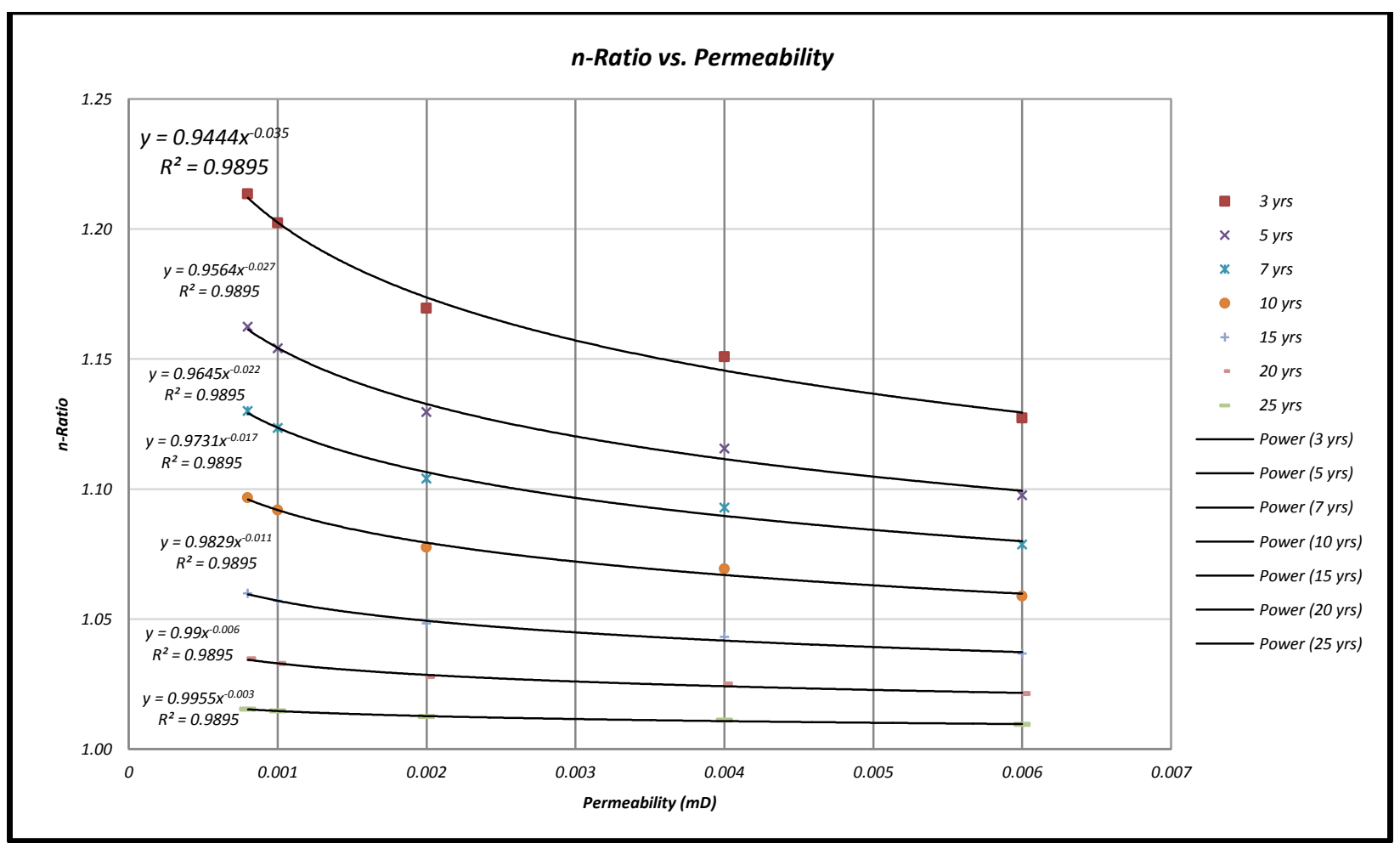

Figure F-25: n-Ratio vs. Permeability - 13 Stages

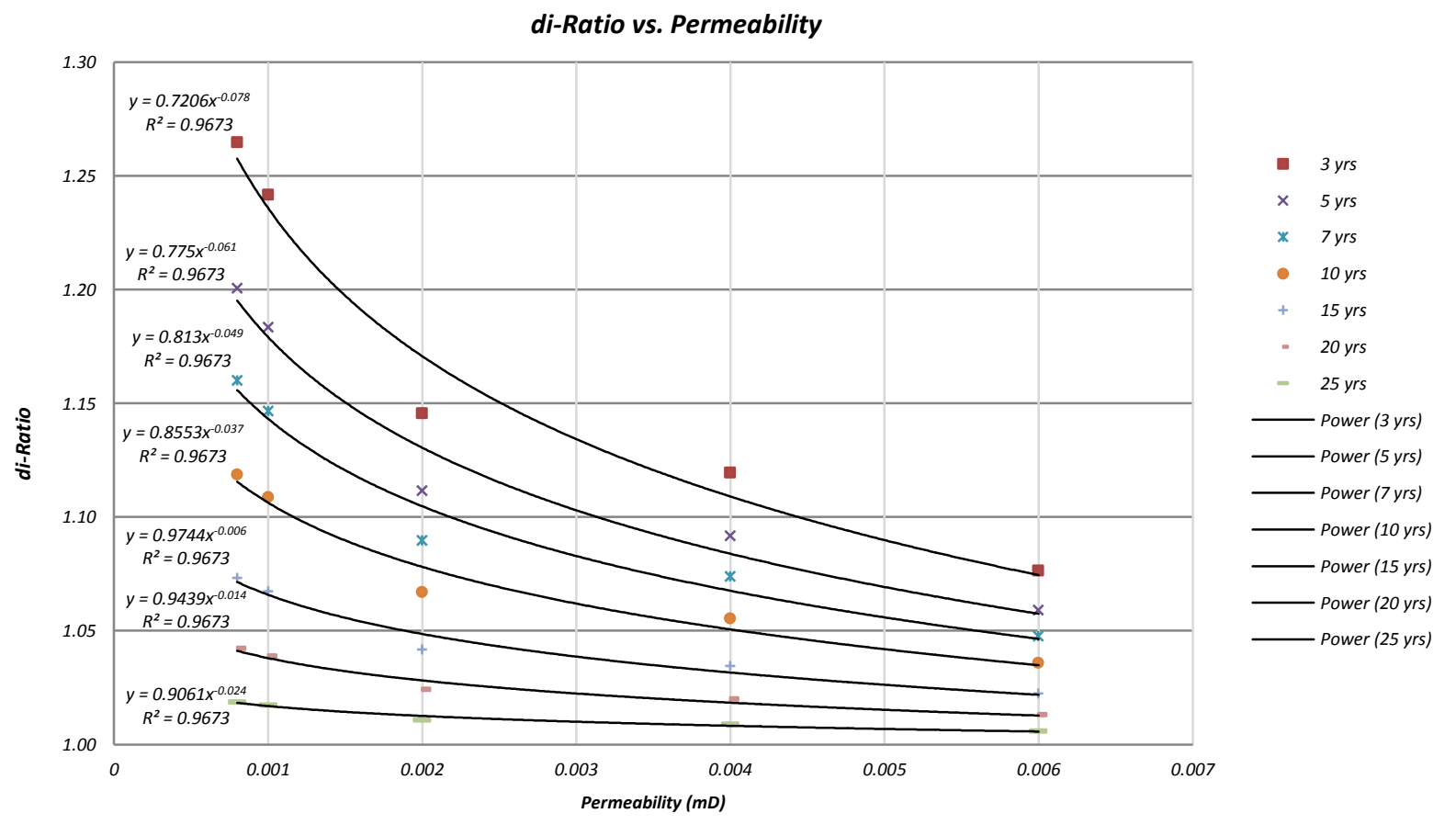

Figure F-26: $d_{i}$-Ratio vs. Permeability - 13 Fractures 


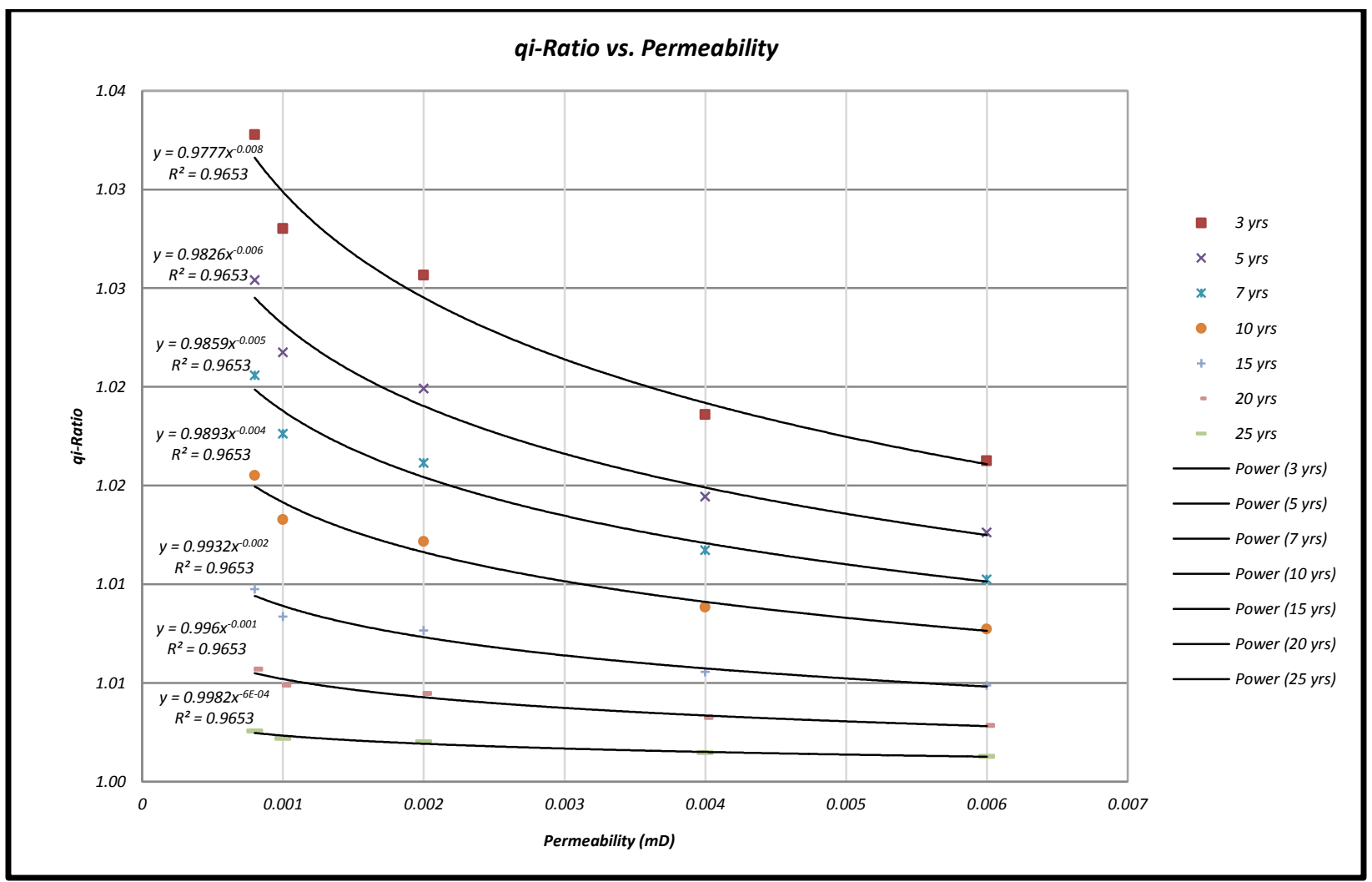

Figure F-27: $q_{\mathrm{i}}$-Ratio vs. Permeability - 13 Stages

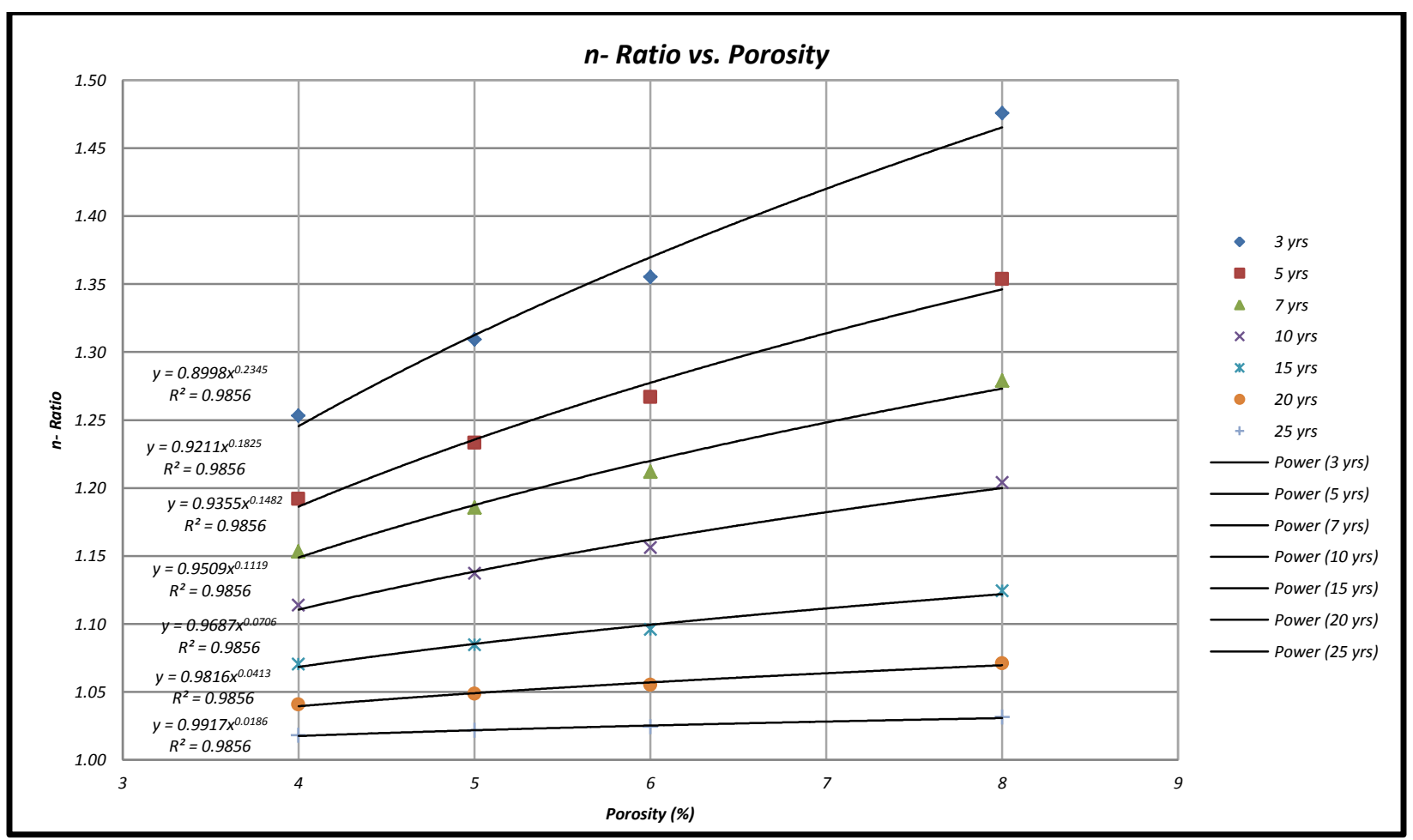

Figure F-28: n-Ratio vs. Porosity - 13 Stages 


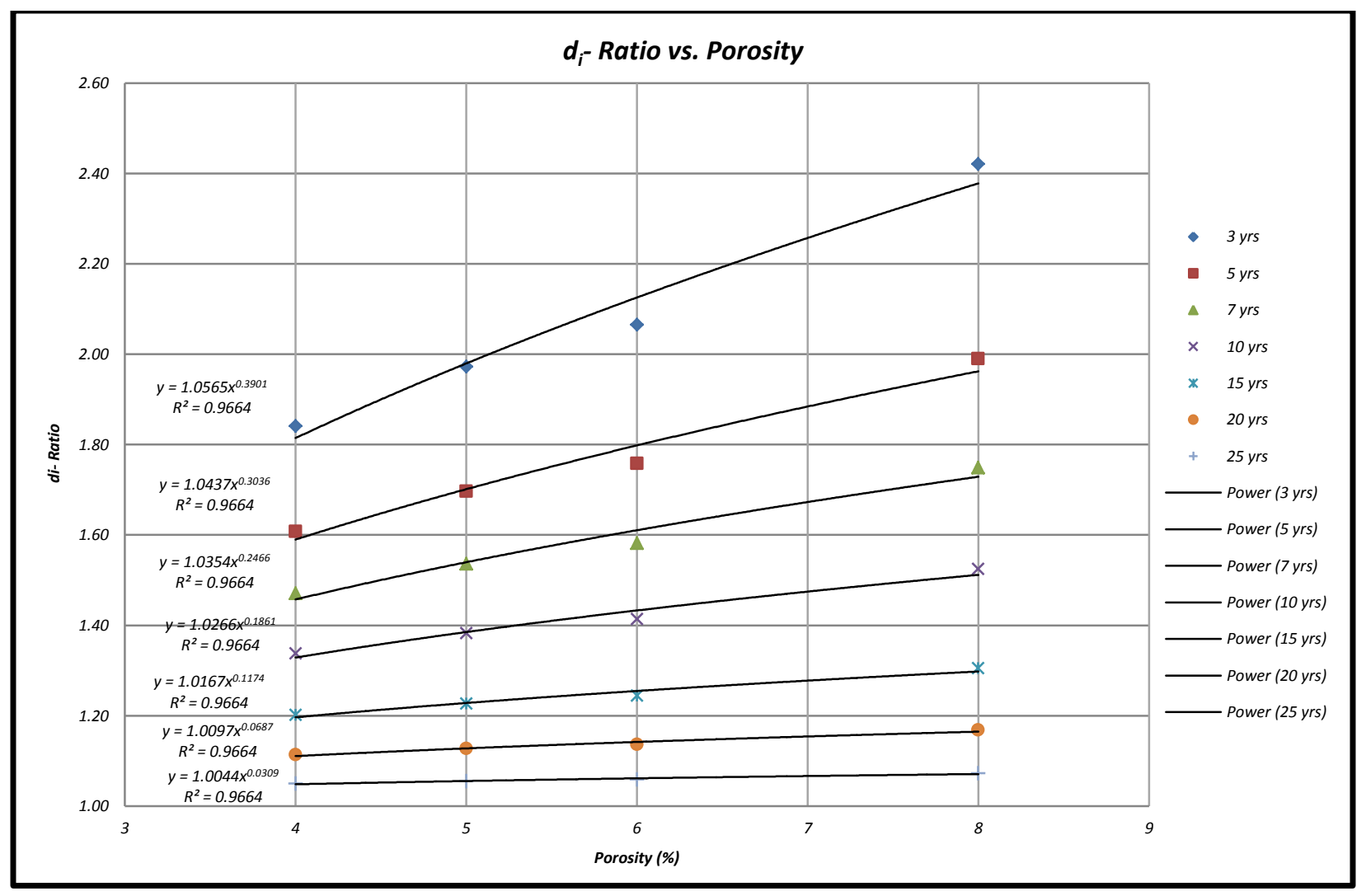

Figure F-29: $d_{i}$-Ratio vs. Porosity - 13 Stages

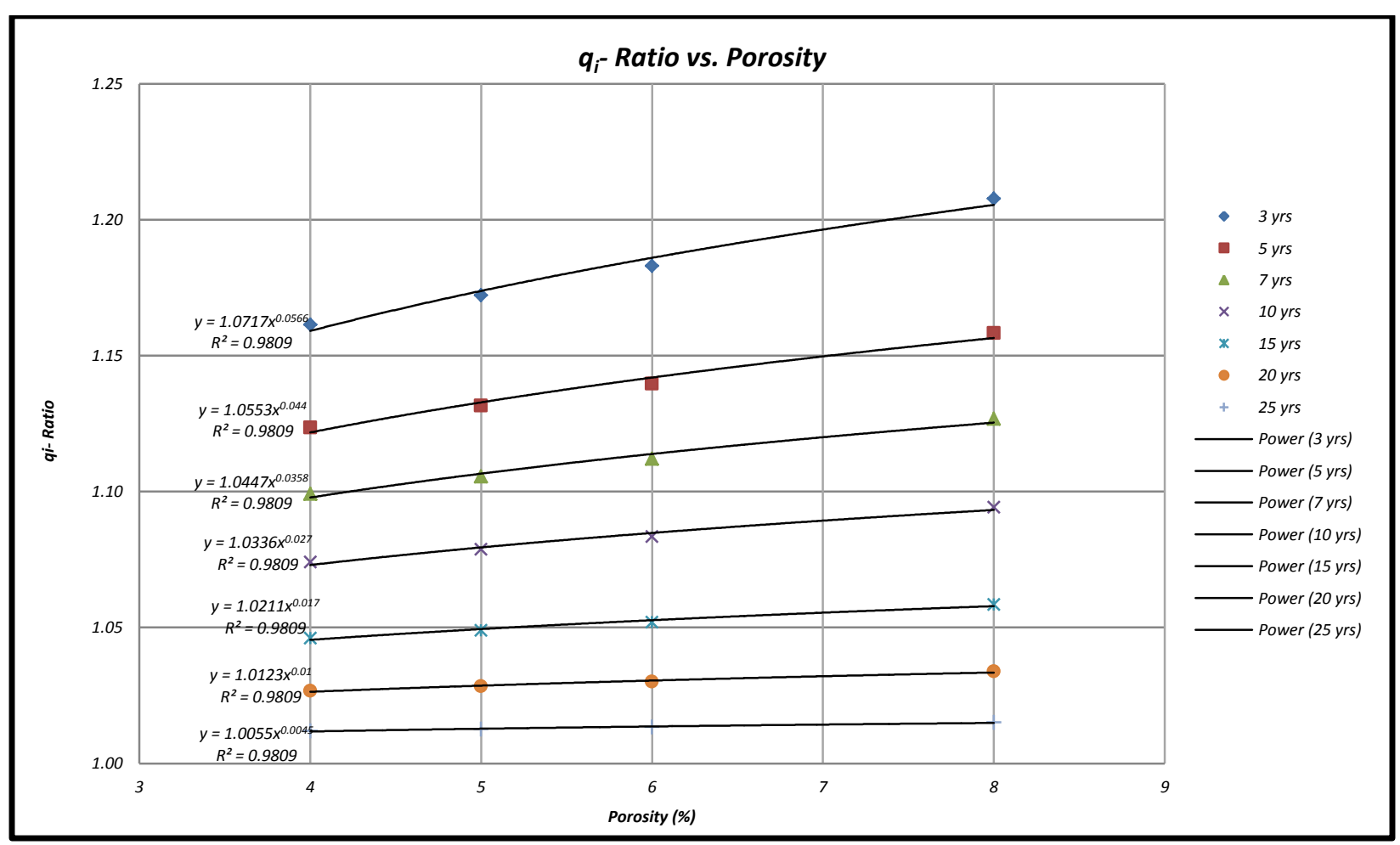

Figure F-30: $q_{i}$-Ratio vs. Porosity - 13 Stages 


\section{F.2.2. Duong Decline Curve Analysis}

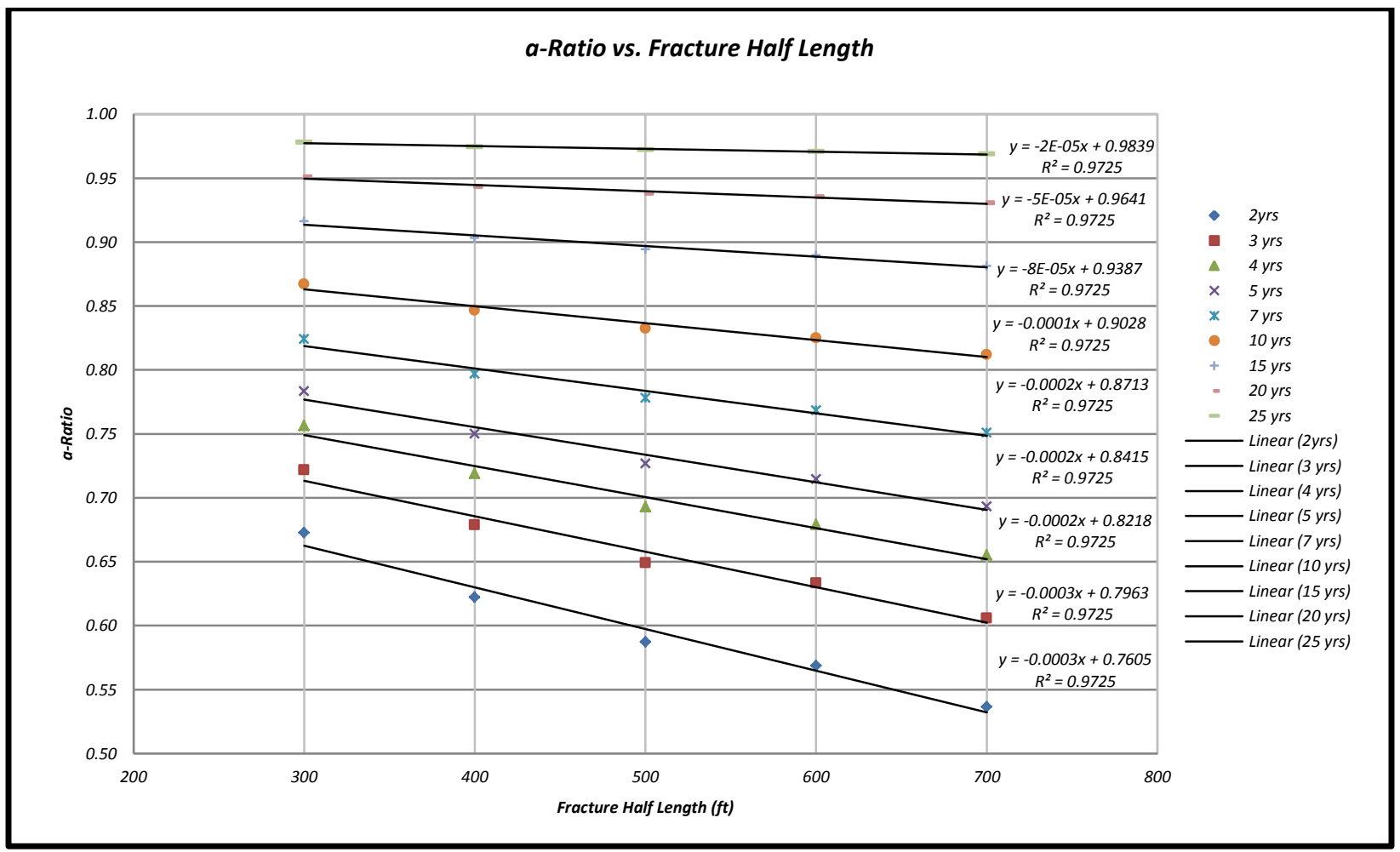

Figure F-31: a-Ratio vs. Fracture half-Length - 13 Stages

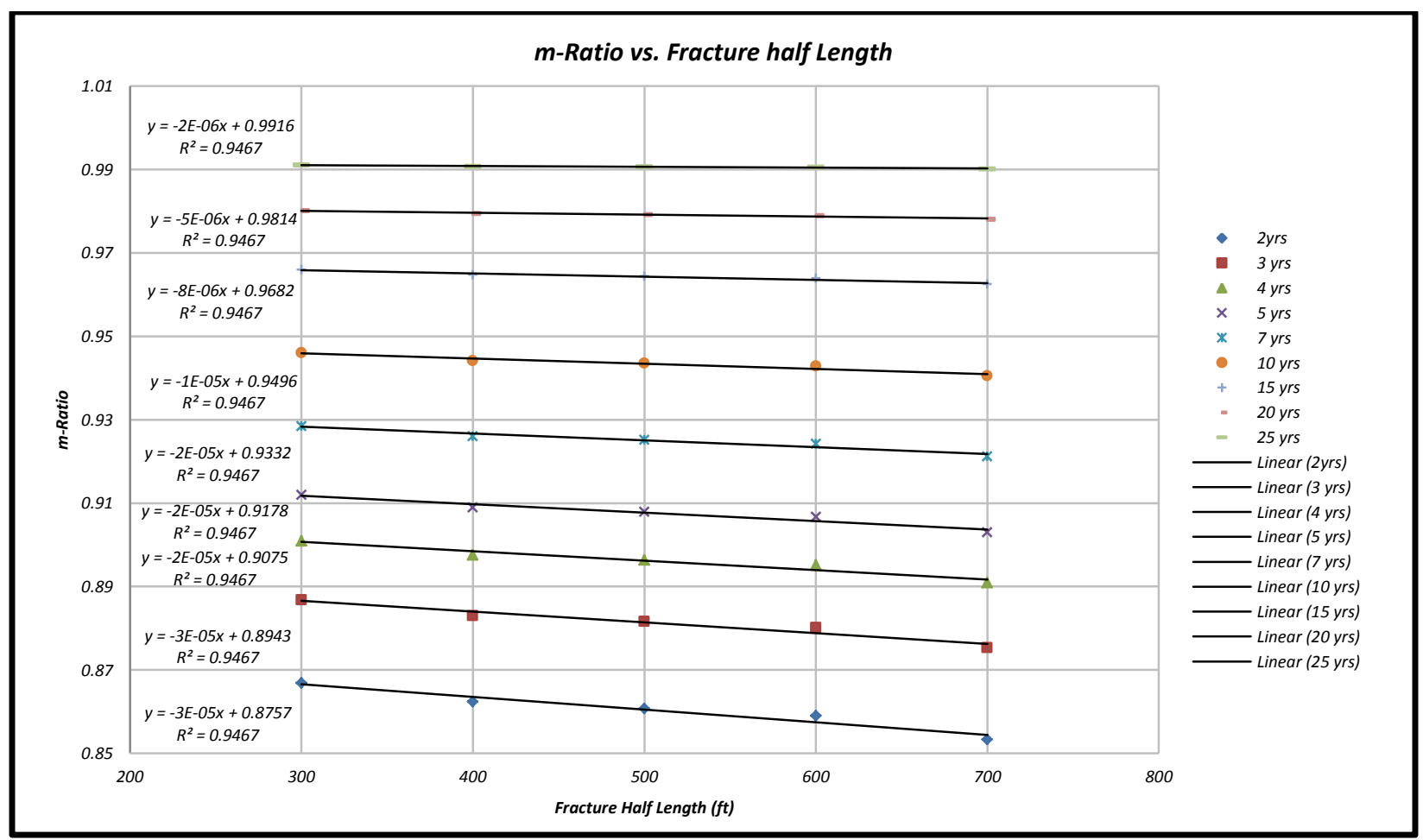

Figure F-32: m-Ratio vs. Fracture Half Length - 13 Stages 


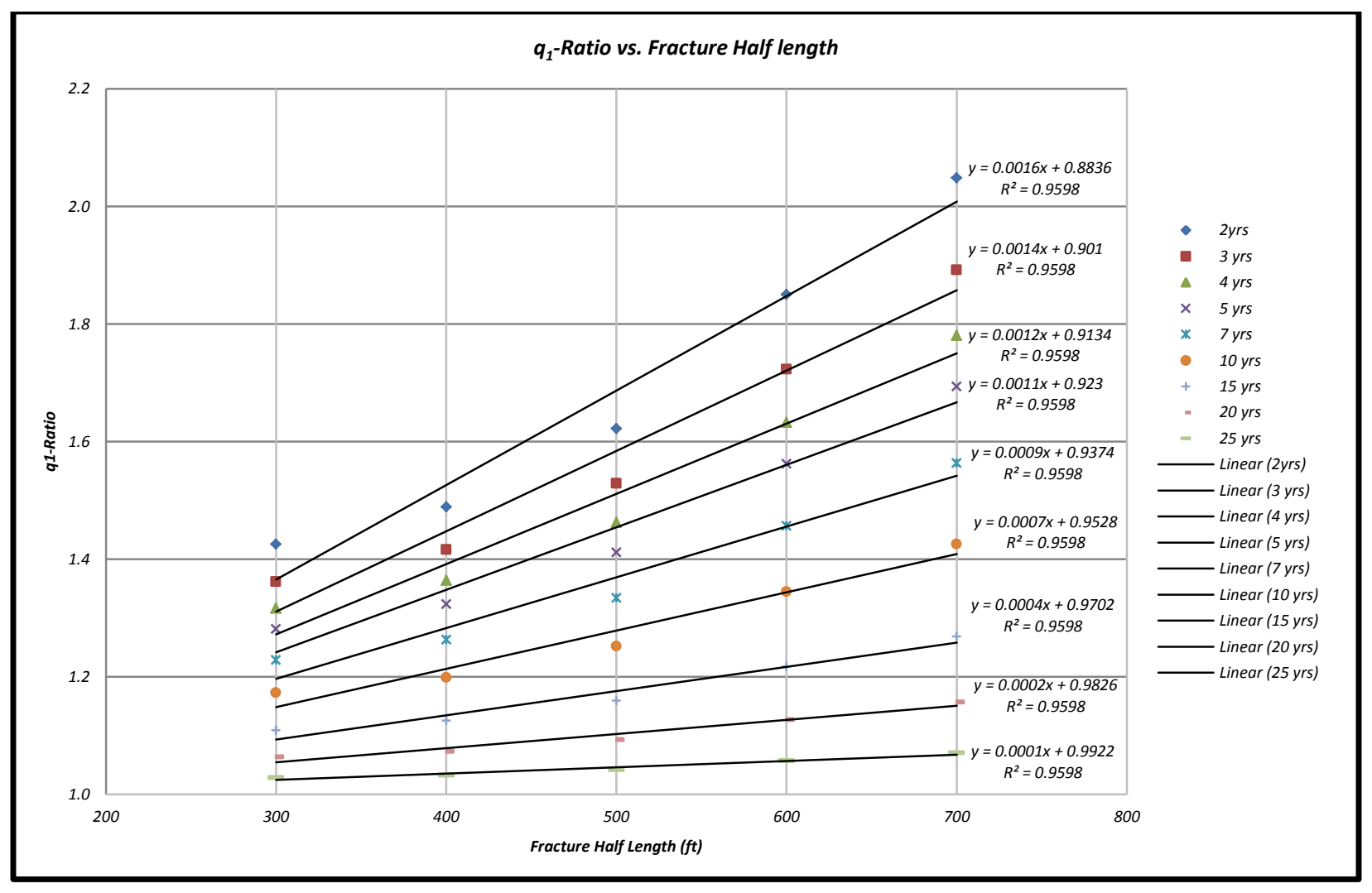

Figure F-33: $q_{1}$-Ratio vs. Fracture Half Length - 13 Stages

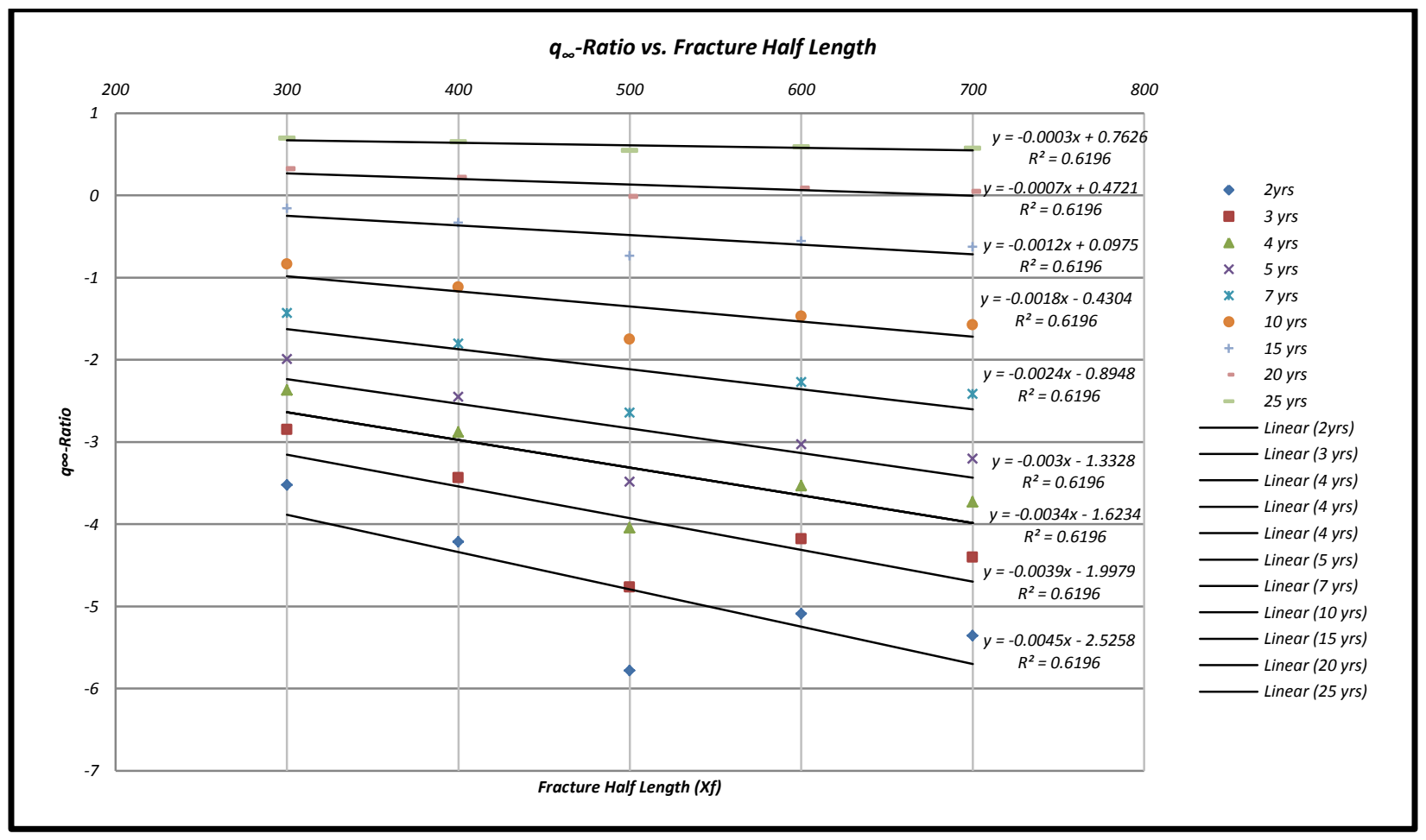

Figure F-34: $q_{\infty}$-Ratio vs. Fracture Half Length - 13 Stages 


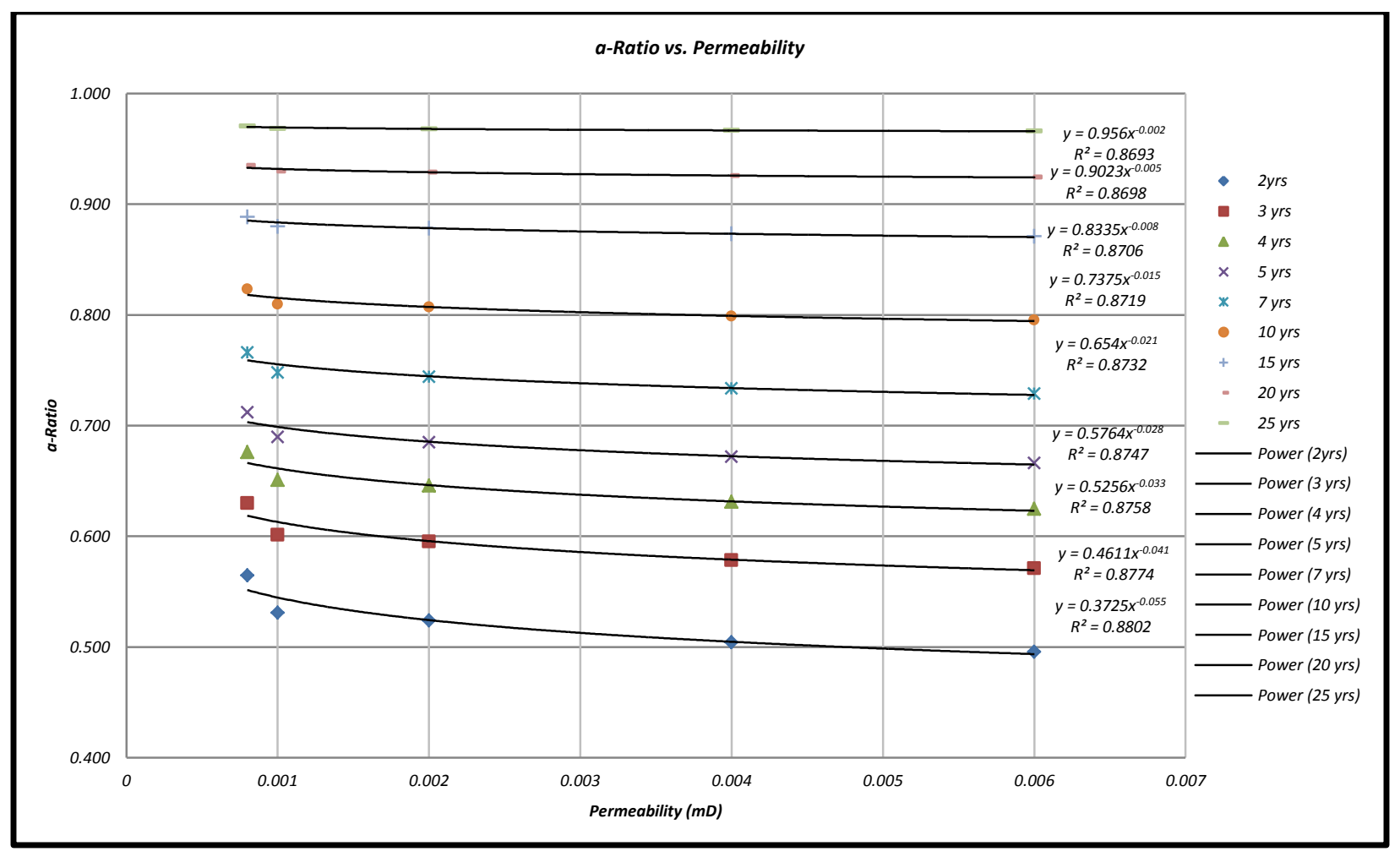

Figure F-35: a-Ratio vs. Permeability - 13 Stages

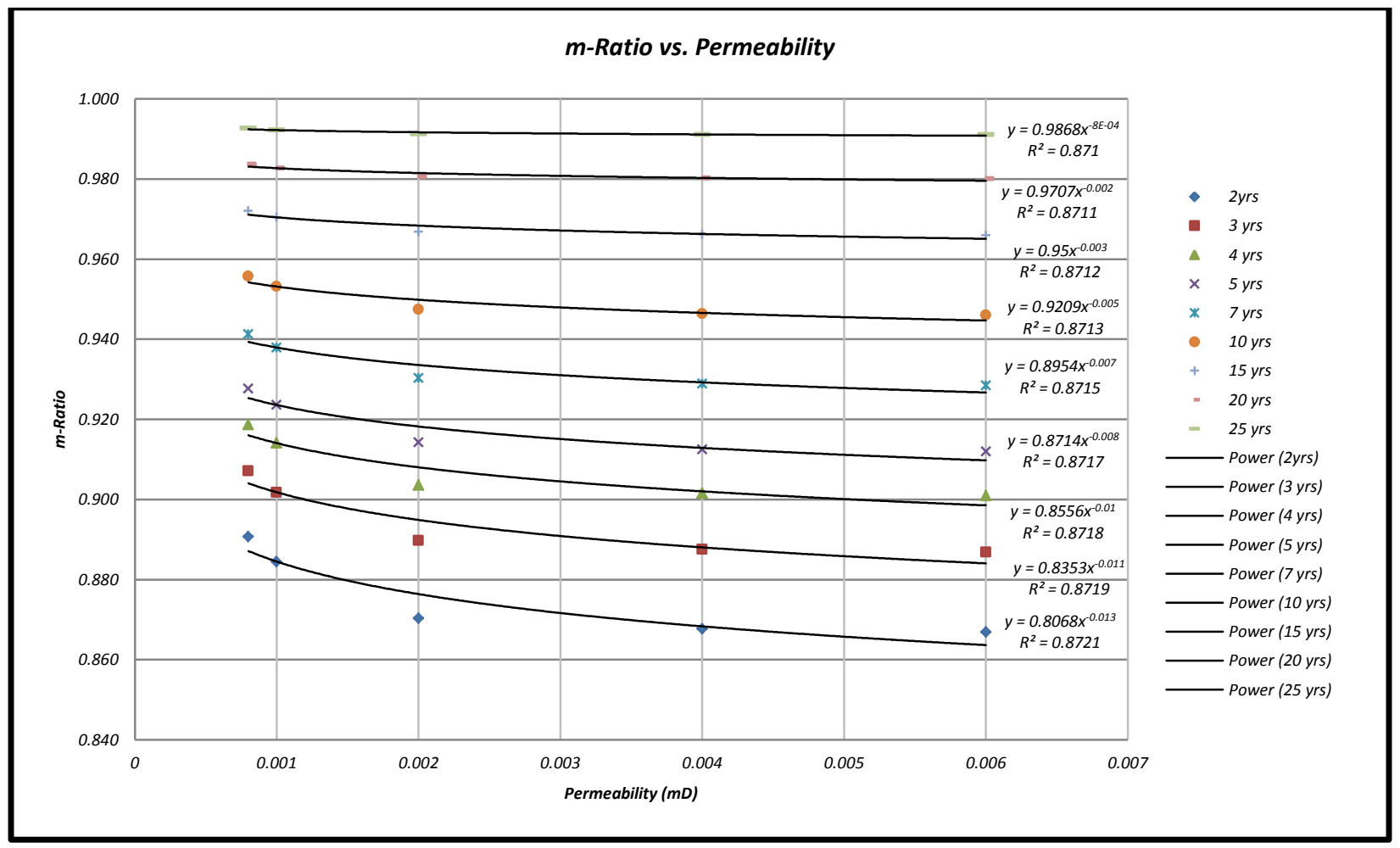

Figure F-36 : m-Ratio vs. Permeability - 13 Stages 


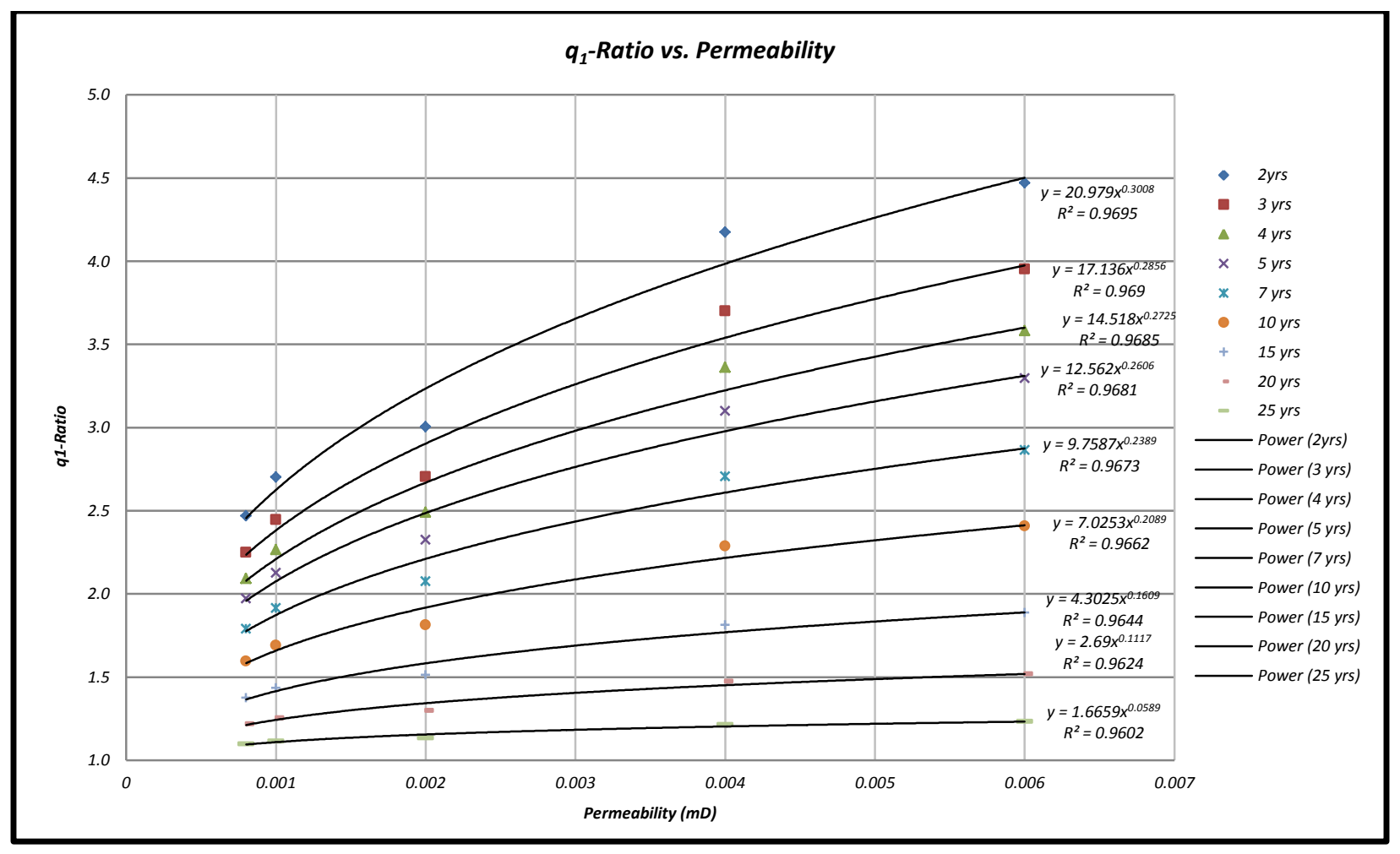

Figure F-37: $q_{1}$-Ratio vs. Permeability - 13 Stages

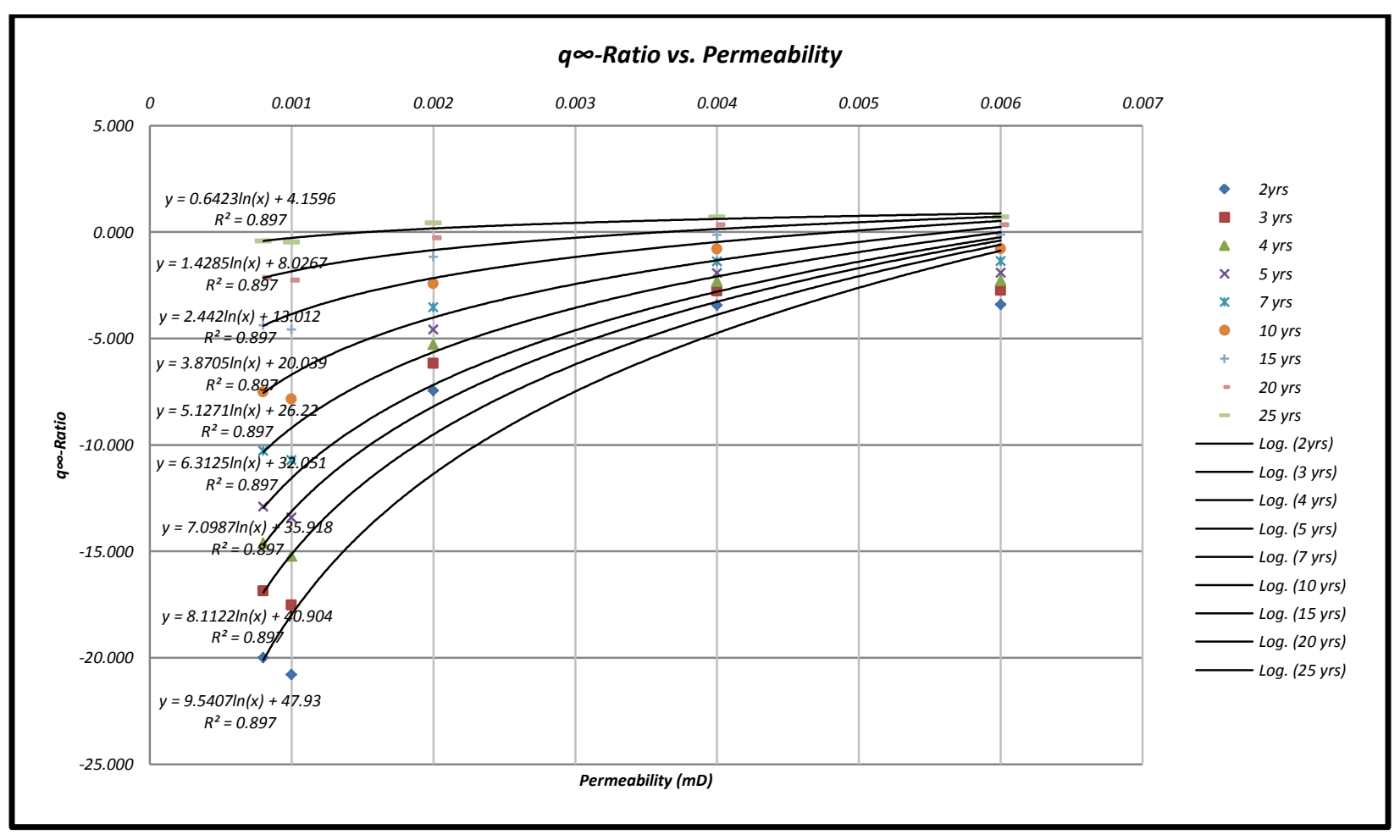

Figure F-38: $q_{\infty}$-Ratio vs. Permeability - 13 Stages 


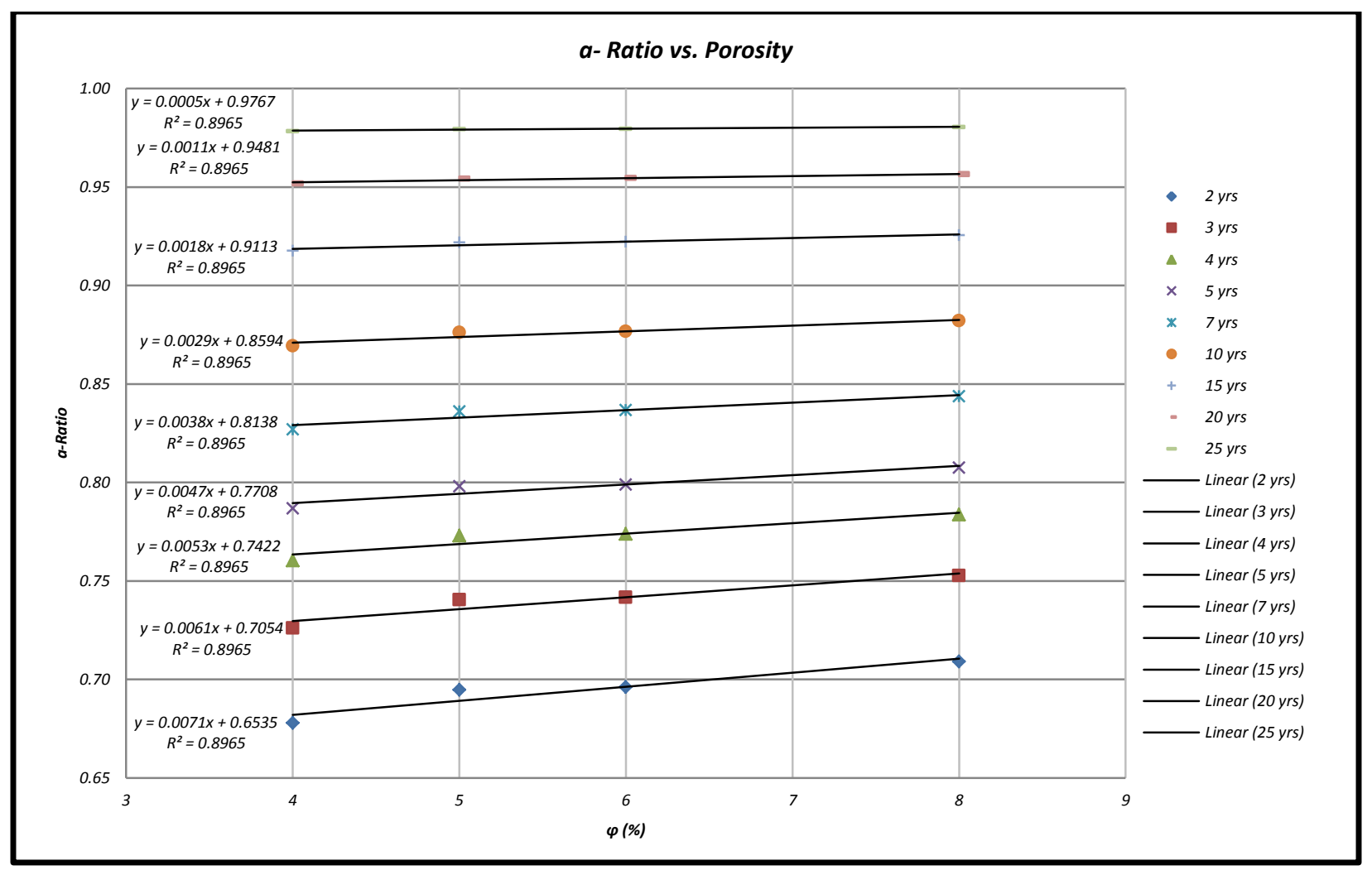

Figure F-39: a-Ratio vs. Porosity - 13 Stages

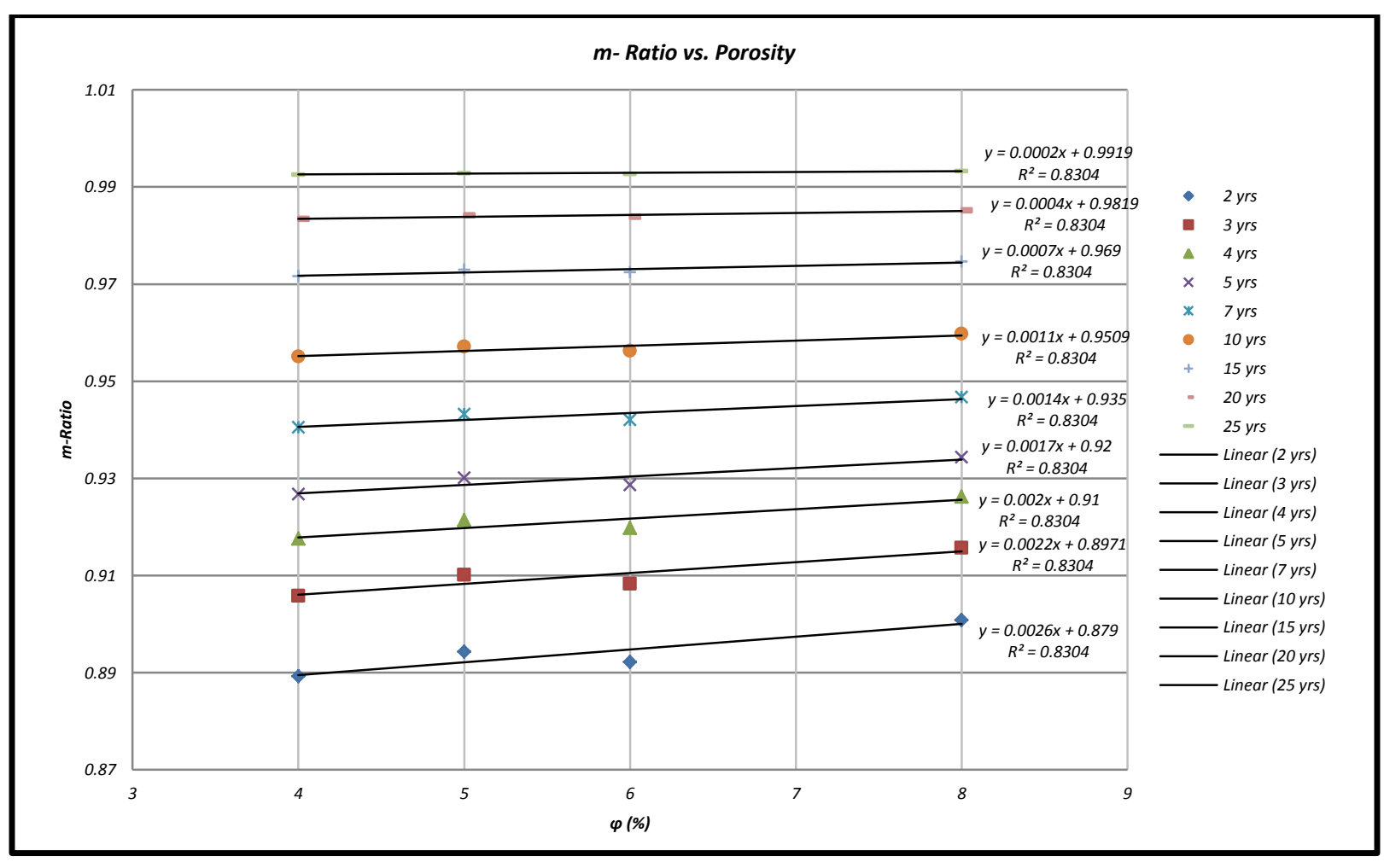

Figure F-40: m-Ratio vs. Porosity - 13 Stages 


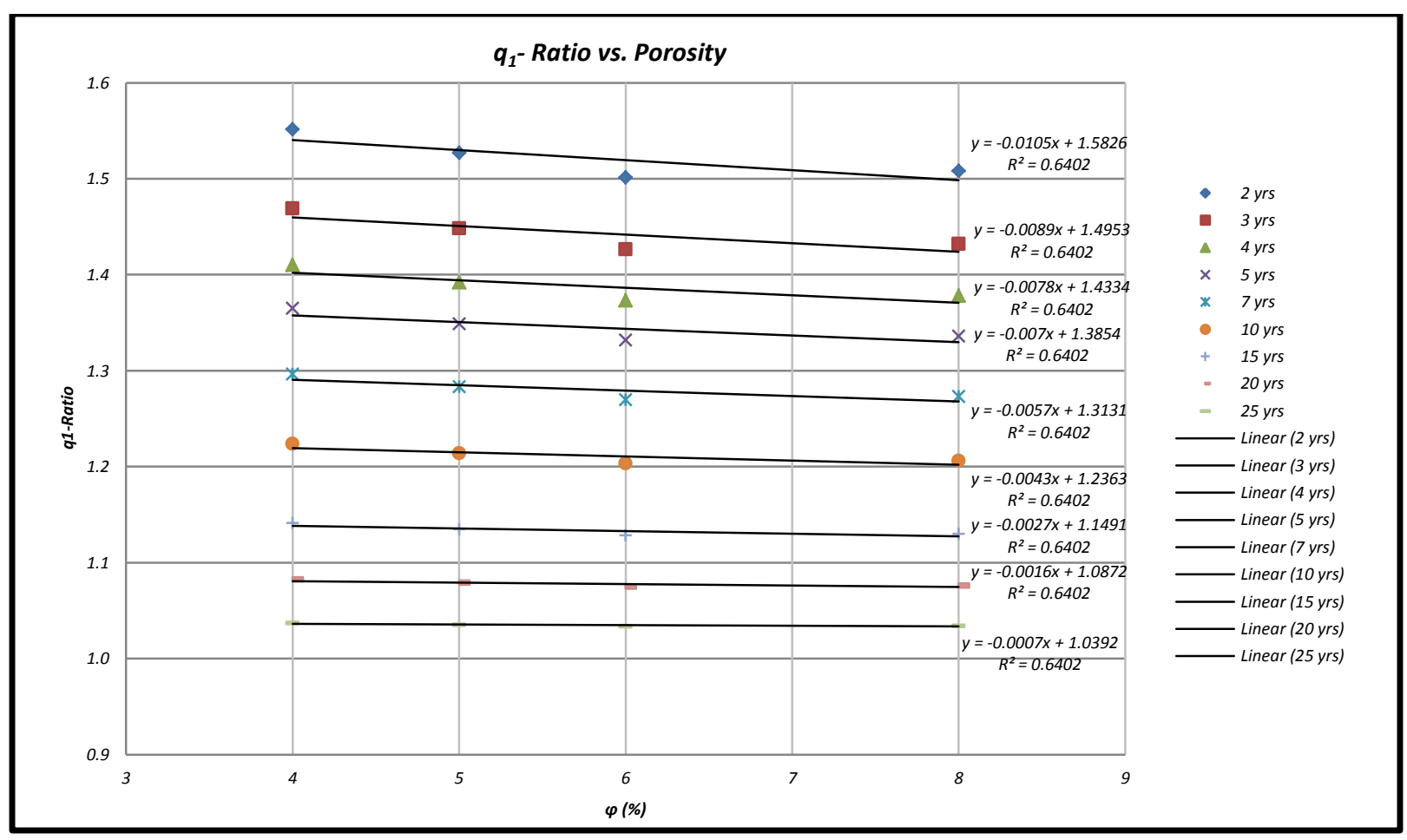

Figure F-41: $q_{1}$-Ratio vs. Porosity - 13 Stages

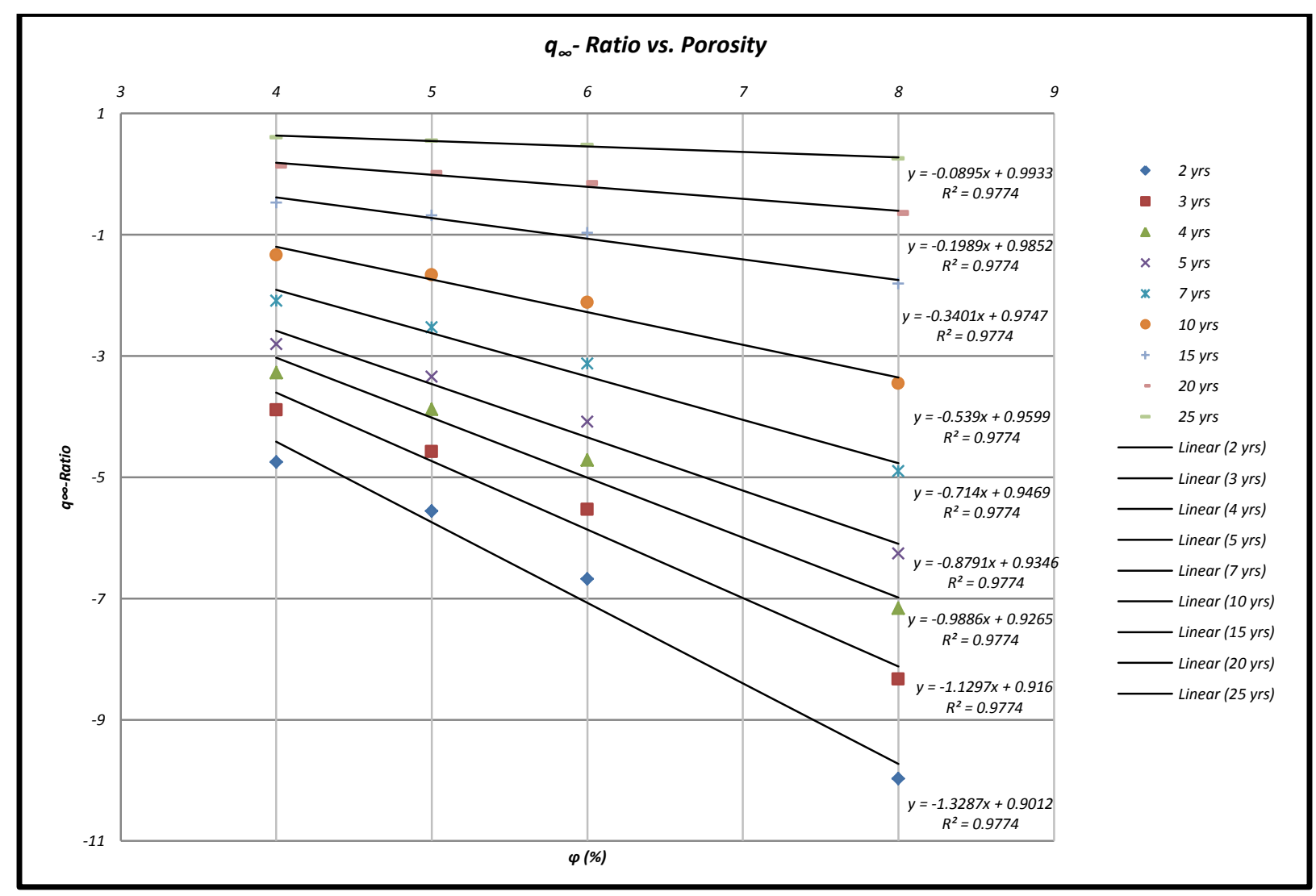

Figure F-42: $q_{\infty}$-Ratio vs. Porosity - 13 Stages 


\section{G. Confirmation with Field Data}

Values of the ratios when computed at 3.5 years of production history using Arps and Duong models' derived correlations both for seven- and thirteen- stage cases were shown in Table G-1 through Table G-4.

Table G-1: 7 Stages- Arps Well \#1 Ratio Values

\begin{tabular}{|c|c|c|c|}
\hline \multicolumn{4}{|c|}{7 Stages- Well\# 1 - Ratio Values } \\
\hline Years & $n$ & $d_{i}$ & $q_{i}$ \\
\hline 3.45205 & 1.441131 & 2.5175246 & 1.230663 \\
\hline
\end{tabular}

Table G-2: 7 Stages- Duong Well \#1 Ratio Values

\begin{tabular}{|l|c|c|c|c|}
\hline \multicolumn{5}{|c|}{7 Stages - Well \#1- Ratio Values } \\
\hline Years & $a$ & $m$ & $q_{1}$ & $q^{\infty}$ \\
\hline 3.45205 & 0.645115 & 0.911297756 & 2.398687 & -18.0775708 \\
\hline
\end{tabular}

Table G-3: 13 Stages- Arps Well \#1 Ratio Values

\begin{tabular}{|c|c|c|c|}
\hline \multicolumn{4}{|c|}{13 Stages - Well\# 1 - Ratio Values } \\
\hline Years & $n$ & $d_{i}$ & $q_{i}$ \\
\hline 3.45205 & 1.158378 & 1.1360454 & 1.024048 \\
\hline
\end{tabular}

Table G-4: 13 Stages- Duong Well \#1 Ratio Values

\begin{tabular}{|l|c|c|c|c|}
\hline \multicolumn{5}{|c|}{13 Stages - Well \#1- Ratio Values } \\
\hline Years & $a$ & $m$ & $q 1$ & $q^{\infty}$ \\
\hline 3.45205 & 0.619911 & 0.896446646 & 2.600062 & -5.74106433 \\
\hline
\end{tabular}

In the next step, the predicted Arps and Duong models constants were shown along with the actual constants values at 3.5 years. As stated previously, predicted values were obtained by dividing the actual value by the ratio for both seven and thirteen fractures cases. 
Table G-5: 7 Stages - Arps Well 1 Actual and Predicted Values

\begin{tabular}{|c|c|c|}
\hline \multicolumn{3}{|c|}{7 Stages - Well \#1 } \\
\hline Arps Constants & Actual - 3.5 Years & Predicted - 30 Years \\
\hline$n$ & 1.540921 & 1.0692443 \\
\hline$d_{i}$ & 0.006155 & 0.0024447 \\
\hline$q_{i}$ & 1.965478 & 1.597089 \\
\hline
\end{tabular}

Table G-6: 7 Stages - Duong Well 1 Actual and Predicted Values

\begin{tabular}{|c|c|c|}
\hline \multicolumn{3}{|c|}{13 Stages - Well \#1 } \\
\hline Duong Constants & Actual - 3.5 years & predicted -30 years \\
\hline$a$ & 0.717052 & 1.11151008 \\
\hline$m$ & 0.995263 & 1.092137896 \\
\hline$q_{1}$ & 6.53 & $\mathbf{2 . 7 2 2 7 7 6 9 2}$ \\
\hline$q_{\infty}$ & -0.61 & $\mathbf{0 . 0 3 3 5 1 5 4 3 1}$ \\
\hline
\end{tabular}

Table G-7: 13 Stages - Arps Well 1 Actual and Predicted Values

\begin{tabular}{|c|c|c|}
\hline \multicolumn{3}{|c|}{13 Stages - Well \#1 } \\
\hline Arps Constants & Actual - 3.5 Years & Predicted - 30 Years \\
\hline$n$ & 1.54092089 & 1.33024045 \\
\hline$d_{i}$ & 0.006154637 & 0.005417598 \\
\hline$q_{i}$ & 1.965478132 & 1.919322169 \\
\hline
\end{tabular}

Table G-8: 13 Stages - Duong Well 1 Actual and Predicted Values

\begin{tabular}{|c|c|c|}
\hline \multicolumn{3}{|c|}{13 Stages - Well \#1 } \\
\hline Duong Constants & Actual - 3.5 years & predicted -30 years \\
\hline$a$ & 0.717052 & 1.156701354 \\
\hline$m$ & 0.995263 & 1.110230952 \\
\hline$q_{1}$ & 6.53 & $\mathbf{2 . 5 1 1 8 9 6 8 1 6}$ \\
\hline$q_{\infty}$ & -0.61 & $\mathbf{0 . 1 0 5 5 3 4 0 1 5}$ \\
\hline
\end{tabular}

The generated production data (at 3.5 years) by Fekete simulator, for each case (Table 4-34), were matched to Well 1 production history at 3.5 years (Figure G-1 through Figure G-3). 


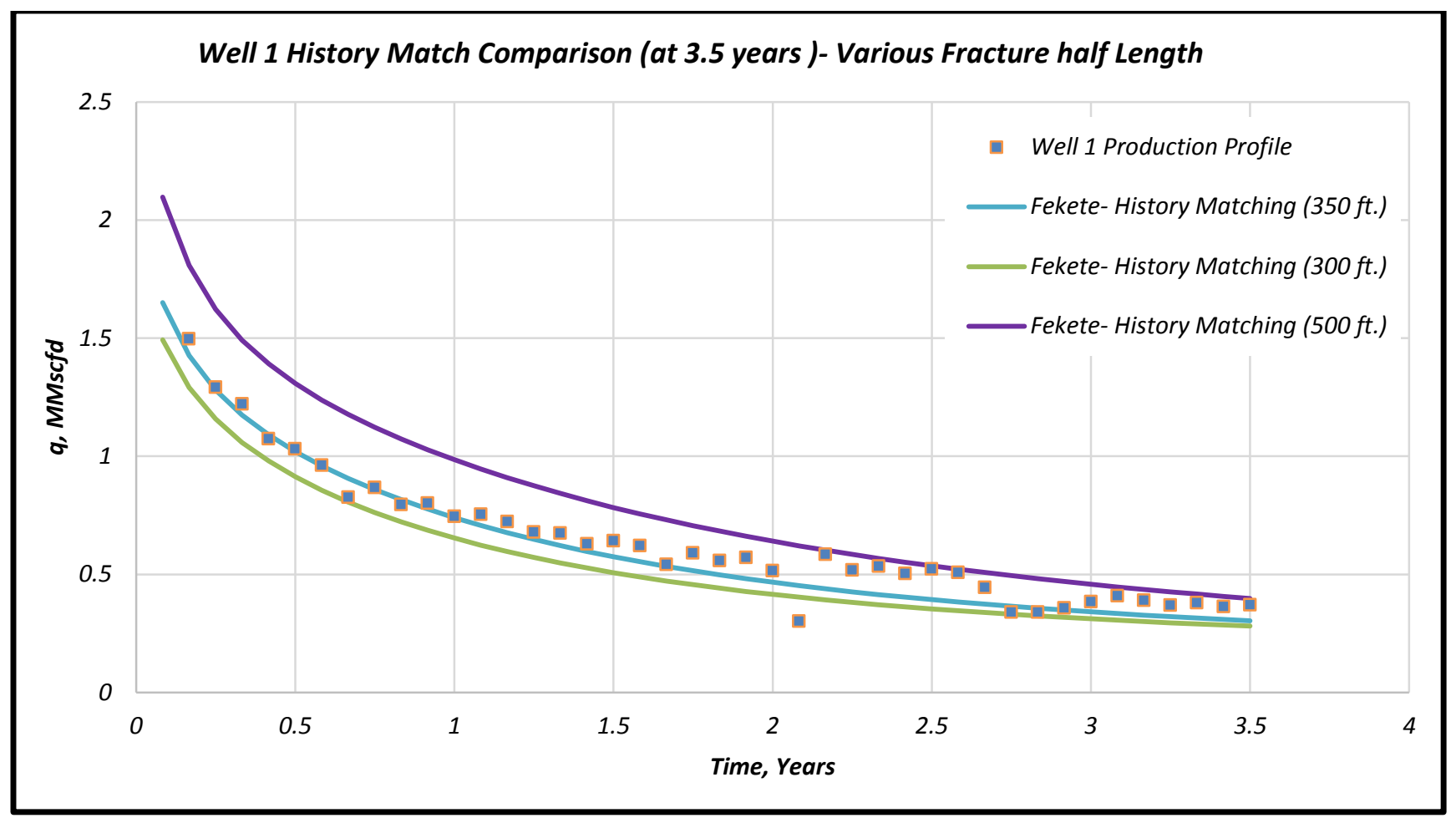

Figure G-1: Well 1 History Match Comparison (at 3.5 years) - Various Fracture half Length

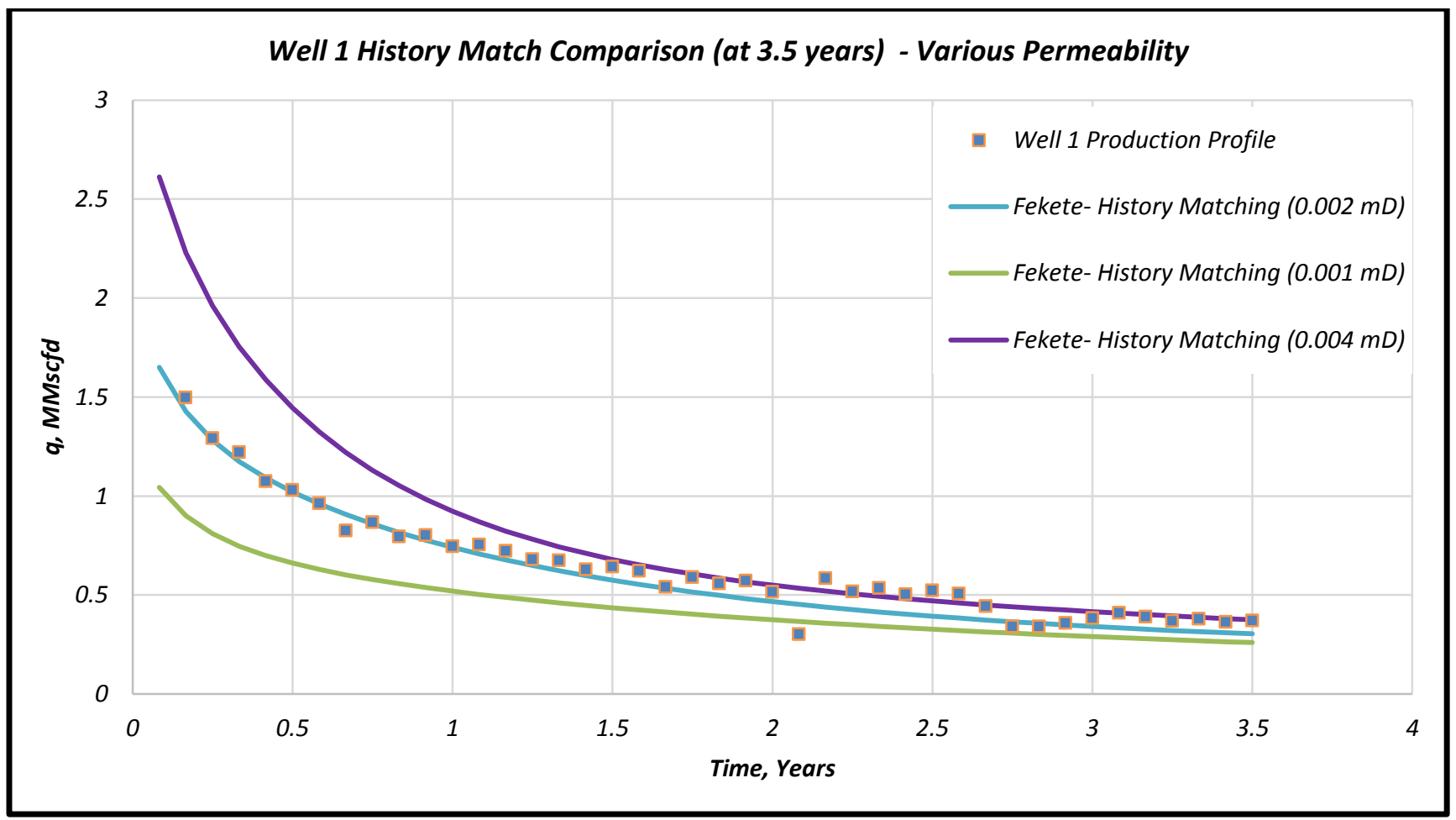

Figure G-2: Well 1 History Match Comparison (at 3.5 years) - Various Permeability 


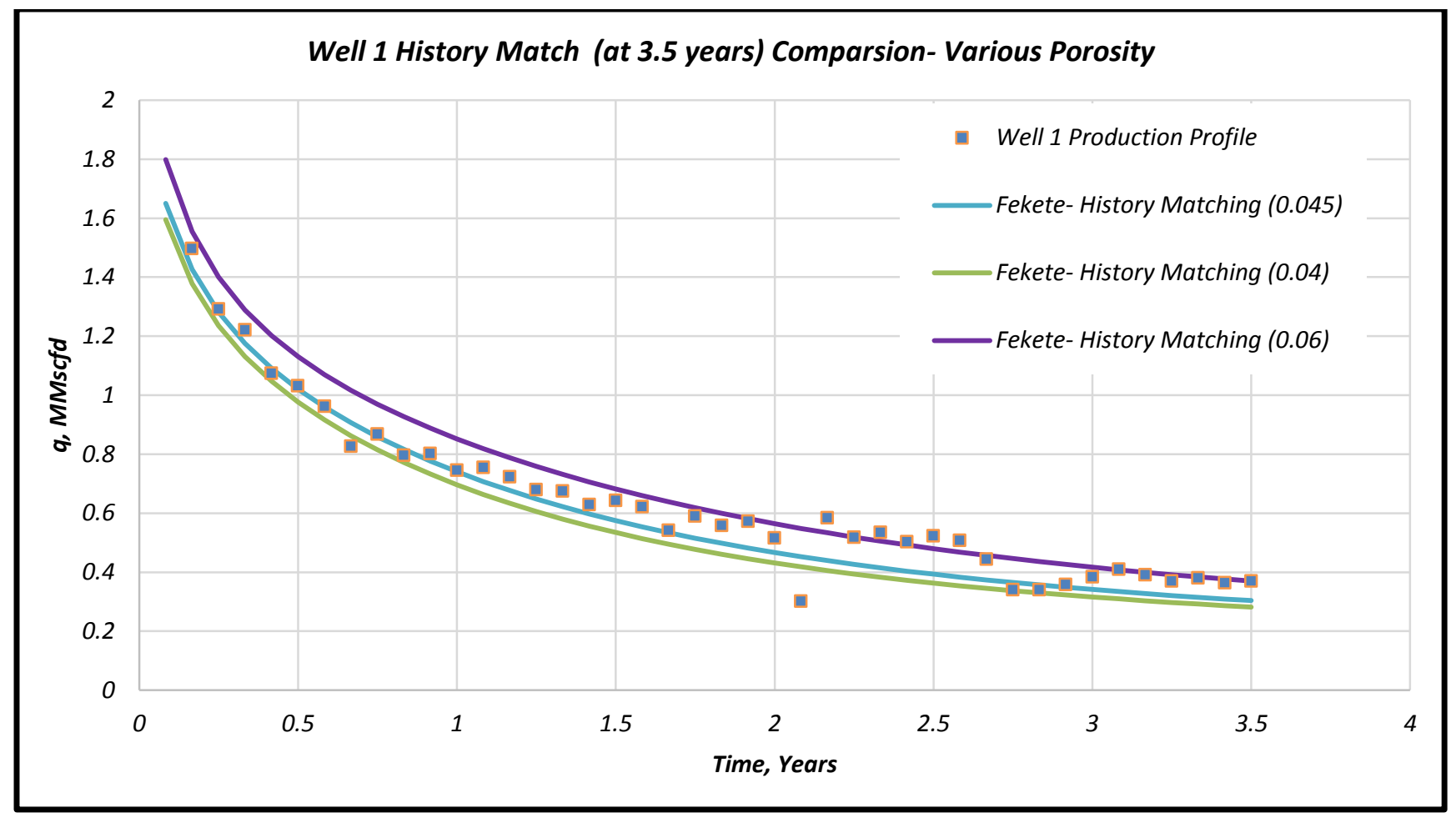

Figure G-3: Well 1 History Match Comparison (at 3.5 years) - Various Porosity 